\title{
Living up to standards : interoperability governance and standards adoption in government information networks
}

Citation for published version (APA):

Henning, F. (2015). Living up to standards : interoperability governance and standards adoption in government information networks. [Doctoral Thesis, Maastricht University]. Uitgeverij Boekenplan. https://doi.org/10.26481/dis.20150624fh

Document status and date:

Published: 01/01/2015

DOI:

$10.26481 /$ dis.20150624fh

Document Version:

Publisher's PDF, also known as Version of record

Please check the document version of this publication:

- A submitted manuscript is the version of the article upon submission and before peer-review. There can be important differences between the submitted version and the official published version of record.

People interested in the research are advised to contact the author for the final version of the publication, or visit the DOI to the publisher's website.

- The final author version and the galley proof are versions of the publication after peer review.

- The final published version features the final layout of the paper including the volume, issue and page numbers.

Link to publication

\footnotetext{
General rights rights.

- You may freely distribute the URL identifying the publication in the public portal. please follow below link for the End User Agreement:

www.umlib.nl/taverne-license

Take down policy

If you believe that this document breaches copyright please contact us at:

repository@maastrichtuniversity.nl

providing details and we will investigate your claim.
}

Copyright and moral rights for the publications made accessible in the public portal are retained by the authors and/or other copyright owners and it is a condition of accessing publications that users recognise and abide by the legal requirements associated with these

- Users may download and print one copy of any publication from the public portal for the purpose of private study or research.

- You may not further distribute the material or use it for any profit-making activity or commercial gain

If the publication is distributed under the terms of Article $25 \mathrm{fa}$ of the Dutch Copyright Act, indicated by the "Taverne" license above, 


\section{Living up to Standards}

Interoperability Governance and Standards Adoption in Government Information

Networks 
(C) Florian Henning, the Netherlands, 2015

All rights reserved. No part of this publication may be reproduced, stored in a retrieval system, or transmitted in any form, or by any means, electronic, mechanical, photocopying, recording or otherwise, without the prior permission in writing, from the author.

ISBN 9789086663644

Cover Photo is a derivative of the photo "3 Foot Flat Cable" by Flickr user "Incase" and licensed under Creative Commons license CC BY 2.0

Publisher: Uitgeverij Boekenplan 


\title{
Living up to Standards
}

\section{Interoperability Governance and Standards Adoption in Government Information Networks}

\author{
Dissertation \\ to obtain the degree of doctor at Maastricht University, \\ on the authority of the Rector Magnificus, Prof. dr. L.L.G. Soete \\ in accordance with the decision of the Board of Deans, \\ to be defended in public on Wednesday, 24 June 2015, at 14:00 hours
}

by Florian Henning 
Supervisor

Prof. Dr. Robin Cowan

Co-Supervisors

Prof. Dr. Victor Bekkers, Erasmus University Rotterdam

Dr. Rita Walczuch

Assessment Committee (in alphabetic order)

Prof. Dr. Friso den Hertog (Chairman)

Dr. Tomasz Janowski, United Nations University

Prof. Dr. Marcel Thaens, Erasmus University Rotterdam

Dr. Mark Vluggen

Funding Acknowledgement

Financial support for carrying out the work presented in this dissertation has been received by the following organisations in the Netherlands:

- Ministry of the Interior and Kingdom Relations

- ICTU Foundation. 


\section{ACKNOWLEDGEMENTS}

Before embarking on this dissertation, I have been told by many people that I would need to get ready for a long and lonely endeavour. But whilst it was a long road, it never was lonely, and I was fortunate to have had many people around me that inspired, helped and encouraged me along this journey. I could never have written this dissertation without their support, and I would like to express my deepest gratitude to them.

First of all, I would like to thank my supervisory team: Robin Cowan, Rita Walczuch, and Victor Bekkers. I cannot thank them enough for all the time and effort they invested in this dissertation, and for being a constant source of ideas, support and encouragement. I cannot count all the meetings, phone calls and emails in which they helped me by challenging and enriching my ideas, and pointed me to solutions when I could not find them. I have learned so much from them, and I am deeply grateful for that.

I also want to express my gratitude to the assessment committee for their time and effort in reviewing this dissertation: Friso den Hertog, Tomasz Janowski, Marcel Thaens, and Mark Vluggen. I also want to thank the members of the corona for engaging with the dissertation and contributing to its defence ceremony.

During this PhD I had the honour of getting to know and working with a number of colleagues in the area of my research, whose ideas and support had an important influence. Most of all, I want to express my deepest gratitude to Tomasz Janowski and Elsa Estevez, who invited me for a visiting fellowship at the UNU-IIST Center for Electronic Governance in Macao. I cannot thank them enough for all the advice, support, opportunities and inspiration that they shared with me, and our academic adventures across the globe are something that I will always cherish.

There were so many other people who shared ideas and advice with me that influenced this dissertation that I cannot mention them all here, but I would like to name some of them who took the time to think along with me at various points in the PhD process. I would like to thank Frank Bannister, Antonio Cordella, Hein van Duivenboden, Ursula Glunk, Hannes Günter, Vincent Homburg, Marijn Janssen, Hiroko Kudo, Albert Meijer, Adegboyega Ojo, Bernike Pasveer, Marcel Thaens and Arre Zuurmond for helping me with finding orientation and focus in the early phases of the research and commenting on drafts.

I would also like to express my gratitude to Peter Berrevoets, Mark Brugman, Wolfgang Ebbers, Gerard van der Hoorn, Pieter Lagas, Xander van der Linde, Paul Oude Luttighuis, Bas van Luxemburg, Judith van der Merwe-Koedijk, Jan Konings, Paul Nijenhuis, John Remmerswaal and Peter Waters for sharing their time and expertise on the Dutch context and advising me when I was searching for suitable cases for my research.

A special thank you goes to Gar Yein $\mathrm{Ng}$ for working with me in the area of this dissertation's topic in my first year, and to Francesco Contini and Philip Langbroek for their feedback and advice in this regard. 
I also would like to thank Paul Coenen and Niklas Funk for identifying relevant sources for the literature review in Chapter 2 when they wrote their Master thesis under mine and Rita's co-supervision on this dissertation's topic. I also would like to thank the student assistants who helped with the transcription of interviews: Francis Buysse, Arno Coppens, Gea Meijers, and Nikki Remkes. I am also very grateful to those who have shared their time for proofreading parts of this dissertation: my parents for meticulously reading the thesis from cover to cover, and Ad and Cindy Notten for helping me with the Dutch translation of the dissertation summary at the end of this book.

This dissertation would not exist without the institutional support that I was fortunate to receive. I have been fortunate to receive not only generous financial and institutional support from Stichting ICTU and the Dutch Ministry of Internal Affairs and Kingdom Relations, but also the invaluable guidance and support from my advisors at ICTU: GerritJan van 't Eind whose brainchild this project was and who supported it well beyond his time at ICTU, as well as Ferry Carlier and Tim Berkelaar. They have been an invaluable source of advice and have played a key role in opening many doors that have made this research possible.

This dissertation would also not have been possible without all the people from the two case studies who have shared their time, experiences and support. I guaranteed to keep names confidential, but I want to express my deepest appreciation to all the interviewees from the two cases who were willing to share their experiences, insights and time with me. I am especially indebted to two partners who provided me with access and advice with regard to the case studies: Eduard Renger for the Digitaal Klantdossier, and Wouter de Haan for Studielink.

Most of all, I would like to single out the support I received from and at the joint institute of the Maastricht Graduate School of Governance and UNU-MERIT, which provided me with an academic home during my PhD. I would like to start by thanking the institute directors who provided the framework of opportunities for my PhD: Chris de Neubourg, Luc Soete and Bart Verspagen. I am also greatly indebted to the academic team managing and supporting the MGSOG/UNU-MERIT PhD programme: Mindel van de Laar, Robin Cowan, Franziska Gassmann, Eddy Szirmai.

I would also like to thank the academic staff at the institute for creating an inspiring environment in which I could grow as a researcher in the company of great minds. In particular, I would like to thank the colleagues who I've been lucky to work with on various initiatives. I would like to thank my past and present colleagues from the research group on ICT-enabled Innovation and Societal Transformations that worked with me on various project ideas. In particular, I would like to thank Martin Rehm for introducing me to the world of e-Learning and for his friendship.

My gratefulness also belongs to the past and present support staff at the institute whose efforts provided such essential foundations for all academic work at our institute. In particular, I want to thank Eveline in de Braek, Eric Engelen, Wilma Coenegrachts, Janneke Knaapen, Herman Pijpers, Annemarie Rima, Susan Roggen, and Marc Vleugels. 
I have been fortunate to be part of a large community of PhD fellows at our institute, and I would like to thank all of them for including me in that community. In particular, I would like to thank everyone from my $\mathrm{PhD}$ cohort who embarked together with me on this adventure and those I was lucky to share an office with over the years. There are many more names among them than would fit on this page, but I would like to mention in particular a few who were always there for me with advice and encouragement for this PhD: Britta Augsburg, Sachin Badkas, Robert Bachmüller, Pascal Beckers, Jessica and Alex HagenZanker, Metka Hercog, Mahmut Kobal, Zina Nimeh, Lina Salanauskaite, Esther Schüring, Renée Speijcken, Eze Tacsir, Sonila and Florian Tomini, and Sepideh Yousefzadeh. To all others who I could not mention here, please know that I did not forget you!

I've found a second institutional home during my visiting fellowship at UNU-IIST in Macao. First, I want to thank in particular Tomasz Janowski and Elsa Estevez for inviting and hosting me as a visiting fellow. I also would like to thank my colleagues and friends at the Center for Electronic Governance. In particular I want to thank the friends who made my time in Macao such a special memory: Stephan Arlt, Pui Chan and Dominik Schleipen, Han Ei Chew, Zamira Dzhusupova, Johannes and Melanie Faber, Saeed Ul Hassan, Wendy Hoi, Pat Rhienmora, Martin Schäf, Victor Vicente, and Longfei Zhu.

Finally, I am so grateful to my friends and family who have been there for me in this time and without whom this book would never have made it to the light of day. I was lucky to be friends with many fascinating people that made my life in Maastricht so enjoyable - too many to all fit here, but I want to especially thank the "Wycker Grachtstraat family" who shared a roof and so much more with me, in particular Ana Maria, Mahmut, Metka, and Melissa. I also want to thank my fantastic paranymphs Ana Maria Daza-Clark and Ad Notten, who have been a tremendous source of support and encouragement in the preparation of the defence of this thesis. Thank you to Josh and Sarah Hays for their friendship and travelling so far to support me. Finally, I want to thank all the friends who shared my passion for music and sport whenever I needed to clear my head and who spent countless hours with me on the bike, on the running trails, in the pool or behind the music instruments. Especially, I want to mention Ad, Hans, Koen, Martin, Maurice, Ruud, Robert, Sjoerd, and my friends from Triathlon Club Maastricht.

I would have never made it to neither the starting line nor the finish line of this PhD without the endless love and support I was so fortunate to have from my family. I know that this $\mathrm{PhD}$ must at times have tested you as much as it tested me, but without failure you were always there for me. Melissa, I am so lucky to have you in my life, and I do not know how I would have been able to do this without the light that you bring into my every day by sharing your love, encouragement and ideas. To my older brother Tobi, thank you for always having some advice I could turn to. Finally, I am so endlessly grateful to my wonderful parents, who have always been there for me and given everything for me. Finishing this PhD is also your achievement, and I want to dedicate it to you. 


\section{TABLE OF CONTENTS}

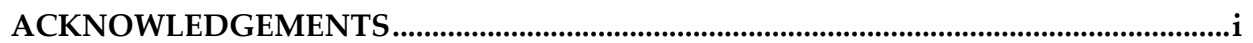

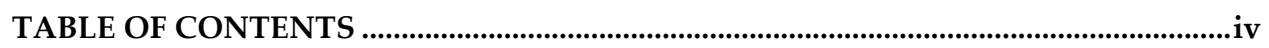

LIST OF FIGURES .......................................................................................................

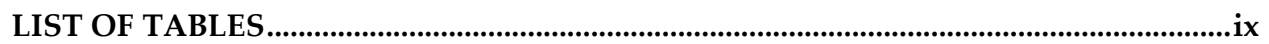

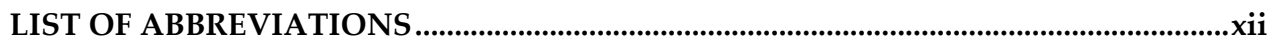

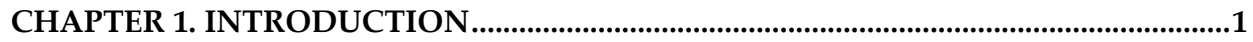

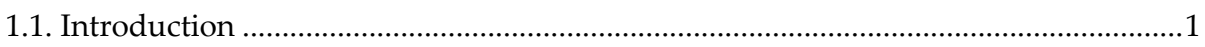

1.2. From e-Government to e-Governance .........................................................................

1.3. Government Information Networks and Information Sharing .................................6

1.4. Interoperability, a Key Enabler of Information Sharing ............................................

1.5. Standards Adoption and the Need for Interoperability Governance ...........................14

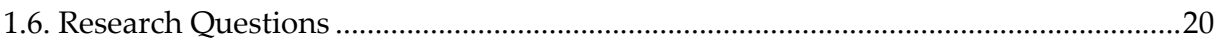

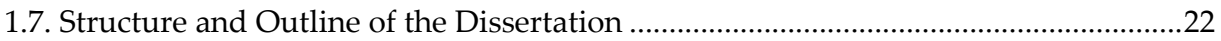

CHAPTER 2. TOWARDS A THEORY OF INTEROPERABILITY STANDARDS

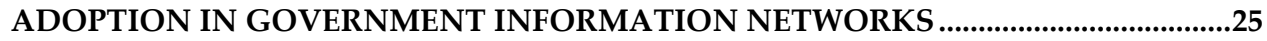

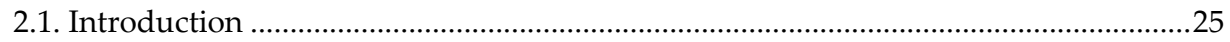

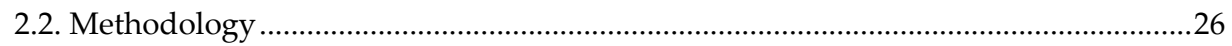

2.3. Theoretical Foundations: Diffusion of Innovations and Technology Acceptance

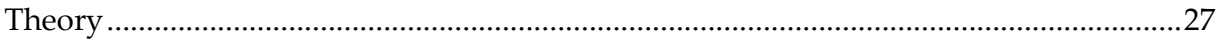

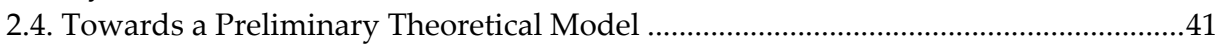

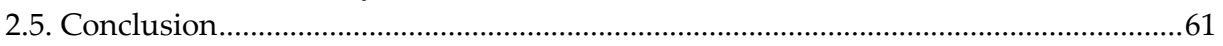

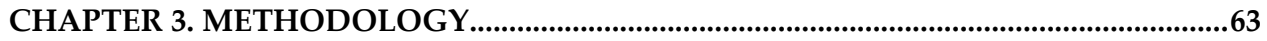

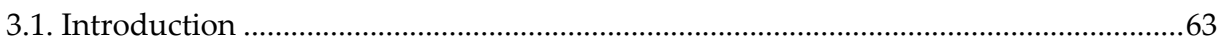

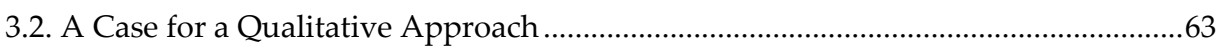

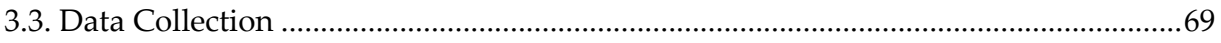

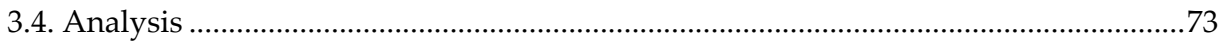

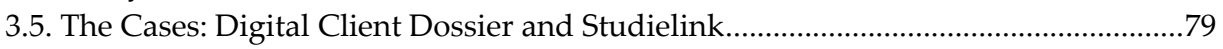

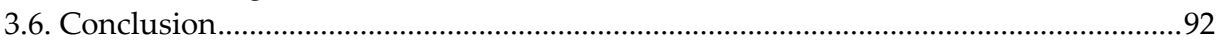

CHAPTER 4. THE PROCESS AND IMPLICATIONS OF INTEROPERABILITY STANDARDS ADOPTION FOR ORGANISATIONS IN GOVERNMENT

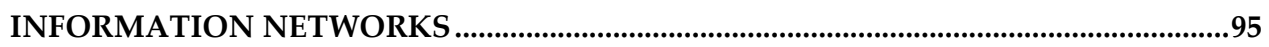

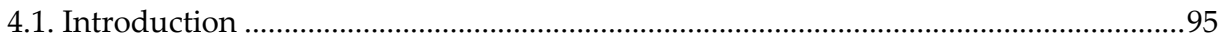

4.2. IOP Standards in Government Information Networks ............................................97

4.3. Implications of IOP Standards Adoption for Organisations ........................................100

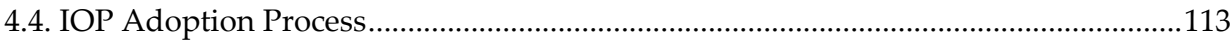

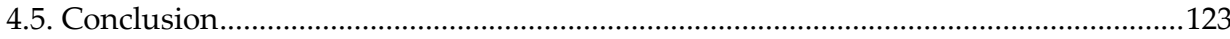

Annex A. Detailed Results from the Content Analysis of Adoption Implications ...........128 
CHAPTER 5. DETERMINANTS FOR THE ADOPTION OF INTEROPERABILITY STANDARDS IN GOVERNMENT INFORMATION NETWORKS - EVIDENCE FROM

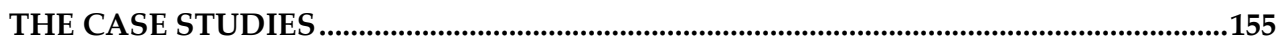

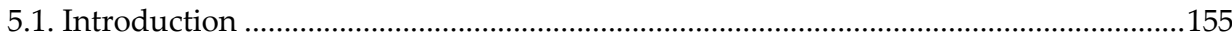

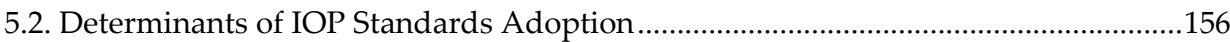

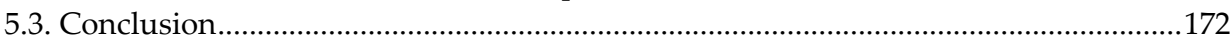

Annex B. Detailed Results from the Content Analysis of Determinants............................178

CHAPTER 6. THE EFFECTIVENESS OF DIFFERENT INTEROPERABILITY GOVERNANCE MODES ACROSS NETWORK COMPLEXITIES .....................................235

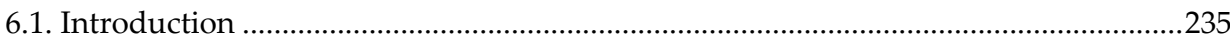

6.2. Theoretical Background: The Relationship of IOP Governance Centralisation and Network Complexity .237

6.3. The Effectiveness of Different Degrees of IOP Governance Centralisation Across Network Complexities: Findings from the Case Studies ....................................................241

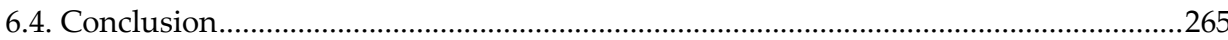

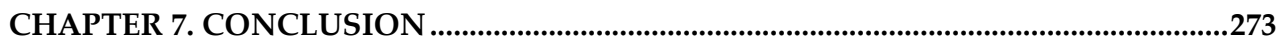

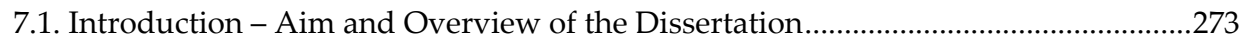

7.2. Findings and Contribution to Theory and Practice .......................................................274

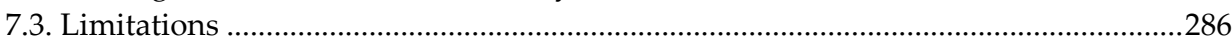

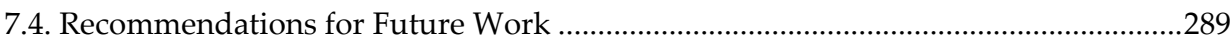

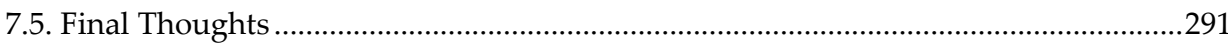

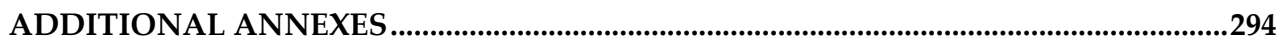

Annex C. Full References for Determinants Identified in Chapter 2 ................................295

Annex D. IOP Standards in the Case Studies ....................................................................299

Annex E. Attributes Description for Adoption Efforts and Results Constructs.................304

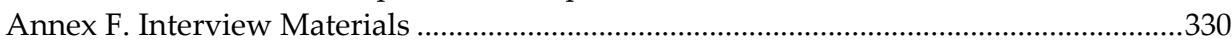

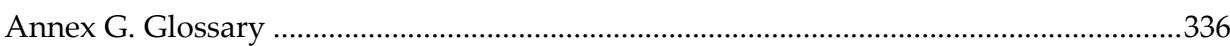

Annex H. Original Versions of Translated Quotes .................................................................339

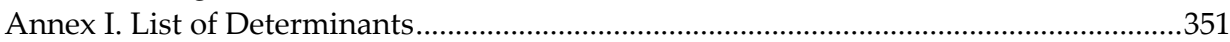

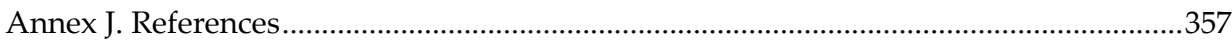

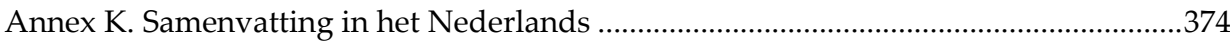

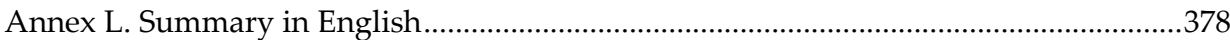

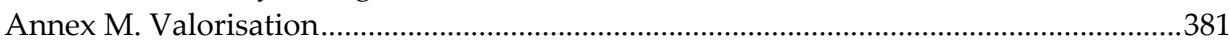

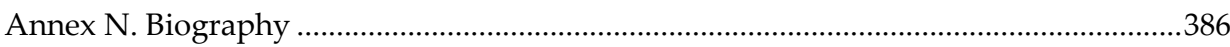

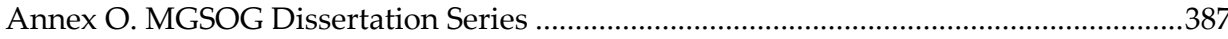




\section{LIST OF FIGURES}

Figure 1.1. Mapping of key conceptual domains ..............................................................

Figure 1.2. Stage-model for government transformation ..................................................

Figure 1.3. Role of IOP for government information sharing .............................................14

Figure 1.4. Chapter structure of the dissertation .....................................................................23

Figure 2.1. The ICT-specific diffusion of innovations model .................................................30

Figure 2.2. Basic structure of Technology Acceptance Models..............................................33

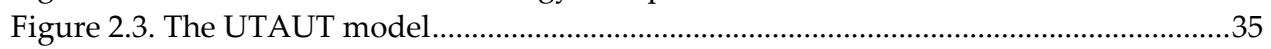

Figure 2.4. Distinct domains indicating need for context-specific theory ..............................39

Figure 2.5. Theoretical model (main determinant constructs) ...............................................42

Figure 2.6. Preliminary theoretical model (main constructs and sub-constructs).................60

Figure 3.1. Screenshot of the coding process in atlas.ti.........................................................75

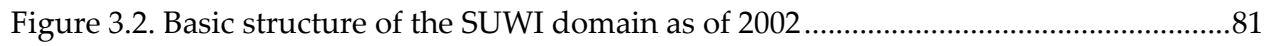

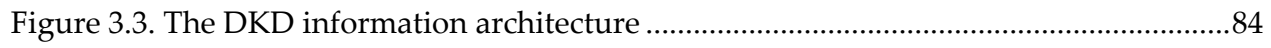

Figure 3.4. Structure of the DKD inter-organisational network ...........................................86

Figure 3.5. The Studielink information architecture ..............................................................90

Figure 3.6. Structure of the Studielink inter-organisational network ....................................91

Figure 4.1. Quotations for individual IOP dimensions......................................................98

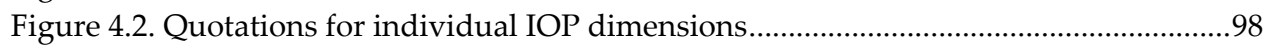

Figure 4.3. Co-occurrence of IOP dimensions and implications codes....................................99

Figure 4.4. Overview of Implications discussed in Section 4.3, Annex A and Annex E.......102

Figure 4.5. Evaluation of implications from IOP standards adoption ...................................111

Figure 4.6. Co-ocurrence of evaluation codes and Results.....................................................111

Figure 4.7. Co-ocurrence of evaluation codes and Adoption Effort sub-constructs ................112

Figure 4.8. Levels of actors in standardisation processes .....................................................113

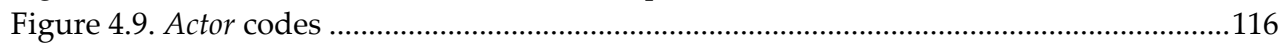

Figure 4.10. Adoption Process ………................................................................................119

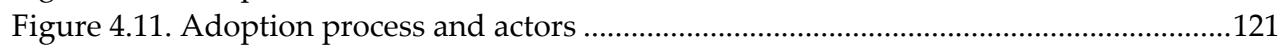

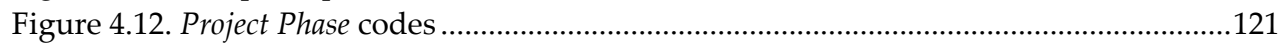

Figure 4.13. Co-occurrences of Project Phase and Results codes ............................................122

Figure 4.14. Co-occurrences of Project Phase and Adoption Efforts codes ..............................122

Figure 5.1. Overview of determinants discussed in Section 5.2, Annex A and Annex B .....157

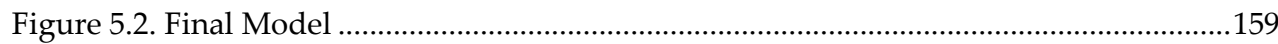

Figure 6.1. Quotation frequencies for adoption determinants............................................242

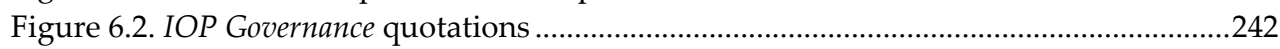

Figure 6.3. Co-occurrences of Network Complexity and Evaluation quotations ........................243

Figure 6.4. Brokerage (average quotation frequencies per case) ............................................24

Figure 6.5. Stakeholder Involvement (average quotation frequencies per case)........................248

Figure 6.6. Coercion (average quotation frequencies per case) ................................................254

Figure 6.7. Accountability quotations (average quotation frequencies per case) ....................259 
Figure Annex A.1. Aggregate frequencies for a) both Implications constructs, b) Adoption Efforts sub-constructs, and c) Results sub-constructs

Figure Annex A.2. Efficiency variables (frequencies per variable) ........................................131

Figure Annex A.3. Data Management variables (frequencies per variable) ............................132

Figure Annex A.4. Effectiveness variables (frequencies per variable) ......................................134

Figure Annex A.5. Resource Acquisition variables (frequencies per variable).........................136

Figure Annex A.6. Coordination variables (frequencies per variable) ....................................138

Figure Annex A.7. External-Relations Results dimensions (frequencies per dimension).......140

Figure Annex A.8. Political Effects variables (frequencies per variable)..................................140

Figure Annex A.9. Image variables (frequencies per variable) ...............................................142

Figure Annex A.10. Return-on-Investment Results variables (frequencies per variable)........144

Figure Annex A.11. Network-Level Results variables (frequencies per variable) .....................146

Figure Annex A.12. Legal Efforts variables (frequencies per variable) .....................................151

Figure Annex A.13. Resource Costs variables (frequencies per variable) ................................151

Figure Annex B.1. Adoption determinants quotations (aggregated frequencies).................179

Figure Annex B.2. Co-occurrences of determinant constructs with IOP dimensions............180

Figure Annex B.3. Co-occurrences of determinant constructs with Actor codes....................181

Figure Annex B.4. Co-occurrences of determinant constructs with Adoption Phase codes...182

Figure Annex B.5. IOP Governance quotations (frequencies per sub-construct) ....................193

Figure Annex B.6. Guidance quotations (frequencies per dimension).....................................194

Figure Annex B.7. Decision-Making Centralisation quotations (frequencies per dimension) 199

Figure Annex B.8. Brokerage quotations (frequencies per variable).......................................201

Figure Annex B.9. Enforcement quotations (frequencies per dimension).................................202

Figure Annex B.10. Accountability quotations (frequencies per variable)...............................203

Figure Annex B.11. Coercion quotations (frequencies per variable) ......................................204

Figure Annex B.12. Network Complexity quotations (frequencies per dimension).................205

Figure Annex B.13. Task Complexity quotations (frequencies per variable) ...........................208

Figure Annex B.14. Interaction Complexity quotations (frequencies per dimension) ..............210

Figure Annex B.15. Trust quotations (frequencies per dimension) .......................................211

Figure Annex B.16. Information Infrastructure quotations (frequencies per dimension) .......212

Figure Annex B.17. Mimetic Dynamics quotations (frequencies per dimension) ....................213

Figure Annex B.18. Network-External Environment quotations (frequencies per sub-

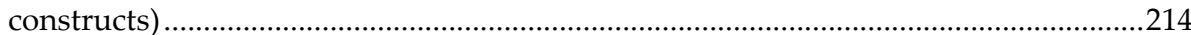

Figure Annex B.19. Political Environment quotations (frequencies per dimension) ..............215

Figure Annex B.20. Public Pressure quotations (frequencies per variable) ...........................216

Figure Annex B.21. Constituency Characteristics quotations (frequencies per variable) ........217

Figure Annex B.22. Policy and Institutions quotations (frequencies per dimension) .............218

Figure Annex B.23. Legal Framework quotations (frequencies per variable) ............................2.219

Figure Annex B.24. Budgetary Framework quotations (frequencies per variable)...................219

Figure Annex B.25. Administrative Structure quotations (frequencies per variable)...........220

Figure Annex B.26. Results quotations (frequencies per sub-construct)................................221

Figure Annex B.27. Adoption Efforts quotations (frequencies per sub-construct) ..................222

Figure Annex B.28. IOP Standards Characteristics quotations (frequencies per variable) .....224

Figure Annex B.29. Organisation-Specific Determinants quotations (frequencies per subconstruct). 
Figure Annex B.30. Organisational Structure quotations (frequencies per variable)..............226

Figure Annex B.31. Relational Mechanisms quotations (frequencies per variable) .................229

Figure Annex B.32. ICT Capability quotations (frequencies per variable) …..........................230 


\section{LIST OF TABLES}

Table 1.1. Definition of the e-Government concept...............................................................

Table 1.2. Definition of the e-Governance concept....................................................................

Table 1.3. Definition of the Government Information Network concept ..............................

Table 1.4. Definition of the Interoperability concept.............................................................10

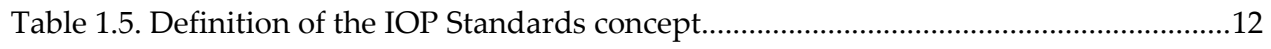

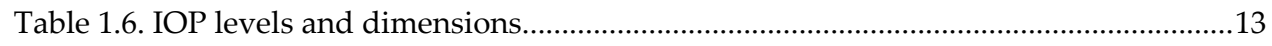

Table 1.7. Definition of the IOP Architecture concept ............................................................13

Table 1.8. Definition of the IOP Standards Adoption concept..............................................16

Table 1.9. Definition of the IOP Governance concept ............................................................18

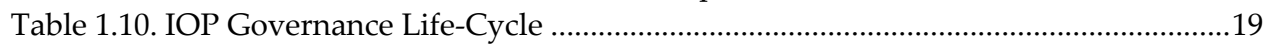

Table 2.1. Application of major innovation adoption models at individual and organisational

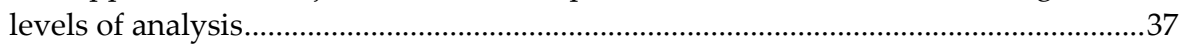

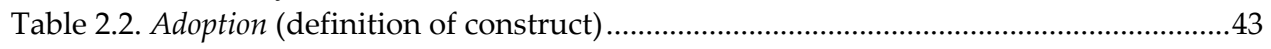

Table 2.3. IOP Governance construct (definition of construct) ..................................................4

Table 2.4. Decision-Making Centralisation (definitions of sub-construct and dimensions) ....44

Table 2.5. Enforcement (definitions of sub-construct and dimensions)....................................45

Table 2.6. Guidance (definitions of sub-construct and dimensions)........................................46

Table 2.7. Network-External Environment (definition of construct)........................................47

(Table 2.8. Political Environment (definitions of sub-construct and dimensions) ....................47

Table 2.9. Policy and Institutions (definitions of sub-construct and dimensions) ....................48

Table 2.10. Network Characteristics (definition of construct) ...................................................49

Table 2.11. Network Complexity (definitions of sub-construct and dimensions)......................50

Table 2.12. Trust (definition of sub-construct) .........................................................................50

Table 2.13. Mimetic Dynamics (definition of sub-construct)..................................................51

Table 2.14. Domain Structure (definition of sub-construct) .....................................................51

Table 2.15. Information Infrastructure (definition of sub-construct) ............................................52

Table 2.16. Organisation-Specific Determinants (definition of construct) ..................................52

Table 2.17. Organisational Capacity (definitions of sub-construct and dimensions)...............54

Table 2.18. IOP Standards Characteristics (definition of construct) ..........................................55

Table 2.19. Adoption Efforts construct (definitions of construct and sub-constructs) ............56

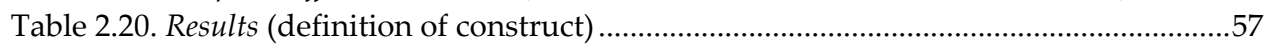

Table 2.21. Internal-Operations Results (definitions of sub-construct and dimensions) ..........58

Table 2.22. External-Relations Results (definitions of sub-construct and dimensions) ............59

Table 3.1. Operationalisation of variables for case selection......................................................68

Table 3.2. Variable variation matrix across the two cases .......................................................69

Table 3.3. Interviewees of the DKD case..................................................................................

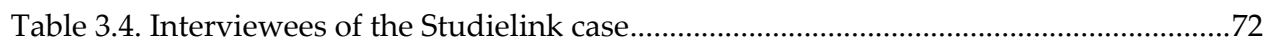

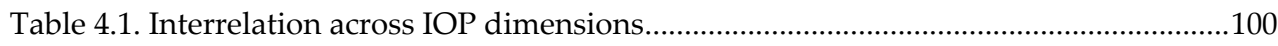

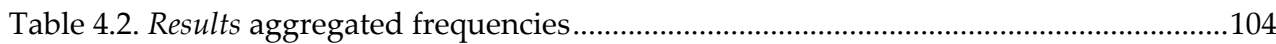

Table 4.3. Adoption Efforts aggregated frequencies ................................................................105 
Table 4.4. Actors and roles in the IOP standards adoption process.......................................118

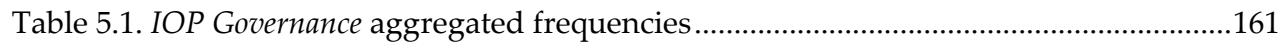

Table 5.2. Network Characteristics aggregated frequencies ......................................................163

Table 5.3. Network-External Environment aggregated frequencies ............................................165

Table 5.4. IOP Standards Characteristics aggregated frequencies.............................................165

Table 5.5. Organisation-Specific Determinants aggregated frequencies.....................................166

Table 5.6. Adoption Implications aggregated frequencies ......................................................167

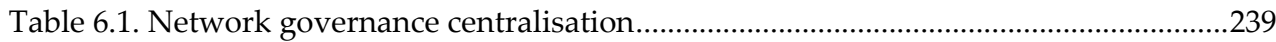

Table Annex A.1. Internal-Operations Results (aggregated frequencies) ...............................130

Table Annex A.2. Operations Costs (definitions of variable and attributes)...........................131

Table Annex A.3. Usability (definitions of variable and attributes) .......................................132

Table Annex A.4. Data Quality (definitions of variable and attributes)..................................133

Table Annex A.5. Data Security (definitions of variable and attributes) .................................133

Table Annex A.6. Service Quality (definitions of variable and attributes) ..............................134

Table Annex A.7. Responsiveness (definitions of variable and attributes)................................135

Table Annex A.8. Internal Autonomy (definitions of variable and attributes) .........................136

Table Annex A.9. Information Acquisition (definitions of variable and attributes).................137

Table Annex A.10. Financial Resources Acquisition (definitions of variable and attributes)..138

Table Annex A.11. Reporting (definitions of variable and attributes) ....................................139

Table Annex A.12. Uncertainty Reduction (definitions of variable and attributes) ................139

Table Annex A.13. External Autonomy (definitions of variable and attributes) ......................141

Table Annex A.14. Responsibility (definitions of variable and attributes)................................141

Table Annex A.15. Results Demonstrability (definitions of variable and attributes) ..............142

Table Annex A.16. Accountability Image (definitions of variable and attributes) ...................143

Table Annex A.17. Reach Expansion (definitions of dimension and attributes) ......................143

Table Annex A.18. Sow-Harvest Equality (definitions of variable and attributes)...................144

Table Annex A.19. Timing (definitions of variable and attributes) .........................................145

Table Annex A.20. Network Effectiveness (definitions of variable and attributes) ...................146

Table Annex A.21. Future Innovation (definitions of variable and attributes).........................147

Table Annex A.22. Organisational Efforts (frequencies per variable) .......................................147

Table Annex A.23. Process Efforts (definitions of variable and attributes)..............................148

Table Annex A.24. Organisational Structure Efforts (definitions of variable and attributes).149

Table Annex A.25. Technological Efforts (definitions of sub-construct and attributes) ..........149

Table Annex A.26. Semantic Efforts (definitions of sub-construct and attributes) ..................150

Table Annex A.27. Legal Efforts (definitions of sub-construct and variables) .........................151

Table Annex A.28. Infrastructure Costs (definitions of variable and attributes).....................152

Table Annex A.29. Training Costs (definitions of variable and attributes) ..............................152

Table Annex B.1. Average quotation frequencies per case and interviewee role for the IOP

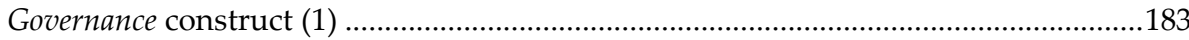

Table Annex B.2. Average quotation frequencies per case and interviewee role for the IOP

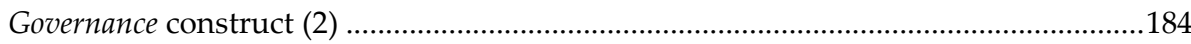

Table Annex B.3. Average quotation frequencies per case and interviewee role for the Results construct (1). 
Table Annex B.4. Average quotation frequencies per case and interviewee role for the Results construct (2) 186

Table Annex B.5. Average quotation frequencies per case and interviewee role for the Adoption Efforts construct

Table Annex B.6. Average quotation frequencies per case and interviewee role for the Network Characteristics construct (1)....

Table Annex B.7. Average quotation frequencies per case and interviewee role for the Network Characteristics construct (2).

Table Annex B.8. Average quotation frequencies per case and interviewee role for Organisation-Specific Characteristics (1)

Table Annex B.9. Average quotation frequencies per case and interviewee role for Organisation- Specific Characteristics (2).

Table Annex B.10. Average quotation frequencies per case and interviewee role for the Network-External Environment construct.

Table Annex B.11. Average quotation frequencies per case and interviewee role for the IOP Standards Characteristics construct

Table Annex B.12. Leadership and Support quotations (percentage per variable) ....................197

Table Annex B.13. Communication quotations (frequencies per variable) ..............................198

Table Annex B.14. Stakeholder Involvement quotations (frequencies per variable).................200

Table Annex B.15. Network Characteristics quotations (frequencies per sub-construct)........205

Table Annex B.16. Diversity quotations (frequencies per variable) ........................................206

Table Annex B.17. Domain Structure quotations (frequencies per dimension) ......................209

Table Annex B.18. Organisational Capacity quotations (frequencies per dimension) ............225

Table Annex B.19. Human Resources quotations (frequencies per variable) ...........................226

Table Annex B.20. Management Practices quotations (frequencies per variable)....................228

Table Annex B.21. Manager Characteristics quotations (frequencies per variable).................231 


\section{LIST OF ABBREVIATIONS}

\begin{tabular}{|c|c|}
\hline ANW & Algemene Nabestandenwet (General Law on Surviving Relatives) \\
\hline AOW & Algemene Ouderdomswet (General Law on Old Age) \\
\hline ARPANET & Advanced Research Projects Agency Network \\
\hline AWBZ & $\begin{array}{l}\text { Algemene Wet Bijzondere Ziektekosten (General Law on Special } \\
\text { Health Costs) }\end{array}$ \\
\hline BIBOB & $\begin{array}{l}\text { Bevordering Integriteitsbeoordelingen door het Openbaar Bestuur } \\
\text { (Law on Enhancing Integrity Checks by Public Administrations) }\end{array}$ \\
\hline BKWI & $\begin{array}{l}\text { Bureau voor Keteninformatisering Werk en Inkomen (Office for } \\
\text { Chain Informatisation Work and Income) }\end{array}$ \\
\hline BRON & $\begin{array}{l}\text { Basis Register Onderwijsnummer (Basic Registry Educational } \\
\text { Number) }\end{array}$ \\
\hline BSN & Burger Service Nummer (Citizen Service Number) \\
\hline BUS & Bijstandsuitkeringenstatistiek (Social Benefit Statistic) \\
\hline $\mathrm{CAB}$ & Change Advisory Board \\
\hline CBS & Centraal Bureau voor de Statistiek (Central Statistical Agency) \\
\hline CMK & $\begin{array}{l}\text { Centraal Meldpunt Ketenwijzigingen (Central Registry for Chain } \\
\text { Changes) }\end{array}$ \\
\hline CP-ICT & Coördinatiepunt ICT (Coordination Point for ICT) \\
\hline CRI-HO & $\begin{array}{l}\text { Centraal Register Inschrijvingen Hoger Onderwijs (Central Registry } \\
\text { of Enrolments in Higher Education) }\end{array}$ \\
\hline $\mathrm{CVZ}$ & College van Zorgverzekeringen (Board of Health Insurances) \\
\hline CWI & $\begin{array}{l}\text { Centrale Organisatie voor Werk en Inkomen (Central Organisation } \\
\text { for Work and Income) }\end{array}$ \\
\hline DGA & Domeingroep Architectuur (Domain Group Architecture) \\
\hline DIB & Domeingroep ICT Beheer (Domain Group ICT Administration) \\
\hline DigiD & Digitale Identiteit (Digital Identity) \\
\hline DIVOSA & $\begin{array}{l}\text { Vereniging van Directeuren voor Sociale Arbeid (Association of } \\
\text { Directors for Social Work) }\end{array}$ \\
\hline DKD & Digitaal Klantdossier (Digital Client Dossier) \\
\hline DMG & $\begin{array}{l}\text { Domeingroep Gegevens en Berichten (Domain Group Data and } \\
\text { Messages) }\end{array}$ \\
\hline DPB & $\begin{array}{l}\text { Domeingroep Privacy \& Beveiliging (Domain Group Privacy and } \\
\text { Security) }\end{array}$ \\
\hline DUO & Dienst Uitvoering Onderwijs (Executive Service for Education) \\
\hline DVB & Digitaal Verzekeringsbericht (Digital Insurance Message) \\
\hline e-GIF & e-Government Interoperability Framework \\
\hline e-Governance & Electronic Governance \\
\hline
\end{tabular}




\begin{tabular}{|c|c|}
\hline e-Government & Electronic Government \\
\hline EA & Enterprise Architecture \\
\hline EDI & Electronic Data Interchange \\
\hline EIF & European Interoperability Framework \\
\hline ERP & Enterprise Resource Planning \\
\hline EU & European Union \\
\hline G2B & Government-to-Business \\
\hline G2C & Government-to-Citizen \\
\hline G2CS & Government-to-Civil-Society \\
\hline G2G & Government-to-Government \\
\hline GBA & Gemeentelijke Basisadministratie (Municipal Basic Registry) \\
\hline GBA-V & $\begin{array}{l}\text { Gemeentelijke Basisadministratie - Verstrekkingen (Municipal } \\
\text { Basic Registry - Provision Service) }\end{array}$ \\
\hline GEA & Government Enterprise Architecture \\
\hline GEMNET & Gemeentelijk Network (Municipal Network) \\
\hline GSD & Gemeentelijke Sociale Dienst (Municipal Social Service) \\
\hline $\mathrm{HBO}$ & Hoger Beroepsonderwijs (Higher Professional Education) \\
\hline ICT & Information and Communication Technology \\
\hline IDT & Diffusion of Innovations Theory \\
\hline IF & Interoperability Framework \\
\hline IMS-LIP & Instructional Management Systems - Learner Information Package \\
\hline IND & $\begin{array}{l}\text { Immigratie en Naturalisatie Dienst (Immigration and } \\
\text { Naturalisation Agency) }\end{array}$ \\
\hline Inspectie SZW & $\begin{array}{l}\text { Inspectie Sociale Zaken en Werkgelegenheit (Inspection for Social } \\
\text { Affairs and Employment) }\end{array}$ \\
\hline IOE & Innovation-Organisation-Environment Model \\
\hline IOP & Interoperability \\
\hline IOR & Inter-Organisational Relations \\
\hline IOS & Inter-Organisational System \\
\hline IS & Information System \\
\hline ISIS & $\begin{array}{l}\text { Integriertes Steuerungs- und Informationssystem (Integrated } \\
\text { Steering- and Information System) }\end{array}$ \\
\hline ISO & International Organization for Standardisation \\
\hline IWI & Inspectie Werk en Inkomen (Work and Income Inspection) \\
\hline KING & $\begin{array}{l}\text { Kwaliteitsinstituut Nederlandse Gemeenten (Quality Institute for } \\
\text { Dutch Municipalities) }\end{array}$ \\
\hline KVA & Studielink Generic Adapter \\
\hline KvK & Kamer van Koophandel (Chamber of Commerce) \\
\hline
\end{tabular}


LADOK Lokalt ADB-Baserat Dokumentationssystem (Local EDP-based Documentation System)

MinBZK Ministerie van Binnenlandse Zaken en Koninkrijksrelaties (Ministry of Internal Affairs and Kingdom Relations)

MinOCW Ministerie van Onderwijs, Cultuur en Wetenschap (Ministry of Education, Culture and Science)

MinSZW Ministerie van Sociale Zaken en Werkgelegenheit (Ministry of Social Affairs and Employment)

MM

Motivational Model

MPCU

Model of PC Utilisation

$\mathrm{NAO}$

Network Administrative Organisation

$\mathrm{NOiV}$

Nederland Open in Verbinding (Netherlands Open in Connection)

NORA

Nederlandse Overheids Referentie Architectuur (Dutch

Government Reference Architecture)

NPM

New Public Management

OECD

Organisation for Economic Co-operation and Development

PvE

Programma van Eisen (Requirement Specifications)

PWG

Proces Werk Groep (Process Working Group)

RDW

Rijksdienst voor het Wegverkeer (Agency for Road Traffic)

RMC

Regionale Meld- en Coördinatiefunctie (Regional Registry for

School Dropouts)

ROI

ROSA

Return-on-Investment

SAGA

Reference Onderwijs Sector Architectuur (Reference Architecture for the Education Sector)

SAP

Standards and Architecture for e-Government Applications

SBAP
Administration of Persons)

Systemanalyse und Programmentwicklung (System Analysis and Program Development)

SCT

Social Cognitive Theory

SDV

Stuurgroep Dienstverlening (Steering Group on Service Provision)

SGR

SIOD

SUWI Gegevensregister (SUWI Data Register)

SIS

Sociale Inlichtingen en Opsporingsdienst (Social Information and Investigation Service)

Student Information System

SKI Stuurgroep Ketenservices ICT (Steering Group on Chain Services ICT)

SLA Service Level Agreement

SOAP Simple Object Access Protocol

SQ

Sub-Question

STUF

Standaard Uitwisselingsformaat (Standard Exchange Format) 


\begin{tabular}{|c|c|}
\hline SUWI & Structuur Uitvoeringsorganisatie Werk en Inkomen \\
\hline SUWI-ML & SUWI Markup Language \\
\hline SUWINET & SUWI Network \\
\hline SVB & Sociale Verzekeringsbank (Social Insurance Bank) \\
\hline $\mathrm{t}$-Government & Transformative Government \\
\hline TAM & Technology Acceptance Model \\
\hline $\mathrm{TCP} / \mathrm{IP}$ & Transmission Control Protocol/Internet Protocol \\
\hline TOE & Technology-Organisation-Environment Model \\
\hline ТРВ & Theory of Planned Behaviour \\
\hline TRA & Theory of Reasoned Action \\
\hline TWG & Technische Werk Groep (Technical Working Group) \\
\hline UCAS & Universities and Colleges Admissions Service \\
\hline UK & United Kingdom \\
\hline UM & Maastricht University \\
\hline US(A) & United States (of America) \\
\hline UWV & $\begin{array}{l}\text { Uitvoeringsinstituut Werknemersverzekeringen (Employee } \\
\text { Insurances Agency) }\end{array}$ \\
\hline $\mathrm{VCH}$ & Virtual Clearing House Higher Education \\
\hline VIS & Verificatie Informatie Systeem (Verification Information System) \\
\hline VNG & $\begin{array}{l}\text { Verenining van Nederlandse Gemeenten (Association of Dutch } \\
\text { Municipalities) }\end{array}$ \\
\hline VSNU & Vereniging van Universiteiten (Association of Universities) \\
\hline WAR & Wijzigingsadviesraad (Change Advisory Council) \\
\hline WBP & $\begin{array}{l}\text { Wet Bescherming Persoonsgegevens (Law on Personal Data } \\
\text { Protection) }\end{array}$ \\
\hline WERKbedrijf & UWV Employment Agency \\
\hline WEU & Wet Eenmalige Gegevensuitvraag (Single Data Request Act) \\
\hline WGB & $\begin{array}{l}\text { Werkgroup Gegevens en Berichten (Working Group Data and } \\
\text { Messages) }\end{array}$ \\
\hline WR & Wijzigingsraad (Change Council) \\
\hline WSDL & Web Service Description Language \\
\hline WSRP & Web Service for Remote Portlets \\
\hline WW & Werkloosheidswet (Law on Unemployment) \\
\hline WWB & Wet Werk en Bijstand (Law on Work and Support) \\
\hline WWW & World Wide Web \\
\hline XML & Extensible Markup Language \\
\hline XSD & XML Schema Definition \\
\hline
\end{tabular}





\section{CHAPTER 1.}

\section{INTRODUCTION}

\subsection{Introduction}

The past two decades have seen substantial transformations of public governance by means of information and communication technologies (ICTs), including administrative structures, operations and paradigms on how governments interact with their stakeholders. This is generally referred to as Electronic Governance (e-Governance ${ }^{1}$ ). One major aspect of such transformation is the increasing shift in many countries towards governing through ICTenabled inter-organisational networks (referred to as Government Information Networks), with the primary objectives of making governance more efficient and effective. Achieving these objectives essentially rests upon the ability of the organisations in these networks to electronically exchange information and services among each other - in other words, they must be "interoperable". To achieve interoperability (IOP), organisations need to adhere to a common set of standards and agreements. Achieving IOP, however, is challenging because often organisations in Government Information Networks do not adopt and comply with these standards. This dissertation aims at contributing a better understanding of IOP standards adoption by organisations in Government Information Networks, in particular the process, actors, drivers and barriers behind their adoption, and aims at providing insights and guidance how to best approach the governance on IOP in such networks.

This chapter aims to provide a basis for the subsequent chapters by defining the key concepts of the dissertation, introducing the research problem and the research questions, and providing an overview of the structure and contents of the remainder of the dissertation. Sections 1.2 through 1.5 introduce the key concepts of the dissertation (see Figure 1.1 below for a mapping of key conceptual domains). Section 1.2 first introduces the concepts of e-Government and e-Governance and situates their evolution against the historical background of the emergence of multi-actor networks as a form of governance. Section 1.3 describes the need for information sharing for such forms of governance and introduces the concept of Government Information Networks. Section 1.4 then defines the concept of IOP as a key enabler for information sharing in Government Information Networks. Section 1.5 subsequently describes the challenges of achieving IOP in Government Information Networks and the need for appropriate IOP Governance structures. The main research question is presented in Section 1.6 along with a number of

\footnotetext{
${ }^{1}$ Only brief definitions of the key concepts are given in this introduction paragraph. Full discussions and definitions of the concepts are given in the following sections below.
} 
sub-questions. Finally, Section 1.7 concludes the chapter with an outlook of the remainder of the dissertation and an outline of the subsequent chapters.

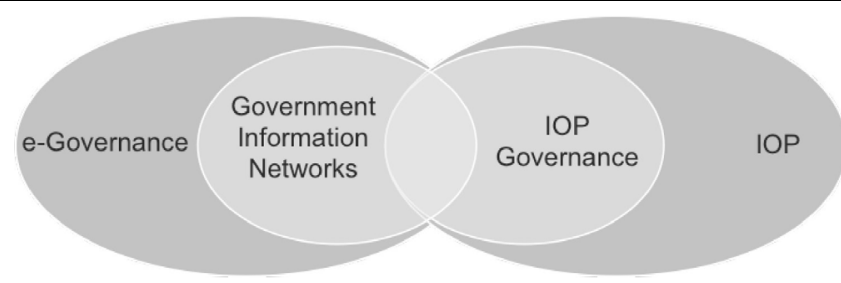

Figure 1.1. Mapping of key conceptual domains

\subsection{From e-Government to e-Governance}

Whilst they are often incorrectly used as synonyms, e-Government and e-Governance are different concepts. This section discusses how e-Governance, the concept at the focus of this dissertation, has emerged as an extension of the former, and where they differ.

\subsubsection{The e-Government Concept}

E-Government is defined here as "the use of information and communication technology (ICT) in public administration to change structures and processes of government organisations" (Löfstedt, 2005). This definition reflects the emphasis made in many eGovernment definitions on the transformational role of ICT for government operations (Grönlund \& Horan, 2004). By referring to "government organisations" only and not mentioning other actors, this definition also sets it apart from the e-Governance concept which captures ICT-enabled transformation of the relationships of government with nongovernmental partners (see Section 1.2.2 on the following page for a detailed conceptual differentiation).

E-Government is often seen as a catalyst for improvements of the way governments work. The Organisation for Economic Co-operation and Development (OECD, 2003) for instance defines e-Government as "the use of information and communication technologies, and particularly the Internet, as a tool to achieve better government" and specifies the following ways in which it can make government "better": 1) improving the efficiency of public administrations; 2) improving public service provision for customers; 3) improving the outcomes of specific policies; 4) contributing to economic policy objectives; 5) serving as a major catalyst for administrative modernisation and reform; and 6) contributing to better democracy. Whilst the specific goals behind e-Government are manifold and vary by context, this agenda is illustrative of the most common expectations from e-Government held by governments (cf. also Bekkers \& Zouridis, 1999).

\section{e-Government}

\begin{tabular}{l|l} 
Definition & $\begin{array}{l}\text { The use of information and communication technology (ICT) in public administration to } \\
\text { change structures and processes of government organisations }\end{array}$
\end{tabular}

Table 1.1. Definition of the e-Government concept 
It should be noted, however, that there is a considerable lack of consensus in defining and using the e-Government concept. There is no single widely agreed definition of eGovernment. Rather, the literature offers a diverse array of definitions that reflect different perspectives and normative standpoints. Some definitions are "narrow" and for instance focus on specific technologies such as the Internet, describing e-Government as "utilizing the Internet and the World Wide Web (WWW) for delivering government information and services to citizens" (United Nations \& American Society for Public Administration, 2002). Others argue for defining it independently from specific technologies such as the Internet and independently from specific purposes. Yildiz (2007) for instance defines e-Government simply as "the application of digital ICTs in the public sector". Under this definition, for instance an email sent by one civil servant to another in principle would also be seen as an instance of e-Government. This "wide" type of definition is considered too broad for the context of this dissertation, and not in line with the transformative orientation of eGovernment definitions generally found in practice and academic research (see Grönlund \& Horan, 2004 for an extensive discussion).

An additional definitional problem is that many sources make synonymous use of the concepts of e-Government and e-Governance, despite their distinct meanings. It is important, however, to appreciate this difference here, as it reflects historical developments that are at the centre of this dissertation: the evolution from traditional bureaucracy towards governance by networks. To understand the development of the transformative emphasis of e-Government and how the concept of e-Governance evolved from it, we need to look at the intertwining of technological evolution and the emergence of new public administration concepts from the 1990s onwards that emphasised the need for structural public sector reforms.

\subsubsection{The e-Governance Concept}

E-Governance is defined here as the transformative application of ICT in public governance systems and processes - "governance" being the framework through which government and its partners (such as the private sector and civil society) make decisions and manage their day-to-day activities, and the ways in which they interact with one another, and society at large (based on Asgarkhani, 2005).

\begin{tabular}{|l|l|}
\hline e-Governance & $\begin{array}{l}\text { The transformative application of ICT in public governance systems and processes - } \\
\text { "governance" being the framework through which government and its partners (such as the } \\
\text { private sector and civil society) make decisions and manage their day-to-day activities, and } \\
\text { the ways in which they interact with one another, and society at large }\end{array}$ \\
\hline
\end{tabular}

Table 1.2. Definition of the e-Governance concept

The essential difference between the two concepts hence is that e-Government is concerned with the ICT-enabled transformation of government-internal operations alone (including service provision). E-Governance includes this government-internal transformation through ICT, but goes beyond this narrow focus and refers to ICT-enabled transformation of the relationships of government with non-governmental stakeholders towards collaborative partnerships (Grönlund \& Horan, 2004). A key transformation of government-stakeholder relationships, and at the central focus of this dissertation, is the shift towards using ICT to 
facilitate governance by means of collaborative multi-actor networks (Estevez, 2009). To fully understand the evolution of the e-Governance concept, we therefore need to look at the historical background behind this shift. As the following discussion argues, its emergence can be seen as resulting from an interaction of technological development, changes in the nature and role of government, and an evolution in concepts of public management and governance (Brown, 2005).

Whilst they are often conceived of as phenomena that emerged over roughly the past 20 years, the origins of e-Government and e-Governance lie with the first uses of ICT by governments several decades back (Brown, 2005; Grönlund \& Horan, 2004; Yildiz, 2007). In contrast to current definitions that refer directly to the provision of public services (cf. Silcock, 2001; United Nations \& American Society for Public Administration, 2002), early usage of ICTs in the public domain was restricted to facilitation of centralised internal government processes, such as large-scale computations by mainframe computers in computation-intensive domains such as social security. Such centralised government usage of computers can be dated back to the 1950s, predating a gradual evolution towards more decentralised public-sector deployment of ICTs which resulted from the increasing combination of computing and telecommunications from the 1960s onwards. This evolution towards distributed public-sector computing was accelerated by the widespread diffusion of personal computers among civil servants from the 1980s onwards, and experienced a drastic jump forwards from the 1990s onwards with the evolution of the Internet into a powerful and ubiquitous network for electronic communication, far beyond the public realm (Yildiz, 2007). Even this early use of ICT in the public sector was never "neutral": a number of authors have studied the use of ICT in the public sector long before the advent of the Internet, arguing that ICT is typically used by public-sector stakeholders not as a neutral tool, but rather a means to achieve their respective political goals, improve their positions and shift power relations to their favour (cf. Kling, 1978; Kraemer \& Dutton, 1979; Kraemer \& King, 1986; Laudon, 1974).

Whilst this technological evolution laid the foundations for e-Government and eGovernance, up to the mid-1990s most governmental ICT-applications were limited to the government bureaucracy (i.e. e-Government). The evolution of the concept of e-Governance however - in short, the use of ICT for transforming the relation of government with its external stakeholders - only fully took hold from the 1990s onwards, after the traditional bureaucratic model was increasingly challenged by new public administration concepts that emphasised the need for structural public sector reforms.

The traditional ("Weberian") model of bureaucracies is characterised by the vertical separation of functional administrative units and predictability of production processes based on strict rules and accountability (Ho, 2002). It emphasises the grouping of officials with similar functions into the same administrative departments with multiple layers of management, resulting in the creation of large, hierarchically structured units ("silos" or "stove-pipes") (Meesters \& Zuurmond, 2008). While having the advantage of safeguarding predictability due to its emphasis on functional separation and strict accountability structures, this model came increasingly under pressure from the 1980s onwards (see also Fountain, 2001). It was precisely its emphasis on rigid routinisation, with rules becoming an 
end in themselves, which often made such bureaucracies largely inflexible, and prevented governments from responding appropriately to the challenges posed to them by a changing environment (Welp, Urgell, \& Aibar, 2007). In particular, the modern welfare state increasingly came under pressure through a mix of economic, demographic, social and political changes: faced with ever-increasing expectations from their constituencies, whilst having to deal with increasingly scarce resources to meet them, public administrations were pressed hard to become more efficient in carrying out their tasks, improve public services and to better involve citizens (Bekkers \& Zouridis, 1999). The existing traditional bureaucratic structures, associated with high inflexibility along strongly hierarchical lines of command that were more rule-oriented than focused on results, were soon identified as the major barrier to the needed efficiency-oriented reforms (Welp et al., 2007).

In the search for alternative administrative structures, governments initially started to look at the private sector for inspiration, which gradually led to the New Public Management (NPM) reform movement. NPM emphasised the re-organisation of public administration according to a market logic and governance mechanisms lent from the private sector. In essence, it was based on the vision of an "entrepreneurial" government that would see citizens as its "clients" and is characterised by decentralised and flexible administrative structures. As the various disadvantages of NPM-style reforms (such as for instance accountability problems and unintended consequences on resource allocation) gradually became clear and were increasingly abandoned, a new paradigm increasingly took hold: governance by networks (Dunleavy, Margetts, Bastow, \& Tinkler, 2005).

This paradigm tried to improve governance by shifting from traditional hierarchical management and communication towards a "network-administrative model" of collaborative governance with multidirectional communication between stakeholders (Fountain, 2001; Ho, 2002; Welp et al., 2007). The resulting administrative transformations have received a number of different labels, such as "network governance" (Kickert, Klijn, \& Koppenjan, 1997c), "joined-up government" (6, 2004), "whole-of-government" (Christensen \& Laegreid, 2007), or "connected governance" (United Nations, 2008). Whilst they differ in their nuances, they all describe the general reform movement from hierarchic towards "heterarchic" architectures of public administrations. More precisely, such heterarchy builds on "collaborative networks": multi-stakeholder governance entities where several organisations, public agencies and non-state stakeholders directly collaborate in the implementation of public policy in a collective partnership, marked by decision-making processes that are formal, consensus-oriented, and deliberative, with joined infrastructure, business processes, and relationships (Ansell \& Gash, 2007; Fedorowicz, Gogan, \& Williams, 2007). They supplant the vertical sectoral boundaries of traditional service delivery with collaborative structures that cross-cut and integrate previously separate organisations with service-specific, rather than department-specific portfolios - resulting in joint services of various departments that are oriented at citizens' "life events" rather than following bureaucratic structures (United Nations, 2008). In the following, the term Connected Governance will be used to describe such governance arrangements.

Achieving Connected Governance, however, requires a great deal of collaboration among networked organisations. Three general components of collaboration can be identified in the 
existing literature: sharing activities, sharing power, and joint structures (Ansell \& Gash, 2007). "Sharing activities" refers to the integration of the work processes of single organisations into boundary-spanning activities for joint problem solving (Ansell \& Gash, 2007; Bryson, Crosby, \& Middleton Stone, 2006; Gray \& Wood, 1991b; Kahn, 1996; Kraus, 1980; McGuire, 2006). It thus means acting together within the shared structure, and includes a wide array of possible activities such as for instance information sharing with partners, disseminating expertise and collective learning, sharing political authority, financial resources, sharing ICT with other organisations, and sharing staff and time.

"Sharing power" means that networked organisations participate in debating and deciding on the rules governing their partnership (Kraus, 1980; Thomson \& Perry, 2006), and that they reconcile their individual interests with the collective interest (Thomson \& Perry, 2006). It builds on a formal, collective, deliberative and consensus-oriented decision-making process on administrative decisions (Ansell \& Gash, 2007; Kraus, 1980). Stemming from this is the criterion of shared responsibility among collaborating actors (Gray, 1989; Kraus, 1980; Thomson \& Perry, 2006). Shared responsibility goes beyond joint decision-making and implies stakeholders' accountability for their involvement (Pasquero, 1991).

The creation of "joint structures" in the network refers to "structured agreements" between actors on the architecture within which partners interact (Ansell \& Gash, 2007). In particular, this implies that facilities are created for sharing resources, such as information, capabilities, turf, authority, financial assets, and people (Ansell \& Gash, 2007; Bardach, 1998; Bryson et al., 2006; Gray \& Wood, 1991b; Kahn, 1996; McGuire, 2006; Thomson \& Perry, 2006). Shared structure can thus be measured as the creation of a common infrastructure between partnering organisations.

ICT play a significant role in this development towards Connected Governance, both as catalyst and as enabler (United Nations, 2008). With their increasing capabilities for storing, processing and exchanging vast amounts of data, ICT were increasingly endorsed by national governments and international organisations as important tools to support these network-oriented reform efforts. This usage of ICT to enable Connected Governance gradually resulted in the phenomenon of "Government Information Networks", which is conceptualised in the following section.

\subsection{Government Information Networks and Information Sharing}

Government Information Networks are defined by Janowski et al. as "all ICT-enabled policy networks, collaboration networks and governance networks" (Janowski, Pardo, \& Davies, 2011). They define "policy networks" as "a collection of actors - government agencies, legislative offices, interest groups, etc., with a stake in a given sector and the capacity to help determine the success or failure of public policies in this sector"; "collaboration networks" as networks that "deliver public services, produce public value or generally contribute to the implementation of public policies when no government organisation or the private sector can do this effectively on its own"; and "governance networks" as networks that "integrate both policy-making and policy-implementation" through the contributions of government, business and civil society organisations (Janowski et al., 2011). Whilst the Government Information Network concept thus deliberately includes partnerships with 
non-governmental actors, it is not restricted to this and may also be used to describe government-only networks.

Government Information Networks

Definition

All ICT-enabled policy networks, collaboration networks and governance networks

\section{Table 1.3. Definition of the Government Information Network concept}

One of the first governments to make ICT an integral aspect of such public-sector reform was the US federal government with its National Performance Review (1993), resulting in the "Reinventing Government" movement as "an effort to reorient the focus of government operations from an inward-looking approach to an outward-looking one by emphasizing the concerns and needs of end users" (Ho, 2002). A key result of the "Reinventing Government" movement was the creation of a one-stop, cross-sectoral, government portal (Yildiz, 2007). A central objective behind these efforts was that "citizens no longer need to know which departments are responsible for what in the 'network' production of services. The functional departmental structure and production process of public services behind the operation of the 'one-stop service center' becomes 'invisible' to users" (Ho, 2002). ${ }^{2}$ More and more governments across the globe pursued similar ambitions of creating interorganisational public electronic services as an alternative to departmentalized service provision. In the Netherlands for instance, the government "utilizes a strategy of collaboration and partnerships which are aimed at sharing services and work with the focus on delivering more joined-up, citizen centric online services" (Janssen, Joha, \& Weerakkody, 2007).

The Digital Client Dossier (Digitaal Klantdossier, DKD), one of the two Government Information Networks used as case studies in this dissertation, can serve as a good illustrative example for this. The DKD is a network of over 400 organisations in the Dutch social security domain, including government agencies, municipal governments, semigovernmental bodies and private partners. This organisational network is centred around the digital linkage ("dossier") of work- and income-related data that these various organisations hold on their clients (such as social security numbers, income information, data on education, work history, housing etc.). This dossier provides the foundation for various services and work processes that require the linkage of such data, ranging from an online platform for work seekers, matching work seekers to job vacancies, automatic prefilling of electronic forms for benefits applications, checking the eligibility of individuals for receiving unemployment benefits, and many other purposes. Importantly, the DKD facilitates the provision of work- and income-related services to clients in joint service centres called "Work Plazas" (werkpleinen), where it enables previously separately operating organisations to provide one common front office for their clients.

\footnotetext{
${ }^{2}$ A one-stop service centre can be defined as "an umbrella organization that operates on top of existing functional departments and is intended to maximize the convenience and satisfaction of users through service integration. As the gateway for specific client groups such as businesses, residents, or visitors, the one-stop service center collects information about user demand for inquiries and service assistance and processes the information centrally. It then coordinates with functional departments such as local police, city planning, and transportation to deliver public services and carry out holistic planning" (Ho, 2002).
} 
The trend towards ICT-enabled Connected Governance and Government Information Networks is also reflected in most e-Governance "maturity" or "growth" models. Such models have been devised as analytical tools for assessing the sophistication of national eGovernance programs at various levels (cf. Klievink \& Janssen, 2009; Layne \& Lee, 2001; United Nations \& American Society for Public Administration, 2002). They are ideal-type models that observe and project abstract trends of e-Governance developments, and generally reflect a normative emphasis on Connected Governance, where increasing integration is considered to yield more sophisticated e-Governance. One illustrative example is the model by Klievink and Janssen (2009) depicted in Figure 1.2, which distinguishes between five ideal-type stages, each with increasing degrees of "connectedness": 1) "stovepipes" (few applications, services or products are interconnected, and no information is shared); 2) "integrated organizations" (ICT and services are integrated within organizations, but there is little inter-organizational integration); 3) "nationwide portal" (a nationwide portal is introduced to provide access to services for citizens, and to provide access for public agencies to information); 4) "inter-organizational integration" (integrated cross-agency services can be accessed via the portal); 5) "demand-driven, joinedup government" (instead of clients requesting services, the portal searches the relevant services and makes recommendations). The higher the maturity level in this and similar models, the more we can see a reflection of the elements of transformed government.

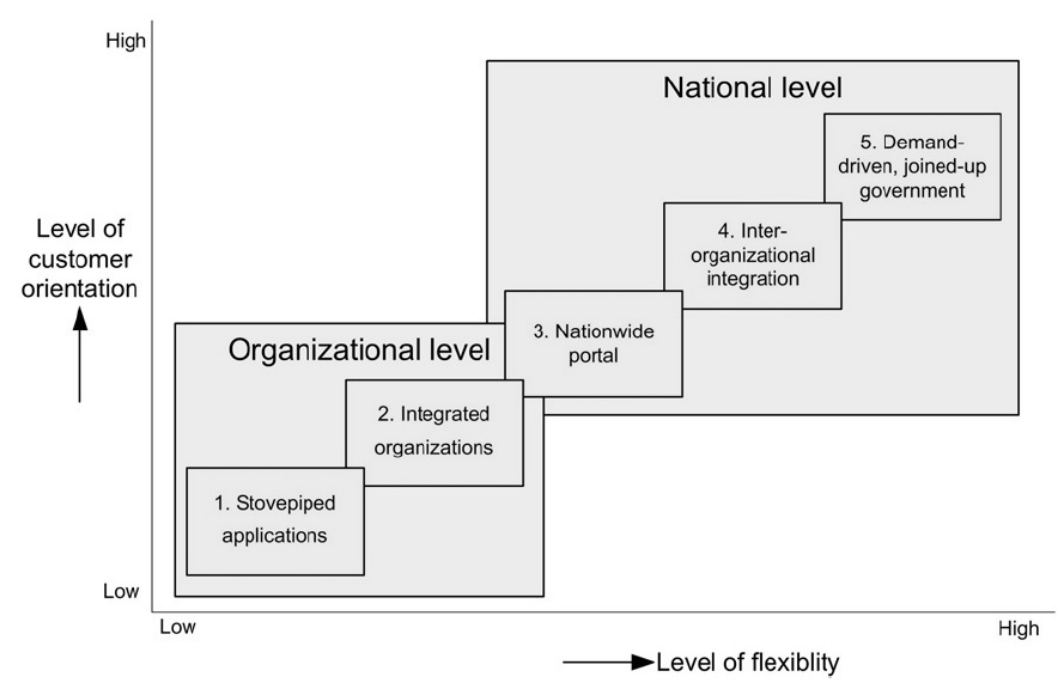

Figure 1.2. Stage-model for government transformation (Klievink \& Janssen, 2009)

Connected Governance by means of Government Information Networks involves the joint collection, re-use and sharing of data and work processes across organisations and informational domains (United Nations, 2008). Hence, Government Information Networks build on the capability of networked organisations to share information with each other (cf. Caffrey, 1998; Dawes, 1996; Estevez, Fillottrani, \& Janowski, 2012; Estevez, Fillottrani, Janowski, \& Ojo, 2010; Pardo, 2007). In general, three categories of benefits from government information-sharing can be identified: technical, organisational and political (Dawes, 1996; 
Gil-Garcia, Chengalur-Smith, \& Duchessi, 2007). Technical benefits include for instance the formation of a shared infrastructure and reduced duplication of data collection, processing and storage with an associated reduction of administration costs (Caffrey, 1998). Organisational benefits include improved decision-making, reduced administrative burden and costs, better enforcement due to the availability of more and higher-quality information (Gil-Garcia, Chun, \& Janssen, 2009). Political benefits include increased accountability, better service provision, as well as improved interactivity, responsiveness and an improved public image as a result (Gil-Garcia et al., 2009; Kinder, 2003).

Generally, most e-Governance maturity models and accounts of Connected Governance portray integration and information sharing as per se desirable, emphasising the promised benefits. However, there are also many authors pointing out that there are not only benefits to government information sharing, but that due to the advanced possibilities for linking data on individuals which it enables, it also involves risks of serious threats to privacy (cf. Dawes, 1996; Estevez et al., 2012; Estevez et al., 2010; Gil-Garcia et al., 2009). In particular when invoking concerns of national security, governments have shown to prioritise the possibilities for wide-ranging surveillance offered by data-linkage over privacy concerns. This can be, and in many cases also has been, in direct conflict with civil rights, and can erode general public trust in government. There is thus a need for a continuous debate on such risks and the implementation of checks to prevent them from materialising.

However, it is important to note that this dissertation exclusively focuses on the functionaladministrative aspects of government information sharing (i.e. how IOP can be achieved if we do want functioning government information sharing). Due to this focus, it would therefore be far beyond the scope of this dissertation to engage with and take a position in the ethical debate (i.e. whether government information sharing is a good thing and whether we should have it). It recognises the essential importance and complexity of the ethical debate, and therefore argues that to pay justice to its importance it needs to be led separately, and addressed in depth from a variety of viewpoints, including philosophical and ethical considerations, legal standpoints, as well as political and administrative perspectives. However, by shedding light on the functional issues behind IOP in Government Information Networks, in particular by providing an enhanced understanding of various stakeholders' motivations on this issue, this dissertation can nevertheless indirectly also contribute to a more informed knowledge basis for such debates on its ethical implications.

\subsection{Interoperability, a Key Enabler of Information Sharing in Government Information Networks}

Successful information-sharing in Government Information Networks thus necessitates the well-functioning communication between organisations' back-offices, where information output of one organisation can be understood and processed by another organisation. "Back-office" refers to the supporting office or process of a service delivery, which a client does not directly interact with when requesting a service (Bekkers, 2007). This is where the processing of information that is necessary for the provision of the service happens - for instance a request for necessary information from another agency. A front-office, in contrast, 
is the physical or virtual unit of a service provider that clients of an e-service, such as citizens or businesses, directly interact with (Bekkers, 2007).

However, before such communication among back-offices can take place in a seamless manner and benefits from information sharing can materialise, their systems must become compatible (Cowan, 1993) - in technological terms such as for instance common data formats, in terms of common definitions and understandings of exchanged information, and by means of joint work processes and organisational structures (cf. Bekkers, 2007; GilGarcia, Pardo, \& Cresswell, 2010; Laskaridis et al., 2007; Pardo, 2007). Effective Government Information Networks thus rest on the creation of a common (i.e. standardised) environment that ensures compatibility of organisations' systems (organisational and technological) and enables them to communicate with each other. Hence, a crucial requirement for Government Information Networks is that the systems of the various organisations in the network need to be compatible. Their ability to "talk to each other" based on a set of standards and agreements is called "interoperability" (IOP). IOP can be defined as "the ability of a system or process to use information and/or functionality of another system or process through the adherence to common standards" (dos Santos \& Reinhard, 2006).

\section{Interoperability}

\begin{tabular}{|l|l|}
\hline Definition & $\begin{array}{l}\text { The ability of a system or process to use information and/or functionality of another } \\
\text { system or process through the adherence to common standards }\end{array}$ \\
\hline
\end{tabular}

\section{Table 1.4. Definition of the Interoperability concept}

There are three essential implications to this definition. First, IOP is distinct from the concept of integration (Gottschalk, 2009; Scholl \& Klischewski, 2007; Vernadat, 2010). Whilst integration refers to the removal of organisational barriers by connecting the necessary functional units (such as information technology, people or processes) so that they act as an integrated entity, IOP refers to a loosely coupled integration where "component systems are autonomous and continue to exist on their own but can as well work as components of the integrated system" (Vernadat, 2010). Thus, inter-organisational integration does not automatically yield IOP, although integration often requires IOP in order to be successful.

Second, IOP is different from "interoperation, which describes the actual process when "independent or heterogeneous information systems or their components controlled by different jurisdictions/administrations or by external partners smoothly and effectively work together in a predefined and agreed upon fashion" (Scholl \& Klischewski, 2007). IOP on the other hand refers to the ability to interoperate. This distinction is particularly relevant because it points out that IOP should not be seen as an end in itself, but rather as a means to an end (i.e. facilitating the information exchange that enables Government Information Networks to produce public value).

Third, and most important in the context of this dissertation, IOP necessitates the adherence to a common set of standards and agreements among the organisations in Government Information Networks that ensure that their systems can communicate seamlessly with each other (cf. also EPAN, 2004; Gottschalk, 2009). Standards can be defined as "abstract specifications of the necessary features of a component that make it compatible with the rest 
of a system" (Schmidt \& Werle, 1998). There is, however, significant variety of types and definitions of standards, mainly because standards apply to a great diversity of areas, from the size of screws or bolts to interface design in telecommunications to business processes (Brunsson, Rasche, \& Seidl, 2012). Definitional confusion is often the result of applying the narrow terms of the characteristics of one particular standards type when defining the general concept of "standard". In order to situate the concept of "IOP standards" used in this dissertation within this typological landscape, the key types of standards are therefore briefly explained in the paragraphs below.

A key differentiation of standards is based on the way in which they are set, and concerns the distinction between "de jure" and "de facto" standards (cf. David \& Greenstein, 1990; Egyedi, 1996; Kauffman \& Tsai, 2010). De facto standards emerge as a result of convergence among potential adopters in their usage around a specific standard which thus assumes authority through its wide usage, but without being developed by a formal standardssetting body (Egyedi, 1996). De facto standards can be either sponsored or unsponsored (David \& Greenstein, 1990) ${ }^{3}$ : unsponsored standards, whilst being publicly documented, have no identified creator or sponsoring agency. Sponsored standards, on the other hand, are characterised by a sponsoring entity that holds a proprietary interest in the standard. In contrast to de facto standards, de jure standards are created through a formal process governed by a standards-setting organisation (Egyedi, 1996). They can be either published by voluntary standards-setting organisations or mandated by government agencies with regulatory authority (David \& Greenstein, 1990). Both these types of standards are included under the concept of IOP standards defined further below.

Other typological differentiations are concerned with the object of standardisation, rather than the process. A central distinction here concerns the difference between technological ${ }^{4}$ and non-technological standards (Brunsson et al., 2012). The former type is also sometimes referred to as "compatibility standards" and was originally coined to describe the specifications to enable a technological component to interoperate with the larger system in which it is incorporated (David \& Greenstein, 1990). Non-technological standards, on the other hand, are specifications for non-technical objects (usually processes or outcomes), and can be found in many domains from quality control to environmental management or financial reporting (Brunsson et al., 2012). They can be differentiated into process standards and outcome standards: whilst the latter only defines outcomes that adopters of the standard have to deliver, the former only specifies the processes and steps designed to achieve particular outcomes (Brunsson et al., 2012).

Both the terms "standard" and "IOP" are frequently misconceived as being restricted to technological standards - possibly because most early studies of standards focused on standardisation in the technological domain, and possibly because technological standards are more common and tangible in most persons' encounter with standards. However, both concepts have evolved from this narrow emphasis on technological standardisation towards a multi-dimensional concept which also includes standardisation in organisational and

\footnotetext{
${ }^{3}$ See also Arthur (1989) for the distinction between sponsored and unsponsored technology.

"Often, in the literature the term "technical" can be found as a synonym for "technological".
} 
semantic dimensions (Jiménez, 2012). Therefore, in this dissertation the term "IOP standard" is used as an adaptation of the above-mentioned definition by Schmidt and Werle (1998) in order to emphasise its multi-dimensional conception in the context of this dissertation. Its definition is given in the box below.

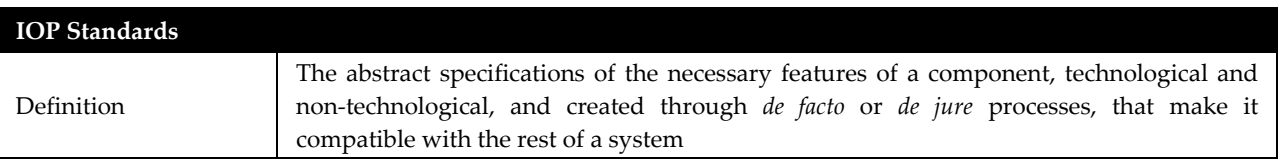

\section{Table 1.5. Definition of the IOP Standards concept}

Most commonly, a differentiation is made between the three dimensions of technological, semantic and organisational IOP (cf. Gottschalk, 2009). These dimensions are described in the following paragraphs, and a schematic overview of IOP levels and dimensions, including examples of typical objects of standardisation, is shown in Table 1.6.

Technological IOP refers to the "plumbing" of a Government Information Network, i.e. the standards that regulate the linkage of applications and services (Vernadat, 2010). It includes specifications for areas such as the network infrastructure, transfer mechanisms and data exchange protocols, interfaces, as well as technological aspects of accessibility and security (Chituc, Zazevedo, \& Toscano, 2009).

Semantic IOP concerns the "meanings" of exchanged information: the specifications that ensure that the communicating component systems interpret shared information in a consistent way (Vernadat, 2010). Relevant aspects of an IOP architecture in the semantic dimension include data definitions and ontologies, syntax and structure of information, common knowledge management methodologies, specifications that ensure the understanding of the mutual data use such as for instance adaptation and recombination of information (Chituc et al., 2009; Solli-Saether, 2010).

Organisational IOP refers to institutions and processes that enable separate organisations to exchange services in a way that allows them to operate effectively together (Gottschalk \& Solli-Saether, 2009; Vernadat, 2010). However, the organisational IOP dimension is arguably more ambiguous than the other two dimensions (Kubicek, Cimander, \& Scholl, 2011). Bekkers (2007) provides a more specific description, identifying several subordinate dimensions of organisational IOP: administrative IOP (non-conflicting jurisdictions and accountability), legal IOP (compatible legal regimes), operational IOP (compatible working processes and task routines), and cultural IOP (compatible organisational norms, values and communication practices). Elements of the organisational dimension of IOP include administrative structures such as roles and responsibilities, legal regimes such as jurisdictions and accountability, business processes and workflow, resource allocation and budgetary mechanisms, management models and performance evaluation, strategies and goals, organisational culture and skill and competence development (Bekkers, 2007; dos Santos \& Reinhard, 2012; Fountain, 2001; see also Kinder, 2003; Pardo, 2007; Scholl \& Klischewski, 2007; Vernadat, 2010).

There is also a differentiation between levels of IOP. Gasco (2012) differentiates between different levels of IOP that reflect the different degrees of e-Government maturity as 
discussed earlier: "intra-administrative IOP" concerns IOP of various units within the same organisation. "Horizontal IOP" refers to IOP among different organisations but at the same governmental level, such as IOP between various local administrations. "Vertical IOP" also concerns IOP among different organisations, but also across various government levels, for instance between local and state bodies. Finally, "cross-border IOP" refers to IOP among various national governments, such as for instance pursued by the EU's IOP policy.

In order to support the development of IOP, many national governments and international organisations have published lists of IOP standards and architectural guidelines in the form of IOP frameworks (IFs) and Government Enterprise Architectures (GEAs). An IF is a list that specifies the collection of standards, policies and guidelines that entities such as government agencies, their partners and citizens should adopt in order to become interoperable (dos Santos \& Reinhard, 2012; Guijarro, 2007). Examples of IFs are the European Union's (EU) EIF (European Interoperability Framework), or the UK's e-GIF (eGovernment Interoperability Framework). A GEA is a "blueprint" describing an approach for aligning the components of a government's architecture (i.e. the set of its key elements such as information, human and physical resources and their relationships) with each other, based on an abstract and holistic architectural description (Chen, Doumeingts, \& Vernadat, 2008; Guijarro, 2007). Examples of GEAs are the Netherlands' NORA (Netherlands Government Reference Architecture) or Germany's SAGA (Standards and Architecture for e-Government Applications).

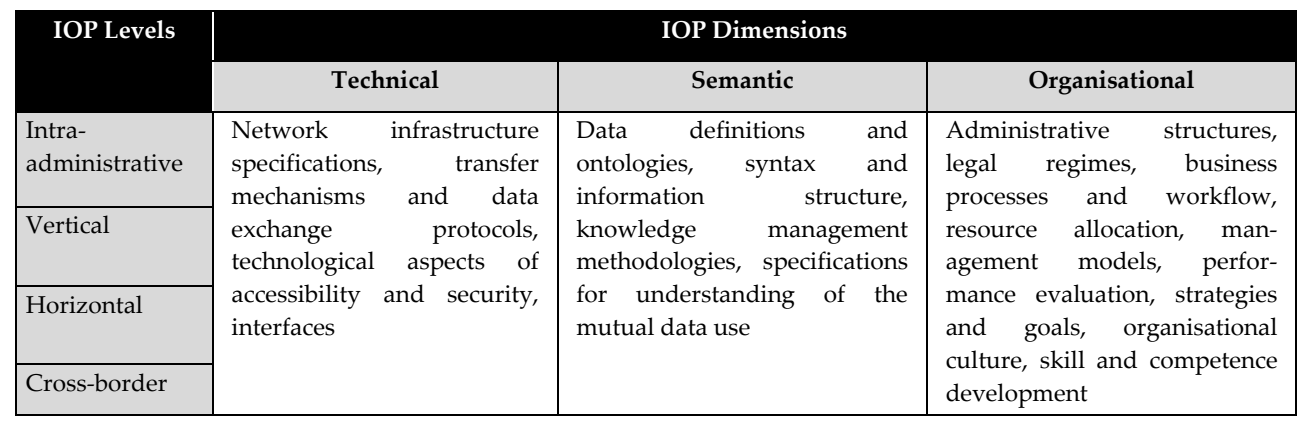

Table 1.6. IOP levels and dimensions (with examples of typical standards categories)

Unlike IFs and GEAs that provide unified frameworks to specify standards at the national or supranational levels, the set of standards in Government Information Networks is usually not collectively published in one document. Rather, it is a loose, and often unstructured collection of various standard specification documents, contracts, and informal agreements. Such a set of IOP standards in a Government Information Network is here called a network's "IOP architecture", and can be defined as that network's "range of technical specifications, systems, standards, guidelines and policies that are supplementary to each other" (dos Santos \& Reinhard, 2006).

IOP Architecture

Definition

The range of technical specifications, systems, standards, guidelines and policies that are supplementary to each other

Table 1.7. Definition of the IOP Architecture concept 
Only when all partners adhere to this IOP architecture can seamless communication between back-offices work and can the benefits of inter-organisational e-Governance be achieved. A basic model of the role of IOP for government information sharing, showing the situations before and after standards adoption, is provided in Figure 1.3 below. However, as the following section argues, the desired IOP between organisations is often not achieved, which points to a need for better-targeted governance regarding IOP in order to facilitate the adoption of IOP standards by organisations in Government Information Networks.

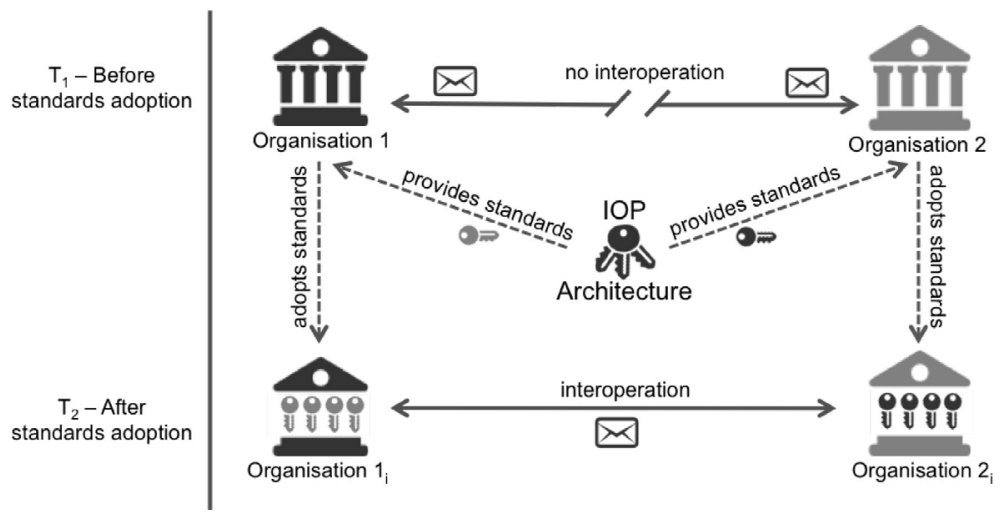

Figure 1.3. Role of IOP for government information sharing

\subsection{Standards Adoption and the Need for Interoperability Governance}

Whilst increasing numbers of Government Information Networks emerge and governments try to facilitate their operations by publishing IFs and GEAs, actually achieving interoperable e-Governance proves to be difficult. Standardisation is a complex process, involving many and diverse actors that might share an aversion to incompatibility, but might not agree on how to overcome it by means of standards (Schmidt \& Werle, 1998). There is widespread consensus in both governmental and academic assessments that in most cases, Government Information Networks have continuously encountered substantial difficulties with back-office collaboration because of difficulties to achieve IOP (Bekkers, 2007; dos Santos \& Reinhard, 2012; European Communities, 2010a; Fountain, 2001; Pardo, 2007; Scholl \& Klischewski, 2007).

At European level, the European Commission for instance has stated already in 2003 that "the reality today is the emergence of 'islands' of e-Government that are frequently unable to interoperate due to fragmentation resulting from uncoordinated efforts in developing the services, at all levels of public administration" (European Communities, 2003). Seven years later, it still pointed out the lack of IOP among public authorities as a major stumbling block in the EU's Digital Agenda: "Europe does not yet reap the maximum benefit from interoperability. Weaknesses in standard-setting, public procurement and coordination between public authorities prevent digital services and devices used by Europeans from working together as well as they should" (European Communities, 2010a). Similarly, the Malmö Ministerial declaration on e-Government declared that there is a need for 
"promoting a common culture of collaboration and [for] improving the conditions for interoperability of our administrations" (European Communities, 2009). Taking into account these assessments, the European Interoperability Framework stresses the importance of governance and coordination of IOP initiatives across administrative levels (European Communities, 2010b).

Assessments of the degree of IOP at national levels are mostly not more favourable. In the Netherlands for instance, the lack of IOP in public administration was formally recognised in 2007 with the Ministry of Economic Affairs publishing the "Action Plan Netherlands Open in Connection" (Actieplan Nederland Open in Verbinding, NoiV), which called for stronger steering and commitment in terms of policy and governance for achieving IOP and launched the NOiV programme. A study on the governance of IOP commissioned by the Standardisation Forum (Forum Standaardisatie), a body in charge of standardisation in the Dutch public administration, found that a significant threat to the further development of eGovernance in the Netherlands is that adoption and compliance with standards gets too little attention in current governance on IOP: in particular, the study finds that whilst making agreements and setting standards is not so much the problem, the actual problem is a lack of commitment and compliance by the organisations in the administration (Thaens, 2009). The Standardisation Forum also commissioned a study on the state of IOP in intersectoral public service networks, which found that "there is a very limited degree of IOP across sectors and that the applications are very divergent in their nature" (Capgemini, 2010, translation from Dutch by the author). The study also points out that achieving such IOP is in particular dependent on the capacity and commitment of the implementing executive organisations to make the necessary investments in IOP. Therefore, it argues, there is a need for proper change management and governance to create momentum and willingness among these parties to adopt the necessary standards. Furthermore, in 2011, the Scientific Council for Government Policy (Wetenschappelijke Raad voor het Regeringsbeleid, 2011) provided an extensive analysis to the cabinet that warns that there is a discrepancy between the Government's ambitions to shift towards networked governance, and the fragmentation that characterises the situation in reality. It argues that whilst through the use of ICT, the government de facto has developed into an "information government" which is characterised by networked information streams between sectors and organisations, the politicaladministrative thinking is not aligned with this shift and is instead still marked by isolated "islands" of approaches and applications. ${ }^{5}$

Achieving IOP in Government Information Networks is challenging because it requires that all organisations in the network adopt and comply with the IOP standards from its IOP architecture. IOP standards adoption consists of the formal adoption decision (whether to adopt or reject the standard) and the actual deployment of the standard (its implementation and compliance) (cf. Bala \& Venkatesh, 2007). This reflects a tradition in the adoption literature which conceptualises adoption as consisting of multiple stages where the adoption

\footnotetext{
${ }^{5}$ It should be noted that the Netherlands is repeatedly among the "top performers" in the UN's e-Government ranking, in particular on its "Online Service Index" which aims to measure the degree of "connected governance" achieved in a country: in 2010 it was ranked $12^{\text {th }}$, and in 2012 it was ranked $5^{\text {th }}$ on this index (United Nations, 2010, 2012). It might thus be assumed that given the persistence of IOP problems for such a top performer, many other countries that score lower on this dimension face similar or even bigger problems with achieving IOP.
} 
decision is conceptually distinguished from subsequent stages such as implementation or compliance (cf. Cooper \& Zmud, 1990; Kwon \& Zmud, 1987; Tornatzky \& Klein, 1982).

However, several authors in the adoption literature have also argued that depending on context and objectives of a study, an "aggregate" conceptualisation of adoption that includes adoption decision and implementation or compliance is more meaningful (Fichman, 2001; Tornatzky \& Klein, 1982), and various studies (also from the fields of e-Government and public-sector innovation) have use such aggregated definitions (cf. Damanpour \& Schneider, 2006; Dimitrova \& Chen, 2006; Heeks \& Santos, 2009; Iacovou, Benbasat, \& Dexter, 1995). For for the context under study here - the achievement of IOP in Government Information Networks - merely deciding to adopt a standard without complying with it would in fact be meaningless as it cannot result in IOP. Hence, only by including compliance does adoption thus become a meaningful concept for the context under study here. As a result of the previous points, the data collected for this study aggregates adoption and compliance (see the formulation of interview questions in Annex F). In line with the above arguments and the underlying context and data for this study, IOP standards adoption is defined here as organisations' actual adoption of, and compliance with the IOP standards specified in the IOP architecture of a Government Information Network. ${ }^{6}$

\begin{tabular}{|l|l|}
\hline \multicolumn{2}{|l|}{ IOP Standards Adoption } \\
\hline Definition & $\begin{array}{l}\text { Organisations' actual adoption of, and compliance with the IOP standards specified in } \\
\text { the IOP architecture of a Government Information Network }\end{array}$ \\
\hline
\end{tabular}

Table 1.8. Definition of the IOP Standards Adoption concept

Adopting a network's IOP architecture necessarily requires the organisations in the networks to undergo changes by mutual adjustment with regard to administrative, legal, operational, technical, semantic, and cultural dimensions (Bekkers, 2007). Adjustments in these domains can impose considerable pressure for transformation on organisations, and participating in Government Information Networks thus often requires substantial investments in organisational change from the partnering organisations. The necessary collaboration among managers of the partnering organisations to achieve IOP is thus necessary, but often missing. Ideally, network partners would have the willingness and resources to take the necessary steps for such change in order to reach IOP. However, in practice this proves to be a highly challenging goal. Partner organisations cannot, or do not always want to make the organisational changes that are implied by adoption of the standards from a network's IOP architecture. In short, lacking adoption of IOP standards by partner organisations is one of the key barriers to successful Government Information Networks.

In order to get a more detailed understanding of the challenges with regard to the adjustments that are necessitated by various IOP standards, some examples of common challenges in the three IOP dimensions are given in the following paragraphs. In the technological IOP dimension, the key challenge is that organisations operate old "legacy systems" that do not allow automated data exchange because they do not allow interoperation along the above-mentioned aspects (Kubicek et al., 2011). This requires

${ }^{6}$ See also Section 2.4.1 for an elaboration of this concept. 
investments into changing these systems, or in some cases, even replacing them. However, organisations often are uncertain about such technological change and do not know how to prepare for it (OECD, 2003). In the semantic IOP dimension, the challenge is that organisations often already have developed highly specific data definitions over time, which typically have become deeply inscribed into the core of these organisations such as business models, service catalogues, and laws and regulations (Solli-Saether, 2010).

With regard to the organisational IOP dimension, the challenge is that Government Information Networks are confronted with incompatibilities in all aspects of organisational IOP, especially with increasing numbers of organisational boundaries to be crossed, and of organizational processes to be changed (Pardo, 2007). One problem is the fragmentation of government along constitutional, legal, and jurisdictional lines (Scholl \& Klischewski, 2007). In addition, organisational managers need to coordinate the collaborative work processes (Fedorowicz et al., 2007) since "the development of separate operating procedures, control mechanisms, information flows, and work flows makes such integration exceedingly difficult, leading to serious problems, quick disintegration, or outright failures of information system initiatives that depend on not only information integration, but process integration" (Pardo, 2007). Developing new inter-organisational processes can require substantial changes to organisations' business processes, which even can cause "ripple effects" and impose adjustment requirements on other stakeholders (Fedorowicz, Gelinas Jr., Gogan, \& Williams, 2008). Finally, adjustments to organisational culture may often be necessary, "especially in public sector projects, given the diversity of perspectives, objectives, values, and cultures among project participants (Dawes, 1996; Dawes and Pardo, 2002) and given that IT projects in the public sector have an important political component" (LunaReyes, Gil-Garcia, \& Cruz, 2007).

Organisational IOP is arguably the most important dimension, and at the same time also the most difficult to achieve because these aspects are deeply entwined with the core structures of organisations, and have grown from social, political and economic structures that have developed over time (Fountain, 2007; Laskaridis et al., 2007; Pardo, Nam, \& Burke, 2012). Fountain (2007) even argues that "in many cases, the reason for presumed technology failure lies in inadequately conceptualized and managed organizational change efforts meant to build collaborative inter-organizational capacity". Moreover, organisational IOP is also the least structured dimension: "organizational IOP, in contrast [to the other dimensions], seems to be a residual category without [existing] standardizations. These different degrees of structuring at the three levels contrast with the relevance of each for achieving interoperation. If there is no coordination between different units' workflows, no effective e-Government service involving their collaboration can be constructed" (Kubicek et al., 2011).

Given both the necessity and the challenge of achieving IOP for functioning Government Information Networks, the governance of IOP becomes a key factor for achieving it (Abramowicz, Bassara, Wisniewski, \& Zebrowski, 2008; Klischewski \& Askar, 2012; Kubicek, 2009; Kubicek et al., 2011; Pardo \& Burke, 2009; Pardo et al., 2012). Cowan (1993) argues that governments should play a key role for ICT standardisation in general, by setting appropriate standards and by encouraging their adoption and diffusion. This 
argument is in line with more general arguments that the way in which collaborative publicsector networks are governed is an important influence on network performance (Provan \& Kenis, 2008; Span, Luijkx, Schols, \& Schalk, 2012).

Broadly speaking, "IOP governance" concerns the institutional structure of decision-making on IOP standards. Irrespective of the actual subject domain of interest, "governance" can be defined as "the definition of rules, processes and procedures guiding strategic decisions; roles, relationships and responsibilities of organizations/people involved; objective evaluation metrics of performance" (Abramowicz et al., 2008). ${ }^{7}$ With regard to the governance of IOP, many definitions are based on the concept of "IT governance", which refers to "specifying the decisions, rights and accountability framework to encourage desirable behavior in the use of IT" (Weill \& Ross, 2004). The definition of IOP governance adopted here comes from Pardo and Burke (2009), who define it as "the existence of appropriate decision-making rules and procedures to direct and oversee government IOP initiatives that are planned or underway".

\begin{tabular}{|l|l|}
\multicolumn{2}{|l|}{ IOP Governance } \\
\hline Definition & $\begin{array}{l}\text { The existence of appropriate decision-making rules and procedures to direct and oversee } \\
\text { government IOP initiatives that are planned or underway }\end{array}$ \\
\hline
\end{tabular}

Table 1.9. Definition of the IOP Governance concept

Kubicek and Cimander (2009) make a more detailed differentiation and distinguish between a "political governance" aspect of IOP governance (i.e. the negotiation and implementation of an IOP architecture) and an "IT governance" aspect (i.e. the management of the actual operation of information sharing between systems).

The circumstances for IOP governance in Government Information Networks are significantly different from those in the private sector (Kubicek et al., 2011). Whereas management in private-sector settings can make use of hierarchical lines of command, these are largely absent in multi-organisational networks in the public sector: "the great challenge for the governance of cross-agency public services and for achieving the necessary interoperation arises from the lack of established vehicles for negotiating agreements, and frequently such vehicles have to be created" (Kubicek et al., 2011).

Kubicek, Cimander and Scholl (2011) present a life-cycle model for IOP governance which comprises several phases during which this conflict between hierarchical and distributed decision-making plays out. In their model, IOP governance begins with an initiation phase, in which the service domain of an e-Governance project is mapped and a stakeholder analysis is carried out to identify their needs and wants. The next stage is the choice of an IOP governance model for specifying the applicable IOP standards. Two choices apply at this stage: whether to specify the standards by existing or by newly created institutions, and how to represent the involved organisations in the specification process. With regard to the

\footnotetext{
${ }^{7}$ It should be noted that there are many definitions of governance, referring to a quite diverse array of issues including corporate governance, global governance, "good" governance, network governance, and others. A discussion of this conceptual diversity is beyond the scope and relevance of this dissertation, and hence a "generic" definition is adopted here. For an encompassing discussion of the governance concept, the interested reader is referred to (Kjaer, 2004) and (Kitthananan, 2006).
} 
former, they identify four possible options: to use existing institutions in the planning of the project (the most commonly chosen option), to use an existing working group made up of representatives from involved organisations, to create a new permanent institution, or to create a new temporary working group. With regard to stakeholder participation, there are three options: no representation at all, representation of selected organisations in a pilot, or representation of all organisations.

The next phase in the life-cycle model is the choice of an organisational model for achieving IOP in the collaborative network. Here, the choice is to either opt for using a centralised intermediary (such as for instance a data clearing house), or to opt for standardisation in a federational structure that involves striking agreements with regard to coordinated workflows and technical standards. The next stage is the selection, or definition, of the applicable standards, followed by the implementation stage. At this stage, two fundamental choices have to be made with regard to legitimisation and authorisation, resulting in a total of four options: first, adoption of IOP standards is either made mandatory or a voluntary choice. Second, each of these options can be either codified by legislation, or by contractual agreements. This choice generally depends on the necessity of full adoption of the IOP standards. The implementation stage is followed by the operational phase, in which IOP governance becomes concerned with the support of interoperation. Here, the choice is, in line with the chosen organisational model, between federative standardisation and supportive intermediary services. Finally, the last phase of the IOP governance life cycle is evaluation, and, if required, making the necessary changes such as updating standards. The life-cycle is presented below in Table 1.10.

\begin{tabular}{|l|l|}
\hline Phase & Key Steps and Choices \\
\hline Initiation & $\begin{array}{l}\text { Mapping service domain } \\
\text { Stakeholder analysis }\end{array}$ \\
\hline $\begin{array}{l}\text { Selecting model for } \\
\text { standards setting }\end{array}$ & $\begin{array}{l}\text { Specify standards by new or existing institutions } \\
\text { How to represent stakeholders in the standards-setting process }\end{array}$ \\
\hline $\begin{array}{l}\text { Selecting organisa- } \\
\text { tional model }\end{array}$ & Centralised intermediary or federational structure \\
\hline $\begin{array}{l}\text { Setting/implementing } \\
\text { applicable standards }\end{array}$ & $\begin{array}{l}\text { Mandatory or voluntary standards adoption } \\
\text { Codification by legislation or contractual agreements }\end{array}$ \\
\hline Operation & Federative standardisation support or intermediary support services \\
\hline Evaluation & Evaluating and making necessary changes \\
\hline
\end{tabular}

Table 1.10. IOP Governance Life-Cycle (adapted from Kubicek et al., 2011)

As the IOP governance life cycle model presented above shows, an important choice for IOP governance in Government Information Networks throughout the life cycle of the governance process is whether decisions on IOP should be made in a centralised, top-down manner at network level with adoption being mandatory, or whether they should be made in a decentralised, bottom-up manner that leaves organisations autonomous with regard to adoption of IOP standards. The academic literature is in debate whether centralised and topdown approaches or decentralised and bottom-up approaches are more suitable for successfully governing IOP in Government Information Networks (Bekkers, 2007; Brown, O'Toole, \& Brudney, 1998; Homburg \& Bekkers, 2002; Span et al., 2012). 
On the one hand, the arguments for a centralised approach essentially point to the complexity of public-sector networks, especially in terms of number and diversity of actors, and the resulting difficulty to reach agreements if decision-making in the network is not located centrally. Central steering in public management is associated with clear goals, more streamlined information flows, lower costs, and increased control (Kickert, Klijn, \& Koppenjan, 1997a). With regard to the management of e-Governance, centralised steering has been argued to be more cost effective, avoid duplication and improve consistency, share resources and improve compatibility of systems (Heeks, 2006).

On the other hand, there is a substantial number of authors pointing out the limitations of centralised governance in public networks and e-Governance, arguing for decentralised approaches or hybrid compromises between top-down and bottom-up rule. Centralised governance, these accounts argue, are flawed by the limited information available to central steering actors (being remote from implementation), failing to use the knowledge and resources of local actors (cf. Heeks, 2006; Kickert et al., 1997a). They argue that centralised governance reinforces bureaucratisation and hence limits effectiveness and efficiency (van Gunsteren, 1976). Criticisms of centralised governance are also expressed by many authors in the domain of e-Governance (for a review see Heeks, 2006) and include heavy time consumption and communication costs (due to longer information flows), limited responsiveness to user requirements (design-reality gaps of system design), as well as higher inflexibility and increased vulnerability due to dependence on a central steering actor.

Given that both approaches to governance of IOP have advantages and disadvantages, it is difficult to know how governance structures should be designed in order to ensure collaboration among partners in public networks such as Government Information Networks (Dekker, 2004; Span et al., 2012; van Slyke, 2007). Several authors argue that this choice of governance approach in collaborative public-sector networks should be made with view to the specific circumstances and characteristics of each inter-organisational network, so that a context-sensitive approach to network governance is chosen (cf. Provan \& Kenis, 2008; Span et al., 2012). Similarly, Heeks (2006) argues that for the management of eGovernance projects and networks, hybrid approaches that reconcile the centralised and decentralised approaches are most suitable.

The key question, however, remains where along the spectrum between centralisation and decentralisation such a hybrid approach should be chosen. Heeks argues that there is no one-size-fits-all answer to this question, and that the choice essentially depends on the characteristics of a given e-Governance project or network. Therefore, in order to devise an appropriate IOP governance approach in Government Information Networks, it is important to identify and understand the role of the factors determining the adoption of IOP standards by organisations in these networks. This provides the basis for the research questions presented in the following section.

\subsection{Research Questions}

This dissertation addresses the issue of lacking IOP in Government Information Networks described in the previous section. Drawing on the fact that IOP requires the adoption and 
adherence to standards and agreements by partnering organisations, it attempts to enhance our understanding of what determines the adoption of such IOP standards by organisations, and in particular, how the achievement of IOP in such Government Information Networks can be governed. The main research question of this dissertation therefore is: "What are the factors that determine the adoption of IOP standards by organisations in Government Information Networks, and what are their implications for effective IOP governance?"

In order to answer this overall research question, this dissertation addresses the following sub-questions (SQs):

SQ1) How can we conceptualise IOP standards adoption in Government Information Networks? In order to understand the adoption of IOP standards, we need to establish a precise understanding of what exactly it is that adoption decisions are made about, and what the implications of IOP standards are for the organisations adopting them. As the discussion in Chapters 2 and particularly Chapter 4 show in detail (see Section 1.7 below for a brief outline of individual chapters), despite the plentiful assessments of the necessity for IOP and descriptions of the lack of it, there is surprisingly little known about the actual adoption of IOP standards. Hence, a number of questions in this regard are left unanswered or insufficiently addressed: first, what are the kinds of IOP standards encountered in Government Information Networks? Can we categorise them in a meaningful way in order to make informed statements about the determinants of IOP standards adoption? Second, what are the implications of these IOP standards for organisations: what are the efforts required for adoption, and what are the results from adoption? Third, what are the processes of IOP standards adoption in Government Information Networks? And related to this, what are the relevant actors that are involved in these processes?

SQ2) What are the factors that determine the adoption of IOP standards by organisations in Government Information Networks? As the theory review in Chapter 2 argues, existing research investigating IOP standards adoption in Government Information Networks is scarce, and lacks appropriate models on adoption determinants. Hence, in order to understand how IOP in Government Information Networks can effectively be governed, we need to understand what the factors are that influence organisations in these networks: what are the relevant factors that have a significant influence on the intention for IOP standards adoption? And which factors are relatively more and which ones relatively less relevant for organisations' adoption of IOP standards?

SQ3) As the discussion in Section 1.5 above and the detailed elaboration in Chapter 6 show, there is no consensus in the literature on whether inter-organisational networks (including Government Information Networks) should be governed by centralised or decentralised structures. Therefore, an important question to address is how do different degrees of IOP governance centralisation affect the adoption of IOP standards in Government Information Networks, and how can this be explained? Should the degree of governance centralisation be dependent on a network's characteristics such as network complexity? And if so, which degree of governance centralisation should be used in which context of network complexity? 


\subsection{Structure and Outline of the Dissertation}

This dissertation addresses these questions by means of the following chapter structure (visualised in Figure 1.4 below). First, Chapter 2 presents a literature review that establishes the theoretical background for the study of adoption determinants and produces a preliminary theoretical model for studying the adoption of IOP standards by organisations in Government Information Networks. In the first part, the chapter delineates the relevant fields of literature, reviews the relevant studies in these fields, and identifies the gaps in the literature that this dissertation aims to close. The second part of the chapter then synthesises a preliminary model of IOP standards adoption determinants from the relevant literature. This model provides the theoretical basis for the empirical analysis in Chapters 4 to 6 .

Chapter 3 presents the methods used for data collection and analysis and thus establishes the methodological foundation for the ensuing empirical chapters. It describes and provides the methodological motivations underlying the qualitative case study method used. The chapter also gives a detailed overview of the two Government Information Networks studied as cases, including their policy background, information infrastructure and IOP governance structure.

Chapter 4, based on the case study data, provides an empirically based conceptualisation of IOP standards adoption in Government Information Networks. In particular, it discusses the various implications of IOP standards adoption for organisations (i.e. adoption efforts and results from adoption). This is followed by an analysis of the standards-adoption process, and of the actors involved in this process. It thus addresses SQ1 presented above.

Chapter 5 investigates the determinants of IOP standards adoption based on data from the case studies. It thus addresses SQ2 presented above by validating and refining the theoretical model developed in Chapter 2. Each of the determinants specified in the theoretical model is discussed in detail, together with its relative relevance for stakeholders. Based on this analysis, a complete theoretical model on the determinants of IOP standards adoption by organisations in Government Information Networks is presented at the end of the chapter.

Chapter 6 then addresses SQ3 presented above, and analyses how different degrees of IOP governance centralisation affect the adoption of IOP standards in Government Information Networks. In particular, the chapter investigates whether the effect of different degrees of IOP governance centralisation on standards adoption depends on how it matches a key characteristic of Government Information Networks: the complexity of the network. The chapter first discusses previous theory on the relationship between governance centralisation and network complexity. Subsequently, by means of a comparative analysis of the two case studies, several propositions are developed on the interdependence of IOP governance centralisation and network complexity in their effects on IOP standards adoption in Government Information Networks.

Chapter 7 then provides the overall conclusions for this dissertation. It gives a summarising synthesis of the findings along the main research questions addressed, and discusses its 
contributions to theory and practice. Finally, the chapter discusses the limitations of the dissertation, and concludes by giving recommendations for future work on this topic.

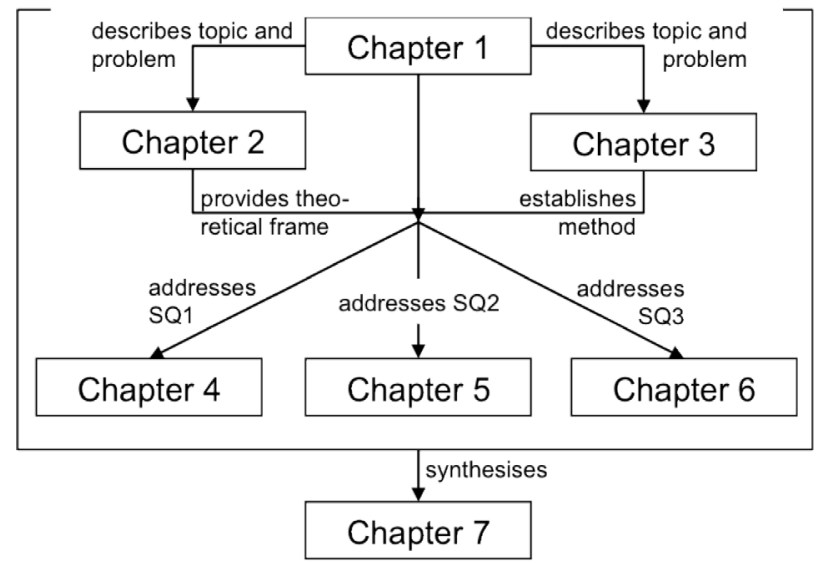

Figure 1.4. Chapter structure of the dissertation 



\section{TOWARDS A THEORY OF INTEROPERABILITY STANDARDS ADOPTION IN GOVERNMENT INFORMATION NETWORKS 8}

\subsection{Introduction}

The previous chapter has introduced the focus of this dissertation on the adoption of IOP standards by organisations in Government Information Networks. This chapter aims to anchor this dissertation theoretically in the relevant fields of theory, and to derive a preliminary theoretical model for the adoption of IOP standards in Government Information Networks, as a basis for the investigations carried out in the following chapters.

This is approached by structuring the chapter into five main sections. Following this introduction, a brief description of the method used is given (Section 2.2). In Section 2.3, the key fields of literature with relevance to adoption determinants are then discussed. This section begins with discussing the relevance of the literature on the diffusion of innovations for the topic of this study, and reviews the relevant studies in this field (Section 2.3.1). This is followed by a discussion of relevant theories on technology acceptance (Section 2.3.2). The chapter also identifies some shortcomings in the applicability of currently existing theory for studying IOP standards adoption in Government Information Networks (Section 2.3.3). In Section 2.4 then, the chapter therefore develops a preliminary theoretical model for understanding the adoption of IOP standards in Government Information Networks, based on an extensive review of the literature from the relevant fields, such as public administration and inter-organisational relations. Sections 2.4.1 through 2.4.8 each present one of the key constructs of the model, and the entire preliminary model is then presented in Section 2.4.9. This preliminary model presented at the end of this chapter is then used and refined as a guiding theoretical framework for the empirical analysis in subsequent chapters. The conclusions of the chapter are presented in Section 2.5.

\footnotetext{
${ }^{8}$ A summarised version of parts of this chapter has been published as Henning (2013a). An extended version of this paper has been invited for publication in a special issue in Government Information Quarterly on the ICEGOV2013 conference and submitted for review. Parts of this chapter draw on literature surveys carried out by Paul Coenen and Niklas Funk, carried out as part of their MSc theses which were guided and supervised by the author together with Dr. Rita Walczuch, Maastricht University.
} 


\subsection{Methodology}

For this chapter's purpose of synthesising a model of determinants from extant literature, first a selection had to be made of what constitutes the relevant body of research. Two general approaches could be used for this. Either, a "rigid" selection approach could be taken, in which all publications matching pre-specified keywords in a specified interval (i.e. in a particular period and particular journals or indexed databases) are selected and then analysed. An alternative strategy is to delineate the field through a more targeted approach based on informed judgement of relevance through the researcher. In that approach, based on the knowledge of the subject matter and of a number of relevant initial sources, a "snowballing" strategy is used to identify additional search parameters (such as new search terms and references to related studies), thus resulting in an incrementally growing body of relevant literature (Ridley, 2012).

The former approach has the appeal of a more rigid and easily replicable method which might for instance be useful for "systematic literature reviews" that aim at establishing the state of the art or trends in a specific field. However, it is argued here that the latter approach is more meaningful for the purpose of this chapter - a "meta-synthesis" or "narrative synthesis" aiming at identifying and integrating the most relevant and contextspecific sources to construct a model in an under-theorised field. The reason is that it is more flexible and purposeful to allow the selection of literature to be guided by substantive content instead of fixed pre-specified parameters. Hence, the strategy used here was to first identify two fundamental theories with relevance to adoption models and the bodies of relevant literature around them: the diffusion of innovations theory and the technology acceptance theory (elaborated in Sections 2.3.1 and 2.3.2). In addition, the public administration literature fields of public-sector innovation, e-Governance, interorganisational relations and network governance were identified as additional areas of relevance (elaborated at the end of Section 2.3.3). Subsequently, based on an initial pool of studies in all these fields, the above-mentioned snowballing approach was then used for identifying additional studies in these areas. In total, this approach yielded a pool of over 140 studies that were reviewed, providing a substantial basis for a theoretical metasynthesis.

The second step then was to distil from this pool of relevant literature a list of potential determinants of IOP standards adoption. From this body of literature, a total of 401 variables and concepts have been extracted and compiled as an initial "source list" of potential determinants. The final step was then to synthesise and condense all the identified determinants into a meaningful and useable model. Since many determinants were mentioned in multiple studies (although often with different names or labels), there was considerable conceptual overlap in this source list. To address this, where two or more items from the list of identified determinants were referring to the same (or highly similar) concept, they have been collated and renamed into a new determinant. In addition, where determinants in the list were related, but not similar enough to be meaningfully collated, they have been grouped together under a higher-order determinant which constitutes a more abstract "umbrella" for these related determinants. This umbrella determinant would be either another determinant from the source list (in case it included one which represented 
the appropriate concept and level of abstraction), or a new one labelled by the researcher. This was an iterative procedure, during which the entire source list (including the higherorder determinants) was repeatedly "combed through" with the purpose of further reduction and grouping into a theoretical framework (cf. Gibbs, 2007; Kelle, Prein, \& Bird, 1995). ${ }^{9}$ This regrouping resulted in a model with four hierarchical levels of determinants. This multi-level structure is explained in detail in Section 2.4. Before describing the model synthesis, the next section first delineates the relevant fields of theory.

\subsection{Theoretical Foundations: Diffusion of Innovations and Technology Acceptance Theory ${ }^{10}$}

\subsubsection{Diffusion of Innovations Theory}

This section argues that IOP standards can be seen as innovations and that therefore, the diffusion of innovations literature forms a suitable basis to inform the study of the diffusion and adoption of IOP standards in Government Information Networks. Several authors have previously argued that the diffusion of innovations literature provides key theories for understanding the adoption of innovations by public sector organisations in general, as well as the adoption of IOP standards by organisations in Government Information Networks. Osborne and Brown (Osborne \& Brown, 2005) argue that the determinants of successful innovation adoption proposed in the diffusion of innovations theory provide a good framework for analysing the adoption of innovations by public service organisations. Others (Chen, 2010; Heeks \& Santos, 2009) have argued along the same line that the diffusion of innovation literature is of particular relevance to the study of IOP standards in Government Information Networks because they can be seen as innovations.

In their book on innovation in public service organisations, Osborne and Brown (2005) define innovation as "the introduction of newness into a system usually, but not always, in relative terms and by the application (and occasionally invention) of a new idea. This produces a process of transformation that brings about a discontinuity in terms of the subject itself (such as a product or service) and/or its environment (such as an organization, market or a community)". This definition emphasises three defining characteristics derived from previous literature that explain how IOP standards fall under this definition.

First, it points out that innovations imply "newness". This is an essential feature of innovations as shown in Roger's (2003) seminal definition of innovations as "an idea, practice, or object that is perceived as new by an individual or other unit of adoption. It

\footnotetext{
${ }^{9}$ Whilst it would be problematic to produce a final theoretical model by this approach of collating variables from studies of different fields, including different levels of analysis, it should be emphasised that this is not a problem for the creation of a preliminary model. This is because the preliminary model is used as a heuristic device in the empirical analysis (see Chapter 3). As such, the identified variables are merely a means to an end, a most-inclusive tool to investigate whether potentially relevant concepts or ideas find support in the empirical data. Only if confirmed, these variables can then legitimately be included in a final theoretical model.

${ }^{10}$ It should be noted that the purpose of these sections, and this chapter in general, is to establish a theoretical justification for the relevance of these fields of theory for the purposes of this study. Therefore, the studies reviewed here are not presented in the detail of all variables specified by them, but only the main constructs and model structure are discussed. The individual significant variables from these models are included in the construction of the preliminary conceptual model in the second part of the chapter.
} 
matters little, so far as human behaviour is concerned, whether or not an idea is 'objectively' new as measured by the lapse of time since its first use or discovery. It is the perceived or subjective newness of the idea for the individual that determines his or her reaction to it. If the idea seems new to the individual, it is an innovation". It should be noted that this does not mean "absolute" newness (i.e. the first overall implementation of an idea), but instead refers to "relative" newness (i.e. perceived newness as in a first encounter by the adopter). In the context studied in this dissertation, IOP standards clearly imply such (relative) newness for the organisations that have to adopt them. For instance, an IOP standard that is used to enable the electronic interchange of data between organisations in a Government Information Network could very well have been created years before it eventually gets selected as part of that particular network's IOP architecture. It is thus, in absolute terms, not necessarily "new". Nevertheless, it might be something completely new for some or all organisations in that network once it becomes part of its IOP architecture. Even though the standard may have been around in other contexts for a long time, the affected organisation might not have known about it. Or, even in the case that it was generally aware of the standard's existence, it might never have been of any relevance to the organisation because there was no consideration of adopting it. In either case, the standard presents "newness" for the organisation.

Second, and related to the previous point, is the notion of discontinuity. According to Osborne and Brown (2005), innovation in the public sector is characterised by "discontinuous change", i.e. it represents a "break with organizational structures, processes and/or skills from the past". This is important in this dissertation's context as it reflects the emphasis in the definition of e-Governance on the transformational use of ICT as part of governance. As argued in Chapter 1 (and elaborated upon in Chapter 4), the adoption of an IOP standard by its very nature implies transformation of organisational structures, processes, relations, skills, culture and more (except of course those cases where an organisation already uses that standard, which is a situation irrelevant to studying adoption).

Third, the definition by Osborne and Brown emphasises that an innovation is distinct from the concept of invention in that it concerns the implementation of a new idea, not just the act of invention itself. With view to IOP standards, this is implied in the act of adoption and compliance with a standard, emphasised in the definition of IOP standards adoption given in Chapter 1. Whilst an IOP standard might have been around for some time in other settings, it is its actual implementation by organisations in a Government Information Network which makes it an innovation. Innovations can also be catalysts for subsequent innovations. Hence, just like implementation of ICT-innovations can lead to e-Governance innovations, IOP standards according to the above definition are innovations that can lead to further innovations that build on IOP. IOP standards, thus, should be seen as one category of innovations in a chain of other innovations - being simultaneously based on previous innovations and being a catalyst for future innovations.

In short, whenever an organisation is confronted with an IOP standard which it had not previously already adopted, this standard can be seen as an innovation in line with the above-mentioned arguments and definitions from the existing literature. Hence, because it 
aims to explain how an innovation spreads within a given context (such as an interorganisational network), the diffusion of innovations theory can be seen as an appropriate basis for developing a theoretical model to explain the rationale behind decisions of organisations in Government Information Networks to adopt IOP standards.

The classic diffusion of innovations theory (IDT) is grounded in sociology and has been used since the 1960s to explain "the process in which an innovation is communicated through certain channels over time among the members of a social system" (Rogers, 2003). Rogers' theory derives five attributes of innovations which influence the adoption rate of an innovation: Relative Advantage, Compatibility, Complexity, Trialability, and Observability (Rogers, 2003). "Relative Advantage" refers to the degree to which an innovation is perceived to be better than its precursor. "Compatibility" concerns how the innovation is perceived to fit into the individual's existing values and needs, as based on past experience. "Complexity" is the perception of how difficult the innovation will be to use, and "Trialability" concerns the perception of how easy it is to try out and experiment with the innovation before adopting it. ${ }^{11}$ Finally, "Observability" is the degree to which the results from using an innovation are perceived to be visible to others. It is important to note that the focus of the theory is the (subjective) perception of the innovation, rather than the innovation's primary (objective) characteristics. This is because the behaviour of potential adopters is determined by how they perceive an innovation's primary attributes (different people might have different perceptions that would lead to different behaviour). Such perceptions, however, are also influenced by other factors besides the actual primary characteristics of the innovation, and are therefore not a suitable measure of influence on adoption (Moore \& Benbasat, 1991). In a meta-analysis of findings from the literature on the role of innovation characteristics for their adoption, Tornatzky and Klein (1982) found "Compatibility", "Relative Advantage" and "Complexity" to have the most significant relationships to innovation adoption.

Many authors in the past have applied the IDT framework for studying the diffusion of ICT, and produced a number of various adaptations to specific contexts. ${ }^{12}$ Moore and Benbasat (1991) adapted Rogers' IDT to specifically study the adoption of ICT by individuals. Their model differs from the original IDT in two fundamental respects: First, Moore and Benbasat argue that not the perceptions of the innovation itself should be measured as determinants of adoption (as in the original IDT), but rather the perception of using that innovation. This reasoning is based on Ajzen and Fishbein's argument that attitudes towards an object can differ from attitudes towards a behaviour concerning that object (Ajzen \& Fishbein, 1980). They argue that "innovations diffuse because of the cumulative decisions of individuals to adopt them" (Moore \& Benbasat, 1991). Second, Moore and Benbasat propose an adaptation of Rogers' predictors of adoption in order to explain ICT adoption by individuals: in addition to "Relative Advantage" and "Compatibility", they specified as predictors "Ease of Use" (building on Rogers' "Complexity" construct, this refers to the perceived ease or

\footnotetext{
${ }^{11}$ Trialability has also been shown in more recent research (Korteland \& Bekkers, 2007) to be of importance for organisations to see in how far an innovation can be experimented with and tailored to fit the organisation's context (Compatibility).

${ }^{12}$ As will be explained in the following section on technology acceptance theory, various such adaptations of IDT had a considerable influence on the development of technology acceptance theories, including UTAUT.
} 
difficulty to use the technology), "Image" (how much the use of an innovation is perceived by individuals to improve their status in their social environment), "Visibility" (in how far it is observable that others in the social environment also use the technology), "Results Demonstrability" (referring to Rogers' "Observability" construct, i.e. in how far the results from using the technology can be observed and communicated to others), and finally, "Voluntariness" (referring to the degree to which using the technology is free from coercion). An adaptation of Moore and Benbasat's model is presented below in Figure 2.1.

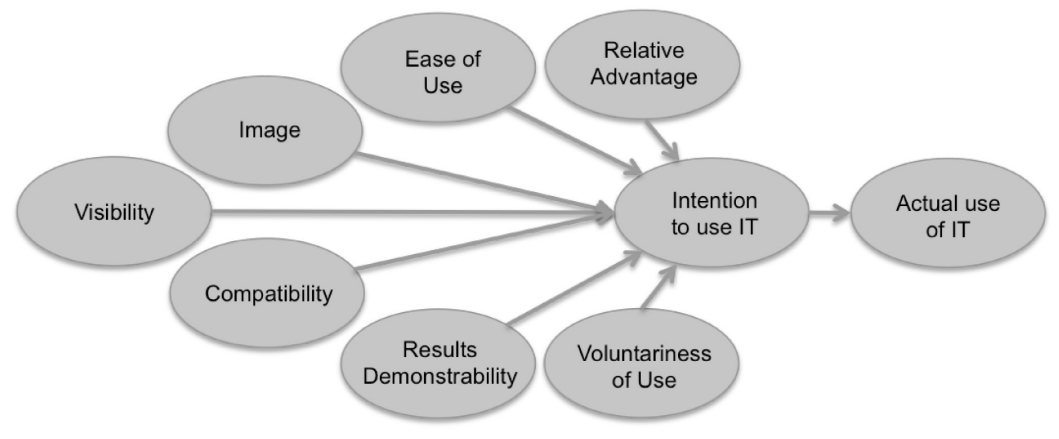

\footnotetext{
Figure 2.1. The ICT-specific diffusion of innovations model (adapted from Moore \& Benbasat, 1991) ${ }^{13}$
}

IDT has also been applied to the adoption of ICT at the organisational level. In their study of the implementation of ICT innovations by organisations, Cooper and Zmud (1990) found that next to technological characteristics of the innovation, also the characteristics of the associated tasks play a significant role (in particular "Task Complexity" and "Task Compatibility"14). There has, however, been criticism regarding the use of the original IDT to explain innovations inside organisations. As Chau and Tam (1997) argue, the original IDT had been designed to predict the diffusion of innovations through communication processes among individuals in a wider population, rather than organisational settings. They argue that IDT is not readily applicable for explaining the diffusion of innovations in organisational settings, because it does neither account for differences in the unit of analysis, nor for the specificity of various organisational contexts. They do, therefore, argue for using another model, the technology-organization-environment model (TOE). Originally presented by Tornatzky and Fleischer (1990), TOE identifies three elements that influence the process by which ICT innovations are adopted in organisations: the external environmental context (including issues such as uncertainty in the economic environment), characteristics of the ICT innovation (such as perceived benefits and perceived barriers) and the organisational technology context (including the complexity of the organisation's ICT infrastructure, satisfaction with existing systems, and formalisation of its ICT policy).

\footnotetext{
${ }^{13}$ The article by Moore and Benbasat focuses on measurement of perceptions only. The constructs "Intention" and "Actual Use" are thus outside the scope of the original article, but were added here in alignment with the basic structure of technology acceptance models (see Figure 2.2).

${ }^{14}$ Defined in analogy to the "Complexity" and "Compatibility" constructs from IDT.
} 
This variant of IDT has been applied by a number of studies on the diffusion of ICT innovations in organisations. Several studies have utilised a TOE model for studying the diffusion of standards in inter-organisational systems. For instance, studies on the adoption of Electronic Data Interchange (EDI) have found "External Pressures" (e.g. competitive pressure or government pressure) in the organisation's environment as well as "Organisational Readiness" (e.g. financial resources and ICT sophistication) to form critical adoption determinants, next to "Perceived Benefits" of the technology (Chwelos, Benbasat, \& Dexter, 2001; Iacovou et al., 1995; Kuan \& Chau, 2001). Similar models have also been used in studies on the determinants of the adoption of $\mathrm{XML}^{15}$ and web services e-business standards (Chen, 2003), and on the adoption of information system process innovations (Mustonen-Ollila \& Lyytinen, 2004).

A diffusion model that is very similar to TOE is the innovation-organisation-environment framework (IOE), developed by Nelson and Shaw (2005) in a study on the diffusion of business process standards in inter-organisational systems. In this framework, IDT is adapted in order to include perceived attributes of the innovation, attributes of the organisation, and attributes of the external environment and of the standard-setting organisation. A particularly relevant contribution of their approach is to introduce a dynamic explanation, by proposing a multi-stage technology adoption framework that aims at a dynamic comparison between diffusion determinants at both the adoption and deployment stages. ${ }^{16}$

TOE-type extensions of IDT have also been applied in e-Governance specific contexts. Akbulut (2003) uses an IOE framework in her study on US local governments' participation in electronic information sharing with state agencies, including network effects theory and transaction cost theory to understand the motivations for information sharing. In a study on the diffusion of a standardised e-customs solution across EU member states, Raus et al. (2009) include several variables on the organisational environment (network effects of the standard and technological edge) in addition to the traditional IDT innovation characteristics. Ahn (2010) studied the factors influencing the adoption of e-government systems in US municipalities, identifying as determinant constructs the nature of the system, the political environment and structural attributes of the local government organisation, including organisational capacity. Veit et al. (Veit, Parasie, \& Huntgeburth, 2011), in a study on the factors driving the adoption of e-procurement solutions in German local governments, identified the relative advantage of the innovation, organisational readiness and facilitating environmental factors as determinants. In his study on the adoption determinants of common data exchange standards by German municipalities, Parasie (2010) uses an adaptation of the TOE-type model from Chwelos et al. (2001), specifying as main constructs "External Pressure", "Organisational Readiness" and "Perceived Benefits".

\footnotetext{
${ }^{15}$ Extensible Markup Language is a widely used standard for information exchange over the internet, providing a set of rules for "packaging" digital information in a both machine-readable and human-readable format for the exchange between remote computers and applications.

${ }^{16}$ Whilst Rogers explicitly recognises diffusion as a dynamic process that unfolds over time, his original IDT nevertheless associates the role of determinants very much with only one particular stage of the diffusion process ("adoption decision").
} 
Without discarding the usefulness of IDT, the TOE framework and related studies thus point out that it is important to tailor its application to the specificity of the respective context, in particular with regard to the differences of organisational settings and the dynamic nature of the diffusion process. Most studies in the IDT tradition have slightly differing variations of the model specification in terms of constructs and variables used. If these are meaningfully tailored to the context, IDT models can thus provide useful explanations for the study of IOP standards adoption in Government Information Networks.

IDT is, however, not the only theory that has been prominently used to study the adoption of e-Governance innovations. The technology acceptance theory features equally as a prominent theoretical basis in the existing studies on the adoption of e-Governance. Its relevance to the subject of this dissertation is discussed in the next section.

\subsubsection{Technology Acceptance Theory}

Since IOP standards of e-Governance projects are related to ICT innovations, it is equally relevant to include the literature on (information) technology acceptance theory. ${ }^{17}$ Both strands of theory are in fact very close relatives. However, an important distinction is that whilst the IDT school generally investigates the factors determining the spread of an innovation throughout a social system, technology acceptance theories analyse the determinants for adoption of ICT by individual adopting agents within such a system. In other words, whilst IDT analyses adoption from the viewpoint of a certain population, technology acceptance theories approach adoption from the viewpoint of an individual in an organisation, or the viewpoint of a single organisation amidst a population of organisations.

Accordingly, the two theory strands have their origin in different disciplines. While IDT is based on a sociological approach, technology adoption models have their roots in the psychological literature, which has accumulated a substantial body of theory that aims at explaining what factors influence certain behaviours. Many technology adoption models are derived from the field of social psychology, in particular from the Theory of Reasoned Action (TRA) (Fishbein \& Ajzen, 1975). The most significant contribution of this theory was to show that a certain behaviour of an individual (such as for instance the adoption of a given technology) is first and foremost dependent on that individual's intention to behave in this way - and that this intention is in turn dependent on the attitudes of the individual to that behaviour. In the vocabulary of TRA, these attitudes are referred to as "beliefs". In other words, the beliefs held by an individual with regard to certain aspects of the behaviour in question are determinants of the intention to carry out this behaviour. These beliefs, in turn, are formed in dependency on a range of external circumstances ("antecedents").

\footnotetext{
${ }^{17}$ The sequence of the discussion of the main theories in this section (TRA, TPB, and TAM) is based on the structure and presentation of the argument developed by Venkatesh and colleagues (2003) that based on a synthesis of innovation diffusion theory and technology acceptance theories, the UTAUT model (see Section 2.3.3) is a suitable model for explaining ICT adoption in organisations, and has been combined with a discussion of additional related theories.
} 
The distinction between these belief constructs and their external antecedents is conceptually important. In TRA, Ajzen and Fishbein (1975) describe the belief constructs as cognitive processes (information processing) that take place in response to external circumstances: "On the basis of direct observation or information received from outside sources or by way of various inference processes, a person learns or forms a number of beliefs about an object. That is, he associates the object with various attributes. In this manner, he forms beliefs [...]. The totality of a person's beliefs serves as the informational base that ultimately determines his attitudes, intentions, and behaviours." The belief constructs presented in TRA were "Subjective Norm" and "Individual Attitude". The former refers to the importance attributed by the individual to the evaluation of its behaviour by relevant peers (i.e. whether they are believed to think that it should adopt a technology or not). The latter construct refers to an individual's feelings about the behaviour (i.e. how they emotionally react to the acceptance of a technology).

TRA has subsequently been applied to many diverse contexts (for a review, see Sheppard, Hartwick, \& Warshaw, 1988). It has also been followed by a number of other models, but its basic structure, as represented in Figure 2.2 (i.e. actual behaviour explained by intention, intention explained by beliefs to the behaviour, and beliefs explained by external antecedents) has remained the underlying logic of most subsequent technology acceptance models. ${ }^{18}$

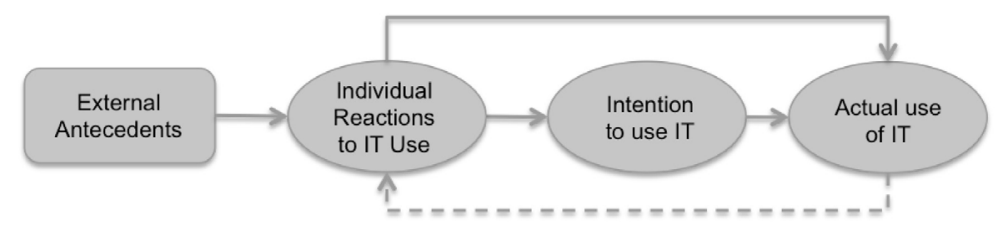

Figure 2.2. Basic structure of Technology Acceptance Models (adapted from Venkatesh, 2003)

One application of TRA that is tailored to the use of ICT is the Technology Acceptance Model (TAM) (Davis, 1989). The initial determinants of behavioural intention presented by TAM were "Perceived Usefulness" and "Perceived Ease of Use". "Perceived Usefulness" is the belief held by individuals that using the technology will improve their job performance, and "Perceived Ease of Use" refers to the individual's belief whether using the ICT is free of effort. Subsequently, TAM has been revised in many forms and combinations with other models. Venkatesh and Davis (2000), for instance, have included the "Subjective Norm" construct from TRA into TAM to better explain acceptance in mandatory settings. Roberts and Henderson (2000) used TAM to test the acceptance of personal computers by government employees, and successfully validated the model's applicability to public sector settings.

In 1991, Ajzen developed the Theory of Planned Behaviour (TPB) as an extension to TRA (Ajzen, 1991). TPB added "Perceived Behavioural Control" as an additional attitudinal

\footnotetext{
${ }^{18}$ This is also the basic structure underlying the IDT model variant by Moore and Benbasat (1991) presented earlier.
} 
determinant of behavioural intention. In addition, "Perceived Behavioural Control" was also shown to simultaneously have an effect on behaviour directly. "Perceived Behavioural Control" refers to the belief that there are internal and external constraints attributed to the behaviour in question. In other words, this describes the extent to which individuals believe that they are able to perform the behaviour in relation to their own abilities and external obstacles.

\subsubsection{Towards an Integrative Theoretical Framework of ICT Innovation Adoption}

Most of the above-mentioned technology adoption theories have been used in various combinations and synthesised models, reflecting the need to integrate the plethora of various theories into unified frameworks. Various authors have attempted to build integrative models in the private-sector context by combining constructs and variables from different theories, for instance in studying computer use in an organisational setting (Taylor \& Todd, 1995), organisational innovation adoption (Frambach \& Schillewaert, 2002), the individual and organisational determinants of information systems' success (Sabherwal, Jeyaraj, \& Chowa, 2006), critical success factors for enterprise application integration (Lam, 2005), organisational and interorganisational factors differentiating between "proactive" versus "reactive" adopters of EDI (Premkumar \& Ramamurthy, 1995), and the study of the adoption of ICT standards in supply chains (Nelson \& Shaw, 2001).

Integrative models have also been developed in studies of ICT adoption in the public-sector context. Whilst there is only little research with regard to the adoption of standards in the eGovernance context, there has been considerable use of technology acceptance theories for studying the adoption of specific e-Governance applications, for instance regarding the adoption of e-Government services by citizens (Bélanger \& Carter, 2008; Hung, Chang, \& Yu, 2006; Shareef, Kumar, Kumar, \& Dwivedi, 2010) and businesses (Chu, Hsiao, Lee, \& Chen, 2004; Lee, Kim, \& Ahn, 2011), the acceptance of e-Governance systems by government employees in inter-organisational settings (Hung, Tang, Chang, \& Ke, 2009), the diffusion of e-Government innovations throughout the public sector (Chu et al., 2004; Korteland \& Bekkers, 2007) as well as studies on the integration and use of public service information systems by public organisations (Chen, 2010).

One of the most widely and successfully applied synthesis models on information technology adoption is the Unified Theory of Acceptance and Use of Technology (UTAUT) by Venkatesh et al. (2003). The authors of the UTAUT study reviewed eight dominant theories on adoption and diffusion of technologies in the field of information systems with the aim of synthesising a unified model from these theories. Outperforming all its constituent models in explanatory power ${ }^{19}$, the model specifies four main determinant constructs influencing the behavioural intention of an individual to use a certain technology: "Performance Expectancy", "Effort Expectancy", "Social Influence" and "Facilitating Conditions". These are direct determinants of intention of usage and, in the case of the

\footnotetext{
${ }^{19}$ The test of UTAUT by Venkatesh et al (2003) produced an $\mathrm{R}^{2}$ value of $70 \%$, i.e. their application of the model explained $70 \%$ of the variation in the dependent construct ("Actual Use of IT"). This is significantly higher than the $\mathrm{R}^{2}$ value of the tests of the individual models that UTAUT synthesises.
} 
"Facilitating Conditions" construct, also of usage behaviour. The UTAUT authors define "Performance Expectancy" as "the degree to which an individual believes that using the system will help him or her to attain gains in job performance". "Effort Expectancy" refers to the "degree of ease associated with the use of the system". "Social Influence" is "the degree to which an individual perceives that important others believe he or she should use the new system". Finally, "Facilitating Conditions" refer to "the degree to which an individual believes that an organizational and technical infrastructure exists to support use of the system". ${ }^{20}$ The full UTAUT model is presented below in Figure 2.3.

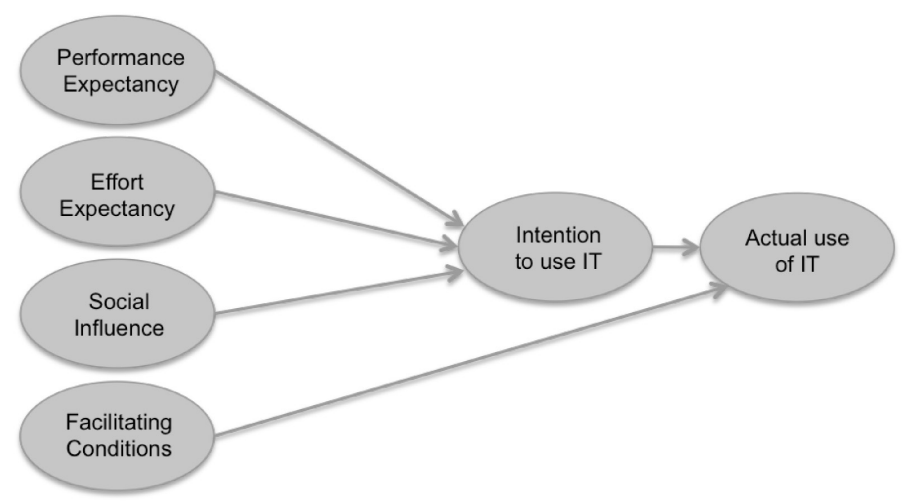

Figure 2.3. The UTAUT model (adapted from Venkatesh et al., 2003) ${ }^{21}$

UTAUT has also been shown in a number of studies and across diverse country contexts to be a valid model when applied to the e-Governance context. It has for instance been used for explaining the adoption of e-Governance innovations by citizens (Al-Shafi, Weerakkody, \& Janssen, 2009; Al-Sobhi, Weerakkody, \& El-Haddadeh, 2011; AlAwadhi \& Morris, 2008; Joseph, 2010; Schaupp, Carter, \& McBride, 2010; van Dijk, Peters, \& Ebbers, 2008; Wang \& Shih, 2009). In addition, it has also been used to understand the usage of e-Governance innovations within government organisations (Gupta, Dasgupta, \& Gupta, 2008; Zhan, Wang, \& Xia, 2011).

However, as the following paragraphs argue, none of the models from the body of theory discussed in this chapter provides a suitable model variant for the particular context of IOP standards adoption in Government Information Networks. Existing models leave some significant gaps, which prevent a full understanding of the circumstances that will enable Government Information Networks to achieve IOP and fulfil their project goals. In particular, there are three main limitations of existing models with regard to analysing the organisational adoption of IOP standards in Government Information Networks.

\footnotetext{
${ }^{20}$ The argumentation of TOE-type extensions to IDT is similar to technology acceptance models such as UTAUT. In particular, its argument that the characteristics of the technology or innovation, the organisation and the external environment are important determinants of adoption, is consistent with UTAUT's acknowledgement of the influence of external antecedents for the belief constructs, in particular the "facilitating conditions" construct.

${ }^{21}$ The moderating variables identified by the original UTAUT model (Gender, Age, Experience, Voluntariness of Use) are omitted from this figure for purposes of clearer presentation, and because they partly refer to variables which are very specific to individual-level analysis (such as Gender and Age), and thus not relevant for the purposes of this study.
} 
First, as mentioned above, technology acceptance models, including UTAUT, in essence are developed for the micro-level of analysis, and thus aim at explaining the adoption behaviour of individuals, and not of organisations. Kamal (2006) argues that most ICT innovation adoption models neglect that the "reality of innovation adoption and implementation within organisational settings may require modifications to these models". However, whilst the technology acceptance models mentioned in this section, including UTAUT, take the individual as unit of analysis, this does not mean that the determinants that they identify could not possibly also be used as a basis to inform a theoretical framework for studying adoption at the organisational level. It has been argued earlier by Benbasat and Moore (1991) that individual-level adoption models can be developed into a tool for studying adoption and diffusion of ICT innovations within organisations because organisations' decisions to adopt innovations in essence consist of cumulative decisions made by individuals in a social system (such as an organisation). Similarly, Samuelson \& Björk (2010) argue that although UTAUT focuses on the individual, it can be used for studying adoption on the organisational level since an organisation consists of individuals making decisions based on the environments that are relevant to them. Organisational adoption, therefore, can be conceptualised as being determined by the accumulation of individual adoption decisions within the organisation, in particular (but not only) those made by key decision-makers.

Nevertheless, in their original form, technology acceptance models such as UTAUT are not suitable for explaining what shapes the behaviour of organisations as entities of their own, and need to be adapted to fit this context. As a review of the application of innovation adoption models shows (see Table 2.1 below), UTAUT had not yet been applied to the organisational level at the time of the review (Jeyaraj, Rottman, \& Lacity, 2006). Since then, only one study was found that explored the possibility to use UTAUT for the analysis of organisational adoption (Samuelson \& Björk, 2010). The authors of that study hold that the original UTAUT constructs are relevant both for a decision-maker in the organisation's management as well as for individuals who decide whether to adopt a technology, and argue that the variables can have different effects for each of these levels. Therefore, they argue, an organisational-level model adaptation needs to consist of carefully chosen and empirically grounded variables. As Chau and Tam (1997) argue, findings on individuallevel adoption cannot be directly generalised to the organisational level, but need to recognise the differences in the unit of analysis, environment, and technology characteristics. This organisational context is not addressed yet by the existing models that are specifically developed to explain the specific motivational reasoning of individuals.

The second limitation of the body of theory reviewed in this chapter is that there hardly are any models that address the specific context of IOP in Government Information Networks. The following paragraphs argue that despite the existence of an extensive body of general theory on diffusion of innovations and technology acceptance, there is a need for specific theory on the distinct context investigated here. First, the general value of context-specific theorising is discussed, followed by an argumentation why the specific context of IOP in Government Information Networks should be seen as a distinct context. 


\begin{tabular}{llcc}
\hline \multicolumn{1}{c}{ Theory } & \multicolumn{1}{c}{ Source } & $\begin{array}{c}\text { Used in } \\
\text { individual adoption } \\
\text { studies }\end{array}$ & $\begin{array}{c}\text { Used in organisational } \\
\text { adoption studies }\end{array}$ \\
\hline $\begin{array}{l}\text { Innovations Diffusion Theory } \\
\text { Perceived Characteristics of Innovations }\end{array}$ & $\begin{array}{l}\text { Rogers, 2003 } \\
\text { Moore \& Benbasat, 1991 }\end{array}$ & $\mathrm{X}$ \\
Technology Acceptance Model & Davis, 1989 & $\mathrm{X}$ \\
$\begin{array}{l}\text { Theory of Planned Behaviour } \\
\text { Theory of Reasoned Action }\end{array}$ & Ajzen, 1991 & $\mathrm{X}$ & $\mathrm{X}$ \\
$\begin{array}{l}\text { Unified Theory of Acceptance and Use } \\
\text { of Technology }\end{array}$ & Fishbein \& Ajzen, 1975 & $\mathrm{X}$ & $\mathrm{X}$ \\
$\begin{array}{l}\text { Diffusion/Implementation Model } \\
\text { Tri-Core Model }\end{array}$ & Kwon \& Zmud, 1987 2003 & & $\mathrm{X}$ \\
\hline
\end{tabular}

Table 2.1. Application of major innovation adoption models at individual and organisational levels of analysis (Jeyaraj et al., 2006)

At the general level, the question on the value of context-specific theorising touches upon more fundamental debates about the necessity of abstraction for theory-building. On the one hand, the highest degree of abstraction is found in "grand theories", aiming at highly abstract explanations of social phenomena instead of more detailed explanations that are tailored to specific contexts (TRA, introduced earlier in this section, can be considered an example of such a "grand theory"). On the other hand, there is the constructivist position, which strongly rejects such highly abstract theoretisations and argues that instead, all phenomena are specific to particular contexts such as time, space, or social setting. In its strongest form, the constructivist position holds that "the only generalization is that there is no generalization" (Lincoln \& Guba, 1985). This, however, is a rather extreme position, which would essentially make it impossible to develop any useful theory at all (as theory by its nature implies some degree of generalisation). A more moderate position argues for an adequate degree of abstraction in theory-building that aims at explaining phenomena characterised by a "broader recognizable set of features" (Williams, 2002). This reflects the nature and purpose of what Merton (1968) described as "middle-range theories" theoretical generalisations that have validity under specific contexts or conditions that can be empirically observed. By inversion, this also implies that "grand theories" that do not match the key features of a given context are insufficient explanations, and create a need for additional theory in that context. As the paragraphs below argue, there are a number of reasons to assume that the context of IOP in Government Information Networks concerns a special intersection of several distinct characteristics that warrant a context-specific theory to guide future research and practice in this area. Such a model needs to provide a complementary synthesis of theory from three key areas.

First, IOP standards are closely linked to information systems, and as such are innovations with unique and distinct features that set them apart from other innovations. If there was no need for context-specific studies of ICT, one generic theory of innovation adoption would be sufficient to explain everything and, as a consequence, the entire body of literature that theorises the adoption of ICT as a distinct type of innovation would be unjustified. However, rather than assuming such an "exhaustive" role, IDT and technology acceptance models should instead be understood as "grand theories" that provide an umbrella for context-specific applications with specific variables that are tailored to the distinct 
characteristics of ICT innovations and IOP standards that render "general" innovation models insufficient to fully explain their adoption (cf. Chau \& Tam, 1997).

The key characteristic that sets standards apart from most other types of innovation is their pervasiveness. Because they affect the processing of information that is at the basis of any modern organisation, IOP standards are inherently pervasive in their effects. In contrast to other general-purpose technologies (e.g. electricity), IOP standards cross-cut through virtually all organisational domains and applications and thus affect virtually any process in an organisation, often in fundamental ways (for a detailed discussion of the pervasive role of standards, see Busch, 2011). This pervasiveness is also linked to the systemic nature of IOP standards, which are typically part and parcel of some larger information system that is made from "complementors" (Shapiro \& Varian, 1999). Because these parts are often contributed by a number of actors, their diffusion by nature typically builds on the interaction within networks of different actors. Furthermore, in contrast to other generalpurpose technologies, IOP standards cross-cut through technological, semantic and organisational aspects of organisations.

Second, the context under study here concerns a particular kind of networked environment where adoption does not take place in the confined space of individuals or individual organisations, but of multiple organisations. Whilst both the IDT and technology acceptance strands of theory take into account the embedding of adopting agents into networked settings (see for instance the "Visibility" and "Image" constructs in IDT, or the "Subjective Norm" and "Social Influence" constructs in technology acceptance theories), this is different from the type of network-innovation that standards represent and which is typically covered by network-externalities models. Hence, IOP standards adoption in Government Information Networks is likely to be influenced by a number of determinants that are specific to networked environments that need to be taken into account to complement existing models.

Third, the context of Government Information Networks is distinct because the public-sector environment in which they are set has significantly different characteristics from the private-sector environment which most ICT adoption theories apply to. The differences between public and private organisations have been studied for several decades (for a review of research since the 1950s, see Perry \& Rainey 1988), and the distinct management issues of public organisations have led to the emergence of public management as its own field of study, with a distinct set of theories. The existing literature in this area cites a range of differences. Rainey (2009; see also Rainey, Backoff, \& Levine, 1976) lists three general groups of distinct characteristics.

The first group are distinctive environmental factors that characterise public organisations, such as (Rainey, 2009): i) a lack of economic markets and reliance on governmental resource attribution; ii) more complex legal and regulatory constraints; and iii) higher exposure to external political influences. The second group of characteristics is that public organisations have distinctive relationships with their environment (Rainey, 2009). In particular, they: i) are primarily tasked with producing public value and managing public goods; ii) often operate in a unique environment of highly coercive and monopolistic mechanisms; and iii) are subject to greater public scrutiny, including higher expectations on issues such as 
fairness, responsiveness, and accountability. Finally, the third group of features is that public organisations are argued to have distinctive arrangements of organizational roles, structures, and processes, including (Rainey, 2009): i) facing a greater diversity and ambiguity of goals; ii) featuring distinctive managerial roles and leadership practices that are more prone to external interventions and have less decision-making autonomy and flexibility; iii) having distinct organisational structures (e.g. more red tape); iv) facing different incentive structures; and v) relatedly, facing distinct work attitudes and performance of individuals. Therefore, since private-sector adoption models do not fully account for this distinct public-sector setting, we need to also look at the literature on the adoption of other types of innovations by public-sector organisations to complement other relevant models.

The intersection of all these distinct characteristics together creates a unique environment with a specific set of determinants for innovation adoption, and in particular for IOP standards adoption. Hence, there is thus a relevance for a theory that is context-specific to the set of features attributed to these three contexts that are not captured by existing innovation and ICT adoption theories, as indicated by the intersection of the three circles in Figure 2.4 below.

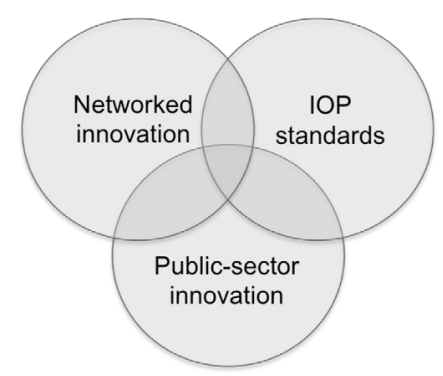

Figure 2.4. Distinct domains indicating need for context-specific theory

It is argued here that besides being an area which had not been studied sufficiently before, this intersection is also a highly relevant area to investigate. As Chapter 1 elaborated in detail, Government Information Networks increasingly play a role in policy implementation. Yet, as Chapter 1 also reports, existing assessments acknowledge that the effectiveness of these networks is often limited by their difficulties to achieve IOP. To understand the factors to support IOP standards adoption and the governance requirements for that, we need a solid theory to guide us. One might be tempted to argue that there is no need for a new theory and that instead, it would be sufficient to simply list all determinants identified by the plethora of existing models in more or less related contexts as reviewed earlier in this chapter (such as the private sector, individual-level adoption etc.). However, this dissertation argues that the assumption that this could provide a valid theory and basis for policy-making for the distinct context outlined in this section is bound to be mere speculation. The relevant contribution of the framework developed in this dissertation therefore is to provide theory synthesis and theory building instead of simply listing determinants from other fields, and to progress from simply assuming their contextual 
relevance to their validation by means of empirical evidence. In an under-theorised context like the one under study, the theory synthesis and exploratory theory building contributed by this dissertation is thus a needed first step.

However, except the model developed in the exploratory study by Veit and Parasie (2010), there are currently no models that are geared to an explanation of the adoption behaviour specifically related to IOP standards in Government Information Networks. Moreover, existing studies on IOP in e-Governance contexts have addressed a range of issues, from the necessity of IOP to conceptual frameworks and technical discussions - but have so far largely neglected the importance of investigating the intentions and experiences of stakeholders with regard to adoption of IOP standards: how do organisations reason about IOP architectures, and what does adoption imply for organisations? Such questions are important to ask if we want to be able to transpose present models from the individual to the organisational level. Therefore, we first require a proper conceptualisation of what the particular behaviour in question (i.e. IOP standards adoption) means for organisations. As has been argued above, there still remains a gap in current research to provide a structured and empirically founded framework to explain, and measure, this specific behavioural context. While individual adoption behaviour has received considerable attention, the organisational level has so far been neglected. Furthermore, while previous technology adoption research has addressed the adoption of specific information systems, the adoption of IOP standards in the context of Government Information Networks has received hardly any consideration. As such, previous models are not suited for explaining the adoption of IOP standards.

The third limitation, related to the previous one, is that (partly owing to their roots in organisational psychology), technology acceptance models such as UTAUT focus on the cognitive process of intention and behaviour formation. As a result, they restrict themselves to constructs measuring attitudinal beliefs, so that the current variants of UTAUT are thus limited to specifying only reflective items ${ }^{22}$ for the various constructs and are primarily concerned with the quantitative measurement of these constructs and of the relations between them. However, the purpose of such reflective measurement is different from this dissertation's objective - which is primarily to understand the determinants on which the attitudinal beliefs, and thus of organisational IOP standards adoption, depend. As Venkatesh and colleagues (2003) acknowledge, "future research should focus on integrating UTAUT with research that has identified causal antecedents of the constructs used within the model [...] in order to provide a greater understanding of how the cognitive phenomena that were the focus of this research are formed". It is therefore important to identify the "causal antecedents" to the attitudinal belief constructs. In line with its root theory TRA, these causal antecedents refer to the external circumstances, in contrast to referring to the cognitive processing of information about these circumstances. Venkatesh and colleagues

\footnotetext{
${ }^{22}$ Reflective items are measured variables considered to be caused by a latent construct (cf. Hair, Black, Babin, Anderson, \& Tatham, 2010), rather than variables measuring what causes a latent construct (which are called formative items). In other words, they are "reflecting" the concept behind the latent variable (like being "symptoms" of it), rather than being its causal antecedents. Reflective measurement is a useful approach when the intention is to estimate a quantitative score for a specific construct, and it is for instance taken when quantitatively testing a model for its validity.
} 
(2003) indicate as examples of possible antecedents for instance system characteristics, individual ability constructs, and task-technology fit.

As other authors before have argued (Bala \& Venkatesh, 2007), in the context of interorganisational standardisation none of these theories are typically used in isolation, and therefore, it is appropriate to situate them into a multi-theoretical framework (see also Korteland \& Bekkers, 2007). To this end, this dissertation draws upon the public administration literature in order to contextualise the model and add relevant conceptual dimensions. This means that in order to establish a meaningful model on the adoption of IOP standards in Government Information Networks, we need to adopt a multi-theoretical framework that, next to the literature fields discussed in the previous sections, also takes into account the relevant theories from the public administration literature on public-sector innovation, e-Governance, inter-organisational relations and network governance.

Relevant literature fields in this area include the adoption and implementation of eGovernance services (e.g. Ebbers \& van Dijk, 2007), standards adoption (e.g. Andersen, Veit, Medaglia, \& Henriksen, 2010; Dahl \& Hanssen, 2006; Parasie, 2010; Veit \& Parasie, 2010), government information sharing (e.g. Akbulut, 2003; Dawes, 1996; Gil-Garcia et al., 2007; Yang \& Maxwell, 2011; Yang, Zheng, \& Pardo, 2011), the institutional implications of eGovernance (e.g. Ansell, 2006; Fountain, 2001, 2009; Gasco, 2003; Gil-Garcia \& MartinezMoyano, 2007; Smith, 2009; Williams et al., 2009), the motivations for inter-organisational partnership formation (e.g. Oliver, 1990; Schermerhorn, 1975), organisational networks design and architecture (e.g. Bekkers, 2009; Bryson et al., 2006; Gulati \& Singh, 1998), the emergence and development of organisational networks (e.g. Ring \& Van De Ven, 1994), characteristics and outcomes of inter-organisational networks (e.g.Agranoff \& McGuire, 1998; Benson, 1975; Brown et al., 1998; Hjern \& Porter, 1981; O'Toole, 1997), collaboration within networks (e.g. Bardach, 2001; Bryson et al., 2006; Daley, 2008; Dawes \& Eglene, 2008; Gray, 1989, 2000; Gray \& Wood, 1991a, 1991b; Kraus, 1980; Thomson \& Perry, 2006; Thomson, Perry, \& Miller, 2009), the management of networks (e.g. Ansell \& Gash, 2007; Kickert et al., 1997c; O'Toole, Hanf, \& Hupe, 1997; Provan \& Kenis, 2008) and management of organisational integration processes (e.g. Bekkers, 2007; Westholm, 2005). The following sections conduct a meta-synthesis of all the previously mentioned fields into a preliminary theoretical model on the determinants of IOP standards adoption by organisations in Government Information Networks.

\subsection{Towards a Preliminary Theoretical Model}

Since the central questions of this dissertation require a multi-theoretical lens, the following sections thus develop a (preliminary) multi-theoretical theoretical model on the adoption of IOP standards in Government Information Networks. This model is developed by building on an extensive review of relevant studies in the fields of information systems and public administration mentioned above, identifying the relevant factors that apply to the distinct context under study here. The presented model compiles the relevant determinants that were identified from this body of literature into seven determinant constructs. ${ }^{23}$ To structure

\footnotetext{
${ }^{23}$ Throughout the text of this dissertation, all determinants are highlighted in capitals and italics when referring to them as an analytical category, and written in normal font in all other instances. For the reader's reference, a list with references to the definitions of all determinants mentioned throughout this dissertation is provided in Annex I.
} 
the large amount of determinants identified from the literature into a systematic framework, the model subdivides each of these determinant constructs into three subordinate conceptual levels, according to the following hierarchy (each representing levels of decreasing abstraction and more concrete determinants): 1) Determinant constructs, 2) Subconstructs, 3) Dimensions, and 4) Variables. ${ }^{24}$ The determinants identified from the literature are discussed in turn in the following sections. Each of these sections in this chapter only lists the identified determinants - their role and significance is then discussed in the empirical discussions in Chapters 4 and 5. Next to a construct capturing Adoption, the model specifies seven constructs of determinants of adoption: IOP Governance (the determinants regarding the governance of a network's IOP architecture), Network Characteristics (the determinants related to the inter-organisational network and its characteristics), NetworkExternal Environment (determinants related to the environment external to the network, beyond the immediate network-level), Organisation-Specific Determinants (pertaining to the individual organisations in the network and their characteristics), IOP Standards Characteristics (determinants related to the characteristics of the IOP standards), Adoption Efforts (efforts experienced by organisations during the adoption process), and Results (consequences resulting from the adoption of IOP standards). These determinants and their predicted role for IOP standards adoption are summarised in Figure 2.5 below. For the purpose of giving an initial overview, this figure is a simplified version of the full model, and does not show their subordinate conceptual levels (the model including sub-constructs is displayed in Figure 2.6). Each of these determinant constructs, together with their sublevels, is discussed in the following sections of this chapter.

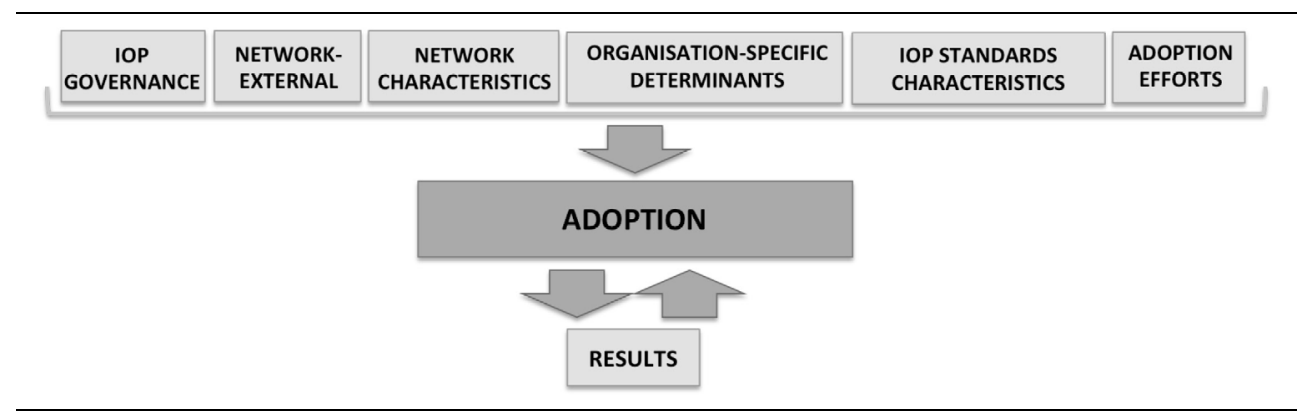

\section{Figure 2.5. Theoretical model (main determinant constructs)}

\subsubsection{Adoption}

Adoption is an adaptation of the "Use Behaviour" construct from the UTAUT model to the specific context of this study: the adoption of IOP standards by organisations in Government Information Networks. In the UTAUT model, the "Use Behaviour" construct refers to the actual usage of ICT by individuals (see Venkatesh et al., 2003). In the context of this study, the literature on collaboration in inter-organisational relations provides a useful starting point for conceptualising this construct. As Chapter 1 discussed in more detail,

\footnotetext{
${ }^{24}$ Due to space considerations, it is not possible to display all determinants at all four levels in one figure or table, and therefore individual figures and tables in this dissertation present a selection of levels. For examples of this layered hierarchy of determinants, the reader is referred to Figure 4.4 and Table 4.2 and Table 4.3 , as well as Figure 5.1 and Table 5.1 through Table 5.6.
} 
inter-organisational collaboration can be understood as the cooperative activities among partners in inter-organisational networks, referring to a behaviour that consists of partners establishing and acting together within a shared structure.

Thomson and colleagues point out that collaboration is not a binary variable (Thomson et al., 2009). It thus is a spectrum with varying degrees of collaboration. The collaboration behaviour in the context of this dissertation refers to the actual adoption of, and the compliance with, IOP standards specified in the context of a Government Information Network. The conceptualisation of the construct in the context of this study is therefore dependent on the conceptualisation of "IOP standards". Chapter 1 defined IOP standards as the abstract specifications of the necessary features of a component, technological and nontechnological, and created through de facto or de jure processes, that make it compatible with the rest of a system (based on Schmidt \& Werle, 1998). As mentioned in Chapter 1, for standards adoption we can distinguish between the formal adoption decision (whether to adopt or reject the standard) and the actual deployment of the standard (its implementation and compliance) (cf. Bala \& Venkatesh, 2007).

In conclusion, the Adoption construct can thus be conceptualised as organisations' actual adoption of, and compliance with the IOP standards specified in the IOP architecture of a Government Information Network. Adoption is predicted to be influenced by all seven determinant constructs, discussed in turn in the following sections. This construct is not further sub-divided into subordinate conceptual levels (sub-constructs, dimensions or individual variables).

\begin{tabular}{|l|l|}
\hline Adoption & $\begin{array}{l}\text { The adoption of, and the compliance with the IOP standards specified in the IOP } \\
\text { architecture of a given Government Information Network }\end{array}$ \\
\hline
\end{tabular}

Table 2.2. Adoption construct (definition)

\subsubsection{IOP Governance}

IOP Governance is conceived here as the construct covering those determinants that pertain to the decision-making rules and procedures to direct and oversee government IOP initiatives that are planned or underway (Pardo \& Burke, 2009). It thus refers to the manner by which strategic management (decision-making, coordination and oversight) on the IOP architecture $^{25}$ in a Government Information Network is governed by means of the use of institutions, structures of authority and collaboration (cf. Abramowicz et al., 2008; EPAN, 2004; Provan \& Kenis, 2008). It encompasses the governance of setting the IOP architecture, governance of its adoption process, and governance of its use once adopted. The subconstructs that the literature review identified for this determinant construct are DecisionMaking Centralisation, Enforcement, and Guidance from organisation-external actors. Each of these is composed of a number of dimensions (each in turn composed of a set of variables), explained in more detail below.

\footnotetext{
${ }^{25}$ The term "IOP architecture" is defined "range of technical specifications, systems, standards, guidelines and policies" (see Table 1.7). It hence is the object of IOP governance and should thus not be misconceived as the process of setting the range of IOP standards.
} 
Table 2.3. IOP Governance construct (definition)

\subsubsection{Decision-Making Centralisation}

Decision-Making Centralisation can be conceptualised as the distribution of decision-making authority among partner organisations in the network, determining the ownership given to them by involving them in the procedures of making strategic decisions with regard to the governance of the network's IOP architecture (cf. Crosby \& Bryson, 2010; Dawes \& Eglene, 2008; Provan \& Kenis, 2008) ${ }^{26 \Delta 1}$. Two dimensions for this sub-construct have been identified from the literature. These are Brokerage and Stakeholder Involvement. These are assumed as two key defining characteristics of Decision-Making Centralisation, because Brokerage concerns the question whether there is a central decision-making actor, and Stakeholder Involvement concerns the degree to which other stakeholders involved in the decision-making process. ${ }^{27}$

Brokerage refers to the existence and characteristics of an IOP coordination body that is formally charged with the coordination of the network and its IOP architecture. The relevant variables for this dimension are the existence of a broker (Broker Existence) (Bekkers, 2007; Cimander \& Kubicek, 2009; Provan \& Kenis, 2008; van Dijk, 2007), and that broker's own governance and structure (Broker Mission) (Nelson \& Shaw, 2005).

\begin{tabular}{|l|l|}
\hline Decision-Making Centralisation \\
\hline Definition & $\begin{array}{l}\text { The distribution of decision-making authority among partner organisations in a given } \\
\text { Government Information Network, determining the ownership given to them by involving } \\
\text { them in the procedures of making strategic decisions with regard to the governance of the } \\
\text { network's IOP architecture }\end{array}$ \\
\hline Dimensions for this sub-construct \\
\hline Brokerage & $\begin{array}{l}\text { The existence and characteristics of an IOP coordination body that is formally charged with } \\
\text { the coordination of the network and its IOP architecture (variables: Broker Existence, } \\
\text { Broker Mission) }\end{array}$ \\
\hline $\begin{array}{l}\text { Stakeholder } \\
\text { Involvement }\end{array}$ & $\begin{array}{l}\text { The level of stakeholders' participation in the network's IOP governance (variables: Design } \\
\text { and Use of Forums, Partners Participation, User Participation, IOP Standards Adaptation, } \\
\text { Organisational Structure Adaptation, Policy Adaptation,) }\end{array}$ \\
\hline
\end{tabular}

Table 2.4. Decision-Making Centralisation sub-construct (definitions of sub-construct and its dimensions, including variables in brackets)

The second dimension, Stakeholder Involvement, refers to the level of stakeholders' participation in the network's IOP governance, determining the ownership given to them by involving them in the procedures of making strategic decisions with regard to the governance of the network's IOP architecture (cf. Bekkers, 2007; Bryson et al., 2006; Yang \& Maxwell, 2011) ${ }^{\Delta 2}$. The variables identified from the literature for this dimension include the

\footnotetext{
${ }^{26}$ Due to the extensive scope of the literature review, some determinants were mentioned in a larger number of reviewed studies, partly resulting in very long in-text references. For better readability, in these cases from here onwards only the references to the three most recently published sources are indicated, and the full list of references for these determinants can be found in Annex C. All instances where in-text references have been shortened in this manner are indicated by the symbol ${ }^{\Delta}$.

${ }^{27}$ A more detailed explanation of the role of Brokerage and Stakeholder Involvement for Decision-Making Centralisation is given in Section 6.2.1.
} 
design and use of forums for communicating, making and implementing joint decisions (Crosby \& Bryson, 2010), the actual level of partner organisations' participation in IOP governance (Kamal, 2006), the participation of end users in planning and development of the IOP architecture (Kamal, 2006), the degree to which adaptations are made to the IOP standards based on the input from stakeholders (Ebbers \& van Dijk, 2007), the degree to which stakeholder input into arrangement of the network's structure (e.g. in the task division and task co-ordination of organizations) has an influence (Ebbers \& van Dijk, 2007), as well as the acknowledgement of stakeholder input into the design of the network's policy framework (Ebbers \& van Dijk, 2007). Enforcement

Enforcement, the second sub-construct for IOP Governance, refers to the mechanisms in place for compelling adoption and compliance with the IOP architecture of a given Government Information Network. Its component dimensions are Coercion and Accountability.

Coercion refers to pressure mechanisms exerted by more powerful actors on which an adopting organisation is dependent, constraining the partner organisations from noncompliant behaviour regarding the IOP standards (cf. Dawes \& Eglene, 2008; Fountain, 2007; Nelson \& Svara, 2011) ${ }^{\Delta 3}$.

The Accountability dimension refers to the control mechanisms for organisations' compliance with a network's IOP standards. It includes as variables the formalised obligations through institutionalisation of the IOP standards (whether the IOP standards are clearly documented and formally institutionalised, such as for instance by legal or contractual obligations) (Bekkers, 2007; Crosby \& Bryson, 2010; Kamal, Weerakkody, \& Irani, 2011), as well as the degree to which outcome-oriented accountability systems are used that track inputs, processes, and outcomes (Kamal et al., 2011; Soares \& Amaral, 2011; Yang \& Maxwell, 2011) $\Delta 4$.

\begin{tabular}{|l|l|}
\hline Enforcement & $\begin{array}{l}\text { The mechanisms in place for compelling adoption and compliance with the IOP } \\
\text { architecture of a given Government Information Network }\end{array}$ \\
\hline Dimensions for this sub-construct \\
\hline Coercion & $\begin{array}{l}\text { Pressure mechanisms exerted by more powerful actors, constraining the partner } \\
\text { organisations from non-compliant behaviour regarding the IOP standards (no variables) }\end{array}$ \\
\hline Accountability & $\begin{array}{l}\text { The control mechanisms for an organisation's compliance with the project's IOP } \\
\text { standards (variables: Formalised Obligations, Tracking Systems) }\end{array}$ \\
\hline
\end{tabular}

Table 2.5. Enforcement sub-construct (definitions of sub-construct and its dimensions, including variables in brackets)

\subsubsection{Guidance}

The third sub-construct of IOP Governance is Guidance, which refers to Leadership and Support, as well as Communication provided from actors outside of the organisation.

The Leadership and Support dimension pertains to influence factors describing the existence and role of a committed and qualified leadership that can help secure the necessary resources and support required for the adoption of the network's IOP standards (dos Santos \& Reinhard, 2012; Emerson, Nabatchi, \& Balogh, 2011; Soares \& Amaral, 2011) ${ }^{45}$. The 
variables of this dimension include informal leadership provided outside of formalised structures (Dawes \& Eglene, 2008), and the presence of a "champion", usually a peer who is committed to the adoption efforts (Kamal, 2006; Kamal et al., 2011). It also builds upon sufficient and effectively allocated funding (Kamal et al., 2011; Nelson \& Svara, 2011; Williams et al., 2009) ${ }^{\Delta 6}$, as well as resilient network management (Crosby \& Bryson, 2010). Another factor that is mentioned in the literature is administrative creativity, i.e. the existence of processes through which new ideas in the organisation are generated and accepted (Nelson \& Svara, 2011; West \& Berman, 1997). Furthermore, the leadership dimension builds upon efficient conflict management (Bryson et al., 2006; Crosby \& Bryson, 2010; Nelson \& Shaw, 2005), the existence of sufficient reward structures (Yang \& Maxwell, 2011), trust- and consensus building activities (Crosby \& Bryson, 2010), legitimacy-building activities (Bryson et al., 2006; Crosby \& Bryson, 2010), as well as knowledge-building mechanisms to ensure continuous learning and flexibility of the leadership to adapt to insights gained (Dawes \& Eglene, 2008; Nelson \& Svara, 2011; Tambouris, Tarabanis, Peristeras, \& Liotas, 2007) ${ }^{\Delta 7}$.

Communication, the second dimension for the Guidance sub-construct, refers to the degree to which effective communication mechanisms are in place within the network to enhance coordination and to support the adoption of IOP standards (Kamal, 2006; Nelson \& Shaw, 2005). The variables belonging to this dimension are the degree to which a strategic plan is specified and communicated (Crosby \& Bryson, 2010; Kamal et al., 2011; Nelson \& Svara, 2011) ${ }^{\Delta 8}$, the setting of realistic goals (Gil-Garcia et al., 2007), a clear assignment of responsibilities among partners (Soares \& Amaral, 2011), mechanisms for dissemination of knowledge that can be used to guide the efforts to develop IOP, e.g. through trainings or information materials (Andersen et al., 2010; Hellman, 2010; Soares \& Amaral, 2011) ${ }^{\Delta 9}$, clear and complete documentation of the IOP standards (Nelson \& Shaw, 2005), and availability of clarifying support to understand the usage and effects of the IOP standards, e.g. through helpdesks or consultant teams (Ebbers \& van Dijk, 2007).

\begin{tabular}{|l|l|}
\hline Guidance & $\begin{array}{l}\text { The leadership, external support, and communication provided from actors outside of } \\
\text { the organisation }\end{array}$ \\
\hline Definition & $\begin{array}{l}\text { The existence and role of a committed leadership that can help secure the necessary } \\
\text { resources and support required for the adoption of the network's IOP standards } \\
\text { (variables: Championship, Informal Leadership, Resilience, Conflict Management, } \\
\text { Trust- and Consensus-Building, Legitimacy-Building, Administrative Creativity, } \\
\text { Funding, Reward Structures, Knowledge-Building Activities) }\end{array}$ \\
\hline Communication & $\begin{array}{l}\text { The degree to which effective communication mechanisms are in place within the } \\
\text { network to enhance coordination and to support the adoption of IOP standards } \\
\text { (variables: Knowledge Dissemination, Documentation Quality, Clarification, Plan, } \\
\text { Realistic Goals, Clear Responsibilities) }\end{array}$ \\
\hline
\end{tabular}

Table 2.6. Guidance sub-construct (definitions of sub-construct and its dimensions, including variables in brackets)

\subsubsection{Network-External Environment}

The Network-External Environment construct captures those determinants of IOP standards adoption that pertain to the wider environment beyond the immediate network-level. The 
sub-constructs that the literature review identified for this determinant are the Political Environment, and Policy and Institutions. Each of these sub-constructs, including their composite dimensions and variables, are explained in more detail in the two following sections.

\begin{tabular}{|l|l|}
\hline Network-External Environment \\
Definition & $\begin{array}{l}\text { The determinants of IOP standards adoption that pertain to the wider environment beyond } \\
\text { the immediate network-level }\end{array}$ \\
\hline
\end{tabular}

Table 2.7. Network-External Environment construct (definition)

\subsubsection{Political Environment}

Political Environment refers to the political dynamics and power relations in the wider (inter)national environment of the network (cf. Dawes \& Eglene, 2008; Emerson et al., 2011). Its dimensions are Public Pressure and Constituency Characteristics. Previous research shows that peer influence is particularly important for government organisations, as indicated by the fact that public-sector organisations display a higher degree of control by external stakeholders than private organisations (Pugh, Hickson, \& Hinings, 1969). This argument has also been confirmed in the specific context of information technology adoption by organisations (Jeyaraj et al., 2006).

Public Pressure refers to the pressures exerted by public stakeholders (cf. Kamal et al., 2011; Nelson \& Svara, 2011; Walker, 2008), including political interest and demand from government (van Dijk, 2007), citizen demand (Kamal et al., 2011; Oliver, 1990; Tolbert, Mossberger, \& McNeal, 2008), and public scrutiny such as investigative assessments of the network (Landsbergen \& Wolken, 2001).

Constituency Characteristics describe the nature of the client community served by the Government Information Network. In particular, the variables identified in this dimension are the size of the community (Jun \& Weare, 2010; Kamal, 2006; Nelson \& Svara, 2011) (10 $^{\Delta 10}$ and its socio-economic environment (Akbulut, 2003; Kamal, 2006).

\begin{tabular}{|l|l|}
\hline Political Environment & $\begin{array}{l}\text { The political dynamics and power relations in the wider (inter)national environment of } \\
\text { the network }\end{array}$ \\
\hline Definition & $\begin{array}{l}\text { Pressures exerted by public stakeholders (variables: Citizen Demand, Government } \\
\text { Demand, Public Scrutiny) }\end{array}$ \\
\hline Public Pressure & $\begin{array}{l}\text { The nature of the clients community served by the Government Information Network } \\
\text { (variables: Community Socio-Economic Environment, Community Size) }\end{array}$ \\
\hline $\begin{array}{l}\text { Constituency } \\
\text { Characteristics }\end{array}$
\end{tabular}

(Table 2.8. Political Environment sub-construct (definitions of sub-construct and its dimensions, including variables in brackets)

\subsubsection{Policy and Institutions}

The Policy and Institutions sub-construct refers to the national and international institutional and policy infrastructure affecting e-Governance initiatives and IOP (Emerson et al., 2011; Luna-Reyes et al., 2007; Tolbert et al., 2008) ${ }^{\Delta 11}$. More specifically, it consists of the 
dimensions of EGOV and IOP Policy, the Administrative Structure, the Legal Framework and the Budgetary Framework.

EGOV and IOP Policy refers to the strategies, instruments and mechanisms at national and international level to support e-Governance initiatives and IOP (Hellman, 2010; Soares \& Amaral, 2011; Yang \& Maxwell, 2011) ${ }^{\Delta 12}$. No individual variables have been identified from the literature to further sub-divide this dimension.

The Administrative Structure dimension describes the structure of the bureaucratic apparatus at the various governmental levels (cf. Fountain, 2001, 2007; Westholm, 2005). In particular, the literature mentions as a relevant variable in this dimension the degree to which the bureaucracy is fragmented along constitutional, legal, and jurisdictional lines, often referred to as "stovepipes" (Fountain, 2001, 2007; Scholl \& Klischewski, 2007).

The Legal Framework dimension denotes the framework of legislation and regulation affecting e-Governance initiatives and IOP (cf. Andersen et al., 2010; dos Santos \& Reinhard, 2012; Soares \& Amaral, 2011) ${ }^{\Delta 13}$. The variables for this dimension are privacy legislation and regulation (Hellman, 2010; Landsbergen \& Wolken, 2001; Soares \& Amaral, 2011) 414, intellectual property-rights legislation and regulation (Tambouris et al., 2007), and law and regulations regarding public procurement (Tambouris et al., 2007). Another variable identified from the literature concerns the degree of ambiguity or disharmony in legislation (Hellman, 2010; Soares \& Amaral, 2011; Tambouris et al., 2007) ${ }^{\Delta 15}$.

Finally, the Budgetary Framework dimension captures the institutional framework related to budgetary issues that affect e-Governance initiatives and IOP. It includes as relevant influence factors the budgetary mechanisms that allocate funding to the initiatives and distribute them among project partners (Kamal et al., 2011; Nelson \& Svara, 2011; Williams et al., 2009) ${ }^{\Delta 16}$ and economic governance of IOP, for instance through incentives such as subsidized pricing or direct subsidies (Andersen et al., 2010; Tambouris et al., 2007).

\begin{tabular}{|l|l|}
\hline Policy and Institutions & $\begin{array}{l}\text { The national and international institutional and policy infrastructure affecting e- } \\
\text { Governance initiatives and IOP }\end{array}$ \\
\hline Dimensions for this sub-construct \\
\hline EGOV and IOP Policy & $\begin{array}{l}\text { The strategies, instruments and mechanisms at national and international level to } \\
\text { support e-Governance initiatives and IOP (no variables) }\end{array}$ \\
\hline $\begin{array}{l}\text { Administrative } \\
\text { Structure }\end{array}$ & $\begin{array}{l}\text { The structure of the bureaucratic apparatus at the various governmental levels (variables: } \\
\text { Stovepipes) }\end{array}$ \\
\hline Legal Framework & $\begin{array}{l}\text { The framework of legislation and regulation affecting e-Governance initiatives and IOP } \\
\text { (variables: IP Legislation, Public Procurement Legislation, Privacy Legislation, } \\
\text { Ambiguous Legislation) }\end{array}$ \\
\hline Budgetary Framework & $\begin{array}{l}\text { The institutional framework related to budgetary issues that affect e-Governance } \\
\text { initiatives and IOP (variables: Budgetary Mechanisms, Economic IOP Governance) }\end{array}$ \\
\hline
\end{tabular}

Table 2.9. Policy and Institutions sub-construct (definitions of sub-construct and its dimensions, including variables in brackets)

\subsubsection{Network Characteristics}

Network Characteristics are conceptualised as the construct covering those determinants that pertain to the characteristics of a given Government Information Network. The main sub- 
constructs that the literature review identified are Network Complexity, Trust, Mimetic Dynamics, Domain Structure and Information Infrastructure. Each of these is explained in more detail in the respective sections below.

\section{Network Characteristics}

\begin{tabular}{|l|l} 
Definition & The characteristics of a given Government Information Network
\end{tabular}

Table 2.10. Network Characteristics construct (definition)

\subsubsection{Network Complexity}

Network Complexity captures the determinants referring to those features of a given Government Information Network that complicate the interactions within the network and make it difficult for organisations in the network to align with each other in order to adopt its IOP standards. Three dimensions for Network Complexity have been identified from the literature. These are Structural Complexity, Network Diversity and Task Complexity.

Structural Complexity refers to the degree to which the size of the network (i.e. the number of partners) increases the difficulty of alignment within the network (cf. dos Santos \& Reinhard, 2012; Provan \& Kenis, 2008; Scholl \& Klischewski, 2007) ${ }^{\Delta 17}$. With a higher number of partners, the number of potential relations between organisations drastically increases, as does the potential for diversity that needs to be overcome in order to achieve IOP. Therefore, larger networks create a bigger need for coordination in order to harmonise the network participants' activities towards the achievement of a joint goal such as IOP (Provan \& Kenis, 2008). No additional variables have been identified from the literature to further sub-divide the Structural Complexity dimension.

Network Diversity refers to difficulties of alignment across organisations resulting from the heterogeneity of partner organisations in the network along various aspects that constrain any harmonisation activities between them (cf. Dawes \& Eglene, 2008; Gil-Garcia et al., 2007; Hellman, 2010). The variables for this dimension include diversity in organisational capacities, such as different levels of development between organisations (Yang et al., 2011), differences in power and status (Ansell \& Gash, 2007; Bala \& Venkatesh, 2007; Crosby \& Bryson, 2010) ${ }^{\Delta 18}$ and inequalities in organisational resources (Ansell \& Gash, 2007; Hellman, 2010; Oliver, 1990), as well as semantic diversity and technical diversity in information infrastructures (Bekkers, 2007; Lee \& Kim, 2007) and data definitions (Bekkers, 2007). Additional variables are of strategic nature, such as diversity of organisational goals and problem interpretations (dos Santos \& Reinhard, 2012; Samuelson \& Björk, 2010; Yang \& Maxwell, 2011) ${ }^{\Delta 19}$. Other variables relate to operational diversity, i.e. differences in organisations' structure and procedures (Hellman, 2010; Yang \& Maxwell, 2011; Yang et al., 2011) ${ }^{\perp 20}$, administrative boundaries (dos Santos \& Reinhard, 2012; Yang \& Maxwell, 2011; Yang et al., 2011) ${ }^{\Delta 21}$, or legal diversity (Bekkers, 2007). Additional variables are culture and value diversity (Hellman, 2010; Samuelson \& Björk, 2010; Yang \& Maxwell, 2011) ${ }^{\Delta 22}$, the degree to which the network is a mix of public and private organisations (Soares \& Amaral, 2011; Tambouris et al., 2007; Yang et al., 2011) ${ }^{\Delta 23}$, and geographic distance between organisations (Yang \& Maxwell, 2011; Yang et al., 2011). 
Task Complexity describes the complexity of the (policy) problem that the network is attempting to solve (Crosby \& Bryson, 2010; dos Santos \& Reinhard, 2012) ${ }^{424}$. The variables for this dimension include the degree of interdependence of partner organisations in achieving the task (Bekkers, 2007; Kumar \& van Dissel, 1996; Provan \& Kenis, 2008), the type of information to be shared with others (dos Santos \& Reinhard, 2012; Scholl \& Klischewski, 2007) and the type and level of collaboration required from partners (Bryson et al., 2006; Crosby \& Bryson, 2010).

\begin{tabular}{|l|l|}
\hline Network Complexity & $\begin{array}{l}\text { The features of the network that complicate the interactions within a given Government } \\
\text { Information Network and make it difficult for organisations in the network to align } \\
\text { with each other in order to adopt its IOP standards }\end{array}$ \\
\hline Dimensions for this sub-construct \\
\hline $\begin{array}{l}\text { Structural Network } \\
\text { Complexity }\end{array}$ & $\begin{array}{l}\text { The degree to which the size of the network increases the difficulty of alignment within } \\
\text { the network (no variables) }\end{array}$ \\
\hline Network Diversity & $\begin{array}{l}\text { The difficulties of alignment across organisations resulting from the heterogeneity of } \\
\text { partner organisations in the network along various aspects (variables: Developmental } \\
\text { Diversity, Power Diversity, Resource Diversity, Goal Diversity, Operational Diversity, } \\
\text { Administrative Boundaries, Technical Diversity, Semantic Diversity, Culture and Value } \\
\text { Diversity, Geographic Proximity, Public-Private Mix) }\end{array}$ \\
\hline Task Complexity & $\begin{array}{l}\text { The complexity of the (policy) problem that the network is attempting to solve } \\
\text { (variables: Type of Information Shared, Type/Level of Collaboration, Interdependence) }\end{array}$ \\
\hline
\end{tabular}

Table 2.11. Network Complexity sub-construct (definitions of sub-construct and its dimensions, including variables in brackets)

\subsubsection{Trust}

Trust, i.e. the expectation of reciprocal respect of conventions and agreements, is also mentioned in the literature as an important network characteristic that influences networklevel interactions (cf. Bekkers, 2009; Emerson et al., 2011; Provan \& Kenis, 2008) ${ }^{\triangle 25}$. It is not only shown to be an initial requirement for the formation of collaborative ventures (cf. Fountain, 2007; Luna-Reyes et al., 2007), it is also a key factor for sustaining such arrangements (cf. Bryson et al., 2006). The determinants identified from the literature are not located at separate conceptual levels, hence only the level of "variables" is specified to further sub-divide this sub-construct, without the necessity of an intermediate "dimensions" layer. As individual variables of this sub-construct, the literature presents transparency of the partner organisations (Soares \& Amaral, 2011), prior experiences with each other (Ansell \& Gash, 2007; Crosby \& Bryson, 2010; Dawes \& Eglene, 2008) ${ }^{\Delta 26}$, inter-organisational trust (e.g. where a boundary spanner in one organization trusts and respects the other organization) (Gil-Garcia et al., 2007; Kamal, 2006; Provan \& Kenis, 2008) ${ }^{\Delta 27}$ and interpersonal trust (between two boundary spanners across organisations) (Brass, Galaskiewicz, Greve, \& Wenpin, 2004; Kamal, 2006).

\begin{tabular}{|l|l|}
\hline Trust & $\begin{array}{l}\text { The expectation of reciprocal respect of conventions and agreements (variables: Prior } \\
\text { Experiences, Inter-Organisational Trust, Inter-Personal Trust) }\end{array}$ \\
\hline Definition
\end{tabular}

Table 2.12. Trust sub-construct (definition, including variables in brackets) 


\subsubsection{Mimetic Dynamics}

The Mimetic Dynamics sub-construct refers to network characteristics that create opportunities for imitation among network partners (cf. Bala \& Venkatesh, 2007; DiMaggio \& Powell, 1983; Teo, Wei, \& Benbasat, 2003). Like with the Trust sub-construct, the determinants identified from the literature are not located at separate conceptual levels, hence only the variable-level is specified here. The literature mentions the following variables that are grouped under this sub-construct: frequency of interaction with other organisations in the network (Dahl \& Hanssen, 2006), the existence of a critical mass of adopters (Kamal et al., 2011; Nelson \& Svara, 2011; Tolbert et al., 2008) ${ }^{\wedge 28}$, and the degree of homophily with early adopters, i.e. the degree to which organisations that are "pioneers" in adopting the standards are similar to the focal organisation (Dahl \& Hanssen, 2006). This is closely related to network theory: as for instance Granovetter (1983) argues, there is a relationship between network structure and the way information (and by extension, mimicry) travels within network. The key point here is that persuasive information travels more easily across network clusters with strong ties than across a network that predominantly consists of weak ties, where information is more diverse and less persuasive for mimicry since critical mass, homophily, and frequent interaction are all likely to be lower.

\section{Mimetic Dynamics}

\begin{tabular}{|l|l}
\hline Definition & $\begin{array}{l}\text { Network characteristics that create opportunity for imitation among network partners } \\
\text { (variables: Critical Mass, Homophily, Frequent Interaction) }\end{array}$
\end{tabular}

Table 2.13. Mimetic Dynamics sub-construct (definition, including variables in brackets)

\subsubsection{Domain Structure}

Domain Structure describes the general nature of the policy domain(s) in which the network operates (cf. Andersen et al., 2010; Dawes \& Eglene, 2008). The determinants identified from the literature for this sub-construct are not located at separate conceptual levels, so that no intermediate dimensions are specified for this sub-construct. The variables for this subconstruct include the time since when the domain has operated (Samuelson \& Björk, 2010), turbulences in the domain such as for instance financial or political uncertainties (Bryson et al., 2006; Crosby \& Bryson, 2010), the need for innovation when there is a perceived gap between the expected and actual performance of the domain (Bingham, 1976 ; Ebbers \& van Dijk, 2007; Nelson \& Svara, 2011), pressures to adopt resulting from the need to stay competitive (Crosby \& Bryson, 2010; Jun \& Weare, 2010; Kamal et al., 2011) ${ }^{\perp 29}$, and options for unilateral action, in which organisations are able to achieve their goals by themselves rather than collaborating in a network (Ansell \& Gash, 2007; Crosby \& Bryson, 2010; Emerson et al., 2011) ${ }^{\triangle 30}$.

\section{Domain Structure}

\begin{tabular}{l|l} 
Definition & $\begin{array}{l}\text { The general nature of the policy domain(s) in which the network operates (variables: } \\
\text { Competitive Forces, Unilateral Options, Need for Innovation, Turbulence, Time) }\end{array}$
\end{tabular}

Table 2.14. Domain Structure sub-construct (definition, including variables in brackets) 


\subsubsection{Information Infrastructure}

The Information Infrastructure sub-construct denotes those determinants pertaining to the state of the domain-level arrangement of technology, tools, facilities, people and procedures supporting the handling of information (Andersen et al., 2010). The determinants identified from the literature for this sub-construct are not located at separate conceptual levels, and are therefore grouped at the variable-level. Its variables are the technical environment, i.e. the status and stability of technology and applications in the network (Dawes \& Eglene, 2008; Gil-Garcia et al., 2007), as well as the prior presence and usage of standards in the domain (Samuelson \& Björk, 2010).

Information Infrastructure

\begin{tabular}{|l|l|}
\hline Definition & $\begin{array}{l}\text { The state of the domain-level arrangement of technology, tools, facilities, people and } \\
\text { procedures supporting the handling of information (variables: Technical Environment, } \\
\text { Existence of Standards) }\end{array}$ \\
\hline
\end{tabular}

Table 2.15. Information Infrastructure sub-construct (definition, including variables in brackets)

\subsubsection{Organisation-Specific Determinants}

The Organisation-Specific Determinants construct is defined here as those determinants that pertain to the characteristics and support capacities of the individual organisations in the Government Information Network needed for the adoption of IOP standards.

\begin{tabular}{|l|l|}
\hline Organisation-Specific Determinants \\
Definition & $\begin{array}{l}\text { The characteristics and support capacities of the individual organisations in a given } \\
\text { Government Information Network needed for the adoption of IOP standards }\end{array}$ \\
\hline
\end{tabular}

Table 2.16. Organisation-Specific Determinants construct (definition of construct)

\subsubsection{Organisational Capacity}

The organisation-specific determinants mentioned in the literature focus on organisational capacities, and hence are grouped here under the sub-construct Organisational Capacity. This sub-construct can be understood as an adaptation of the "Perceived Behavioural Control" construct that features typically in technology-acceptance models (UTAUT for instance identifies as relevant items for "Perceived Behavioural Control" the possession of the necessary resources and knowledge to use the technology). The Organisational Capacity subconstruct can be conceptualised as the existence of organisation-internal facilitating conditions needed for the adoption of IOP standards, including support capacities and resources. The relevant dimensions identified in the literature pertaining to this subconstruct are Financial Resources, ICT Capability, Organisational Structure, Human Resources, Manager Characteristics, Management Practices, and Relational Mechanisms. Each of them is explained in more detail below.

The Financial Resources dimension refers to the financial means (in particular the organisation's budget) that are available to the organisation that are needed for carrying out the required activities and acquire the necessary other resources (dos Santos \& Reinhard, 2012; Nelson \& Svara, 2011; Soares \& Amaral, 2011) ${ }^{\wedge 31}$. No subordinate conceptual levels were specified for this dimension. 
The ICT Capability dimension refers to the existence of a support infrastructure related to ICT assets such as software and hardware (Kamal et al., 2011; Samuelson \& Björk, 2010; Williams et al., 2009) ${ }^{\triangle 32}$. The relevant variables include the sophistication of the ICT infrastructure (Kamal et al., 2011; Samuelson \& Björk, 2010; Williams et al., 2009) ${ }^{\Delta 33}$, and support from the ICT department (Chen, 2010; Jun \& Weare, 2010; Kamal et al., 2011).

Next, the Organisational Structure dimension pertains to the existence of capacities related to the organisation's structural characteristics (Bingham \& O'Leary, 2006; Kwon, Pardo, \& Burke, 2009; Nelson \& Svara, 2011). The variables identified for this dimension are organisational size (Dahl \& Hanssen, 2006; Kamal, 2006; Kamal et al., 2011) ${ }^{\Delta 34}$ and internal unity (Jun \& Weare, 2010; van Dijk, 2007).

Another dimension of Organisational Capacity is Human Resources, i.e. the existence of a support infrastructure related to the capacity of its staff (cf. Andersen et al., 2010; Landsbergen \& Wolken, 2001). An important aspect of this are variables related to competences, including the amount of human resources available to support the IOP standards adoption (Soares \& Amaral, 2011), staff's ICT know-how (Kamal et al., 2011; Samuelson \& Björk, 2010; Yang \& Maxwell, 2011) ${ }^{\triangle 35}$, their knowledge of business processes (Bryson, Stone, Crosby, \& Saunoi-Sandgren, 2009), knowledge of the policy domain (Kamal, 2006; Kamal et al., 2011), experience with the relevant IOP standards (Zhu, Kraemer, Gurbaxani, \& Xu, 2006), awareness of the relevant information resources in their organisation and its environment (Dawes, 1996; Landsbergen \& Wolken, 2001), as well as networking experience (Daley, 2008; Gil-Garcia et al., 2007; Soares \& Amaral, 2011) ${ }^{\Delta 36}$. Related to these variables, this dimension also includes as a variable the general support infrastructure in the organisation for internal training activities (Tambouris et al., 2007). Next to such competences, it also includes staff motivation as an important factor (Nelson \& Svara, 2011; Soares \& Amaral, 2011; Yang \& Maxwell, 2011) ${ }^{\wedge 37}$.

Manager Characteristics are another important dimension of Organisational Capacity. Organisational managers tasked with the implementation and use of IOP standards need to possess the necessary characteristics and skills to lead their organisation through the adoption of the IOP standards (cf. Agranoff \& McGuire, 1999; Agranoff \& McGuire, 2001). The relevant variables for this dimension are the organisational top managements' general background, particularly educational (Damanpour \& Schneider, 2006; Kearney, Feldman, \& Scavo, 2000; Nelson \& Svara, 2011) ${ }^{\triangle 38}$, their attitude to innovation (Damanpour \& Schneider, 2006; Kamal, 2006; Nelson \& Svara, 2011) ${ }^{\triangle 39}$, their ICT skills (Kamal, 2006), their power within the organisation (Krebs \& Pelissero, 2010; Nelson \& Svara, 2011) and their tenure status (Kearney et al., 2000; Nelson \& Svara, 2011).

In addition, Organisational Capacity can be characterised by the dimension of Management Practices that are conducive to IOP standards adoption (cf. Andersen et al., 2010; dos Santos \& Reinhard, 2012; Scholl \& Klischewski, 2007) ${ }^{\Delta 40}$. Such practices include making feasibility assessments (Nelson \& Shaw, 2005), formulating strategic plans (Chen, 2010), life-cycle oriented procurement methods (Landsbergen \& Wolken, 2001), top management support (Ebbers \& van Dijk, 2007; Gil-Garcia et al., 2007; Kamal et al., 2011) ${ }^{\Delta 41}$ and a centralised decision-making structure within the organisation (Jun \& Weare, 2010; Kamal et al., 2011; Nelson \& Svara, 2011) ${ }^{\Delta 42}$. In addition, knowledge management, i.e. the stimulation of 
organisational learning and training, is also identified in the literature as an influence factor (Boudreau \& Robey, 2005).

The final dimension for Organisational Capacity is Relational Mechanisms, i.e. the ability of an organisation to invest in purposeful relationships (cf. Bala \& Venkatesh, 2007). A central variable in this dimension is the size and strength of the existing network of an organisation (Bryson et al., 2009; Crosby \& Bryson, 2010; Emerson et al., 2011) ${ }^{\Delta 43}$. Other variables pertaining to this construct include relational specificity (i.e. the willingness of the organisation to sustain relationships with particular partners), and relationship extendibility (i.e. the flexibility of the organisation for partnering) (Bala \& Venkatesh, 2007). This in turn is related to another variable: the organisation's visibility to potential new partners (Whetten \& Leung, 1979).

\begin{tabular}{|c|c|}
\hline \multicolumn{2}{|l|}{ Organisational Capacity } \\
\hline Definition & $\begin{array}{l}\text { The existence of organisation-internal facilitating conditions needed for the adoption of } \\
\text { IOP standards }\end{array}$ \\
\hline \multicolumn{2}{|c|}{ Dimensions for this construct } \\
\hline Financial Resources & $\begin{array}{l}\text { The financial means that are available to the organisation, and that are needed for } \\
\text { carrying out the required activities and acquiring the necessary resources (no variables) }\end{array}$ \\
\hline ICT Capability & $\begin{array}{l}\text { The organisational support infrastructure related to ICT assets such as software and } \\
\text { hardware (variables: ICT Infrastructure, ICT Department Support) }\end{array}$ \\
\hline $\begin{array}{l}\text { Organisational } \\
\text { Structure }\end{array}$ & $\begin{array}{l}\text { The organisational support infrastructure related to the organisation's structural } \\
\text { characteristics (variables: Organisation Size, Internal Unity) }\end{array}$ \\
\hline Human Resources & $\begin{array}{l}\text { The organisational support infrastructure related to the capacity of its staff (variables: } \\
\text { Human Resources Amount, Staff Motivation, ICT Know-How, Business-Process Know- } \\
\text { How, Policy Domain Know-How, Training, IOP Standards Experience, Information } \\
\text { Awareness, Networking Experience) }\end{array}$ \\
\hline $\begin{array}{l}\text { Manager } \\
\text { Characteristics }\end{array}$ & $\begin{array}{l}\text { Organisational managers' characteristics and skills to lead their organisation through } \\
\text { the adoption of the IOP standards (variables: Manager's Attitude to Innovation, } \\
\text { Manager's Background, Manager's ICT Skills, Manager's Power) }\end{array}$ \\
\hline Management Practices & $\begin{array}{l}\text { Managerial practices in the organisation that are conducive to IOP standards adoption } \\
\text { (variables: Decision-Making Centralisation, Top Management Support, Feasibility } \\
\text { Assessment, Knowledge Management, Strategic Plan, Monitoring) }\end{array}$ \\
\hline Relational Me & $\begin{array}{l}\text { The ability of an organisation to invest in purposeful relationships (variables: Relational } \\
\text { Specificity, Relationship Extendibility, Visibility, Existing Networks) }\end{array}$ \\
\hline
\end{tabular}

Table 2.17. Organisational Capacity sub-construct (definitions of sub-construct and dimensions, including variables in brackets)

\subsubsection{IOP Standards Characteristics}

The IOP Standards Characteristics construct is an adaptation of the "Technology" or "Innovation" determinants discussed in Section 2.3.1 under the TOE and IOE models, and is defined as the general attributes of the IOP standards (cf. Ahn, 2010; Raus et al., 2009; Veit et al., 2011) ${ }^{444}$. The determinants identified from the literature for this construct are not conceptually grouped at separate levels, and are therefore only specified at the variablelevel. The key variables included in this construct are trialability, i.e. the possibility for organisations for trying out and experimenting with the IOP standards before their formal adoption (Mustonen-Ollila \& Lyytinen, 2004; Raus et al., 2009; Rogers, 2003) ${ }^{\Delta 45}$, and the maturity of the IOP standards, i.e. the degree to which they are free from risk and uncertainty (cf. Akbulut, 2003; Mustonen-Ollila \& Lyytinen, 2004; Veit et al., 2011). 
IOP Standards Characteristics

\begin{tabular}{l|l} 
Definition & The general attributes of the IOP standards (variables: Trialability, Maturity)
\end{tabular}

Table 2.18. IOP Standards Characteristics construct (definition, including variables in brackets)

\subsubsection{Adoption Efforts}

The Adoption Efforts determinant can be understood as an organisational-level adaptation of the "Effort Expectancy" construct that is typically included in technology acceptance models and refers to those determinants that capture the efforts needed for adoption (and compliance). For instance, UTAUT's "Effort Expectancy" construct is defined as "the degree of ease associated with the use of the system" and includes the sub-constructs "Ease of Use" and "Complexity", which refer to the degree to which using an innovation is perceived as being difficult to understand and use. Whilst these UTAUT constructs measure individuallevel perceptions, such considerations are equally valid at the organisational level. However, the considerations of an organisation with regard to efforts are not necessarily identical to those of an individual. In the first place, the effort-related considerations that are made on behalf of an organisation consider the efforts and costs at all levels in the organisation, and thus also reflect an aggregation of efforts encountered by all the individuals within that organisation. But in addition, organisational-level effort expectancy also takes into consideration the cost impacts that the standards adoption has on the organisation as an entity to overcome potential barriers and challenges to adoption of the standards. In the remainder of this section, an organisational-level adaptation of Adoption Efforts and its sub-constructs is developed.

Adoption Efforts can be conceptualised as the extent of efforts required from an organisation during the adoption process, i.e. the efforts that are required to deal with complexities and inflexibilities in the various spheres of the organisation (Bala \& Venkatesh, 2007; Kamal, 2006; Samuelson \& Björk, 2010) ${ }^{\Delta 46}$. The relevant determinants mentioned in the literature can be grouped into sub-constructs pertaining to Technological Efforts, Organisational Efforts, Legal Efforts, and Resource Costs. For all of these sub-constructs, the determinants identified from the literature are not conceptually grouped at separate levels, and are therefore only specified at the variable-level without the necessity for an intermediate dimensions-level.

The Technological Efforts sub-construct refers to the efforts required by the degree of technological difficulty and costs of adopting the IOP standards (cf. Andersen et al., 2010; Dawes \& Eglene, 2008; Williams et al., 2009) ${ }^{\Delta 47}$. This especially pertains to the required information infrastructure: the arrangement of technology, tools, facilities, people and procedures which supports the handling of information.

Another sub-construct is Organisational Efforts, i.e. the required efforts to fit the IOP standards into organisational structures and processes (cf. Bala \& Venkatesh, 2007; Kamal, 2006; Yang \& Maxwell, 2011) ${ }^{\Delta 48}$. For the largest part, the individual variables that were identified from the literature for this sub-construct relate to intra-organisational efforts, such as efforts of aligning existing business processes and operations with the IOP standards (Kamal, 2006; Nelson \& Shaw, 2005), efforts of aligning organisational values with the IOP standards (Kamal, 2006), and efforts for training staff within the organisation for compliance 
with the IOP standards (Williams et al., 2009). It also includes variables related to interorganisational efforts, such as efforts related to the maintenance of relationships with partners (Oliver, 1990), and efforts for monitoring and enforcing compliance by others (Oliver, 1990).

Legal Efforts, i.e. the efforts to overcome legal obstacles (cf. Zhu et al., 2006), is a further subconstruct that can be grouped under Adoption Efforts. The individual variables that were identified from the literature for this sub-construct refer to the efforts required by the legal framework that specifies regulation and legislation (Andersen et al., 2010; dos Santos \& Reinhard, 2012; Soares \& Amaral, 2011) ${ }^{\Delta 49}$. This includes in particular variables regarding legal issues in the domains of intellectual property legislation (Tambouris et al., 2007), public procurement legislation (Tambouris et al., 2007) and privacy legislation (Hellman, 2010; Landsbergen \& Wolken, 2001; Soares \& Amaral, 2011) ${ }^{\Delta 50}$. An additional variable, representing a cross-cutting issue for all these legal domains, is formed by the efforts that organisations face when confronting ambiguous and disharmonious legislation (Hellman, 2010; Soares \& Amaral, 2011; Tambouris et al., 2007) ${ }^{\Delta 51}$.

Finally, Resource Costs of adoption form the fourth sub-construct for Adoption Efforts, which describes the resource costs made for adoption, in particular financial costs (cf. Kamal et al., 2011; Weitzel, Beimborn, \& Konig, 2006; Zhu et al., 2006) ${ }^{\Delta 52}$. In terms of individual variables, the literature identified technological infrastructure costs, such as cost of new technology and exit costs from existing infrastructure (Kamal, 2006; Tambouris et al., 2007; Williams et al., 2009), as well as administrative costs such as costs for the necessary staff training (Williams et al., 2009), costs for maintaining relationships and monitoring compliance by others (Oliver, 1990), and increased transaction costs for participants as a result from adoption (Kumar \& van Dissel, 1996).

\begin{tabular}{|c|c|}
\hline Definition & $\begin{array}{l}\text { The extent of efforts required from an organisation during the adoption process, i.e. the } \\
\text { efforts that are required to deal with complexities and inflexibilities in the various } \\
\text { spheres of the organisation }\end{array}$ \\
\hline \multicolumn{2}{|c|}{ Sub-constructs for this construct } \\
\hline Technological Efforts & $\begin{array}{l}\text { The efforts required by the degree of technological difficulty and costs of adopting the } \\
\text { IOP standards (no variables) }\end{array}$ \\
\hline Organisational Efforts & $\begin{array}{l}\text { The required efforts to fit the IOP standards into organisational structures and processes } \\
\text { (variables: Maintaining Relationship Efforts, Monitoring/Enforcement Efforts, Training } \\
\text { Efforts, Process Efforts, Value Efforts) }\end{array}$ \\
\hline Legal Efforts & $\begin{array}{l}\text { The efforts to overcome legal obstacles (variables: Legal Framework, IP Legislation, } \\
\text { Public Procurement Policies, Privacy Legislation, Ambiguous Legislation) }\end{array}$ \\
\hline Resource Costs & $\begin{array}{l}\text { The resource costs of adoption (variables: Infrastructure Costs, Training Costs, } \\
\text { Maintaining Relationship Costs, Monitoring/Enforcement Costs, Transaction Costs) }\end{array}$ \\
\hline
\end{tabular}

Table 2.19. Adoption Efforts construct (definitions of construct and sub-constructs, including variables in brackets)

\subsubsection{Results}

The Results determinant is conceptualised as the consequences, manifest and expected, resulting from the adoption of IOP standards (cf. Dawes \& Eglene, 2008), and can be understood as an organisational-level adaptation of the "Performance Expectancy" construct which is typically included in technology acceptance models. For instance, in the 
original UTAUT model, the "Performance Expectancy" construct concerns considerations regarding the usefulness and outcome expectations from using an information system, and includes a sub-construct named "Outcome-Expectations" which refers to job-related performance expectations and personal expectations (Venkatesh et al., 2003). Hence, in technology acceptance models, the "Performance Expectancy" construct in fact functions merely as an antecedent of the intention to adopt - leaving the actual consequences resulting from adoption unaccounted for. Whilst acknowledging this function as an antecedent, the Result construct in our model, however, also aims to reflect the actual consequences resulting from adoption. The Results construct in our model thus comprises two kinds of results: manifest results from actual adoption, as well as expected results that actors anticipate based on experiences from previously adopted standards or related contexts of adoption. Therefore, in difference to the other determinants, a two-way causal relationship is specified between Results and Adoption, where Results can be a determinant of adoption in the form of expected results, as well as a consequence of adoption (manifest results).

The Results and Adoption Efforts determinants are closely linked in their effect on organisations' intention for adopting IOP standards - both are "implications" of adoption. The literature on strategic public management is instructive here, since it focuses on organisational decision-makers' strategic choices and makes a distinction between inputs and outputs and their effects as motivating and demotivating factors (Gil-Garcia et al., 2007; Schermerhorn, 1975). A common method employed by organisations is a business case analysis which weighs inputs (efforts) and expected or anticipated outputs (results) of a project (cf. Vaidya, Sajeev, \& Callender, 2006 for an example of using this method in the context of public-sector ICT adoption). For this reason, these two determinants are discussed together as "implications" 28 in a dedicated chapter (Chapter 4), separate from the other determinants listed here (Chapter 5).

\section{Results}

Definition

The consequences, manifest and expected, resulting from the adoption of IOP standards

\section{Table 2.20. Results construct (definition)}

Most of the relevant determinants mentioned in the literature can be grouped into two subconstructs: On the one hand, there are those dimensions pertaining to Internal-Operations Results: Effectiveness, Efficiency, Resource Acquisition, Data Management, and Coordination. On the other hand there are the dimensions that relate to External-Relations Results: Political Effects, Image, and Reach Expansion.

\subsubsection{Internal-Operations Results}

The Internal-Operations Results sub-construct is defined as the consequences resulting from the adoption of IOP standards on an organisation's internal operations (cf. Kamal, 2006). One of the key Internal-Operations Results is Effectiveness. This dimension refers to the output of the organisation, such as its contribution to solving domain-level problems (cf. Landsbergen \& Wolken, 2001). The variables identified in the literature for this dimension

\footnotetext{
${ }^{28}$ It is important to note that the concept of "implications" is not restricted to denote "consequences" or outputs alone, but also includes the required inputs.
} 
are the effects of IOP standards adoption on the quality of the services provided by the organisation (Chen, 2010; Gil-Garcia et al., 2007; Kubicek et al., 2011) ${ }^{\Delta 53}$, responsiveness of the organisation (Landsbergen \& Wolken, 2001), its ability to solve operational problems (Dawes, 1996), and effects on the creation of public value through the organisation's contribution to policy goals (Crosby \& Bryson, 2010; Dawes, 1996; Dawes \& Eglene, 2008).

Another major dimension related to internal operations is Efficiency. It is related to Effectiveness, but rather than the former dimension's focus on output, Efficiency refers to the ratio of output to input (cf. Jun \& Weare, 2010; Kubicek et al., 2011; Samuelson \& Björk, 2010) ${ }^{\Delta 54}$. The individual variables for this dimension are the effects of IOP standards adoption on operations costs (Gil-Garcia et al., 2007; Kubicek et al., 2011; Samuelson \& Björk, 2010) ${ }^{\triangle 55}$, speed in carrying out operations (Samuelson \& Björk, 2010; Weitzel et al., 2006), as well as the usability (ease of use) of information processing (Kamal, 2006; Kubicek et al., 2011).

The Resource Acquisition dimension refers to the effects of IOP standards adoption on the acquisition of complementary resources for the organisation (cf. Brass et al., 2004; Oliver, 1990; Schermerhorn, 1975). In particular, this includes as variables the acquisition of expertise (Bala \& Venkatesh, 2007; Oliver, 1990), information (Samuelson \& Björk, 2010), and financial resources (Kamal et al., 2011). Data Management is specified as a dimension which refers to effects of IOP standards adoption on data management (Kubicek et al., 2011; Samuelson \& Björk, 2010; Tseng, Yen, Hung, \& Wang, 2008) ${ }^{\Delta 56}$. The individual variables that were identified for this dimension are data quality and consistency (Kamal et al., 2011; Kubicek et al., 2011; Samuelson \& Björk, 2010) ${ }^{\Delta 57}$, reliability of data processing by adherence to common standards (Kamal, 2006; Kubicek et al., 2011), and data security and privacy (Kamal et al., 2011).

\begin{tabular}{|l|l|}
\hline Internal-Operations Results \\
\hline Definition & $\begin{array}{l}\text { The consequences resulting from the adoption of IOP standards on the organisation's } \\
\text { internal operations }\end{array}$ \\
\hline Dimensions for this sub-construct \\
\hline Effectiveness & $\begin{array}{l}\text { Effects from adoption on the output of the organisation (variables: Responsiveness, } \\
\text { Service Quality, Problem-Solving, Policy Contribution) }\end{array}$ \\
\hline Efficiency & $\begin{array}{l}\text { Effects from adoption on the organisation's input-output ratio (variables: Operations } \\
\text { Cost, Operations Speed, Usability) }\end{array}$ \\
\hline Resource Acquisition & $\begin{array}{l}\text { Effects from adoption related to the organisation's acquisition of complementary } \\
\text { resources (variables: Expertise Acquisition, Information Acquisition, Financial Resources } \\
\text { Acquisition) }\end{array}$ \\
\hline Data Management & $\begin{array}{l}\text { Effects from adoption on data management (variables: Data Security, Data Quality, Data } \\
\text { Processing Reliability) }\end{array}$ \\
\hline Coordination & $\begin{array}{l}\text { Effects from adoption on the coordination of programmes and services (variables: } \\
\text { Uncertainty Reduction, Goal Clarification, Reporting) }\end{array}$ \\
\hline
\end{tabular}

Table 2.21. Internal-Operations Results sub-construct (definitions of sub-construct and its dimensions, including variables in brackets)

Coordination refers to the effects of IOP standards adoption on the coordination of programmes and services through integrated planning and service delivery (Bala \& Venkatesh, 2007; Gil-Garcia et al., 2007; Zhu et al., 2006) ${ }^{458}$. The individual variables grouped under this dimension are uncertainty reduction due to more clarity about organisation's internal and external contingencies as a result of increased access to 
information (Brass et al., 2004), as well as clarification of the organisation's own goals (Dawes, 1996) and the effects of adoption on reporting and decision support (Samuelson \& Björk, 2010).

\subsubsection{External-Relations Results}

The dimensions pertaining to External-Relations Results describe the effects on interorganisational interaction resulting from adopting the IOP standards, including professional relations among individuals (cf. Dawes, 1996; Tseng et al., 2008). The first dimension is Political Effects, i.e. the effects related to political power vis-a-vis other actors. As individual variables, this includes the effects of IOP standards adoption on the organisation's competitiveness and power vis-a-vis other organisations (Jun \& Weare, 2010; Kamal et al., 2011; Yang \& Maxwell, 2011) ${ }^{\Delta 59}$, effects on interdependences and organisations' autonomy (Gil-Garcia et al., 2007; Soares \& Amaral, 2011; Yang \& Maxwell, 2011) ${ }^{\Delta 60}$, as well as the effects on the degree to which the organisation is on equal footing vis-a-vis its partners in terms of its influence on programme-related decisions (Gil-Garcia et al., 2007).

Another important dimension is Image, which refers to the effects of IOP standards adoption on the organisation's status and alignment with normative pressures in its environment of peers (cf. Moore \& Benbasat, 1991; Schermerhorn, 1975; Teo et al., 2003) ${ }^{\Delta 61}$. This dimension thus refers to the organisation's reputation among its peers in terms of substantive issues, rather than "image" in the sense of intangible marketing-related public perception. Hence, the individual variables for this dimension are demonstrability of (positive) results from adoption (Gil-Garcia et al., 2007; Moore \& Benbasat, 1991; Rogers, 2003), the development of an innovative image of the organisation (Brass et al., 2004), its image in terms of transparency and accountability (Dawes, 1996; Gil-Garcia et al., 2007; Tseng et al., 2008), its legitimacy with external stakeholders (Brass et al., 2004; Dawes, 1996; Oliver, 1990), and the clarity of the organisation's role for others (Dawes, 1996).

Finally, the Reach Expansion dimension refers to the effects from IOP standards adoption on the reach of the organisation in terms of partners and operational fields (Dawes, 1996; Weitzel et al., 2006; Zhu et al., 2006). No additional subordinate conceptual levels were identified to further sub-divide this dimension.

\begin{tabular}{|l|l|}
\hline \multicolumn{2}{|l|}{ External-Relations Results } \\
\hline Definition & $\begin{array}{l}\text { The consequences resulting from the adoption of IOP standards on the organisation's } \\
\text { external relations }\end{array}$ \\
\hline Definition of dimensions \\
\hline Political Effects & $\begin{array}{l}\text { Effects from adoption related to political power vis-a-vis other actors (variables: Power, } \\
\text { Credibility, External Autonomy, Equality) }\end{array}$ \\
\hline Image & $\begin{array}{l}\text { Effects from adoption related to the organisation's status and alignment with normative } \\
\text { pressures in its environment of peers (variables: Clarity of Image, Results } \\
\text { Demonstrability, Innovation, Accountability Image, Legitimacy) }\end{array}$ \\
\hline Reach Expansion & $\begin{array}{l}\text { Effects from adoption related to the reach of the organisation in terms of partners and } \\
\text { operational fields (no variables) }\end{array}$ \\
\hline
\end{tabular}

Table 2.22. External-Relations Results sub-construct (definitions of sub-construct and its dimensions, including variables in brackets) 


\subsubsection{Preliminary Conceptual Model}

Based on the preceding sections, a preliminary model on the organisational adoption of IOP standards in Government Information Networks is presented. The full model structures the identified determinants along four levels of conceptual hierarchy that are decreasing in abstraction and thus represent increasingly concrete levels of determinants: constructs, subconstructs, dimensions, and variables. At the centre is the "dependent" construct: Adoption (organisations' actual adoption of, and compliance with the IOP standards specified in the IOP architecture of a Government Information Network). The model proposes Adoption to be continuous (i.e. not binary, since standards can be adopted partially to various degrees), and that this degree is influenced by a range of determinants that can be grouped into seven main determinant constructs. These constructs are IOP Governance (determinants regarding the governance of a network's IOP architecture), Network Characteristics (determinants related to the inter-organisational network and its characteristics), Network-External Environment (determinants related to the environment external to the network, beyond the immediate network-level), Organisation-Specific Determinants (determinants pertaining to the individual organisation and its assets), IOP Standards Characteristics (determinants related to the general characteristics of the IOP standards), Adoption Efforts (efforts required from an organisation during the adoption process), and Results (consequences resulting from the adoption of IOP standards). The latter, in contrast to the other constructs, is proposed to have a two-directional relationship with Adoption. This reflects the reasoning that whilst Results are a consequence of adoption, they can simultaneously play a role as antecedent by influencing adoption in the form of anticipated results. The preliminary model is presented in Figure 2.6 below. For the purpose of presenting an overview, Figure 2.6 only presents the two highest levels of abstraction: constructs and sub-constructs.

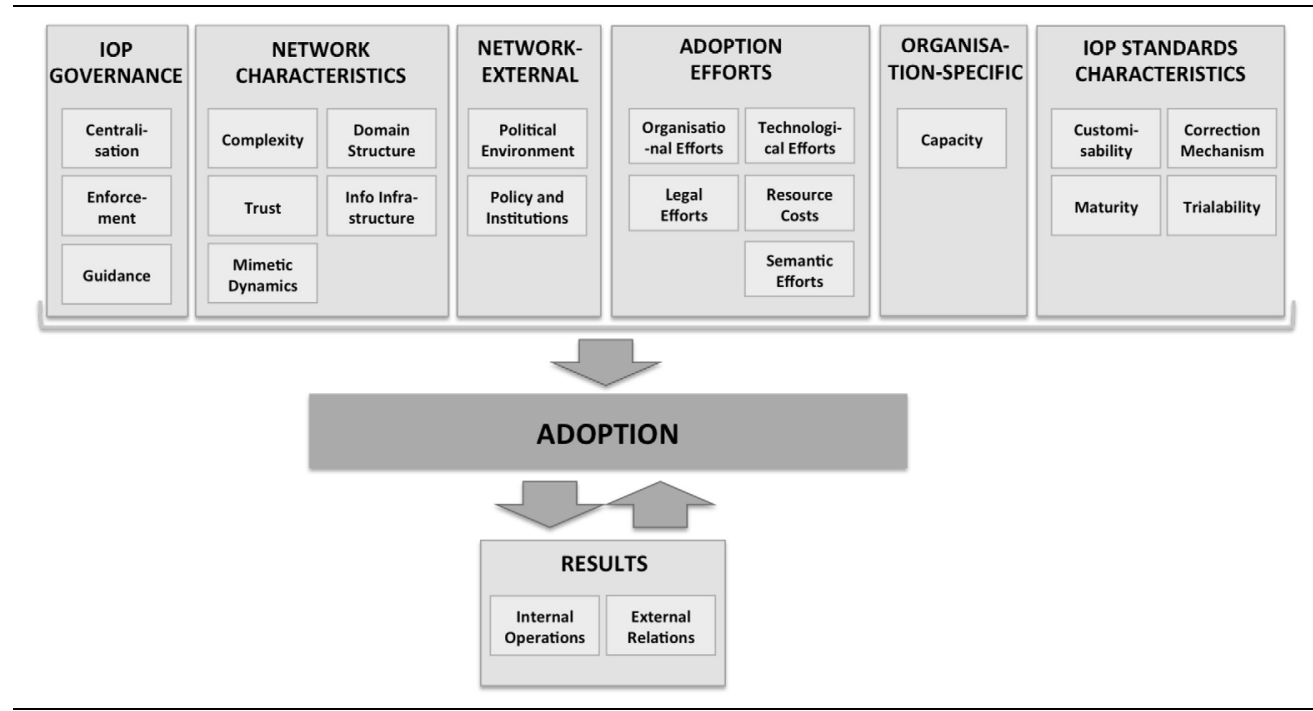

Figure 2.6. Preliminary theoretical model (main constructs and sub-constructs) ${ }^{29}$

${ }^{29}$ Only the levels of constructs and sub-constructs are displayed here, the levels of dimensions and variables are not shown for better readability. 


\subsection{Conclusion}

This chapter constructed a preliminary theoretical model of the determinants of IOP standards adoption by organisations in Government Information Networks, which provides the basis for the analysis in the subsequent chapters of this dissertation. The chapter first argued that the innovation diffusion and technology acceptance theories form the theoretical anchors for the topic of this dissertation. However, since there is a plethora of different models from these strands of theory, there is a need for a synthesis of existing models.

The chapter also elaborated why, despite their relevance as theoretical foundations, current models from these literature strands are limited in their ability to fully explain IOP standards adoption by organisations in Government Information Networks, and thus need a refined context-specific model. First, technology acceptance models are largely focusing on the micro-level of analysis, explaining adoption decisions of individuals, but not of organisations. Second, there are many models on different types of innovations and information technologies, but no models on the specific context of IOP standards adoption in an e-Governance context. And third, these models explain the cognitive processes of belief formations behind individuals' adoption decisions, but generally do not include factors from the external environment that affect these belief formations. Therefore, the chapter argued that an integrative, multi-theoretical model is needed which identifies the determinants of organisations' adoption decision concerning IOP standards in Government Information Networks.

The chapter therefore conducted an extensive literature review of studies in relevant bodies of literature (particularly the public administration literature on public-sector innovation, eGovernance, inter-organisational relations and network governance). It identified all determinants of adoption that were mentioned in these studies, and grouped and integrated them in a model which synthesises them into seven main determinant constructs: IOP Governance, Network Characteristics, Network-External Environment, Organisation-Specific Determinants, IOP Standards Characteristics, Adoption Efforts, and Results. These determinant constructs constitute the highest level of abstraction in the model, and each of them consists of three subordinate levels (sub-constructs, dimensions, and variables) that are decreasing in abstraction and represent increasingly concrete level of determinants.

However, this model is only of preliminary nature since it has been derived from the literature review, and not been validated. In order to see whether all of the specified determinants indeed play a role, and whether it misses any relevant determinants, it needs to be validated. The subsequent chapters address how this validation was addressed (Chapter 3), and show the results from the validation (Chapters 4 and 5). Chapter 4 focuses on the two "implications" determinants (Adoption Efforts and Results), and the remainder of the determinants is addressed in Chapter 5. The final model is provided at the end of Chapter 5. Chapter 6 then investigates the relationship between the IOP Governance and Network Characteristics constructs, and the significance of this relationship for their effect on IOP standards adoption. 



\section{CHAPTER 3.}

\section{METHODOLOGY}

\subsection{Introduction}

This chapter provides a description of the methodological approach behind the empirical analyses in the following chapters. It thus has two main objectives. First, it aims at describing the qualitative case study approach of this dissertation, and to explain the motivation why this method is suitable for addressing the research questions introduced in Chapter 1. Second, the chapter aims at giving an overview of the selected cases, in order to give actual practice-based examples of the Government Information Network concept introduced earlier, and to give the reader an initial understanding of the cases' context as a basis for the following empirical chapters.

The chapter is structured along these objectives. Section 3.2 provides an argument for the motivation to use an interpretative approach and qualitative case studies as the empirical basis for this dissertation. It explains the exploratory (Section 3.2.1) and comparative purposes of the case studies (Section 3.2.2), and the case selection techniques that were deployed in line with these purposes. Section 3.3 presents the methods used for data collection, including an overview of the interview process and the consulted document sources. Section 3.4 then details how the collected empirical data was analysed by means of both inductive and deductive analytical techniques. In Section 3.5, the chapter then provides an introduction and overview of the two Government Information Networks that were selected as cases for this dissertation. For both these cases, the section details the policy background and inter-organisational network, each network's information infrastructure, and the IOP governance structure. Finally, Section 3.6 provides a summary and conclusion of the chapter.

\subsection{A Case for a Qualitative Approach}

The research questions presented in Chapter 1 are addressed in this dissertation by investigations based on qualitative research methods. The exploratory nature of several key research questions, and the need to investigate processes and interpretations that underlie the formation of adoption behaviour, strongly suggest the collection of qualitative data. An interpretive analysis of qualitative data, notably of the in-depth information gained from interviews with stakeholders and the analysis of key documents, is regarded as a preferred method for these purposes as it allows to identify and describe in rich detail what the factors are that influence adoption, to provide the necessary detail for an in-depth understanding of how stakeholders experience their role and relevance, for analysing the adoption process, as well as for giving empirically founded recommendations about which institutional 
governance designs are conducive to support the achievement of IOP in Government Information Networks. The insights gained from such an interpretive analysis can additionally serve as a basis to assess the relative importance of various determinants by means of a "semi-quantitative" content analysis ${ }^{30}$.

\subsubsection{Exploratory Purposes of the Case Studies}

To reflect the above reasoning for a qualitative approach, the main part of this dissertation rests on case study research. Owing to the exploratory nature of the research, the data that is required needs to be rich in detail, which suggests a small-N design that allows for an indepth analysis. This "exploratory nature" refers to the goal of identifying the relevant determinants and of generating hypotheses about their effects. Furthermore, since, as Chapter 2 has argued, there is little theoretical guidance on the processes of behaviour formation with regard to IOP standards adoption in Government Information Networks, we need to allow for a flexible adjustment of the investigation to the pursuit of informative evidence as the analysis progresses. Such open-ended exploration within the selected cases is required to yield the information that is necessary to establish a grounded understanding of IOP and IOP standards adoption, the identification of relevant actors, processes of behaviour formation, adoption processes and problems. In terms of requirements for case selection, this means that we need cases that are representative instances of our population of interest (i.e. Government Information Networks).

Due to this study's need for small-N in-depth analysis rather than a large-N quantitative analysis, it used a purposive sampling strategy. This means that we need to select our cases according to a good match of the cases' relevant characteristics with the previously developed theoretical framework (see Chapter 2), rather than through random sampling (in which any possible case would have an equal likelihood of turning up in the final selection). The reasoning behind this is that with small-N studies, random sampling can have a higher likelihood of being unrepresentative of the population they are assumed to be part of (Seawright \& Gerring, 2008). While purposive sampling does not allow any probabilistic analyses as large-N random sampling does, and thus has limited external validity, its strength instead lies in internal validity: the generation of detailed explanations of mechanisms apparent in selected representative cases, allowing limited generalizations that apply to cases that are similar to those under study (Bennett, 2004). It therefore requires having a clear delineation of the population of instances that have such sufficient similarity in relevant characteristics (Seawright \& Gerring, 2008), which this study does by providing a detailed description of relevant "control" variables that are kept constant in the selection of cases (discussed in the next section).

In order to enhance the representativeness of the findings from the exploratory analysis in Chapters 4 and 5, the study adopted a "diverse cases" selection strategy (Gerring, 2008; Seawright \& Gerring, 2008). The idea of such a "diverse cases" design is to ensure maximum variance along the selected salient dimensions of the research, and thus to be representative

\footnotetext{
${ }^{30}$ Both the interpretive analysis and the content analysis are explained in detail in Section 3.4.
} 
of the full variation in the population of interest ${ }^{31}$. Ideally, a case selection according to this strategy encompasses the full range of values on the selected explanatory variables of interest. One advantage of this design is that it allows the researcher to investigate the causal processes by which a certain explanatory variable (or, as in our case, the interaction of several explanatory variables) yield certain outcomes. In addition, being the small-N counterpart to the use of stratified sampling in large-N probabilistic analyses, the "diverse cases" approach has been argued to have stronger representativeness than any other smallN case selection techniques (Gerring, 2008).

As the discussion of determinants in Chapter 2 has shown, there is a large pool of relevant variables that could be potentially chosen as variables of interest. However, it is not possible to include all relevant variables in the selection frame, as this would imply that a very large number of cases would need to be studied - even if this were practically feasible, it would effectively defeat the very purpose of the argument made earlier about the advantages of small-N research in this context. Therefore, a selection of specific variables had to be made.

This dissertation consequently selected as its focus the investigation of a particular theoretical argument which had hitherto not been empirically investigated: the theoretical argument, originally put forward by Provan and Kenis (2008; cf. also Span et al., 2012), that the effectiveness of network outcomes (in our case, IOP standards adoption) depends in particular on a matching configuration of a network's IOP governance centralisation ${ }^{32}$ and the network's complexity ${ }^{33}$. In essence, their key argument is that with increasing complexity of the inter-organisational network, stronger centralisation of governance yields more effective network-level outcomes (this argument is discussed in detail in Chapter 6, which intends to empirically validate it). ${ }^{34}$ Whilst the Provan and Kenis paper is an influential study informing many subsequent studies on network governance, its theoretical argument has so far not been empirically validated. Therefore, it is relevant to focus in this dissertation on the two central variables from their theory. Next to this theoretical motivation, the selection of these two variables also is inductively justified. At the outset of this dissertation project, a number of "scoping interviews" were conducted by the author with a range of scholars and practitioners active in the field of e-Governance about "hot topics" in this field in order to determine a theoretically as well as practically relevant focus for this dissertation research. ${ }^{35}$ The relation between the complexity of inter-organisational collaborative constellations in e-Governance and the suitable degree of governance centralisation was one of the key topics that these experts repeatedly mentioned.

\footnotetext{
${ }^{31}$ Representativeness here thus means that the scope of variation along the relevant dimensions in the researched population is covered. It should be noted that this does not mean that it is mirroring the distribution of that variation in the researched population. Representativeness is related, but not synonymous to the concept of "generalisability".

${ }^{32}$ The concept of IOP governance centralisation is discussed in detail in Section 6.2.1 and defined as "the extent to which the administration of the IOP architecture of a given Government Information Network is characterised by centralised decision-making in combination with strong top-down enforcement mechanisms".

${ }^{33}$ The concept of network complexity is discussed in detail in Section 6.2.2 and defined as "the combination of the size of the network, the diversity of the organisations in the network and task complexity in the network".

${ }^{34}$ This argument is discussed in detail in Section 6.2.

35 These scoping interviews were led with experts idenfied by the author and academic advisors, as well as through "snowballing" referrals of the interviewees themselves. The interviews included a number of semi-structured interviews with five scholars from Dutch Universities and consultancy firms, as well as more informal conversations with a large number of practitioners from government organisations.
} 
As both IOP governance centralisation and network complexity are continuous variables, this dissertation follows the methodological recommendation of the literature on "diverse cases" design to operationalise continuous variables in a dichotomous fashion by taking the extreme ends of their respective continuous spectrum (Gerring, 2008; Seawright \& Gerring, 2008): complex versus non-complex networks, and centralised vs. decentralised IOP governance. This yields four possible configurations (schematically displayed in Table 3.2 further below). Selecting cases that include these four configurations allowed the researcher to trace the detailed mechanisms that link a certain interaction of network complexity and governance approach to a particular outcome regarding IOP standards adoption. As Section 3.2.2 will explain, this selection framework was combined with a comparative design, so that both exploratory and comparative purposes could be addressed by means of a final selection of two cases.

\subsubsection{Comparative Purposes of the Case Studies}

The case study design of this research aims not only to be exploratory. It also has a comparative purpose, in its goals to see whether certain configurations of governance centralisation and network complexity are more appropriate for yielding a positive outcome in terms of IOP adoption. By comparing whether stakeholders from both complex and noncomplex networks perceive different governance approaches to have different effects on IOP adoption in these contrasting network settings, the study investigates whether a certain governance approach is more successful in absolute terms, or whether different network complexities indeed require different governance approaches. In other words, the contrasting cases here function as a "robustness check" of whether our assumption based on the argument by Provan and Kenis (2008) holds: if the data from both the complex network as well as the non-complex network confirm our assumption that more complex Government Information Networks require more centralised IOP governance, we can assume that this argument has a higher degree of validity.

This additional, comparative purpose of the dissertation requires selecting the cases also according to a comparative logic. The diverse cases design described above simultaneously also satisfies the criteria of such a comparative case design. This is because studying the four possible configurations mentioned above (i.e. both centralised and decentralised governance in both complex and non-complex networks) provides the possibility to compare the interaction of governance approach and network complexity - as long as the other relevant factors are kept constant. Conceiving of this "interaction term" (having four possible values, as described above) as this dissertation's main variable of interest makes it possible to address its comparative purpose by adopting a "most-similar" design.

Most-similar case study designs are a comparative design that is derived from the "method of difference" presented in Mill's "System of Logic" (Mill, 1904 [orig. 1843]) as an inductive method to investigate causality. As such, a most-similar design seeks to identify the key features that are different in (otherwise) similar cases, in order to account for an observed outcome. In other words, it compares a minimum of two cases that are similar on all the measured explanatory variables ("control" variables), except the explanatory variable(s) of interest. This "neutralizes" the effect of other variables that potentially could account for the variation in the outcome, thus isolating the (co)variation of outcome and explanatory 
variable of interest (see also Ebbinghaus, 2005; Gerring, 2008). In this sense, it roughly resembles the logic behind a controlled experiment - but again, focusing on internal validity since its non-random small-N selection bars it from external generalisation beyond cases that are similar to the ones studied.

But what is the explanatory variable of interest, and what are the control variables that need to be kept constant? As mentioned above, the comparative investigation of this dissertation is interested in the influence of the interaction of two variables on IOP standards adoption: IOP governance centralisation and network complexity. This interaction term consequently forms one single variable. Or to put it differently, since this variable actually consists of two explanatory variables, we can in fact speak of a "dual" most-similar case-study design. This comparison allows us to see whether either network complexity or governance centralisation have an absolute effect (i.e. they are independent of each other) or whether, as Provan and Kenis (2008) postulate, there is an interaction effect (i.e. they depend on each other). If, for instance, the dissertation's results were to show that a centralised IOP governance approach is always more successful in situations of both complex and noncomplex networks, this would suggest that there is no interaction effect and that higher governance centralisation has an absolute effect on the adoption of IOP standards. If, on the other hand, the research results were to show that a centralised IOP governance approach is more successful in complex networks, this would suggest that there indeed is an interaction between governance centralisation and network complexity.

Several other variables are kept constant to strengthen the most-similar design as much as possible: First of all, both cases are Government Information Networks that require an automated, digital information exchange in public-sector organisation networks based on requirements for technological, semantic and organisational standardisation. As the detailed discussion of the two cases in Section 3.5 explains, in both networks the main actors are all dependent on information being shared electronically by partners throughout the network by means of a central application and shared processes. Furthermore, the "age" of the networks is kept constant by choosing Government Information Networks that have already been operational for more than one year at the time of data collection. Finally, the external environment is held constant through choosing cases in the same country, the Netherlands, ensuring that the general information infrastructure, the political environment, and institutional policy frameworks are similar. ${ }^{36}$

For the two main explanatory variables of interest, variation is sought along the following dimensions. The operationalisation of the two variables of interest for the case selection is shown in Table 3.1 below. The degree of network complexity is assessed along the three conceptual dimensions specified for this: Structural Complexity, Network Diversity and Task Complexity. ${ }^{37}$ Structural Complexity was operationalised as the number of participating organisations. Network Diversity, the heterogeneity of partner organisations in the network, was operationalised for the case selection by the following variables: Public-Private Mix (i.e. whether or not the network consists of only public-sector organisations or a mix of public

\footnotetext{
${ }^{36}$ The cases are, however, from different policy domains (social security and higher education).

${ }^{37}$ See Sections 2.4.4.1 and 6.2.2 for a discussion of these dimensions.
} 
and private organisations), Goal Diversity (indicated by whether all partner organisations are from the same or from different policy domains), and Operational Diversity (the diversity of project-related tasks carried out by organisations in the network, i.e. whether all organisations in the network have the same task within the project or whether there are different tasks to be performed by different organisations). Task Complexity was indicated by the Interdependence variable, i.e. in how far the partner organisations are dependent on other organisations in the network for their contribution to the achievement of the desired network-level outcome.

The assessment of the other independent variable of interest, IOP governance centralisation, was also based on selected relevant determinants identified in the theoretical review: Brokerage and Stakeholder Inclusion: the former was assessed by whether or not there is a broker body in the network (Broker Existence), and the latter was assessed by the degree to which partner organisations are participating in the network's IOP governance (Partners Participation). ${ }^{38}$

\begin{tabular}{l|l|l|l|l|l|}
\hline $\begin{array}{l}\text { Selection } \\
\text { Variable }\end{array}$ & \multicolumn{3}{|c|}{$\begin{array}{l}\text { Network } \\
\text { Complexity }\end{array}$} & \multicolumn{2}{c|}{ OP Governance Centralisation } \\
\hline $\begin{array}{l}\text { Operationa- } \\
\text { lisation }\end{array}$ & $\begin{array}{l}\text { Structural } \\
\text { Complexity } \\
\text { (Number of } \\
\text { participating } \\
\text { organisations) }\end{array}$ & $\begin{array}{l}\text { Network Diversity } \\
\text { (Public-Private } \\
\text { Mix, Goal Diver- } \\
\text { sity, Operational } \\
\text { Diversity) }\end{array}$ & $\begin{array}{l}\text { Network } \\
\text { Diversity } \\
\text { (Interdepen- } \\
\text { dence) }\end{array}$ & $\begin{array}{l}\text { Brokerage } \\
\text { (Broker Existence) }\end{array}$ & $\begin{array}{l}\text { Stakeholder Inclusion } \\
\text { (Partners Partici- } \\
\text { pation) }\end{array}$ \\
& & & & \\
\end{tabular}

Table 3.1. Operationalisation of variables for case selection

With regard to the assessment of potential cases to match the selection to the above criteria, the study uses the following "sampling" procedure. First, the researcher identified a pool of potentially possible cases through web searches, searching the relevant literature (for instance previous case studies), and through interviews with practitioners in the field. "Possible" cases at this stage meant that it was checked whether the identified projects were matching the criteria of the "control variables" described above. This pool of projects was then further narrowed down based on the publicly available documentation on these cases, so that only those cases that appeared to be the most markedly positioned at the endpoints of the two (continuous) variables of interest (network complexity and IOP governance centralisation) were chosen for further consideration. Subsequently, the researcher conducted scoping interviews with key stakeholders from each of the remaining projects in this narrower pool of possible cases in order to inform the final selection of cases with more in-depth qualitative information on how they "scored" along the relevant dimensions of interest. Eventually, this procedure resulted in the selection of two cases: The Digital Client Dossier (Digitaal Klantdossier, DKD) and Studielink. Section 3.5 describes both cases in detail.

There is a need to explain how the four variable configurations, discussed above, can be analysed by means of only two case studies ${ }^{39}$. The answer is that it is possible to ensure

\footnotetext{
${ }^{38}$ See Sections 2.4.2.1 and 6.2.1 for a discussion of these dimensions.

${ }^{39} \mathrm{~A}$ "case" here should be understood in terms of its common conception in qualitative case research, as a coherent phenomenon which may include "within-case" variation along certain variables of interest (such as for instance one kind of Government Information Network which features many standards with different governance approaches). The
} 
sufficient variation for a comparative analysis by means of combining both cross-case and within-case analysis. In other words, this means that across both cases, there is variation in the network complexity variable, with the DKD case representing a highly complex network (see detailed discussion in Section 3.5.1.1), and Studielink a non-complex network (detailed discussion in Section 3.5.2.1). Variation in the governance centralisation variable can be found within each case, with governance approaches differing across the various IOP standards within each case (see Sections 3.5.1.3 and 3.5.2.3 for a detailed discussion). In total, both cross-case and within-case variations combined thus yield a matrix of the four necessary variable configurations, as shown in Table 3.2 below.

\begin{tabular}{|l|c|c|}
\hline Cross-case & Non-complex network & Complex Network \\
\hline Within-case & $\begin{array}{c}\text { Studielink } \\
\text { (Standards } \mathrm{x} \text { ) }\end{array}$ & $\begin{array}{c}\text { DKD } \\
\text { (Standards x) }\end{array}$ \\
\hline Centralised Governance & $\begin{array}{c}\text { Studielink } \\
\text { (Standards y) }\end{array}$ & $\begin{array}{c}\text { DKD } \\
\text { (Standards y) }\end{array}$ \\
\hline Decentralised Governance &
\end{tabular}

Table 3.2. Variable variation matrix across the two cases

\subsubsection{Practical Motivations for the Case Studies}

Finally, there are also a number of practical benefits of choosing the selected cases. First, choosing Government Information Networks from the Netherlands meant that the empirical data (i.e. relevant organisations, interviewees, and documentation) were within geographical proximity, which meant that it was easier to access the data in the first place and also to re-consult it more easily when it was necessary (for instance following up with interviewees, or returning to their organisation to meet with additional stakeholders). Second, fluent academic language proficiency of the researcher in Dutch meant that interviewees were potentially more easily accessible and that the risk of relevant information being "lost in translation" during the interviews and in their analysis was minimised. And third, since the research for this dissertation was sponsored by ICTU Foundation and the Dutch Ministry of Internal Affairs and Kingdom Relations (Ministerie van Binnenlandse Zaken en Koninkrijksrelaties, MinBZK), choosing cases from the Netherlands meant that access to a lot of information and documentation surrounding the Dutch e-governance context in general, as well as with regard to the chosen cases in particular, was made accessible to the researcher.

\subsection{Data Collection}

The data collected in the cases consists both of interviews with relevant stakeholders, as well as relevant documentation from the cases. Interviews have been conducted in both cases with key informants from partner organisations in the two networks, as well as informants at network level. While the unit of analysis is the individual organisation (in line with the main research question), these organisations are represented by their respective key informants. These are typically project managers in charge of the respective initiatives in

concept of a "case" used here should thus not be mistaken for the conception typically used in quantitative research, where it denotes an individual data point in a given parameter space (where for instance every standard and governance approach would each constitute a separate case). 
their organisation and thus in possession of a broad overview of the network's development and the various attitudes held towards it throughout the organisation.

The approach to use the perceptions of key informants as representatives of their organisations is not a new one and has been used in the past in many studies, including in the information systems literature (cf. Bala \& Venkatesh, 2007; Chau \& Tam, 1997). In an early study on inter-organisational collaboration, Schermerhorn pointed out the relevance of individuals as the unit of analysis in studies of organisational behaviour (in particular, interorganisational collaboration), by arguing that key individuals such as organisational managers are the central actors when it comes to making decisions on behalf of the organisation (Schermerhorn, 1975). This suggests that such key decision-makers in the organisation will be in an informed, as well as influential position to report on the organisational intention and decision to adopt IOP standards. Furthermore, it has been argued earlier by Benbasat and Moore (1991) that individual-level adoption models can be developed into a tool for studying adoption and diffusion of ICT innovations within organisations, because organisations' decisions to adopt such innovations in essence consist of cumulative decisions made by individuals in a social system (such as for instance an organisation). Organisational adoption, therefore, can be conceptualised as being determined by the cumulative individual adoption decisions within the organisation. Since these decision-makers are chosen to take decisions in the interest of the organisation and thus determining organisational behaviour, they therefore also most closely represent the intention "of the organisation".

In total, the author conducted 36 interviews with 37 interviewees in the period from January until September $2011^{40}$. The interviewees were selected based on their position in the organisations of interest. In order to gain an initial overview of applicable key informants, the project manager at the network level was asked to provide a list of the project managers in the participating organisations. The researcher then subsequently contacted these persons with an invitation email to participate in the research. In addition to this strategy, several interviewees were also added at a later stage by means of a "snowballing strategy", in which interviewees made suggestions for other relevant informants to interview (cf. Tansey, 2007; Weiss, 1994).

The invitation was sent to all interviewees in the study, and in order to ensure that interviewees' answers would be as focused and informative as possible, it included some information about the general background of the study, as well as the interview questions to be asked. Table 3.3 and Table 3.4 show a list of all interviewees of this study per case, including some key descriptive characteristics. In order to safeguard that the interviewees could speak freely and to reduce the risk of their statements being subject to any social desirability bias, interviewees were guaranteed that their statements would be anonymised. ${ }^{41}$

\footnotetext{
${ }^{40}$ Interviewees $24 \mathrm{a}$ and $24 \mathrm{~b}$ were interviewed together.

${ }^{41}$ See Annex F3 for a copy of the informed consent form.
} 


\begin{tabular}{|c|c|c|c|c|}
\hline ID & Level & Organisation type & Organisation description & Interviewee function \\
\hline 1 & Organisation & Umbrella organisation & Municipalities' umbrella body & Programme Manager \\
\hline 2 & Network & Network broker & Coordination body & Product Manager \\
\hline 3 & Network & Network broker & Coordination body & Head of Department \\
\hline 4 & Network & Network broker & Coordination body & Head of Department \\
\hline 5 & Network & Network broker & Coordination body & Head of Department \\
\hline 6 & Network & Network broker & Coordination body & Director \\
\hline 7 & Organisation & Umbrella organisation & Municipalities' umbrella body & Head of Department \\
\hline 8 & Organisation & Partner organisation & Only information supplier & Project Leader \\
\hline $\left.9^{*}\right)$ & Organisation & Partner organisation & Non-adopting organisation & Network Manager \\
\hline $\left.10^{*}\right)$ & Organisation & Umbrella organisation & Municipalities' umbrella body & Programme Manager \\
\hline 11 & Organisation & Partner organisation & $\begin{array}{l}\text { Core organisation of social } \\
\text { security chain }\end{array}$ & Programme Manager \\
\hline 12 & Organisation & Partner organisation & $\begin{array}{l}\text { Core organisation of social } \\
\text { security chain }\end{array}$ & Executive Officer \\
\hline 13 & Organisation & Partner organisation & Only information recipient & Project Leader \\
\hline $\left.14^{*}\right)$ & Organisation & Partner organisation & $\begin{array}{l}\text { Core organisation of social } \\
\text { security chain }\end{array}$ & Programme Manager \\
\hline 15 & Organisation & Partner organisation & Municipality & $\begin{array}{l}\text { Departmental Executive } \\
\text { Officer }\end{array}$ \\
\hline 16 & Organisation & Umbrella organisation & Municipalities' umbrella body & Manager \\
\hline 17 & Organisation & Umbrella organisation & Municipalities' umbrella body & Network Manager \\
\hline 18 & Organisation & Partner organisation & $\begin{array}{l}\text { Core organisation of social } \\
\text { security chain }\end{array}$ & Manager \\
\hline 19 & Organisation & Partner organisation & Municipality & Head of Department \\
\hline 20 & Organisation & Partner organisation & Only information supplier & ICT manager \\
\hline $\left.21^{*}\right)$ & Network & Network broker & Coordination body & Programme Manager \\
\hline 22 & Organisation & Umbrella organisation & Municipalities' umbrella body & Head of Department \\
\hline 23 & Organisation & Partner organisation & Only information supplier & Project Leader \\
\hline
\end{tabular}

Table 3.3. Interviewees of the DKD case (IDs marked with *) were used for open coding)

The interviews followed a semi-structured format along a question guide ${ }^{42}$ that was customised to the position of the interviewee (organisational representative or network-level manager). The challenge in creating question guides for semi-structured interviews is to keep the number of questions strictly limited in order to allow for flexibility and in-depth answers (in contrast to a survey questionnaire which can ask many questions in a short time), whilst at the same time ensuring that all important areas are covered. It was thus impossible to ask the interviewees about each individual determinant identified in the theoretical model. Furthermore, many determinants only resulted from the analysis of the data and hence could not yet be included in the initial question guide (although some newly identified issues were discussed in follow-up discussions with the interviewees). Instead, at the core of the question guide were a limited number of broader questions that covered the seven main determinant constructs identified in the theoretical model, as well as the Adoption construct. These were framed by an introduction question about the role of the interviewee in the case, and a rounding-off question that explicitly asked for additional

${ }^{42}$ See Annexes F1 and F2 for a copy of the question guide. 
issues that had not yet been addressed in the interview. While all points on the question guide were covered in the interview, sufficient flexibility was allowed for the conversation to cover these issues in the natural flow of the conversation. In general, the interviews lasted around one hour, with the shortest interview lasting around 45 minutes and the longest one approximately two hours. Each interview was recorded and has subsequently been transcribed. Following Richards' (2005) argument, full (verbatim) transcription is only needed if the intention is to analyse the nuances of meanings in people's accounts (as in for instance discourse analysis or rhetoric analysis), but not if the research interest is in deriving factual information or an overview of attitudes (as in this study). Hence, full transcription was not deemed necessary for this research. Nevertheless, since the majority of transcription has been delegated to research assistants who were asked to produce full verbatim transcripts, all but four interviews were transcribed verbatim. ${ }^{43}$ The transcripts have subsequently been sent to the interviewees for confirmation of their correctness, with the invitation to provide clarification where deemed necessary. In only a few instances, interviewees suggested minor corrections at this stage (all of which for mere clarification purposes). No interviewee expressed any wish to distance himself or herself from his or her transcribed statements, or suggested any form of "censoring" in the form of exclusion or significant alteration of the recorded data.

\begin{tabular}{|c|c|c|c|c|}
\hline ID & Level & Organisation type & Organisation description & Interviewee function \\
\hline $24 a$ & Network & Network broker & Main network coordination body & Network Manager \\
\hline $24 \mathrm{~b}$ & Network & Network broker & $\begin{array}{l}\text { Main coordination body of the } \\
\text { network }\end{array}$ & Network Manager \\
\hline 25 & Organisation & External stakeholder & $\begin{array}{l}\text { Student information system } \\
\text { supplier }\end{array}$ & Project Leader \\
\hline $\left.26^{*}\right)$ & Organisation & External stakeholder & $\begin{array}{l}\text { Student information system } \\
\text { supplier }\end{array}$ & Project Leader \\
\hline $\left.27^{*}\right)$ & Organisation & Partner organisation & University & Project Leader \\
\hline 28 & Organisation & Partner organisation & $\begin{array}{l}\text { Polytechnical University } \\
\text { (Hogeschool) }\end{array}$ & $\mathrm{CIO}$ \\
\hline 29 & Organisation & Partner organisation & $\begin{array}{l}\text { Polytechnical University } \\
\text { (Hogeschool) }\end{array}$ & Functional administrator \\
\hline 30 & Organisation & Partner organisation & University & Project Leader \\
\hline 31 & Organisation & Partner organisation & University & $\mathrm{CIO}$ \\
\hline 32 & Organisation & Partner organisation & $\begin{array}{l}\text { Polytechnical University } \\
\text { (Hogeschool) }\end{array}$ & Project Leader \\
\hline 33 & Network & Steering group & Separate coordination body & Chairman \\
\hline 34 & Organisation & Partner organisation & $\begin{array}{l}\text { Polytechnical University } \\
\text { (Hogeschool) }\end{array}$ & Executive Board Member \\
\hline 35 & Organisation & Partner organisation & Governmental body & Project Leader \\
\hline $\left.36^{*}\right)$ & Network & Network broker & Main network coordination body & Director \\
\hline
\end{tabular}

Table 3.4. Interviewees of the Studielink case (IDs marked with *) were used for open coding)

\footnotetext{
${ }_{43} 27$ interviews have been transcribed by research assistants. The assistants were trained beforehand to follow a custom transcription scheme specifying precise guidelines for the transcript format. All transcripts produced by research assistants were full transcripts (i.e. no selectivity in transcription was allowed in order to prevent bias).
} 
The data resulting from these interviews thus represent experienced-based insights of key informants, mostly with explanations and examples from their cases, about which factors they perceive to generally determine adoption in their organisation and Government Information Network, how the processes of adoption unfold and which roles are played by the various actors involved, as well as the relation between network complexity and governance centralisation in their effect on standards adoption.

In terms of project documentation analysed, the data covered a wide selection of documents from the cases. These documents included binding documents such as legislation, contracts, mutual agreements and memoranda of understanding. It also included project documentation such as strategic plans, standard specifications, implementation guidelines, reports from risk analyses, pilot studies, records such as meeting memos and other internal reports. Finally, third party assessments such as previous academic research and consultancy reports were included as well. It should be noted that the interview data formed the backbone of the analysis, whereas the project documentation was rather used as "background" information and as such served to provide a detailed understanding of the cases' context and for clarifications and corroboration of interviewee statements, rather than being subjected to the coding analysis which was applied to the interviewee data (described below).

\subsection{Analysis}

The backbone of the data analysis was an interpretive approach based on qualitative coding of the collected data. Qualitative coding, broadly described, refers to the "tagging" of fragments of the data with analytical categories, referred to as "codes". More concretely, "it is an approach that disaggregates the text (notes or transcripts) into a series of fragments, which are then regrouped under a series of thematic headings" (Atkinson, 1992, cited in Silverman, 2010). Each instance of tagging a text segment with a code is in the remainder of this dissertation referred to as a "quotation". The term "quote" is used to describe the in-text citation of such a "quotation", or parts thereof.

The qualitative coding technique, as used in this study, should not be confused with the (different) understanding of "coding" in quantitative studies (Richards, 2005). Essentially, qualitative coding is not about mere data reduction, i.e. the replacement of the original data with a code. Instead, by on the one hand discovering themes and conceptual categories as they emerge from the data, and on the other hand by assembling fragments of raw data that relate to these conceptual categories, qualitative coding is not only a way of organising the data - it forms an essential component of the qualitative analytical process (cf. Coffey \& Atkinson, 1996; Miles \& Huberman, 1994; Saldaña, 2009).

This study used coding on the one hand as a "filing" technique for structuring the data by collecting all related bits of data from the entire body of interview data in order to be retrieved at a later point (Lewins \& Silver, 2007), and thus to go beyond the mere data records to the conceptual categories behind them. This enabled the researcher to relate it to existing and newly generated theory, by allowing to reflect on the meanings of the coded segments, explore patterns among the thematic categories and detect possible relations among them, for instance by comparing cases or instances of data along these conceptual 
categories (Richards, 2005). On the other hand, and in contrast to the application of predetermined categories to data in quantitative analysis, qualitative coding was used in this study by the researcher to build and refine theory in an inductive way, either by generating new categories in addition to the ones provided by established theory, or by refining them (Richards, 2005).

The codes used in this study were compiled in a codebook that resulted from a combined approach of both deductive and inductive code generation, a strategy for qualitative data analysis that is widely recommended in qualitative methodology (cf. Lewins \& Silver, 2007; Miles \& Huberman, 1994). Deductive code generation is a theory-driven approach to code creation. It is typically applied in instances where a clear idea of "what to look for" in the data already exists - for instance for theory-testing or investigations into the transferability of a given theory to a different social context (Lewins \& Silver, 2007). A deductive code generation strategy therefore seemed suitable for this dissertation's purpose of synthesising a model on the determinants of IOP standards adoption. For the deductive coding, an initial codebook (the "deductive codebook") has therefore been informed by this dissertation's research questions and by distilling the relevant conceptual categories from the literature in relevant fields of theory. The codes listed in this deductive codebook thus mirror the determinants identified in the preliminary framework from Chapter 2, and were compiled according to the methodology described in Section 2.2. ${ }^{44}$

A common criticism about deductive coding is that it potentially imposes limitations to the validity of the analysis, because it imposes a static conceptual grid which is difficult to escape and forfeits the unique advantage of qualitative analysis of being exploratory. In order to address this limitation, this dissertation has combined the deductive with an inductive coding approach, by keeping the deductive codebook open to changes and new additions (cf. Lewins \& Silver, 2007; Miles \& Huberman, 1994). The inductive approach to coding is essentially a data-driven approach to code-creation. Its origin is the classic "grounded theory" approach developed by Strauss and Corbin (1998), where through an iterative process, codes are created "bottom-up" from the data. In this study, the theorydriven code list has been complemented with a list of codes derived through the method advocated by Strauss and Corbin. In a first round of "open coding", a sample of seven interviews transcripts (taken from both cases, including both network-level and organisational-level respondents) ${ }^{45}$ have been read and freely labelled according to "what is going on", resulting in a long list of potential codes. In a second round, these codes have then been consolidated and regrouped into broader, more meaningful categories (called "axial coding" in Strauss and Corbin's terminology). ${ }^{46}$ Where this process resulted in the identification of a new determinant that had not yet been specified as part of the preliminary

\footnotetext{
${ }^{44}$ See Section 2.2 for a detailed description of the method used to identify these determinants.

${ }^{45}$ The interviews used for the open coding are indicated in Table 3.3 and Table 3.4 with *) behind the interviewee ID.

${ }^{46}$ The approach for consolidating the inductively identified codes mirrors the approach described in Section 2.2: the genuinely new concepts were added as separate codes to the list, and where they were conceptually related, but not similar enough to be meaningfully collated, they have been grouped together under a higher-order "umbrella" code for these related codes. This umbrella code would be either labelled with the most suitable code from this grouped set of codes (in case it included one which represented the appropriate concept and level of abstraction), or with a new label created by the researcher.
} 
theoretical framework, this was included as an additional determinant in the codebook. ${ }^{47}$ Next, in order to derive the final codebook (i.e. the one used for the empirical analysis), these inductively identified codes were then integrated into the deductive codebook.

The study used the final codebook then for coding the empirical data collected from both cases. This was done by using the qualitative data analysis software atlas.ti. ${ }^{48}$ Figure 3.1 below shows a screenshot from the coding in atlas.ti in order to provide a visual illustration.

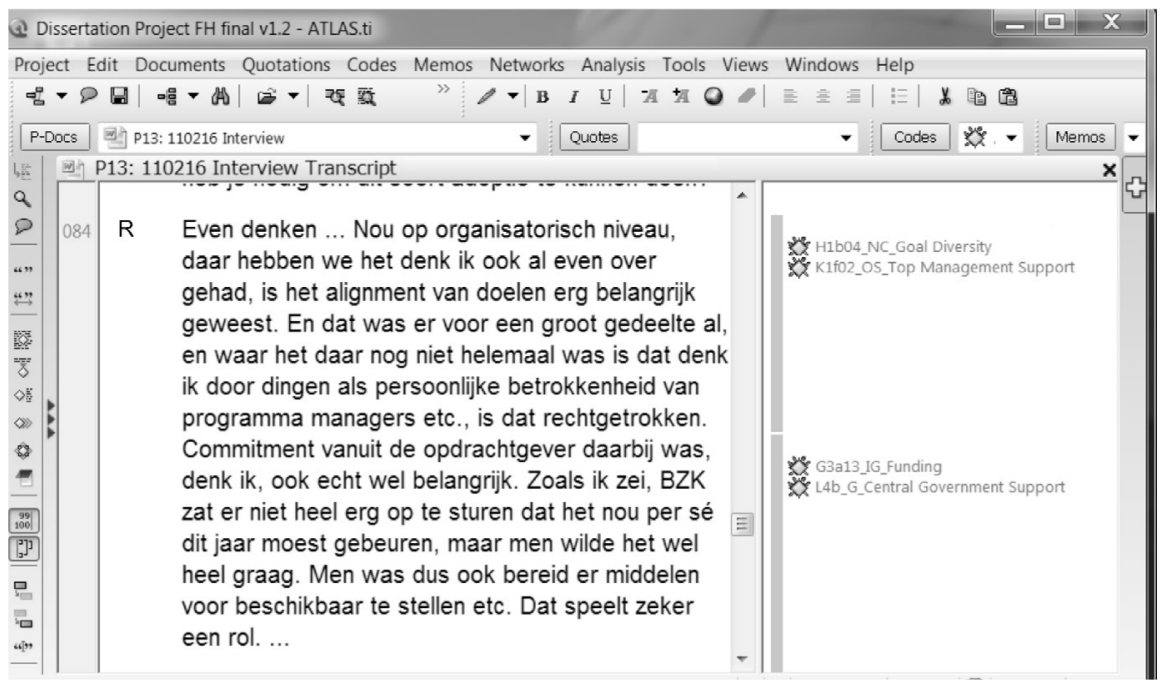

Figure 3.1. Screenshot of the coding process in atlas.ti (right-hand pane shows the length of the coded quotation and codes applied)

With regard to the coding units (i.e. the level of detail of text to which the codes were applied), the study chose to use "units of meaning", a widely used approach in qualitative analysis. Rather than using physical linguistic separations such as words, sentences or paragraphs, "units of meaning" consist of the expression of an idea, which might be anything from a cluster of words to a cluster of sentences, and even paragraphs - as long as this segment represents a unique idea or concept (Budd, Thorp, \& Donohew, 1967; Minichiello, Aroni, \& Hays, 2008). Units of meaning were considered more appropriate for this study's purposes, because what we want to compile with codes is instances of concepts or ideas as they appear in the complexity of verbal accounts - rather than neatly delineated, isolated units of textual data (Kracauer, 1952; Saldaña, 2009). For the same reason, the

\footnotetext{
${ }^{47}$ All inductively identified determinants are listed in in the summary tables of Chapter 4 (Table 4.2 and Table 4.3 ) and Chapter 5 (Table 5.1 through Table 5.6). There was no "minimum" amount of how often a new code needed to appear in order to be added to the codebook at this stage of the analysis. The purpose behind this was to cast the net for the analysis as wide as possible, so that anything that was "new" (i.e. not yet listed among the deductively identified codes) could be included in the subsequent analysis. In the semi-quantitative content analysis (described in detail towards the end of this section) a criterion for relevance then was applied: if a code received less than $1 \%$ of all quotations in their respective higher-order determinant, it has been considered as not relevant and indicated as "not confirmed" in the above-mentioned summary tables in Chapters 4 and 5.
}

${ }^{48}$ See www.atlasti.com. 
coding procedure also recognised the possibility for a unit of meaning to relate to multiple codes simultaneously (Miles \& Huberman, 1994), so multiple coding of the same text segment was applied where appropriate.

After having coded all the data, the analysis then proceeded by two distinct methods of analysis: an interpretive analysis, and a semi-quantitative content analysis based on the frequency of quotations. Next to the actual coding, the interpretive analysis consisted of thoroughly studying the 'excerpt files' of coded material per each code to discover patterns of meaning in the data. In doing so, this study largely followed Weiss' (1994) descriptions of both issue-focused and cased-focused analysis. In the issue-focused analysis, the purpose is to identify the relevant issues for the theoretical categories (i.e. the UTAUT constructs and their external causal antecedents, as well as their sub-dimensions). In addition, by means of a process-tracing strategy, this allowed identifying the possible causal pathways between determinants of IOP standards adoption (including their sub-dimensions) and Adoption. In the case-focused analysis, the focus of the analytical reading was on the comparison across interviewees and across the DKD and Studielink cases.

It is important here to discuss the epistemological position of this dissertation between positivist and interpretivist approaches. To this end, it is necessary to understand that the distinction between interpretivism and positivism as epistemologies is conceptually different from the methodological differentiation between qualitative and quantitative methods, and that whilst positivist approaches often go in hand with quantitative methods, they can be done with qualitative methods as well (Myers \& Klein, 1999). This dissertation is primarily interpretivist in both its epistemological foundation and methodological approach, in its reading of the data from the case studies to "understand phenomena through social constructions such a language, consciousness, shared meanings, documents, tools, and other artifacts" (Myers \& Klein, 1999) and to inductively contextualise and enrich the theoretical framework from which it started. However, it also reflects parts of positivist empistemology in the sense that it starts from a set of deductively identified formal propositions that are subjected to empirical validation (Myers \& Klein, 1999): both a range of deductively identified adoption determinants that are proposed in a formal framework (Chapters 2, 4 and 5), as well as a specific theory (Provan \& Kenis, 2008) with formal propositions on the relation between network governance and network centralisation (Chapter 6). In this combination, it can be seen as reflecting Lee's (1991) argument that interpretivism and positivism are not mutually exclusive and instead can be integrated into a complementary framework. ${ }^{49}$

However, it needs to be highlighted that this validation is carried out by means of an interpretive analysis which has some fundamental differences from quantitative methods that aim at measurement of causalities, and which are often associated with positivism. Such an approach to the topic of this dissertation would aim at an "exact" measurement of

\footnotetext{
${ }^{49}$ Lee's (1991) framework consists of three levels of understanding: the "subjective understanding" (everyday understandings and resulting behaviour of the researched subjects themselves), the "interpretive understanding" (the researcher's reading of the subjective understanding), and the "positivist understanding" (theory or propositions created by the researcher to explain subjects in general, drawing also on factors not part of the other two levels). According to Lee, the interpretive approach is used to move from the first via the second to the third level in a process of inductive theory generation, and the resulting theory is then subjected to positivist testing.
} 
observable values in specific determinants and adoption (or adoption intention), for instance by means of survey instruments, in order to measure possible causality and effect sizes. An interpretive approach does not allow to draw this kind of conclusions. Instead, the approach taken here aims at identifying, based on experienced-based perceptions and insights of key informants from concrete case studies, possible causal explanations and providing in-depth accounts of the processes and possible causal mechanisms at work. Given the exploratory nature of this dissertation's research questions and the limited possibilities to implement a quantitative measurement to the vast array of possible adoption determinants that were identified, this is both the more suitable and feasible approach over a quantitative approach of measuring causality.

The semi-quantitative content analysis can be seen as an extension of the interpretive approach, building upon the qualitative coding of the data. It was based on analysing the frequencies of quotations for individual codes, as well as their "co-occurrences". The frequencies of quotations show how often a given code has been applied to the data. By thus showing how often the concept behind the code (for instance a particular determinant) was mentioned in the interviews, this gives an indication about the relative relevance of that concept to stakeholders. The quotation frequency for a given code could also serve to indicate where a determinant that was identified based on the literature might in fact not be relevant in the context under study. Hence, all determinants that received less than $1 \%$ of all quotations in their respective higher-order determinant were flagged as "not confirmed". 50 The content analysis also allowed making comparisons across groups of interviewees, both across cases and across organisational stakeholders and stakeholders at network level (in the following chapters referred to as "interviewee levels"). ${ }^{51}$

The quotation frequencies were also used for an analysis of "co-occurrences". A cooccurrence exists when the same quotation is tagged with two or more codes. ${ }^{52}$ By showing how often specific concepts are discussed together, co-occurrences are useful to give indications about the relationships between concepts, and to make comparisons of relationships across concepts. For instance, it can be used to compare how often the codes for the main adoption determinants were discussed together with the code for Adoption.

\footnotetext{
${ }^{50}$ The non-confirmed determinants are listed in the summary tables of Chapter 4 (Table 4.2 and Table 4.3 ) and Chapter 5 (Table 5.1 through Table 5.6).

${ }^{51}$ Given that in total 4,331 quotations are included in the analysis, this can be considered to be a substantially large "sample" of quotations to reliably assess the relative distributions across determinants (within the confines of the studied cases). However, in several instances when the distribution within a determinant at a lower hierarchical level (mostly the level of "dimensions") are considered, much smaller "sample sizes" resulted. Following the rule of thumb that a sample size of 30 is an essential minimum for quantitative analysis, any frequency distribution with an $\mathrm{N} \leq 30$ reported in these sections does not make any claims to represent "significant" differences. Since such low figures therefore should be regarded as not reliable, generally no discussion is provided in the respective sections about these differences - only in a few cases where the distributions are particularly noteworthy, a brief (and purely indicative) discussion is given.

${ }^{52}$ The co-occurrence tool in atlas.ti lists all codes that co-occur in the margin area, by combining the operators WITHIN, ENCLOSES, OVERLAPS, OVERLAPPED BY and AND. So, if for instance a single quotation is coded by two codes, or if in overlapping quotations each of the two quotations is coded by one of the codes, this would count as a single co-occurrence. (The operators WITHIN and ENCLOSES retrieves quotations that are contained in one another, e.g. A WITHIN B retrieves all quotations coded with A that are contained within data segments coded with B. The OVERLAP operators retrieve overlapping quotations, e.g. A OVERLAPS B retrieves all quotations coded with A that overlap quotations coded with B. The AND operator finds quotations that match all specified codes).
} 
It is important to point out at this point that a clear limitation of this analysis of frequencies is that it only counts the instances of a concept or theme being mentioned in the interviews, but cannot capture what exactly is being said in each instance. Individual quotations of a given code could thus possibly contain quite different and possibly even opposing statements. For example, where the code Decision-Making Centralisation was applied, it is possible that the resulting quotations include statements that argue that there was either too much or too little centralisation of decision-making. Therefore, the reader needs to be aware that inferences drawn from this content analysis can be considered as indicative conclusions only. This means that they cannot be interpreted as definitive evidence, and other explanations might be conceivable. However, except for a few determinants at lower conceptual levels, the amount of quotations from which the frequency distributions are derived is generally substantial enough to give these interpretations considerable weight. Moreover, the frequencies are generally not taken as isolated evidence, but the conclusions drawn are derived against the background of other data from the cases, and where possible are triangulated with documentation and full interview quotes. Therefore, although the conclusions from the content analysis cannot be more than indicative and will need to be validated by future research, they do provide a useful first indication as to relative relevance of the various determinants, as well as the relationships between them.

Moreover, it should be noted that due to the research design, the interviewees' answers do not distinguish between accounts of actual experiences and expectancies regarding the role of the various determinants. However, given the objective of identifying the determinants of adoption behaviour, making this distinction between actual experience and expectations is not necessary: for instance, whether a given Result from adoption (for example gains in Efficiency) is something an interviewee has experienced in the past of the network, or whether it is something the interviewee expects to materialise in the future as a result of adoption - both cases are considered as an influence on adoption behaviour.

Perhaps the most-often discussed limitation of interpretive research is that textual data by nature is "messy" and prone to be ambiguous. However, past epistemological debates in the philosophy of science have established wide acceptance of the unique value that such interpretivist qualitative analysis can provide (cf. Lazar, 2004; Richards, 2005). The key issue is to ensure a high degree of internal consistency of the coding and analysis done by the individual researcher for reasons of validity and reliability, although to expect perfect consistency would be utopian. Only in a perfect world would every bit of textual data corresponded neatly by default to the analytical codes and their definitions, and would each researcher assign specific codes to individual units of meaning in an absolutely identical manner. However, the study took several measures in order to minimise this limitation.

A first safeguard to address this was to assign detailed definitions to each code in the codebook in order to ensure that they could be applied consistently. In addition, the coding was done using atlas.ti, a software package for qualitative data analysis. Besides being more efficient, using a software package for qualitative analysis is also a means to enhance the reliability of the data analysis (cf. Kelle et al., 1995; Lewins \& Silver, 2007; Seale, 2010). Another means to enhance the validity and reliability of the analysis included the triangulation of data (Silverman, 2010; Weston et al., 2001). Thus, where possible, 
conclusions drawn from the analysis of interview data were corroborated with document data, and vice versa. Further measures adopted from the recommendations by Weston and colleagues (2001) were to collect data that were as 'rich' as possible (in the form of verbatim transcripts), the subsequent verification of transcripts by the interviewees, and that the analysis included an active search for any discrepant evidence that could potentially contradict the conclusions drawn.

Nevertheless, there inevitably were instances when the researcher could not disambiguate with total certainty whether a particular interviewee statement really should be coded with a particular code or not. Wherever possible in these instances, ambiguous statements were clarified with the respective interviewees in follow-up discussions as to their intended meaning. In many instances, this "triangulation of interpretation" enabled the researcher to assign the matching codes with reasonable certainty. However, such clarification with the interviewee was not possible in every single instance of ambiguity, and in these cases no code was assigned at all in order to prevent mis-coding. Whilst this still introduces some bias to the analysis, it is preferable to assigning a potentially inappropriate code. Moreover, whilst such instances of ambiguity are an inevitable aspect of any interpretive analysis, such instances were few enough to not expect that they significantly affected the analysis.

\subsection{The Cases: Digital Client Dossier and Studielink}

\subsubsection{The Digital Client Dossier (Digitaal Klantdossier, DKD)}

The Digital Client Dossier (Digitaal Klantdossier, DKD) is a virtual electronic dossier of work and income related data that various public agencies in the Netherlands hold on their clients, such as citizens or businesses (the types of agencies are listed in detail in Section 3.5.1.1 below). In essence, it consists of a nation-wide digital linkage of these agencies' databases, which aims to assist the tasks of professionals working in the work and income $\left(\mathrm{SUWI}^{53}\right)$ domain by allowing them to collate relevant information on individual clients into a digital dossier. Broadly stated, the objectives behind DKD are to reduce the administrative burden and costs for citizens as well as agencies by means of automated electronic sharing of client-related information, while at the same time making the service delivery better and more effective.

\subsubsection{Policy Background and Inter-Organisational Network}

The SUWI domain forms part of the social security sector, one of the oldest policy sectors in the Netherlands, with the earliest sectoral policy dating back over a century. The domain has been fundamentally restructured by the "SUWI Act" from 2002, and the DKD is a result from this reorganisation.

The SUWI domain is in itself a highly interdependent domain, whose services are provided in collaboration of a range of public, semi-public and private bodies. The central organisation in the social security sector is the Ministry of Social Affairs and Employment

${ }^{53}$ Named after the Act on the Implementation Structure for Work and Income (Structuur Uitvoeringsorganisatie Werk en Inkomen). 
(Ministerie van Sociale Zaken en Werkgelegenheit, MinSZW), which bears the overall political responsibility for the domain, setting policies and monitoring their implementation. The work and income related policies and services are administered by the Employee Insurances Agency (Uitvoeringsinstituut Werknemersverzekeringen, UWV), the Employment Agency (UWV WERKbedrijf), the Municipal Social Services (Gemeentelijke Sociale Dienst, GSD) and the Social Insurance Bank (Sociale Verzekeringsbank, SVB). As the core partners of the SUWI domain, they carry out various tasks aimed at reintegrating citizens into the labour market as fast as possible in order to minimize their reliance on social welfare benefits.

The UWV is tasked with the administration and provision of unemployment benefits (Werkloosheidswet, WW). The mission of the UWV WERKbedrijf is the collection of client data for UWV and GSDs, as well as the re-integration of work seekers into the labour market. The SVB is tasked with the administration of the social insurances, such as pension (Algemene Ouderdomswet, AOW), "surviving relatives" benefits (Algemene Nabestandenwet, ANW), and child support. The responsibility of the GSDs is the administration of (income) support to those who are not able to support themselves. This support is known as WWB, in reference to the Law on Work and Support that forms its basis (Wet Werk en Bijstand, WWB). Together with UWV and UWV WERKbedrijf, the GSDs provide their services in joint service centres, called "work plazas" (werkpleinen). About 100 of these work plazas exist throughout the country. ${ }^{54}$

This structure of the domain is a relatively recent arrangement resulting from the SUWI Act, which reflected the general development towards comprehensive inter-organisational service provision discussed in Chapter 1. The most important provisions of the SUWI Act were a redistribution of tasks that went hand in hand with the merger of the manifold organisations previously in charge of social insurances into the newly created UWV and UWV WERKbedrijf's predecessor (Centrale Organisatie voor Werk en Inkomen, CWI), as well as a new structure for information exchange in the domain based on Suwinet and Suwinet Inkijk (both essential parts of the DKD information infrastructure, explained in Section 3.5.1.2). The resulting structure of the domain is depicted in Figure 3.2.

Most notably, these actors are interdependent in administering two major groups of processes: income-related processes that concern social benefit payments, and work-related processes concerning the reintegration of clients into the labour market. These processes require a high degree of information exchange between the partners. For instance, checking the eligibility of individuals for receiving unemployment benefits, or matching work seekers to open vacancies requires access to a range of client data that is held in the databases of other bodies, such as social security numbers, medical information, income information or data on education and previous work history.

Before the DKD, if a person became unemployed and wanted to receive unemployment (WW) benefits, he or she had to first do an "intake" at a work plaza in their vicinity. This means becoming registered with the UWV WERKbedrijf as work seeker and applicant for a WW benefit. This required going through a lengthy intake process with a UWV

\footnotetext{
${ }^{54}$ Between 2012 and 2015, this number is being reduced to 30 work plazas.
} 
WERKbedrijf case manager, during which the applicant would have to provide a lot of personal information, including paper-based documentation as evidence. Unless a matching job could directly be found, the paper file with the applicant's data was passed on by post to the UVW, where his or her eligibility for a WW benefit was checked. If no WW benefit was granted, or if the applicant's available benefit had run out, he or she was deferred to the municipality in order to apply for social welfare benefit (WWB) at the GSD. Here, they would have to again provide the same information and proofs as in the first intake at UWV WERKbedrijf. In short, clients had to run to a range of different offices, often providing the same information over and over. Not surprisingly, this system was burdensome and prone to errors (Keller, Groen, \& van Lunteren, 2005).

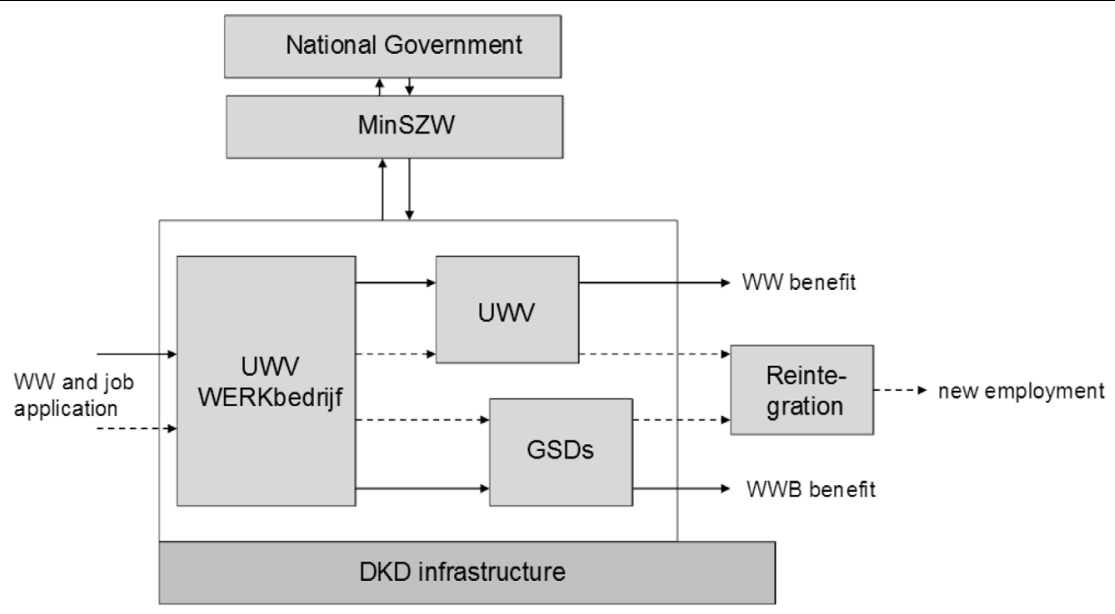

\footnotetext{
Figure 3.2. Basic structure of the SUWI domain as of 2002 (adopted from Torabkhani, Smits, \& van der Pijl, 2007). Horizontal arrows show client streams for social benefit request (solid) and job request (dotted). Vertical lines indicate decisions
}

In 2005, the "Keller Commission" was therefore asked to carry out an analysis of how the service delivery to clients of the SUWI domain could be improved. In its final report, it specifically recommended the creation of an electronic dossier in the SUWI domain. This was soon followed by the assignment to CWI, UWV and the GSDs to develop the DKD and given shape by the "Programme DKD Phase One". The DKD's aim is to reduce this administrative burden, by making data that a citizen had previously provided electronically accessible to his or her SUWI case manager, so that the only thing that would need to be checked is whether this data is still correct. This is called a "reverse intake". DKD Phase One, which ran from 2005 until 2008, focused predominantly on setting up the necessary information infrastructure, including technological infrastructure, the IOP architecture, work processes and a sufficient quality of the source databases.

In 2008, the Single Data Request Act (Wet Eenmalige Gegevensuitvraag, WEU) was passed. In order to enhance the re-use of public sector information, this law provides that the SUWI actors are not allowed any more to ask their clients for data which they had previously 
provided to the government. The WEU marked the start of "DKD Phase Two", which ran until the end of 2011 and focused on extending the functionalities of DKD and improving its usage. ${ }^{55}$

In particular as a result of WEU, over time a range of additional organisations, public and private, became connected to the DKD, next to the core SUWI domain partners (GSD, UWV, UVW WERKbedrijf and SVB). In terms of their role in the network, we can basically distinguish between data suppliers (organisations whose databases feed into DKD) and data recipients (who can look up data from the DKD).

The data suppliers are UWV, UWV WERKbedrijf, GSDs, SVB, the Executive Service for Education (Dienst Uitvoering Onderwijs, $\mathrm{DUO}^{56}$ ), the Municipal Basic Registry Provision Service (Gemeentelijke Basisadministratie - Verstrekkingen, GBA-V ${ }^{57}$ ), the Verification Information System (Verificatie Informatie Systeem, VIS ${ }^{58}$ ), the Chamber of Commerce (Kamer van Koophandel, $\mathrm{KvK}^{59}$ ), the Agency for Road Traffic (Rijksdienst voor het Wegverkeer, $\mathrm{RDW}^{60}$ ) as well as the Cadastre ${ }^{61}$.

The data recipients are UWV, UWV WERKbedrijf, the GSDs, DUO, the Inspection SZW (Inspectie SZW ${ }^{62)}$, the Immigration and Naturalisation Agency (Immigratie en Naturalisatie Dienst, IND ${ }^{63}$ ), the municipal tax bailiffs (Gemeentelijke Belastingdeurwaarders), the BIBOB Office (Bureau BIBOB ${ }^{64}$ ), the Regional Registry for School Dropouts (Regionale Meld- en

\footnotetext{
${ }^{55}$ It should be noted that the DKD is neither an application itself, nor the actual "dossier". Rather, it is a policy programme consisting of various projects and applications that emerged from the SUWI Act and WEU.

${ }^{56}$ As a subsidiary of the Ministry of Education, Culture and Science, the main task of this organisation is to execute educational policy. Inter alia, it holds educational data about individuals such as information about degrees earned and time spent studying.

${ }^{57}$ The GBA is the system of municipal basic registries of personal data (such as name, address, birth date, nationality etc.). GBA-V is a central updated list of all GBAs at national level and is geared with an online service to supply GBA data to authorised recipients.

${ }^{58}$ VIS is a private company that keeps a database on fraudulent identity documents and provides an information service to private and public organisations.

${ }^{59}$ The KvK is an independent service organisation that supports entrepreneurship. It also administers the National Trade Registry (Nationaal Handelsregister), which is the national basic registry on information concerning companies and legal persons.

${ }^{60}$ The RDW is the government agency administering the Dutch registry on motorised vehicles and related documents such as license plates and driving licenses.

${ }^{61}$ The Cadastre a semi-public body that registers and provides data concerning the location of real estate property and associated rights such as ownership and mortgages.

${ }^{62}$ The Inspection SZW is a public body charged with monitoring the execution of legislation in the SUWI domain. Originally, the DKD data recipients included the Work Inspection (Arbeidsinspectie), and the Social Information and Investigation Service (SIOD), but they were fused in 2012 with several other inspections into one body, the SZW Inspection.

${ }^{63}$ As a subsidiary body of the Ministry of Foreign Affairs, the IND is charged with the administration of immigration policy.

${ }^{64}$ A subsidiary of the Ministry of Justice and Security that is tasked with the administration of the Law on Enhancing Integrity Checks by Public Administrations (Wet Bevordering Integriteitsbeoordelingen door het Openbaar Bestuur, BIBOB). Upon request by a public body, the BIBOB office will investigate and give advice whether there is a risk that a particular license, subsidy or government contract might be misused for criminal activity.
} 
Coördinatiefunctie, RMCs ${ }^{65}$ ), the Board of Health Insurances (College van Zorgverzekeringen, $\mathrm{CVZ}^{66}$ ), and citizens. ${ }^{67}$

\subsubsection{Information Infrastructure}

Implementing the DKD required an elaborate information infrastructure. In the creation and administration of this information infrastructure, the SUWI partners are supported by "infomediaries" (Soeparman, van Duivenboden, \& Oosterbaan, 2009), i.e. organisations that provide support concerning knowledge management, information exchange and ICT use in inter-organisational systems. These are the Information Office (Inlichtingebureau), formerly the Coordination Point for ICT (Coördinatiepunt ICT, CP-ICT ${ }^{68}$ ), and most notably, the Office for Chain Informatisation Work and Income (Bureau voor Keteninformatisering Werk en Inkomen, BKWI). The responsibility of the BKWI was to develop the necessary architectures, which resulted in the SUWI chain architecture (SUWI Ketenarchitectuur), which consists of a service- and process architecture layer, an information architecture, a process-support architecture and a technical architecture.

Technically, the DKD has a complex functional architecture, which is schematically shown in a simplified version in Figure 3.3. It builds upon a linkage of the partners' databases through a secured national network (Suwinet). Importantly, the exchanged data is never centrally stored, but each individual dossier only exists for the duration of an individual information request. Each organisation thus remains responsible for its own data. These information requests are managed ad hoc by a central broker application (Suwinet Broker), managed by BKWI. This broker serves information request by collecting and collating data from the various sources and routing them to the respective recipients. The data suppliers supply their data to the broker either through intermediary broker applications and web services (as in the case of most of the municipal databases), or through intermediary registries or servers (as in the case of the UWV and UWV WERKbedrijf applications). The Suwinet Broker then routes the collated data messages to the data recipients, whilst authentication mechanisms (such as Single Sign-On via DigiD ${ }^{69}$ for clients) regulate data access and "filter" the available information to display only the information that match the requesting person's access rights (usually being determined by a professional's job function).

\footnotetext{
${ }^{65}$ These are regional registries in which the municipal school attendance officers (leerplichtambtenaren) have to register anyone dropping out of secondary education without a diploma.

${ }^{66}$ The CVZ is a semi-public body charged with advice and administration concerning the General Law on Special Health Costs (Algemene Wet Bijzondere Ziektekosten, AWBZ). Its main task in the SUWI domain is to implement legislation concerning special groups, in particular health care for pensioners and unemployed.

${ }^{67}$ Until 2012, a public body created for administering the special social benefit for artists called Kunstenaars\&Co was also connected to the DKD. However, with the abolition of this benefit as of 2012, Kunstenaars\&Co has ceased to assume this function.

${ }^{68}$ The CP-ICT has ceased to exist and its role has been assumed by the Quality Institute for Dutch Municipalities (Kwaliteitsinstituut Nederlandse Gemeenten, KING).

${ }^{69}$ DigiD is an identity verification system used by government bodies to authenticate the identity of their clients for online services. It allows Single Sign-On, which refers to the ability of users access an interconnected array of information systems or services upon logging in to one of them (without the need to sign on to each of them separately).
} 
Requests for a dossier can be made by means of several applications that are available to professionals and clients. For SUWI professionals, the most-used application is SuwinetInsight (Suwinet-Inkijk). It is a generic application to which professionals can log in and specify a client's civil service number (Burger Service Nummer, BSN) to look up the data on this person which they are authorised to see. In addition, there are also various in-house applications from the individual organisations through which professionals can access the dossier (e.g. the Sonar application of UWV WERKbedrijf). Clients themselves can access their own data (upon authentication) via the internet through a range of websites and portals (such as werk.nl and mijnoverheid.nl). The broker system also features a generic correction mechanism, which signals if the exchanged data is incorrect, thus improving the overall data quality in the network.

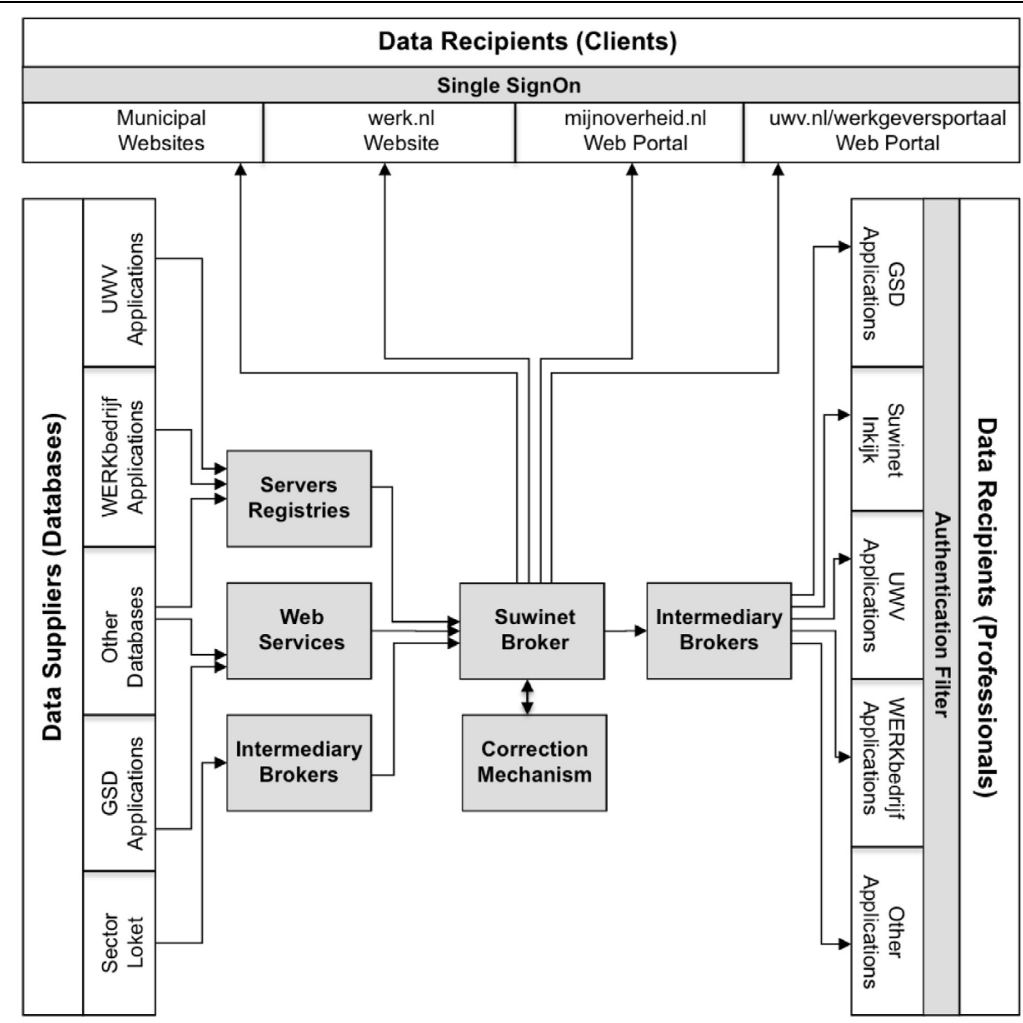

Figure 3.3. The DKD information architecture (simplified based on BKWI, 2010)

This information infrastructure contains an IOP architecture consisting of a range of IOP requirements, such as for instance data formats, semantic definitions of the data catalogued in the SUWI Data Register (SUWI Gegevensregister, SGR), the SuwiML transaction standard for data transmission, a range of security procedures described in what is called the "Norm Framework" ("Normenkader"), and various agreements on joint work processes. Annex C gives a detailed overview of this IOP architecture. 


\subsubsection{IOP Governance}

Being tasked with the development of the domain's information architecture, the BKWI is the core broker organisation in the SUWI domain's IOP governance. However, the BKWI is only administering the information architecture, but has no mandate to enforce compliance with it.

At the bottom of the IOP governance structure, there are various working groups that contain representatives of all chain partners. These groups prepare proposals for discussion in the three domain groups. An important one is the Working Group Data and Messages (Werkgroep Gegevens en Berichten, WGB), which oversees consistency in the SGR and discusses issues such as the naming and specification of the data objects in the SGR, or the inclusion of new data objects. It includes the Chain Council for Service and Support (Ketenoverleg Service en Support, KOSS), where the service desks of the partner organisations discuss operational alignment. It also includes the Change Advisory Board (Change Advisory Board, CAB), a separate negotiation body in which all data suppliers and recipients together coordinate the changes to the data structure. Changes can be filed continuously by partners at the online Central Registry for Chain Changes (Centraal Meldpunt Ketenwijzigingen, $\mathrm{CMK}$ ), and are then collected every month for discussion in the domain group.

One level up are four domain groups, which discuss the proposals from the working groups and consist of representatives of the major partners. Who is represented here depends on the size of the organisation, its usage of the system, and its degree of data supply. The Domain Group Data and Messages (Domeingroep Gegevens en Berichten, DGB) convenes once a year in order to decide upon the changes proposed by the WGB. The Domain Group Privacy and Security (Domeingroep Privacy \& Beveiliging, DPB) regulates issues related to personal information and data security that are formalised in the "Norm Framework". The Domain Group ICT Administration (Domeingroep ICT Beheer, DIB) is concerned with maintenance and administration issues that are formalised in form of Service Level Agreements (SLAs). The Domain Group Architecture (Domeingroep Architectuur, DGA) decides on architectural changes, and evaluates project plans in the light of the architecture.

All these subordinate bodies are headed by two steering groups: the Steering Group on Service Provision (Stuurgroep Dienstverlening, SDV) and the Steering Group on Chain Services ICT (Stuurgroep Ketenservices ICT, SKI). The latter takes decisions on proposals worked out by its subordinate "domain groups", and subsequently acts as a "guardian" of these agreements (if a partner does not live up to them, they can be held accountable in this steering group). Together, these steering groups report to the Programme Council DKD (Programmaraad DKD), which is the decision-making body at the strategic level. It consists of representatives of the "big partners", such as directors of the association of GSD managers (Vereniging van Directeuren voor Sociale Arbeid, DIVOSA), the Association of Dutch Municipalities (Verenining van Nederlandse Gemeenten, VNG), and UWV. Besides being responsible for relations with the Ministries, the main role of the Programme Council $\mathrm{DKD}$ is its function as the final decision-making body on all proposals prepared in subordinate bodies. The DKD network structure is shown in Figure 3.4 below. 
Whilst the first impression might suggest a highly decentralised governance structure, the degree of centralisation in fact varies considerably across various IOP issues within the programme, and in particular across the duration of the project. Whilst one standard might be governed through a decidedly bottom-up process that is dominated by the working groups and domain groups, decisions on another standard might be largely determined by the steering groups. The IOP governance in the DKD network therefore cannot be classified as entirely decentralised or centralised. This variation is described in detail in Chapter 6.

In conclusion, the DKD can be categorised as consisting of a fairly complex interorganisational network. The number of organisations involved is over 400 , stemming from a diverse background including both public and private organisations. The network is highly interdependent, requiring a high degree of information exchange and integrated work processes, in particular among the core SUWI partners. In terms of IOP governance of the $\mathrm{DKD}$, the description in this section has shown that there is a range of different bodies that govern IOP in the various dimensions of the DKD, and that the degree of IOP governance centralisation varies considerably across various IOP issues within the programme, and therefore cannot be classified as entirely decentralised or centralised.

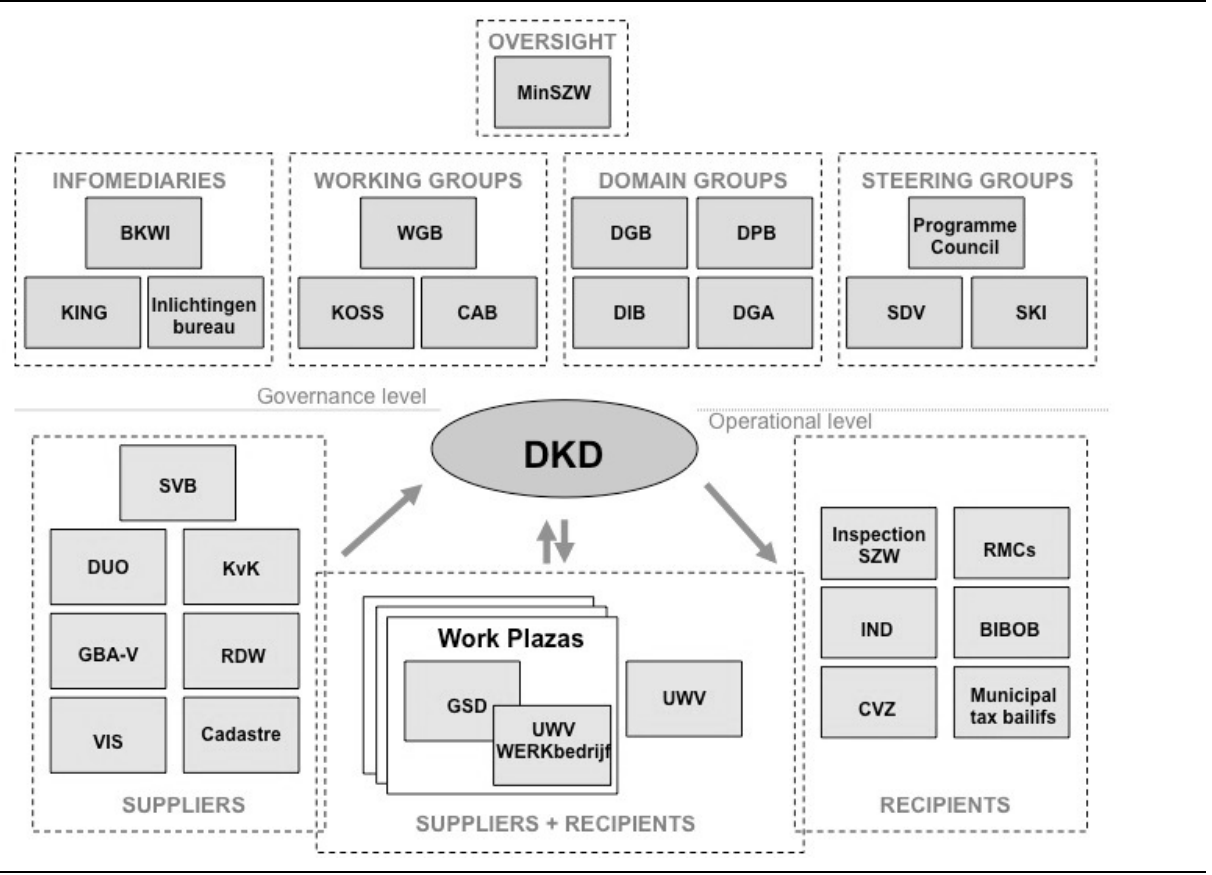

Figure 3.4. Structure of the DKD inter-organisational network

\subsubsection{Studielink}

To put it in very simplified terms, Studielink can be seen as the higher education sector's DKD, a "digital student dossier". More precisely speaking, it is a collective ICT application for handling registration of students in the Dutch higher education sector (universities and polytechnic universities), based on the electronic exchange of student registration data via a 
central broker application. Broadly stated, the general goal behind Studielink is to address increasing interdependence in the higher education domain. It thus aims at improved and more coherent service provision to clients by joint and coordinated action in the domain, the standardisation of basic student registration data and the reduction of administrative costs, and to create a platform for future innovation in the higher education sector.

\subsubsection{Policy Background and Inter-Organisational Network}

The background for the development of Studielink was that information provision in the higher education sector had over time become increasingly complex as a result of various developments, such as increased mobility of students, and the developments towards "lifelong learning", accompanied by the individualisation and diversification of higher education. Due to these developments, higher education institutions were becoming more and more interdependent and faced higher administrative burdens and costs. There was therefore an increasing need for alignment and collaboration in the higher education sector. Inspired by similar data exchange projects in the higher education sectors of Sweden $\left(\mathrm{LADOK}^{70}\right)$ and the UK (UCAS $\left.{ }^{71}\right)$, the Dutch higher education institutions looked for possibilities to make the registration process more efficient by means of electronic data exchange among them. The objectives behind the development of Studielink, mentioned above, resonate this need.

Studielink had its origin in 2002 with a project called Virtual Clearing House Higher Education (Virtual Clearinghouse Hoger Onderwijs, VCH). VCH was set up as a foundation (now Studielink foundation), based on an initiative from the higher education institutions to address the various challenges in their domain. In 2005, VCH was overhauled and renamed into its current name, Studielink. Only a couple of higher education institutions were connected at this point. Political uncertainty around the project as a result of what is referred to as the "study rights debate" initiated by the Ministry of Education, Culture and Science (Ministerie van Onderwijs, Cultuur en Wetenschap, MinOCW) in 2006 did not help and drew the project into crisis. ${ }^{72}$

Studielink was then restarted in 2007, and with release 2.0 becoming operational in October 2007, 38 higher education institutions were connected to Studielink. However, several bugs in the system (notably the accusation that student registrations "got stuck" in Studielink ${ }^{73}$ ) caused public criticism and parliamentary inquiries to the Ministry. Release 3.0 in 2009 brought additional functionalities to Studielink, notably the integration with the Dutch

\footnotetext{
${ }^{70}$ Local EDP-based Documentation System (Lokalt adb-baserat dokumentationssystem, LADOK): www.ladok.se.

${ }^{71}$ Universities and Colleges Admissions Service: www.ucas.com.

72 The 'leerrechtencrisis' resulted when parliament passed a legislative proposal (WHOO) initiated in 2006 by then state secretary Mark Rutte of MinOCW that aimed to introduce a voucher system into higher education. The proposal foresaw that students would receive a fixed amount of vouchers with which they could pay for their studies at a higher education institution of their choice, thus increasing competition and quality among higher education institutions. Studielink, which was foreseen as an application facilitating this system, came under criticism when a parliamentary inquiry questioned that Studielink would be ready in time for the start of the leerechten system (planned for September 2007). This even resulted in a temporary stop of the Studielink development in 2006. The WHOO legislative proposal was eventually stopped.

${ }^{73}$ See: Schriftelijke vraag van het Kamerlid Leijten van de Tweede Kamer der Staten-Generaal aan de minister van Onderwijs, Cultuur en Wetenschap (ingezonden d.d. 24 juli, kenmerk 2070826240).
} 
national online authentication system DigiD, and the possibility of paying tuition fees through Studielink. As of February 2010, the use of DigiD became mandatory for registering in higher education for all students registered in the Netherlands. Release 4.0, which went live at the end of 2011, brought a new look and feel to the front-office, which aimed at increasing usability and user-friendliness.

The central organisation in the Dutch higher education domain is the MinOCW. The MinOCW bears the overall political responsibility for the domain, setting policies and monitoring their implementation. The implementation of policy in the domain is largely commissioned to DUO. At the core of the Studielink network are all publicly financed 56 higher education institutions (17 universities and 39 polytechnic universities), and DUO. Other organisations in the network include the umbrella organisations of the higher education institutions, the HBO Council (HBO-Raad) of the polytechnic universities and the Association of Universities (Vereniging van Samenwerkende Nederlandse Universiteiten, VSNU), the 11 Student Information System (SIS ${ }^{74}$ ) suppliers operating in the Dutch higher education domain, and SURF foundation. SURF is a collaborative organisation for the higher education domain, with the specific agenda of advancing innovation in network services and ICT in the domain. For Studielink, SURF acts as an infomediary organisation, being charged with its support and administration. SURF has outsourced certain tasks to private companies. These tasks are incident and problem management, including the administration of the Studielink service desk (outsourced to Chronotech), and the operation of the ICT infrastructure (outsourced to ASP4ALL).

With around 70 organisations, the Studielink network is thus much smaller than the DKD network. Whilst it also includes both public and private-sector organisations, there is much less diversity as they all operate in the same domain (in contrast to the highly inter-sectoral composition of the DKD network). The diversity of primary tasks of partner organisations within Studielink is very limited: DUO, the universities and HBOs (polytechnic universities) all have the same type of task, regarding exchange of student registration data. The SIS providers are technological facilitators attached to different educational institutions, and thus their tasks are largely similar to those of the educational institutions. The remaining actors do not have a direct involvement in the data exchange itself, but rather are representative bodies that act on the strategic level.

\subsubsection{Information Infrastructure}

Studielink's information architecture consists of a front-office, a mid-office and a message broker component. The front office is formed by a core component of Studielink: the online portal for students to register for a particular study programme at an institution. If a student registers for a certain study programme through the portal, the student has to fill in a range of general personal information (such as name, address etc.) and information regarding previous education. Once this is submitted, the Studielink application sends this

\footnotetext{
${ }^{74} \mathrm{~A}$ SIS is an electronic system used for managing student-related information. In their functionality, they resemble Enterprise Resource Planning (ERP) systems used by businesses. Just like ERP systems, they typically are structured based on various modules, which are facilitating a range of student-related business processes such as admissions and enrolment, educational records, teaching schedules etc.
} 
information to the university to which the student applied, and simultaneously to DUO in order to control whether the applying student fulfils the requirements for that study programme: by means of the BSN of the student provided via DigiD, DUO performs an identity check through its connection to the $\mathrm{GBA}^{75}$, the municipalities' basic registry on persons. In its own database, the Basic Registry Educational Number (Basis Register Onderwijsnummer, BRON), DUO also checks whether the student has the relevant prior degrees that are required for the selected study programme. If this check is passed, both DUO and the higher education institutions begin their internal processes for registering the student in their internal systems: the SIS for the higher education institutions, and the Central Registry of Enrolments in Higher Education (Centraal Register Inschrijvingen Hoger Onderwijs, CRI-HO) for DUO. These systems send status updates to Studielink, and the student receives an email notification if further action is required. Next to enrolment, students can also de- register from a study programme through Studielink. As of Studielink release 3.0, students can also use the front office platform for paying their tuition fee.

The mid-office is the 'heart' of Studielink. It is the component where all relevant data, including communication data are kept and processed. It is fed with data input from the front office and the broker, and its output is sent to either of these components.

The exchange of this information between Studielink and the higher education institutions takes place in the form of the XML messages using the SOAP protocol. ${ }^{76}$ Studielink's central "broker" component facilitates the transport of the messages between partner organisations and their internal systems. ${ }^{77}$ The link between the Studielink broker and the higher education institutions' internal SIS is facilitated by means of two adapters: a "specific adapter" handles transport and integration of the messages to the SIS (taking care of any translation that might be necessary), and a "generic adapter" handles the communication towards the Studielink broker, including a verification of message content (see Figure 3.5). Some SIS can also directly connect with the broker, without needing the adapters.

A range of technological, semantic and organisational IOP standards is linked to this architecture. As a system that facilitates business processes (regarding student registration) between various organisations and their internal systems, a range of agreements regarding its information infrastructure and IOP architecture needs to be made among partners. These include data format standards (e.g. the Instructional Management Systems Learner Information Package, IMS-LIP ${ }^{78}$ ) and data transmission protocols (such as SOAP), adapter specifications (including XSD and WSDL), Requirement Specifications (Programma van Eisen, $\left.\mathrm{PvEs}^{79}\right)$, use cases describing the standardised working processes with regard to the

\footnotetext{
75 The connection of DUO to the GBA is called Sectoral Basic Administration of Persons (Sectorale Basisadministratie Personen), and concerns an application component that links to the segment of the GBA that contains persons with higher educational data.

${ }^{76}$ SOAP (Simple Object Access Protocol) is one of the many XML-based languages that have been developed over time.

${ }_{77}$ Whilst typically, a broker application is part of a mid-office, in this case it is separately presented to emphasise its distinct function of message routing and transport (whereas the mid-office here is concerned with data storage and processing).

${ }^{78}$ IMS-LIP is an international XML-based standard that has been particularly developed for communication concerning study-programme related activities.

${ }^{79}$ This is the translation of a functional change request into technical specifications.
} 
shift from paper-based student enrolment to digital enrolment, and service level agreements (SLAs) in which the agreements on responsibilities regarding business processes among the partners are formalised. They are discussed in detail in Annex D.

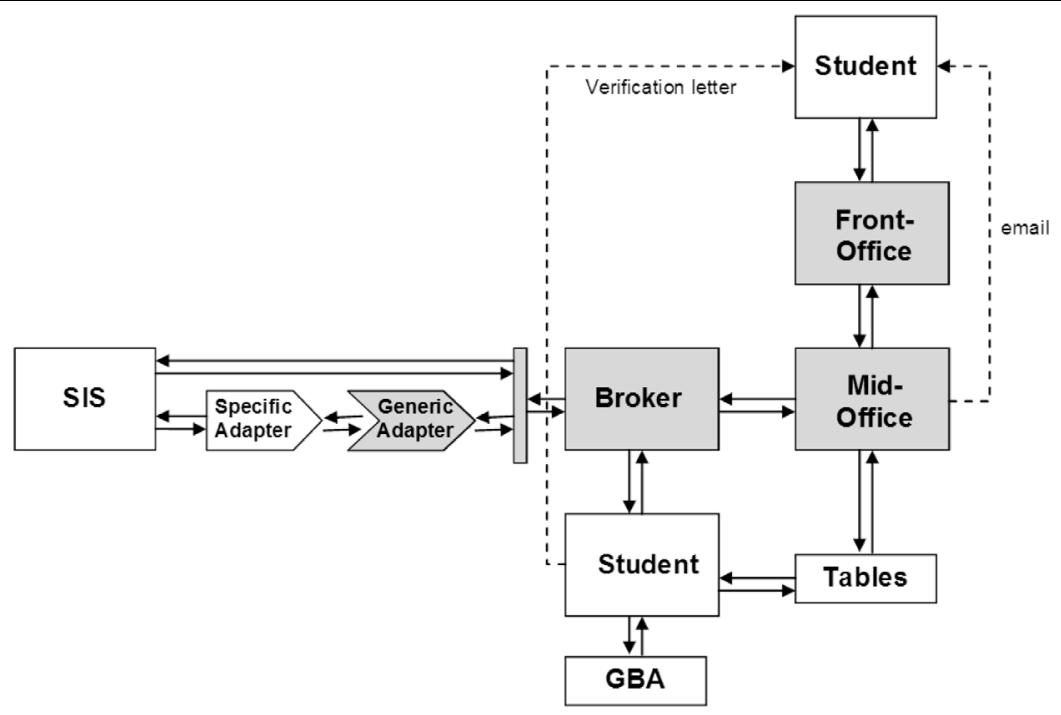

Figure 3.5. The Studielink information architecture (Stichting Studielink, 2008)

\subsubsection{IOP Governance}

A range of working groups and committees, with representatives of the various organisations involved, have been set up to jointly make up the IOP governance structure in Studielink. The decisions on changes to Studielink (and its IOP standards) are made through a bottom-up decision-making process that sequentially proceeds from a decentralised preparation of decisions in working groups towards the taking of the final decision by the board of Studielink Foundation, the central decision-making body.

At the bottom of this process is the Process Working Group (Proces Werk Groep, PWG), consisting of representatives from DUO and educational institutions (there is a representative for each "SIS group", i.e. for each group of institutions that share the same SIS). It keeps track of developments (e.g. legislative changes) that require adaptation of work processes concerning student enrolment, and passes its recommendations on to the Technical Working Group (Technische Werk Groep, TWG). The TWG also consists of representatives from DUO and educational institutions, as well as the SIS suppliers. It considers how the recommendations of the PWG can be given shape technologically. The Change Advisory Council (Wijzigingsadviesraad, WAR), also consisting of representatives from DUO and educational institutions, in turn takes up the recommendations of the technical working group and advises the Studielink board on which changes have to be made to Studielink. In doing so, it takes into account in particular the strategic and budgetary aspects. The Change Council (Wijzigingsraad, WR) then makes the definite 
selection of the changes to be included into the final change request. It consists of the Studielink board and the director of DUO.

Finally, the board of Studielink foundation takes the decision on the changes (and associated IOP standards), but only after having consulted the VSNU, HBO-Council and MinOCW whether they support it. Finally, there also is the Studielink Coordinator Council (Studielink Coördinatorenoverleg). Each higher education institution has its own Studielink coordinator, who is mandated to represent them towards the Studielink organisation and network. This forum is composed of these coordinators and meets several times per year to discuss general development of Studielink. This governance structure is shown in Figure 3.6.

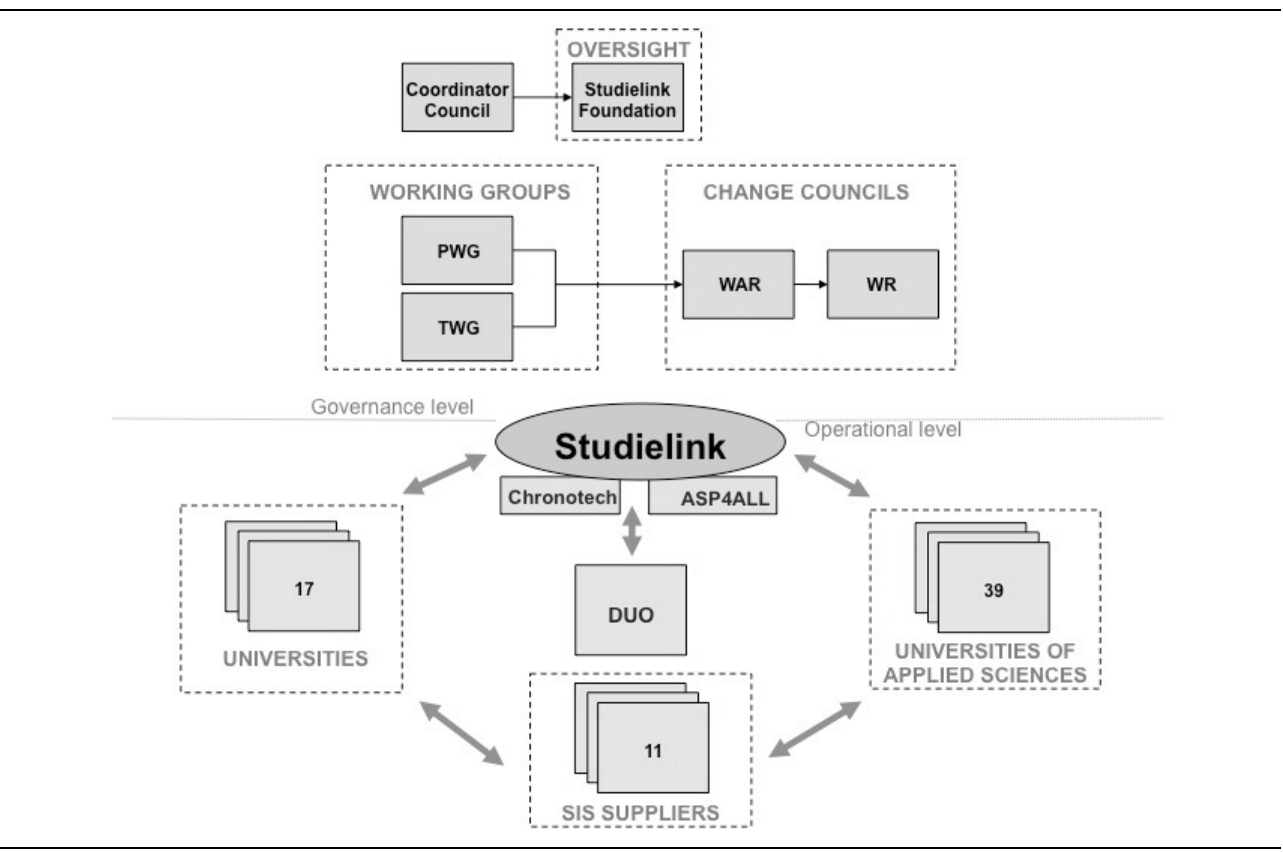

\section{Figure 3.6. Structure of the Studielink inter-organisational network}

In conclusion, we can categorise Studielink as consisting of a relatively non-complex interorganisational network. The number of organisations involved, approximately 70 , is much smaller than the DKD network (comprising over 400 organisations). Whilst it also includes both private and public sector organisations, they all operate in the same domain, sharing very similar domain-level tasks. In terms of IOP governance of Studielink, there are several bodies governing IOP in the various dimensions of Studielink. Whilst at first sight it might give the impression of having a highly decentralised governance, the analysis in Chapter 6 shows that in fact, the degree of centralisation varies considerably across various IOP issues within the programme, and in particular across the duration of the project. 


\subsection{Conclusion}

This chapter has presented the case-based methodological approach used for the remainder of the dissertation and introduced the two cases used for the main part of the analysis: DKD and Studielink. It has argued that due to the exploratory nature of several key research questions, and the need to investigate processes and interpretations that underlie the formation of collaborative behaviour, qualitative data analysis is best suited to answer the research questions addressed by this dissertation. In order to serve both the exploratory and comparative purposes of this research, a dual most-similar case selection frame was chosen. This means that the two selected cases are varying along two dimensions that are of central interest to this study: IOP governance centralisation (within-case variation) and network complexity (cross-case variation).

Based on a qualitative analysis of the interview and documentary data described in this chapter, the following chapters empirically address the research questions of this dissertation. Chapters 4 and 5 validate and refine the preliminary theoretical model developed earlier. Chapter 6 then uses the DKD and Studielink cases for a comparative analysis, investigating how the effectiveness of IOP governance centralisation depends on its alignment with the complexity of government information networks. 

THE PROCESS AND IMPLICATIONS OF

INTEROPERABILITY STANDARDS ADOPTION FOR

ORGANISATIONS IN GOVERNMENT INFORMATION

NETWORKS 80

\subsection{Introduction}

By drawing on empirical data from the DKD and Studielink cases, this chapter aims to provide a more detailed understanding of IOP standards adoption: what does it mean for organisations in Government Information Networks to adopt IOP standards, and how are they going about it? To this end, it pursues several objectives. First, it aims to provide a better understanding of the (possible) implications of IOP standards adoption for organisations ("implications" being used here to jointly denote the constructs Adoption Efforts and Results together ${ }^{81}$ ). A better understanding of the implications of standardisation for adopting organisations, including the key attributes of adoption efforts and of the results from adoption, can lead to a more detailed understanding of the feasibility of adoption and to a more accurate assessment of the likely success of standards, and thus provide a better basis for IOP governance.

Second, the chapter aims to provide a better understanding of the standards-adoption process within organisations. Taking a process perspective on standards adoption "allows for a comprehensive analysis of standards' trajectories, standardization practices and agents of change" (Botzem \& Dobusch, 2012). Standards adoption has been described as a dynamic process consisting of many micro-activities, but these activities are under-explored, with little theory to aid research and practice (Slager, Gond, \& Moon, 2012): "more research is needed to explore the incorporation of standards [...] at an intra-organizational level". "Unblackboxing" this process can thus contribute to better IOP governance, through identifying for instance the main phases of the process and the key activities taking place throughout the process.

\footnotetext{
${ }^{80}$ A summarised version of parts from an earlier version of this chapter has been published as (Henning, 2013b).

${ }^{81}$ The Adoption Efforts construct is discussed in detail in Section 2.4.7 and defined as "efforts required from an organisation during the adoption process" (Table 2.19), and Results is discussed in Section 2.4 .8 and defined as the "consequences, manifest and expected, resulting from the adoption of IOP standards" (Table 2.20).
} 
Third, the chapter aims to investigate which actors are involved in standards adoption, and how they are involved. Whilst standards adoption has been described as a process involving a multitude of actors, the specific types of actors and their roles in the process remain underexplored, without detailed identification and classification of actors (cf. Sandholtz, 2012; Slager et al., 2012). According to Botzem and Dobusch (2012), different actors play a role in different phases of the standardisation process, and the same actors can be involved across several phases of standardisation. Having a better overview of the different roles in the standards adoption process contributes to knowing, assisting, and leading the stakeholders towards a desired standardisation outcome. Finally, the chapter aims to provide casespecific assessments for the DKD and Studielink cases, explaining the implications of the IOP standards for partner organisations in these two cases, how their adoption has taken place, and which actors played what kind of roles.

Consequently, this chapter addresses the first set of research sub-questions (SQ1), introduced at the end of Chapter 1. The overall question of the chapter is "how can we conceptualise IOP standards adoption in Government Information Networks"? To this end, several related questions are addressed: First, what are the different kinds of IOP standards in Government Information Networks? Can we classify them in a sensible way in order to make informed statements about the determinants of IOP adoption? Second, what are the implications of adopting these IOP standards for organisations: what are the efforts required for adoption, and what are the results from adoption? Third, what are the processes of IOP standards adoption in Government Information Networks? And related to this, who are the relevant actors in IOP standards adoption?

The chapter is therefore organised as follows: in this introduction section (4.1), the overall objectives of the chapter and their motivation are laid out, followed by the research questions and an outline of the chapter structure. The following sections address the individual research questions by drawing on the case study data ${ }^{82}$ : In Section 4.2 , the types of IOP standards found in the cases are discussed, aiming to address the first sub-question introduced above. Section 4.3 then discusses the implications of IOP standards adoption for organisations, addressing the second sub-question presented above. Here, due to the richness in detail of the results, the chapter opts for a condensed presentation in the form of a summary discussion of the key findings in order to enhance the readability of the chapter, whilst the bulk of detailed results is presented in Annexes ${ }^{83}$ for the interested reader. Section 4.4 subsequently discusses in full detail the third sub-question, related to the IOP adoption process and the role of the various stakeholders throughout the process are discussed. The chapter then provides conclusions and recommendations for IOP governance in Section 4.5.

\footnotetext{
${ }^{82}$ It should be noted that in line with the nature of these research questions, the contribution of this chapter (as well as Chapter 5) is thus not a comparative analysis that provides propositions about the association between configuration of various determinants and their likely outcome (like addressed in Chapter 6). Instead, its contribution is to provide a detailed account of the "dependent variable" of this research (Adoption), as well as to discuss some key "explanatory variables" (determinants) and their role. (The remainder of determinants will be investigated in a similar manner in Chapter 5). As a result of this reasoning, the decision was for the analysis of individual determinants in Section 4.3 to present the data from both cases together and not to separate them for a comparative analysis.

${ }^{83}$ Annex A provides the detailed results of the content analysis for each determinant at the four conceptual levels constructs, sub-construct, dimension and variable (see Section 3.4 for a description of the method) - as well as the identification of the attributes for each variable. For the reader interested in yet more detail, Annex E provides illustrative data from the cases used to identify the conceptual elements of the key determinant variables.
} 
The findings presented in this chapter build on a combination of interpretive and content analysis, explained in Chapter 3. As detailed in Section 3.4, in view of the exploratory nature of the research questions, the interpretive approach taken here differs from quantitative methodology that would aim at measuring possible causality and effect sizes. Instead, it uses qualitative interview data representing experienced-based insights of key informants about the determinants and process of IOP standards adoption, in order to identify which factors stakeholders perceive to generally determine adoption, and to provide in-depth accounts of the possible causal mechanisms and processes at work. As Section 3.4 (as well as Section 7.3) discuss in detail, the frequency-based content analysis of quotations allows valuable insights, but like any methodology it also comes with its own set of limitations - in particular, the degree of limited sensitivity to the precise content of individual quotations which results from aggregating and "counting" them. Although certain measures can be taken to address them (in this case for instance triangulation with other data from the cases), it is important to understand the inferences from the content analysis as a contribution of empirically grounded, yet indicative theoretical "propositions" that provide a basis for validation by future research.

\subsection{IOP Standards in Government Information Networks}

This section addresses the first sub-question of this chapter: what are the different kinds of IOP standards in Government Information Networks? Can we classify them in a sensible way in order to make informed statements about the determinants of IOP adoption? The findings in this regard validate the three-dimensional conceptualisation of IOP introduced in Chapter 1 as a useful analytical framework ${ }^{84}$, but they also add several insights that suggest that the picture is less simple than this general trichotomy at first suggests.

As a starting point, the results confirm that the three-dimensional conceptualisation of IOP into technical, semantic, and organisational IOP dimensions provides a useful typology for analysing the IOP architecture of Government Information Networks. As the percentage of quotations ${ }^{85}$ given the significant overall quotation frequency $(\mathrm{N}=314)$ for these IOP dimensions shows (Figure 4.1), despite some differences in the extent to which the interviewed stakeholders mentioned the IOP dimensions, all three dimensions do play a considerable role for them.

However, looking more closely into the data on these dimensions allows adding several relevant nuances to this overall picture. The first of these findings is that whilst all three dimensions do matter to stakeholders in Government Information Networks, the analysis revealed that there are clear differences in their relative relevance to different stakeholders, in particular if their different governance levels are taken into account. Overall, as Figure 4.1 shows, the interviewees mentioned technological and organisational IOP the most often (the latter slightly less than the former). Semantic IOP is mentioned with a considerably lower frequency, suggesting that it plays a less important role.

\footnotetext{
${ }^{84}$ See Section 1.4 (in particular Table 1.6) for an explanation of this typology.

${ }^{85}$ The methods of analysis (including re-occurring terms such as "quotation" and "co-occurrence") are explained in Section 3.4.
} 


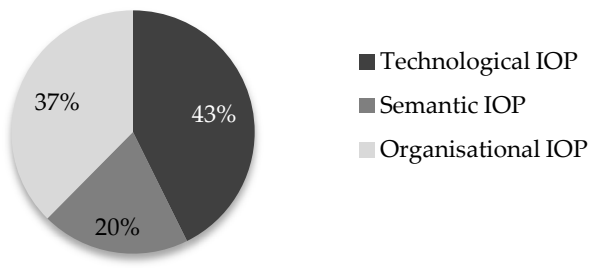

Figure 4.1. Quotations for individual IOP dimensions (rounded percentage of total quotations for all IOP dimensions, $\mathrm{N}=314$ )

Moreover, Figure 4.2 suggests that the higher the governance level at which stakeholders are situated, the more "holistic" their view on IOP issues becomes: as the average quotation frequencies ${ }^{86}$ for the three IOP dimensions within each interviewee role (i.e. organisational stakeholders and network-level stakeholders) show, the distribution for network-level stakeholders is considerably less skewed away from semantic IOP than for organisational stakeholders, who clearly show considerably less concern for semantic IOP than for the other two dimensions. A possible explanation for this is that semantic IOP often can be a more "hidden" issue for organisational stakeholders (in the sense that changes to technology or processes have a more visible impact than semantic definitions, as for instance also shown in Figure $4.3 \mathrm{~b}$ further below). It therefore might rather be a concern that is shared by those stakeholders that are in charge of coordinating IOP in the entire network, and thus need to view IOP more holistically across all three dimensions. (This also explains the fact that technological IOP is relatively more often mentioned at organisational level.)

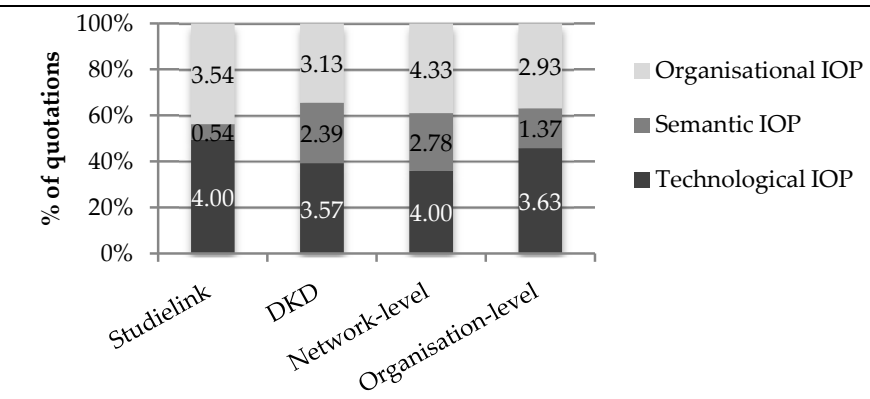

Figure 4.2. Quotations for individual IOP dimensions (average frequencies of quotations per case and interviewee role ${ }^{87}$, shown as percentage of total quotations for all IOP dimensions; average frequencies are displayed within the bars)

Figure 4.2 also shows that semantic IOP plays a considerably larger role in DKD than in Studielink, as well as for network-level stakeholders in comparison with organisational

${ }^{86}$ Since each group of interviewees and both cases had a different amount of interviewees, a comparison based on absolute quotation frequencies would give a misleading picture. Therefore, the frequencies were normalised into "average frequencies", i.e. the average quotation frequencies per case and interviewee role, calculated by dividing the absolute frequencies for a specific code by the number of interviews in the group (case or interviewee level) that is shown.

${ }^{87}$ The data for the individual cases is shown in the bars labelled "DKD" and "Studielink", and the data for the interviewee roles in the bars labelled "Network-level" and "Organisation-level". 
stakeholders. This difference across cases might be explained by the fact that the semantic IOP architecture in DKD is more complex than in Studielink (cf. Annex D2).

The second finding to enhance the common three-dimensional conceptualisation of IOP is that the three IOP dimensions are associated to different degrees with the individual implications of adoption. This is shown in Figure 4.3 below, indicating that there is considerable variation in the share of co-occurrences ${ }^{88}$ of IOP dimensions across particular implication types. The figures show the co-occurrence of quotations for IOP dimensions and for adoption implications, and thus allow us to analyse with what kind of implications the stakeholders associate the different IOP dimensions (Figure 4.3a for Results Figure 4.3b for Adoption Efforts). These figures show an interesting difference between Results and Adoption Efforts implications in this regard: whilst across the Results implications (with the exception of Network-Level Results where only one co-occurrence was recorded) the ratio of the three IOP dimensions is very similar to the overall ratio shown in Figure 4.1, there is substantial differentiation in the degree to which IOP dimensions are associated with the different Efforts implications. This variation is the most visible in the dimension-specific Efforts categories in Figure 4.3b (i.e. Organisational Efforts, Technological Efforts, Semantic Efforts), where we can for instance see that under Semantic Efforts, semantic IOP takes the biggest share (although it generally is the least mentioned, as shown above in Figure 4.1). Whilst this association between IOP dimensions and dimension-specific Efforts categories itself might not be particularly surprising, it suggests that we cannot simply assume that the overall ratio of IOP dimensions shown in Figure 4.1 holds everywhere, but that instead there is a need for a differentiated account across adoption implications.

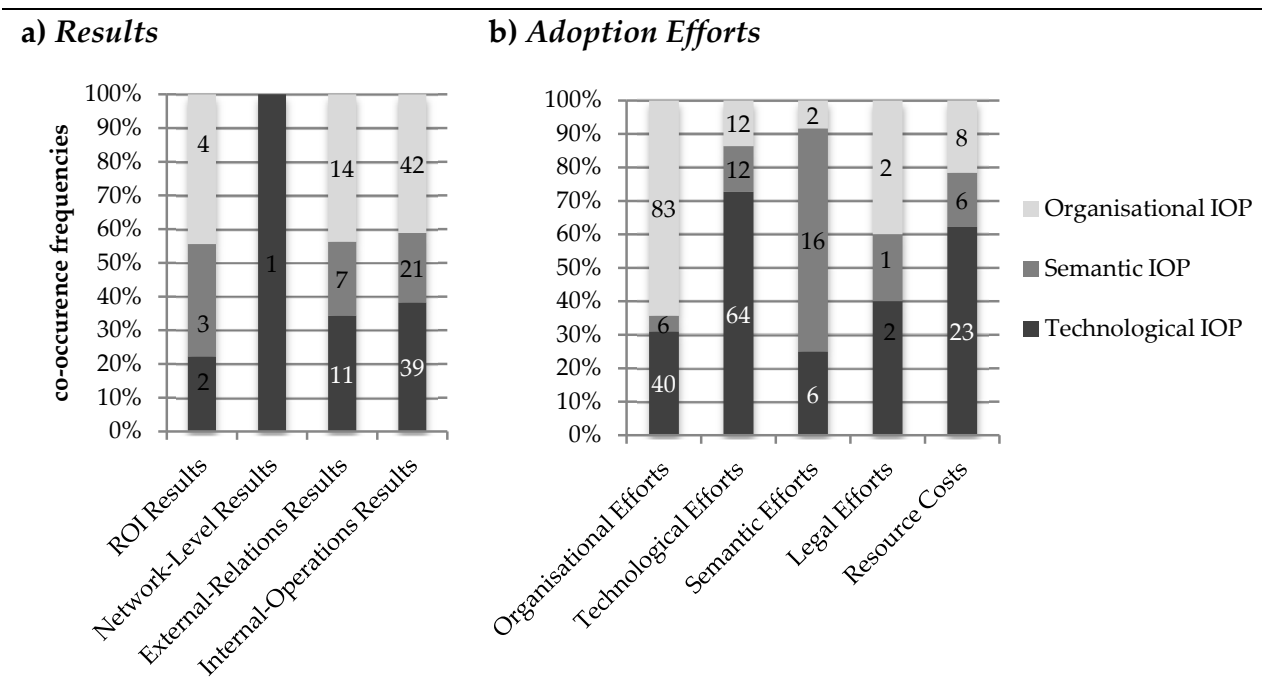

Figure 4.3. Co-occurrence of IOP dimensions and implications codes (aggregate frequencies of co-occurrences for each Results and Adoption Efforts sub-construct are shown within the bars)

${ }^{88}$ See Section 3.4 for a detailed definition of this term. 
The third key finding to add relevant nuances to the existing three-dimensional concept of IOP is that the analysis also found a considerable degree of interrelation between the three IOP dimensions. This is suggested by both Figure 4.3 and Table 4.1. Figure 4.3 shows that all IOP dimensions (albeit to various degrees) were mentioned by interviewees in relation with nearly all implications dimensions - even categories like Semantic Efforts, which are more specifically tied to a distinct IOP dimension. This conclusion is also underlined by Table 4.1 below, which shows that co-occurrences of quotations are relatively widely spread across all three IOP dimensions. This means that whilst the different IOP dimensions are useful analytical categories, the different kinds of standards are often interconnected and should not be seen in isolation from each other.

\begin{tabular}{|l|c|c|c|}
\hline & Technological IOP & Semantic IOP & Organisational IOP \\
\hline Technological IOP & 134 & 33 & 49 \\
\hline Semantic IOP & 33 & 62 & 17 \\
\hline Organisational IOP & 49 & 17 & 118 \\
\hline Share of co-occurrences & $61 \%$ & $60 \%$ & $55 \%$ \\
\hline
\end{tabular}

Table 4.1. Interrelation across IOP dimensions. Diagonal (black) shows the overall count of quotations for each IOP dimension (including those that co-occur with the other dimensions). White cells show the counts of co-occurrences of quotations across two IOP dimensions (row/column). Last row shows the share of quotations within each IOP dimension that co-occur with the other two IOP dimensions

In summary, the analysis validated the three-dimensional conceptualisation of IOP into technological, semantic, and organisational IOP, but added several relevant nuances to this picture. Whilst the different IOP dimensions are useful analytical categories, the different kinds of standards associated with each of those dimensions are often linked to each other, and hence it is important to take a holistic perspective that takes such connections into account. The analysis found that stakeholders at higher governance levels tend to have more of such a holistic view on IOP issues, also taking into account semantic IOP which organisation-level stakeholders tend to consider less. However, given that at the organisational level the differences in the relative relevance of the individual IOP dimensions are more marked, and that overall the three IOP dimensions are associated by stakeholders to different degrees with the various adoption implications, such a holistic perspective needs to be complemented by a differentiated view on the different roles that the IOP dimensions play across adoption implications.

\subsection{Implications of IOP Standards Adoption for Organisations}

This section provides a summary discussion on the key findings regarding the second subquestions of this chapter: what are the implications that the adoption of IOP standards can have for organisations in Government Information Networks? As mentioned earlier, the results on this part of the analysis have yielded a high level of detail, resulting from both the nested multi-level nature of the theoretical framework used here, as well as from the combination of both interpretive and semi-quantitative content analysis methods. Due to this rich detail of the results on this question, this section therefore only gives a condensed summary of the key findings, in order to enhance the chapter's readability and prevent the central findings from being obscured by the high level of detail. The interested reader is 
referred to the Annexes where the evidence and findings are presented in full detail: Annex A shows the detailed results of the content analysis at all conceptual levels, and Annex E provides illustrative data from the cases used to identify the conceptual elements of the most relevant determinant variables.

"Implications" is used in the following to jointly denote both Adoption Efforts (efforts required from an organisation during the adoption process, e.g. resource costs), and Results (consequences, manifest and expected, resulting from the adoption of IOP standards, e.g. efficiency-related results). This closely follows the analytical distinction introduced in Chapter 2. The analysis conducted for this section hence also provides a validation of the theoretical framework regarding Adoption Efforts and Results. To provide an orientation for the reader through the layered conceptual structure followed in this chapter, a schematic overview of the constructs, sub-constructs, dimensions and variables ${ }^{89}$ related to Results and Adoption Efforts implications is provided by Figure 4.4 on the following page.

As the discussion of findings in this section shows, the overall picture resulting from the analysis is that the issue of adoption implications is by far more complex than the identification of the related concepts through the literature review in Chapter 2 has let us assume. In particular, four key findings emerge from the empirical analysis, all contributing to further develop the initially presented framework.

First, the initially identified concepts only show the surface of the implications from IOP standards adoption, and the case studies allowed revising the framework by (dis)confirming the pre-specified determinants, and identifying several additional determinant concepts at the higher, more abstract conceptual levels, as well as previously unaccounted conceptual dimensions within the lower conceptual level of variables. Second, the identified adoption implications are of significantly different relevance across all stakeholder groups, and across IOP dimensions, asking for a differentiated perspective across these groups and dimensions. Third, and related to the previous point, the analysis suggests that a key stumbling block for achieving IOP in Government Information Networks is that stakeholders seem to attach more relevance to immediate intra-organisational implications, rather than to network-level implications and longer-term strategic and institutional developments. And fourth, the analysis showed that the identified adoption implications display considerable interrelations, which asks for a holistic perspective across the various adoption implications. Each of these key findings is discussed in turn in the following sub-sections 4.3.1 through 4.3.4. Section 4.3.5 then reports the findings from the analysis of stakeholders' evaluation of the various implications (presented in complete detail).

${ }^{89}$ This four-level conceptual hierarchy of the conceptual model is introduced in Section 2.4. 


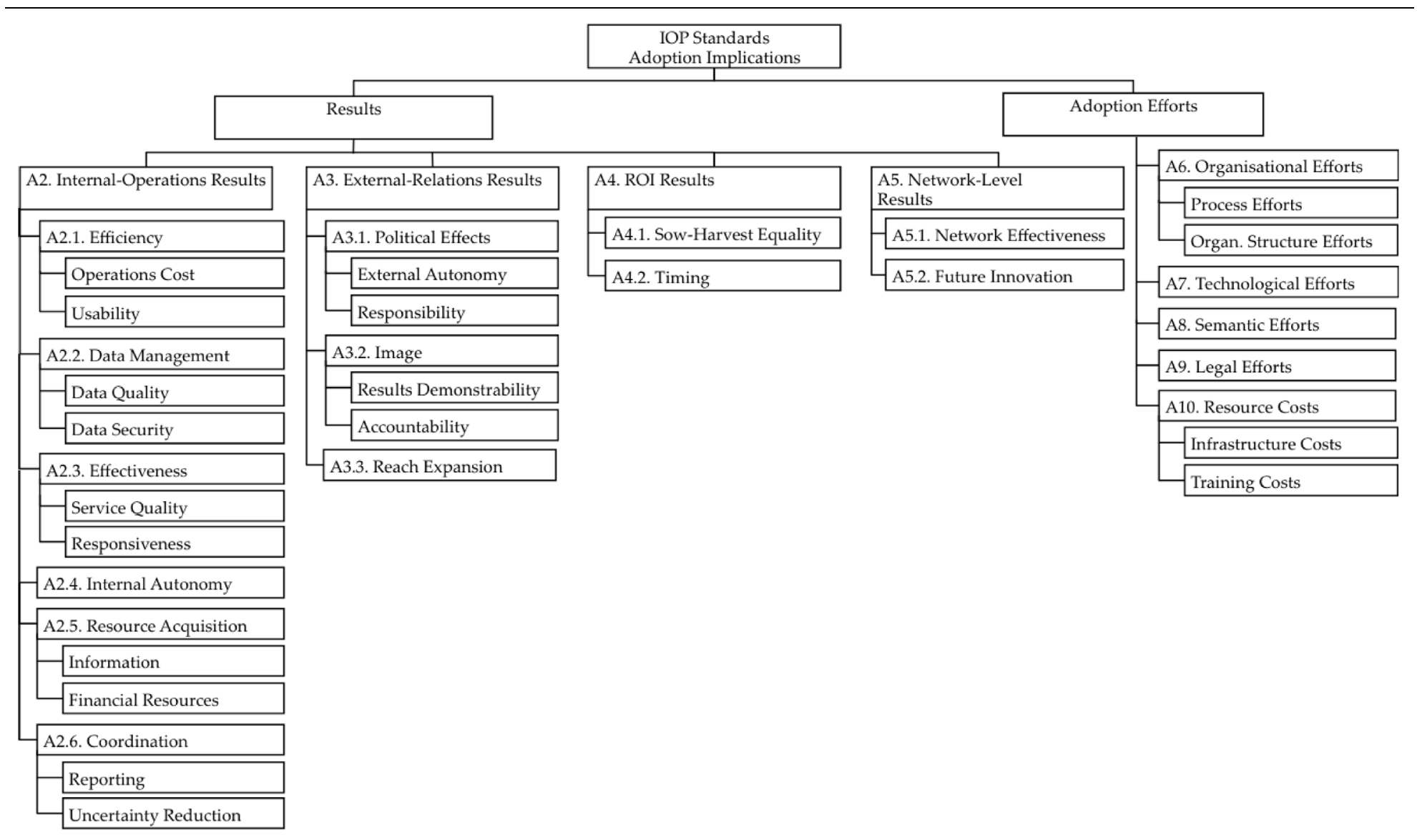

\section{Figure 4.4. Overview of Implications discussed in Section 4.3, Annex A and Annex E (including section numbers)}




\subsubsection{Towards a Revised Framework: Confirming, Contesting and Inducing Determinants}

The first key contribution from the analysis is the validation and expansion of the theoretical framework from Chapter 2 by confirming most of the implications determinants, by contesting parts of it, as well as identifying several relevant determinant concepts inductively from the case study data, which the previously specified framework, developed from the extant literature in Chapter 2, had missed (all reported below in Table 4.2 and Table 4.3, showing the aggregated quotation frequencies ${ }^{90}$ for Results and Adoption Efforts respectively).

The tables below show that in total, three additional sub-constructs, one dimension, and eight variables were identified inductively from the analysis - suggesting that the extant literature had not yet provided an exhaustive framework for conceptualising IOP adoption implications. Furthermore, eight variables specified in previous theory were not confirmed by the data (Table 4.2 and Table 4.3). Hence, besides its key contribution of integrating the concepts synthesised from previous theory into a structured conceptual framework of implications from adopting IOP standards, the current analysis adds to previous theory by identifying new relevant adoption implications as well as contesting previously identified implications.

Moreover, the analysis shows that the existing theory informing the conceptual level of "variables" had not yet captured the conceptual dimensions that exist within each of these determinants. For the key variables, the current analysis identifies such conceptual dimensions (in the following termed "attributes"), thus providing an essential basis for constructing measurement models for future quantitative analyses in this area. The identified attributes are defined in Annex A, and detailed illustrative data for each of them is presented in Annex E.

\footnotetext{
90 "Aggregated frequencies" refers to the sum of the quotations from all variables that belong to the specific construct, sub-construct or dimension in question. It should be noted in this context that for all determinants at levels higher than variables, an additional code was specified to capture the few statements that were "generic" in nature about that determinant but did not specifically match any of its subordinate codes. Where in the following the frequencies for subordinate codes of such a higher-level determinant are reported, the quotations for the general code are generally not counted in the total aggregation (so for instance in Table 4.2 reporting the variables for Efficiency, there is no variable included called "Efficiency"). However, where that aggregated determinant itself is reported as part of a higher-order determinant, the quotations for its general code are included in the total frequency count (e.g. the quotations for the generic "Efficiency" code are included in the count for Efficiency as part of Internal-Operations Results).
} 


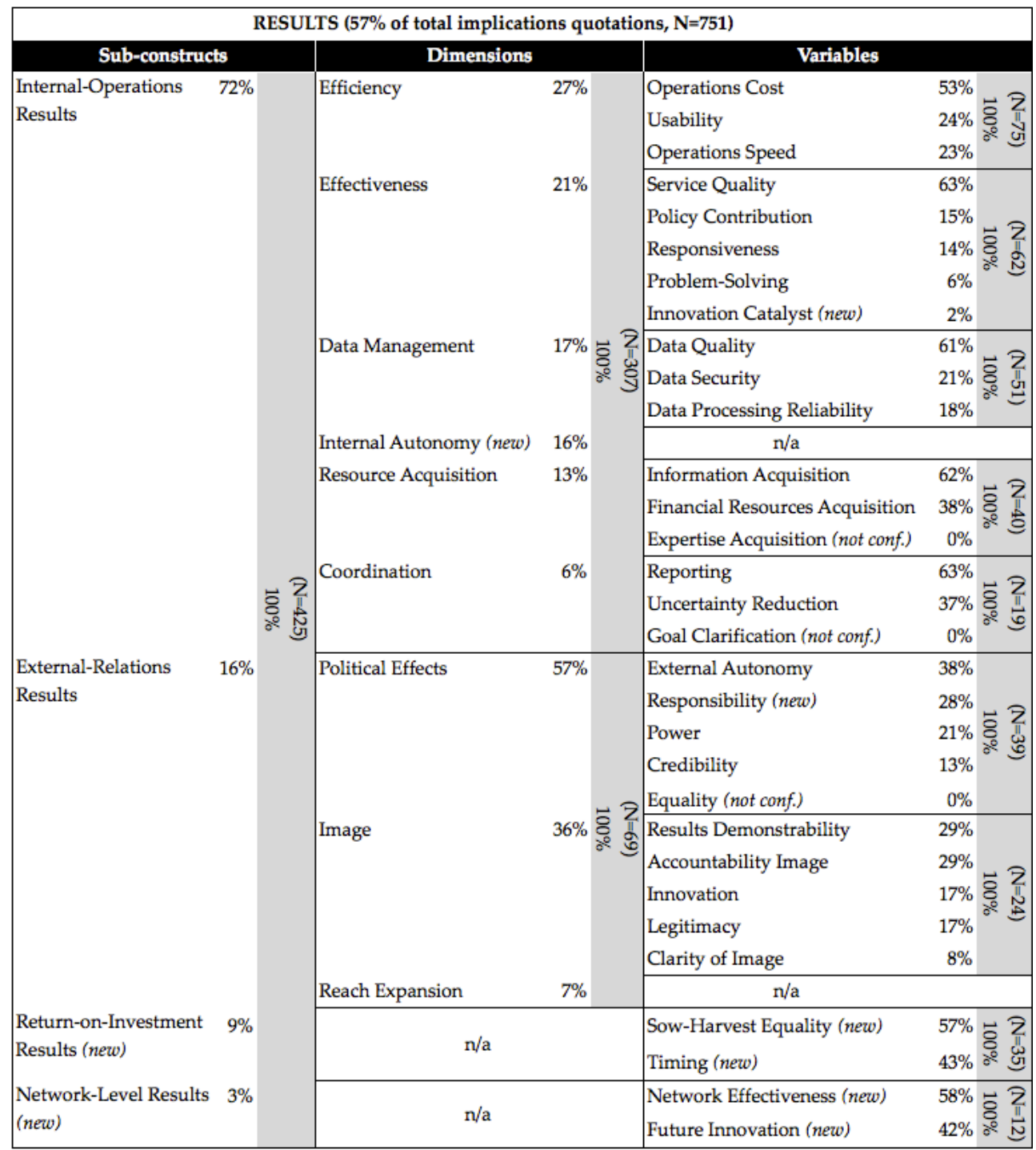

Table 4.2. Results aggregated quotations (grouped per higher-level concept along the hierarchical structure from Figure 4.4). The $\mathrm{N}$ in the vertical grey columns refers to the total quotations for each group, and the percentages refer to the share of each concept within its group (displayed percentages are rounded, full values add up to $100 \%$ ). Inductively identified determinants are indicated with "(new)", and contested determinants with "(not conf.)" 


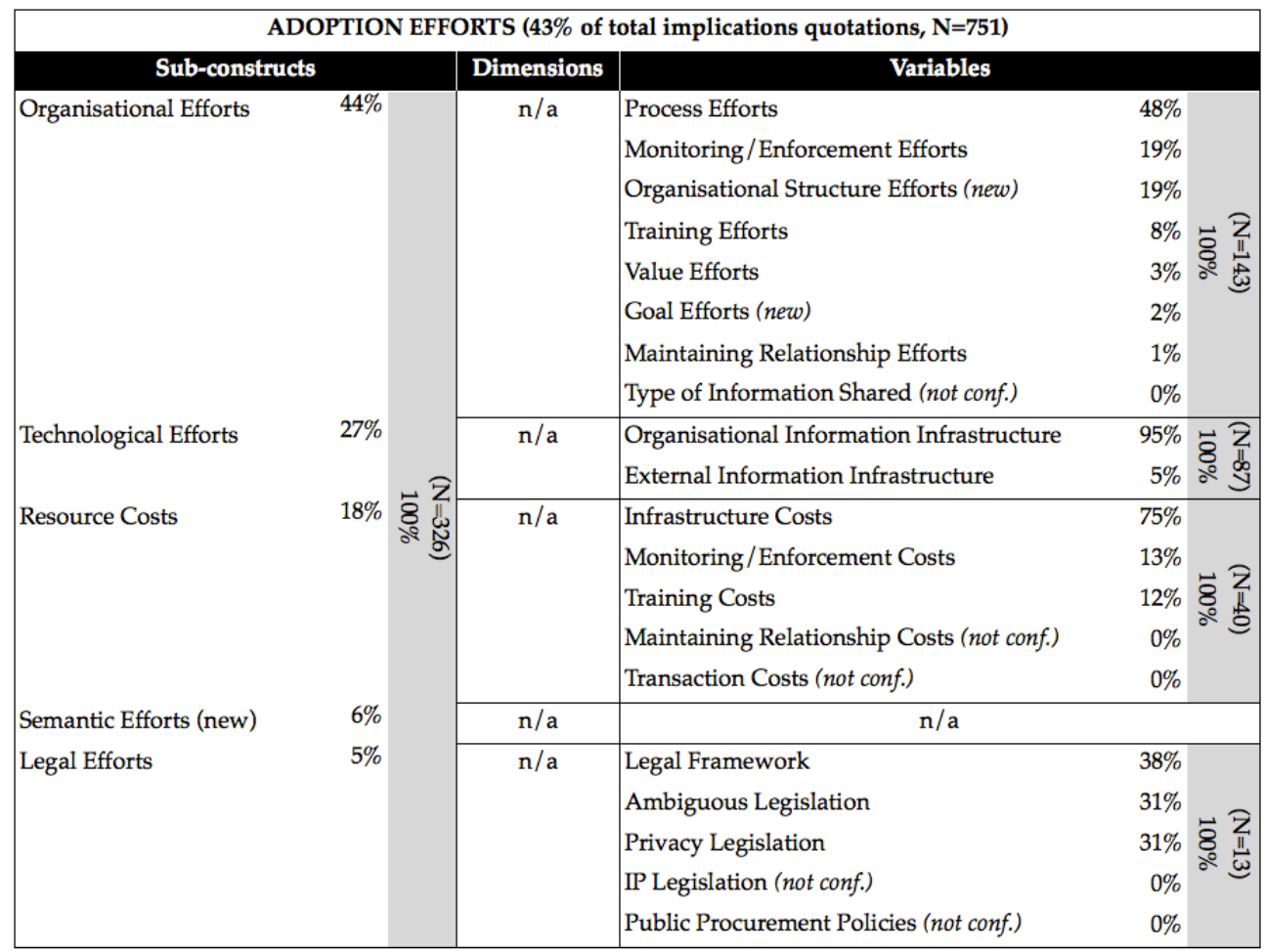

Table 4.3. Adoption Efforts aggregated frequencies (grouped per higher-level concept along the hierarchical structure from Figure 4.4). The $\mathrm{N}$ in the vertical grey columns refers to the total quotations for each group, and the percentages refer to the share of each concept within its group (displayed percentages are rounded, full values add up to $100 \%$ ). Inductively identified determinants are indicated with "(new)", and contested determinants with "(not conf.)"

\subsubsection{Different Relevance of Implications}

A second key finding from the content analysis displayed in Table 4.2 and Table 4.3, as well as Figure Annex A.1 is that the various adoption implications do not carry the same relevance, both within and across stakeholder groups, and across IOP dimensions. This suggests that a differentiated perspective needs to be taken across these groups and IOP dimensions. Based on the frequencies with which individual implications were mentioned in the interviews, the analysis thus provides guidance as to which of these areas are most salient and need to receive particular attention.

One central conclusion about the differences in relevance is that the most general level of implications, the analysis shows that the majority of quotations in the interviews was coded with codes belonging to the Results construct, which suggests that the interviewed stakeholders are slightly more concerned with the results from IOP standards adoption than with the efforts for adoption (for details see Annex A1). 
Furthermore, the IOP standards have an impact on various aspects of the partner organisations' operations and strategy, and require various types of organisational change from them. The quotation frequencies display clear differences concerning which efforts are greater and more relevant for stakeholders - showing that it is the organisational issues that matter most for them (see Table 4.3). Organisational issues seem to be the most difficult for organisations - partly because they are less "graspable", and partly because they affect historically grown and deeply rooted aspects of organisations. This is supported by the observation that Process Efforts and Organisational Structure Efforts have the biggest and second-biggest shares (see Table 4.3 and Annex A6 for details). However, whilst organisational issues might be the most difficult for organisations, the data suggests that in terms of resource costs associated with adoption, it is clearly the technological aspects that have the biggest impact. This can be seen in Table 4.3, showing that the Infrastructure Costs variable has by a big margin the largest share of quotations in the Resource Costs subconstruct (see also Annex A10).

With regard to IOP standards adoption, the data suggest that stakeholders reason primarily according to a functionally-oriented logic and a short-term perspective (emphasising the immediate implications for their organisations' operations or status), rather than investing in longer-term visions and institutional development. This conclusion is suggested by several observations from Table 4.2 summarised below. One indication for this is the overall low share of Coordination quotations, which suggests that organisations do not give much consideration to longer-term strategy and institutional development (see also Annex A2 for details). Moreover, of the relatively few quotations addressing Coordination, not a single one concerned Goal Clarification, the variable in this dimension which most directly relates to the development of organisational and network-level strategy and vision (see also Annex A2.6). Another observation along these lines is that the Expertise Acquisition variable was not confirmed in the data (Table 4.2 and Annex A2.5), which suggests that when it comes to expected resource acquisition, organisations think more in terms of resources that provide immediate operational value (i.e. information and financial resources) rather than resources that develop their value more in the longer-term (i.e. expertise). Along the same lines is the observation that the External-Relations Results sub-construct is dominated by Political Effects and Image (Table 4.2 and Annex A3), both representing conceptual dimensions that have to do with the immediate implications on organisations' operations and their status vis-a-vis other actors in the network (such as their own power and legitimacy). Reach Expansion on the other hand, concerned much more with longer-term strategy and network-level development (i.e. widening organisations' network), seems to only play a minor role in terms of External-Relations Results (Table 4.2 and Annex A3).

Furthermore, and related to the previous point, the results suggest that for stakeholders, Efficiency and Effectiveness are the two most relevant results from adoption (Table 4.2 and Annex A2). This observation is in line with the fact that much of the e-governance literature highlights efficiency (especially cost savings) and effectiveness gains (especially better 
public services) as two of the most important benefits from e-governance (cf. OECD, 2003). ${ }^{91}$ The emphasis in the literature on the reduction of administrative costs and burden is reflected by the observation that within the Efficiency dimension, the most frequently mentioned issue is Operations Costs (Table 4.2 and Annex A2.1). Whilst Operations Costs can also include cost types such as time or human resource costs, the central attribute which interviewees mentioned for this variable are the financial cost savings that result from IOP standards adoption, and several interviewees also stressed this as the most important implication from IOP standards adoption overall (Annex A2.1.1). However, the analysis also identified an important caveat to the commonly held view that e-governance is all about saving costs: as the interpretive analysis of the interview data showed, costs can also rise as a result from IOP standards adoption (for instance when the improved services result in increased client requests, see Annex A2.1.1). Such possible long-term effects of cost increases are generally not mentioned in the e-governance literature, or at most in the context of cost escalations during the project development.

Finally, the analysis suggests that in their reasoning about IOP standards adoption, stakeholders put an emphasis on output legitimacy. This is suggested by the clear majority of Service Quality quotations, the most-often mentioned determinant within the Effectiveness dimension (Table 4.2 and Annex A2.3), suggesting that output legitimacy is the central concern. However, achieving IOP does not seem to always lead to such better services: the picture painted by the interviewees is not only positive, as the service towards customers does not necessarily improve for all organisations as a result of standardisation - for instance when organisations have clients with different needs which might not equally well be served by a standardised service (see Annex A2.3.1). This points to a caveat for the oftencirculated picture of e-governance as being all about service improvements to public clients such as citizens or businesses. Moreover, the emphasis on output legitimacy is underlined by the results regarding Resource Acquisition, where the clear majority of quotations relates to Information Acquisition (Table 4.2 and Annex A2.5). This clearly shows that stakeholders put a heavy emphasis on operations-enhancing resources (such as information) rather than being driven by profit motivations (relatively smaller share of Financial Resources Acquisition).

\subsubsection{Focus on Intra-Organisational Implications, Lack of Network-Level Thinking}

A third key finding is that a key stumbling block for achieving IOP in Government Information Networks seems to be that intra-organisational concerns are given much more attention by stakeholders than both the necessary network-thinking and longer-term strategic and institutional development across a network. The frequencies in Table 4.3 show that stakeholders place an overwhelming emphasis on Internal-Operations Results which

\footnotetext{
${ }^{91}$ It is possible that the emphasis placed by the interviewees on Efficiency and Effectiveness is in itself a consequence from the parading of these two issues in the academic and practice-oriented literature as central aspects. Whilst this question has no bearing on the relevance of these aspects in relation to stakeholders' adoption decision (whether based on what they read or what they experience, either way they cite it as an important determinant), this raises interesting questions about the origins of stakeholders' knowledge, and in how far it is based on experience from practice or simply a reproduction of other actors' accounts.
} 
concern the immediate implications for their organisations' operations - whilst only a marginal fraction of quotations concerns the Network-Level Results of IOP standards (see also Annex A1). The analysis thus suggests that partner organisations are concerned primarily with their own organisations before considering the network level.

Moreover, the fact that the Network-Level Results sub-construct and its two dimensions, Network Effectiveness and Future Innovation, are identified from the interview data and not based on the literature review suggests that the inward-looking bias towards organisationinternal implications is not limited to the interviewed stakeholders, but also pervades the existing literature on the subject (see also Annex A5).

This inwards-looking bias is by no means limited to the Results construct, but is also manifest in the Adoption Efforts implications. One observation suggesting that organisations are largely inwards-looking in their considerations is the observation that Maintaining Relationship Efforts and Level of Collaboration variables have the lowest share among Organisational Efforts (Table 4.3, see also Annex A6). This conclusion is also in line with the observation that the two variables within the Resource Costs sub-construct that are not confirmed by the case study data - the Maintaining Relationship Costs and Transaction Costs variables - are both by definition network-oriented variables (Table 4.3 and Annex A10).

However, this is not to say that stakeholders show no network-level thinking at all. The data shows that some degree of consideration of network-level results is present (Table 4.2, see also Annex A1). In fact, interviewees also display an understanding that some efforts are inevitable in order to also derive benefits from the network for their organisation (Section 4.3.5). This conclusion is closely related to the following key finding, that the willingness to incur efforts from adoption is very much a matter of weighing them against the expected benefits from the network.

\subsubsection{Interrelations Among Implications: the Need for a Holistic Perspective}

The fourth key finding from the data is that several interesting interrelations among the identified implications exist. Therefore, notwithstanding the need for dedicating attention to individual implications that appeared to be particularly relevant for stakeholders, this asks for taking a holistic perspective that takes into account the entire range of adoption implications.

First, the analysis suggests that the stakeholders generally think in terms of trade-offs between the different implications, weighing the adoption efforts against the individual results. One observation pointing in this direction is the considerable amount of cooccurrences of Results and Adoption Efforts (190 co-occurrences in total): many text segments in the interviews were coded simultaneously with both Adoption Efforts codes and codes that are (predominantly) concerning benefits-related Results. Two observations suggest that this is not stemming from merely coincidentally discussing these implications together, but in fact points to a conscious "weighing" of Results and Adoption Efforts. One is simply that the interpretive analysis shows that interviewees also state this manner of reasoning explicitly (see Annex A6). Another observation which suggests a conscious "weighing" is the 
inductive identification of the Return-on-Investment Results sub-construct (see Annex A4), together with its dimensions Timing and Sow-Harvest Equality, which shows that Results (returns) are explicitly put in relation to the Adoption Efforts (investment). ${ }^{92} \mathrm{~A}$ noteworthy observation in this context is that regarding the Timing dimension, several interviewees mentioned that the benefits from standardisation generally materialise only with a considerable time lag after an investment had been made - so that in the short term, often only the efforts get noticed while the results are overlooked (see Annex A4.2).

Second, the analysis also reveals interrelations between different kinds of Adoption Efforts. As the interpretive analysis shows, there are interrelations between various effort categories, for instance between semantic and technological efforts, and between process efforts and technological efforts (see Annex A8 and A6.1). For instance, interviewees reported that implementing technical IOP standards can have a substantial effect on business processes. Together, this suggests that the various implications cannot be seen in isolation, and in particular that it should avoid any technology-deterministic approaches that disregard the connection of technological standards with semantic and organisational issues.

\subsubsection{Evaluation of Implications}

The previous sections have provided a summary discussion of the key findings from the content analysis of the adoption implications. This section presents (in full detail) the findings regarding the question how these implications are evaluated by stakeholders in Government Information Networks.

There is already a substantial body of literature in organisational theory on the issue of attitude or resistance to change, mostly in the private sector context (for a review, see Buchanan, Claydon, \& Doyle, 2006; Buchanan et al., 2005), but also with a number of studies on attitudes to change in public agencies (cf. Osborne \& Brown, 2005; Rainey, 1999; Stummer \& Zuchi, 2010; Vann, 2004; Wise, 1999). There are two reasons in particular why a study on standardisation-related change in a public-sector context can nevertheless provide an addition to the existing knowledge on this issue.

First, whilst the existing evidence is inconclusive on whether or not there are significant differences in public and private sector attitudes to organisational change (cf. Bysted \& Hansen, 2013; Rainey, 1999 for reviews of this debate), it would be ill-guided to take this as a basis to stop there and simply assume that attitude to change in the public sector does not warrant a more targeted investigation - especially given the numerous accounts in the literature of the differences in nature between private- and public-sector organisations (cf. Rainey, 1999; Rainey, 2009 for an overview). Whilst they find no evidence between private and public sector employees' innovation-mindedness, Bysted \& Hansen (2013) for instance caution "about just transferring the knowledge from one sector to another, because we still need to understand the specific condition for innovativeness in public organizations".

And second, it cannot simply be assumed that all change processes in either the public or private sector work according to the same logic and mechanisms. On the contrary, there is

\footnotetext{
${ }_{92}$ The difference of the Return-on-Investment Results sub-construct from the other Results sub-constructs is that this code was applied when they were explicitly put in relation.
} 
evidence that the type of change and the policy domain or government sector have an effect on innovative attitudes (Bysted \& Hansen, 2013). Similarly, Wise (1999) argues that "generally, we need to move beyond overgeneralizations about change resistance in public organizations to identify the factors that can influence variations in reform implementation and to analyze their impact in different branches of government". Hence, there is a need to better understand the diverse nature of different organisational settings and types of change. Therefore, rather than trying to come up with an over-generalised model on publicsector change (or even more general, organisational change), it is important to provide a detailed understanding of how change processes unfold in particular contexts such as standardisation efforts in the public-sector setting.

Therefore, this chapter also aims at providing a more detailed understanding of the reality of stakeholders' attitudes to the various changes resulting from standardisation in Government Information Networks. ${ }^{93}$ To this end, in the analysis all quotations that are containing an unambiguous statement about whether interviewees see a particular implication as generally positive or negative for their organisation, were additionally coded with a Positive Evaluation or a Negative Evaluation code. ${ }^{94}$

Figure 4.5 gives insight into the evaluation of implications (overall) by the interviewees. The figure shows clearly that in general there is a rather equal distribution of positive and negative evaluations. This distribution is very similar across both cases and interviewee levels. It is in particular worth noting that there is hardly any difference between evaluations by interviewees at the organisational and network-levels - in fact, the latter even have a slightly higher share of negative statements about IOP adoption implications. This suggests that the opinion of a majority of those who govern these two Government Information Networks is (even if slightly) more negative than positive, even though one would expect that stakeholders at network level are typically pushing for IOP and would therefore also evaluate it more positively than those at organisational level. However, this holds also when looking at implication categories that by their nature are very closely aligned with the supposedly different interests of both levels: a comparison across stakeholder levels of evaluations for Network-Level Results shows no significant differences (63\% positive evaluations at organisational level versus $60 \%$ at network-level). Similarly, a comparison across interviewee levels for Internal-Operations Results shows very similar proportions across both stakeholder levels (62\% positive evaluations at organisational level versus $57 \%$ at network-level). An explanation for the high share of critical statements on IOP adoption by network-level stakeholders can be that these stakeholders are more aware of all possible implications surrounding IOP standards adoption, and thus are giving more critical accounts.

\footnotetext{
${ }^{93}$ The reader should note that the ambition of this chapter is not to conduct a side-by-side comparison with privatesector cases. Rather, its contribution is to provide an in-depth analysis of the context of public-sector standardisation.

${ }^{94}$ The criterion used to establish whether a statement was "unambiguous" was whether key verbal markers were present such as terms and phrases that clearly indicate an evaluation (e.g. "advantage", "disadvantage", "good/bad for us" etc.). Nevertheless, such interpretative judgement is inevitably subject to the risk of researcher bias inherent to all interpretive research approaches (see Section 3.4 for a detailed discussion of the general steps taken to address this, and Section 7.3 for a discussion on the implications of such limitations for the conclusions that can be drawn).
} 


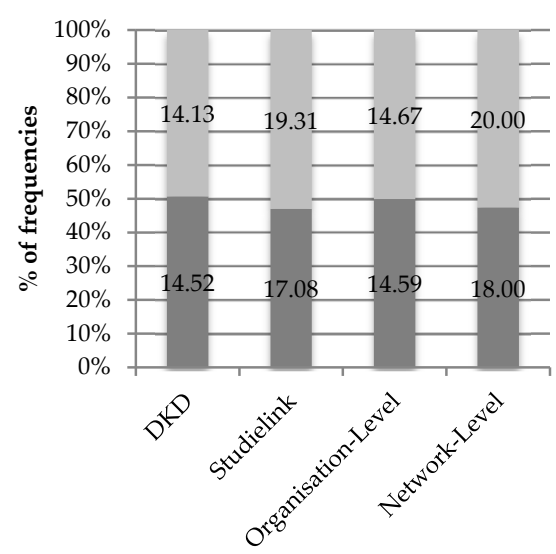

$\square$ Negative Evaluation

- Positive Evaluation

Figure 4.5. Evaluation of implications from IOP standards adoption (aggregate frequencies for Adoption Efforts and Results coded with Positive/Negative Evaluation codes; indicated values are average frequencies of quotations per case and interviewee role, shown as percentage of total quotations per group; average frequencies are displayed within the bars)

Figure 4.6 and Figure 4.7 display the co-occurrences of evaluation quotations with the types of implications from IOP standards adoption (Results and Adoption Efforts, respectively). Figure 4.6 shows that there is considerable variation of evaluation across different Results dimensions. This breakdown shows that, while the overall majority of Results codes cooccurs with a positive evaluation, this can be the opposite for individual Results dimensions. For example, whilst Efficiency results have a clear majority of positive evaluations, Internal Autonomy results are clearly more negatively evaluated.

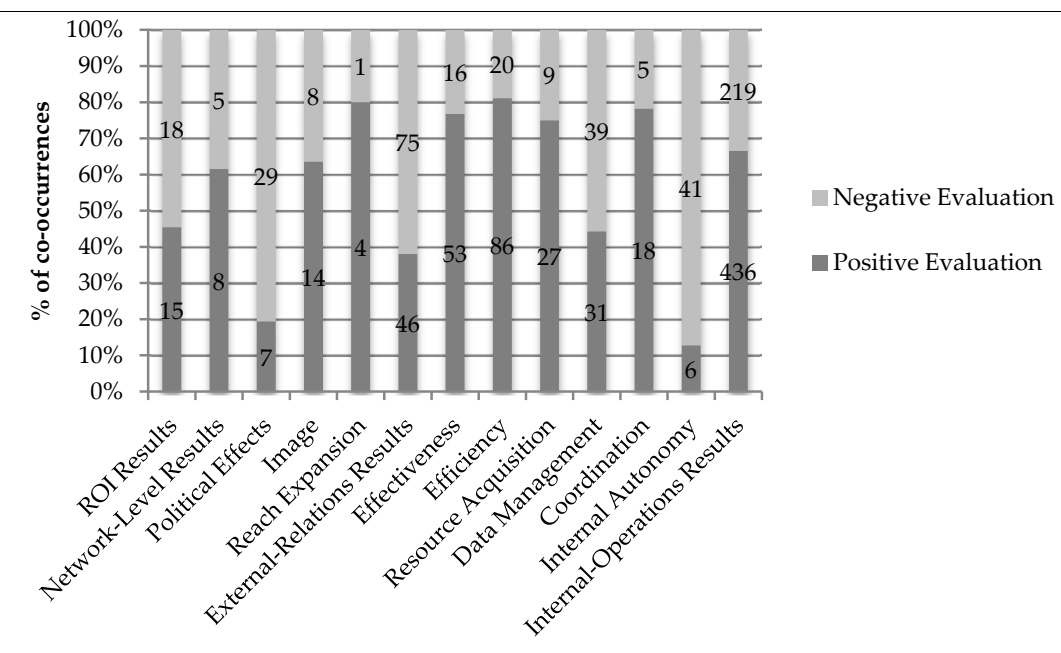

Figure 4.6. Co-ocurrence of evaluation codes and Results (aggregate frequencies per sub-construct/dimension; indicated values are co-occurrence frequencies) 
In comparison to this considerable variation of evaluation across Results codes (Figure 4.6), all Adoption Efforts codes are all very clearly evaluated negatively (Figure 4.7): overall, the proportions of positive and negative evaluations do not vary greatly across individual Adoption Effort sub-constructs. Only one sub-construct (Resource Costs) has marginally less than $80 \%$ co-occurrences with a negative evaluation, whilst all other effort categories remain above.

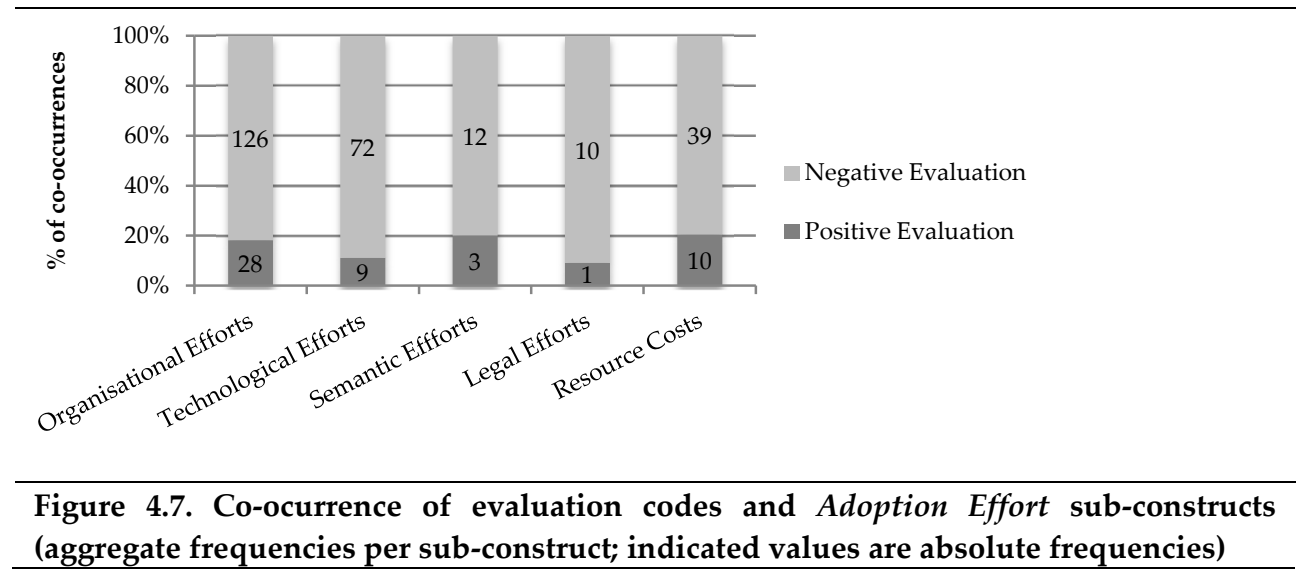

However, a limitation concerning the data behind Figure 4.7 needs to be acknowledged. Given the nature of the Adoption Effort codes as representing "costs" for the organisations and as such something inherently "negative", it is counter-intuitive that there should be any positive evaluations for these sub-constructs at all (in fact roughly between 10-20\% in the data). However, when closely reading the content of those quotations coded simultaneously with an adoption effort and a positive evaluation, it becomes clear that these positive evaluations of efforts should in fact be regarded as "noise" from the coding procedure, and the positive evaluations of efforts should actually be close to zero. The reason is that for virtually all instances where Adoption Efforts were coded with a positive evaluation, interviewees actually would complain about that effort (negative evaluation), but would then also go on to observe some benefits that can result from such efforts in the longer term. It was in these instances impossible to disentangle the positive and negative evaluations by coding, since the larger text passage that was coded (the "unit of meaning") concerns the Adoption Effort, and the segment about the long-term benefits would be embedded into that passage - and adding a code about its long-term results and associated benefits thus inevitably resulted in a co-occurrence of the "effort" with a positive evaluation. An example is the following quotation ("noise" in italics):

\footnotetext{
But then the counter argument [to comply with the standard] usually is 'we're not used to doing it this way, this is not how our processes are designed'. And from Studielink we're always trying to point out these advantages. And [name of a HBO institution] is a good example for this. They changed their process and offered a digital bank authorisation, and by September $1^{\text {st }}$ they had 2 million [Euro] more cash revenue than in the previous year. For an institution's cash flow this is of course very beneficial. ${ }^{95}(\mathrm{Q} 24: 3)^{96}$
}

\footnotetext{
${ }^{95}$ Since the interviews have been conducted and transcribed in Dutch, the quotes in this dissertation have been translated by the author into English. The original Dutch quotations can be found in Annex $\mathrm{H}$.
} 
In conclusion, this section has shown that the picture of implications of IOP standards adoption is significantly more complex than previously discussed, and that it requires both a holistic perspective as well as a specific understanding of the differences between individual implication categories. The next section will show that when adding the adoption process and involved actors to this picture, it becomes even more complex.

\subsection{IOP Adoption Process}

This section addresses the question about the nature of the IOP standards adoption process, and what role the various actors play in this process. First, based on the case study data, Section 4.4.1 discusses which actors are involved in the IOP standards adoption process, and what roles they play in this process. Then, Section 4.4.2 uses the empirical findings from the case studies to investigate the nature of the standards adoption process.

\subsubsection{Actors and Roles in the IOP Adoption Process}

As mentioned before, several authors argue that multiple actors are involved in "constant negotiation" during standards adoption processes (Williams et al., 2009) and that different stakeholders may play different roles either at individual points or across the entire standardisation process (Slager et al., 2012). Attempting to categorise the involved actors, Slager and colleagues (2012) argue that "standardization work is distributed amongst a wide range of actors, including the standard maker, standard adopters and external third parties". In his study of standards compliance, Sandholtz (2012) describes standardisation as an interaction between actors across three levels (displayed in Figure 4.8 below): the operational level within an organisation ("group level"), the management level within an organisation ("organisation level"), and the inter-organisational level ("institutional field").

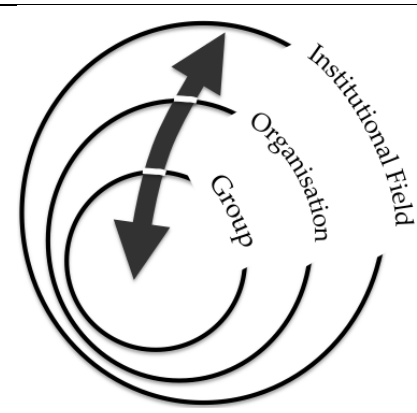

Figure 4.8. Levels of actors in standardisation processes (based on Sandholtz, 2012)

The actors identified in the DKD and Studielink case studies can be grouped under these categories. The following three sections discuss each of these three levels in more detail, and

\footnotetext{
${ }^{96}$ The format (Qx:y) is used for referencing quotes from the interviews. It is based on the unique identifiers that the atlas.ti software package gives to individual quotations. The first number $(x)$ indicates the interview number (see interviewee tables in Chapter 3), and the second number (y) is a consecutive numbering of the quotation in that interview. Thus, Q24:60 refers to a quote from the $60^{\text {th }}$ consecutive quotation instance from interview 24 .

The quotes referenced in the text amount to a vast body of text - far too much to be printed here. However, a text file containing all cited quotations can be requested from the author.
} 
Table 4.4 at the end of Section 4.4.1.3 provides a summary of the various actor groups and their key roles in the IOP standards adoption process.

\subsubsection{Organisation Level: Intra-Organisational Management-Level Actors}

According to Sandholtz (2012), intra-organisational implementation actors ("practitioners") play a crucial role for standards adoption: "It is at this level of analysis-the myriad technical and functional departments, work groups, and other subunits in complex organizations - that a standard's fortunes are ultimately determined."

A key type of actors identified from the interviews in the case studies are top-level managers in organisations adopting IOP standards, situated in most cases in the management board of the organisation. This is often the level where final decisions are taken, and top managers are therefore key actors who need to be convinced for adopting IOP standards. For instance in the Kadaster organisation, it is the board which decides on whether or not to participate in a specific Government Information Network and whether to adopt its IOP standards (Q36:8). In other cases, however, interviewees reported that the top management might not be interested in carrying out the adoption analysis and decision themselves, because they fear that the matter could become too technical for them:

\footnotetext{
'What is there? What isn't there yet? What needs to still come? What does that imply for my organisation?' Managers should ask these questions. Furthermore, they often do not know how it works; they also find this subject matter very difficult. They like to look away, and concern themselves with other things that they do understand. (Q23:10)
}

Possibly this is one reason why many organisations in both the DKD and Studielink case have senior project managers that are dedicated to prepare decisions about their organisation's collaboration in these networks: for instance, each municipality in DKD had its own "Project Leader DKD" (Q7:23), and each institution participating in Studielink has a "Studielink Coordinator". Especially in large organisations like UWV, there can be several different departments involved, so that the adoption processes might even be organised into a programme, with an internal programme manager taking overall responsibility within the organisation (Q11:1). This suggests that in response to IOP standards adoption, also new structures are developing within organisations. Another way of such intra-organisational departmentalisation of standardisation decisions is the formation of a project group (often consisting of various organisational units) that manages the process together:

\footnotetext{
So what do you need? Internally, you need to create a project group, and that consists of process managers. That consists of ICT people in technology, but also the managers of the apps. So you need the functional and technical managers. And you need the users. And you need a manager. Because you are going to change things. What I just said, the maintenance processes, you are going to change them. And the manager needs to authorise this. And he needs to make it known that the process will change [...]. So the project group consists of at least five disciplines, there often are more people in there but you need at least five disciplines. (Q17:21)
}

Another key type of actors within adopting organisations is formed by dedicated units that in many organisations have the task to investigate the details of standardisation decisions and provide advice to the board, such as for instance the "Strategy Department" in the case of the Kadaster organisation (Q11:8). Such units may even take specific types of standardisation decisions. For example in the Kadaster organisation, the "Material 
Administration" (Materiebeleid) department takes the actual adoption decision of some standards, because it has the most knowledge on standardisation (Q8:14). Another type of such internal organisational units is formed by intra-organisational deliberative bodies. In DKD for instance it is the local aldermen who set the agenda within municipalities on whether or not to adopt DKD's IOP standards (Q10:15). So while the board needs to be committed to a certain standard, the actual decision may also be made at a lower level in the organisation. One important conclusion from this is therefore that not all standard adoption decisions are taken by the same actor or set of actors within an organisation, but that the picture is in fact much more complex.

\subsubsection{Group Level: Intra-Organisational Operational-Level Actors}

Based on the empirical data from the cases, it appears that next to the management level, a crucial role for IOP standards adoption in an organisation is played by operational-level work units (Q10:11): even when adoption decisions are made by the top management, the actual compliance can be largely determined by the operational staff (Q11:8), both in the front office and back office of an organisation. Translating management-level decisions into actual implementation and compliance decisions at the operational-level can thus be a complex and difficult task, as illustrated by the following quote:

\footnotetext{
If you are in the position to translate this statement from the board, to say 'I find it important that this is done', in a good way into a change process at the operational level, then you've got a very important condition fulfilled. [...] So to make the translation from the Board to real changes, and that change process to the operational level, is much more complex. (Q26:27)
}

\subsubsection{Institutional Field: Inter-Organisational Actors}

Although it might at first sight appear to be purely a matter of organisational actors, a range of organisation-external stakeholders are involved in IOP standards adoption, from planning to actual implementation and compliance. This level involves actors that are part of the formal IOP governance structure of the Government Information Network, as well as organisation-external actors who are involved on a more informal basis.

Figure 4.9 shows the quotation frequencies for the different types of actors at the interorganisational level. ${ }^{97}$ Whilst it suggests that with nearly half of codes assigned to it, the network broker organisations play a dominating role in the inter-organisational level, it also indicates that adoption is not only influenced by the network broker, but instead is a concerted activity that involves several types of organisation-external actors at once.

The central type of actor is formed by brokers and similar "infomediary" 98 organisations. Slager and colleagues (2012) argue that "the role of intermediaries in standardization [is] by providing knowledge, expertise and a source of legitimacy. [...] The work carried out by these third parties both strengthens the expertise needed to legitimize the standard in the field and contributes to the monitoring of standard adopters' behaviour". This is confirmed

\footnotetext{
${ }^{97}$ An extra code was created for each type of inter-organisational Actor.

${ }_{98}$ Infomediaries were defined in Section 3.5.1.2 as organisations that provide support concerning knowledge management, information exchange and ICT use in inter-organisational systems (Soeparman et al., 2009).
} 
in the interviews, not only by the significant majority of Actor quotations that fall in this category $(45 \%)$, but also by individual statements from interviewees. Infomediary organisations are not only involved in the adoption process, but also may play a significant role for partner organisations in relation to standards compliance, for instance by taking on technical support and monitoring roles (Q19:9).

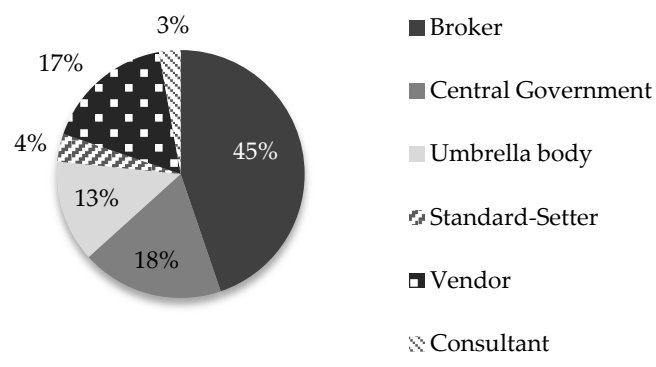

Figure 4.9. Actor codes (frequencies per code, shown as rounded percentage of total quotations for all Actor codes, $\mathrm{N}=\mathbf{2 4 8}$ )

Another key group of actors in IOP governance of Government Information Networks are political actors at ministerial level in the central government (Kamal, 2006; Kamal et al., 2011; Soares \& Amaral, 2011). 18\% of Actor quotations from the interviews fall in this category. As Chen (2012) points out: "the adoption and use of information technology are as much a managerial decision as a political decision; the decision usually occurs against the backdrop of administrative reform". Certainly for partner organisations that are ministerial departments (such as for instance DUO), the go-ahead decision needs to come from the ministerial level which for instance makes the crucial decision whether to grant the necessary funding - otherwise the organisation has little choice but to reject the adoption of that standard (Q23:11).

Furthermore, (sectoral) umbrella organisations are actors that can play a significant role in decision-making on standards adoption. This type of actor was identified inductively from the interview data. $13 \%$ of Actor quotations fall in this category. In Studielink for instance, the institutions' umbrella bodies (HBO Council and VSNU) played a central role as the actual commissioning bodies of Studielink. The HBO Council, for instance, took a binding commitment decision, which in fact obliged all $\mathrm{HBO}$ institutions to go along with the project (Q24:4).

Vendors also are a group of actors that play a significant role in the adoption process (Kamal, 2006), from the setting of standards to their adoption and implementation by organisations. $17 \%$ of Actor quotations fall in this category. In both cases, interviewees gave examples of how vendors are participating in the standard-setting process, albeit in a more advisory role. One example in the Studielink case is the participation of the SIS vendors in the Technical Working Group (TWG), which forms part of the Change Advisory Council (WAR) that determines functional changes to Studielink (Q24:50). Another role they can take during the standard development is to participate as a testing partner in the 
development process (Q26:1). Vendors can also play a considerable role by providing technical support, both during standards implementation (Q3:13) and maintenance (Q23:12). They also play an influential role regarding organisations' intention for standards adoption through the way in which they decide to implement standards in the systems they supply: either incentivising organisations to comply with standards by "wiring" certain standards into their applications, effectively forcing the standards upon all their organisational clients (Q16:22), or actually increasing adoption efforts through deliberately not implementing the standards in their systems, for instance out of concern that standardisation would take away their competitive advantage (Q34: 14).

Standard-setters are a group of actors whose main role is the development and administration of the IOP standards used in a network (Dahl \& Hanssen, 2006). The development of standards involves both the strategic development decisions (Q24:49) such as for instance ensuring consistency across standards (Q2:14) or coordination with other standard-setting bodies (Q18:8), as well as more technical development including testing (Q28:3). Standard-setters also are the actors who then publish and disseminate a standard (Q4:12). Finally, the administration and maintenance of standards is a role performed typically by these actors, for instance updating the standards (Q24:49) or providing support for a standard such as documentation or trainings (Q20:5). Depending on the network and the particular standard concerned, these roles can be performed by bodies from outside the Government Information Network (e.g. international standard-setting organisations such as the International Organization for Standardisation ISO), or by other actors within the network, either brokers (Q2:14) or even partner organisations that have an influential position that enables them to act as setters of a de facto standard (Q20:5). This can also explain why, although standard-setting is undoubtedly an important function for standardisation, it only accounts for $4 \%$ of the Actor quotations: most standards in both DKD and Studielink cases are indeed set and maintained by the broker organisations, which suggests that many quotations relating to standard-setting in fact are absorbed by the large share of Broker quotations.

Finally, consultants are a group of actors that influence the standards adoption process through various roles (Kamal, 2006). They were, however, mentioned by interviewees only to a minor extent (3\% of Actor quotations). They can be involved in developing standards by providing external advice. For instance, in the DKD case a consultancy firm was contracted at one point to investigate the existing standards landscape as part of the standards development efforts (Q13:9). Consultants can even take on some broker functions: in several conflicts between parties in the DKD case for instance, consultancy firms were hired to provide a second opinion from an external party as a means to identify compromises and resolve the stalemate between parties (Q21:3). Another role which was mentioned in both cases was to engage consultancy firms for monitoring and evaluation purposes, such as for instance operational audits (Q33:9).

Table 4.4 below provides a summary of the various actor groups and their key roles in the IOP standards adoption process. 


\begin{tabular}{|c|c|c|}
\hline Organisation-External Actors & \multicolumn{2}{|c|}{ Organisation-Internal Actors } \\
\hline Institutional Field & Organisation Level (Management) & Group Level (Operational) \\
\hline $\begin{array}{l}\text { Central Government } \\
-\quad \text { Initiation } \\
-\quad \text { Political agenda-setting and } \\
\text { decisions } \\
\text { - } \quad \text { Funding decisions }\end{array}$ & $\begin{array}{l}\text { Top-level Managers } \\
-\quad \text { Make final decisions } \\
\text { - } \quad \text { Might delegate analysis } \\
\text { and decisions }\end{array}$ & $\begin{array}{l}\text { Front-office Operational Staff } \\
-\quad \text { Standards } \\
\text { implementation }\end{array}$ \\
\hline $\begin{array}{ll}\text { Broker/Infomediary Bodies } \\
\text { - } & \text { Network brokerage } \\
\text { - } & \text { Provide expertise and legitimacy } \\
\text { - } & \text { Technical assistance } \\
\text { - } & \text { Compliance monitoring } \\
\end{array}$ & $\begin{array}{ll}\text { Senior } & \text { Project Managers } \\
- & \text { Project leader or } \\
& \text { programme manager } \\
- & \text { Standards analysis } \\
- & \text { Prepare decisions } \\
\end{array}$ & $\begin{array}{l}\text { Back-office Operational Staff } \\
-\quad \text { (Technical) standards } \\
\text { implementation }\end{array}$ \\
\hline $\begin{array}{ll}\text { Umbrella Organisations } \\
- & \text { Initiation } \\
- & \text { Might take on infomediary } \\
& \text { functions }\end{array}$ & $\begin{array}{ll}\text { Project } & \text { groups } \\
- & \text { Combine various } \\
\text { organisational units } \\
-\quad \\
\text { Joint management of } \\
\text { standardisation }\end{array}$ & \\
\hline $\begin{array}{ll}\text { Standard-Setters } \\
- & \text { Standards development } \\
- & \text { Standards publication and } \\
& \text { dissemination } \\
- & \text { Standards maintenance }\end{array}$ & $\begin{array}{ll}\text { Dedicated Units } \\
-\quad \text { Standards analysis } \\
-\quad \text { Advise top-level } \\
& \text { management }\end{array}$ & \\
\hline \begin{tabular}{ll}
\multicolumn{2}{l}{ Vendors } \\
- & Advisory roles in standards- \\
& setting \\
- & Technical support \\
- & Standards-(non)compliant \\
& system design \\
\end{tabular} & $\begin{array}{ll}\text { Deliberative Bodies } \\
-\quad & \text { Set standardisation agenda } \\
- & \text { Might take standardisation } \\
& \text { decisions }\end{array}$ & \\
\hline $\begin{array}{l}\text { Consultants } \\
\text { - } \quad \text { Advisory roles in standards- } \\
\text { setting } \\
\text { - } \quad \text { Monitoring and evaluation }\end{array}$ & & \\
\hline
\end{tabular}

Table 4.4. Actors and roles in the IOP standards adoption process

\subsubsection{IOP Standards Adoption Process}

Solli-Saether (2010) argues that developing IOP is a sequential process of increasing maturity and a hierarchical process that is not easily reversed. Several other authors have in a similar vein characterised standardisation processes as sequential processes that consist of various phases that organisations pass through. According to these authors who argue for a sequential nature of standards adoption, standards development and adoption follows a sequential, multi-stage model (Solli-Saether, 2010).

Similarly, Rogers (2003) distinguishes five major phases of the innovation decision process, which he defines as "the process through which an individual (or other decision-making unit) passes from gaining initial knowledge of an innovation to forming an attitude toward the innovation, to making a decision to adopt or reject, to implement the new idea, and to confirm this decision". Accordingly, the five stages of the innovation decision process are 1) "Knowledge" (when the adoption agent first learns of the innovation); 2) "Persuasion" (when the adoption agent forms a positive or negative attitude toward the innovation); 3) "Decision" (when a concrete choice for or against adoption is made); 4) "Implementation" (when the adoption agent puts the innovation to use); and 5) "Confirmation" (when the previous decision is reinforced or reversed). 
Bala and Venkatesh provide a stage-model of standards adoption. They distinguish between stages in the adoption of business process standards (2003): first, there is the stage of awareness of the standard, possibly including the initiation of formal trial and evaluation. Second, there is the phase of adoption or rejection, where a decision is made for adoption or non-adoption. This is followed by a phase of limited deployment with an implementation of only some standards, limited to parts of an inter-organisational exchange. Finally, there is the phase of general deployment, marked by the implementation of an elaborate set of standards that allows a complete inter-organisational exchange.

There is thus substantial diversity in how the different authors conceptualise the adoption process. In fact, there is only a very small common denominator among these models: whilst all of the models discussed here suggest a stage-like process of adoption consisting of multiple successive phases, there is so much diversity with regard to the distinction of these phases that the only common ground is the very basic distinction shown in Figure 4.10. In this most basic of process models, the adoption decision forms a central point that separates the innovation/standards adoption process into two major parts: phases prior to the adoption decision (including Rogers' stages of Knowledge, Awareness, Trial, Persuasion), and the post-adoption phases (including Implementation and Confirmation). Given that current theory does not agree on a more concrete framework, the analysis presented in the following sections takes this as its starting point and tries to shed more light on what happens within the "black box" of these two phases.

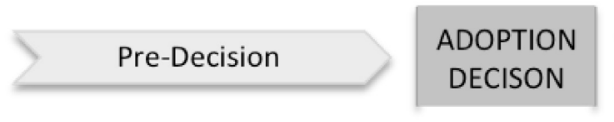

\section{Post-Decision}

\section{Figure 4.10. Adoption Process}

\subsubsection{Pre-Adoption-Decision Phases}

In the case studies, the IOP standards adoption process was initiated in several ways. Often, the political level initiated the process. In the DKD case for instance, it was legislation (WEU) that forced the core SUWI chain partners to share their data and as a consequence, to adopt the IOP standards that are necessary for digital data exchange. The process can also be initiated by actors at the network level, such as infomediary organisations. This can for instance be seen in the Studielink case, where Studielink Foundation pursued a strategy of actively convincing institutions to adopt Studielink and its IOP standards. In some cases, however, it is the adopting organisations themselves that initiate the adoption process: in DKD for instance, a data recipient organisation which is not part of the core SUWI chain first has to formally file a request with BKWI to receive data, which would then result in a change procedure for a new DKD release (Q5:18).

Such new DKD releases, and new IOP standards in general, are usually first tested by organisations. If successful, the implementation then goes ahead and there might be training events in the organisation. A similar procedure can occur again if changes are made to the application or standard afterwards. This is for instance also the case in Studielink with updates of the specific adapter (Q28:7). In most cases, the eventual adoption decision for an 
IOP standard is preceded by an initial feasibility analysis, including the viability of alternative options (Q11:8). This can cover various issue domains, such as for instance technical as well as legal issues:

\footnotetext{
It starts with a simple factual analysis of what do the standards specify and what don't they specify, and if we want to do specific things, is that formally possible - because of course there are all kinds of legal frames around it. That is simply a factual analysis that you very well can do together with the partner organisations. Because they too understand that it is difficult for UWV to completely lose their autonomy for these sorts of things. So you start with such a factual analysis of legal and technical aspects. (Q11:6)
}

It also typically involves an analysis of costs, which may also be repeated at various points in time, and even lead to different assessments (Q13:10). Obviously, those organisations that are under a legal obligation to adopt the IOP standards would not openly reject the adoption of these standards. Of course they might nevertheless decide not to comply later on, as discussed further below. Organisations without such a legal obligation, however, can take more of a "pick-and-choose" approach to standards adoption, and based on their initial analysis, adopt some of the standards while rejecting others (Q35:5). In some cases, where the legal obligation is not clear-cut, even formally obliged organisations can openly reject adoption. One example of this from the DKD case is the situation when UWV declined to adopt prescribed changes to an internal message format it used (called Digital Insurance Message, DVB $\left.{ }^{99}\right)(\mathrm{Q} 11: 5)$.

\subsubsection{Post-Adoption-Decision Phases}

Based on the interpretive analysis of the data, three separate phases were identified inductively for the post-adoption-decision phase: 1) a Planning Phase, referring to the concrete steps taken in preparation of deploying the IOP standard; 2) an Implementation Phase, concerning the actual implementation, i.e. putting into place the necessary infrastructure for the standard deployment; and 3) the Operational Phase, which covers everything that happens after implementation of the standard (including what Rogers called "Confirmation"). These phases can serve as a framework for a process-based analysis of adoption implications in the post-adoption-decision stage, which is reported below. The complete distinction of adoption process phases, together with the relevant actors, is displayed in Figure 4.11 below.

A general observation about the adoption process is that it typically is not something that happens overnight, but is a rather lengthy process. In the DKD case, the duration for the adoption of all required standards for data exchange via DKD was at least nine months, but could in some cases even take up to four years (Q5:20). One possible reason is that the process of adoption also is not necessarily always steady and evenly progressing, but can incur interruptions, as both organisation-internal as well as organisation-external factors determine the speed of the process (Q5:20). But even without interruptions, the adoption of a single standard can take several months: for instance, the actual implementation (starting from the adoption decision) of Studielink's "specific adapter" took about three months (Q30:15).

\footnotetext{
${ }^{99}$ Digitaal Verzekeringsbericht.
} 


\section{ADOPTION}

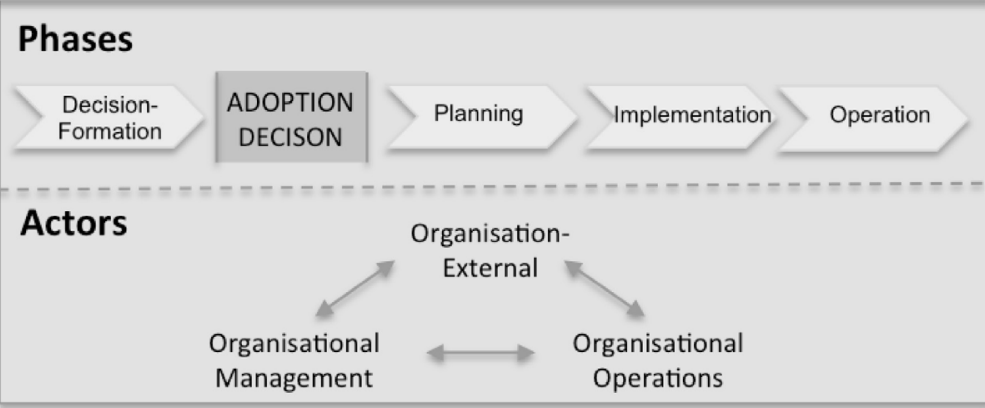

Figure 4.11. Adoption process and actors. Top panel shows the phases identified, and bottom panel shows the actor types that interact at all phases of the adoption process

Figure 4.12 shows the distribution of quotations for the Project Phase codes. However, due to the low number of overall quotations for this code, the results need to be interpreted with caution and the conclusions drawn below can only be seen as indicative. Still, they are reported here because they suggest interesting (albeit preliminary) propositions about the post-adoption-decision process that future research should follow up upon. One likely reason for the overall low number of quotations for these codes is that there were no interview questions targeted specifically at this issue, as they have been identified inductively from the interview data during the analysis. Most of the interview questions instead focused on the pre-adoption-decision phase, which can explain the low overall number of quotations for the three post-adoption-decision phases. It can also indicate, however, that the identified phases have more of an analytical value, but that the interviewed stakeholders themselves do not necessarily think of the adoption process so much in terms of phases rather than a continuous process.

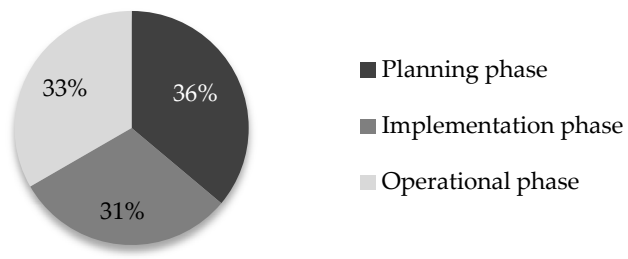

Figure 4.12. Project Phase codes (frequencies per code, shown as rounded percentage of total quotations for all Project Phase codes, N=36)

As shown in Figure 4.12, the quotations related to project phases are very evenly distributed across planning, implementation and operational phases. However, this picture becomes more nuanced once we look at co-occurrences of project phase quotations with the various implications in terms of Adoption Efforts and Results: as Figure 4.13 and Figure 4.14 show, looking at the co-occurrences of project phase codes with Results and Adoption Efforts codes 
highlights a much more pronounced variation between the phases. In both, we see that roughly half of the co-occurrences with effort codes fall to the operational phase. The remainder is shared by planning and implementation phases, with the latter clearly representing the smallest part. This may suggest that when planning the adoption of IOP standards, significant consideration is given to its implications. However, the finding that the operational phase takes the largest share may indicate that many of the implications materialise only at this point in a project. It is more difficult to explain why the implementation phase has a relatively low share of co-occurrences with implications in terms of Adoption Efforts and Results. One possible explanation is that implementation is a relatively brief period of time in the project when compared to its planning or the actual operation, so that it gives less opportunity for implications (both Adoption Efforts and Results) to materialise.

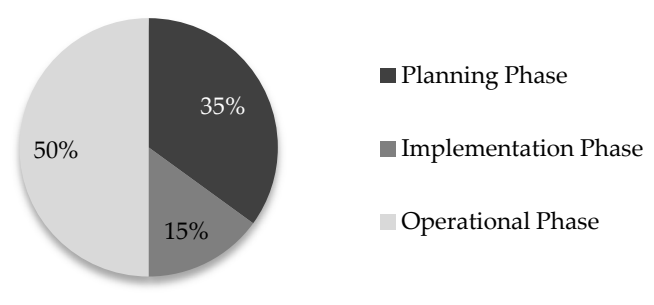

Figure 4.13. Co-occurrences of Project Phase and Results codes (Results codes are aggregated, figure shows frequencies per Project Phase code as rounded percentage of all co-occurrences of Project Phase and Results codes, $\mathrm{N}=\mathbf{2 0}$ )

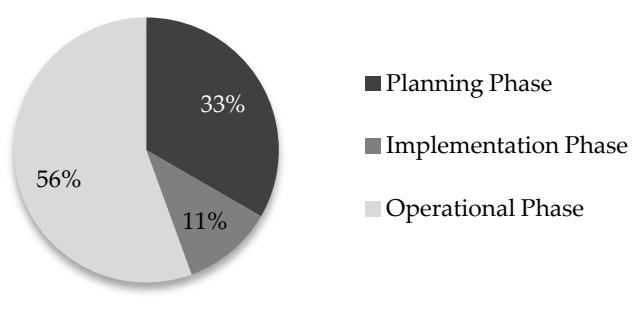

Figure 4.14. Co-occurrences of Project Phase and Adoption Efforts codes (Adoption Efforts codes are aggregated, figure shows frequencies per Project Phase code as rounded percentage of all co-occurrences of Project Phase and Adoption Efforts codes, $\mathrm{N}=18$ )

A crucial issue after the adoption of a standard is (non-)compliance with that standard (or in Rogers' terms, "Confirmation"). This issue arises in the operational phase. Whilst discontinuity of compliance can happen in an explicit manner, more common seem to be practices of "silent" non-compliance. Brunsson et al (2012) describe this as "decoupling between talk and action", in which the organisation presents its practices as being in compliance with the standard, instead of truly aligning them with the standards' 
specifications. Instances of this practice could be found in both cases. In DKD for instance, interviewees reported that on average there are 30-40 municipalities that do not supply their data to the DKD, without facing sanctions (Q19:32). Often, such non-compliance originates at the operational level in the organisations. For instance, an often-mentioned complaint is that, while the legally binding standard of using electronic data during the intake had formally been adopted at organisation-level in the municipality, the operational-level staff of the GSDs nevertheless sticks to old practices and asks clients for paper evidence (Q3:20). Another example for "silent" non-compliance which several respondents mentioned was that after the "Queen's Day attack" in 2009100, the attacker's license plate (which had appeared in national TV) was used by officials in several municipalities in order to look up personal data on the attacker via DKD, obviously out of personal interest and not with a professional mandate (Q17:28).

In some instances, non-compliance can be a form of what Egiyedi and Dahanayake (2012) call "deviant adoption", i.e. a partial adoption of a standard. They differentiate between two kinds of deviant adoption. On the one hand, they refer to intentional deviant adoption as an aggressive market strategy by organisations, in which they embrace a standard, but either omit some of its specifications, or extend or adapt it. This also appeared in the data from the case studies, where in some situations (particularly when there were no other means for the organisation to exert influence on the standards such as consultation procedures) noncompliance was used as a strategy in order to influence the standard-setting "from the demand-side" (Q19:25). Another example from the DKD was the prescription to use a specific application at the very beginning of the intake process. The prescription used for this was to use it "at the beginning of the intake process", which was "misunderstood" by several organisations (reportedly not truly accidentally), who fitted this into their idiosyncratic processes, so that eventually this standard did not lead to the envisaged IOP (Q16:16).

On the other hand, Egiyedi and Dahanayake (2012) mention unintentional deviant adoption, for instance as a result from ambiguous standard description. Such non-compliance as a result of badly specified standards also occurred in both cases (Q16:15/Q24:21). One example of unintentional deviant adoption is "accidental" non-compliance: for instance in the $\mathrm{DKD}$, situations were mentioned where a new project manager who was not yet aware of the obligation to file change requests with the designated consultation body simply implemented an internal change, thus unconsciously circumnavigating certain standards requirements.

\subsection{Conclusion}

Building on empirical data from the DKD and Studielink cases, this chapter aimed at providing a more detailed understanding of IOP standards adoption. The main research question it addressed is: "how can we conceptualise IOP standards adoption in Government Information Networks"? To this end, it asked three sub-questions: what the different kinds

\footnotetext{
${ }^{100}$ On 30 April 2009, during the annual “Queen's Day" celebrations, a man drove his car at high speed into the parade of the Dutch royal family in the Dutch city of Apeldoorn, killing eight spectators and injuring ten. The parade, including the attack, was broadcast live on Dutch national TV.
} 
of IOP standards in Government Information Networks are; what the implications of adopting these IOP standards are for organisations in such networks; and what the processes and actors are of IOP standards adoption in Government Information Networks. Overall, the analysis presented in this chapter suggests that the picture of IOP standards adoption is much more intricate than previous theory and the framework synthesised from the literature in Chapter 2 had proposed.

To address the first sub-question, the chapter began with a discussion of the different dimensions of IOP. This discussion has shown that the three-dimensional conceptualisation of IOP into dimensions of technical, semantic, and organisational IOP provides a useful framework for analysing the IOP architecture of Government Information Networks and for distinguishing between the types of standards associated with these dimensions. From the empirical data, it appeared that despite some differences in the degree to which interviewees mentioned the different IOP dimensions (with the more "visible" dimensions of technological and organisational IOP being mentioned more often than the more abstract issues of semantic IOP), all three dimensions nevertheless play a considerable role for the interviewed stakeholders. The comparison across stakeholder levels revealed an interesting difference: network-level stakeholders appeared to be considerably more concerned with semantic IOP than organisation-level stakeholders. This suggests that the higher the governance level, the more "holistic" the view on IOP issues becomes, with a more equal consideration of all three IOP dimensions. Nevertheless, the observation that also at the organisation-level all three IOP dimensions are discussed to a considerable extent, implies that IOP governance cannot afford to neglect any individual dimension. This argument is also supported by the evidence that in organisational practice the IOP dimensions are highly interrelated. IOP governance should thus not treat them independently, and for instance address technical IOP as a separate issue from organisational standards, but take into account the entire picture in a holistic governance approach.

This does, however, not mean that IOP governance should not target specific "problem areas". The chapter also has found that the different IOP dimensions are associated to different degrees with the various implications of adoption, i.e. there was variation in the share of co-occurrences of particular implication types across IOP dimensions. IOP governance thus needs to take an issue-focused approach by taking into account how the different types of IOP standards have different effects across the organisational life.

To address the second sub-question, the chapter analysed the (possible) implications of IOP adoption on organisations in Government Information Networks. First, the analysis provided an empirically based validation and revision of the implications specified in the theoretical framework which had been identified from the literature review in Chapter 2 . Most of the determinants related to Results and Adoption Efforts were confirmed, validating the majority of the preliminary framework. However, the analysis also was able to significantly revise the framework by contesting several determinants that had been previously specified, and by adding several new determinant concepts that were identified inductively based on the data. Moreover, the analysis identified a range of conceptual elements ("attributes") for the key implications variables that had previously been unaccounted for (see Annex A and Annex E). 
As the analysis highlighted, the different IOP standards have an impact on various attributes of the partner organisations' operations and strategy, and require various types of organisational change from them. Based on the frequencies with which individual implications were mentioned in the interviews, the analysis in Section 4.3 provided guidance as to which of these areas are most salient and need to receive particular attention in IOP governance.

A key finding in this regard is that stakeholders seem to reason primarily according to an organisation-centric functionalist logic (with an emphasis on the short-term implications for their own organisation), rather than in network-wide longer-term visions and institutional development. In particular, with regard to results from adoption, the analysis has found that Internal-Operations Results are much more frequently mentioned than any other category. Whilst External-Relations Results of IOP standards adoption are certainly not unimportant to stakeholders, the former is clearly more of a key concern and needs to be targeted as such by any IOP governance body. Here, it is in particular the dimensions of Efficiency and Effectiveness that are of the biggest relevance. Whilst this confirms the general tenor in the egovernance literature highlighting these as key benefits, in particular with regard to reduction of administrative costs and the improvement of service quality, the analysis here also identified a caveat to this picture since it has shown that in the long run, the pursuit of achieving IOP can also contribute to cost increases and even the deterioration of service quality. In policy practice, this possibility for decreasing efficiency and effectiveness should become much more prominent in the planning and governance of IOP in Government Information Networks.

In terms of Adoption Efforts, the largest role for stakeholders at the organisational level seems to be played by Organisational Efforts. This is in line with the above-mentioned observation that organisational IOP plays the largest role for network-level managers, and suggests that this type of implications from IOP adoption needs to be a specific target area for IOP governance. However, the analysis also has shown that there are interrelations between various effort categories, for instance between semantic and technological efforts. IOP governance thus also needs to carefully address these interlinkages by means of a holistic governance design. This necessitates not only taking into account positive associations between types of implications, but also the possible trade-offs between them: as shown by the substantial number of co-occurrences between Adoption Efforts and Results quotations, by the inductive identification of the Return-on-Investment Results sub-construct, and by the interpretive analysis of interviewees' statements in this context, adoption efforts are typically weighed by organisational stakeholders against the possible benefits from IOP standards adoption.

The analysis of stakeholders' evaluation of IOP standards adoption has shown that the stakeholders evaluate the various types of implications with different degrees of positive and negative evaluations. In other words, they have a more negative stance towards adoption implications in some areas, which suggests that there also is stronger resistance to change in these areas. For IOP governance, this implies that "resistance to change" is a more nuanced picture that requires a more targeted approach to those areas where opposition is strongest. This is especially so since the findings also indicate that stakeholders in the 
organisations do have an understanding that certain efforts are inevitable when wanting to reap benefits from IOP standards in the long run, and thus are not generally "hostile" against IOP standards adoption across all areas. In the same vein, the significant number of negative evaluations for various Results implications suggests that the results from adoption should not be taken as synonymous with "benefits from adoption". A potentially concerning finding is that among those interviewees that were at a governing (i.e. networklevel) position in the studied Government Information Networks, there were more negative than positive evaluations. While this could mean that there is scepticism about the implications of IOP adoption among those governing it, it could also indicate that they are simply more aware of critical issues around the implications of IOP adoption.

To address the third sub-question, the chapter aimed to "un-blackbox" the IOP standards adoption process, and to investigate what kinds of actors play which roles along this process. In both cases, the analysis has shown that the standards adoption process was an interaction between multiple actors that can be grouped under three main categories: two intra-organisational actor categories (management-level actors and operational-level actors), as well as inter-organisational actors. The findings on the role of these actors have at least three major implications for IOP governance.

First, the analysis has shown clearly that network-level infomediaries, in particular network brokers, play a very important role for IOP standards adoption, at least currently in the selected case studies. However, the respondents also mentioned (in considerable frequencies) other actors as playing a role for adoption. One important conclusion for IOP governance is thus that it needs to approach IOP standards adoption as a concerted interplay of actors, and based on thorough stakeholder analyses, to set up a governance approach that facilitates this interaction in an effective manner. This is particularly relevant with regard to the next two points.

Second, IOP governance needs to take into account the finding that an organisation's toplevel management's decisions play a central role for the adoption of IOP standards in their organisations, and that this decision formation is based on their weighing of costs and benefits of this for their organisation. Whilst the implications discussed in this chapter have a crucial influence on this, Chapter 5 will address the wider range of determinants for this decision formation in more detail.

Thirdly, not all decisions on all standards are always taken by the same actor, and the organisational board is not the only intra-organisational actor that IOP governance should take into account. Whilst the top management in the organisation certainly needs to be committed to a certain standard, the actual adoption decision may also be taken at a lower level. And even when the organisational board has endorsed a specific IOP standard, the operational level still has a significant impact on its actual adoption and compliance. Again, this means that IOP governance needs to take into account the range of determinants that influence adoption decisions at all levels in the organisation (which will also be addressed in Chapter 5). The identification of the range of actors in the adoption process, as well as the development of a validated framework of adoption determinants (including adoption implications) provided in this and the next chapter makes an important addition to the existing theory on these two issues (discussed in Chapter 2 and Section 4.4.1 respectively). 
The chapter also aimed at providing a better understanding of the nature of IOP standards adoption processes in the two case studies. It confirmed that standards adoption can be analysed with frameworks that present it as a sequential process that consists of various phases. Whilst there are different such models that each specify different phases, the chapter made the argument that their commonality is a separation of two major parts: the phases prior to the adoption decision (including Knowledge, Awareness, Trial, Persuasion), and the post adoption-decision phases (including Implementation and Confirmation). The phase prior to the adoption decision in the case studies is where the initial decision adoption is formed, based on the range of determinants (which may be explored through deliberation, or even trialing of the standards).

However, the phase after the adoption decision was shown to play an important role for IOP as well, as it is here where the implications of IOP standards adoption determine whether (and how) organisations will comply with the standards over time. Three phases were proposed to analyse this part of IOP standards adoption: planning, implementation, and operational phases. The most significant in terms of implications are the planning and operational phases, which implies that significant consideration is given to implications from IOP standards when planning for their implementation. However, the finding that the operational phase takes the largest share indicates that many of the implications materialise only at this point in a project. For IOP governance, this means that a major part of attention should focus on this point at which non-compliance might manifest itself. A tricky issue here is the finding that such non-compliance is seldom explicit and can possibly go unnoticed for a considerable period of time, with potentially detrimental consequences for the entire Government Information Network. IOP governance thus needs to monitor adoption and compliance with particular care at this stage.

In conclusion, this chapter has shown that IOP standards adoption is a process in which the interaction and (individual and joint) decisions of multiple actors have to be well aligned, and need to be steered over an extended period of time with a targeted as well as holistic view on the various determinants that influence these decisions. The direct implications from IOP standards adoption are a key factor, but only one part of these determinants. The following chapter will take into account the other determinants playing a role at organisational and network levels in order to provide the larger picture. 


\section{Annex A. Detailed Results from the Content Analysis of Adoption Implications}

This section presents the full detail of results from the content analysis on adoption implications, which has been discussed in a summarised form in Section 4.3 of Chapter 4 . The presentation of results here closely follows the theoretical framework introduced in Chapter 2. To provide an orientation for the reader through the layered conceptual structure of this framework, a schematic overview of the constructs, sub-constructs, dimensions and variables $^{101}$ discussed in the following sections is provided by Figure 4.4 in Chapter 4 .

This annex is structured as follows. First, an overview is given and general observations are provided, before discussing the individual implications and their significance for organisational stakeholders in more detail one by one: Results are discussed in Section A2 (Internal-Operations Results), Section A3 (External-Relations Results), Section A4 (Return-onInvestment Results), and Section A5 (Network-Level Results). This is followed by a discussion of Adoption Efforts: Organisational Efforts in Section A6, Technological Efforts in Section A7, Semantic Efforts in Section A8, Legal Efforts in Section A9, and Resource Costs in Section A10.

\section{A1. Overview}

Figure Annex A.1 below shows the aggregated frequencies ${ }^{102}$ for all implications at the level of constructs (Figure Annex A.1a), and at the level of sub-constructs (Figure Annex A.1b for Adoption Efforts and Figure Annex A.1c for Results). Figure Annex A.1a shows that a majority of quotations (57\%) in the interviews was coded with codes belonging to the Results construct, which suggests that the interviewed stakeholders are slightly more concerned with the results from IOP standards adoption than with the efforts for adoption.

We can observe some general patterns across Efforts and Results constructs when looking at how often interviewees were mentioning particular Efforts and Results sub-constructs in Figure Annex A.1b and Figure Annex A.1c. Figure Annex A.1b shows the aggregated frequencies for Adoption Efforts sub-constructs. One additional sub-construct, Semantic Efforts, was identified inductively from the case study data. ${ }^{103}$ It is defined and discussed in Section A8 below. The figure shows that among all Adoption Efforts sub-constructs, Organisational Efforts are the most-often mentioned (44\%), followed by Technological Efforts (27\%), Resource Costs (18\%), Semantic Efforts (6\%) and Legal Efforts (5\%).

Figure Annex A.1c shows the aggregated frequencies for the Results sub-constructs. Two additional sub-constructs have been identified inductively from the case study data: Returnon-Investment Results and Network-Level Results. They are defined and discussed in Sections

\footnotetext{
${ }^{101}$ This four-level conceptual hierarchy of the conceptual model is introduced in Section 2.4.

${ }^{102}$ See the footnote in Section 4.3.1 regarding the calculation of aggregated frequencies.

${ }^{103}$ The method used for inductive identification of additional determinants is described in Section 3.4. All inductively identified determinants (sub-constructs, dimensions and variables) are labelled as "new" in the summary tables of Chapter 4 (Table 4.2 and Table 4.3) and Chapter 5 (Table 5.1 through Table 5.6).
} 
A4 and A5, respectively. Concerning the main (top-level) Results sub-constructs, it is striking that Internal-Operations Results are much more frequently mentioned by stakeholders than any other sub-construct, making for roughly three quarters of the total amount of resultsrelated codes (72\%). The remaining quarter is dominated by External-Relations Results (16\%), and to a lesser degree (9\%) by Return-on-Investment Results. Only a small fraction of quotations concerns the Network-Level Results of IOP standards adoption (3\%).

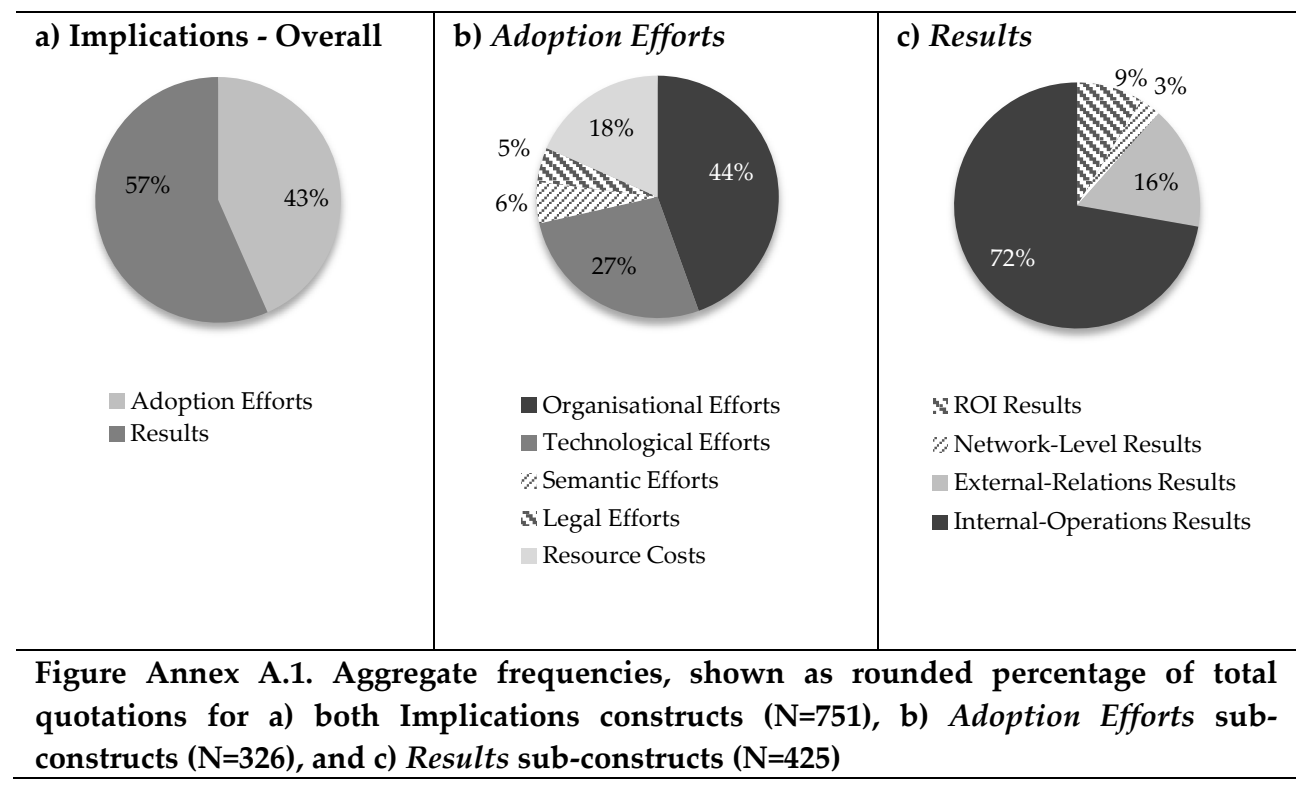

In the following, the individual implications dimensions and their significance for organisational stakeholders will be discussed in more detail, following the structure laid out at the beginning of this section. The discussion follows the conceptual hierarchy of constructs, sub-constructs, dimensions and variables as introduced in Chapter 2 (Section 2.4). For each of the constructs, sub-constructs and dimensions discussed, first their definition from the theoretical framework is given, followed by a discussion of the relative distributions of their sub-dimensions. It should be noted that for reasons of streamlined focus and readability, the depth of empirical detail in the discussion of implications at the level of variables is filtered by a selective approach: first, rather than presenting an in-depth discussion of all individual variables, the discussion focuses on the higher-level concepts (constructs, sub-constructs and dimensions). At the variables-level, only the top two ${ }^{104}$ variables for each dimension are discussed in more detail, whereas the results for the remaining variables for that dimension are only presented in the figures. And second, the discussion of implications in the following sections limits itself to briefly presenting and describing in more detail for each variable its conceptual elements that were identified

104 "Top two" means those variables that were the most frequently mentioned within that dimension. In those cases where two variables within the same dimension had an identical or highly similar frequency of quotations, a choice was made for the one where the most aspects were identified in the analysis. 
through the analysis (in the following termed "attributes"). ${ }^{105}$ For the interested reader, a more detailed discussion of these attributes with illustrative data from the cases can be found in Annex E. 106

\section{A2. Internal-Operations Results}

The Internal-Operations Results sub-construct was defined as the consequences resulting from the adoption of IOP standards on the organisation's internal operations (see Table 2.21).

One additional dimension was identified inductively from the case study data: Internal Autonomy. It is defined and discussed in Section A2.4 below. As Table Annex A.1 below shows, the frequencies with which the listed internal-operations results ${ }^{107}$ were mentioned by the interviewees do not show huge variation: except for Coordination (6\%), their share of quotations ranges between 13\% (Resource Acquisition) and 27\% (Efficiency). Overall, it thus seems that (almost) all internal-operations results are of significant relevance for the stakeholders. The individual dimensions for Internal-Operations Results are discussed in the following sections.

\begin{tabular}{|l|r|}
\hline Dimension & Percentage (N=307) \\
\hline Efficiency & 27 \\
\hline Effectiveness & 21 \\
\hline Data Management & 17 \\
\hline Internal Autonomy & 16 \\
\hline Resource Acquisition & 13 \\
\hline Coordination & 6 \\
\hline
\end{tabular}

Table Annex A.1. Internal-Operations Results dimensions (aggregated frequencies per dimension, shown as rounded percentage of total quotations for Internal-Operations Results, N=307)

\section{A2.1. Efficiency}

The Efficiency dimension was defined as the effects from IOP standards adoption on the organisation's input-output ratio (see Table 2.21).

As shown in Figure Annex A.2, Efficiency results are (by a margin of 5\%) the most often mentioned results related to an organisation's internal operations. Within this dimension, the two most frequently addressed issues are Operations Costs (53\%) and Usability (24\%) -

\footnotetext{
${ }^{105}$ Furthermore, the reader is advised to keep in mind that attributes are defined as the "conceptual elements of a given determinant". As such, they generally are only specified at the conceptual level of variables (all other levels in the theoretical framework have subordinate conceptual levels), but should not be conceived of as a $5^{\text {th }}$ conceptual level. Hence, for those few sub-constructs and dimensions where no subordinate levels were specified in Chapter 2, "attributes" are here specified at these higher conceptual levels.

${ }^{106}$ It should also be noted that the list of attributes identified for each variable makes no claim to be exhaustive: rather, these are all the attributes that were mentioned by interviewees in the studied cases. Whilst the in-depth nature of the interviews was used as strategy to guarantee the broadest possible coverage of salient issues, it is not possible to exclude that there may be other aspects that were simply nevertheless not mentioned in this set of interviews.

${ }^{107}$ The reader is reminded that the convention used in this dissertation is to highlight the determinants in capitals and italics when referring to them as analytical category (e.g. as a code), whilst in all other instances the concept itself is written in normal font.
} 
both discussed in the sections below. Operations Speed, however, seems to be almost equally relevant (23\%).

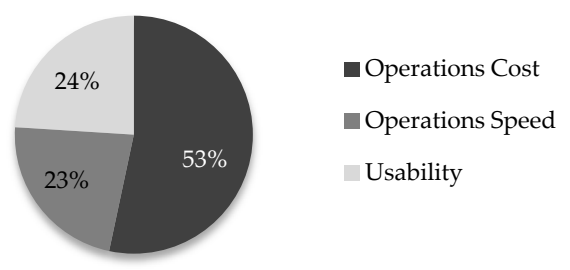

\footnotetext{
Figure Annex A.2. Efficiency variables (frequencies per variable, shown as rounded percentage of total quotations for Efficiency, $\mathrm{N}=75$ )
}

\section{A2.1.1. Operations Costs}

Operations Costs was defined as the effects of IOP standards adoption on the costs of operations in the organisation (see Table 2.21). One attribute of this variable which was mentioned frequently by interviewees are financial cost savings that result from IOP standards adoption. In fact, some interviewees mentioned this as the most important determinant overall (Q24:60). Cost savings mentioned in the interviews are also not only purely financial, but also concern time savings (Q24:33). As IOP standards adoption can enable the automation of previously manual control activities, fewer monitoring activities might be needed. Similar to time savings, human resource costs can be reduced due to administrative burden reduction (Q29:7). Furthermore, interviewees reported material and hardware cost savings as a result from adopting the IOP standards, for instance cost savings related to mailings and archiving as a result from switching from paper-based processes to electronic information exchange (Q26:19).

Interviewees also mentioned opportunity costs that can result from non-adoption, such as costs for conversion that may arise in situations when many partners in the network are already using a given standard (Q7:35). However, operations costs were reported by interviewees not only as a matter of saving cost - in fact, costs can possibly also rise as a result from IOP standards adoption, for instance when the improved services result in increased client requests (Q30:17).

\begin{tabular}{|c|c|}
\hline Definition & The effects of IOP standards adoption on the costs of operations in the organisation \\
\hline \multicolumn{2}{|l|}{ Attributes for this variable } \\
\hline Financial Cost & $\begin{array}{l}\text { Effects on financial costs as a result from IOP standards adoption (e.g. savings } \\
\text { resulting from economies of scale) }\end{array}$ \\
\hline Time Cost & $\begin{array}{l}\text { Effects on time costs (i.e. man hours) as a result from IOP standards adoption (e.g. by } \\
\text { enabling automation of previously manual processes) }\end{array}$ \\
\hline Human Resource Cost & $\begin{array}{l}\text { Effects on human resource costs (e.g. salaries) as a result from IOP standards } \\
\text { adoption (e.g. savings due to process simplification and time savings) }\end{array}$ \\
\hline Material/Hardware Cost & $\begin{array}{l}\text { Effects on material and hardware costs as a result from IOP standards adoption (e.g. } \\
\text { mailing and archiving costs) }\end{array}$ \\
\hline $\begin{array}{l}\text { Opportunity Costs from } \\
\text { Non-Adoption }\end{array}$ & $\begin{array}{l}\text { Opportunity costs that may arise from non-adoption (e.g. conversion costs when the } \\
\text { partners in the network are already using the standard) }\end{array}$ \\
\hline
\end{tabular}

Table Annex A.2. Operations Costs variable (definitions of variable and its attributes) 


\section{A2.1.2. Usability}

Usability was defined as the effects from IOP standards adoption on the ease of use and handling of organisation-internal systems (see Table 2.21). One attribute of Usability is that when the information exchange in the network makes client data readily available for partner organisations, IOP standards adoption is seen as providing a big usability benefit for organisations (Q31:12). As the interviews showed, the increased usability is also due to the process simplification resulting from IOP adoption (Q19:10). For instance, previously necessary work steps can become obsolete, either because they are taken over by other organisations, or because they are taken over by automation. Not only can the processes become simplified, but interviewees also reported that the interfaces can become less complex (Q4:21). Furthermore, due to the reduction of paper-based processes, standardsbased digital data supply can reduce burdensome regulation on paper archives (Q36:11).

\begin{tabular}{|c|c|}
\hline \multicolumn{2}{|l|}{ Usability } \\
\hline Definition & $\begin{array}{l}\text { The effects from IOP standards adoption on the ease of use and handling of organisation- } \\
\text { internal systems }\end{array}$ \\
\hline \multicolumn{2}{|c|}{ Attributes for this variable } \\
\hline $\begin{array}{l}\text { Availability of Client } \\
\text { Data }\end{array}$ & $\begin{array}{l}\text { Effects on availability of client data (e.g. forms that are pre-filled without requiring case } \\
\text { workers to file requests with other data sources) }\end{array}$ \\
\hline Process Complexity & $\begin{array}{l}\text { Effects on number and length of work steps (e.g. shortening or eradicating steps as a } \\
\text { result from automating or sharing processes with others) }\end{array}$ \\
\hline Interface Complexity & $\begin{array}{l}\text { Effects on the complexity of user interfaces (e.g. simplification as a result from integration } \\
\text { of previously separate interfaces into joint applications) }\end{array}$ \\
\hline $\begin{array}{l}\text { Archiving } \\
\text { Complexity }\end{array}$ & $\begin{array}{l}\text { Effects on archiving procedures (e.g. replacement of paper archives with electronic } \\
\text { archives) }\end{array}$ \\
\hline
\end{tabular}

Table Annex A.3. Usability variable (definitions of variable and its attributes)

\section{A2.2. Data Management}

The Data Management dimension was defined as the effects from IOP standards adoption on data management in the organisation (see Table 2.21). The two most frequently addressed issues in this dimension are Data Quality (by a large margin, 61\%) and Data Security (21\%). Data Processing Reliability, however, seems to be almost equally relevant (18\%).

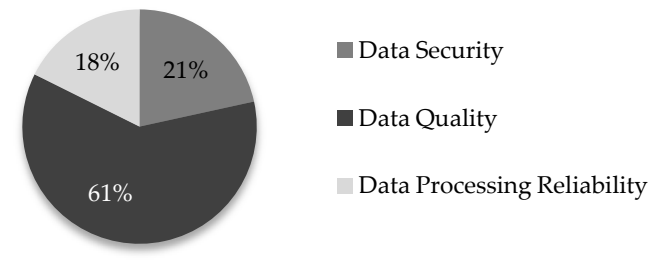

Figure Annex A.3. Data Management variables (frequencies per variable, shown as rounded percentage of total quotations for Data Management, $\mathrm{N}=51$ )

\section{A2.2.1. Data Quality}

Data Quality was defined as the effect of IOP standards adoption on client and program information quality, including comprehensiveness and consistency (see Table 2.21). 
One key attribute mentioned here is that the specification of minimum data quality requirements can significantly enhance the overall network-wide information quality (Q24:32). Interviewees also mentioned that the information exchange in the network raises the awareness in partner organisations for the mutual importance of data quality, thus also enhancing data quality practices (Q15:9). Another attribute of better data quality is that IOP standards adoption is reported to affect the reliability of data, since the connection with other data sources facilitates corroboration and consistency checks on data authenticity (Q4:22). Next to this, as a result of IOP-enabled information exchange, the available information is expected by respondents to be more up-to-date and timely (Q30:31).

However, interviewees also pointed out that having all data completely up-to-date is rather utopian, also because the clients themselves often have more updated information than is registered in the databases (Q1:30). Respondents thus voiced critical concerns in relation to the increased dependency of their own organisation on others' accurate data entry (Q10:8). In a situation of automated information exchange, this can create substantial problems.

\begin{tabular}{|c|c|}
\hline \multicolumn{2}{|l|}{ Data Quality } \\
\hline Definition & $\begin{array}{l}\text { The effect of IOP standards adoption on client and program information quality, } \\
\text { including comprehensiveness and consistency }\end{array}$ \\
\hline \multicolumn{2}{|l|}{ Attributes for this variable } \\
\hline $\begin{array}{l}\text { Data Quality } \\
\text { Requirements }\end{array}$ & $\begin{array}{l}\text { Effects on data quality as a result from requirements about minimum data quality } \\
\text { (e.g. quality enhancement through audit requirements) }\end{array}$ \\
\hline Data Quality Awareness & Effects on awareness in organisations for the mutual importance of data quality \\
\hline Data Reliability & $\begin{array}{l}\text { Effects on reliability of data in terms of authenticity and consistency (e.g. enhanced } \\
\text { reliability through mutual data corroboration) }\end{array}$ \\
\hline Data Timeliness & $\begin{array}{l}\text { Effects on how accurately organisations' data reflects the current reality (e.g. } \\
\text { enhanced timeliness due to standardised data entry processes) }\end{array}$ \\
\hline Data Quality Dependency & $\begin{array}{l}\text { Effects on the dependency on partners' data quality (e.g. when using data that has } \\
\text { been combined from various sources) }\end{array}$ \\
\hline
\end{tabular}

Table Annex A.4. Data Quality variable (definitions of variable and its attributes)

\section{A2.2.2. Data Security}

Data Security can be defined as the effects of IOP standards adoption on safeguarding the security and privacy of exchanged information (see Table 2.21). One key attribute of this are the potential implications in terms of data abuse, for instance the possibility that the data is used beyond the legal mandate or the intended purpose. Security standards are aimed at safeguarding data security and prevent such abuse. However, interviewees also pointed out that when such standards are not complied with, the electronic information exchange in fact actually gives greater potential for data abuse (Q6:3). An additional problem is that there is a risk of losing control over privacy protection (Q14:13).

\begin{tabular}{|l|l|}
\hline Data Security & $\begin{array}{l}\text { The effects of IOP standards adoption on safeguarding the security and privacy of exchanged } \\
\text { information }\end{array}$ \\
\hline Attributes for this variable \\
\hline Data Abuse & $\begin{array}{l}\text { Effects in terms of the legitimacy of use of the shared (e.g. checking clients' data without } \\
\text { authorisation or mandate) }\end{array}$ \\
\hline Control Loss & $\begin{array}{l}\text { Effects on control over protection of privacy (e.g. less control over privacy protection as data } \\
\text { owned by the organisation is shared with, and used by external partners) }\end{array}$ \\
\hline
\end{tabular}

Table Annex A.5. Data Security variable (definitions of variable and its attributes) 


\section{A2.3. Effectiveness}

The Effectiveness dimension was defined as the effects from IOP standards adoption on the output of the organisation (see Table 2.21). The addressed variables in this dimension are (in order of the frequency of their quotations): Service Quality (by a vast margin, 63\%), Policy Contribution (15\%), Responsiveness (14\%), Problem-Solving (6\%) and Innovation Catalyst (2\%). The latter is a variable that was added based on the inductive coding round of the interview data, and refers to the effects of IOP adoption as a kick-start and accelerator for triggering innovation in the organisation, such as for instance new services. ${ }^{108}$ However, it only seems to play a minor role.

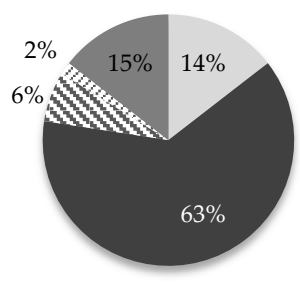

$$
\begin{aligned}
& \text { Responsiveness } \\
& \text { Service Quality } \\
& \text { \% Problem-Solving } \\
& \text { Innovation Catalyst } \\
& \text { Policy Contribution }
\end{aligned}
$$

Figure Annex A.4. Effectiveness variables (frequencies per variable, shown as rounded percentage of total quotations for Effectiveness, $\mathrm{N}=62$ )

\section{A2.3.1. Service Quality}

Service Quality was defined as the effects of IOP standards adoption on the quality of service provision to clients (see Table 2.21). A key service improvement that interviewees see as resulting from IOP standards adoption is the burden reduction for clients, for instance that services can be provided much faster (Q10:2). Furthermore, respondents stated that clients

\begin{tabular}{|c|c|}
\hline Definition & The effects of IOP standards adoption on the quality of service provision to clients \\
\hline \multicolumn{2}{|c|}{ Attributes for this variable } \\
\hline $\begin{array}{l}\text { Administrative Burden } \\
\text { for Clients }\end{array}$ & $\begin{array}{l}\text { Ease of receiving services for clients (e.g. burden reduction through faster access and } \\
\text { service provision) }\end{array}$ \\
\hline Integrated Services & $\begin{array}{l}\text { Integrated front-offices through back-office integration (e.g. single office or portal for } \\
\text { inter-organisational service provision) }\end{array}$ \\
\hline Targeting of Services & $\begin{array}{l}\text { Effects on targeting of service provision (e.g. more context-aware services as a result of } \\
\text { better information availability for service providers) }\end{array}$ \\
\hline
\end{tabular}
have to spend less time and effort due to the integrated nature of service delivery (Q10:16). Another outcome mentioned is that as a result of ready availability of background information on a client from partners' databases, service provision can become more targeted and informed (Q9:16).

Table Annex A.6. Service Quality variable (definitions of variable and its attributes)

\footnotetext{
${ }^{108}$ For example, one of the main objectives of Studielink is to provide a platform for future innovation in the higher education sector. Another illustrative example from the DKD case is that one interviewee for instance reported that their organisation's primary reason for participating in the network is simply to stay involved in innovative developments across the government, much more than the DKD's official objectives (Q18:5).
} 
However, the picture painted by the interviewees is not only positive, as the service towards customers does not necessarily improve for all organisations as a result of standardisation. For instance, organisations have different types of constituencies with different needs, which are possibly not equally well served by a standardised service (Q31:4).

\section{A2.3.2. Responsiveness}

Responsiveness has been defined as the fast and effective reaction of an organisation to problems and tasks (see Table 2.21). A key attribute of Responsiveness that interviewees discussed is the ability to react more quickly and provide services faster with less waiting time (Q15:9). Furthermore, as a result of widening the information base, IOP standards adoption may also result in the ability to act proactively without the need to be prompted by a client request (Q19:13). IOP standards adoption also can allow to have earlier contact with clients, for instance in order to provide information early on (Q26:4).

\begin{tabular}{|c|c|}
\hline \multicolumn{2}{|l|}{ Responsiveness } \\
\hline Definition & Fast and effective reaction of an organisation to problems and tasks \\
\hline \multicolumn{2}{|c|}{ Attributes for this variable } \\
\hline Speed of Reaction & $\begin{array}{l}\text { Speed of reaction to service requests (e.g. reduced waiting time for clients due to online } \\
\text { portals replacing information exchange by post) }\end{array}$ \\
\hline Proactive Action & Servicing clients without being prompted by the client \\
\hline Early Contact & $\begin{array}{l}\text { How early contact with clients and service provision can be initiated (e.g. earlier } \\
\text { information provision through online channels) }\end{array}$ \\
\hline
\end{tabular}

Table Annex A.7. Responsiveness variable (definitions of variable and its attributes)

\section{A2.4. Internal Autonomy}

The Internal Autonomy dimension has been inductively derived from the data and was thus not included in the preliminary model presented in Chapter 2. The Internal Autonomy dimension can be defined as the effects from IOP standards adoption in terms of autonomous internal action, including the implications for the organisation's flexibility to change its structure or processes. The dimension has not been further divided into individual variables.

A key attribute of Internal Autonomy is the loss of internal control as a result from IOP standards adoption, for instance with regard to control over the contact with clients (Q14:25). Implied in this is that organisation-specific idiosyncratic problem-solving approaches can get lost, since local conditions create problem interpretations and objectives that can differ from the network-wide standards (Q30:5).

Loss of autonomy is also observed with regard to internal change management, for instance because organisations might have to comply with standardised change procedures such as collective impact analyses (Q11:4). By imposing fixed release schedules, the network-wide change management approach not only restricts organisations in terms of what changes they may implement, but also in terms of when they may implement such changes. Interviewees also mentioned the loss of control over external relations management as an implication from IOP standards adoption in relation to internal autonomy (Q20:10). 
Another such implication which is perceived by partner organisations in the cases is that there can be a future loss of autonomy, by being "locked in" to subsequent standardisations once they have adopted a standard (Q14:21). However, while the interviews showed some clear reservations from organisations about autonomy losses, many interviewees also simultaneously signalled an understanding for the necessity of such autonomy losses if the benefits from the network are to be reaped (Q16:16). Ultimately, it seems, the willingness to incur autonomy losses is not just a matter of expected benefits, but also of how these benefits are weighed against the expected efforts that come with it (Q24:19).

\begin{tabular}{|l|l|}
\hline \multicolumn{2}{|l|}{ Internal Autonomy } \\
Definition & $\begin{array}{l}\text { The effects from IOP standards adoption in terms of autonomous internal action, } \\
\text { including the effect on the organisation's flexibility to change its structure or processes }\end{array}$ \\
\hline Attributes for this variable \\
\hline Internal Control & Effects on control over processes within the own organisation \\
\hline $\begin{array}{l}\text { Idiosyncratic } \\
\text { Approaches }\end{array}$ & $\begin{array}{l}\text { Effects on strategies and processes that are tailored to local conditions, interpretations } \\
\text { and objectives }\end{array}$ \\
\hline $\begin{array}{l}\text { Internal Change } \\
\text { Management }\end{array}$ & $\begin{array}{l}\text { Effects on internal procedures and timing for managing change (e.g. as a result of fixed } \\
\text { release schedules and collective impact procedures) }\end{array}$ \\
\hline $\begin{array}{l}\text { External Relations } \\
\text { Management }\end{array}$ & $\begin{array}{l}\text { Effects on designing and maintaining external relations and obligations (e.g. difficulties } \\
\text { to uphold previously made agreements) }\end{array}$ \\
\hline Future Autonomy & $\begin{array}{l}\text { Effects on future autonomy (e.g. getting on a path dependency where initial adoption } \\
\text { implies subsequent autonomy impacts in the future) }\end{array}$ \\
\hline $\begin{array}{l}\text { Understanding for } \\
\text { Autonomy Impacts }\end{array}$ & Willingness to incur autonomy impacts as an investment in receiving (future) benefits \\
\hline
\end{tabular}

Table Annex A.8. Internal Autonomy variable (definitions of variable and its attributes)

\section{A2.5. Resource Acquisition}

The Resource Acquisition dimension has been defined as the effect of IOP standards adoption on an organisation's access to complementary resources (see Table 2.21). Of its three variables specified based on the literature (Expertise Acquisition, Information Acquisition, and Financial Resources Acquisition) only the latter two were mentioned by the interviewees. The Expertise Acquisition variable was not confirmed in the data from the cases. Of the variables that were mentioned, Information Acquisition accounts for a much higher share of quotations in this dimension (62\%), as compared to Financial Resources Acquisition (38\%).

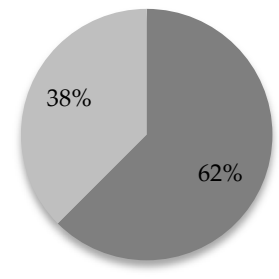

Information Acquisition

Financial Resources

Acquisition

Figure Annex A.5. Resource Acquisition variables (frequencies per variable, shown as rounded percentage of total quotations for Resource Acquisition, N=40) 


\section{A2.5.1. Information Acquisition}

Information Acquisition was defined as the effects of IOP standards adoption on accessibility of information (see Table 2.21).

A key implication that can be identified from the quotations for this variable is the possibility of automated information provision, rendering manual information retrieval unnecessary (Q4:24). Interviewees also mentioned as an implication that as a result of becoming more interoperable with partners, there is more timely information accessible for their organisations (Q12:17). In addition, respondents mentioned access to more complete information, which allowed their organisations to have an encompassing picture of their clients from the beginning (Q19:6). Finally, IOP standards adoption is also seen as resulting in the provision of richer management information about their own organisation, thus allowing better internal analyses (Q34:9).

\begin{tabular}{|c|c|}
\hline Definition & The effects of IOP standards adoption on accessibility of information \\
\hline \multicolumn{2}{|l|}{ Attributes for this variable } \\
\hline $\begin{array}{l}\text { Automated Information } \\
\text { Provision }\end{array}$ & $\begin{array}{l}\text { Replacement of manual information retrieval by automated processes (e.g. by means } \\
\text { of pre-filled forms) }\end{array}$ \\
\hline $\begin{array}{l}\text { Timeliness of } \\
\text { Information }\end{array}$ & $\begin{array}{l}\text { Effects on the degree to which information reflects current reality (e.g. up-to-date } \\
\text { client information through live data links) }\end{array}$ \\
\hline $\begin{array}{l}\text { Completeness of } \\
\text { Information }\end{array}$ & $\begin{array}{l}\text { Effects on the range of accessible information on clients (e.g. providing a more } \\
\text { complete picture of the client due to data exchange) }\end{array}$ \\
\hline $\begin{array}{l}\text { Management } \\
\text { Information }\end{array}$ & $\begin{array}{l}\text { Management information that allows for analyses of relevant structures and processes } \\
\text { (e.g. in the own organisation) }\end{array}$ \\
\hline
\end{tabular}

Table Annex A.9. Information Acquisition variable (definitions of variable and its attributes)

\section{A2.5.2. Financial Resources Acquisition}

Financial Resources Acquisition has been defined as the effects of IOP standards adoption on the organisation's access to financial resources (see Table 2.21).

One way in which adoption can contribute to acquisition of financial resources is by making the organisation more effective. On the one hand, this means that organisations may run less risk of losing money (Q22:12). On the other hand, becoming more effective can also mean being able to acquire resources faster (Q24:6). Next to acquisition of more financial resources, IOP standards adoption was also mentioned in the interviews as a means to safeguard the status quo of financial resource acquisition - or rather that conversely, noncompliance can also mean that previously guaranteed resources or benefits are not available any more unless new processes are complied with (Q31:7).

At the same time, however, it should be mentioned that these benefits are not evenly distributed across all organisations in the network (Q27:11). Furthermore, it was also mentioned in the interviews that the return on investment for the adoption of IOP standards can also come with considerable delay (Q26:22). Finally, IOP standards adoption can possibly also create a potential for revenue losses if data exchange in the network is not functioning properly (Q24:38). 


\begin{tabular}{|l|l|}
\hline \multicolumn{2}{|l|}{ Financial Resources Acquisition } \\
\hline Definition & The effects of IOP standards adoption on the organisation's access to financial resources \\
\hline Attributes for this variable \\
\hline Financial Risk & $\begin{array}{l}\text { Effects on the risk of losing financial resources (e.g. through enhanced monitoring and } \\
\text { detection of flawed or fraudulent processes) }\end{array}$ \\
\hline $\begin{array}{l}\text { Speed of Resource } \\
\text { Acquisition }\end{array}$ & Effects on the speed of acquiring resources (e.g. faster revenue collection) \\
\hline Safeguard Status Quo & $\begin{array}{l}\text { Effects on the risk of losing previously secure resources (e.g. loss of previously } \\
\text { guaranteed benefits in case of non-compliance) }\end{array}$ \\
\hline $\begin{array}{l}\text { Return-on-Investment } \\
\text { Distribution }\end{array}$ & $\begin{array}{l}\text { Equality of the distribution of financial return-on-investment (e.g. some organisations } \\
\text { having higher returns than others) }\end{array}$ \\
\hline $\begin{array}{l}\text { Return-on-Investment } \\
\text { Timeliness }\end{array}$ & $\begin{array}{l}\text { Timeliness of financial return-on-investment (e.g. delays in reaping the financial } \\
\text { benefits from investments) }\end{array}$ \\
\hline Revenue Loss & Effects related to the potential for losing revenue \\
\hline
\end{tabular}

Table Annex A.10. Financial Resources Acquisition variable (definitions of variable and its attributes)

\section{A2.6. Coordination}

The Coordination dimension has been defined as the effect of IOP standards adoption on the coordination of programmes and services (see Table 2.21). The variables for this dimension, as identified in Chapter 2, were Goal Clarification, Uncertainty Reduction, and Reporting. Of these, the interviewees only mentioned the latter two, with a large majority of quotations related to Reporting (63\%), and the smaller share to Uncertainty Reduction (37\%). The Goal Clarification variable was not confirmed by the case study data. ${ }^{109}$ It should be noted that overall, this dimension only yielded a relatively small number of quotations (19 in total). ${ }^{110}$

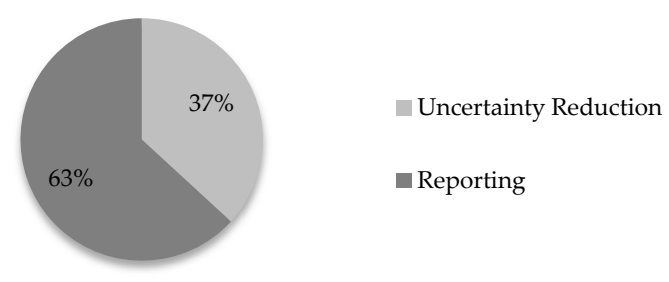

Figure Annex A.6. Coordination variables (frequencies per variable, shown as rounded percentage of total quotations for Coordination, $\mathrm{N}=19$ )

\section{A2.6.1. Reporting}

Reporting was defined as the effects of IOP standards adoption on reporting and decision support (see Table 2.21).

\footnotetext{
${ }^{109}$ The method used for exclusion of previously specified determinants from the model is described in Section 3.4 in Chapter 3. All non-confirmed determinants are presented in Table 4.2 (Results), Table 4.3 (Adoption Efforts), Table 5.1 (IOP Governance), Table 5.2 (Network Characteristics) and Table 5.5 (Organisation-Specific Determinants).

${ }^{110}$ As explained in more detail in Section 3.4, "small" amounts of quotations are here regarded as any number of quotations below 30 . They are considered as too small to make any claims of significant differences, and should be regarded as purely indicative.
} 
The central attribute that interviewees mentioned for this variable is that IOP standards adoption can make a wider range of reporting data available to their organisation, because it allows to access information held by other organisations (Q31:7). Furthermore, the pooling of data on clients enables organisations to tap on valuable management information (Q34:9). The sharing of information may not only provide access to a wider range and updated information, but interviewees also pointed out that it can provide the potential to have a clearer and more centralised organisation of the reporting data (Q30:18).

\begin{tabular}{|l|l|}
\hline Reporting & The effect of IOP standards adoption on reporting and decision support \\
\hline Definition & $\begin{array}{l}\text { Effects in terms of the range of reporting data that is available to an organisation (e.g. } \\
\text { wider range due to access to other organisations' data) }\end{array}$ \\
\hline Range of Data & $\begin{array}{l}\text { Effects on the availability of management information (e.g. more updated management } \\
\text { information due to real-time data exchange) }\end{array}$ \\
\hline $\begin{array}{l}\text { Management } \\
\text { Information }\end{array}$ & $\begin{array}{l}\text { Effects on the clarity of organising the data (e.g. better accessibility to reporting data due } \\
\text { to centralised management information) }\end{array}$ \\
\hline Organisation of Data
\end{tabular}

Table Annex A.11. Reporting variable (definitions of variable and its attributes)

\section{A2.6.2. Uncertainty Reduction}

Uncertainty Reduction was defined as the effects from IOP standards adoption on the uncertainty facing the organisation (see Table 2.21). The interview analysis yielded only two attributes of this variable. One attribute that was mentioned is that respondents perceive the adoption of IOP standards as a means of "future-proofing" the own organisation (Q8:11). Another issue that interviewees mentioned in relation to this variable was that information sharing based on IOP standards can provide a tool to reduce the possibility for fraud by clients (Q1:18).

\begin{tabular}{|l|l|}
\hline \multicolumn{2}{|l|}{ Uncertainty Reduction } \\
\hline Definition & The effects from IOP standards adoption on the uncertainty facing the organisation \\
\hline Attributes for this variable \\
\hline Future-Proofing & $\begin{array}{l}\text { Effects on aversion of future uncertainties facing the organisation (e.g. in relation to future } \\
\text { developments of standardisations or networking) }\end{array}$ \\
\hline Fraud Detection & $\begin{array}{l}\text { Effects on the possibility to detect fraudulent behaviour (either fraud by clients or in the } \\
\text { organisations themselves) }\end{array}$ \\
\hline
\end{tabular}

Table Annex A.12. Uncertainty Reduction variable (definitions of variable and its attributes)

\section{A3. External-Relations Results}

As Figure Annex A.7 shows, the most-mentioned dimension of External-Relations Results is that of Political Effects, which makes for more than half of its quotations (57\%). Image results account for a significant part as well (36\%). Reach Expansion, on the other hand, seems to only play a minor role for the interviewees $(7 \%)$. 


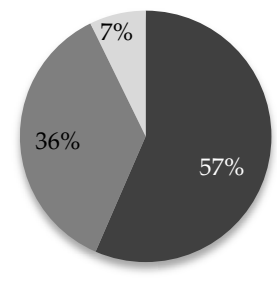

Political Effects

Image

Reach Expansion

Figure Annex A.7. External-Relations Results dimensions (aggregated frequencies per dimension, shown as rounded percentage of total quotations for External-Relations Results, $\mathrm{N}=69$ )

\section{A3.1. Political Effects}

The Political Effects dimension has been defined as the effects from IOP standards adoption related to political power vis-a-vis other actors (see Table 2.22). The variables identified from the literature for this dimension were External Autonomy (38\%), Power (21\%), Credibility (13\%), and Equality. The latter one did not appear in the interview data. On the other hand, an additional variable, Responsibility, accounting for $28 \%$ of quotations, was identified inductively from the case study data and defined as the effects from IOP standards adoption in terms of the responsibilities and obligations that the organisation needs to take on. The two most-often mentioned variables under Political Effects are thus External Autonomy and Responsibility.
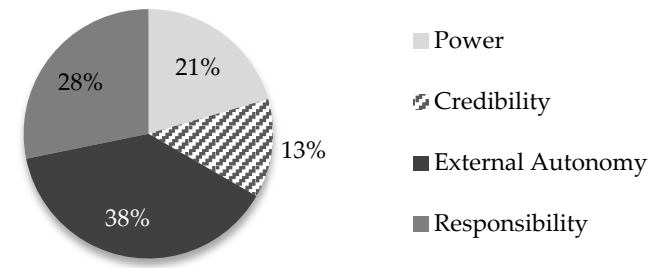

Figure Annex A.8. Political Effects variables (frequencies per variable, shown as rounded percentage of total quotations for Political Effects, $\mathrm{N}=39$ )

\section{A3.1.1. External Autonomy}

External Autonomy can be defined as the effects from IOP standards adoption on interdependence in terms of external relations (see Table 2.22). One attribute of this variable which interviewees mentioned is the delegation of decision-making about external relations of the organisation to other actors (Q1:13). Another major attribute are the implications of IOP standards adoption for their organisation's autonomy in fulfilling obligations to external actors, for example in situations of conflicting standards from several networks in which the organisation is involved (Q11:6). This is also manifested in relation to the dependence of organisations' accountability on external stakeholders (Q4:15). 


\begin{tabular}{|l|l|}
\hline External Autonomy & $\begin{array}{l}\text { The effects from IOP standards adoption on interdependence in terms of external } \\
\text { relations }\end{array}$ \\
\hline Definition & $\begin{array}{l}\text { Effects in terms of delegating decision-making on external relations to other actors (e.g. } \\
\text { obligations to collaborate with "unwanted" partners) }\end{array}$ \\
\hline $\begin{array}{l}\text { Delegation of } \\
\text { Decision-Making }\end{array}$ & $\begin{array}{l}\text { Effects on the autonomy in fulfilling obligations towards external actors (e.g. when } \\
\text { dealing with conflicting standards from various networks) }\end{array}$ \\
\hline External Obligations & $\begin{array}{l}\text { Effects in terms of the dependence of organisations' accountability on external actors } \\
\text { (e.g. liability for what partners do with exchanged data) }\end{array}$ \\
\hline External & Accountability
\end{tabular}

Table Annex A.13. External Autonomy variable (definitions of variable and its attributes)

\section{A3.1.2. Responsibility}

Responsibility is a code that resulted from the inductive coding and was defined as the effects from IOP standards adoption in terms of the responsibilities and obligations that the organisation needs to take on. One attribute of this variable are effects on the responsibilities for the organisation's own data (Q8:5). Even data-supplying organisations that are not officially obliged to conform to any IOP standards, can effectively end up with a higher workload as a result of their participation in the network. Interviewees also reported that their organisation experienced a loss of control in terms of their responsibility for the use of their own data by others (Q8:22). Organisations can also be confronted with complexity in arranging (new) responsibilities resulting from the IOP standards adoption (Q13:13). Finally, another implication related to Responsibility is the possibility that conflicting responsibilities can emerge as a result of adopting specific IOP standards (Q21:9).

\begin{tabular}{|l|l|}
\hline Responsibility & $\begin{array}{l}\text { The effects from IOP standards adoption in terms of the responsibilities and obligations, } \\
\text { that the organisation needs to take on }\end{array}$ \\
\hline Definition & $\begin{array}{l}\text { Effects on the responsibility for the organisation's own data (e.g. having to explain own } \\
\text { data semantics to partner organisations) }\end{array}$ \\
\hline $\begin{array}{l}\text { Responsibility for Own variable } \\
\text { Data }\end{array}$ & $\begin{array}{l}\text { Effects on the responsibility held for how partners use other organisations' data (e.g. } \\
\text { liability for data abuse by others) }\end{array}$ \\
\hline $\begin{array}{l}\text { Responsibility for Dath Others } \\
\text { New Responsibilities }\end{array}$ & $\begin{array}{l}\text { Effects in terms of newly added responsibilities and obligations (e.g. contractual } \\
\text { obligations on performance and maintenance such as SLAs) }\end{array}$ \\
\hline $\begin{array}{l}\text { Conflicting } \\
\text { Responsibilities }\end{array}$ & $\begin{array}{l}\text { Effects that conflict with other (earlier) obligations of an organisation (e.g. conflicting } \\
\text { requirements as to what data must and can be shown) }\end{array}$ \\
\hline
\end{tabular}

Table Annex A.14. Responsibility variable (definitions of variable and its attributes)

\section{A3.2. Image}

This dimension was defined as the effects from adoption related to the organisation's status and alignment with normative pressures in its environment of peers (see Table 2.22). The five variables identified for Image were (in descending order of their share of quotations): Accountability Image and Results Demonstrability (both 29\%), Innovation and Legitimacy (both $17 \%)$, and Clarity of Image (8\%). It should be noted that this dimension only yielded a relatively low number of quotations (24 in total). 


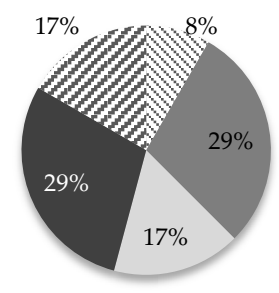

$$
\begin{aligned}
& \text { Clarity of Image } \\
& \text { Results Demonstrability } \\
& \text { Innovation } \\
& \text { Accountability Image } \\
& \text { Legimitacy }
\end{aligned}
$$

\section{Figure Annex A.9. Image variables (frequencies per variable, shown as rounded percentage of total quotations for Image, $\mathrm{N}=24$ )}

\section{A3.2.1. Results Demonstrability}

This variable was defined as the demonstrability of results from IOP standards adoption to others (see Table 2.22). One attribute of this variable which has been mentioned in the interviews was the demonstrability of "positive" results for output legitimacy towards external stakeholders, such as government stakeholders and citizens (Q10:3). Interviewees also reported that their organisations take pride in being "among the first" and most innovative in their sector (Q18:5). This pressure for demonstrating results can be even higher when there is high ownership of the Government Information Network within the organisations (Q36:22).

\begin{tabular}{|l|l|}
\hline \multicolumn{2}{|l|}{ Results Demonstrability } \\
\hline Definition & The demonstrability of results from IOP standards adoption to others \\
\hline Attributes for this variable \\
\hline Output Legitimacy & $\begin{array}{l}\text { Effects on the legitimacy of the organisation in terms of its output (e.g. usage of } \\
\text { integrated service delivery as image booster) }\end{array}$ \\
\hline Bandwagoning & $\begin{array}{l}\text { Effects in terms of how much the organisation is seen as being at the forefront of } \\
\text { innovation }\end{array}$ \\
\hline Ownership & $\begin{array}{l}\text { Effects in terms of feeling accountable as (co-)owner of the information exchange (e.g. } \\
\text { collective responsibility for the information) }\end{array}$ \\
\hline
\end{tabular}

Table Annex A.15. Results Demonstrability variable (definitions of variable and its attributes)

\section{A3.2.2. Accountability Image}

Accountability Image has been defined as effects from IOP standards adoption on the public accountability of the organisation (see Table 2.22). As interviewees reported, this can be seen as one of the core intended outcomes towards citizens and clients (Q15:15). This is also because transparent client information management is seen as a contribution to general political goals of government (Q19:26). Interviewees also discussed that the mutual crosschecking of data, which is enabled by IOP standards, can lead partner organisations to more accountability in terms of data quality (Q27:15). Furthermore, IOP standards adoption can also function as a safeguard against flawed or corrupted processes (Q34:1). 


\begin{tabular}{|l|l|}
\hline \multicolumn{2}{|l|}{ Accountability Image } \\
Definition & $\begin{array}{l}\text { The effects from IOP standards adoption on the public accountability of the } \\
\text { organisation }\end{array}$ \\
\hline Attributes for this variable \\
\hline $\begin{array}{l}\text { Information Management } \\
\text { Transparency }\end{array}$ & Effects on transparency of information management \\
\hline $\begin{array}{l}\text { Data Quality } \\
\text { Accountability }\end{array}$ & $\begin{array}{l}\text { Effects on the accountability in terms of data quality (e.g. enhanced accountability } \\
\text { through mutual cross-checking) }\end{array}$ \\
\hline $\begin{array}{l}\text { Protection from Flawed } \\
\text { Processes }\end{array}$ & $\begin{array}{l}\text { Effects on protection from flawed processes (e.g. prevention of corruption through } \\
\text { more management information) }\end{array}$ \\
\hline
\end{tabular}

Table Annex A.16. Accountability Image variable (definitions of variable and its attributes)

\section{A3.3. Reach Expansion}

This dimension has been defined as effects from adoption related to the reach of the organisation in terms of partners and operational fields (see Table 2.22). One attribute mentioned for this dimension in the interviews is market expansion, i.e. that IOP standards adoption can serve an organisation to reach more clients (Q27:17). Furthermore, it was also seen by some interviewees as a way to widen the professional network of an organisation and acquire more partners (Q14:18). Here, there can also be an expectation that standards adoption is a way of future-proofing the own organisation in terms of expanding its organisational network (Q8:11).

\begin{tabular}{|l|l|}
\hline Reach Expansion & $\begin{array}{l}\text { The effects from adoption related to the reach of the organisation in terms of partners and } \\
\text { operational fields }\end{array}$ \\
\hline Attributes for this dimension \\
\hline Clients Reach & Effects on reach to clients (e.g. wider client base as result from enhanced communication) \\
\hline Partner Reach & $\begin{array}{l}\text { Effects on reach to partners (e.g. wider professional network due to better knowledge about } \\
\text { the organisation's peers) }\end{array}$ \\
\hline
\end{tabular}

Table Annex A.17. Reach Expansion dimension (definitions of dimension and its attributes)

\section{A4. Return-on-Investment Results}

The sub-construct Return-on-Investment Results is a result from the inductive coding, and has been defined as the match or mismatch in the relation between efforts and benefits materialisation from IOP standards adoption, i.e. in how far the expectations of stakeholders in the network are met by its outcomes. The key difference of this sub-construct from the other Results sub-constructs is that this captures those instances in the interviews where stakeholders explicitly put Results and Efforts in relation to each other, effectively describing the weighing of one against the other. Overall, this sub-construct was mentioned by stakeholders only to a limited degree (35 quotations), and the inferences from this therefore need to be regarded as indicative only. Two additional determinants were identified from the data that are conceptually subordinate to the Return-on-Investment Results sub-construct: Sow-Harvest Equality and Timing. Since there is no reason to layer them at different conceptual levels, no intermediate "dimensions"-level is specified and these two determinants are grouped at the variables-level. The distribution of quotations between 
these two variables is relatively even, with Sow-Harvest Equality being discussed slightly more with a share of $57 \%$ of the discussion ( $43 \%$ for Timing). Both variables are defined and discussed in turn below.

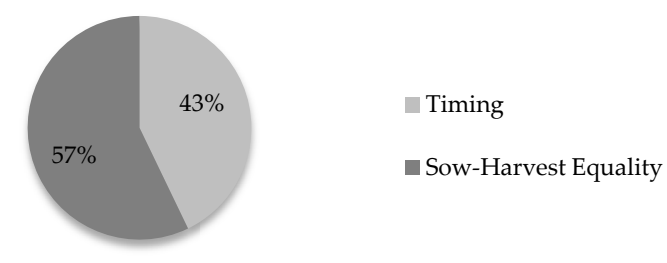

Figure Annex A.10. Return-on-Investment Results variables (frequencies per variable, shown as rounded percentage of quotations for Return-on-Investment Results, N=35)

\section{A4.1. Sow-Harvest Equality}

Sow-Harvest Equality is a result from the inductive coding, and has been defined as the degree of equality in the distribution of results (returns) from IOP standards adoption among partners in the network, in relation to their efforts (investments) made. There were four attributes of Sow-Harvest Equality discussed in the interviews, each related to a different level at which such (in)equality can occur. The first level is inequality within organisations, where some departments in an organisation in the network might benefit, while others in the same organisation have to make disproportionate efforts without taking the same share in positive results (Q7:21). The second level of Sow-Harvest Equality is inequality across organisations, where returns and investments are disproportionately distributed across partner organisations in the network, for instance due to the fact that the key results from IOP standards adoption are less aligned with the goals of one organisation than with others (Q21:5). Yet another level of Sow-Harvest Equality concerns the policy level: some goals might be pursued at the political level (such as central government and ministerial levels), but not be relevant to certain executing organisations at the implementation level (Q29:19). Finally, stakeholders also discussed Sow-Harvest Equality across policy sectors, where crosssectoral standardisation yields more or less balanced results across the various participating policy sectors (Q35:14).

\begin{tabular}{|l|l|}
\hline Sow-Harvest Equality & $\begin{array}{l}\text { The degree of equality in the distribution of results (returns) from IOP standards } \\
\text { adoption among partners in the network, in relation to their efforts } \\
\text { (investments) made }\end{array}$ \\
\hline Attributes for this variable & $\begin{array}{l}\text { Sow-Harvest Equality within organisations (e.g. between different departments } \\
\text { in the same organisation) }\end{array}$ \\
\hline $\begin{array}{l}\text { Intra-Organisational Sow- } \\
\text { Harvest Equality }\end{array}$ & $\begin{array}{l}\text { Sow-Harvest Equality across organisations (e.g. across partner organisations in } \\
\text { the same government information network) }\end{array}$ \\
\hline $\begin{array}{l}\text { Inter-Organisational Sow- } \\
\text { Harvest Equality }\end{array}$ & $\begin{array}{l}\text { Sow-Harvest Equality across policy levels (e.g. between the political level and } \\
\text { implementation level) }\end{array}$ \\
\hline $\begin{array}{l}\text { Policy-Level Sow-Harvest } \\
\text { Equality }\end{array}$ & Sow-Harvest Equality across policy sectors \\
\hline $\begin{array}{l}\text { Cross-Sectoral Sow-Harvest } \\
\text { Equality }\end{array}$
\end{tabular}

Table Annex A.18. Sow-Harvest Equality variable (definitions of variable and its attributes) 


\section{A4.2. Timing}

Timing is a result from the inductive coding, and has been defined as the synchronicity of efforts and expected results, i.e. the absence of any delays in the materialisation of returns on investment.

One attribute of this variable mentioned in the literature was the possibility for such delays stemming from miscalculations of business cases, when inaccurate or unrealistic timing estimates are given with regard to ROI (Q29:17). Another type of delays that was mentioned by the interviewees were delays caused by lengthy negotiations among stakeholders in the run-up and during IOP standards adoption (Q10:19). Interviewees also mentioned the distribution of such delays across stakeholders, and discussed that there can be an uneven distribution of such delayed results materialisation, either within (Q38:8) or across organisations (Q26:22). Finally, it should also be noted that several interviewees mentioned that the benefits from standardisation are rarely instantaneous and generally need more time to materialise than the patience of stakeholders affords, so that often in the short term, only the efforts get noticed, obscuring the long-term benefits (Q34:1/36:2).

\begin{tabular}{|l|l|}
\hline Timing & $\begin{array}{l}\text { The synchronicity of efforts and expected results, i.e. the absence of any delays in the } \\
\text { materialisation of returns on investment }\end{array}$ \\
\hline Attributes for this variable \\
\hline $\begin{array}{l}\text { Inaccurate } \\
\text { Estimates }\end{array}$ & Inaccurate or unrealistic estimates regarding the timing of returns on investment \\
\hline $\begin{array}{l}\text { Lengthy } \\
\text { Negotiations }\end{array}$ & $\begin{array}{l}\text { Delays in the timing of returns on investment due to lengthy negotiations between } \\
\text { stakeholders before and during IOP standards adoption }\end{array}$ \\
\hline Delay Distribution & The distribution of delays in results materialisation within or across organisations \\
\hline
\end{tabular}

Table Annex A.19. Timing variable (definitions of variable and its attributes)

\section{A5. Network-Level Results}

The sub-construct Network-Level Results is a result from the inductive coding, and has been defined as the results from IOP standards adoption for the network as a whole (i.e. as opposed to the organisation-level implications, e.g. for how an organisation performs or interacts within the network).

Overall, this sub-construct was mentioned by stakeholders only to a very limited degree (12 quotations), and the following discussion can therefore only be interpreted as indicative and not as exhaustive. Two conceptually subordinate determinants were identified for this subconstruct: Network Effectiveness and Future Innovation. Like Return-on-Investment Results, these determinants were not located at different conceptual levels and are therefore specified only at the level of variables. The distribution between these two variables is relatively even, with Network Effectiveness being discussed slightly more with a share of $58 \%$ of the discussion (42\% for Future Innovation). Both variables are defined and discussed in turn below. 


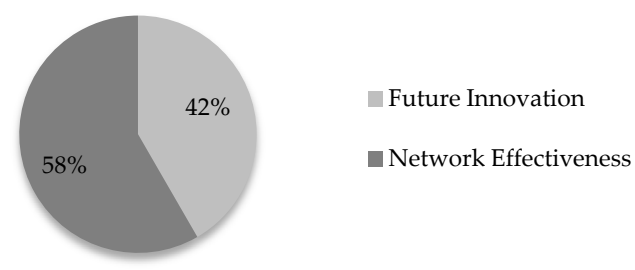

Figure Annex A.11. Network-Level Results variables (frequencies per variable, shown as rounded percentage of total quotations for Network-Level Results, $\mathrm{N}=12$ )

\section{A5.1. Network Effectiveness}

Network Effectiveness is a result from the inductive coding, and has been defined as the results from IOP standards adoption on the effectiveness of the network as a whole in terms of reaching its objectives. Whilst only a small number of quotations was coded with this variable, two types of Network Effectiveness could be identified in the discussion. The first is network-specific effectiveness, referring to contributions of IOP results to goals that are specific to the tasks and ambitions of the Government Information Network itself and the sector(s) within which it operates (Q35:13). General effectiveness, the other type, refers to contributions of IOP results to goals whose nature is broader than the network itself, such as developing a more efficient and effective public-sector information management in general (Q19:26).

\begin{tabular}{|l|l|}
\hline Network Effectiveness & $\begin{array}{l}\text { The results from IOP standards adoption on the effectiveness of the network as a } \\
\text { whole in terms of reaching its objectives }\end{array}$ \\
\hline Definition & $\begin{array}{l}\text { Contributions of IOP results to the tasks and goals of the Government Information } \\
\text { Network itself and the sector(s) within which it operates }\end{array}$ \\
\hline $\begin{array}{l}\text { Effectiveness } \\
\text { General Effectiveness }\end{array}$ & $\begin{array}{l}\text { Contributions of IOP results to goals whose nature is broader than the network itself } \\
\text { (e.g. better public-sector information management) }\end{array}$ \\
\hline
\end{tabular}

Table Annex A.20. Network Effectiveness variable (definitions of variable and its attributes)

\section{A5.2. Future Innovation}

Future Innovation is a result from the inductive coding, and has been defined as the results from IOP standards adoption for future innovation in the network and its policy domain. One key attribute of this variable is formed by the contributions that standardisation can make to serve as a basis for future innovation, for instance by widening the reach of the network or making it more flexible to adapt to future changes in its environment (Q24:38). On the other hand, interviewees also discussed how standardisation possibly can create obstacles for future innovation in the network, for instance by reducing organisations' flexibility to change and innovate (Q19:15). 


\begin{tabular}{|c|c|}
\hline \multicolumn{2}{|l|}{ Future Innovation } \\
\hline Definition & $\begin{array}{l}\text { The results from IOP standards adoption for future innovation in the network and its } \\
\text { policy domain }\end{array}$ \\
\hline \multicolumn{2}{|c|}{ Attributes for this variable } \\
\hline $\begin{array}{l}\text { Basis for Future } \\
\text { Innovation }\end{array}$ & $\begin{array}{l}\text { The contribution that standardisation can make to serve as a basis for future } \\
\text { innovation }\end{array}$ \\
\hline $\begin{array}{l}\text { Obstacles for Future } \\
\text { Innovation }\end{array}$ & $\begin{array}{l}\text { Creation of obstacles for future innovation in the network as a result of } \\
\text { standardisation }\end{array}$ \\
\hline
\end{tabular}

Table Annex A.21. Future Innovation variable (definitions of variable and its attributes)

\section{A6. Organisational Efforts}

This sub-construct has been defined as the actual extent of efforts experienced by an organisation during the adoption process, i.e. the efforts that are required to deal with complexities and inflexibilities in the various spheres of the organisation (see Table 2.19).

\begin{tabular}{|l|r|}
\hline Dimension & Percentage (N=143) \\
\hline Process Efforts & $47 \%$ \\
\hline Monitoring/Enforcement Efforts & $19 \%$ \\
\hline Organisational Structure Efforts & $19 \%$ \\
\hline Training Efforts & $8 \%$ \\
\hline Value Efforts & $3 \%$ \\
\hline Goal Efforts & $2 \%$ \\
\hline Maintaining Relationship Efforts & $1 \%$ \\
\hline Level of Collaboration & $1 \%$ \\
\hline
\end{tabular}

Table Annex A.22. Organisational Efforts variables (frequencies per variable, shown as rounded percentage of total quotations for Organisational Efforts, $\mathrm{N}=143$ )

The variables identified for Organisational Efforts were (in the sequence of their percentage of quotations): Process Efforts (48\%), Monitoring/Enforcement Efforts and Organisational Structure Efforts (both 19\%), Training Efforts (8\%), Value Efforts (3\%), Goal Efforts (2\%), and Maintaining Relationship Efforts (1\%). Both Organisational Structure Efforts and Goal Efforts were identified inductively from the case study data. Organisational Structure Efforts is defined as efforts required by IOP standards adoption in terms of changes that need to be made to the structure of the adopting organisation ${ }^{111}$, and Goal Efforts is defined as the efforts required by IOP standards adoption in terms of changes that need to be made to the adopting organisation's goals and strategy ${ }^{112}$. The two most-frequently mentioned by the interviewees are discussed in the following two sections.

On a general level, two main observations can be noted for this sub-construct. First, many text segments in the interviews were coded simultaneously with both Adoption Effort codes

\footnotetext{
${ }^{111}$ Illustrative examples for Organisational Structure Efforts are for instance in DKD where the specification of access rights to DKD data required municipalities to create and assign the respective roles within their organisation (Q3:14), or in Studielink the need to replace student administration staff with new employees that have the proper skills required for using the new system (Q34:4).

${ }^{112}$ An illustrative example for Goal Efforts is that for instance the basic modus operandi and identity of an organisation can change as a result of adoption, as illustrated in the following quote from the Studielink case: "The fact that the individual architecture of registration has shifted in such a way means that the function of the institutions has become much more a control function. In place of designing and administering the registration process themselves, this is taken over by Studielink and their task now has shifted to control what they have received, whether it is correct" (Q24:7).
} 
and codes that are (predominantly) concerning benefits-related Results. This implicit pattern underlines something that interviewees also stated explicitly: that adoption efforts are usually weighed against the individual benefits that may also result from IOP standards adoption (Q14:12). Second, in the process of creating IOP in Government Information Networks, many (imperfect) workarounds were used (since the process required a lot of time and efforts from partners). In some cases, these workarounds, conceived as mere intermediary solutions, were used for a long time, in fact becoming "new" legacy solutions in their own right, consequently creating more obstacles to IOP in the long run (Q22:6).

\section{A6.1. Process Efforts}

Process Efforts has been defined as those efforts resulting from aligning the IOP standards with existing operations and business processes (see Table 2.19). Such changes to processes can mean that changes are required in the general nature of the existing processes (Q24:7). Rather than shifts in the fundamental nature of business processes, there can also be alterations to existing processes (Q15:1). Another attribute concerns efforts related to changes to the organisation-internal role and task allocation, and the associated costs of changing the internal organisation (Q26:20). Altered process sequences (Q24:20) and timing (Q17:5) are a further attribute of process change efforts. Changes to the communication between the adopting organisation and its clients were identified as another attribute (Q27:12). There can also be 'ripple effects' in terms of unintended efforts as a result of process changes, such as side-effects on other processes in the organisation (Q32:7). Another possible effort next to changed processes is that entire processes may be eradicated by the new system (Q28:6). Conversely, respondents also report how adoption of the standards implied that completely new processes were added (Q23:5). Finally, a general observation on this variable is that it appears from the interviews that there is a tight interrelation of organisational (process) IOP and technological IOP (Q17:6). As interviewees mention that implementing technological IOP standards can have a substantial effect on business processes, there is a need to be cautious with technology-deterministic approaches (Q21:8).

\begin{tabular}{|l|l|}
\hline Process Efforts & $\begin{array}{l}\text { The efforts that result from aligning the IOP standards with existing operations and } \\
\text { business processes }\end{array}$ \\
\hline Definition & $\begin{array}{l}\text { Shifts in the fundamental nature of business processes (e.g. from paper-based } \\
\text { administration to monitoring of digital processes) }\end{array}$ \\
\hline $\begin{array}{l}\text { Change to Nature of } \\
\text { Processes }\end{array}$ & Changes to existing processes \\
\hline $\begin{array}{l}\text { Alterations to Existing } \\
\text { Processes }\end{array}$ & $\begin{array}{l}\text { Changes to the organisation-internal allocation of roles and tasks (e.g. shift from } \\
\text { decentralised to more centralised bundling of work processes) }\end{array}$ \\
\hline $\begin{array}{l}\text { Changed Roles and } \\
\text { Tasks }\end{array}$ & Altered process sequences and timing (e.g. requirement for immediate entry of data) \\
\hline $\begin{array}{l}\text { Changed Process } \\
\text { Sequence/Timing }\end{array}$ & $\begin{array}{l}\text { Changes to the communication between the adopting organisation and its clients (e.g. } \\
\text { altered timing of communication) }\end{array}$ \\
\hline $\begin{array}{l}\text { Changes to } \\
\text { Communication }\end{array}$ & $\begin{array}{l}\text { Effects in terms of unintended efforts as a result of process changes (e.g. side-effects } \\
\text { on other processes in the organisation) }\end{array}$ \\
\hline Ripple Effects & Eradication of entire business processes (e.g. checking of paper evidence) \\
\hline Process Eradication & Creation of new business processes (e.g. new processes for data management) \\
\hline New Processes &
\end{tabular}

Table Annex A.23. Process Efforts variable (definitions of variable and its attributes) 


\section{A6.2. Organisational Structure Efforts}

This variable has been a result of the inductive coding. It was defined as the efforts required by IOP standards adoption in terms of changes that need to be made to the structure of the adopting organisation. One attribute of such efforts which was mentioned by several interviewees was the need for the creation of new roles (Q3:14), jobs (Q24:3), or even organisational units (Q23:9) as a result of IOP standards adoption. However, it is possible that IOP standards adoption not only requires adding new functions, but also former functions and jobs can become obsolete due to the decreased workload resulting from the automation of processes that IOP standards enable (Q21:14). However, respondents also mentioned that there is a trade-off between on the one hand, the cost benefits of reducing staff (e.g. lower-skill functions that can be automated), and on the other hand the added cost of hiring new, highly qualified staff (Q28:33).

\begin{tabular}{|l|l|}
\hline Organisational Structure Efforts \\
\hline Definition & $\begin{array}{l}\text { The efforts required by IOP standards adoption in terms of changes that need to be made } \\
\text { to the structure of the adopting organisation }\end{array}$ \\
\hline Attributes for this variable \\
\hline $\begin{array}{l}\text { Creation of Roles, } \\
\text { Jobs, Units }\end{array}$ & Effects in terms of creating new roles, jobs and units (e.g. creation of dedicated helpdesks) \\
\hline $\begin{array}{l}\text { Eradication of Roles, } \\
\text { Jobs, Units }\end{array}$ & $\begin{array}{l}\text { Effects in terms of eradicating existing roles, jobs and units (e.g. replacement of staff with } \\
\text { more adequately skilled staff) }\end{array}$ \\
\hline
\end{tabular}

Table Annex A.24. Organisational Structure Efforts variable (definitions of variable and its attributes)

\section{A7. Technological Efforts}

Technological Efforts has been defined as efforts required by the degree of technological difficulty and costs of adopting the IOP standards (see Table 2.19). A key impact in this subconstruct is the need for new, or overhauled hard- and software (Q5:16). Another attribute that interviewees mentioned are effort requirements in terms of technical data security functions (Q19:2). Interviewees from both cases also mentioned implications that relate to technological data exchange and transmission functions (Q3:17). Finally, another technological effort mentioned by the interviewees concerns testing efforts, as well as maintenance and repair efforts (Q25:14).

\begin{tabular}{|l|l|}
\hline Technological Efforts & $\begin{array}{l}\text { The efforts required by the degree of technological difficulty and costs of } \\
\text { adopting the IOP standards }\end{array}$ \\
\hline Definition & $\begin{array}{l}\text { Attributes for this variable } \\
\text { requirements for upgrading software) }\end{array}$ \\
\hline New/Overhauled Technology & $\begin{array}{l}\text { Effects related to effort requirements in terms of technological data security } \\
\text { functions (e.g. increased requirements for an organisation's firewall) }\end{array}$ \\
\hline Data Security Efforts & $\begin{array}{l}\text { Effects that relate to technological data exchange and transmission functions } \\
\text { (e.g. infrastructure to monitor the data exchange) }\end{array}$ \\
\hline Data Transmission Efforts & $\begin{array}{l}\text { Effects related to testing, as well as maintenance and repair efforts (e.g. } \\
\text { functionality tests of new versions) }\end{array}$ \\
\hline $\begin{array}{l}\text { Testing and Maintenance } \\
\text { Efforts }\end{array}$
\end{tabular}

Table Annex A.25. Technological Efforts sub-construct (definitions of sub-construct and its attributes) 


\section{A8. Semantic Efforts}

The sub-construct Semantic Efforts is a result from the inductive coding, and has been defined as the efforts required by the degree of difficulty to fit the IOP standards into the semantic structures of the organisation. The efforts related to this sub-construct thus are closely related to semantic IOP standards that aim at ensuring coherence of data definitions.

It is common that various partner organisations use different data definitions. Therefore, a key attribute of Semantic Efforts that respondents discussed concerns efforts related to the needs for data translation to ensure coherent data definitions (Q2:5). As was mentioned before under Technological Efforts, semantic translations can also require that middleware is built (Q7:16). It thus appears that Semantic Efforts and Technological Efforts are interrelated. Next to the implication of needing to build middleware for data translation, interviewees also report that semantic structures are intertwined with the database structure. For instance, to adopt semantic IOP standards of Studielink, the SIS programming needs to be changed in order to ensure that tables across databases are matching (Q28:11). Such translation efforts that are connected to semantic IOP standards adoption also play a role regarding data storage (Q7:11).

But efforts related to Semantic Efforts do not only concern translation. As respondents pointed out, definitions often have historically grown from idiosyncratic organisational contexts and are thus deeply rooted (Q18:2). Therefore, developing a thorough mutual understanding of the joint definitions, respective to organisations' own definitions, is perceived by stakeholders as a significant effort (Q14:28).

\begin{tabular}{|c|c|}
\hline Definition & $\begin{array}{l}\text { The efforts required by the degree of difficulty to fit the IOP standards into the } \\
\text { semantic structures of the organisation }\end{array}$ \\
\hline \multicolumn{2}{|c|}{ Attributes for this sub-construct } \\
\hline Data Translation & Effects related to data translation for ensuring coherent data definitions \\
\hline Middleware & Effects related to middleware requirements for data translation \\
\hline Data Storage & $\begin{array}{l}\text { Effects related to data storage requirements (e.g. ensure that data tables across } \\
\text { databases are matching) }\end{array}$ \\
\hline Mutual Understanding & Effects related to developing a mutual understanding of the joint definitions \\
\hline
\end{tabular}

Table Annex A.26. Semantic Efforts sub-construct (definitions of sub-construct and its attributes)

\section{A9. Legal Efforts}

Legal Efforts was defined as efforts from IOP standards adoption to overcome legal obstacles (see Table 2.19). The three variables that were identified for this sub-construct in Chapter 2 were Legal Framework (38\%), Ambiguous Legislation and Privacy Legislation (both 31\%), Intellectual Property Legislation and Procurement Legislation (no quotations for both). The latter two variables were thus not confirmed by the case study data. As shown in Figure Annex A.12, the share of the three first ones is relatively similar, suggesting that they have a relatively equal significance for stakeholders. 


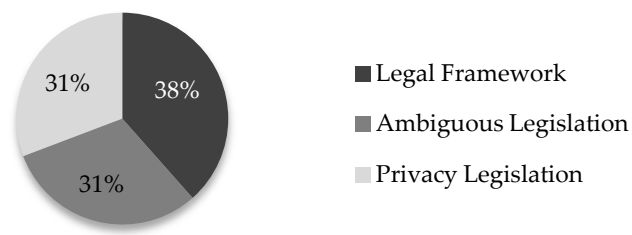

Figure Annex A.12. Legal Efforts variables (frequencies per variable, shown as rounded percentage of total quotations for Legal Efforts, $\mathrm{N}=13$ )

However, it should be noted that the overall number of quotations for Legal Efforts was very low and relatively homogeneous in the nature of the statements, so that not many different attributes could be discerned and the analysis thus remains at the variable level. (As a result, Table Annex A.27 only shows the variable-level). One issue regarding Legal Efforts that was central to most quotations here was the need to perform a legal compatibility analysis (Q11:6), in order to investigate (and if necessary, acquire) the legislative mandate for the organisation to exchange data in the network. Here, the role of Ambiguous Legislation is paramount, because legal ambiguity can pose significant legal obstacles for organisations (Q9:5). Another issue in relation to legal obstacles was Privacy Legislation (Q14:13).

\begin{tabular}{|l|l|}
\hline Legal Efforts & The efforts from IOP standards adoption to overcome legal obstacles \\
\hline Definition & $\begin{array}{l}\text { Effects requiring an investigation of the legislative mandate for the organisation to } \\
\text { exchange data in the network }\end{array}$ \\
\hline $\begin{array}{l}\text { Legal Compatibility } \\
\text { Analysis }\end{array}$ & $\begin{array}{l}\text { Effects from ambiguous legislation (e.g. on the complexity of legal compatibility } \\
\text { analyses) }\end{array}$ \\
\hline Ambiguous Legislation \\
\hline Privacy Legislation & $\begin{array}{l}\text { Effects related to ensuring privacy standard compliance within and beyond the } \\
\text { organisations }\end{array}$ \\
\hline
\end{tabular}

Table Annex A.27. Legal Efforts sub-construct (definitions of sub-construct and its variables)

\section{A10. Resource Costs}

This sub-construct was defined as the resource costs necessitated for IOP standards adoption, including technological and infrastructure costs as well as administrative costs (see Table 2.19). The dimensions specified in Chapter 2 were: Infrastructure Costs (75\%), Monitoring/Enforcement Costs (13\%), Training Costs (12\%), Maintaining Relationship Costs and Transaction Costs (both no quotations). The latter two variables were thus not confirmed.

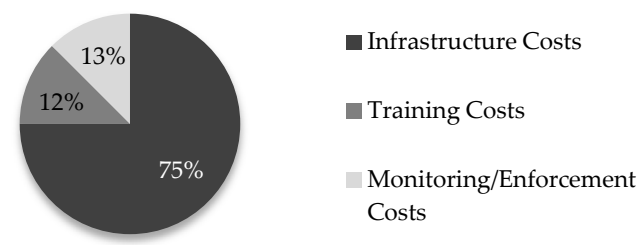

Figure Annex A.13. Resource Costs variables (frequencies per variable, shown as rounded percentage of total quotations for Resource Costs, $\mathrm{N}=40$ ) 


\section{A10.1. Infrastructure Costs}

It is noteworthy that the Infrastructure Costs variable has by a big margin the largest share of quotations in the Resource Costs sub-construct. Infrastructure Costs were defined as the costs of putting in place the required technological infrastructure for the adoption of IOP standards (for both new technology and switching/exit costs) (see Table 2.19).

A major attribute of this dimension concerns the ICT infrastructure costs. This concerns the costs of making changes to the existing ICT infrastructure (Q1:26), but also costs of acquiring new ICT infrastructure (Q5:16). ICT infrastructure costs also include testing and maintenance of new facilities (Q29:17). Some of these activities also include consultancy services that add another layer of costs (Q3:10). Finally, there are costs related to the human resources of organisations that result from IOP standards adoption, as it may require the hiring of new, more qualified personnel to work with the new systems (Q29:17).

\begin{tabular}{|c|c|}
\hline Definition & $\begin{array}{l}\text { The costs of putting in place the required technological infrastructure for the adoption } \\
\text { of IOP standards }\end{array}$ \\
\hline \multicolumn{2}{|l|}{ Attributes for this variable } \\
\hline $\begin{array}{l}\text { ICT Infrastructure } \\
\text { Costs }\end{array}$ & $\begin{array}{l}\text { Costs for changes to the existing ICT infrastructure (e.g. costs for software upgrades } \\
\text { that are necessary for IOP) }\end{array}$ \\
\hline $\begin{array}{l}\text { Testing and } \\
\text { Maintenance Costs }\end{array}$ & Costs regarding the testing and maintenance of the new facilities \\
\hline Consultancy Costs & Costs for consultancy services (e.g. for technical feasibility assessments) \\
\hline Human Resource Costs & $\begin{array}{l}\text { Costs related to the human resource infrastructure of organisations (e.g. hiring of new, } \\
\text { more qualified personnel to work with the new systems) }\end{array}$ \\
\hline
\end{tabular}

Table Annex A.28. Infrastructure Costs variable (definitions of variable and its attributes)

\section{A10.2. Training Costs}

The Training Costs variable has been defined as the costs of staff training that is necessary for IOP standards adoption (see Table 2.19). One attribute of this variable are costs incurred for schooling of staff to comply with the IOP standards (Q29:17). A related cost category is that once employees are better trained, this implies that the organisation also may incur higher costs in terms of salaries (Q17:38).

\begin{tabular}{|l|l|}
\hline \multicolumn{2}{|l|}{ Training Costs } \\
\hline Definition & The costs of staff training that is necessary for IOP standard adoption \\
\hline Attributes & Costs of training activities for employees to work with IOP standards \\
\hline Schooling & Salary costs (e.g. salary increases resulting from employing better-skilled staff) \\
\hline Salaries &
\end{tabular}

Table Annex A.29. Training Costs variable (definitions of variable and its attributes) 



\title{
DETERMINANTS FOR THE ADOPTION OF
}

\author{
INTEROPERABILITY STANDARDS IN GOVERNMENT
}

INFORMATION NETWORKS - EVIDENCE FROM THE

\author{
CASE STUDIES ${ }^{113}$
}

\subsection{Introduction}

By drawing on empirical data from the DKD and Studielink case studies, this chapter investigates the determinants of IOP standards adoption by organisations in Government Information Networks: it asks what influences these organisations to make the necessary investments for adopting and complying with IOP standards. As such, it provides an empirical validation (and refinement) of the determinants listed in the preliminary theoretical model in Chapter 2. In other words, this chapter picks up where Chapter 4 has left off: whilst Chapter 4 has investigated the adoption of IOP standards (explaining its process and implications), the present chapter looks at all explanatory factors (determinants) of such adoption behaviour.

To this end, the chapter aims to contribute a theoretically and empirically founded understanding of the determinants of IOP standards adoption. Whilst the preliminary theoretical model in Chapter 2 has identified an initial list of determinants from the literature, this chapter aims to empirically validate which of these determinants did play a role in the case studies - and which additional determinants could be identified from these cases. Such a grounded knowledge of what the organisation-internal and -external factors are that influence organisations in these networks can contribute to a better understanding of how IOP in Government Information Networks can effectively be governed. Consequently, the chapter addresses the second research question introduced at the end of Chapter 1: "what are the factors that determine the adoption of IOP standards by organisations in Government Information Networks"?

It is important to understand the nature of the analysis used in this chapter and the type of the conclusions it contributes. Like Chapter 4, it builds on a combination of interpretive and semi-quantitative content analysis, which is explained in detail in Chapter 3. As detailed in

\footnotetext{
${ }^{113}$ A summarised version of parts from an earlier version of this chapter has been published as (Henning, 2013a). An extended version of that paper has been invited for publication in a special issue on ICEGOV2013 in Government Information Quarterly and submitted for review.
} 
Section 3.4, in view of the exploratory nature of the research questions the interpretive approach taken here does not aim at measuring possible causality and effect sizes, as a positivist methodology would. Instead, it uses qualitative interview data consisting of stakeholders' experienced-based insights about the determinants and process of IOP standards adoption, in order to identify which factors they perceive to generally determine adoption, as well as to explain the possible mechanisms by which they can affect adoption. As discussed in Section 3.4 (as well as Section 7.3), the analysis of quotation frequencies implies certain limitations - in particular, aggregating and "counting" quotations implies a limited sensitivity to the exact content of individual quotations. Although these limitations are partly mitigated by the methodological safeguards discussed in these sections (such as triangulation with other data from the cases), the inferences from the content analysis should therefore be understood as a contribution of empirically grounded, yet indicative rather than definitive theoretical "propositions" for validation by future research.

Being based on the same combination of interpretive and semi-quantitative content analysis methods as Chapter 4 and on the same multi-level nested framework, the analysis for this Chapter also generated a similar richness of detail. Just as in the previous chapter, this chapter therefore presents the results as a condensed summary focusing on the key findings in order to enhance the chapter's readability, whilst all detailed results are presented in Annex B. This chapter is therefore organised as follows. Following this introduction section (5.1), Section 5.2 provides a summary of the key findings from the analysis regarding the determinants of IOP standards adoption by organisations in Government Information Networks. Finally, Section 5.3 then provides the conclusions for this chapter.

\subsection{Determinants of IOP Standards Adoption}

The key findings from the content analysis on the adoption determinants are summarised in this section, whilst detailed results are presented in Annex B. The general conclusion resulting from the analysis presented in this section is strongly in line with the picture presented in Chapter 4: namely, that the picture of determinants of IOP standards adoption is significantly more complex than the literature review in Chapter 2 had initially suggested. Amongst the richness of results from the empirical analysis on individual determinants, three groups of key findings stand out that serve to further develop the initially presented framework. Each of them is discussed in one of the following three sections. First, an overview of findings concerning the validation and revision of the theoretical model introduced in Chapter 2 is presented (Section 5.2.1). Subsequently, Section 5.2.2 discusses the key findings concerning the differences in relevance of the various determinants to stakeholders. Finally, Section 5.2.2.1 presents selected findings with regard to individual determinant constructs and their conceptual sub-levels. To provide an orientation for the reader through the layered conceptual structure followed in this chapter and Annex $B$, a schematic overview of the constructs, sub-constructs, dimensions and variables ${ }^{114}$ is provided by Figure 5.1 on the following page.

${ }^{114}$ This four-level conceptual hierarchy of the conceptual model is introduced in Section 2.4. 


\begin{tabular}{|c|c|c|c|c|c|c|}
\hline & & & $\begin{array}{c}\text { IOP Standards Adoption } \\
\text { Determinants }\end{array}$ & & & \\
\hline B2. IOP Governance & \begin{tabular}{|l|} 
B3. Network \\
Characteristics \\
\end{tabular} & $\begin{array}{l}\text { B4. Network-External } \\
\text { Environment }\end{array}$ & B5. Results & B6. Adoption Efforts & \begin{tabular}{|l} 
B7. IOP Standards \\
Characteristics \\
\end{tabular} & $\begin{array}{l}\text { B8. Organisation- } \\
\text { Specific Determinants }\end{array}$ \\
\hline B2.1. Guidance & \begin{tabular}{|l|} 
B3.1. Network \\
Complexity \\
\end{tabular} & \begin{tabular}{|l|} 
B4.1. Political \\
Environment \\
\end{tabular} & \begin{tabular}{|l|} 
B2. Internal- \\
Operations Results
\end{tabular} & $-\begin{array}{l}\text { B6. Organi- } \\
\text { sational Efforts }\end{array}$ & ${ }^{\text {Trialability }}$ & \begin{tabular}{|l|} 
B8.1. Organi- \\
sational Capacity
\end{tabular} \\
\hline \begin{tabular}{|l|} 
B2.1.1. Leadership \\
and Support
\end{tabular} & \begin{tabular}{|l|} 
B3.1.1. \\
Diversity
\end{tabular} & $\begin{array}{l}\text { B4.1.1. Public } \\
\text { Pressure } \\
\end{array}$ & $\begin{array}{l}\text { B3. External- } \\
\text { Relations Results }\end{array}$ & \begin{tabular}{|l} 
B7. Techno- \\
logical Efforts
\end{tabular} & Customisability & $\begin{array}{l}\text { B8.1.1. Human } \\
\text { Resources }\end{array}$ \\
\hline \begin{tabular}{|l} 
B2.1.2. \\
Communication
\end{tabular} & \begin{tabular}{|l} 
B3.1.2. Struct. \\
Complexity \\
\end{tabular} & $\begin{array}{l}\text { B4.1.2. Constit. } \\
\text { Characteristics } \\
\end{array}$ & B4. ROI Results & $\begin{array}{l}\text { B8. Semantic } \\
\text { Efforts }\end{array}$ & Maturity & $\begin{array}{l}\text { B8.1.2. Organ. } \\
\text { Structure }\end{array}$ \\
\hline $\begin{array}{l}\text { B2.2. Decision- } \\
\text { Centralisation }\end{array}$ & \begin{tabular}{|l} 
B3.1.3. Task \\
Complexity
\end{tabular} & $\begin{array}{l}\begin{array}{l}\text { B4.1.3. Other } \\
\text { Stakeholders }\end{array} \\
\end{array}$ & $\begin{array}{l}\text { B5. Network-Level } \\
\text { Results }\end{array}$ & B9. Legal Efforts & \begin{tabular}{|l} 
Correction \\
Mechanisms
\end{tabular} & $\begin{array}{l}\text { B8.1.3. Manage- } \\
\text { ment Practices }\end{array}$ \\
\hline \begin{tabular}{|l|}
$\begin{array}{l}\text { B2.2.1. Stakeholder } \\
\text { Involvement }\end{array}$ \\
\end{tabular} & $\begin{array}{l}\text { B3.2. Domain } \\
\text { Structure }\end{array}$ & $\begin{array}{l}\text { B4.2. Policy and } \\
\text { Institutions } \\
\end{array}$ & & \begin{tabular}{|l} 
B10. Resource \\
Costs
\end{tabular} & & $\begin{array}{l}\text { B8.1.4. Relational } \\
\text { Mechanisms } \\
\end{array}$ \\
\hline B2.2.2. Brokerage & \begin{tabular}{|l|} 
B3.3. Interaction \\
Complexity \\
\end{tabular} & \begin{tabular}{|l|} 
B4.2.1. Legal \\
Framework \\
\end{tabular} & & & & $\begin{array}{l}\text { B8.1.5. ICT } \\
\text { Capability }\end{array}$ \\
\hline B2.3. Enforcement & B3.4. Trust & \begin{tabular}{|l|} 
B4.2.2. Budgetary \\
Framework
\end{tabular} & & & & $\begin{array}{l}\text { B8.1.6. Manager } \\
\text { Characteristics } \\
\end{array}$ \\
\hline $\begin{array}{l}\text { B2.3.1. Accounta- } \\
\text { bility }\end{array}$ & \begin{tabular}{|l} 
B3.5. Information \\
Infrastructure
\end{tabular} & $\begin{array}{l}\text { B4.2.3. Administr. } \\
\text { Structure } \\
\end{array}$ & & & & \begin{tabular}{|l|} 
B8.1.7. Financial \\
Resources
\end{tabular} \\
\hline B2.3.2. Coercion & $\begin{array}{l}\text { B3.6. Mimetic } \\
\text { Dynamics }\end{array}$ & \begin{tabular}{|l} 
B4.2.4. eGov/IOP \\
Policy
\end{tabular} & & & & $\begin{array}{l}\text { B8.2. Organi- } \\
\text { sational Needs }\end{array}$ \\
\hline
\end{tabular}

Figure 5.1. Overview of determinants discussed in Section 5.2, Annex A and Annex B (including section numbers) 


\subsubsection{Towards a Final Theoretical Framework}

The first group of findings relates to the development of a final theoretical framework of determinants for the adoption of IOP standards by organisations in Government Information Networks. The first key finding here is a validation of the overall framework introduced in Chapter 2 (see Figure 2.6). As the results from the content analysis presented in Table 5.1 through Table 5.6 show, adoption is determined by a wide range of factors that can be grouped into seven determinant constructs: IOP Governance, Network Characteristics, Network-External Characteristics, IOP Standards Characteristics, Adoption Efforts, Results and Organisation-Specific Determinants. All the constructs specified in the preliminary theoretical framework were shown to play a role for organisational stakeholders' adoption intention (albeit to very different degrees, as discussed further below in Section 5.2.2).

At the same time, a second key finding is that the adoption of IOP standards is not only determined by the concepts specified in the preliminary framework, but that they consist of many sub-concepts, of which several had not been identified and discussed previously (see Table 5.1 through Table 5.6). This is in line with the argument developed in Chapter 4 that existing theory on IOP standards adoption needs to be refined by questioning previously identified determinants, as well as by identifying new ones and integrating them into a structured conceptual framework. In total, as Table 5.1 through Table 5.6 below show, 15 of the determinants that had been specified ex ante based on existing theory were not confirmed in the data. Whilst this does not exclude the possibility that these determinants play some role in different contexts than the ones under investigation here, it suggests that in networks similar to DKD and Studielink, they do not play a significant role. At the least, it reveals a need to scrutinise their validity in future research. Moreover, 51 new determinants were added to the model as a result of the empirical analysis (highlighted in Table 5.1 through Table 5.6). On a more general theoretical level, this suggests that in particular the following areas have been overseen or at least underexplored by previous theory: Leadership and Support (ten new variables identified), Stakeholder Involvement (four new variables identified), Network Complexity (four new variables identified), Interaction Complexity (all variables newly identified), and IOP Standards Characteristics (two new variables identified).

Taken together, the model validation and refinement resulting from the analysis thus provides an important foundation for constructing measurement models that can be used by future studies on IOP standards adoption in Government Information Networks. In addition, the analysis also contributes a theoretical model on the relationships between the relevant concepts. Synthesising the findings from this and the previous chapter, Figure 5.2 summarises the revised theoretical model. For purposes of readability, the levels of dimensions and variables are not shown in this figure but can be found in the list of determinants (Table 5.1 through Table 5.6). The seven determinants are presented at the top and the bottom of the model (Results). A two-directional arrow indicates that Results are conceived of as both an outcome and a determinant of Adoption (explained in Section 2.4.8). Adoption is displayed at the heart of the model. The middle layer shows the identified phases of the adoption process, and the bottom layer shows the main groups of actors involved in the adoption process. 


\begin{tabular}{|c|c|c|c|c|c|c|c|c|}
\hline \multirow{2}{*}{$\begin{array}{c}\text { IOP } \\
\text { GOVERNANCE } \\
\begin{array}{c}\text { Centrali- } \\
\text { sation }\end{array} \\
\end{array}$} & \multicolumn{2}{|c|}{$\begin{array}{c}\text { NETWORK } \\
\text { CHARACTERISTICS }\end{array}$} & \multirow{2}{*}{$\begin{array}{c}\text { NETWORK- } \\
\text { EXTERNAL } \\
\text { Political } \\
\text { Environment } \\
\end{array}$} & \multicolumn{2}{|c|}{$\begin{array}{l}\text { ADOPTION } \\
\text { EFFORTS }\end{array}$} & \multirow{2}{*}{$\begin{array}{l}\text { ORGANISA- } \\
\text { TION-SPECIFIC } \\
\text { Capacity }\end{array}$} & \multicolumn{2}{|c|}{$\begin{array}{l}\text { IOP STANDARDS } \\
\text { CHARACTERISTICS }\end{array}$} \\
\hline & Complexity & $\begin{array}{l}\text { Domain } \\
\text { Structure }\end{array}$ & & $\begin{array}{c}\text { Organisatio- } \\
\text { nal Efforts }\end{array}$ & $\begin{array}{l}\text { Technologi- } \\
\text { cal Efforts }\end{array}$ & & $\begin{array}{l}\text { Customi- } \\
\text { sability }\end{array}$ & $\begin{array}{l}\text { Correction } \\
\text { Mechanism }\end{array}$ \\
\hline Enforcement & Trust & $\begin{array}{l}\text { Info Infra- } \\
\text { structure }\end{array}$ & $\begin{array}{l}\text { Policy and } \\
\text { Institutions }\end{array}$ & Legal Efforts & $\begin{array}{l}\text { Resource } \\
\text { Costs }\end{array}$ & Needs & Maturity & Trialability \\
\hline Guidance & $\begin{array}{l}\text { Mimetic } \\
\text { Dynamics }\end{array}$ & $\begin{array}{l}\text { Interaction } \\
\text { Complexity }\end{array}$ & & & $\begin{array}{l}\text { Semantic } \\
\text { Efforts }\end{array}$ & & & \\
\hline
\end{tabular}

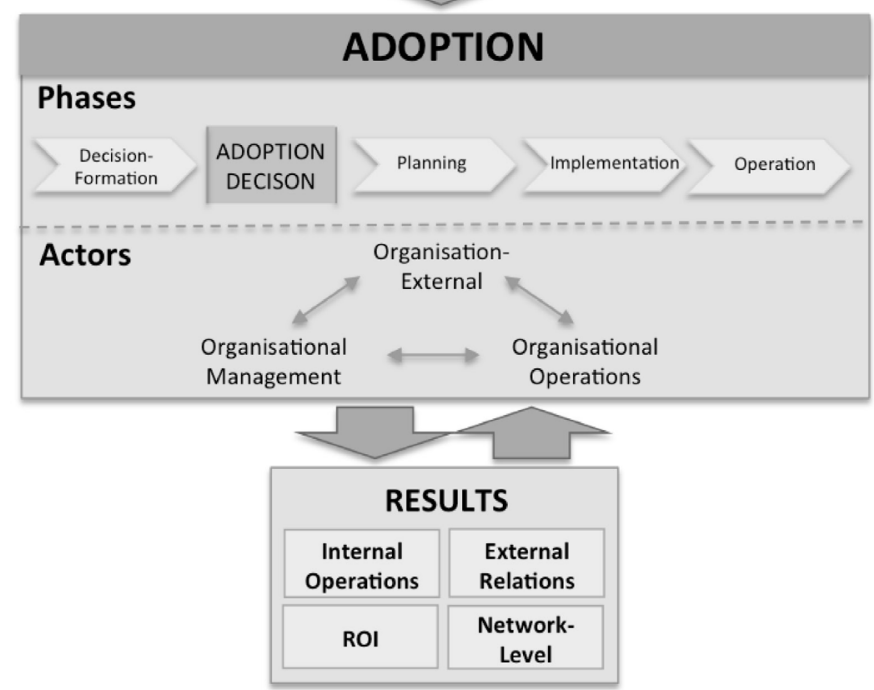

Figure 5.2. Final Model (only constructs and sub-construct shown here, sub-levels are shown in Table 5.1 through Table 5.6) 


\subsubsection{Relative Relevance of IOP Standards Adoption Determinants}

This section presents the key findings drawn from the content analysis regarding the various determinants' relative relevance to the interviewed stakeholders. Overall, the findings presented here are in line with the picture that Chapter 4 found with regard to adoption implications: there are significant differences in terms of their relevance for stakeholders, both overall but also when comparing them across groups (i.e. across stakeholder roles, cases, adoption phases, and support actors). The key conclusion from this section for governing IOP in Government Information Networks thus is that a differentiated perspective needs to be taken that takes into account these differences across determinants and across these groups. In the following, Section 5.2.2.1 first reports the findings on the individual adoption determinants. Section 5.2.2.2 then discusses the overall differences in relevance across types of determinants. Sections 5.2.2.3 through 5.2.2.6 then discuss the differences across stakeholder roles (5.2.2.3), cases (5.2.2.4), adoption phases (5.2.2.5), and support actors (5.2.2.6).

\subsubsection{Findings on Individual Adoption Determinants}

Next to the overall differences in relevance discussed in the following section, the content analysis also produced a number of noteworthy findings concerning individual determinant constructs and their sub-levels. The most relevant of these are summarised below for each of the main determinant constructs (except the Adoption Efforts and Results constructs, which have been discussed in detail in Chapter 4). The reader should note that since this is a summary of findings, only selected sub-constructs, dimension or variables are discussed here, and the remainder of determinants is discussed in Annex B.

\section{IOP Governance}

The detailed results for the IOP Governance construct are reported in Annex B2 and its subsections. The results are summarised in Table 5.1. The key findings, particularly concerning the Enforcement and Guidance sub-constructs, are summarised here. One noteworthy finding is that informal institutions appear to be of central importance to stakeholders - particularly in contexts where formal institutions are not sufficiently established. This can be inferred from the results regarding the Guidance sub-construct. First, at the sub-construct level for IOP Governance, the overall majority of quotations (41\%) falls to Guidance. And second, within the Guidance sub-construct, the results regarding the Communication dimension indicate that in situations with less formalised obligations for adoption, Communication takes on a relatively larger role. This can be seen from Figure Annex B.6, which shows that for Studielink (where compliance is not formally obligatory), the share of Communication quotations is significantly larger than for DKD (i.e. the case where adoption is formally mandated through the obligatory compliance with the WEU law). Moreover, as Table Annex B.13 shows, the Business Case Communication variable has a particularly higher share in the Studielink case. This indicates that it is especially the communication about the value creation through IOP standards adoption that creates a "pull" factor for organisations, substituting the "push" that formalised obligations for adoption could otherwise provide. 


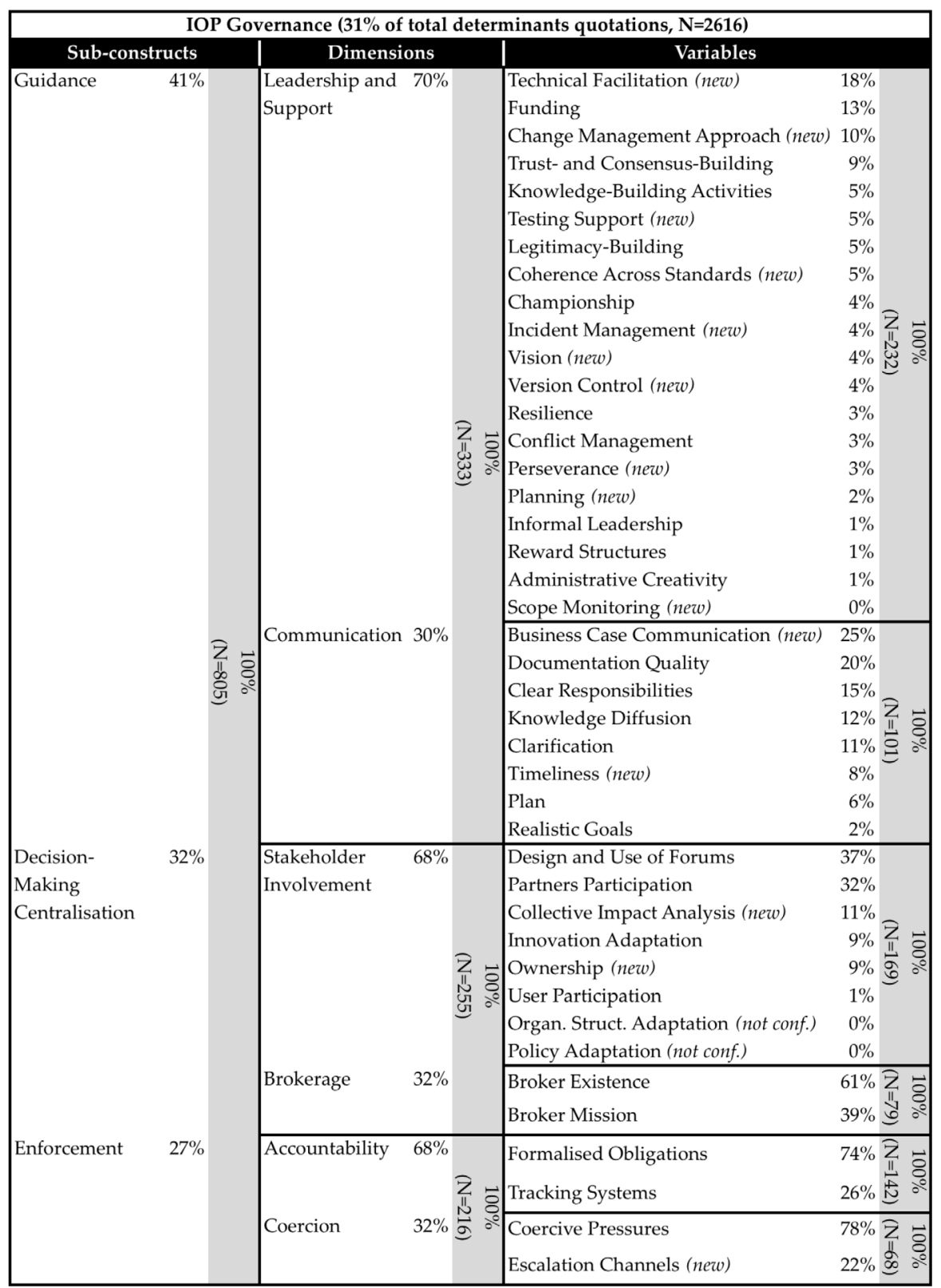

Table 5.1. IOP Governance aggregated frequencies ${ }^{115}$

\footnotetext{
${ }^{115}$ In Table 5.1 through Table 5.6, the frequencies are grouped per higher-level concept along the hierarchical structure from Figure 5.1. The $\mathrm{N}$ in the vertical grey columns refers to the total aggregated quotations for each higher-level concept, and the percentages refer to the share of each concept within its higher-level concept (displayed percentages are rounded, full values add up to $100 \%$ ). Inductively identified determinants are indicated with "(new)", and contested determinants with "(not conf.)". The meaning of "aggregated frequencies" is discussed in Section 4.3.1.
} 
A second and related finding is that at the same time, this does not mean that more formal institutions are not of substantial relevance to stakeholders as well. First, the DecisionMaking Centralisation sub-construct accounts for a considerable share of quotations (31\%), followed closely by the Enforcement sub-construct (27\%). With regard to the former, the large shares of quotations for the variables Design and Use of Forums and Partners Participation suggest that stakeholders find it particularly important how the forums for stakeholder involvement are institutionalised and whether and how partner organisations are (formally) included in decision-making on the IOP architecture. Second, with regard to Enforcement, it appears that the clear majority of quotations in the Enforcement sub-construct concerns Accountability (68\%), of which the largest share is held by the Formalised Obligations variable (74\%). This points to the importance of creating a solid framework of formal institutional foundations in order to support IOP standards adoption.

A third key finding is that it is of particular importance how the mix of formal and informal institutions is aligned with the network's characteristics, in particular its complexity. This is discussed in detail in Section 5.2.2.4 below and in Chapter 6. As Section 5.2.2.4 explains, the results indicate that formal institutions are more relevant for stakeholders in more complex networks. Evidence for this is for instance that the DKD case has a much larger share of quotations regarding the Enforcement sub-construct and its dimensions, in particular the Accountability dimension (Figure Annex B.9). Here, the relative share of quotations for the Formalised Obligations variable is almost twice as large in the DKD case compared with Studielink (Figure Annex B.10).

\section{Network Characteristics}

The detailed results for Network Characteristics are given in Annex B3, and summarised in Table 5.2. The first key finding for this construct is that the results point to the key role played by a network's complexity, with the Network Complexity sub-construct accounting for almost half $(48 \%)$ of all quotations in the Network Characteristics construct, whilst the other sub-constructs only make for a third or less of that share. In particular, the diversity of a network is a central dimension here, telling by the large majority $(70 \%)$ of quotations within the Network Complexity sub-construct. Whilst Structural Complexity also plays a significant role $(21 \%)$, Task Complexity (a mere $9 \%$ ) seems to be a less relevant dimension for stakeholders. This dominant role played by a network's complexity is in line with previous research pointing this out as a key factor which network governance needs to take into account (cf. Provan \& Kenis, 2008; Span et al., 2012), and is a fundamental reason to further investigate how IOP governance is related to network complexity (discussed in Section 5.2.2.4 below and in detail in Chapter 6).

Several findings emerge from the results concerning the remaining sub-constructs. A surprising finding concerning the Domain Structure sub-construct is that competition among organisations seems to be the most relevant factor in this regard. This supports the claims made in previous research that competitive forces are not only a relevant factor in privatesector networks, but also matter considerably in the context of public-sector networks (cf. Crosby \& Bryson, 2010; Jun \& Weare, 2010; Kamal, 2006; Kamal et al., 2011; Nelson \& Shaw, 2005). 


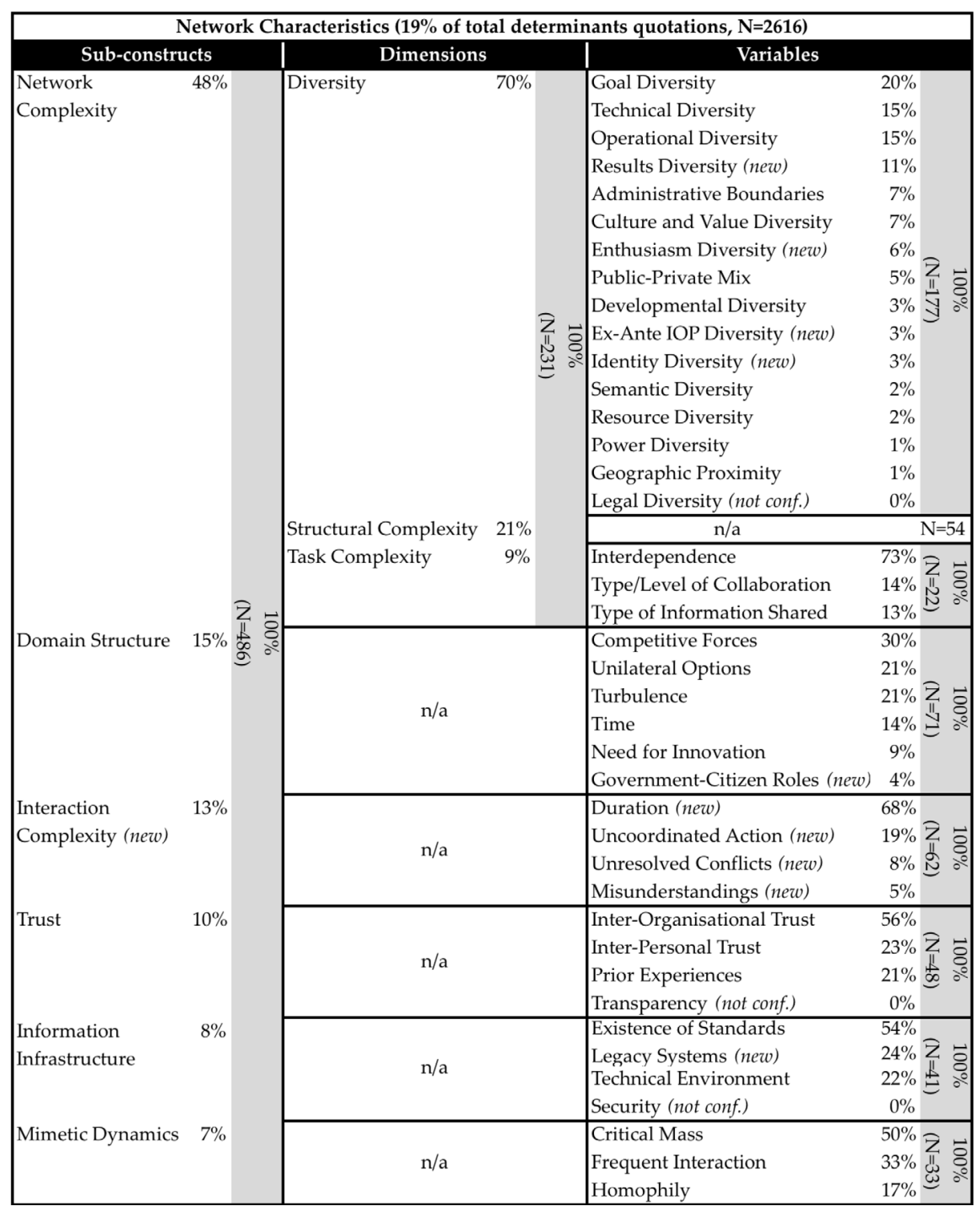

Table 5.2. Network Characteristics aggregated frequencies ${ }^{115}$

Another key finding is the inductive identification of the Interaction Complexity subconstruct, which provides a relevant addition to the factors that previous research had identified in relation to interaction among organisations, which is mostly focusing on trustrelated issues alone. The Interaction Complexity sub-construct, on the other hand, draws attention to the relevance of other interaction-related factors such as the duration of the adoption process, unresolved conflicts, misunderstandings or wayward behaviour of individual partners (see Annex B3.3 for a detailed definition of the variables identified here). As the results indicate, among these factors it is in particular the duration of the adoption 
process that matters to stakeholders: they mention this considerably more with regard to IOP standards adoption than all other aspects of Interaction Complexity (68\% of quotations for the Duration variable). This resonates with the argument developed from the analysis of adoption implications in Chapter 4 (Section 4.3.4) about the importance of organisations' "weighing" of the returns on invested efforts, pointing out that the timing of such "returnon-investment" is an important consideration (see also Annexes A4.2 and B3.3).

The results concerning the Trust sub-construct confirm that trust is a significant factor for organisations' intention to adopt IOP standards. Whilst this has been pointed out by previous theory (cf. Bekkers, 2009; Emerson et al., 2011; Provan \& Kenis, 2008), the results of this analysis show that a differentiation between types of trust should be made and that it is Inter-Organisational Trust (56\%) that matters considerably more than trust between individuals (which, with a share of $23 \%$ nevertheless is an important aspect).

A noteworthy finding regarding the Information Infrastructure sub-construct is the observation that more than half of quotations for the Information Infrastructure sub-construct concern Existing Standards (Table 5.2). This relates to the point made earlier in the context of IOP Governance about the relevance of institutional frameworks, suggesting that it is very important to develop a long-term IOP vision and policies such as IOP frameworks and national catalogues of standards. Such frameworks may ensure that networks in the future can maximise the utilisation of existing standards, so that organisations face less need and efforts to move away from any legacy systems.

Finally, concerning the Mimetic Dynamics sub-construct, a noteworthy finding is that the Critical Mass dimension contributes half of its quotations. This is in line with a central tenet of network effects theory and Rogers' (2003) argument that it is essential to have a critical mass of adopters early on in the process.

\section{Network-External Environment}

Concerning the Network-External Environment, the detailed results are provided in Annex B4. The first key finding here is that the results, summarised in Table 5.3, support the conclusion drawn with regard to the two constructs discussed above, namely that formal institutions including a long-term IOP policy (especially an effective legal framework) play a key role for IOP standards adoption. One observation pointing to this is that the Network-External Environment construct is dominated by quotations from the Policy and Institutions subconstruct (67\%). Within this sub-construct, the most significant dimension clearly is the Legal Framework (47\%), which supports the argument made above about the importance of a formalised legislative basis for effective Government Information Networks. Next to legal frameworks, budgetary issues play a significant role as well: roughly one fourth of quotations come from the Budgetary Frameworks dimension (24\%). Moreover, the significant share of quotations for Administrative Structure (18\%, of which $93 \%$ are contributed by the Stovepipes variable) suggests that in order to support adoption of IOP standards, a suitable administrative structure that avoids administrative fragmentation is an important aspect of the network-external environment. Whilst the Policy and Institutions sub-construct is the dominant aspect regarding the Network-External Environment, the Political Environment also plays a significant role (33\% of quotations for Network-External Environment). Here, it is in 
particular the Government Demand variable that is most important to stakeholders (64\%). This suggests that organisations' participation in Government Information Networks is largely driven by meeting government-internal goals for producing public value, rather than directly responding to the demand of their clients such as citizens and businesses.

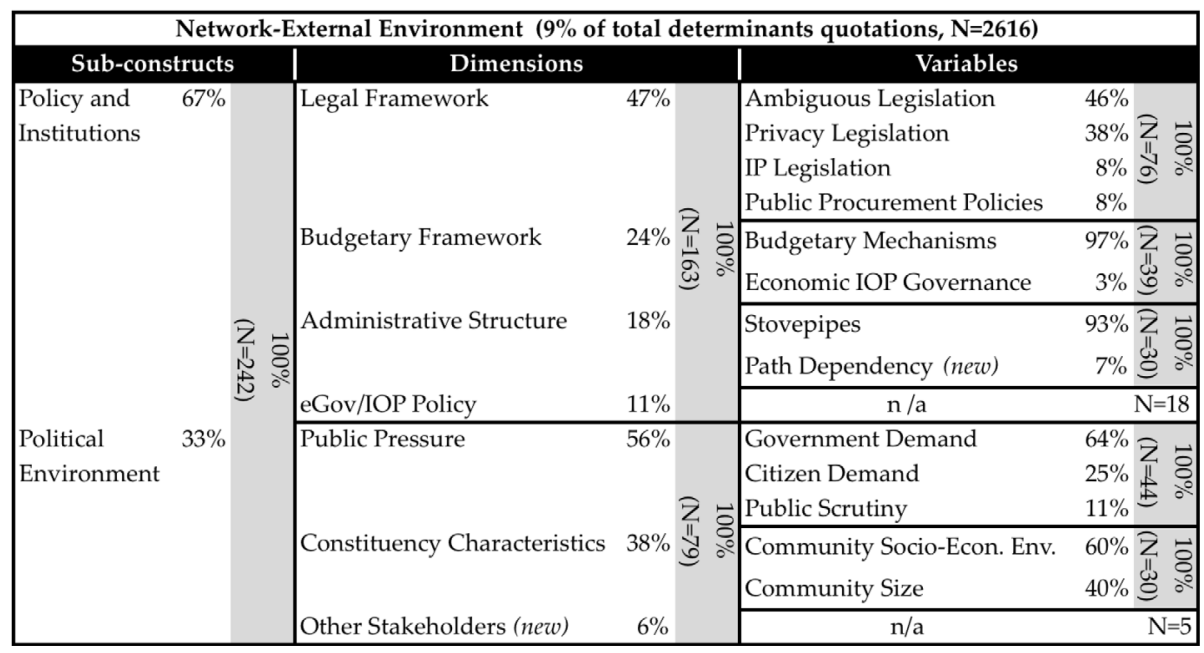

Table 5.3. Network-External Environment aggregated frequencies ${ }^{115}$

\section{IOP Standards Characteristics}

The detailed results for the IOP Standards Characteristics construct are reported in Annex B7. A summary is given in Table 5.4. The most noteworthy finding about this construct is that with only $1 \%$ of all determinants quotations, it appears to not matter much to stakeholders (Table 5.4). This supports the argument (described further in Section 5.2.2.2 below) that technological issues are of much lesser relevance to stakeholders than the more organisational or process-related issues. Within the small amount of quotations that this construct received, Maturity seems to be the most important sub-construct for stakeholders (53\%). This points to the need for a careful selection of standards that ideally have been proven by practice. As such, this also supports the argument made earlier about the beneficial role of utilising to the extent possible carefully curated lists of proven standards such as national standards catalogues or IOP frameworks.

\begin{tabular}{|c|c|c|c|}
\hline \multicolumn{4}{|c|}{ IOP Standards Characteristics ( $1 \%$ of total determinants quotations, $\mathrm{N}=\mathbf{2 6 1 6}$ ) } \\
\hline Sub-constructs & & Dimensions & Variables \\
\hline $\begin{array}{l}\text { Maturity } \\
\text { Correction Mechanisms (new) } \\
\text { Trialability } \\
\text { Customisability (new) }\end{array}$ & $\begin{array}{c}53 \% \\
22 \% \\
16 \% \\
\text { 군 } \\
9 \%\end{array}$ & $\mathrm{n} / \mathrm{a}$ & $\mathrm{n} / \mathrm{a}$ \\
\hline
\end{tabular}

Table 5.4. IOP Standards Characteristics aggregated frequencies ${ }^{115}$ 


\section{Organisation-Specific Determinants}

The detailed results for the Organisation-Specific Determinants construct are reported in Annex B8. The results are summarised in Table 5.5.

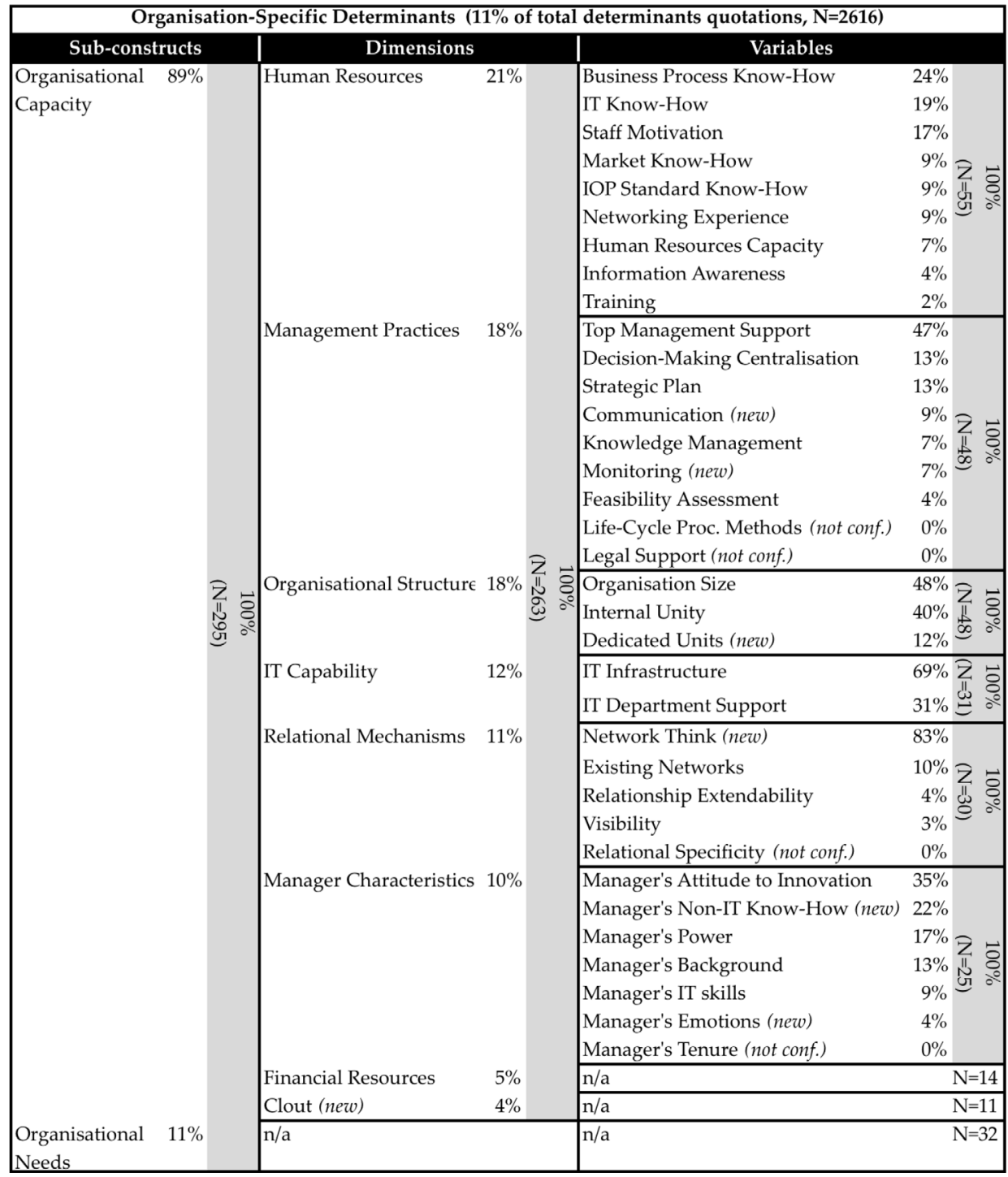

\section{Table 5.5. Organisation-Specific Determinants aggregated frequencies ${ }^{115}$}

The results show a very pronounced dominance of the Organisational Capacity sub-construct $(89 \%)$. It is noteworthy that within this sub-construct, almost all dimensions have received significant shares of quotations, and therefore most of the identified kinds of organisational capacities seem to play a significant role for stakeholders. The only exceptions are the Financial Resources and Clout dimensions, which both have only marginal shares (5\% and 4\% 
respectively). In particular regarding Financial Resources, this seems rather surprising given that Chapter 4 had shown how financial aspects play such a prominent role with regard to Adoption Efforts. This suggests that for facilitating the adoption of IOP standards, "soft" organisational capacities such as human resources and management skills, knowledge and processes are much more important than "hard" factors such as an organisations' mere power or financial resources.

\section{Adoption Implications: Adoption Efforts and Results}

The constructs Adoption Efforts and Results have been discussed in detail in Chapter 4 on adoption implications and are therefore not discussed again in this chapter. Table 5.6 shows the aggregated frequencies for both of these constructs together.

Adoption Implications ( $29 \%$ of total determinants quotations, $\mathrm{N}=\mathbf{2 6 1 6}$ )

\begin{tabular}{|l|l|}
\hline Results & $16 \%$ of total determinants quotations $(\mathrm{N}=425)$ \\
\hline Adoption Efforts & $13 \%$ of total determinants quotations $(\mathrm{N}=331)$ \\
\hline
\end{tabular}

Table 5.6. Adoption Implications aggregated frequencies

\subsubsection{Overall Differences in Relevance Across Types of Determinants}

This section gives a general overview of which types of determinants appear to matter most, and which ones less. First, a general finding in this regard is that when comparing the relevance of the various determinants across the types of IOP standards (technological, semantic and organisational), the relative distribution of the determinant constructs shows hardly any difference (co-occurrences between IOP dimensions and determinants constructs shown in Figure Annex B.2). This suggests that there are no significant differences in the relevance of the various determinant constructs across the different types of IOP standards, all of which thus should receive equal attention in terms of IOP governance.

A second key finding is that the most-frequently mentioned determinants are those from the IOP Governance (31\%) and Network Characteristics constructs (19\%) (see Table 5.1 and Table 5.2). The prominent share of overall quotations taken by these two constructs together give some support to the relevance of analysing them in more detail (which will be addressed in Chapter 6): clearly, given that IOP Governance is the determinant most mentioned by stakeholders, we should assume that achieving IOP in Government Information Networks very much is an issue of network governance. Moreover, the large share of quotations contributed by Network Characteristics suggests that the nature of a particular Government Information Network plays a key role for adoption decisions and thus needs to be a key aspect of any IOP governance design.

The third key finding is that in line with the argument made in Chapter 4, an important factor for the decision to adopt IOP standards is played by the "cost-benefit" analysis that organisations carry out. This is supported by the observation that Results (16\%) and Adoption Efforts (13\%) provide the next-largest shares of quotations, accounting for $29 \%$ of quotations overall (see Table 5.6).

A fourth finding from the overall distribution of quotations is that technology-related determinants are consistently less mentioned than organisational or process-related factors 
and thus seem to matter less to stakeholders. There are several indications for this pattern, notably the observation that the IOP Standards Characteristics construct plays only a negligible role for stakeholders $(1 \%$, see Table 5.4$)$, the small share of the Information Infrastructure sub-construct within Network Characteristics (8\%, see Table 5.2), as well as the (relatively) small share of IT Capability within the Organisational Capacity sub-construct (12\%, see Table 5.5). This is in line with earlier arguments that organisational factors weigh the heaviest for stakeholders' adoption decisions (see also Section 4.3.2). This implies that IOP is about much more than technological standardisation, as which it is too often conceived of. Even more, it implies that IOP should be seen as only a means to an end, and that in fact it is mostly about achieving organisational or process-related goals and outcomes.

\subsubsection{Difference in Relevance Across Stakeholder Roles}

Since the interviewees from the cases were selected to be either managers from individual partner organisations (i.e. organisation-level stakeholders) or managers from the "institutional field" in charge of coordinating the network (i.e. network-level stakeholders), several interesting findings could be gained as a result of comparing the frequencies for the individual determinants across these two stakeholder roles. It should be noted that for reasons of readability, the comparative frequencies at the basis of the findings presented below are not shown in Table 5.1 through Table 5.6, but can be found instead in the presentation of detailed results in Annex B.

The key finding from this comparison is that organisation-level stakeholders seem to be more concerned with the operational reality and implementation of standards (in particular implications for their organisation and its clients), whereas policy and institutional foundations are more reflected upon (and dealt with) by network-level stakeholders. On the one hand, since it is the adopting organisations that incur the biggest costs of having to comply with new standards, there clearly is a bigger concern with adoption implications at the organisational level. One indication in this regard is that the significantly larger share of quotations for the two adoption implications constructs (Results and Adoption Efforts) comes from organisation-level interviewees (see Figure Annex B.1). Another observation pointing to this conclusion is that there also is a bigger concern at this level with ex-ante IOP (i.e. the previous existence of standards), which is a factor that significantly reduces the costs of adopting additional standards (see Figure Annex B.16). Other indications in support of this conclusion are the bigger concern of organisational stakeholders with Organisational Capacities that determine adoption efforts (Figure Annex B.29), as well as the noticeably bigger concern with Public Pressure (in particular Citizen Demand) at this level (see Figure Annex B.19).

On the other hand, policy and institutional issues seem to be more of a concern for networklevel actors. This is most likely because they have more knowledge and practical experience with this through their role as governing actors: all issues related to IOP governance (with the only exceptions of the variables Knowledge-Building Activities and Broker Existence) appear to be more of a concern at network level (see in particular Figure Annex B.1, as well as all figures and tables in Section B2 for individual sub-concepts). In addition, the results show 
that policy and institutional foundations are more dealt with at network level (see the larger share of quotations for Policy and Institutions at this level as shown in Figure Annex B.18).

\subsubsection{Difference in Relevance Across Cases}

The analysis also compared the frequencies of quotations for the individual determinants across the two cases, DKD and Studielink. It found a number of differences across these two cases, pointing out the general necessity for a context-sensitive approach to IOP governance that takes into account the case-specific background. In the following, the key differences observed are summarised for each of the main determinant constructs. As in the previous section, the frequencies from which the findings below are derived are not included in Table 5.1 through Table 5.6, but are presented as part of the detailed results in Annex B.

With regard to IOP Governance and its various sub-constructs, the central finding is that overall, stakeholders in the more complex network (DKD) seem to be more concerned with IOP governance (see Figure Annex B.1). This might be because the larger a network is and the more diverse and interdependent the organisations in it are, the higher the likelihood that there is more divergence among them in terms of their information infrastructure. A case in point is for instance that the DKD case has a more than twice as large share for Interaction Complexity in comparison to the Studielink case (Table Annex B.15). Since there is an inherent tendency of more complex networks to have diverse information infrastructures and a lower capacity for self-governance towards IOP, it also becomes more difficult in such networks to achieve IOP throughout the network. As a result, there is a higher need for (central) coordination of the network's IOP architecture.

The results for IOP Governance indicate that both "strict", top-down governance (e.g. strict enforcement and accountability, centralised decision-making) and "soft", bottom-up governance (e.g. guidance and facilitation, communication and knowledge building) are important, but that different network complexities require different types of approaches to IOP governance. As shown by the results presented in the following paragraphs, stakeholders in the more complex Government Information Network attribute more weight to top-down and centralised aspects of IOP governance, whilst in the less complex network the emphasis is on "soft" governance. ${ }^{116}$

One observation supporting this argument presented above is that stakeholders from the DKD, as a more complex network, attribute more relevance to "hard" IOP governance and enforcement in comparison to Studielink (the less complex network). For instance, many more quotations regarding the Enforcement sub-construct come from the DKD case (Figure Annex B.9). As that figure shows, this holds for both dimensions of Enforcement: Coercion and Accountability. In particular regarding the latter, the quotation frequency for the Accountability dimension is more than double for the DKD than for Studielink. Similar

\footnotetext{
116 The content analysis alone cannot indicate more than a mere association between network complexity and governance approach (strict and centralised control being more often mentioned by stakeholders from complex networks). In order to investigate the assumption that particular governance approaches are also more suitable for a given network complexity, Chapter 6 follows up on this finding with an interpretive analysis of the relationship between network complexity and IOP governance (in particular the concept of IOP governance centralisation, see Section 6.2.1). The discussion here thus limits itself to the key findings from the content analysis in this regard.
} 
conclusions can also be drawn with regard to Decision-Making Centralisation. Whilst the overall distribution of quotations for this sub-construct leans slightly towards the Studielink case, the results for both its dimensions support the same conclusion as above: for the Brokerage dimension, reflecting a central coordination of the network's IOP architecture by a broker, the larger share of quotations comes from DKD, i.e. from the more complex network (Figure Annex B.8). Inversely, in Studielink (the less complex network), the Stakeholder Involvement dimension, reflecting a more decentralised decision-making regarding the network's IOP architecture, is relatively more frequently mentioned (Table Annex B.14).

Likewise, the larger share of quotations for the Guidance sub-construct coming from Studielink stakeholders suggest that less complex networks need more "soft" governance than more complex networks where top-down governance approaches seem more relevant (Figure Annex B.6). At the same time, however, the results also suggest that for more complex networks such as DKD, IOP governance needs to "diversify" more in order to achieve the desired results, whereas in smaller and less complex networks like Studielink, there might be both less capacity, and necessity, for such "leadership diversification": as Table Annex B.12 shows, stakeholders from the DKD case mention a considerably higher variety of Leadership and Support variables. In Studielink on the other hand, no or hardly any quotations could be observed for instance for the variables Planning, Administrative Creativity, Incident Management, Conflict Management, Scope Monitoring and Informal Leadership.

A second key finding regarding IOP Governance from the cross-case comparison is that the Communication dimension is sensitive to case-specific idiosyncrasies. Particularly noteworthy is that the Communication dimension is of considerably higher relevance to stakeholders in the Studielink case (Table Annex B.13). The likely reason for this is that in a network like in Studielink where there is no formal obligation for adoption (unlike in the DKD where the WEU law provided a legal backing for standardisation), "soft "governance plays a much more important role.

A number of considerable differences across cases could also be identified with regard to the other six determinant constructs, summarised in the following paragraphs. Whilst they concern a diverse variety of determinants, they all point to the overall conclusion that Government Information Networks can vary significantly along these aspects and there is therefore a necessity for context-sensitive IOP governance that takes into account the casespecific background and aligns its approach with the various factors that the framework presented here identifies.

With regard to the Network Characteristics construct, one illustrative example for this is the Domain Structure dimension, where a much larger share of Competitive Forces quotations comes from the Studielink case (Table Annex B.17). One plausible explanation for this is that in the higher education sector, there actually is considerable competition for attracting clients (students) - a dynamic that is absent from the work and income domain.

With regard to the Network-External Environment, both the Political Environment and the Policy and Institutions sub-constructs display significant differences across cases that support the above-made argument for the necessity of a context-sensitive IOP governance. With 
regard to the former, there are for example three times as many quotations overall for Studielink in comparison to DKD, which most likely results from the fact that throughout the project, there were big political controversies directly linked to Studielink (see Section 3.5.2.1 for a description of the "study rights debate"). Other examples are the various differences across cases identified for the Public Pressure dimension that could be attributed to the nature of the sector in which the network are operating, as well as its history (Figure Annex B.20). Concerning the Policy and Institutions sub-construct, an interesting difference across cases concerns the relevance of the Administrative Structure dimension, suggesting that stakeholders are considerably more concerned with administrative structures (in particular administrative fragmentation as represented by the Stovepipes variable) in older policy domains such as the work and income domain in which the DKD operates (Figure Annex B.22).

Significant variation across cases can also be observed regarding the Organisation-Specific Determinants construct. In particular with regard to the Organisational Capacity sub-construct, the results indicate that Government Information Networks can differ significantly in terms of the participating organisations and their characteristics (Table Annex B.18).

Similar idiosyncrasies do also play a role regarding the IOP Standards Characteristics construct. For instance, a much larger share of quotations for this sub-construct comes from the Studielink case (Figure Annex B.28) - largely resulting from a higher share of Trialability quotations in this case. A plausible explanation for this is that since Studielink is a much more recent network and many partner organisations had little to no familiarity with the IOP standards in this network, they placed much greater emphasis on the possibility to gain more experience with them.

The differences across cases for the implications constructs Results and Adoption Efforts are less pronounced than for the other constructs, but are nevertheless noticeable. For the Results construct for instance, a significantly larger number of quotations for ROI Results comes from the Studielink case (Figure Annex B.26), which is most likely because higher education institutions operate in a more competitive market environment where a business case becomes much more important. An interesting cross-case difference with regard to the Adoption Efforts construct is for example that it is more often mentioned by interviewees from the Studielink case (Figure Annex B.27), possibly because in this case, the efforts for adoption had to be made over a shorter period of time and therefore had a sharper impact than in the DKD, where standardisation unfolded over a considerably longer time period.

\subsubsection{Difference in Relevance Across Adoption Phases}

The analysis also included an analysis of co-occurrences of the various determinants with the post-adoption-decision project phases (planning, implementation and operational phases) in order to see whether and how the determinants unfold variation in their relevance for stakeholders over time. The central finding from this part of the analysis was that indeed, a number of determinants play a differential role for stakeholders throughout this part of the standards adoption process, which implies that IOP governance needs to take into account these differences, and differentiate across phases to address individual determinants at those points in the process when they play their strongest role. 
Two key findings stand out from this analysis. The first is that overall, the determinants are most relevant to stakeholders in relation to the operational phase (Figure Annex B.4). Hence, this is when IOP governance needs to pay the most attention to determinants' effects on compliance with the standards. A second key finding in this context is that it is the implications of IOP standards adoption (i.e. Results and Adoption Efforts) that vary the most across the three phases: as shown in Figure Annex B.4, the results here confirm the finding from Chapter 4 that adoption implications are the most relevant to stakeholders while planning the adoption of IOP standards and regarding the actual compliance with them.

\subsubsection{Difference in Relevance Across Support Actors}

A co-occurrence analysis also allows to investigate the importance of the various types of support actors ${ }^{117}$ with regard to the individual determinants. Here, the central finding is that there is considerable difference in the actors' roles with regard to determinants (Figure Annex B.3). This is in line with the conclusion from Chapter 4 that IOP governance is a concertation of multiple actors, and that a key consideration for effective IOP governance is to establish a framework for a productive interaction of this array of actors. In particular, the analysis indicates that the Broker is (relatively speaking) the most important type of actor with regard to all determinants constructs - except Network-External Environment, where Central Government plays the leading role. The reason for this most likely is that it is here where the determinants Political Environment and Policy and Institutions are located, both of which are by nature most tightly linked to the role played by political actors.

However, a second key finding here is that IOP governance is not just a matter of publicsector actors like brokers and political actors, but that it is very much a public-private collaboration. This is shown by the large role played by Vendor actors with regard to Adoption Efforts, which as shown earlier, is one of the key adoption determinants: here, vendors are the second-most mentioned actor type behind broker bodies (Figure Annex B.3). As Chapter 4 (particularly Section 4.4.1.3) has already elaborated, vendors play a key role with regard to technical facilitation to reduce adoption efforts (for example, in Studielink the SIS providers often provide a support structure for adoption which many higher education institutions depend on).

Finally, another key finding is the major role played by Umbrella Bodies with regard to Organisation-Specific Determinants (Figure Annex B.3). This finding is particularly interesting because Umbrella Bodies are an actor type that is not usually discussed in the literature. However, as this finding highlights, they should be taken more into consideration, in particular with regard to Organisational Capacity (which accounts for nearly $90 \%$ of Organisation-Specific Determinants).

\subsection{Conclusion}

This chapter aimed to validate and refine the preliminary theoretical model that was generated based on the theory review in Chapter 2, and to identify and explain what the determinants are for the adoption of IOP standards by organisations in Government

\footnotetext{
${ }^{117}$ See Section 4.4.1 for an in-depth analysis of these actor types and their roles.
} 
Information Networks. The specific research question it addressed is: "what are the factors that determine the adoption of IOP standards by organisations in Government Information Networks"? To this end, it used the empirical data from the DKD and Studielink cases.

Overall, the analysis presented in this chapter yields a similar conclusion to what Chapter 4 had already found with regard to the implications from IOP standards adoption: there is a complex interplay of a wide range of determinants for IOP standards adoption, displaying significant variation in terms of their relevance, both overall as well as across specific contexts of different networks, stakeholder levels, project phases and actors involved. Effective IOP governance, therefore, is shown in this chapter to require a context-sensitive approach that takes into account the identified differences.

Based on the findings from the analysis, this section provides conclusions and recommendations for IOP governance. It first provides some general conclusions regarding the overall framework and the relation of the determinant constructs to the IOP dimensions, stakeholder roles, the different cases, support actors, and the temporal dimension. Subsequently, it presents specific conclusions and recommendations for each major determinant construct in turn: IOP Governance, Network Characteristics, Network-External Environment, Adoption Efforts and Results, IOP Standards Characteristics, and OrganisationSpecific Determinants.

Overall, the final framework resulting from the analysis provides an important foundation for constructing measurement models for future research on the determinants of IOP standards adoption, and specifies a theoretical framework for their role with regard to IOP standards adoption. First, all seven previously specified main determinant constructs are shown to play a role for IOP standards adoption, albeit to very different degrees (see Section 5.2.2 and Annex B1). Except the IOP Standards Characteristics construct, they clearly all play a considerable role and thus all need to be carefully taken into account for successful IOP governance. Only the IOP Standards Characteristics construct seems to play a negligible role for the interviewed stakeholders.

Second, the analysis also expanded and revised the previously specified framework. In total, 51 new determinants were added to the model as a result from the inductive coding, including eight full sub-constructs and dimensions (see Section 5.2.1). On the other hand, 15 of the determinants that had been specified ex ante based on the theory were not confirmed in the data from the cases (see Section 5.2.1). Given that this study only investigates two cases, this cannot be taken as a definitive conclusion that these factors would not play a role in other cases (they might have simply been omitted by the interviewees). However, it does raise a question mark on their validity and suggests that future analyses investigate their salience more directly.

As mentioned above, the chapter identified significant differences in terms of the determinants' relevance for stakeholders, both overall but also across IOP dimensions, stakeholder roles, the different cases, support actors, and the temporal dimension, suggesting that a context-specific perspective is most appropriate. Overall, the analysis of the co-occurrences between the main determinant constructs and IOP standards showed that the relative distribution of the determinant constructs is very similar for all three IOP 
dimensions (see Section 5.2.2.2 and Annex B1). We can thus assume that the observed salience of the various determinant constructs is consistent across all IOP dimensions. This suggests that, when designing IOP governance strategies in view of the observed relative salience of these determinants, no differentiation needs to be made whether it concerns technical, semantic, or organisational standards.

However, the analysis also showed that, the technology-related determinants were consistently less mentioned than organisational or process-related determinants. Whilst IOP is too often conceived of as being about mere technological standardisation, this finding implies that IOP is about much more than that. Moreover, it suggests that IOP is only a means to an end, and that in fact it is mostly about achieving organisational or processrelated goals and outcomes.

The chapter presented several differences in the relevance of determinants for network-level and organisation-level stakeholders. Generally, organisation-level stakeholders show more concern with the implementation of standards and their implications for the operations of their organisations, whereas network-level stakeholders tend to reflect more on policy and institutional foundations. IOP governance therefore should give special consideration to the findings and recommendations provided in Chapter 4 regarding the implications of adoption. Moreover, it should also make sure that it maximises the utilisation of the knowledge and practical experience with policy and institutional foundations that is available at network level.

The chapter also presented several findings regarding differences in the relevance of determinants across the two cases, pointing out the general necessity for a context-sensitive approach to IOP governance. First, the findings showed that both "strict", top-down governance and "soft", bottom-up governance are important, but that different network complexities require different types of approaches to IOP governance. In particular, this chapter suggested that due to the stronger tendency of actors towards divergence instead of standardisation in more complex networks, there is a higher need for (central) coordination of the network's IOP architecture, and that IOP governance needs a stronger and more diverse leadership capacity. Moreover, in networks with little formal obligation for adoption (such as a legislative backing for standardisation), "soft" governance such as effective communication strategies play a much more important role.

Second, the chapter also showed that besides Network Complexity, Government Information Networks can vary significantly along the other six determinant constructs. Again, this suggests that for IOP governance, there is therefore a necessity for context-sensitive approaches that take into account case-specific idiosyncrasies.

By looking at the co-occurrences between the determinant constructs and the support actor categories, the chapter also showed that actors' roles are not the same for all determinants (see Section 5.2.2.5). First, it showed that a central role is played by broker bodies with regard to all determinants constructs except Network-External Environment, where the central government plays the leading role. Second, it showed that IOP governance is not just a matter of public-sector actors like broker bodies and political actors, but that it is very much a public-private collaboration, in particular with regard to the involvement of vendors to 
give support regarding the important aspect of Adoption Efforts. And third, the chapter pointed to the major role played by sectoral umbrella bodies with regard to OrganisationSpecific Determinants.

Overall, these findings support the conclusion from Chapter 4 that IOP governance is a concertation of multiple actors, and suggests that the central question for good IOP governance design is thus who to involve, when and how. The keys to this are for instance to determine which support actors have an influence regarding which determinants, and whether and how their support role in this regard could possibly be strengthened in order to enhance their capacity to provide support.

The chapter also investigated the determinant constructs across the temporal dimension, i.e. looking at the co-occurrences between the Adoption Phase codes and the determinant constructs (see Section 5.2.2.4). The findings here suggest that determinants exert most of their influence in the operational phase, so this is when IOP governance actors need to be the most mindful of the potential effects of the various determinants on compliance. Moreover, the analysis concluded that IOP governance also needs to look for differentiation of specific determinants across the phases, and address them in those phases where they play their strongest role.

The remainder of this section discusses the conclusions and recommendations for each major determinant construct in turn. It begins with the IOP Governance construct (see Section 5.2.2.1). With regard to IOP Governance, the content analysis suggests that the achievement of IOP in Government Information Networks is predominantly a matter of effective governance. In this context, the chapter showed that it matters how the mix of formal and informal institutions is aligned with the network's characteristics, in particular its complexity (addressed in detail in Chapter 6).

First, whilst formal institutions are of substantial relevance to stakeholders as well, the analysis showed that it is soft governance and informal institutions that appear to be of primary importance to stakeholders. Guidance, and in particular good leadership clearly is a central issue, in both cases. However, the data also suggests that in smaller and less complex networks, there is relatively less need (and capacity) for strong leadership. This is not at all to say that leadership becomes unimportant in less complex networks - but it supports the argument that there is a connection between Network Complexity and IOP Governance.

Second, the findings on the relation between Communication and Enforcement also showed that such informal governance is particularly relevant in contexts where formal institutions are not sufficiently established. Where there is no formalised obligation for adoption (as in the DKD, where adoption is mandated through the WEU), Communication takes on a relatively larger role - especially communication about the value creation through IOP standards adoption.

Third, regarding Decision-Making Centralisation, the quotations analysis also supports the argument about the positive relation between Network Complexity and IOP Governance: DKD (which is the more complex network) has a very clearly assigned infomediary organisation, and interviewees also attribute relatively more importance to Brokerage. In Studielink (the 
less complex network) on the other hand, Stakeholder Involvement is relatively more often mentioned since stakeholders are actually more exposed to involvement in IOP Governance.

Finally, the analysis also showed that IOP Governance is considerably more reflected upon by network-level actors than by organisational actors. This can have two implications, depending on where one wants to locate decision-making rights (see Chapter 6 for a discussion of this question): either that infomediary organisations would need more support and powers to carry out these governance functions, or that communication and knowledge-building efforts need to be stepped up in order to make sure that adopting organisations share the concern for governance issues and have the necessary know-how to take part in them.

The chapter also yields a number of conclusions regarding Network Characteristics (see Section 5.2.2.1). First, the large share of quotations contributed by Network Characteristics suggests that the nature of a particular Government Information Network plays a key role. Second, Network Complexity (in particular its dimension Network Diversity) as the most-often mentioned sub-construct warrants particular attention when setting up the governance design. Third, the considerable differences across cases throughout the various Network Characteristics suggest that it is important for IOP governance to be aware of the background and the weight of these factors in that specific case in order to design governance in a way that is aligned with these factors. Fourth, the results from the Information Infrastructure analysis suggest that it is very important to have a long-term, sustainable IOP vision so that organisations in the future can build on existing standards and incur less efforts of moving away from their legacy systems. A lesson from the DKD case is that this needs time to emerge, but can go much quicker if the necessary support (e.g. funding) and incentives (e.g. legal obligations) are given. Fifth, the analysis on Mimetic Dynamics suggests that IOP governance should in particular try to create a critical mass of adopters early on in the process.

Regarding Network-External Environment, there are several conclusions to be made (see Section 5.2.2.1). First, the analysis suggests that for both complex and non-complex networks, a sound and sustainable IOP policy based on formal institutions and dedicated policies (in particular a solid legal framework) should be an integral part of an effective IOP governance. Second, the nature and history of the sector in which a network is operating need to be carefully taken into account in order to fully understand the role of the Political Environment for IOP standards adoption. In particular, a suitable administrative structure (free from bureaucratic fragmentation) needs to be sought in order to support adoption of standards. And third, since the findings suggest that organisations' participation in Government Information Networks is largely driven by meeting government-internal goals for producing public value rather than directly responding to the demand of their clients, IOP governance should put more emphasis on the longer-term benefits in terms of public value to the end-users. This can add to the already existing acknowledgement of the government-internal benefits by stakeholders.

As indicated by the significant amount of quotation frequencies for Adoption Efforts and Results, the constructs describing the implications of IOP standards adoption (see Section 5.2.2.1), the analysis also suggests that a significant role for stakeholders' adoption decision 
is played by the implications of adoption and the related "cost-benefit" analysis which organisations carry out. Therefore, IOP governance needs to carefully monitor these implications and their interpretation by partner organisations. The role of these implications and their significance for IOP governance are discussed in detail in Chapter 4.

The low relevance attributed to the IOP Standards Characteristics construct (see Section 5.2.2.1) supports the argument made above that technological issues are of much lower relevance. The dominant share of the Maturity variable suggests that IOP governance should pay attention to deploy only standards in a network that have already been proven to be free from risks and uncertainties, ideally by having been tested and successfully adopted in other, similar contexts.

Concerning the Organisation-Specific Determinants (see Section 5.2.2.1), the analysis revealed a dominance of the Organisational Capacity sub-construct and that most of the identified kinds of organisational capacities seem to play a significant role. It also suggests that IOP governance should put an emphasis on developing organisations' "soft" capacities such as human resources and management skills rather than "hard" factors such as an organisations' mere power or financial resources. Finally, the results suggest that IOP governance should analyse carefully which capacities are present, and which ones are lacking across organisations in a specific Government Information Network in order to provide proper guidance and support to the participating organisations.

In conclusion, this chapter has shown that the adoption of IOP standards by organisations in Government Information Networks is determined by a wide range of factors that can be grouped into a model of seven determinant constructs: IOP Governance, Network Characteristics, Network-External Characteristics, IOP Standards Characteristics, Adoption Efforts, Results and Organisation-Specific Determinants. It has shown that each of these plays a role for adoption, but that there are differences in the relevance of these determinants, in particular when a comparison is made across cases. Therefore, whilst the model proposed in this chapter can be of general use to identify, measure and monitor the determinants of adoption, IOP governance needs to take into account the specific context of a particular Government Information Network and tailor its IOP governance according to this context. This need for such a context-sensitive approach to IOP governance is addressed in more detail in the following chapter. 


\section{Annex B. Detailed Results from the Content Analysis of Determinants}

This Annex presents in full detail the results from the content analysis on adoption determinants, which has been discussed in summarised form in Chapter 5. The presentation of results here closely follows the theoretical framework introduced in Chapter 2. To provide an orientation for the reader through the layered conceptual structure of this framework, a schematic overview of the constructs, sub-constructs, dimensions and variables $^{118}$ discussed in the following sections is provided by Figure 5.1 in Chapter 5.

This Annex is structured as follows. Sections B1 through B8 present the results on the various determinant constructs from the empirical analysis of the DKD and Studielink case studies, in order to validate and refine the preliminary theoretical model introduced in Chapter 2. First, Section B1 gives a high-level overview of the determinants constructs. Then, in Sections B2 through B8 each of the main determinant constructs and their subordinate concepts (sub-constructs, dimensions and variables) are discussed in detail: IOP Governance (Section B2), Network Characteristics (Section B3), Network-External Environment (Section B4), Results (Section B5), Adoption Efforts (Section B6), IOP Standards Characteristics (Section B7) and Organisation-Specific Determinants (Section B8). Together, the results discussed in these sections contribute to a revised version of the theoretical model, which is presented in Section 5.2.1, including a schematic presentation of the model (Figure 5.2) and a complete list of determinants (Table 5.1 through Table 5.6). For the reader's orientation, Figure 5.1 in Section 5.2 provides an overview of where in this Annex the individual determinants are discussed.

\section{B1. Determinant Constructs - Overview}

This section gives an overview of the determinant constructs in a comparative discussion that presents the content analysis for all constructs, and looks at their relevance (i.e. cooccurrences ${ }^{119}$ ) across IOP dimensions, support actors, and project phases.

Figure Annex B.1 shows the distribution of aggregated frequencies ${ }^{120}$ for each of the seven main determinant constructs. The figures illustrate that all the identified constructs play a significant role for IOP standards adoption, with the exception of IOP Standards Characteristics, which only seems to play a marginal role. Figure Annex B.1a shows that the most often-mentioned determinants are those from the IOP Governance (31\%) and Network Characteristics constructs (19\%). The prominent shares taken by these two constructs highlight the relevance of analysing them in more detail (which will be addressed in Chapter 6, looking at the interaction between IOP Governance and Network Complexity in particular). The next-largest shares are taken by the constructs Results (16\%) and Adoption

\footnotetext{
${ }^{118}$ This four-level conceptual hierarchy of the conceptual model is introduced in Section 2.4.

${ }^{119}$ See Section 3.4 for a detailed definition of this term.

${ }^{120}$ The same method for calculating "aggregated frequencies" was used here as described in Chapter 4.
} 
Efforts (13\%). As these constructs represent the implications of IOP standards adoption (discussed in Chapter 4), we can assume that an important role for IOP standards adoption is played by the "cost-benefit" analysis that organisations carry out with regard to IOP standards adoption (as described in detail in Chapter 4). Organisation-Specific Determinants (11\%) and Network-External Environment (9\%) form smaller contributions, but nevertheless seem to play a significant role for adoption. Only the very small share of quotations for IOP Standards Characteristics (1\%) suggests that this construct plays only a minor role for stakeholders.

a)

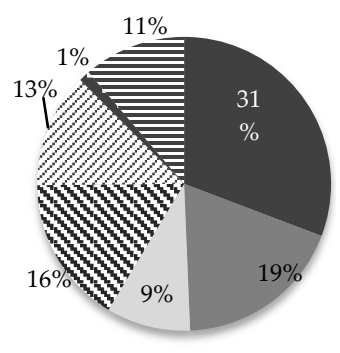

b)

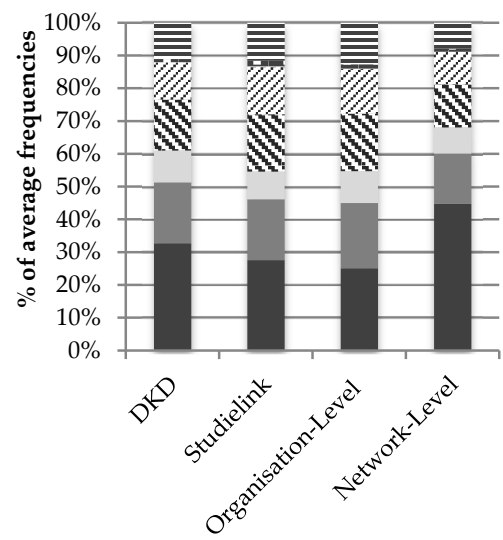

$\equiv$ Organisation-Specific

Determinants

ᄃ IOP Standards

Characteristics

* Adoption Efforts

Results

Network-External

Environment

network Characteristics

- IOP Governance

Figure Annex B.1. Adoption determinants quotations (aggregated frequencies, rounded percentage). Figure a) shows overall quotations distribution $(\mathrm{N}=2616)$ and Figure $\mathrm{b})$ shows the percentage distribution of average quotations frequencies ${ }^{121}$ per case and interviewee role

As Figure Annex B.1b shows, this picture is quite consistent across groups. Given the large pool of quotations from which this is drawn, we can assume that this distribution will be relatively similar for cases that are alike to the DKD and Studielink networks.

An analysis of co-occurrences provides some additional insight on the relation of the individual adoption determinants and IOP dimensions, support actors, and project phases. One question concerning the overall quotation frequencies for the main determinant constructs is whether they play a different role when it comes to the different types of IOP standards (along the three IOP dimensions introduced in Chapter 1). Analysing the cooccurrences between quotations of the determinant constructs and the IOP dimensions shows how many interviewees mentioned the individual adoption determinants when speaking about technological, semantic, or organisational IOP - thus giving an indication as to the role of the determinants across the three IOP dimensions (and vice versa). But as the co-occurrences between the main determinant constructs and IOP standards show (Figure Annex B.2), the relative distribution of determinant constructs is very similar for all three

${ }^{121}$ The same method for calculating "average frequencies" was used here as described in Chapter 4. 
IOP dimensions. If we invert the axes in the figure (not shown here), we can see that the general observation presented in Chapter 4 (Figure 4.1) about the distribution of IOP dimension quotations largely holds across all major determinant constructs: organisational IOP and technological IOP form the largest shares, ranging between roughly $30-50 \%$, and semantic IOP forms the smallest share across all determinant constructs (ranging between $10-20 \%$ approximately).

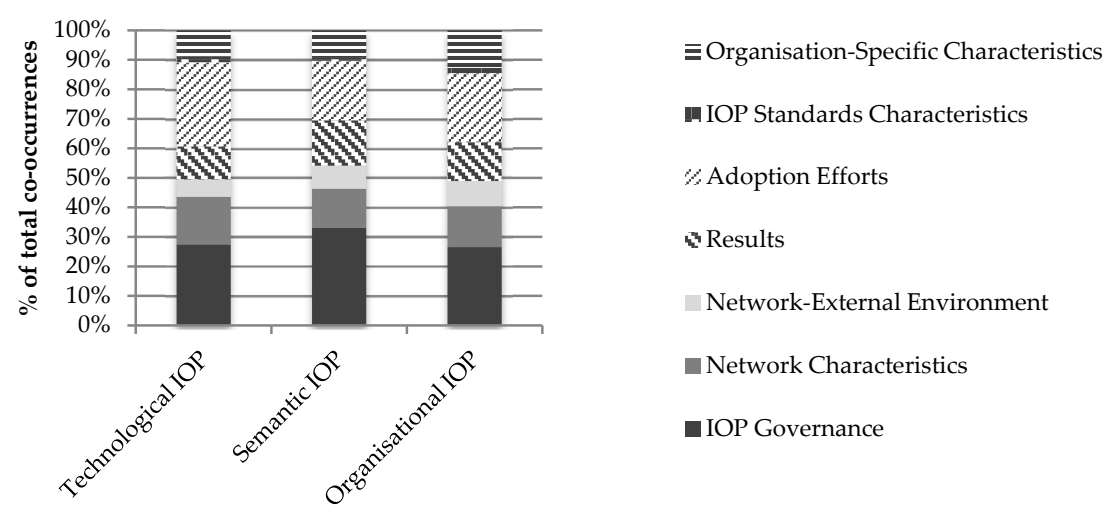

\section{Figure Annex B.2. Co-occurrences of determinant constructs with IOP dimensions}

Another co-occurrence analysis provides some indication as to the role of the various interorganisational actors across the adoption determinants. Analysing the co-occurrences between quotations of the determinant constructs and the Actor codes shows how many interviewees mentioned the individual adoption determinants when speaking about interorganisational actors. Figure Annex B.3 shows these co-occurrences and shows that there is some interesting variation with regard to the roles of the different actors across interviewee groups. ${ }^{122}$ First, Central Government actors appear to play a significantly larger role with regard to determinants from the Network-External Environment. It is here that determinants like Political Environment and Policy and Institutions are located, which are determinants that are by nature closely dependent on the role played by political actors.

Second, there is also some variation for the Broker code: whilst for most other constructs, the share of Broker quotations ranges between roughly 40-50\%, for the Network-External Environment construct it only is less than $30 \%$. This might indicate that determinants in this area are largely out of the influence sphere of such infomediary organisations, and therefore there is less of a role to be played by such organisations here.

Third, with regard to the role of Umbrella Body actors, a noteworthy observation is the relatively larger amount of Umbrella Body quotations that co-occur with Organisation-Specific Determinants, indicating that umbrella bodies play a more significant role with regard to Organisational Capacity (which form the large majority of that construct).

\footnotetext{
122 The co-occurrences for the IOP Standards Characteristics construct cannot be assumed to be reliable sources for inference due to the rather small overall number of quotations for this construct $(\mathrm{N}=32)$.
} 
Fourth, with regard to the Standard-Setter actors, we can see that they are almost exclusively mentioned in relation to IOP Governance and virtually not discussed at all in relation to the other constructs. This is most likely because IOP governance is in essence concerned with setting and administering IOP standards and their adoption and compliance.

Fifth, regarding vendors, whilst they appear to only play a rather small role overall, it is noteworthy that Vendor quotations take a much larger share of co-occurrences with the Adoption Efforts construct than with the others, being the second-most mentioned support actor in this area after the broker. An explanation for this could be that, as Chapter 4 showed, a lot of the adoption efforts have to do with the technical facilitation received by the vendors: for example, the efforts that are required from higher education institutions in Studielink are very much dependent on the support structure provided by their SIS provider.

And finally, we can see that Consultant quotations co-occur rather rarely with all determinant constructs, and virtually do not appear at all in relation to Network-External Environment. In fact, the interviews did not mention consultant services as something that played a structural or formal role with regard to adoption. Rather, interviewees reported consultant involvement only in relation to incidental problems when external advice was required.

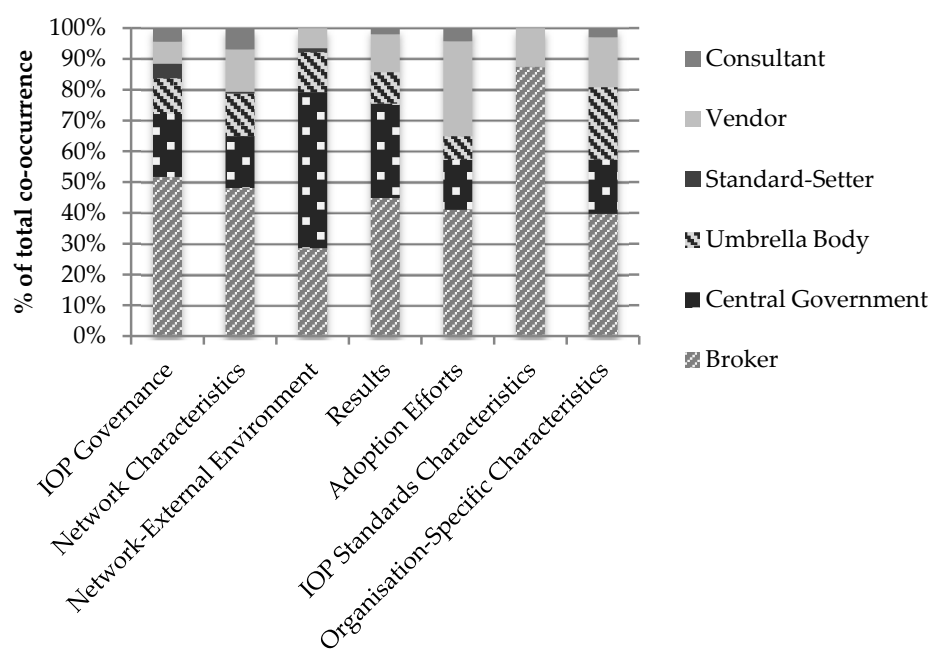

\section{Figure Annex B.3. Co-occurrences of determinant constructs with Actor codes}

A co-occurrence analysis can also provide some insights regarding the role of the adoption determinant across the three phases following the adoption decision (see Section 4.4.2.2 in Chapter 4). Analysing the co-occurrences between quotations of the determinant constructs and the Adoption Phase codes shows how many interviewees mentioned the individual adoption determinants when speaking about the three phases of planning, implementation and operation. Figure Annex B.3 thus allows to derive some insights about the (changing) role of the various determinants across the different phases in the adoption process. Looking 
at the overall frequencies, it is apparent that the most co-occurrences with determinants are in relation to the Operational Phase - suggesting that this phase is where most of the factors play their most influential role.

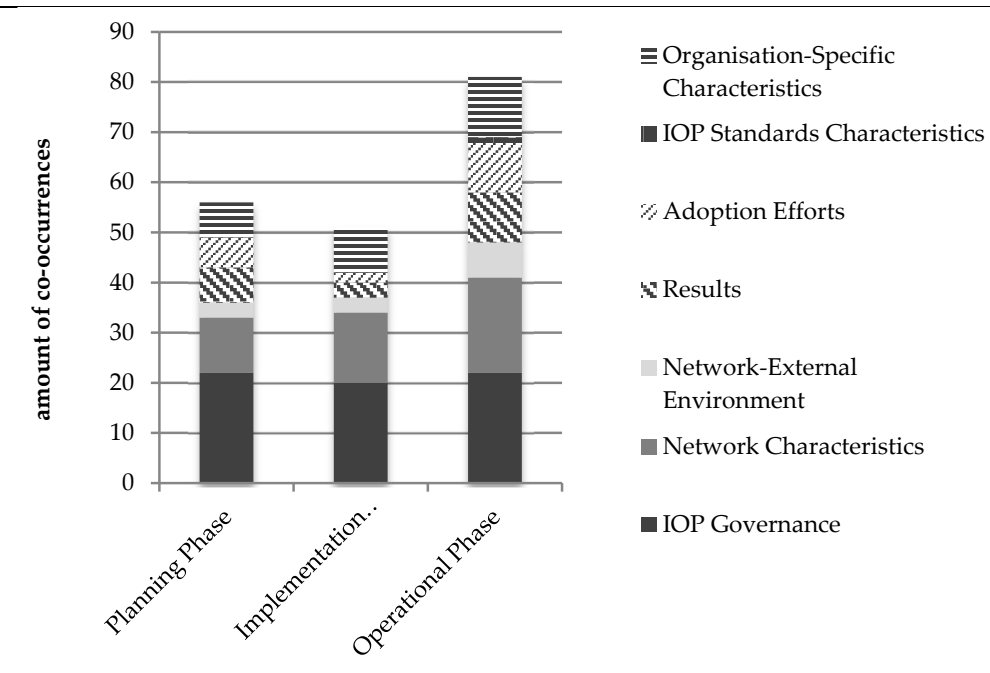

Figure Annex B.4. Co-occurrences of determinant constructs with Adoption Phase codes

It is also possible to discover some variation when we look at the relative distributions of the individual constructs over the three phases. Whilst all constructs vary to some degree in their share across phases, it is the implications from IOP standards adoption (i.e. Results and Adoption Efforts constructs together) that show the largest variation, namely a considerably smaller share during the implementation phase in comparison to the other two phases. This observation is largely in line with the interpretation from Chapter 4, namely that implications from IOP standards adoption have their largest significance when it comes to the planning of implementation and to compliance with IOP standards.

In the following sections, the individual determinants constructs will each be discussed in more detail. Each section contains separate figures or tables that visualise the detailed findings from the content analysis for each determinant group, showing the overall quotation distribution of individual determinants within their parent concept (e.g. all variables per dimension), as well as a comparative display of the average frequencies of quotations per case and interview role. The same data is also presented in overview tables: the overall quotation distribution is shown in Table 5.1 through Table 5.6 in Chapter 5, and the comparative display of the average frequencies of quotations per case and interviewee role is shown in Table Annex B.1 through Table Annex B.11 on the following pages. 


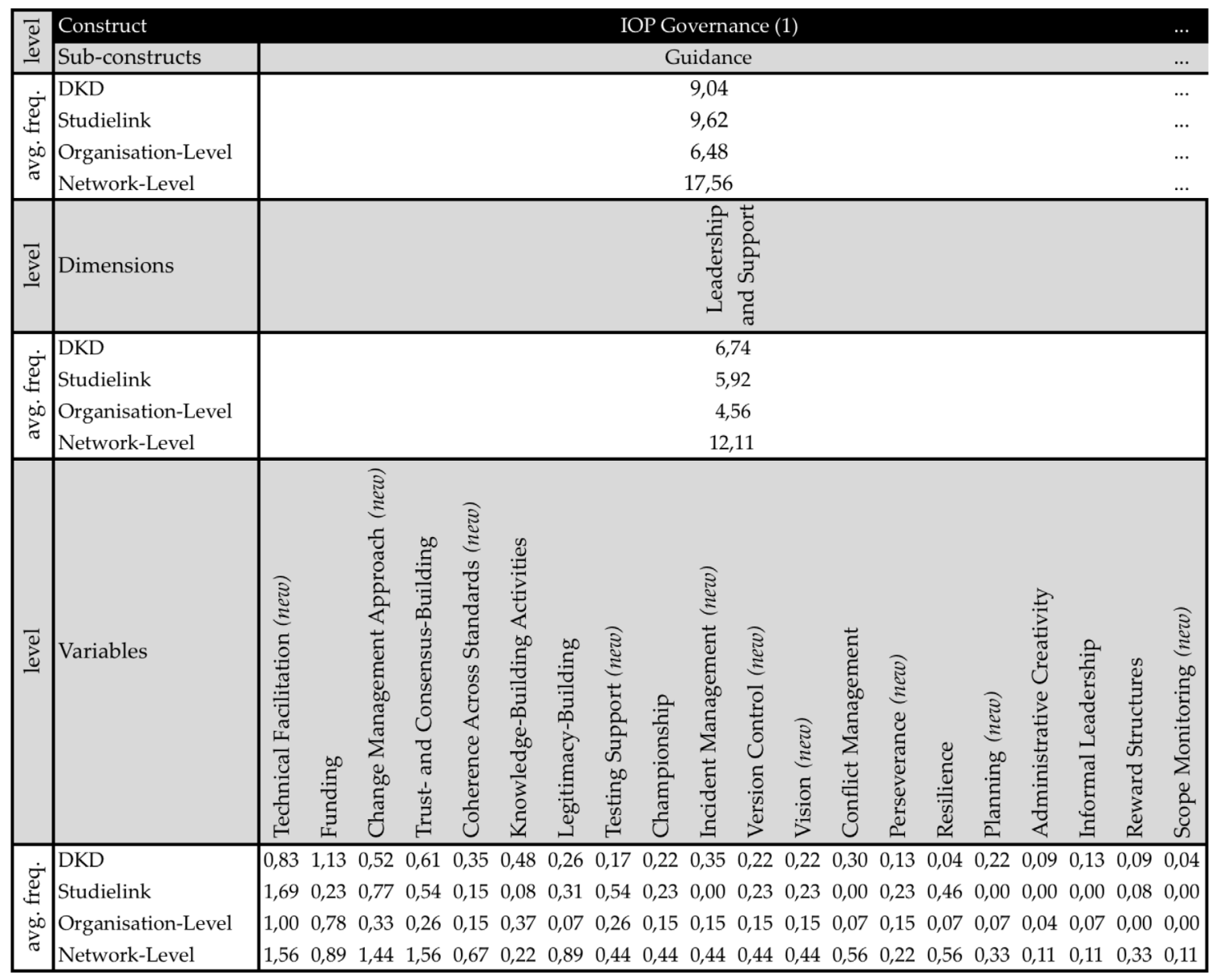

Table Annex B.1. Average quotation frequencies per case and interviewee role for the IOP Governance construct (1) 


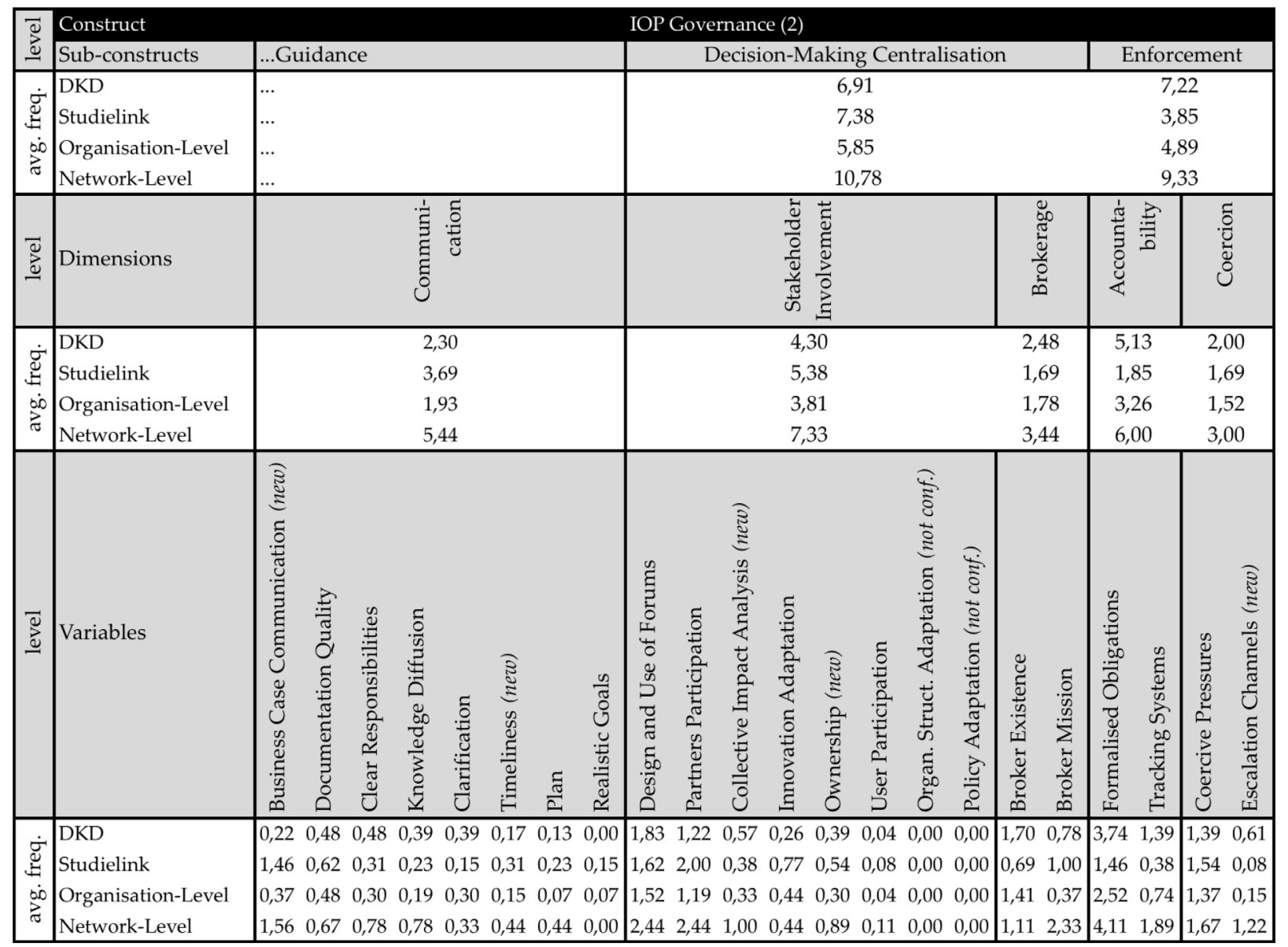

Table Annex B.2. Average quotation frequencies per case and interviewee role for the IOP Governance construct (2) 


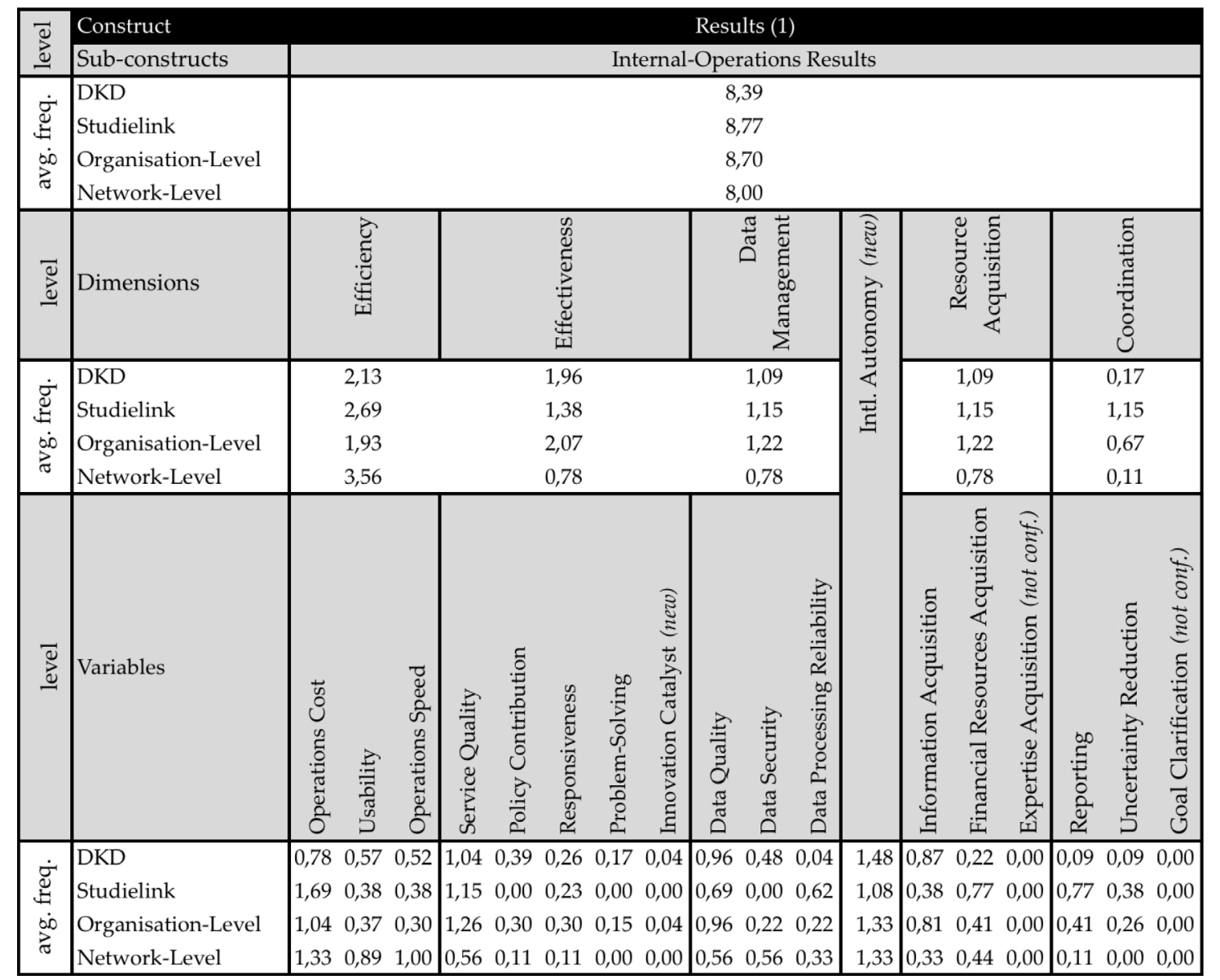

Table Annex B.3. Average quotation frequencies per case and interviewee role for the Results construct (1) 


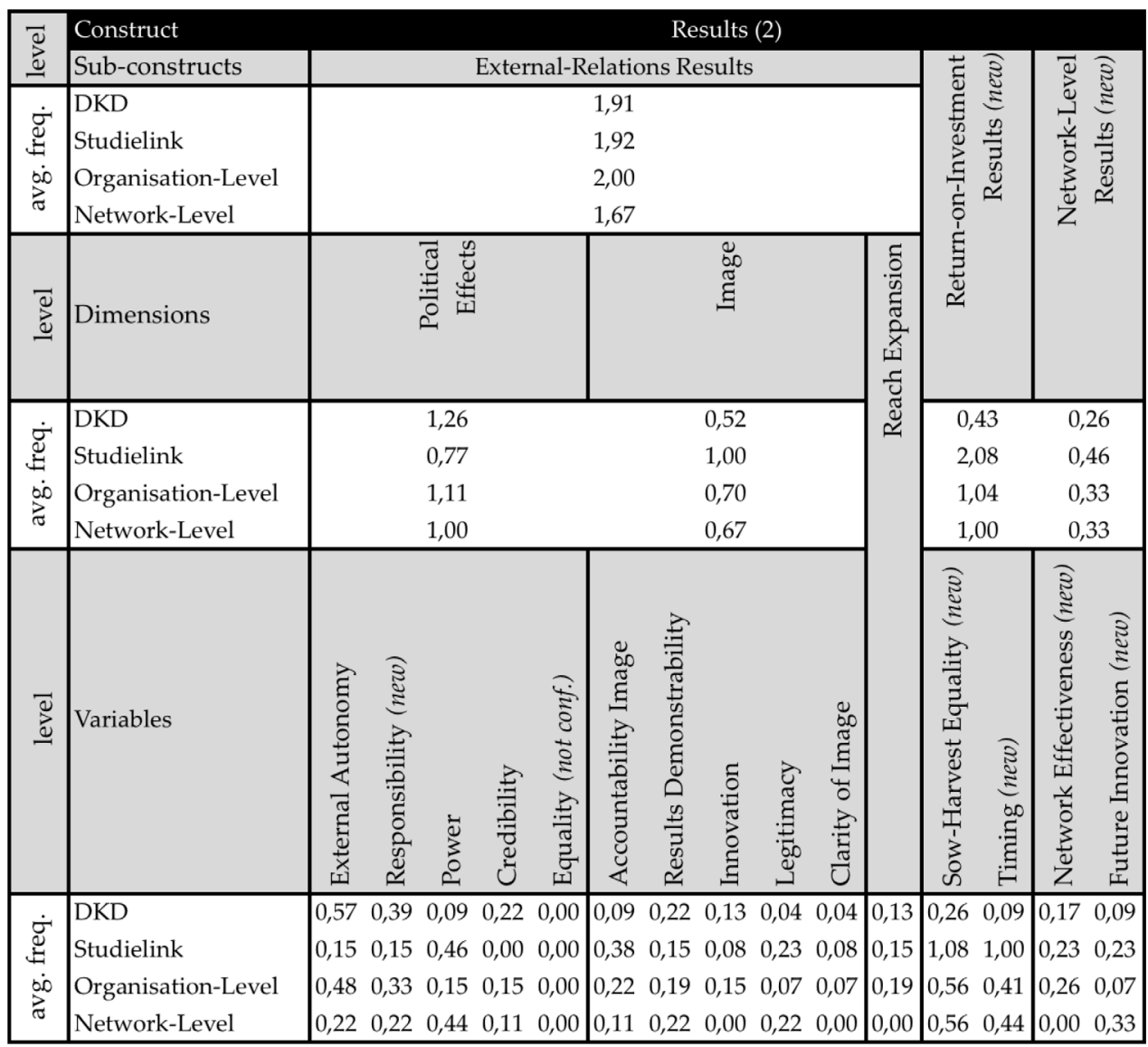

Table Annex B.4. Average quotation frequencies per case and interviewee role for the Results construct (2) 


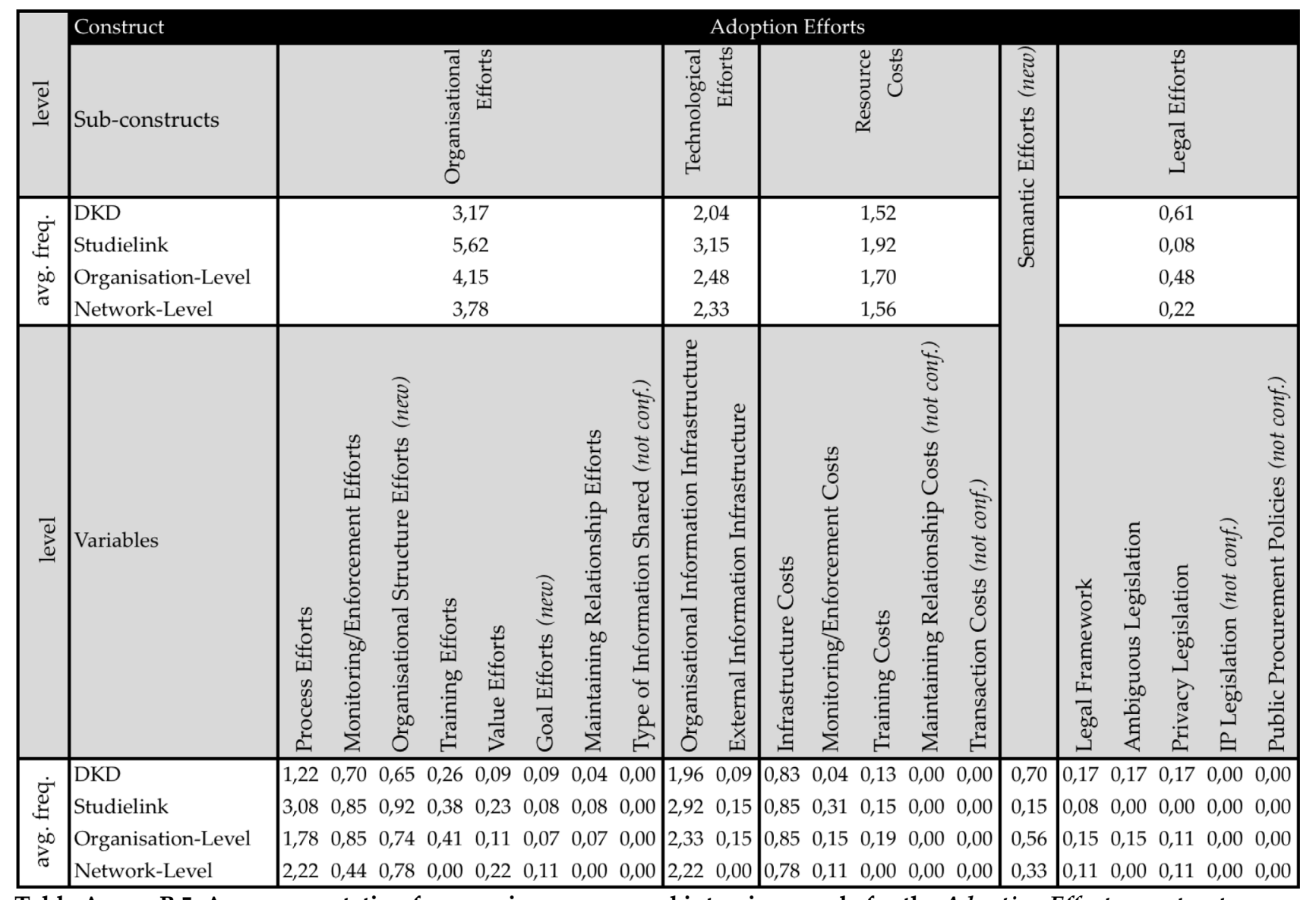

Table Annex B.5. Average quotation frequencies per case and interviewee role for the Adoption Efforts construct 


\begin{tabular}{|c|c|c|c|c|c|c|c|c|c|c|c|c|c|c|c|c|c|c|c|c|c|}
\hline \multirow{2}{*}{ 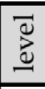 } & Construct & \multicolumn{20}{|c|}{ Network Characteristics (1) } \\
\hline & Sub-constructs & \multicolumn{20}{|c|}{ Network Complexity } \\
\hline \multirow{4}{*}{ 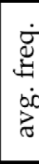 } & DKD & \multicolumn{20}{|c|}{5,78} \\
\hline & Studielink & \multicolumn{20}{|c|}{7,54} \\
\hline & Organisation-Level & \multicolumn{20}{|c|}{6,48} \\
\hline & Network-Level & \multicolumn{20}{|c|}{6,22} \\
\hline $\begin{array}{l}\bar{\Xi} \\
\stackrel{\Xi}{0}\end{array}$ & Dimensions & \multicolumn{16}{|c|}{ Diversity } & \multirow{6}{*}{ 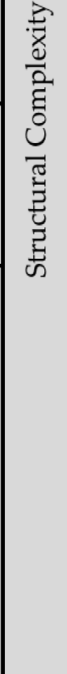 } & \multicolumn{3}{|c|}{$\begin{array}{c}\text { Task } \\
\text { Complexity }\end{array}$} \\
\hline$\sigma$ & DKD & \multicolumn{16}{|c|}{4,13} & & \multicolumn{3}{|c|}{0,57} \\
\hline 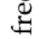 & Studielink & \multicolumn{16}{|c|}{6,31} & & \multicolumn{3}{|c|}{0,69} \\
\hline$\stackrel{\infty 00}{>}$ & Organisation-Level & \multirow{2}{*}{\multicolumn{16}{|c|}{$\begin{array}{r}4,93 \\
489\end{array}$}} & & \multicolumn{3}{|c|}{0,63} \\
\hline$\pi$ & Network-Level & & & \multicolumn{14}{|c|}{4,89} & & & 0,56 & \\
\hline $\overrightarrow{\underline{Q}}$ & Variables & 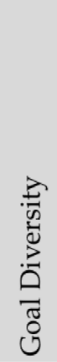 & 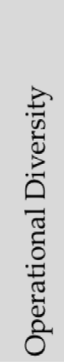 & 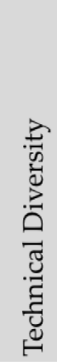 & 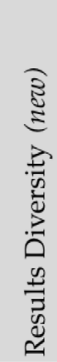 & 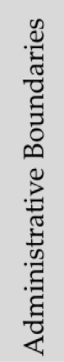 & 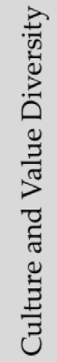 & 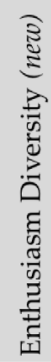 & 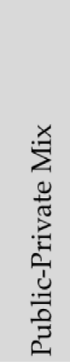 & 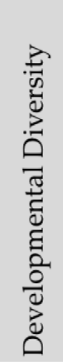 & 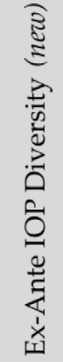 & 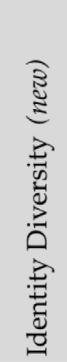 & 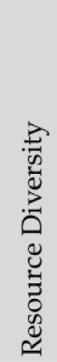 & 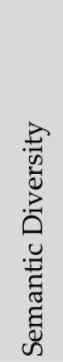 & 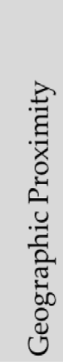 & 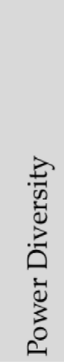 & 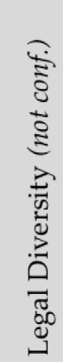 & & 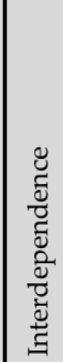 & 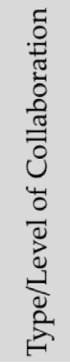 & 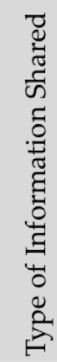 \\
\hline & DKD & 1,04 & 0,43 & 0,43 & 0,22 & 0,52 & 0,35 & 0,17 & 0,26 & 0,13 & 0,13 & 0,09 & 0,04 & 0,17 & 0,04 & 0,00 & 0,00 & 1,65 & 0,39 & 0,09 & 0,09 \\
\hline$\Xi$ & Studielink & 0,77 & 1,15 & 1,23 & 1,00 & 0,00 & 0,31 & 0,46 & 0,15 & 0,15 & 0,15 & 0,23 & 0,15 & 0,00 & 0,00 & 0,08 & 0,00 & 1,23 & 0,54 & 0,08 & 0,08 \\
\hline$\stackrel{\infty}{\longrightarrow}$ & Organisation-Level & 1,04 & 0,70 & 0,70 & 0,52 & 0,41 & 0,30 & 0,26 & 0,15 & 0,11 & 0,19 & 0,15 & 0,11 & 0,11 & 0,04 & 0,04 & 0,00 & 1,56 & 0,52 & 0,04 & 0,07 \\
\hline$\pi$ & Network-Level & 0,67 & 0,67 & 0,78 & 0,44 & 0,11 & 0,44 & 0,33 & 0,44 & 0,22 & 0,00 & 0,11 & 0,00 & 0,11 & 0,00 & 0,00 & 0,00 & 1,33 & 0,22 & 0,22 & 0,11 \\
\hline
\end{tabular}

Table Annex B.6. Average quotation frequencies per case and interviewee role for the Network Characteristics construct (1) 


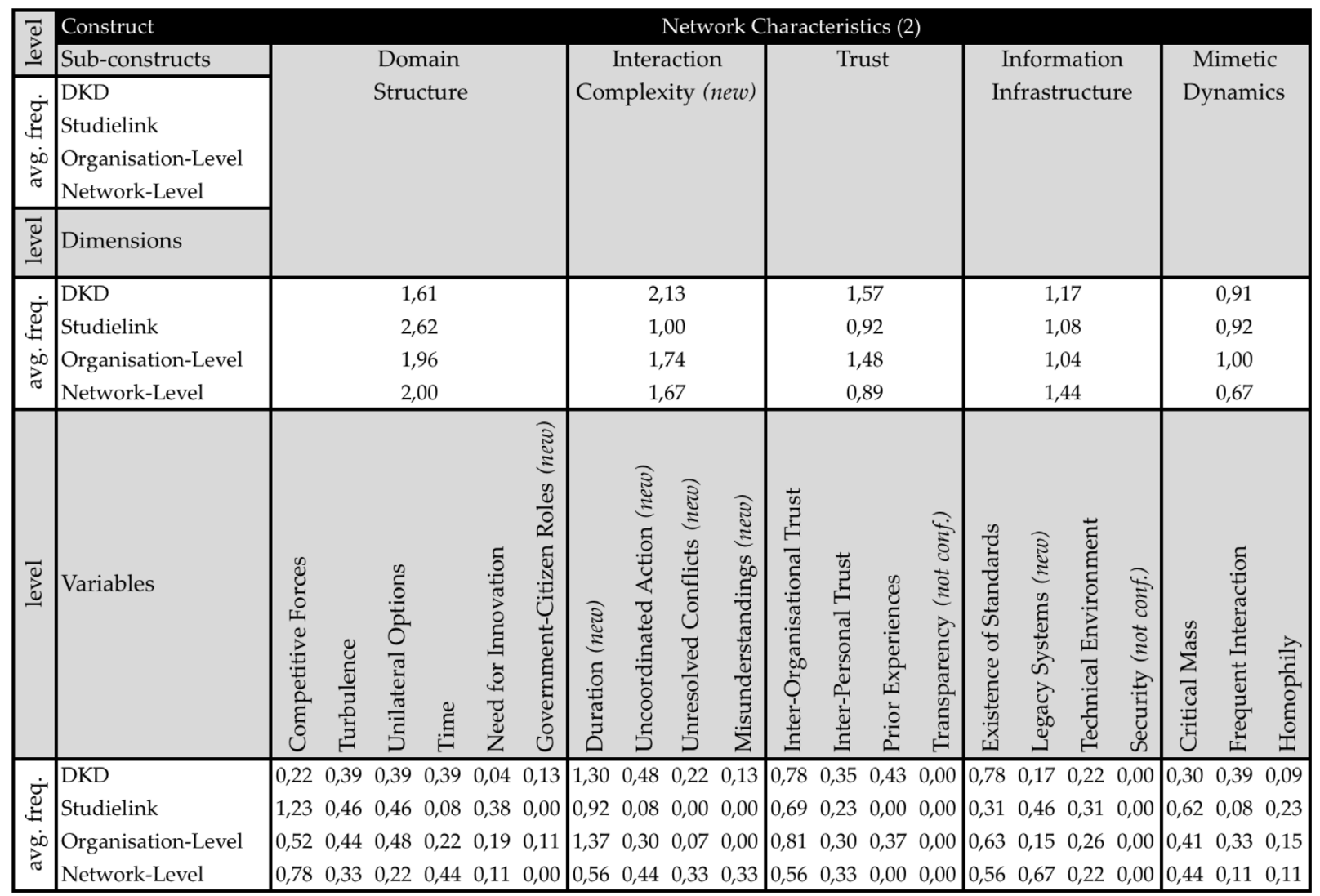

Table Annex B.7. Average quotation frequencies per case and interviewee role for the Network Characteristics construct (2) 


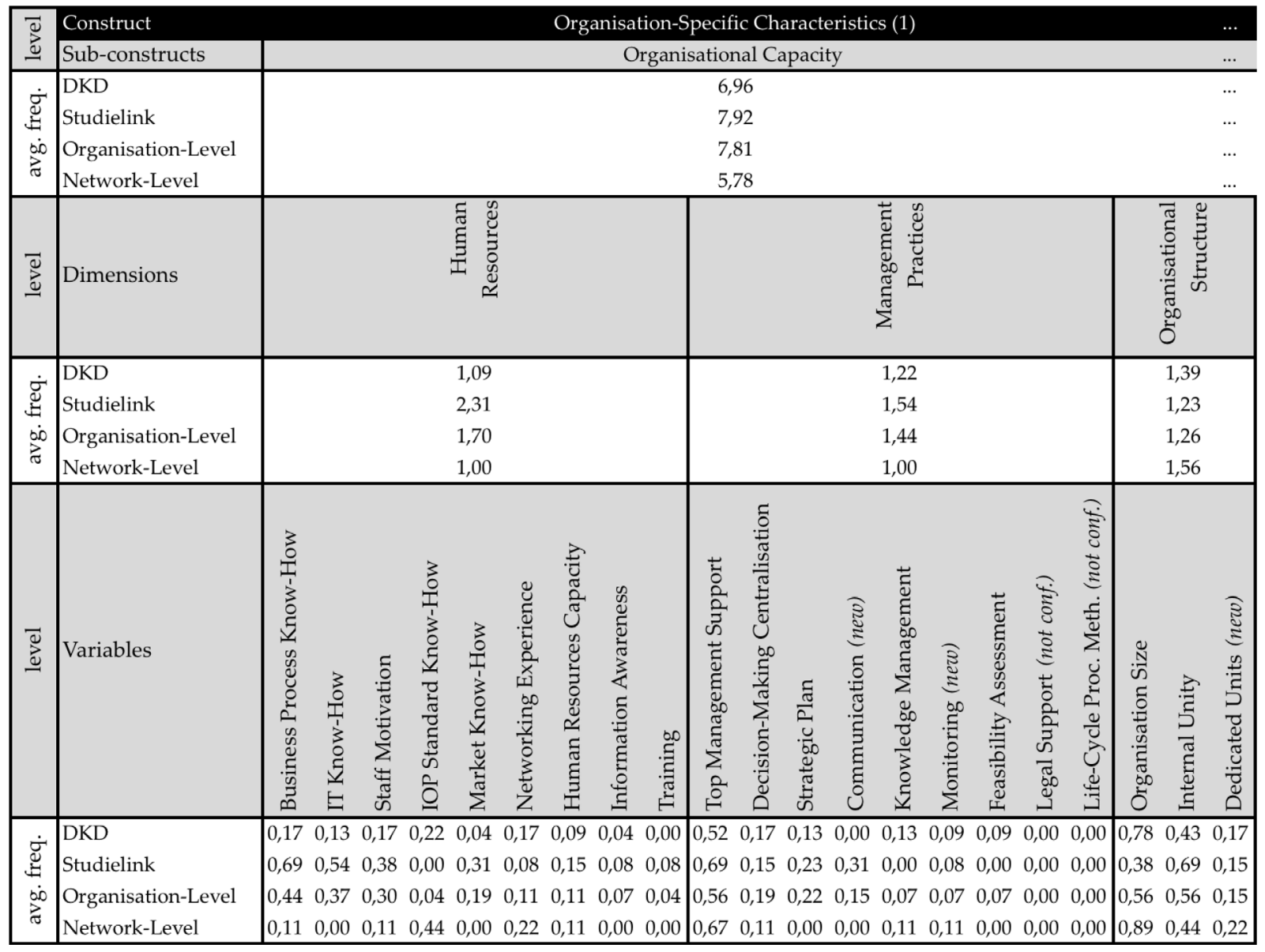

Table Annex B.8. Average quotation frequencies per case and interviewee role for Organisation-Specific Characteristics (1) 


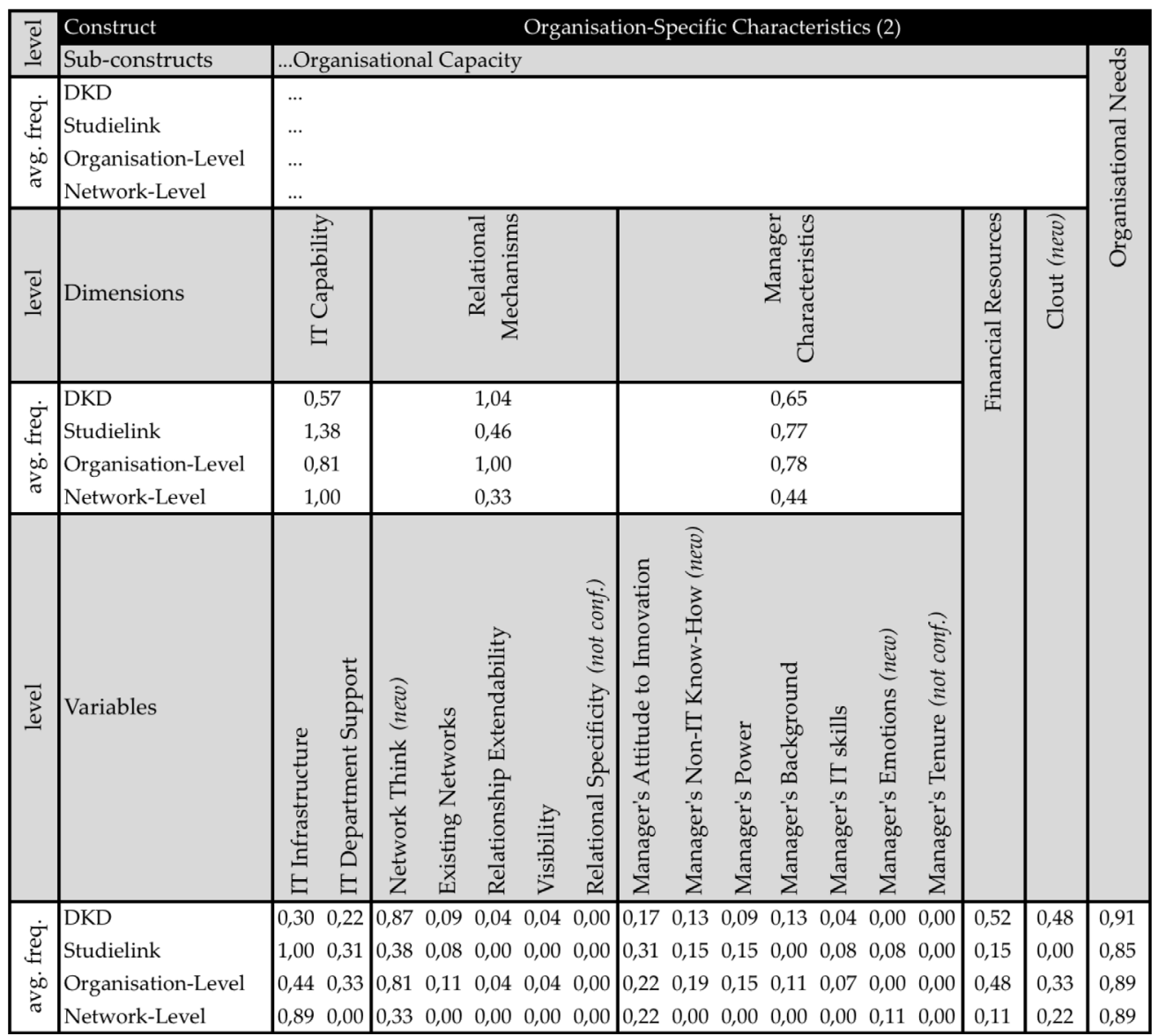

Table Annex B.9. Average quotation frequencies per case and interviewee role for OrganisationSpecific Characteristics (2) 


\begin{tabular}{|c|c|c|c|c|c|c|c|c|c|c|c|c|c|c|c|c|}
\hline \multirow{2}{*}{$\vec{巳}$} & Construct & \multicolumn{15}{|c|}{ Network-External Environment } \\
\hline & Sub-constructs & \multicolumn{9}{|c|}{ Policy and Institutions } & \multicolumn{6}{|c|}{ Political Environment } \\
\hline \multirow{4}{*}{$\begin{array}{l}\ddot{\Xi} \\
\ddot{\oplus} \\
\dot{0} \\
\ddot{\Xi}\end{array}$} & DKD & \multirow{4}{*}{\multicolumn{9}{|c|}{$\begin{array}{l}5,61 \\
2,62 \\
4,19 \\
5,56 \\
\end{array}$}} & \multirow{4}{*}{\multicolumn{6}{|c|}{$\begin{array}{l}1,30 \\
3,77 \\
2,52 \\
1,22\end{array}$}} \\
\hline & Studielink & & & & & & & & & & & & & & & \\
\hline & Organisation-Level & & & & & & & & & & & & & & & \\
\hline & Network-Level & & & & & & & & & & & & & & & \\
\hline 离 & Dimensions & \multicolumn{4}{|c|}{ 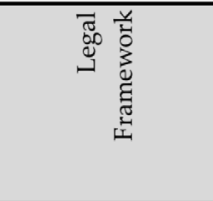 } & \multicolumn{2}{|c|}{ 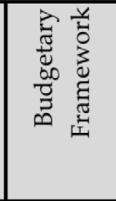 } & \multicolumn{2}{|c|}{ 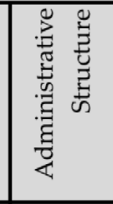 } & \multirow[t]{6}{*}{ 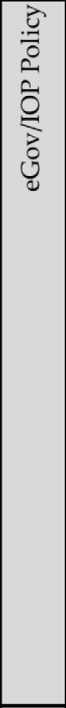 } & & 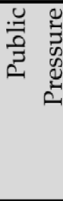 & & 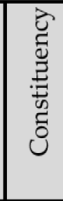 & 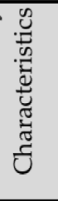 & 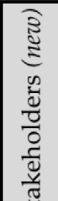 \\
\hline \multirow{4}{*}{ 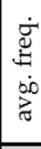 } & DKD & \multirow{4}{*}{\multicolumn{4}{|c|}{$\begin{array}{l}2,57 \\
1,31 \\
1,78 \\
3,11 \\
\end{array}$}} & \multirow{4}{*}{\multicolumn{2}{|c|}{$\begin{array}{l}1,26 \\
0,77 \\
1,07 \\
1,11 \\
\end{array}$}} & \multirow{4}{*}{\multicolumn{2}{|c|}{$\begin{array}{l}1,26 \\
0,08 \\
0,89 \\
0,67 \\
\end{array}$}} & & \multirow{4}{*}{\multicolumn{3}{|c|}{$\begin{array}{l}0,83 \\
1,92 \\
1,33 \\
0,89 \\
\end{array}$}} & \multirow{4}{*}{\multicolumn{2}{|c|}{$\begin{array}{l}0,48 \\
1,46 \\
1,00 \\
0,33 \\
\end{array}$}} & \\
\hline & Studielink & & & & & & & & & & & & & & & $\stackrel{\Xi}{ \pm}$ \\
\hline & Organisation-Level & & & & & & & & & & & & & & & \\
\hline & Network-Level & & & & & & & & & & & & & & & \\
\hline 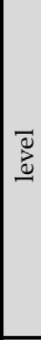 & Variables & 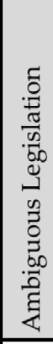 & 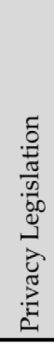 & 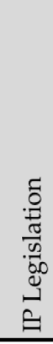 & 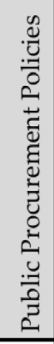 & 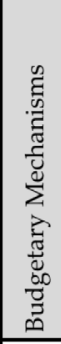 & 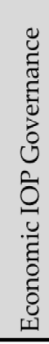 & 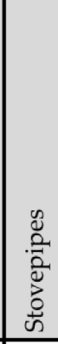 & 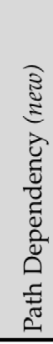 & & 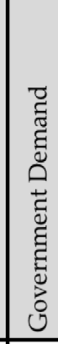 & 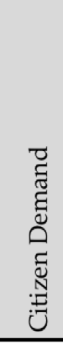 & 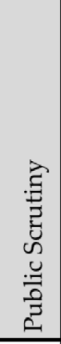 & 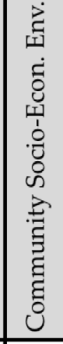 & 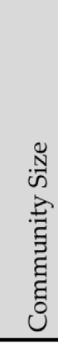 & \\
\hline \multirow{4}{*}{ 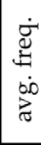 } & DKD & 0,17 & 0,22 & 0,04 & 0,04 & 1,09 & 0,04 & 1,13 & 0,09 & 0,52 & 0,52 & 0,17 & 0,13 & 0,26 & 0,09 & 0,00 \\
\hline & Studielink & 0,15 & 0,00 & 0,00 & 0,00 & 0,77 & 0,00 & 0,08 & 0,00 & 0,46 & 1,23 & 0,54 & 0,15 & 0,00 & 0,15 & 0,38 \\
\hline & Organisation-Level & 0,11 & 0,11 & 0,04 & 0,00 & 1,07 & 0,00 & 0,78 & 0,07 & 0,44 & 0,85 & 0,37 & 0,11 & 0,22 & 0,11 & 0,19 \\
\hline & Network-Level & 0,33 & 0,22 & 0,00 & 0,11 & 0,67 & 0,11 & 0,67 & 0,00 & 0,67 & 0,56 & 0,11 & 0,22 & 0,00 & 0,11 & 0,00 \\
\hline
\end{tabular}

Table Annex B.10. Average quotation frequencies per case and interviewee role for the Network-External Environment construct

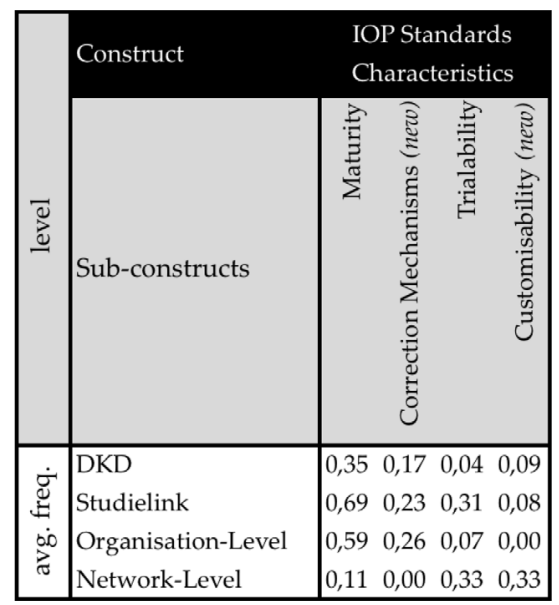

Table Annex B.11. Average quotation frequencies per case and interviewee role for the IOP Standards Characteristics construct 


\section{B2. IOP Governance}

The IOP Governance construct was defined as those determinants that pertain to the decision-making rules and procedures to direct and oversee government IOP initiatives that are planned or underway (see Table 2.3). Its sub-constructs were specified as DecisionMaking Centralisation, Enforcement, and Guidance.

Figure Annex B.5 shows the distribution of aggregated frequencies for the individual subconstructs of IOP Governance. Overall, there is a relatively even distribution of these three sub-constructs, with a slightly larger share of Guidance quotations (Figure Annex B.5a). This resonates the observation that many interviewees strongly stated that there is demand for sound guidance and leadership to facilitate IOP standards adoption. This even distribution is similar across both cases (Figure Annex B.5b). However, when comparing network and organisational level, it becomes clear that considerably more quotations about IOP Governance were observed at network level than at organisational level (more than twice the amount at organisational level). A possible explanation is that it is the network-level where most governance issues are located - which resonates the observation from Chapter 4 that the network-level support actors (in particular infomediaries) play an important role for IOP adoption.

a)

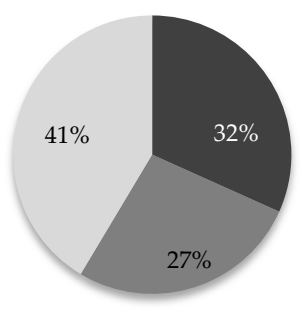

b)

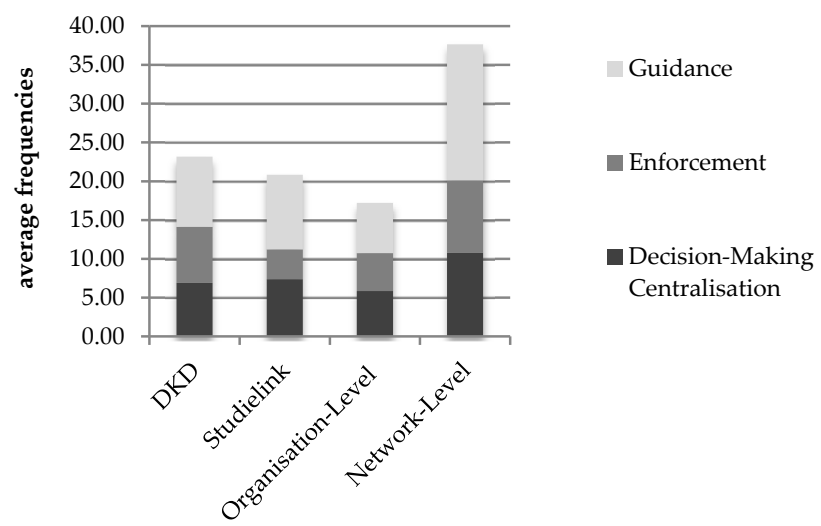

Figure Annex B.5. IOP Governance quotations (aggregated frequencies per subconstruct). Figure a) shows overall quotations distribution (rounded, $\mathrm{N}=804$ ) and Figure b) shows average frequencies of quotations per case and interviewee role

\section{B2.1. Guidance}

Guidance, the most often-mentioned sub-construct of IOP Governance, was defined as those determinants referring to leadership and external support, as well as communication provided from actors outside of the adopting organisation (see Table 2.6). The dimensions specified for this sub-construct accordingly are Leadership and Support and Communication. 
a)

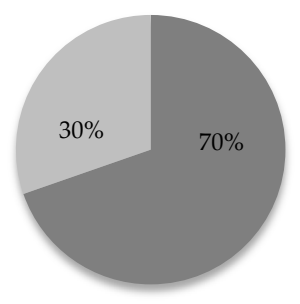

b)

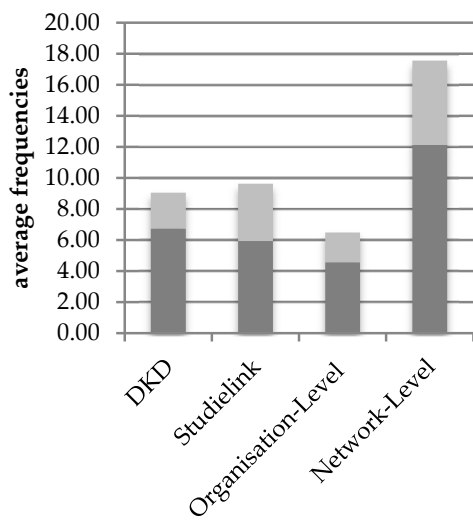

Communication

Leadership and Support

Figure Annex B.6. Guidance quotations (aggregated frequencies per dimension). Figure a) shows overall quotations distribution (rounded, $\mathrm{N}=333$ ) and Figure b) shows average frequencies of quotations per case and interviewee role

Figure Annex B.6 shows the aggregated frequencies for the Guidance dimensions. As with some of the other IOP Governance constructs, also for Guidance we can see a clear disparity between its dimensions, with Leadership and Support (70\%) having a clear dominance over the Communication dimension (Figure Annex B.6a). This ratio is not much different across cases and interviewee roles (Figure Annex B.6b). However, as with other IOP Governance issues, Guidance is mentioned much more at network-level - again indicating that these issues are more of a concern at this level. Both the Leadership and Support and Communication constructs will be discussed in more detail below.

\section{B2.1.1. Leadership and Support}

This dimension was defined as the existence and role of a committed leadership that can help secure the necessary resources and required support for the adoption of the network's IOP standards (see Table 2.6). The inductive coding identified ten new variables for this construct, suggesting that this governance aspect had previously been underexplored. Where inductively identified variables are introduced in the remainder of this Annex, they are defined and briefly described with some illustrative examples from the cases. ${ }^{123}$ Here, they are described in the following paragraphs.

Change Management Approach was introduced as a new variable to capture the influence on adoption from the approach that was taken for managing IOP-related changes (e.g. whether a gradual or "shock-therapy" approach was chosen). An illustrative example of a gradual process for instance is the DKD case, in which change management is highly formalised by means of a regulated process involving dedicated forums such as the Change Advisory

${ }^{123}$ The method used for inductive identification of additional determinants is described in Section 3.4. All inductively identified determinants (sub-constructs, dimensions and variables) are labelled as "new" in Table 5.1 through Table 5.6 in Chapter 5. 
Board (KetenCAB) which administers changes through a gradual and step-wise "structured negotiation" process (Q1:25). An equivalent body in Studielink is the Change Advisory Council (WAR) (Q24:29).

Vision was introduced as an additional variable and refers to the provision of a clear and convincing vision for the objectives and future benefits of the network. An illustrative example is the creation of steering groups, change councils and strategic bodies that provide an overall vision for the network in both cases (see Figure 3.4 and Figure 3.6). In both cases, interviewees also mentioned that in particular changing political agendas can function as an impediment to a clear vision regarding the network (Q22:9 and Q33:21).

Perseverance was also identified inductively and describes the degree to which the leadership of the network is perseverant despite setbacks. An illustrative example of what this means can be seen in the Studielink case, when around 2005 the political ownership of Studielink was not clearly assigned, resulting in a period of stagnation that was eventually resolved through the repeated pressure from the Studielink Board to the Ministry and the umbrella organisations (e.g. by means of formal letters) (Q33:3).

Incident Management is another inductively identified variable and describes the degree to which incidents (technical, political) are managed well (i.e. averting significant damage). An illustrative example to describe this is for instance the institutionalisation of a helpdesk system in both the Studielink and DKD cases. Such an institutionalised incident management role can be outsourced to an external service provider (as done in the Studielink case) or assigned among various network partners (as done in the DKD case) (Q3:19).

Planning is an additional variable that concerns the existence of a strategic plan and of thinking ahead (e.g. making sure that early IOP decisions are not limiting future choices). As an illustration, for instance the organisation of the DKD into a programme management with defined objectives, responsibilities and timelines was cited as a success factor (Q19:29).

Testing Support was introduced as an additional variable and captures the influence of support to organisations by organising testing or piloting opportunities to check the IOP standards. An illustrative example is given for instance in Studielink where piloting trials allowed higher education institutions to experiment with Studielink before full adoption (Q24:44).

Technical Facilitation was also identified inductively and describes the provision of instruments for technical facilitation (such as middleware). As an illustrative example, in the DKD case BKWI for instance provided eight "regional advisors" who travelled around the country and provided technical assistance to municipalities (Q3:19). The provision of the KVA adapter by Studielink to facilitate organisations' connection to the central broker facility (Q24:40) is another example for Technical Facilitation.

Another inductively identified determinant was Coherence Across Standards, which refers to the degree of coherence between for instance technological IOP standards and business process standards (i.e. avoiding contradictory standards across IOP dimensions). For instance, interviewees from the DKD pointed out that organisations can find themselves 
potentially in conflict between standards from national reference architectures such as NORA or GEMMA and sectoral standards from the SUWI domain (Q4:12). In addition, interviewees pointed out that organisations often face problems when they form part of multiple networks that each require them to adopt their respective standards, which can be mutually conflicting (Q17:23).

Version Control was also added as an additional variable and refers to the procedures for ensuring that the correct versions of standards are specified and used. An illustrative example here is the formalised change management procedure regarding the SGR from the DKD case mentioned above, which entails a fixed schedule for drawing up and publishing new versions of the SGR (Q1:25).

Finally, Scope Monitoring was inductively identified and describes the degree to which monitoring is in place that prevents "scope creep" (i.e. a gradual, uncontrolled expansion in scope) of the IOP standards in the network. One illustrative example of this from the DKD case for instance was the use of the "Connection Protocol" by BKWI towards potential adopters such as the municipalities to prevent their tendency to each suggest bilateral agreements as "standards" (Q6:1).

Table Annex B.12 shows the percentage distribution for the individual variables of Leadership and Support (in table form, for better readability due to the high number of variables). In comparison to the other IOP governance issues, the quotation frequencies for the variables of the Leadership and Support dimension are relatively more evenly distributed except four variables that have a significantly larger share (i.e. $\geq 10 \%$ ): Technical Facilitation (18\%), Funding (13\%), Change Management (9\%) and Trust- And Consensus Building (9\%). Some variables proposed in the preliminary theoretical model in Chapter 2 did not appear at all (or virtually not, i.e. $\leq 1 \%$ ) in the case study data: Scope Monitoring, Administrative Creativity, Reward Structures, and Informal Leadership. ${ }^{124}$ However, this should not necessarily mean that these factors cannot play a role in general - but in cases similar to DKD and Studielink, they do not seem to play a large role, actual or desired.

There is not much difference in the overall frequencies for this dimension across cases, but very clearly across interviewee levels, which is in line with the observations about the other IOP governance issues (see Figure Annex B.6). In terms of the relative share of the individual variables for each of these groups, there are several differences that can be observed. Whilst some are too small to make substantiated claims, the most significant ones are described in the following paragraphs.

First, across cases, a relatively strong difference can be observed regarding the Funding variable, where the share is around four times as high among DKD interviewees as it is among Studielink interviewees. This can be attributed to the large financial support scheme in DKD to municipalities to ease the costs of adoption by the municipalities. No such direct financial facilitation was available in Studielink. Another clear difference that can be observed in the cross-case comparison is that there is a considerably higher variety of

\footnotetext{
${ }^{124}$ The method used for exclusion of previously specified determinants from the model is described in Section 3.4. All non-confirmed determinants are presented in Table 5.1 through Table 5.6 in Chapter 5.
} 
variables mentioned in DKD than in Studielink: for instance, in Studielink no (or hardly any) quotations could be observed for the variables Planning, Administrative Creativity, Incident Management, Conflict Management, Scope Monitoring and Informal Leadership. This suggests that for more complex networks such as DKD, IOP governance needs to grab deeper into the box of leadership tools in order to achieve the desired results - whereas in smaller and less complex networks, there might be both less capacity and necessity for such leadership diversification.

\begin{tabular}{|c|c|c|c|c|c|}
\hline Variables & Overall & DKD & Studielink & Org.-Level & Net.-Level \\
\hline Technical Facilitation & $18 \%$ & 0,83 & 1,69 & 1,00 & 1,56 \\
\hline Funding & $13 \%$ & 1,13 & 0,23 & 0,78 & 0,89 \\
\hline Change Management Approach & $10 \%$ & 0,52 & 0,77 & 0,33 & 1,44 \\
\hline Trust- and Consensus-Building & $9 \%$ & 0,61 & 0,54 & 0,26 & 1,56 \\
\hline Knowledge-Building Activities & $5 \%$ & 0,48 & 0,08 & 0,37 & 0,22 \\
\hline Testing Support & $5 \%$ & 0,17 & 0,54 & 0,26 & 0,44 \\
\hline Legitimacy-Building & $5 \%$ & 0,26 & 0,31 & 0,07 & 0,89 \\
\hline Coherence Across Standards & $5 \%$ & 0,35 & 0,15 & 0,15 & 0,67 \\
\hline Championship & $4 \%$ & 0,22 & 0,23 & 0,15 & 0,44 \\
\hline Incident Management & $4 \%$ & 0,35 & 0,00 & 0,15 & 0,44 \\
\hline Vision & $4 \%$ & 0,22 & 0,23 & 0,15 & 0,44 \\
\hline Version Control & $4 \%$ & 0,22 & 0,23 & 0,15 & 0,44 \\
\hline Resilience & $3 \%$ & 0,04 & 0,46 & 0,07 & 0,56 \\
\hline Conflict Management & $3 \%$ & 0,30 & 0,00 & 0,07 & 0,56 \\
\hline Perseverance & $3 \%$ & 0,13 & 0,23 & 0,15 & 0,22 \\
\hline Planning & $2 \%$ & 0,22 & 0,00 & 0,07 & 0,33 \\
\hline Informal Leadership & $1 \%$ & 0,13 & 0,00 & 0,07 & 0,11 \\
\hline Reward Structures & $1 \%$ & 0,09 & 0,08 & 0,00 & 0,33 \\
\hline Administrative Creativity & $1 \%$ & 0,09 & 0,00 & 0,04 & 0,11 \\
\hline Scope Monitoring & $0 \%$ & 0,04 & 0,00 & 0,00 & 0,11 \\
\hline Total & $100 \%$ & 6,39 & 5,77 & 4,30 & 11,78 \\
\hline
\end{tabular}

Table Annex B.12. Leadership and Support quotations (percentage per variable). Column "Overall" shows overall quotations distribution (rounded) in percent $(\mathrm{N}=222)$ and the remaining columns show average frequencies of quotations per case and interviewee role

Second, two differences are noteworthy across interviewee roles. One is that the share of Knowledge-Building Activities is roughly five times as high at organisational level in comparison to the network level. This is rather surprising, since one would expect that such activities would be much more efficient if they were initiated at network level in order to share them across all organisations in the network. However, it is also possible that a lot of the know-how that is necessary for adoption is actually very specific to idiosyncratic organisational contexts, so that knowledge-building efforts at network level can only be of limited use to organisations and need to be supplemented with more local knowledgebuilding. Another marked difference across interviewee levels concerns Legitimacy-Building, which was mentioned much more often by network-level interviewees. This is not surprising, however, as legitimacy of the IOP standards is a concern that is part of IOP governance, and as such should be taken care of by network-level stakeholders. 


\section{B2.1.2. Communication}

This dimension was defined as the degree to which effective communication mechanisms are in place within the network to enhance coordination and to support adoption of IOP standards (see Table 2.6). In addition to the variables specified in the preliminary theoretical framework, two new variables could be identified as a result from the inductive coding: Timeliness and Business-Case Communication.

Timeliness refers to the use of a communication strategy that disseminates relevant information in a timely manner. An illustrative example is for instance when partners from the DKD network felt put under pressure after the SLA for 2010 had been communicated to them very late because it was signed off by the last signatory only at the last minute (Q4:9). Another example is that software suppliers in the Studielink case emphasised their need for timely announcement of new Studielink releases well ahead so that they can adjust their SIS in time to be ready to comply with the standards of the new Studielink version (Q25:29).

Business-Case Communication concerns a clear communication of advantages and costs. An illustrative example from the cases is for instance that in the DKD, interviewees pointed out that organisations would have had more incentives to adopt the standards if there had been a clear and detailed business case that was communicated to them instead of "more general" mentioning of resulting benefits (Q16:19). Inversely, when the news was circulated that one higher-education institution that adopted the digital bank authorisation standard from Studielink had gained about two million increase in revenue, it caused a number of other organisations to follow suit (Q24:30).

\begin{tabular}{|l|r|r|r|r|r|}
\hline Variable & Overall & DKD & Studielink & Org.-Level & Net.-Level \\
\hline Business Case Communication & $25 \%$ & 0,22 & 1,46 & 0,37 & 1,56 \\
\hline Documentation Quality & $20 \%$ & 0,48 & 0,62 & 0,48 & 0,67 \\
\hline Clear Responsibilities & $15 \%$ & 0,48 & 0,31 & 0,30 & 0,78 \\
\hline Knowledge Diffusion & $12 \%$ & 0,39 & 0,23 & 0,19 & 0,78 \\
\hline Clarification & $11 \%$ & 0,39 & 0,15 & 0,30 & 0,33 \\
\hline Timeliness & $8 \%$ & 0,17 & 0,31 & 0,15 & 0,44 \\
\hline Plan & $6 \%$ & 0,13 & 0,23 & 0,07 & 0,44 \\
\hline Realistic Goals & $2 \%$ & 0,00 & 0,15 & 0,07 & 0,00 \\
\hline Total & $100 \%$ & 2,26 & 3,46 & 1,93 & 5,00 \\
\hline
\end{tabular}

Table Annex B.13. Communication quotations (frequencies per variable). Column "Overall" shows overall quotations distribution (rounded) in percent $(\mathrm{N}=101)$ and the remaining columns show average frequencies of quotations per case and interviewee role

Table Annex B.13 shows the frequencies for the individual variables of Communication. The Communication dimension has a varied frequency distribution across variables, ranging from Realistic Goals (2\%) to Business Case Communication (25\%). The most frequently mentioned variables in this dimension are Business Case Communication (25\%), Documentation Quality (20\%), and Clear Responsibilities (15\%).

The overall frequencies for this dimension show a strong variation across interviewee levels (much higher relative frequencies at network-level), which is in line with the observations about the other IOP governance issues. There also is a marked variation across cases, with 
considerably higher frequencies for Studielink. In terms of the relative share of the individual variables for each of these groups, one variable sticks out because it has a very clear difference across cases: the relative share of Business Case Communication quotations in Studielink is about five times the share it received in the DKD case. This is most likely because in Studielink, there was no obligation for adoption, unlike in DKD where the WEU provided a legal backing to stimulate adoption. In addition, since higher education institutions tend to be governed much more by a market logic than organisations in the social security sector, having a clear business case might play a larger role as well.

\section{B2.2. Decision-Making Centralisation}

Decision-Making Centralisation has been defined as the distribution of decision authority among partner organisations in the network, determining the ownership given to them by involving them in the procedures of making strategic decisions with regard to the governance of the network's IOP architecture (see Table 2.4).

Figure Annex B.7 shows the aggregated frequencies for the individual dimensions of Decision-Making Centralisation. Stakeholder Involvement makes for the clear majority (68\%) of quotations within the Decision-Making Centralisation sub-construct (Figure Annex B.7a). There is almost no variation to this distribution across interviewee levels (network and organisational), and only a minor variation across both cases (with Brokerage featuring slightly more in DKD, which might result from the fact that DKD has a very clearly assigned infomediary organisation in the form of BKWI) (Figure Annex B.7b). However, for DecisionMaking Centralisation the relative amount of quotations at network level is roughly double the number that was observed at organisational level. This indicates that the question of centralisation is of relative high relevance among governing stakeholders, and that addressing the question of the appropriate degree of centralisation clearly matters more to these stakeholders.

a)

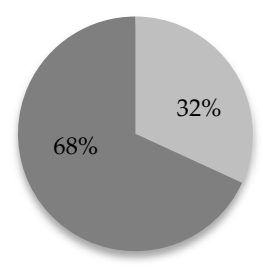

b)

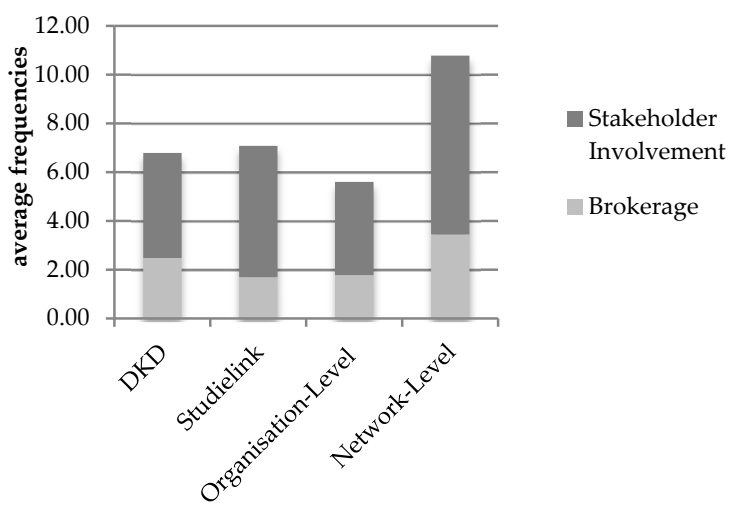

Figure Annex B.7. Decision-Making Centralisation quotations (aggregated frequencies per dimension). Figure a) shows overall quotations distribution (rounded, $\mathrm{N}=246$ ) and Figure b) shows average frequencies of quotations per case and interviewee role 


\section{B2.2.1. Stakeholder Involvement}

Stakeholder Involvement has been defined as the level of stakeholders' participation in the network's IOP governance (see Table 2.4). Two determinants that had been specified in the preliminary theoretical framework were not confirmed in the data from the cases. These are Policy Adaptation and Network Structure Adaptation. On the other hand, two new variables have been added as a result from the inductive coding: Ownership and Collective Impact Analysis.

Ownership is defined here as the degree to which joint responsibility is held by stakeholders. An illustrative example is how the DKD was designed as a programme, with the responsibilities for individual parts assigned to individual partner organisations in order to sustain their involvement (Q19:29). Collective Impact Analysis is here defined as the existence of mechanisms for a collective analysis of impacts from IOP standards, assessed through a participatory and inclusive process. An illustrative example is for instance the change management procedure used in the DKD case, where change requests are registered by means of the CMK application and discussed in regular intervals in the KetenCAB as the collective consultation forum (Q1:25).

\begin{tabular}{|l|r|r|r|r|r|}
\hline Variable & Overall & DKD & Studielink & Org.-Level & Net.-Level \\
\hline Design and Use of Forums & $37 \%$ & 1,83 & 1,62 & 1,52 & 2,44 \\
\hline Partners Participation & $32 \%$ & 1,22 & 2,00 & 1,19 & 2,44 \\
\hline Collective Impact Analysis & $11 \%$ & 0,57 & 0,38 & 0,33 & 1,00 \\
\hline Innovation Adaptation & $9 \%$ & 0,26 & 0,77 & 0,44 & 0,44 \\
\hline Ownership & $9 \%$ & 0,39 & 0,54 & 0,30 & 0,89 \\
\hline User Participation & $1 \%$ & 0,04 & 0,08 & 0,04 & 0,11 \\
\hline Total & $100 \%$ & 4,30 & 5,38 & 3,81 & 7,33 \\
\hline
\end{tabular}

Table Annex B.14. Stakeholder Involvement quotations (frequencies per variable). Column "Overall" shows overall quotations distribution (rounded) in percent ( $=169$ ) and the remaining columns show average frequencies of quotations per case and interviewee role

Table Annex B.14 shows the frequencies for the individual variables of Stakeholder Involvement. As the second column ("Overall") reveals, two variables in this dimension appear to be particularly salient and have a much higher share than the rest: Design and Use of Forums (37\%), and Partners Participation (32\%). The cross-group comparison (remaining columns) shows that there is hardly any difference across cases and interviewee levels in terms of the frequency distribution of the variables in this dimension. However, the relative share of quotations of Stakeholder Involvement is slightly higher in Studielink than in the DKD case, indicating that Studielink interviewees are more concerned with this dimension. A possible explanation is that being situated in a less complex network, Studielink stakeholders are actually more exposed to involvement in IOP governance. It is surprising that the large majority of quotations in this dimension comes from the network level interviewees, which suggests that this dimension as well is more reflected upon by those stakeholders who are in charge of IOP governance. A very similar observation is made about Brokerage, which is discussed next. 


\section{B2.2.2. Brokerage}

Brokerage has been defined as the existence and characteristics of an IOP coordination body that is formally charged with the coordination of the network and its IOP architecture (see Table 2.4).

a)

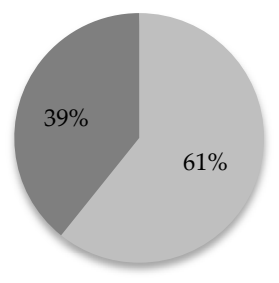

b)

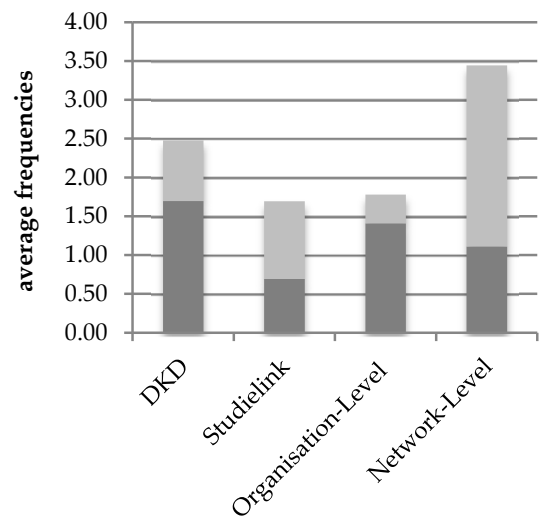

Broker Mission

Broker Existence

Figure Annex B.8. Brokerage quotations (frequencies per variable). Figure a) shows overall quotations distribution (rounded, $\mathrm{N}=79$ ) and Figure b) shows average frequencies of quotations per case and interviewee role

Figure Annex B.8 shows the frequencies for the individual variables of Brokerage. With regard to the Brokerage dimension, we can observe (Figure Annex B.8a) a considerably higher share of quotations for Broker Existence (61\%). Compared to the question of the broker's mission, the mere existence of a broker, or infomediary organisation, might thus be a more important step for IOP governance - although the 39\% of quotations for Broker Mission clearly indicate that this is a highly relevant aspect as well.

Two observations are striking when comparing the relative share of quotations across cases and interviewee levels (Figure Annex B.8b): first, Brokerage is much more often mentioned by DKD interviewees than in Studielink. This can possibly be explained by the fact that coming from a more complex network, DKD interviewees attribute relatively more importance to brokerage. And second, we can see that the relative share of Broker Mission is much higher at network-level than at organisational level. This might be understood in the light that the "strategic" (mission-related) issues surrounding Brokerage are much more reflected at network level, i.e. by interviewees in charge of IOP governance.

\section{B2.3. Enforcement}

Enforcement has been defined as the mechanisms in place for compelling the adoption and compliance with the IOP standards specified by the network's IOP architecture (see Table 2.5). The dimensions identified for this sub-construct were Accountability and Coercion. 
Figure Annex B.9 shows the aggregated frequencies for the individual dimensions of Enforcement. A clear majority of quotations in the Enforcement sub-construct are for Accountability (68\%). However, Coercion, accounting for about a third of quotations (32\%), is nevertheless significant as well (Figure Annex B.9a).

a)

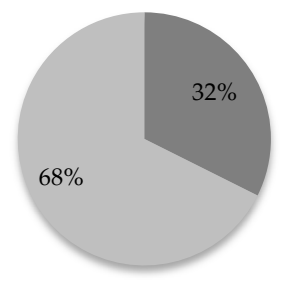

b)

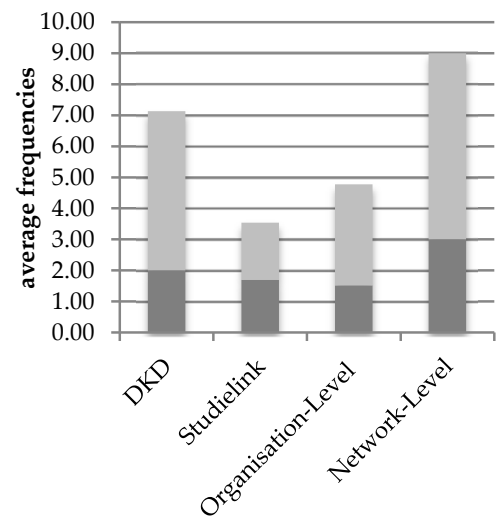

Accountability

- Coercion

Figure Annex B.9. Enforcement quotations (aggregated frequencies per dimension). Figure a) shows overall quotations distribution (rounded, $\mathrm{N}=210$ ) and Figure b) shows average frequencies of quotations per case and interviewee role

Different to the other IOP Governance sub-constructs, Enforcement shows more variation across cases, with many more quotations (relatively) coming from the DKD case (Figure Annex B.9b). Again, this might be because DKD as a more complex network attributes more concern to IOP governance issues like Enforcement. Furthermore, there is a difference across cases in the share of Coercion (accounting for about half of the quotations in Studielink, but less than a third in DKD). At first sight, this is rather counter-intuitive, since one would expect that coercive measures to ensure adoption and compliance would be more of an issue in the more complex network (DKD). However, a closer, qualitative reading of the Studielink quotations for this code reveals that in fact the largest part of these quotations in fact does not concern statements about the actual use of coercion in Studielink case, but about the lack of coercive powers in this case (this includes both critical and positive accounts). There is also a difference in the relative amount of quotations for Enforcement across interviewee roles (roughly twice as much at network-level). Again (as with the Decision-Making Centralisation and Guidance sub-constructs), this lends support to the argument that IOP governance issues are more of a concern at network level.

\section{B2.3.1. Accountability}

The Accountability dimension has been defined as the control mechanisms for an organisation's adoption and compliance with the network's IOP standards (see Table 2.5). Figure Annex B.10 shows the distribution of quotations for the individual variables in this dimension. As Figure Annex B.10a shows, the largest share of quotations in the 
Accountability dimension is held by the Formalised Obligations variable (74\%), with the remainder of quotations for Tracking Systems.

a)

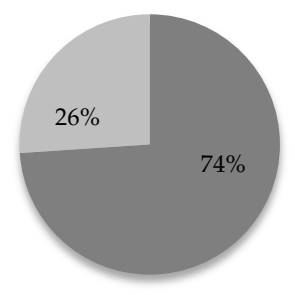

b)

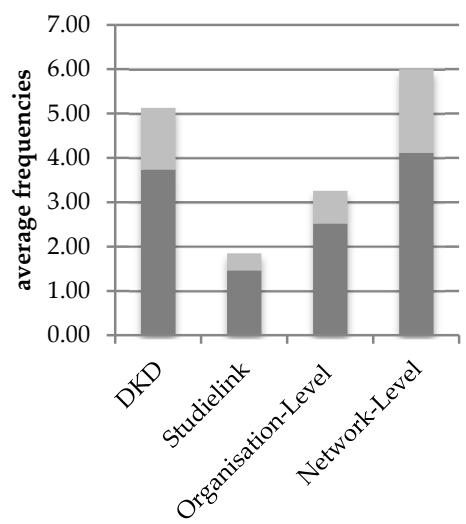

Tracking Systems

Formalised Obligations

Figure Annex B.10. Accountability quotations (frequencies per variable). Figure a) shows overall quotations distribution (rounded, $N=142$ ) and Figure b) shows average frequencies of quotations per case and interviewee role

There is rather little variation in these ratios across cases and interviewee roles. However, the relative frequencies of Accountability quotations are much higher (more than double) for the DKD than for Studielink. Again, a plausible explanation is that DKD as a more complex network has more need for "strict" IOP governance and enforcement. We can also see that network-level interviewees mention Accountability roughly twice as much as organisationlevel interviewees. Like with other IOP governance dimensions, possibly this is because network-level stakeholders are naturally more concerned with IOP governance (and with keeping organisations accountable about adoption and compliance) than the partner organisations themselves.

\section{B2.3.2. Coercion}

This dimension has been defined as the pressure mechanisms exerted by more powerful actors, which constrain the partner organisations from non-compliant behaviour regarding the IOP standards (see Table 2.5). Next to the variables that had already been derived from the literature, the inductive coding identified an additional variable Escalation Channels, referring to the existence of a cascading system of accountabilities that can be deployed to exert influence. An illustrative example is for instance when in the DKD case, BKWI monitored the municipalities' compliance with the data supply agreements, and had the MinSZW send a formal letter to those municipalities that were not complying (Q7:26).

Figure Annex B.11 shows the frequencies for the individual variables of this dimension. As Figure Annex B.11a shows, within the Coercion sub-construct, Coercive Pressures makes for the clear majority of quotations (78\%). Whilst the majority of quotations lies with Coercive 
Pressures across both cases and interviewee roles, the picture is rather varied here. Escalation Channels hardly were mentioned in the Studielink case, which might be a result of the fact that in this case, there are hardly any hierarchical power relationships that could be invoked for escalating conflicts. Similarly, organisational-level interviewees mention Escalation Channels hardly at all in comparison to network-level interviewees. In the latter case, the underlying reason could most likely be that escalation channels are usually invoked by governing actors to coerce organisations into compliance, and thus not by the organisations themselves. Furthermore, just as with previous IOP Governance dimensions, the fact that Coercion receives twice as many quotations at network level than at the organisational level is another reason to assume that IOP governance issues are more of a concern at network level.

a)

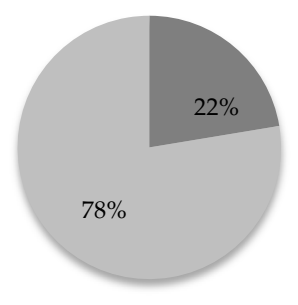

b)

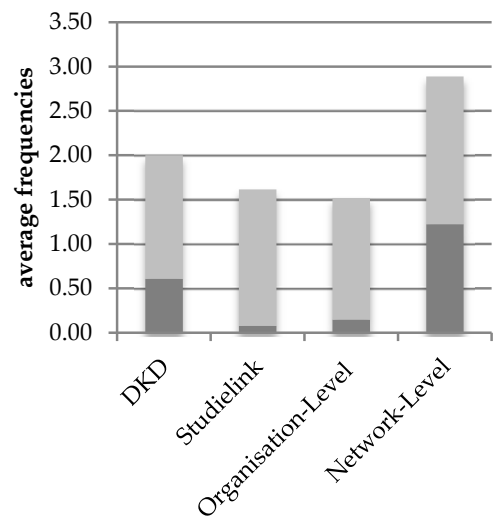

Coercive Pressures

Escalation Channels

\section{Figure Annex B.11. Coercion quotations (frequencies per variable). Figure a) shows overall quotations distribution (rounded, $\mathrm{N}=67$ ) and Figure b) shows average frequencies of quotations per case and interviewee role}

\section{B3. Network Characteristics}

The Network Characteristics construct was defined as those determinants that pertain to the characteristics of the Government Information Network (see Table 2.10). Its major subconstructs were specified as Network Complexity, Trust, Mimetic Dynamics, Domain Structure and Information Infrastructure. As a result of the inductive coding, an additional subconstruct Interaction Complexity was added ${ }^{125}$ in order to describe aspects of interactions during the adoption process: the dimensions identified for this were the Duration of the adoption process, Unresolved Conflicts among partners, Misunderstandings among them, as well as Uncoordinated Action by individual partners.

\footnotetext{
${ }^{125}$ The reason for specifying the inductively identified determinant here at the sub-construct level and not at the variable level (as in the previous instances) is that there are no intermediary conceptual levels that would warrant specifying an additional conceptual layer.
} 
Table Annex B.15 shows the aggregated frequencies for the individual sub-constructs of this construct. As we can see in the column labelled "Overall", the overwhelming majority of quotations in the Network Characteristics construct is held by the Network Complexity subconstruct (48\%). The remainder is more evenly distributed, with shares ranging between $7 \%$ (Mimetic Dynamics) and 15\% (Domain Structure).

When comparing the relative frequencies across cases and interviewee roles, the picture remains largely the same, and there is little variation, both in terms of overall frequencies and distribution of the various dimensions.

\begin{tabular}{|l|r|r|r|r|r|} 
& Overall & DKD & Studielink & Org.-Level & Net.-Level \\
\hline Network Complexity & $48 \%$ & 5,78 & 7,54 & 6,48 & 6,22 \\
\hline Domain Structure & $15 \%$ & 1,61 & 2,62 & 1,96 & 2,00 \\
\hline Interaction Complexity & $13 \%$ & 2,13 & 1,00 & 1,74 & 1,67 \\
\hline Trust & $10 \%$ & 1,57 & 0,92 & 1,48 & 0,89 \\
\hline Information Infrastructure & $8 \%$ & 1,17 & 1,08 & 1,04 & 1,44 \\
\hline Mimetic Dynamics & $7 \%$ & 0,91 & 0,92 & 1,00 & 0,67 \\
\hline Total & $100 \%$ & 13,17 & 14,08 & 13,70 & 12,89 \\
\hline
\end{tabular}

Table Annex B.15. Network Characteristics quotations (aggregated frequencies per subconstruct). Column "Overall" shows overall quotations distribution (rounded) in percent $(\mathrm{N}=486)$ and the remaining columns show average frequencies of quotations per case and interviewee role

\section{B3.1. Network Complexity}

This sub-construct has been defined as those features of the network that complicate the interactions within the Government Information Network and make it difficult for organisations in the network to align with each other in order to adopt its IOP standards (see Table 2.11).

a)

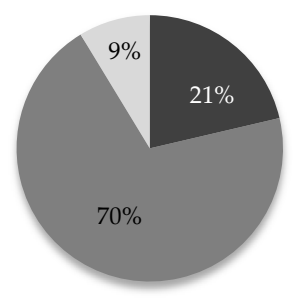

b)

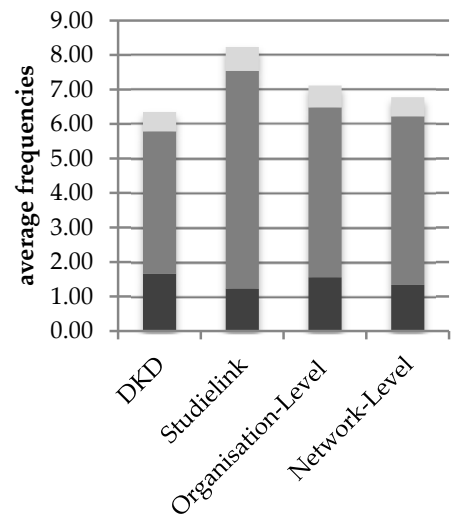

$\square$ Task Complexity

Diversity

- Structural Complexity

Figure Annex B.12. Network Complexity quotations (aggregated frequencies per dimension). Figure a) shows overall quotations distribution (rounded, $\mathrm{N}=231$ ) and Figure b) shows average frequencies of quotations per case and interviewee role 
Figure Annex B.12 shows the aggregated frequencies for the individual dimensions of this sub-construct. The large majority of quotations in the Network Complexity sub-construct is formed by the Diversity dimension (70\%), followed by Structural Complexity (21\%) and Task Complexity (9\%). This picture also is more or less consistent across interviewee levels, with only very minor variation across levels, and some variation across cases.

\section{B3.1.1. Diversity}

This dimension has been defined as the heterogeneity of partner organisations in the network along various dimensions that constrain any harmonisation activities between them (see Table 2.11). The code Legal Diversity, which had been specified in the preliminary theoretical framework has not been confirmed in the data from the cases. On the other hand, four new determinants could be identified as a result from the inductive coding in addition to the variables specified in Chapter 2. They are defined in the following paragraphs.

\begin{tabular}{|l|r|r|r|r|r|}
\hline Variable & Overall & DKD & Studielink & Org.-Level & Net.-Level \\
\hline Goal Diversity & $20 \%$ & 1,04 & 0,77 & 1,04 & 0,67 \\
\hline Technical Diversity & $15 \%$ & 0,43 & 1,23 & 0,70 & 0,78 \\
\hline Operational Diversity & $15 \%$ & 0,43 & 1,15 & 0,70 & 0,67 \\
\hline Results Diversity & $11 \%$ & 0,22 & 1,00 & 0,52 & 0,44 \\
\hline Administrative Boundaries & $7 \%$ & 0,52 & 0,00 & 0,41 & 0,11 \\
\hline Culture and Value Diversity & $7 \%$ & 0,35 & 0,31 & 0,30 & 0,44 \\
\hline Enthusiasm Diversity & $6 \%$ & 0,17 & 0,46 & 0,26 & 0,33 \\
\hline Public-Private Mix & $5 \%$ & 0,26 & 0,15 & 0,15 & 0,44 \\
\hline Developmental Diversity & $3 \%$ & 0,13 & 0,15 & 0,11 & 0,22 \\
\hline Ex-Ante IOP Diversity & $3 \%$ & 0,13 & 0,15 & 0,19 & 0,00 \\
\hline Identity Diversity & $3 \%$ & 0,09 & 0,23 & 0,15 & 0,11 \\
\hline Semantic Diversity & $2 \%$ & 0,17 & 0,00 & 0,11 & 0,11 \\
\hline Resource Diversity & $2 \%$ & 0,04 & 0,15 & 0,11 & 0,00 \\
\hline Power Diversity & $1 \%$ & 0,00 & 0,08 & 0,04 & 0,00 \\
\hline Geographic Proximity & $1 \%$ & 0,04 & 0,00 & 0,04 & 0,00 \\
\hline Total & $100 \%$ & 4,02 & 5,83 & 4,83 & 4,32 \\
\hline
\end{tabular}

Table Annex B.16. Diversity quotations (frequencies per variable). Column "Overall" shows overall quotations distribution (rounded) in percent $(N=169)$ and the remaining columns show average frequencies of quotations per case and interviewee role

First, Ex-Ante IOP Diversity is defined here as the diversity across organisations in terms of the degree of IOP already achieved among them. An illustrative example is for instance in DKD that the SGR semantic standard could build upon the BUS format of the CBS which had already been in use by many organisations in the network (Q17:34). In Studielink, an example is that one vendor's SIS (Osiris) was already used by majority of institutions, and thus reduced the network's diversity as a de facto standard (Q29:15).

Second, Identity Diversity refers to the diversity in terms of organisational identity. An illustrative example is for example in the DKD the contrast between the UWV's selfunderstanding as purely work-related "insurance", and the municipalities' identity as having a responsibility for multi-dimensional social policy execution (Q10:4).

Third, Enthusiasm Diversity is defined here as the diversity in terms of enthusiasm for IOP in the network. This is illustrated for instance in the Studielink case, where one university was 
particularly enthusiastic about joining the network because it was already on the lookout for a way to innovate its student administration, whilst other institutions were not enthusiastic about networked student administration at all (Q36:3).

Fourth, Results Diversity concerns the diversity in terms of how much the organisations are affected by the adoption of the IOP standards. An illustrative example is for instance in Studielink the difference between institutions using an off-the-shelf SIS where the costs for implementing connectivity standards with the Studielink broker are shared by a large user group, and those institutions that were using a custom-made SIS and have to bear the costs by themselves (Q26:14).

Table Annex B.16 shows the frequencies for the individual variables of this dimension. The column "Overall" shows that the individual variables take rather different shares of the overall amount of quotations in this dimension. The three largest shares are taken by Goal Diversity (20\%), Technical Diversity and Operational Diversity (both 15\%). We can also observe that several variables that were specified in the preliminary theoretical model (Chapter 2) were not mentioned at all, or only to a negligible degree $(\leq 1 \%)$ by interviewees: Power Diversity, Geographic Proximity, and Legal Diversity.

In terms of variation of overall frequency, we can see some variation across cases. One interesting difference across cases is that, whilst Studielink was in the case selection categorised as a non-diverse network, there were relatively more quotations coded with Diversity in Studielink than in DKD. This suggests that stakeholders from this case perceive their network as diverse. If we take a closer look at the share of individual variables, we can see that this higher amount of Diversity quotations is more or less caused by a higher number of quotations for only three particular variables: Operational Diversity, Technical Diversity, and Results Diversity codes.

\section{B3.1.2. Structural Complexity}

Structural Complexity refers to the degree to which the network size (i.e. the number of partners in the network) increases adoption efforts (see Table 2.11). There is no subdivision of this dimension into variables. Accounting for $21 \%$ of the quotations in the Network Complexity sub-construct, it appears to play a substantial role in the cases (Figure Annex B.12a). We can also see (Figure Annex B.12b) that it plays a larger role in DKD, i.e. the more complex network.

\section{B3.1.3. Task Complexity}

This dimension has been defined as the degree of interdependence of partner organisations in achieving the network's primary tasks (see Table 2.11). Figure Annex B.13 shows the frequencies for the individual variables of this dimension. The largest share of quotations in this dimension of Network Characteristics is Interdependence (73\%), with the remainder being rather equally shared between the other two variables (13\% for Type of Information Shared and $14 \%$ for Type/Level of Collaboration). 
a)

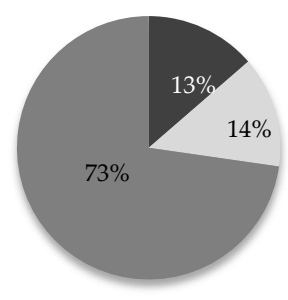

b)

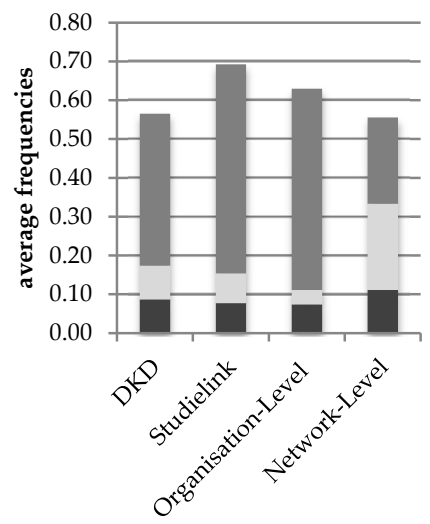

Interdependence

Type/Level of

Collaboration

- Type of Information

Shared

Figure Annex B.13. Task Complexity quotations (frequencies per variable). Figure a) shows overall quotations distribution (rounded, $\mathrm{N}=22$ ) and Figure b) shows average frequencies of quotations per case and interviewee role

Considering the low number of overall quotations $(\mathrm{N}=22)$, it is rather difficult to draw meaningful conclusions on a comparison across cases and interviewee roles for this dimension. ${ }^{126}$

\section{B3.2. Domain Structure}

This sub-construct has been defined as the general nature of the policy domain(s) in which the network operates (see Table 2.10). In addition to the variables specified in the preliminary theoretical framework, the inductive coding resulted in the additional variable Government-Citizen Roles. It is defined here as the distribution of roles between citizen and government, as generally practiced in the domain. An illustrative example for instance is given by the different ideas held by the UWV and the GSDs on their role towards the clients. The UWV on the one hand, with its insurance-point of view and generally dealing more with short-term clients, reasons much more for the initiative being the responsibility of the clients. The GSDs on the other hand, who traditionally deal with a much wider range of social policy issues and have long-term benefit recipients, typically see the initiative being more the government's responsibility (Q10:28).

Table Annex B.17 shows the frequencies for the individual dimensions of this sub-construct. The largest share in this sub-construct is formed by the Competitive Forces variable $(30 \%)$, followed by Unilateral Options (21\%) and Turbulence (21\%).

We can observe considerable variation across cases and interviewee roles. One observation is that it becomes apparent that Studielink interviewees mentioned Domain Structure much more often than DKD interviewees. When looking at the contribution of individual variables

${ }^{126}$ See the discussion in Section 3.4 about the $\mathrm{N} \leq 30$ threshold used to determine what constitutes a quotation amount that is "too small" to be considered as more than indicative. 
per group, we can see that this difference is almost entirely caused by the large share of Competitive Forces quotations in the Studielink case. One explanation could be that higher education institutions actually are in competition with each other for students (and thus, for government funding) - a dynamic which does not exist in the work and income domain. (However, it should be noted that quotations for this variable are also more prominent at network level than at organisational level, which is inconsistent with this explanation). Another interesting difference between cases is that Time was more often mentioned in the DKD case. This is most likely because the work and income domain, having grown as a collaborative sector over many decades, had started to work with electronic information exchange much earlier than organisations in the higher education sector, where information exchange across the sector is a much more recent development. Furthermore, we can observe that Unilateral Options received twice the amount of quotations at organisational level than at network level. As Unilateral Options captures the degree of interdependence of organisations in achieving their joint objectives, it is plausible that it is at the organisational level where interdependencies play the largest role as an adoption determinant.

\begin{tabular}{|l|r|r|r|r|r|}
\hline Variable & Overall & DKD & Studielink & Org.-Level & Net.-Level \\
\hline Competitive Forces & $30 \%$ & 0,22 & 1,23 & 0,52 & 0,78 \\
\hline Unilateral Options & $21 \%$ & 0,39 & 0,46 & 0,48 & 0,22 \\
\hline Turbulence & $21 \%$ & 0,39 & 0,46 & 0,44 & 0,33 \\
\hline Time & $14 \%$ & 0,39 & 0,08 & 0,22 & 0,44 \\
\hline Need for Innovation & $9 \%$ & 0,04 & 0,38 & 0,19 & 0,11 \\
\hline Government-Citizen Roles & $4 \%$ & 0,13 & 0,00 & 0,11 & 0,00 \\
\hline Total & $100 \%$ & 1,57 & 2,62 & 1,96 & 1,89 \\
\hline
\end{tabular}

Table Annex B.17. Domain Structure quotations (frequencies per dimension). Column "Overall" shows overall quotations distribution (rounded) in percent $(\mathrm{N}=70)$ and remaining columns show average frequencies of quotations per case and interviewee role

\section{B3.3. Interaction Complexity}

The Interaction Complexity sub-construct and its variables were specified as a result from the inductive coding, in order to capture those statements from the interviewees referring to the difficulties and problems emerging in inter-organisational interaction during the adoption process. There was no reason to specify the subordinate determinants of Interaction Complexity at separate conceptual levels, and hence no intermediate level of dimensions was specified. The following four variables were identified:

First, Duration is defined as the duration of the adoption process. As several interviewees pointed out, this is typically a lengthy process $(\mathrm{Q} 23: 9)$, which can have negative influences on adoption intention (Q10:19).

Second, Unresolved Conflicts refers to discussions and conflict about the IOP architecture that are not resolved by an agreement. One illustrative example is an on-going discussion which the BKWI had about the Accountability Guideline in the DKD case with the municipalities, which argue that it is not applicable to them (Q6:9).

Third, Misunderstandings concerns the difficulties in interaction resulting from misunderstandings among organisations. An illustrative example is when in the DKD case 
there was a misunderstanding between UWV and GSDs about the phrase "using SONAR at the beginning of the process" in one specification, with the result that the process that was designed by the UWV according to their understanding was very different from what the GSDs had understood (Q21:3).

Fourth, Uncoordinated Action is defined as wayward and volatile behaviour of individual organisations. One illustrative example is when the UWV made some unannounced changes to its internal systems (DVB), that caused repercussions throughout the network because other partners could suddenly not receive the UWV's data any more (Q2:9).

Figure Annex B.14 shows the frequencies for the individual dimensions of this subconstruct. The largest share of quotations in the Interaction sub-construct comes from the Duration variable (68\%). The second-largest share comes from Unresolved Conflicts (19\%), whilst the remainder only makes for much smaller percentages.

a)

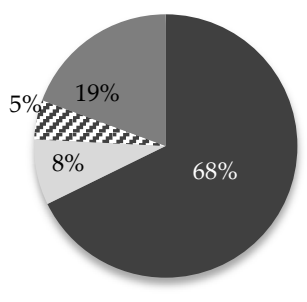

b)

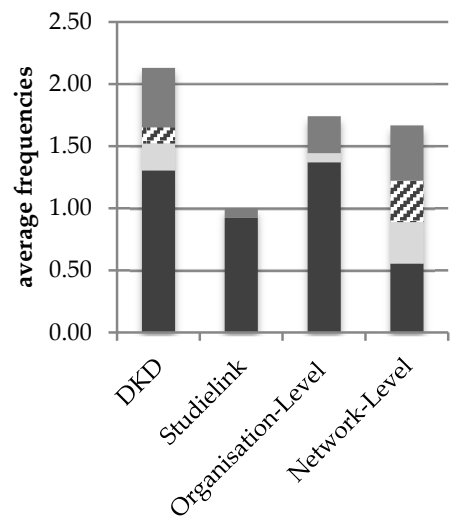

- Uncoordinated Action

Misunderstandings

Unresolved Conflicts

- Duration

\footnotetext{
Figure Annex B.14. Interaction Complexity quotations (frequencies per dimension). Figure a) shows overall quotations distribution (rounded, $\mathrm{N}=62$ ) and Figure b) shows average frequencies of quotations per case and interviewee role
}

Across interviewee levels, the overall relative frequency is very similar. However, in comparison to DKD, Studielink has only half the quotation amount. Since the Interaction Complexity sub-construct refers to problematic issues surrounding interaction during the adoption process, this low amount can be linked back to the fact that Studielink, as the less complex network, has also less likelihood to encounter interaction problems.

This would also explain why some Interaction Complexity variables (Misunderstandings and Unresolved Conflicts) did not appear at all in the Studielink case. Also across interviewee roles, we can observe some variation in the relative shares of individual variables: noteworthy here is the much higher share of Duration quotations at organisation level. It seems thus that the timely achievement of results is more of a concern at this level. Surprisingly, Misunderstandings do not appear to be a concern of organisation-level 
stakeholders - whilst one actually would expect this to play out primarily among the partner organisations.

\section{B3.4. Trust}

Trust has been defined earlier as the expectation of reciprocal respect of conventions and agreements (see Table 2.12). The code Transparency, which had been specified in the preliminary theoretical framework was not confirmed in the data from the cases.

Figure Annex B.15 shows the frequencies for the individual dimensions of this subconstruct. As Figure Annex B.15a shows, about half (56\%) of quotations in this dimension come from the Inter-Organisational Trust dimension, with the remainder being rather equally shared between the other two dimensions.

a)

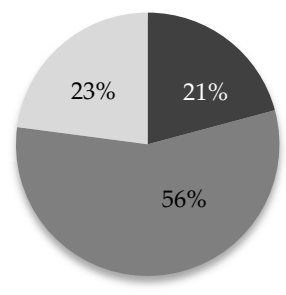

b)

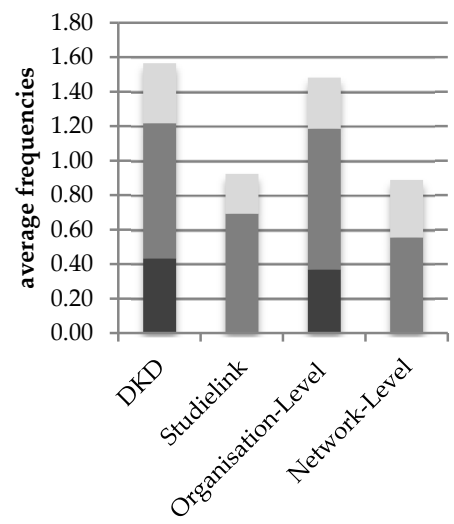

Inter-Personal Trust

- Inter-Organisational Trust

- Prior Experiences

Figure Annex B.15. Trust quotations (frequencies per dimension). Figure a) shows overall quotations distribution (rounded, $\mathrm{N}=48$ ) and Figure b) shows average frequencies of quotations per case and interviewee role

Again, the overall amount of quotations is rather low for drawing strong conclusions. However, one indication in the data that is nevertheless worth noting is that average frequencies at organisational level are almost twice as many as observed at the network level. This would match the expectation that trust is especially of relevance for organisations (since they also expect significant potential risks from adoption), but is not so much a concern at network level. If this is the case, it would also imply that network governors are "out of tune" with the reality and considerations of adopting organisations.

\section{B3.5. Information Infrastructure}

This sub-construct was defined as those factors pertaining to the state of the domain-level arrangement of technology, tools, facilities, people and procedures supporting the handling of information (see Table 2.15). The determinant Security which had been specified in the preliminary theoretical framework was not confirmed in the data from the cases. On the 
other hand, the inductive coding identified an additional determinant: Legacy System, which is defined here as the existence of domain-wide legacy systems that may obstruct achieving IOP. An illustrative example of this from the Studielink case is that DUO was using some old legacy systems that effectively were obstructing Studielink's objective of synchronous message exchange throughout the network (Q24:39).

Figure Annex B.16 shows the frequencies for the individual dimensions of this subconstruct. The biggest share of quotations for this sub-construct is contributed by the previous Existence of Standards dimension (54\%), with the remainder shared (relatively equally) by Legacy Systems (24\%) and Technical Environment (22\%).

a)

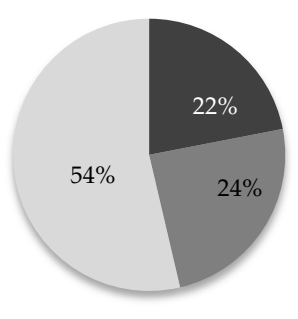

b)

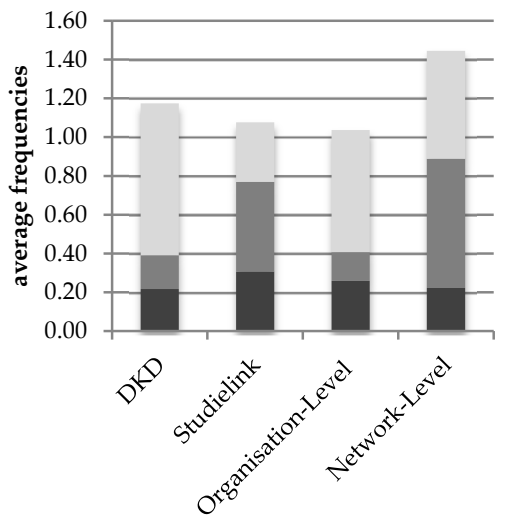

Existence of Standards

Legacy Systems

- Technical Environment

\section{Figure Annex B.16. Information Infrastructure quotations (frequencies per dimension). Figure a) shows overall quotations distribution (rounded, $\mathrm{N}=41$ ) and Figure b) shows average frequencies of quotations per case and interviewee role}

Whilst we can see some interesting variations across cases and interviewee roles in frequencies and share for the individual variables, the overall amount of quotations is too low to draw strong comparative conclusions. Nevertheless, the picture given by the content analysis can be supported by the nature of the cases: considering that the SUWI domain has long-standing experience with electronic information exchange and interviewees mentioned this as a strongly positive influence on adoption, it is not surprising that Existence of Standards received a much higher share of quotations from DKD interviewees than from Studielink. The more "recent" nature of standardisation efforts in Studielink might also explain why Legacy Systems is much more often mentioned in this case. The previous Existence of Standards is also relatively more often mentioned at organisational level, suggesting that this determinant plays a bigger role for organisational stakeholders. A plausible explanation is that it is the adopting organisations that incur the biggest costs of having to comply with new standards, so that ex-ante IOP can ease the costs of adopting additional standards. Furthermore, the quotation frequencies suggest that Legacy Systems play a much bigger role at network level. It should be noted here though that this code concerns domain-wide, and not organisation-specific, legacy systems that hinder the 
achievement of IOP, and it appears that network-level stakeholders are the most informed about the influence of this factor.

\section{B3.6. Mimetic Dynamics}

This sub-construct has been defined in the theoretical framework as those network characteristics that create opportunities for imitation among network partners (see Table 2.13).

Figure Annex B.17 shows the aggregated frequencies for the individual dimensions of this sub-construct. Mimetic Dynamics also has a small number of overall quotations $(\mathrm{N}=30)$, half of which is contributed by the Critical Mass dimension, thus confirming a central tenet of network effects theory. However, the overall amount of quotations is rather low for drawing meaningful comparative conclusions across cases and interviewee roles.

a)

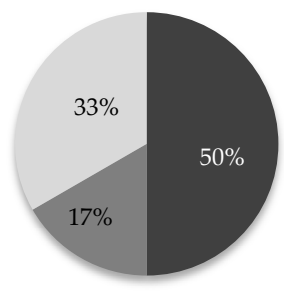

b)

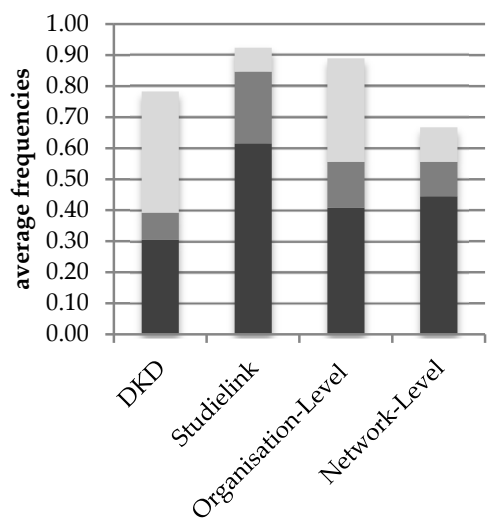

Frequent Interaction

- Homophily

- Critical Mass

\footnotetext{
Figure Annex B.17. Mimetic Dynamics quotations (aggregated frequencies per dimension). Figure a) shows overall quotations distribution (rounded, $\mathrm{N}=30$ ) and Figure b) shows average frequencies of quotations per case and interviewee role
}

\section{B4. Network-External Environment}

This determinant construct has been defined as the dimension capturing those determinants that are pertaining to the wider environment beyond the immediate network-level (see Table 2.7). The main constructs that the literature review identified in this dimension are Political Environment and Policy and Institutions.

Figure Annex B.18 gives an overview for the quotations at the construct level. The NetworkExternal Environment construct is dominated by quotations from the Policy and Institutions sub-construct (67\%), with the remaining third coming from the Political Environment subconstruct. 
a)

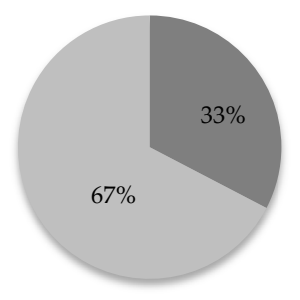

b)

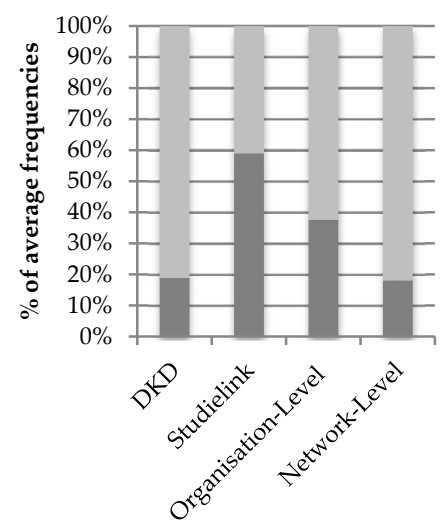

Policy and Institutions

- Political Environment

Figure Annex B.18. Network-External Environment quotations (aggregated frequencies per sub-constructs). Figure a) shows overall quotations distribution (rounded, $\mathrm{N}=\mathbf{2 4 2}$ ) and Figure b) shows average frequencies of quotations per case and interviewee role

There are virtually no differences in terms of overall frequencies of quotations across groups, indicating that this construct is equally significant across all groups. However, we can identify clear disparities across groups in terms of how much the sub-constructs contribute to the overall frequency for each group. Whereas in the Studielink case, Policy and Institutions contributes only about $40 \%$, it accounts for roughly $80 \%$ of quotations in the DKD case. One possible explanation is that electronic information exchange in the SUWI domain is much more regulated by legislation and policy (stemming from the historical origin of the DKD network as a sectoral policy objective, and its function as implementation of the WEU law), whereas Studielink is a network that was created bottom-up in order to meet the challenges of the sector in its environment, without being grounded in any specific legislation or sectoral policy. Across interviewee roles, we can see that network-level stakeholders speak relatively more about Policy and Institutions than about Political Environment. This must not necessarily mean that the latter is less relevant for them, but might be more a reflection of the fact that they have more knowledge of policy and institutions (e.g. relevant legislation or regulations) than stakeholders in adopting organisations, and also make more use of them.

\section{B4.1. Political Environment}

This sub-construct concerns the political dynamics and power relations in the wider (inter)national environment of the network (see (Table 2.8). In addition to those dimensions identified in the preliminary theoretical framework (Public Pressure and Constituency Characteristics), the dimension Other Stakeholders has been identified to capture external stakeholders forming the political environment, as for instance ICT suppliers.

Figure Annex B.19 shows the aggregated frequencies for the individual dimensions of this sub-construct. As Figure Annex B.19a shows, the large majority of quotations for the Political 
Environment sub-construct is formed by the Public Pressure dimension (56\%), followed by Constituency Characteristics (38\%). The Other Stakeholders dimension only contributes $6 \%$.

a)

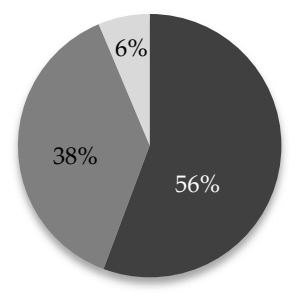

b)

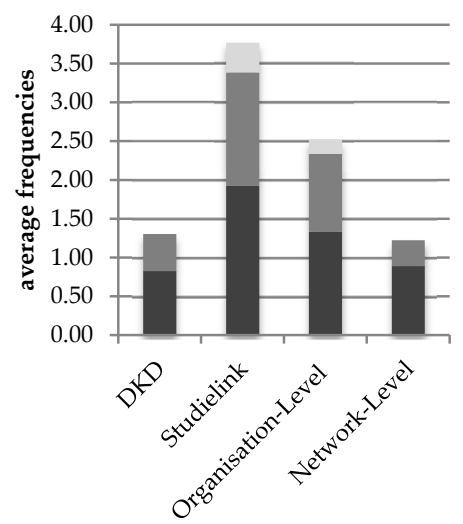

Other Stakeholders

Constituency

Characteristics

Public Pressure

\section{Figure Annex B.19. Political Environment quotations (aggregated frequencies per dimension). Figure a) shows overall quotations distribution (rounded, N=79) and Figure b) shows average frequencies of quotations per case and interviewee role}

The relative amount of quotations differs quite markedly across cases, and across interviewee levels. We can observe about three times as many Political Environment quotations overall for Studielink in comparison to DKD, which might be a result from two issues: first, the fact that throughout the Studielink project there were big political controversies such as the "study rights debate" 127 that had a direct link to the project. And second, the semi-private nature of higher education institutions, which made the constituency characteristics dimension more significant (as organisations are competing for "customers" from these constituencies). Furthermore, the fact that the Other Stakeholders dimension only appears in Studielink interviews is noteworthy, and is possibly a result from the strong role that SIS suppliers play in the network (ICT suppliers in DKD play a significant role as well, but are not as formally included in the network as in Studielink). Concerning the difference in overall quotations across interviewee levels, we can see slightly more than twice as many Political Environment quotations at organisational level. Whilst one would expect that political issues are more prominent at the higher administrative levels (i.e. network and national), the picture makes more sense when we look at the actual numbers of quotations contributed by the individual dimensions: here, we can see that the majority of quotations at the organisational level is actually contributed by Constituency Characteristics. Since constituencies can vary strongly by organisation, it makes sense that this adds mostly to the concerns of organisational-level stakeholders. ${ }^{128}$

\footnotetext{
${ }^{127}$ See Section 3.5.2.1 for a description of the study rights debate.

${ }^{128}$ An additional observation is that the Other Stakeholders dimension only appears at organisational level. However, given that this is only a very small value, and considering the relatively small overall size of quotations for Political Environment, it might be too far-fetched to argue that there is a significant difference across these groups.
} 


\section{B4.1.1. Public Pressure}

This dimension refers to the pressures exerted by public stakeholders (Table 2.8). Figure Annex B.20 shows the frequencies for the individual variables of this dimension. As Figure Annex B.20a shows, it is dominated by the Government Demand variable (64\%), followed by Citizen Demand (25\%) and Public Scrutiny (11\%). The comparison across groups shows some interesting differences in the overall amount of quotations across cases and interviewee levels. First, the data suggests that Public Pressure is more relevant for interviewees from the Studielink case. Taking into account that this is largely due to a bigger share of Citizen Demand quotations in this group, this could be a reflection of the fact that competition for clients is a major concern for organisations in the Studielink case, but not in DKD. Second, the data also suggests that Public Pressure is more relevant for interviewees at the organisation level than at network level. The explanation might be the same here, namely that the larger overall quotation amount for this group is largely contributed by a bigger share of Citizen Demand quotations, reflecting that organisational stakeholders are more concerned with their clients' demands than stakeholders at the network level who are more remote from clients' demands.

a)

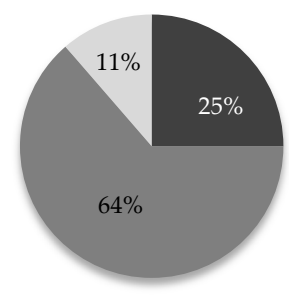

b)

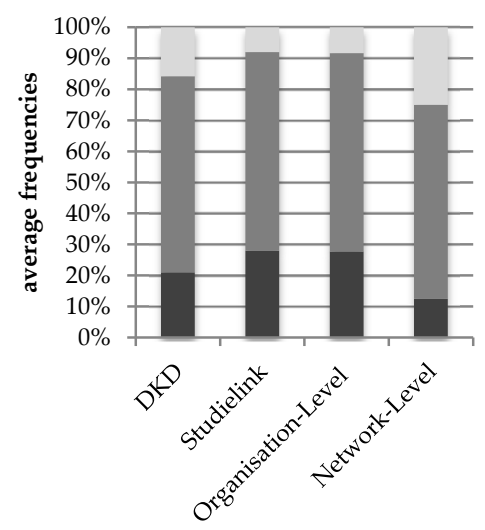

Public Scrutiny

- Government Demand

- Citizen Demand

\footnotetext{
Figure Annex B.20. Public Pressure quotations (frequencies per variable). Figure a) shows overall quotations distribution (rounded, $\mathrm{N}=44$ ) and Figure b) shows average frequencies of quotations per case and interviewee role
}

\section{B4.1.2. Constituency Characteristics}

Constituency Characteristics was defined as the nature of the clients community served by the project network (Table 2.8). Figure Annex B.21 shows the quotations frequency distribution for this dimension, but the overall amount of quotations for this dimension is very small $(\mathrm{N}=10)$, so that it is not possible to make any meaningful statements about this. 
a)

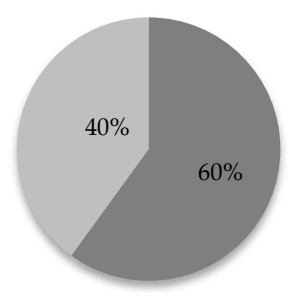

b)

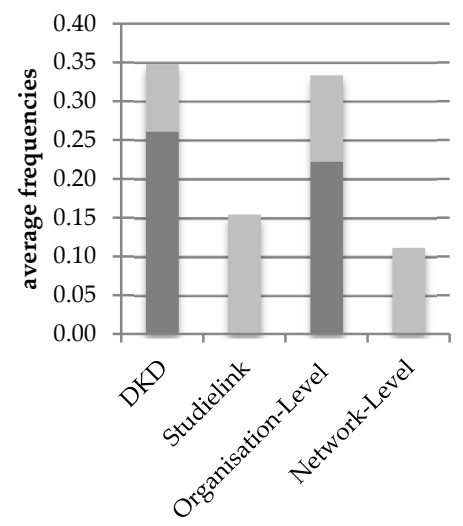

Community Size

- Community Socio-

Economic Environment

Figure Annex B.21. Constituency Characteristics quotations (frequencies per variable). Figure a) shows overall quotations distribution (rounded, $\mathrm{N}=10$ ) and Figure b) shows average frequencies of quotations per case and interviewee role

\section{B4.1.3. Other Stakeholders}

This dimension was added in order to capture external stakeholders forming the political environment. An illustrative example for instance is the role played in Studielink by the vendors (Q34:14) or the universities' and polytechnical universities' umbrella bodies VSNU and HBO-Council (Q30:25). With only five quotations overall, the amount of quotations is too small in order to draw any meaningful conclusions other than assuming that this category was not mentioned sufficiently to be considered a significant determinant of adoption.

\section{B4.2. Policy and Institutions}

This sub-construct concerns the national and international institutional and policy environment affecting e-Governance and IOP initiatives (see Table 2.9). Figure Annex B.22 shows the aggregated frequencies for the individual dimensions of this sub-construct. With contributing almost half of the quotations (47\%), Legal Framework is clearly the most significant dimension in this sub-construct. It is followed by Budgetary Framework (24\%), Administrative Structure (18\%) and eGov/IOP Policy (11\%). 
a)

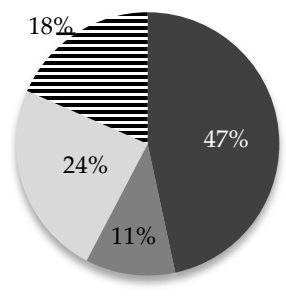

b)

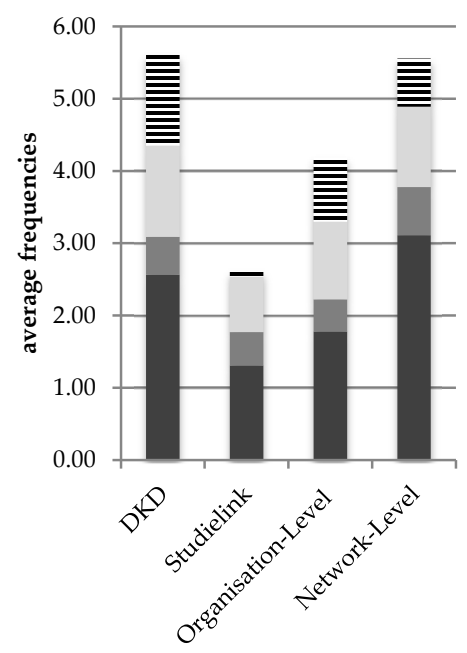

$=$ Administrative

Structure

Budgetary Framework

- eGov/IOP Policy

- Legal Framework

Figure Annex B.22. Policy and Institutions quotations (aggregated frequencies per dimension). Figure a) shows overall quotations distribution (rounded, $\mathrm{N}=163$ ) and Figure b) shows average frequencies of quotations per case and interviewee role

Whilst the shares of individual dimensions do not vary greatly across groups, we can observe substantial differences in terms of overall (relative) quotation frequencies. Across cases, we can observe that DKD has twice the amount of Policy and Institutions quotations of Studielink. This is most likely a result of the strong link of DKD to the overall policy in the work and income domain towards single data request (legislatively embodied in the WEU), and the overall consolidation of the sector.

The overall amount of Policy and Institutions quotations is also higher for network-level respondents in comparison to the organisational level. A possible reason is that stakeholders at organisation-level are more concerned with the operational reality and implementation of standards, whereas the institutional foundations are more dealt with at network level.

\section{B4.2.1. Legal Framework}

Legal Framework has been defined as the framework of legislation and regulation affecting eGovernance and IOP initiatives (see Table 2.9).

Figure Annex B.23 shows the aggregated frequencies for the individual variables of this dimension. The overall amount of quotations for this dimension is very small $(\mathrm{N}=13)$, so that it is very difficult to make any meaningful statements about this. 
a)

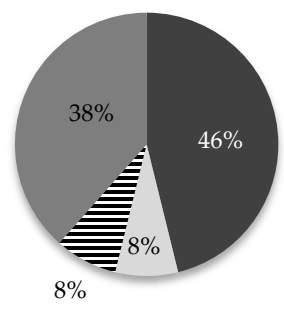

b)

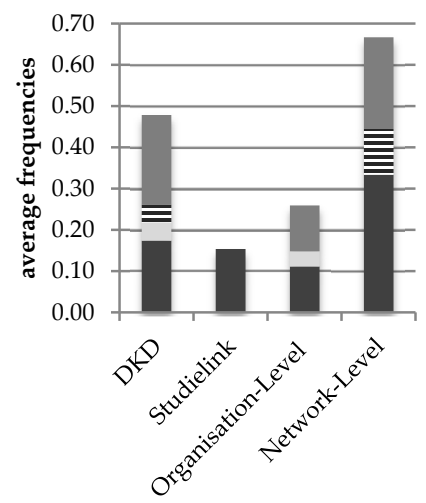

- Privacy Legislation

三 Public Procurement

Policies

IP Legislation

- Ambiguous Legislation

Figure Annex B.23. Legal Framework quotations (frequencies per variable). Figure a) shows overall quotations distribution (rounded, $\mathrm{N}=13$ ) and Figure b) shows average frequencies of quotations per case and interviewee role

\section{B4.2.2. Budgetary Framework}

This dimension captures the institutional framework related to budgetary issues that affect e-Governance and IOP initiatives (see Table 2.9). Figure Annex B.24 shows the aggregated frequencies for the variables of this dimension. Again, the overall quotations amount here is rather small $(\mathrm{N}=36)$. Whilst the conclusions about the distributions should thus be treated carefully, the results for this dimension are so distinct that they should be considered as a strong indication: nearly all (97\%) quotations come from the Budgetary Mechanisms variable, so that it can be assumed that Economic IOP Governance plays a small role.

a)

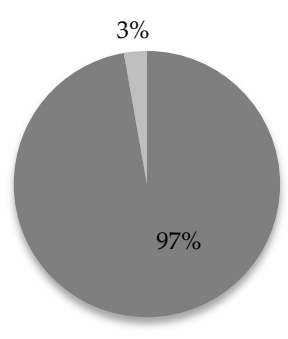

b)

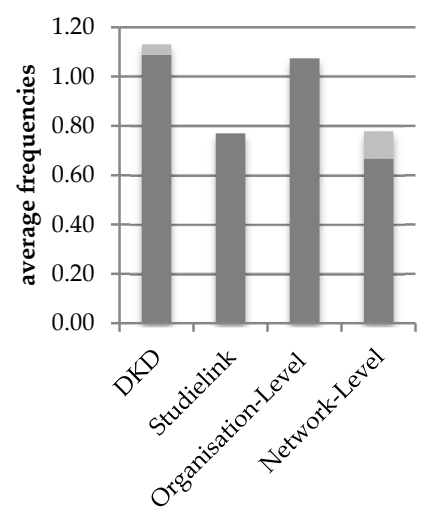

Economic IOP

Governance

- Budgetary Mechanisms

Figure Annex B.24. Budgetary Framework quotations (frequencies per variable). Figure a) shows overall quotations distribution (rounded, $\mathrm{N}=36$ ) and Figure b) shows average frequencies of quotations per case and interviewee role 


\section{B4.2.3. Administrative Structure}

This dimension describes the structure of the bureaucratic apparatus at the various governmental levels (see Table 2.9). In addition to the determinants identified in the literature review, the inductive coding of the interview data identified the additional determinant Path Dependency, which refers to engrained work processes and routines that are hard to change. An illustrative example of this from the DKD is the difficulty to truly integrate the operations of the GSDs and UWV in the work plazas, whilst they had worked separately for decades (Q18:15).

Figure Annex B.25 shows the aggregated frequencies for the individual variables of this dimension. Administrative Structure is another dimension with rather few quotations, so again, results should be considered as indications only. However, just like with the Budgetary Framework dimension, the results also show quite stark differences: overall, Path Dependency only plays a marginal role (7\% quotations overall), whilst the overwhelming majority of quotations (93\%) falls to Stovepipes. Across groups, it is striking that almost no quotations for this dimension come from Studielink, and almost all come from the DKD case. A plausible reason is that higher education institutions do have much less to fight with administrative structures, as their sector is not as old as the social security sector which has much more deeply engrained bureaucratic structures that can play a (positive or negative) role for IOP standards adoption.

a)

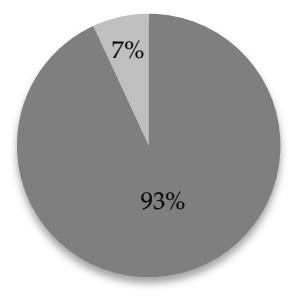

b)

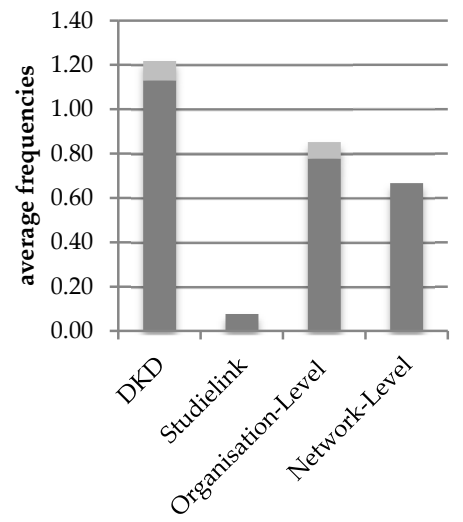

Path Dependency

Stovepipes

\footnotetext{
Figure Annex B.25. Administrative Structure quotations (frequencies per variable). Figure a) shows overall quotations distribution (rounded, $\mathrm{N}=29$ ) and Figure b) shows average frequencies of quotations per case and interviewee role
}

\section{B4.2.4. eGov/IOP Policy}

This dimension was identified as referring to the strategies, instruments and mechanisms put in place at national and international level to support e-Governance and IOP initiatives (see Table 2.9). As this dimension was not further sub-divided into variables, no frequency 
table or diagram is shown for this dimension. From Figure Annex B.22a however, it is visible that this dimension plays a relatively minor role for stakeholders $(11 \%)$ within the Policy and Institutions sub-construct. This observation also seems rather consistent across cases and interviewee roles (Figure Annex B.22b).

\section{B5. Results}

This construct has been defined as the consequences resulting from the adoption of IOP standards, both positive and negative (see Table 2.20). As they have been discussed in depth in Chapter 4 in the context of implications from IOP standards adoption, the discussion in this section limits itself to the level of sub-constructs, and the reader is referred to Chapter 4 for a more detailed discussion of dimensions and variables.

Figure Annex B.26 shows the aggregated frequencies for the individual sub-constructs. The share of the individual sub-constructs in this construct is greatly dominated by InternalOperations Results, contributing about three quarters of the total amount of results-related codes $(72 \%)$. The majority of the remaining quarter is formed by External-Relations Results (16\%), followed by Return-on-Investment Results (9\%). Network-Level Results only contribute a very small share (3\%).

a)

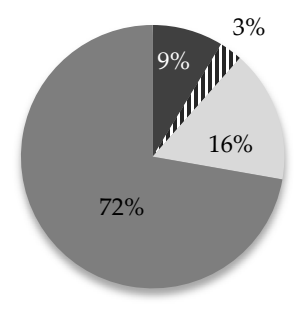

b)

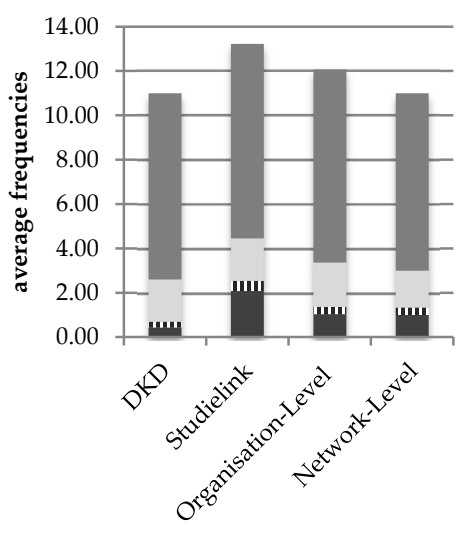

Internal-Operations Results

External-Relations Results

II Network-Level Results

- ROI Results

\footnotetext{
Figure Annex B.26. Results quotations (aggregated frequencies per sub-construct). Figure a) shows overall quotations distribution (rounded, $\mathrm{N}=425$ ) and Figure b) shows average frequencies of quotations per case and interviewee role
}

Across groups, the frequency distribution is very similar overall, with a few noteworthy differences. Across cases, there is a slightly larger contribution of quotations from Studielink, which seems primarily stemming from the significantly larger number of quotations for ROI Results in this case. A reason for this could be that in Studielink, the primary actors (higher education institutions) operate in a more competitive market environment that places a stronger emphasis on a business case that targets organisational returns on investments. In the DKD network, organisations are not as much in direct 
competition with each other, which might be reflected in a lower emphasis on organisational returns on investments. Across interviewee levels, Figure Annex B.26b shows that a slightly larger share of quotations for Results stems from organisation-level interviewees. This is understandable, given the large contribution of Internal-Operations Results - a construct that describes particularly those results from IOP standards adoption that impact the organisations.

\section{B6. Adoption Efforts}

This construct has been defined in the theoretical framework as the actual extent of efforts experienced by an organisation during the adoption process, i.e. the efforts that are required to deal with complexities and inflexibilities in the various spheres of the organisation (see Table 2.19). As this construct has been discussed in depth in Chapter 4 in the context of implications from IOP standards adoption, the discussion here is limited to the level of subconstructs, and the reader is referred to Chapter 4 (Section 4.3), as well as Annex A and Annex $\mathrm{E}$ for a discussion of the more detailed conceptual levels.

Figure Annex B.27 shows the aggregated frequencies for the individual sub-constructs. Organisational Efforts form the largest share (44\%), followed by Technological Efforts (27\%), Resource Costs (18\%), Semantic Efforts (6\%) and Legal Efforts (5\%).

a)

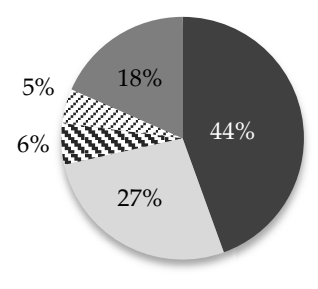

b)

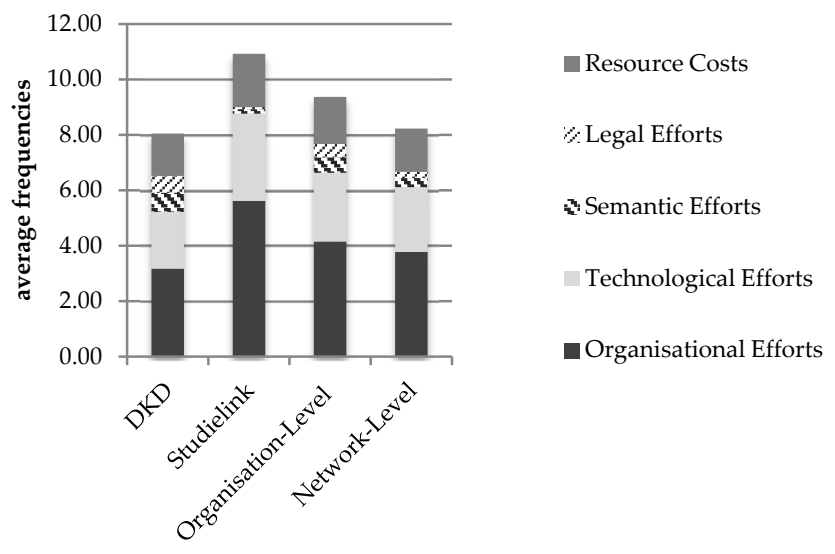

Figure Annex B.27. Adoption Efforts quotations (aggregated frequencies per subconstruct). Figure a) shows overall quotations distribution (rounded, $\mathrm{N}=326$ ) and Figure b) shows average frequencies of quotations per case and interviewee role

The shares of the individual sub-constructs are rather similar to this overall distribution across the groups, with two exceptions in the cross-case comparison. Both concern subconstructs that are visibly more discussed in the DKD case than in Studielink. First, Legal Efforts make for a significantly larger share of quotations in DKD, indicating that the social security domain is subject to a more complex legal framework than the higher education sector, which consequently also results in higher efforts for achieving legal IOP. Secondly, 
we can observe a significantly larger share of Semantic Efforts in DKD, which should be attributed to the fact that semantic standardisation by means of the SGR forms a substantial part of the IOP architecture in the DKD.

From a comparison of overall frequencies, it appears that Adoption Efforts are more discussed by interviewees from the Studielink case than in DKD. One possible explanation for this is that organisational stakeholders in Studielink were confronted with Adoption Efforts more intensively than in DKD, because in the latter case, standardisation unfolded over a considerably longer time period, whereas Studielink developed fast and Adoption Efforts had to be made in a more "compressed" manner. There is also a difference between overall frequencies at organisational and network levels. The observation that organisation-level interviewees discuss Adoption Efforts comparatively more is understandable, since it is in the organisations where stakeholders have to implement the standards.

\section{B7. IOP Standards Characteristics}

This construct was defined as the general attributes of the IOP standards in a Government Information Network's IOP architecture (see Table 2.18). It is composed of four variables: Trialability and Maturity have both been specified based on the literature review in Chapter 2, and the variables Customisability and Correction Mechanisms have been added to this construct as a result from the inductive coding.

Customisability is defined here as the degree to which an IOP standard can be customised by the organisations. It can be regarded as a regulated form of partial compliance with a standard. An illustrative example for this is for instance how the standard deadline for students' registration required by Studielink was for a "transition period" allowed to be circumvented through a workaround by some institutions that were constrained by the functionality limits of their legacy SIS to integrate this deadline into the work process (Q36:9).

Correction Mechanisms refers to the existence of mechanisms to detect and correct faulty data. An example of such a function is for instance the "Correction Mechanism" that is connected to the DKD broker - a technical application that automatically alerts an organisation when it supplies conflicting data.

Figure Annex B.28 shows the aggregated frequencies for the individual variables. The dominant variable is Maturity (53\%). It is followed by Correction Mechanisms (22\%), Trialability (16\%) and Customisability (9\%). The data shows some variation across cases and interviewee levels regarding this distribution. Whilst the difference across interviewee levels is rather small, there is a notably larger overall amount of quotations for IOP Standards Characteristics in the Studielink case, largely contributed by a higher share of Trialability quotations. A possible explanation is that as a much younger network, stakeholders from the Studielink case in general were less familiar with the standards in their network and hence put greater emphasis on their characteristics, in particular the possibility to gain more experience with them. In the DKD network on the other hand, which has a longer history of standardisation, that appears to be not as prominent on stakeholders' agenda. 
a)

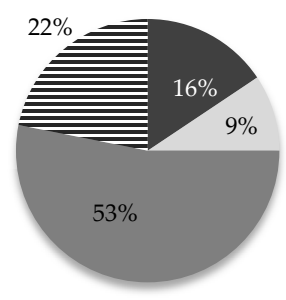

b)

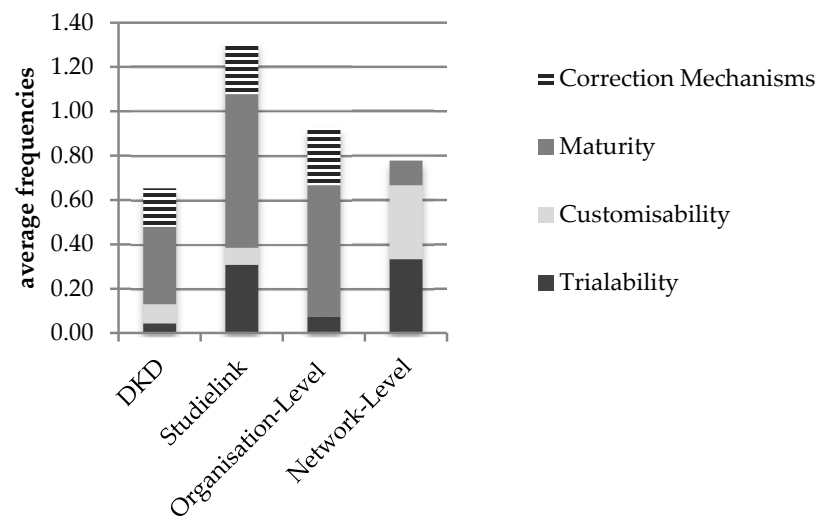

Figure Annex B.28. IOP Standards Characteristics quotations (frequencies per variable). Figure a) shows overall quotations distribution (rounded, $\mathrm{N}=32$ ) and Figure b) shows average frequencies of quotations per case and interviewee role

\section{B8. Organisation-Specific Determinants}

Organisation-Specific Determinants was defined as an umbrella construct to include both Organisational Capacity and Organisational Needs (see Table 2.16). Both of these sub-constructs and their dimensions are discussed in detail in the following sections. Figure Annex B.29 shows the distribution of frequencies for both sub-constructs.

a)

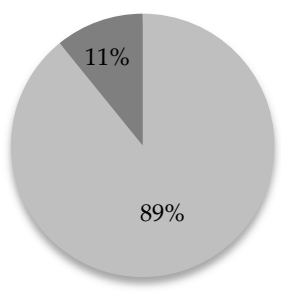

b)

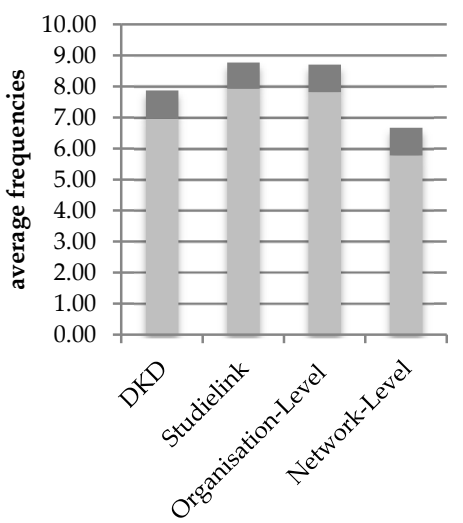

- Organisational Need

- Organisational Capacity

Figure Annex B.29. Organisation-Specific Determinants quotations (frequencies per sub-construct). Figure a) shows overall quotations distribution (rounded, $\mathrm{N}=295$ ) and Figure b) shows average frequencies of quotations per case and interviewee role 


\section{B8.1. Organisational Capacity}

As Figure Annex B.29a shows, Organisational Capacity contributes the large majority of quotations for the Organisation-Specific Determinants construct (89\%). Organisational Capacity has been defined as internal support capacities and resources needed for the adoption of IOP standards (see Table 2.17). In addition to the originally specified dimensions, Clout has been added as a result from the inductive coding procedure. It is defined here as an organisation's power and influence that allows it to control others in the network. In the following sections, this and the remainder of the Organisational Capacity dimensions are discussed in detail.

Table Annex B.18 shows the aggregated frequencies for the individual dimensions of the Organisational Capacity sub-construct. They are relatively evenly spread in terms of contributions: except two outliers with relatively small shares (5\% for Financial Resources and $4 \%$ for Clout), the share of the remainder varies between 21\% (Human Resources) and 10\% (Manager Characteristics).

As the cross-group comparison shows, the issue of Organisational Capacity was discussed with relatively equal frequency across all groups - with the exception of the network-level stakeholders who are slightly less concerned with this issue (most likely since it primarily is an organisational concern).

\begin{tabular}{|l|r|r|r|r|r|}
\hline Dimension & Overall & DKD & Studielink & Org.-Level & Net.-Level \\
\hline Human Resources & $21 \%$ & 1,09 & 2,31 & 1,70 & 1,00 \\
\hline Organisational Structure & $18 \%$ & 1,39 & 1,23 & 1,26 & 1,56 \\
\hline Management Practices & $18 \%$ & 1,22 & 1,54 & 1,44 & 1,00 \\
\hline IT Capability & $12 \%$ & 0,57 & 1,38 & 0,81 & 1,00 \\
\hline Relational Mechanisms & $11 \%$ & 1,04 & 0,46 & 1,00 & 0,33 \\
\hline Manager Characteristics & $10 \%$ & 0,65 & 0,77 & 0,78 & 0,44 \\
\hline Financial Resources & $5 \%$ & 0,52 & 0,15 & 0,48 & 0,11 \\
\hline Clout & $4 \%$ & 0,48 & 0,00 & 0,33 & 0,22 \\
\hline Total & $100 \%$ & 6,96 & 7,85 & 7,81 & 5,67 \\
\hline
\end{tabular}

Table Annex B.18. Organisational Capacity quotations (aggregated frequencies per dimension). Column "Overall" shows overall quotations distribution in percent (rounded, $\mathrm{N}=262$ ) and the remaining columns show average frequencies of quotations per case and interviewee role

\section{B8.1.1. Human Resources}

This dimension pertains to an organisation's support infrastructure related to the human resources capacity (see Table 2.17). Table Annex B.19 shows the frequencies for the individual variables of this dimension. The shares of the individual variables in the Human Resources capacity dimension cover a considerable range, from 2\% (Training) to $24 \%$ (Business Process Know-How).

We can discern some significant differences across groups. Across cases, we can observe that more than twice as many Human Resources quotations come from Studielink in comparison to DKD. This might be due to the fact that Studielink is very specifically linked to an essential front-office business process of universities (student enrolment), and is thus more 
directly used by operational staff. Whilst the $\mathrm{DKD}$, on the other hand, is also related to front-office applications (i.e. client intake), the bulk of it is more related to the back-office and as such, operational staff is less directly affected by its IOP standards. Across stakeholder levels, there is a noticeable majority of quotations coming from the organisation level - which can most likely be attributed to the fact that human resource capacity primarily is an organisational-level issue. For a cross-group comparison of the shares of quotations for each variable, however, the overall amount of quotations is too low to derive solid conclusions.

\begin{tabular}{|l|r|r|r|r|r|} 
& Overall & DKD & Studielink & Org.-Level & Net.-Level \\
\hline Business Process Know-How & $24 \%$ & 0,17 & 0,69 & 0,44 & 0,11 \\
\hline IT Know-How & $19 \%$ & 0,13 & 0,54 & 0,37 & 0,00 \\
\hline Staff Motivation & $17 \%$ & 0,17 & 0,38 & 0,30 & 0,11 \\
\hline Market Know-How & $9 \%$ & 0,04 & 0,31 & 0,19 & 0,00 \\
\hline IOP Standard Know-How & $9 \%$ & 0,22 & 0,00 & 0,04 & 0,44 \\
\hline Networking Experience & $9 \%$ & 0,17 & 0,08 & 0,11 & 0,22 \\
\hline Human Resources Capacity & $7 \%$ & 0,09 & 0,15 & 0,11 & 0,11 \\
\hline Information Awareness & $4 \%$ & 0,04 & 0,08 & 0,07 & 0,00 \\
\hline Training & $2 \%$ & 0,00 & 0,08 & 0,04 & 0,00 \\
\hline Total & $100 \%$ & 1,04 & 2,31 & 1,67 & 1,00 \\
\hline
\end{tabular}

Table Annex B.19. Human Resources quotations (frequencies per variable). Column "Overall" shows overall quotations distribution (rounded, $\mathrm{N}=54$ ) and the remaining columns show average frequencies of quotations per case and interviewee role

\section{B8.1.2. Organisational Structure}

This dimension describes the existence of capacities related to the organisation's structure (see Table 2.17).

a)

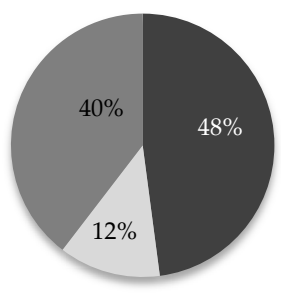

b)

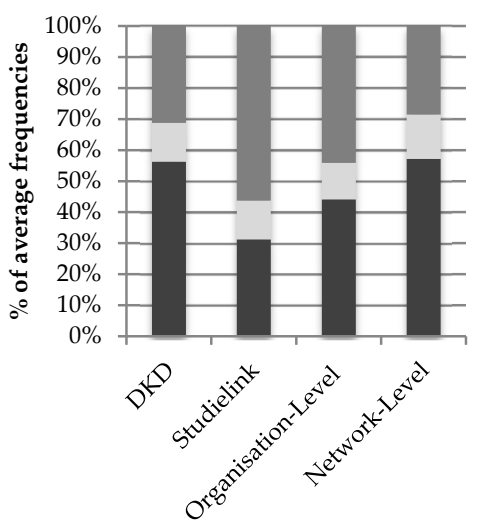

Internal Unity

Dedicated Units

- Organisation Size

Figure Annex B.30. Organisational Structure quotations (frequencies per variable). Figure a) shows overall quotations distribution (rounded, $\mathrm{N}=48$ ) and Figure b) shows average frequencies of quotations per case and interviewee role 
Figure Annex B.30 shows the frequencies for the individual variables of this dimension. Together with Management Practices, Organisational Structure forms the second-largest dimension (18\%) for Organisational Capacity. The variable with the largest share within Organisational Structure is Organisation Size (48\%), followed closely by Internal Unity (40\%). In contrast, Dedicated Units only accounts for $12 \%$. The latter variable was identified inductively from the case data and was defined as the existence of units or departments within the organisation that were specifically set up to support the adoption of IOP standards. An illustrative example for this is that some of the larger municipalities had specific monitoring units set up in order to audit compliance with the Norm Framework (Q5:9).

There is not much difference across groups in terms of overall amount of quotations, but we can observe substantial differences in terms of the distribution of the Internal Unity and Organisation Size variables (Dedicated Units does not show much variation across groups). Whereas Organisation Size takes an approximately twice as large share than Internal Unity in the DKD case, this ratio is roughly the opposite in Studielink. The reason could be that higher education institutions are by their very nature (i.e. being structured into separate faculties with very idiosyncratic institutional cultures) more fragmented, and as such the achievement of internal unity is more of an issue for these organisations. In DKD on the other hand, organisations are generally more internally homogeneous. In addition, there is relatively more variation in size across organisations in the DKD case (e.g. when comparing UWV with the GSD from a small municipality), so the size factor is more often mentioned when interviewees compare their organisation to others in their network. In short, these two observations might be an illustration of the DKD network being more diverse, whereas organisations in Studielink are more homogeneous (whilst being internally more heterogeneous and fragmented than DKD partner organisations).

\section{B8.1.3. Management Practices}

This dimension concerns the managerial practices in the organisation that are conducive to IOP standards adoption (see Table 2.17). Two variables that had been specified for his dimension in the preliminary theoretical framework were not confirmed in the data from the cases. These are Life-Cycle Procurement Methods and Legal Support. On the other hand, two additional variables were identified from the case study data. The first of these is Monitoring, referring to the practice of monitoring IOP-related developments in- and outside of the organisation. As one interviewee from the DKD mentioned for instance, especially the active monitoring of organisation-external developments is important because such developments are rarely formally announced (Q14:1). The other inductively identified variable is Communication, defined here as the internal communication about the IOP standards to be adopted. For instance, interviewees mentioned the importance of the management informing the organisation's staff honestly about the expected impacts (Q29:30), and convincing their staff about the expected benefits (Q32:15).

Table Annex B.20 shows the frequencies for the individual variables of this dimension. The biggest share in the Management Practices dimension is held by the Top Management Support 
variable (47\%), with the remainder varying between $4 \%$ (Feasibility Assessment) and 13\% (Decision-Making Centralisation and Strategic Plan).

\begin{tabular}{|l|r|r|r|r|r|}
\hline & Overall & DKD & Studielink & Org.-Level & Net.-Level \\
\hline Top Management Support & $47 \%$ & 0,52 & 0,69 & 0,56 & 0,67 \\
\hline Decision-Making Centralisation & $13 \%$ & 0,17 & 0,15 & 0,19 & 0,11 \\
\hline Strategic Plan & $13 \%$ & 0,13 & 0,23 & 0,22 & 0,00 \\
\hline Communication & $9 \%$ & 0,00 & 0,31 & 0,15 & 0,00 \\
\hline Knowledge Management & $7 \%$ & 0,13 & 0,00 & 0,07 & 0,11 \\
\hline Monitoring & $7 \%$ & 0,09 & 0,08 & 0,07 & 0,11 \\
\hline Feasibility Assessment & $4 \%$ & 0,09 & 0,00 & 0,07 & 0,00 \\
\hline Total & $100 \%$ & 1,13 & 1,46 & 1,33 & 1,00 \\
\hline
\end{tabular}

Table Annex B.20. Management Practices quotations (frequencies per variable). Column "Overall" shows overall quotations distribution (rounded, $\mathrm{N}=45$ ) and the remaining columns show average frequencies of quotations per case and interviewee role

There is some degree of variation across groups. Whilst the relatively low number of quotations overall means that comparisons can be merely indicative, it is interesting to see that Communication was only mentioned in the Studielink case - it seems plausible that this is linked to the previously discussed observation that partner organisations in the Studielink case are more internally fragmented than those in DKD, and that (good) communication is thus a more important issue. Another observable trend is that, whilst the remainder of variables seems to be highly varied across groups, both the two most frequent variables in the Management Practices dimension (Top Management Support and Decision-Making Centralisation) are more "stable" in terms of the share which they take in all groups.

\section{B8.1.4. Relational Mechanisms}

Relational Mechanisms has been defined as the ability of an organisation to invest in purposeful relationships (see Table 2.17). The determinant Relational Specificity, which had been specified in the preliminary theoretical framework, was not confirmed in the data from the cases. On the other hand, the variable Network Think was inductively derived as an additional variable from the data analysis. It is defined here as the ability in the organisation as a whole to think from the perspective of the network. Under this variable, interviewees for instance mentioned the need for a recognition by organisations of their interdependence for achieving individual and collective goals (Q8:18), a feeling of joint responsibility to collaborate for creating public value (Q10:22), and a feeling of collective ownership of the network (Q12:8).

Figure Annex B.31 shows the frequencies for the individual variables of this dimension. The overall amount of quotations for this dimension is rather small, so the inferences here can be considered as indicative only. The majority of quotations in the dimension is contributed by the Network Think variable (83\%), and the other three variables only contribute shares of $10 \%$ (Existing Networks) or smaller (Relationship Extendability and Visibility).

The share of these latter variables is similarly small across all groups, and at network level they are not even mentioned at all. However, the differences are small, and given the small number of quotations in this dimension, one cannot be sure about the significance of these 
differences. A more marked difference can be seen in the overall amount of quotations across groups: across cases, it appears that Relational Mechanisms was mentioned half as often than in DKD, which could be a result from the fact that DKD is a larger and more heterogeneous network, where an organisation's ability to invest in purposeful relationships is more relevant than in the more "intimate" network of Studielink.

A similar difference can also be seen across interviewee levels, with the organisational level having more than twice the relative amount of Relational Mechanisms quotations. Most likely, the reason is the same as for the other Organisational Capacity dimensions, namely that these are more of a concern for organisational stakeholders than for network-level stakeholders.

a)

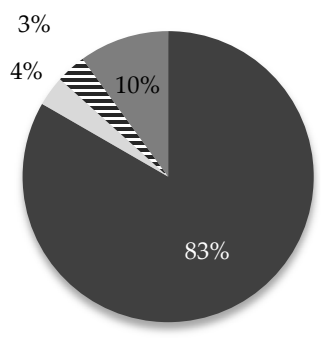

b)

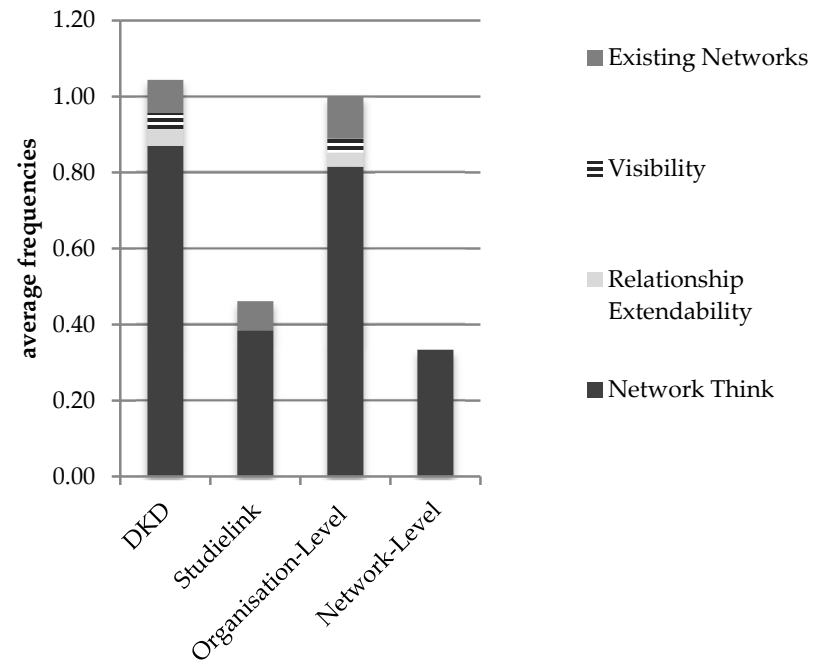

Figure Annex B.31. Relational Mechanisms quotations (frequencies per variable). Figure a) shows overall quotations distribution (rounded, $\mathrm{N}=30$ ) and Figure b) shows average frequencies of quotations per case and interviewee role

\section{B8.1.5. ICT Capability}

This dimension pertains to the support infrastructure related to ICT assets such as software and hardware (see Table 2.17). Figure Annex B.32 shows the frequencies for the individual variables of this dimension. The amount of quotations is not large enough to draw more than indicative conclusions. However, given its size, the relatively large difference between the shares of the two variables should be pointed out, suggesting that ICT Capability is dominated by ICT Infrastructure (69\%), followed by IT Department Support (31\%). 
a)

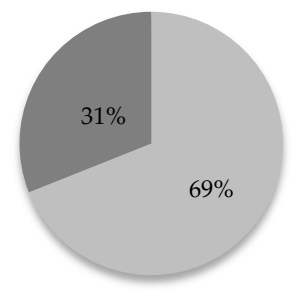

b)

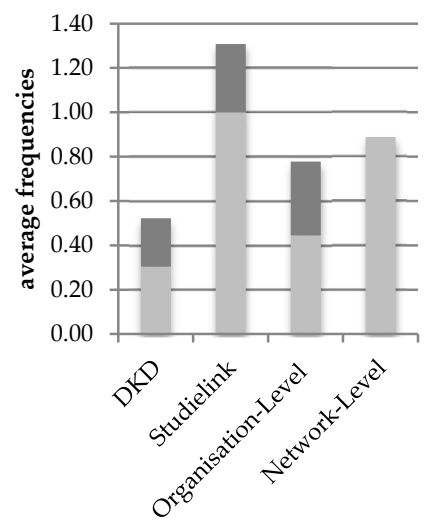

- IT Department Support

- IT Infrastructure

Figure Annex B.32. ICT Capability quotations (frequencies per variable). Figure a) shows overall quotations distribution (rounded, $\mathrm{N}=29$ ) and Figure b) shows average frequencies of quotations per case and interviewee role

\section{B8.1.6. Manager Characteristics}

This dimension has been defined as organisational managers' characteristics and skills that pertain to leading their organisation through the adoption of the IOP standards (see Table 2.17). The determinant Tenure in the Position, which had been specified in the preliminary theoretical framework, has not been confirmed in the data from the cases. On the other hand, the variables Manager's Non-ICT Know How and Manager's Emotions were added in addition to previously specified variables. Manager's Non-ICT Know How was defined as the relevant know-how held by the manager besides ICT-related expertise. Examples for this variable mentioned by the interviewees for instance include the managers' general information management skills (Q34:4), their ability to represent and lead the organisation at network-level (Q14:16), or knowledge of the network's change-management procedures (Q11:13). The Manager's Emotions variable was defined as the emotional and affective reactions of managers in relation to the network. One interviewee reported that emotional responses to standardisation are most common with regard to the implications of organisational IOP standards (Q36:1).

Table Annex B.21 shows the frequencies for the individual variables of this dimension. The Manager Characteristics dimension has received relatively few quotations overall $(\mathrm{N}=23)$. While this makes it difficult to draw conclusions on the smaller differences across groups, it seems safe to assume that the relatively large difference between network-level and organisation-level amount of quotations (the latter receiving more than twice the amount) is because manager's characteristics mostly are noticed within their organisations only, and are not so much considered by network-level actors. 


\begin{tabular}{|l|r|r|r|r|r|}
\hline Variable & Overall & DKD & Studielink & Org.-Level & Net.-Level \\
\hline Manager's Tenure & $0 \%$ & 0,00 & 0,00 & 0,00 & 0,00 \\
\hline Manager's Attitude to Innovation & $35 \%$ & 0,17 & 0,31 & 0,22 & 0,22 \\
\hline Manager's Background & $13 \%$ & 0,13 & 0,00 & 0,11 & 0,00 \\
\hline Manager's IT skills & $9 \%$ & 0,04 & 0,08 & 0,07 & 0,00 \\
\hline Manager's Non-IT Know-How & $22 \%$ & 0,13 & 0,15 & 0,19 & 0,00 \\
\hline Manager's Power & $17 \%$ & 0,09 & 0,15 & 0,15 & 0,00 \\
\hline Manager's Emotions & $4 \%$ & 0,00 & 0,08 & 0,00 & 0,11 \\
\hline Total & $100 \%$ & 0,57 & 0,77 & 0,74 & 0,33 \\
\hline
\end{tabular}

Table Annex B.21. Manager Characteristics quotations (frequencies per variable). Column "Overall" shows overall quotations distribution (rounded, $\mathrm{N}=23$ ) and the remaining columns show average frequencies of quotations per case and interviewee role

\section{B8.1.7. Financial Resources}

This dimension has been defined as the financial means available to the organisation that are needed for carrying out the required activities and acquire the required other resources (see Table 2.17). As it only consists of one determinant, there is no graph or frequency table for this dimension. As we can see in Table Annex B.18, it only plays a small role within the Organisational Capacity construct (5\%). As Table Annex B.18 suggests, this also is not much different across groups.

\section{B8.1.8. Clout}

Clout has been derived from the inductive coding, and has been defined as the organisational power and role that allows it to control others in the chain. In the DKD for instance, some organisations that are only data suppliers to the network were reported to have considerable clout as a de facto standard-setter: if the organisation is a data owner that has no own need for connecting to the network and exchanging, it has considerable clout to impose its own standards on the rest of the project network and does not need to adopt any standards (Q3:35).

As Clout only consists of one determinant, there is no graph or frequency table for this dimension. As we can see in Table Annex B.18, it only plays a relatively small role within the Organisational Capacity construct (4\%). As Table Annex B.18 also shows, this also is more or less consistent across interviewee levels. Across cases, however, Clout is not appearing at all in the Studielink case. This could very likely be a result from the fact that the Studielink network is quite homogeneous, also in terms of power (or clout): the partner organisations in this case are very similar, and there is not nearly the power inequality that can be found in DKD, where organisations differ markedly in size, influence, and representation in the network governance structure.

\section{B8.2. Organisational Needs}

Organisational Needs has been derived from the inductive coding, and has been defined as the organisational need for IOP (e.g. as a result from turbulence within an organisation). The idea behind this sub-construct of Organisation-Specific Determinants is that an organisation's adoption of IOP standards is not only dependent on that organisation's capacity to adopt 
them, but also in how far it needs (and wants) to adopt them. Under this sub-construct, interviewees for instance mentioned organisations' realisation that their organisational mission is dependent on participation in the network (Q13:15). However, in comparison to Organisational Capacity, Organisational Needs only make for a small part $(11 \%)$ of the quotations in the Organisation-Specific Determinants construct overall. 



\section{CHAPTER 6.}

\section{THE EFFECTIVENESS OF DIFFERENT \\ INTEROPERABILITY GOVERNANCE MODES ACROSS \\ NETWORK COMPLEXITIES 129}

\subsection{Introduction}

This chapter is concerned with the effectiveness of IOP governance in Government Information Networks, i.e. the successful achievement of IOP through the adoption of IOP standards by partner organisations in the network. It draws on empirical evidence from the DKD and Studielink case studies in order to investigate the relationship between the effectiveness of IOP governance and the complexity of a given Government Information Network. Previous chapters have shown that IOP governance plays a key role for achieving IOP in Government Information Networks, and that in order to be effective, it needs to be chosen in alignment with the other determinants that influence IOP standards adoption. As shown in Chapter 5, one factor that is of particular relevance to stakeholders in Government Information Networks is the complexity of the network (see Table 2.11 for a definition). Moreover, previous research (cf. Provan \& Kenis, 2008; Span et al., 2012) has argued that the governance of networks needs to match the complexity of the network in order to reach its goals. Therefore, this chapter focuses on the interaction between IOP governance and network complexity in their effect on IOP standards adoption in order to validate this argument.

The overall objective of the chapter thus is to investigate whether and how, in the face of different degrees of network complexity, different degrees of IOP governance centralisation might result in different effects on the adoption of IOP standards. This can contribute to a better understanding of how the governance of a network's IOP architecture should best be organised in different networks. It also aims to contribute an application of the argument originally put forward by Provan and Kenis (2008) and establish whether in the context of Government Information Networks, higher network complexity indeed requires more centralised governance approaches, or whether the effect of IOP governance centralisation on standards adoption is independent of a network's complexity. ${ }^{130}$

\footnotetext{
${ }^{129}$ A shortened version of this chapter has been published as paper submission to the IRSPM 2015 conference (Henning, 2015).

${ }^{130}$ Explained in detail in Section 6.2 below.
} 
The main research question addressed in this chapter thus is the final question that was raised at the end of Chapter 1: "how do different degrees of IOP governance centralisation affect the adoption of IOP standards in Government Information Networks, and how can this be explained"? Several sub-questions are addressed in order to answer this question: What is the influence of different degrees of IOP governance centralisation across networks of different network complexity? Are the effects of IOP governance centralisation on IOP standards adoption independent or moderated by network complexity? In other words, should the degree of IOP governance centralisation be chosen in dependence on other determinants such as network complexity? And if so, which degree of governance centralisation should be used for which level of network complexity?

In order to address these questions, this chapter is organised as follows. This introduction section (6.1) presents the general background and objectives of the chapter, its research questions and structure, as well as key points of analytical context. Section 6.2 presents the theoretical background regarding the relationship between (IOP) governance centralisation and network complexity. The empirical investigation is then discussed in Section 6.3, which presents the findings from the case studies regarding the relationship between IOP governance centralisation and network complexity: in Sections 6.3.1 and 6.3.2 respectively, the influence of IOP governance and of network complexity on adoption in general is discussed, followed in Sections 6.3.3 through 6.3.6 by the development of several propositions on whether and how the effectiveness of different degrees of IOP governance centralisation for IOP standards adoption is dependent on the network complexity in a given Government Information Network. Section 6.4 discusses the conclusions on the significance of the chapter's findings for IOP governance and provides recommendations on selecting an appropriate degree of IOP governance centralisation.

Before moving on to the remainder of the chapter, the reader is advised to consider three general notes of context concerning the data and analysis in this chapter. The first point concerns the comparative perspective taken on the two case studies. Drawing on data from the two cases with contrasting degrees of network complexity allows a heightened degree of corroboration of the findings. However, it would be misguided to assume that in order to confirm that higher network complexity requires more centralised IOP governance, the stakeholders from the complex network (DKD) would need to confirm it whilst the stakeholders from the non-complex network (Studielink) should do the opposite. On the contrary: the reasoning here is that if the data from both the complex network as well as the non-complex network confirm our assumption, we can assume that this argument has a higher degree of validity. In other words, double-checking our assumption against the perceptions of stakeholders in a non-complex network provides a stronger test. In that sense, the contrasting cases here function as a "robustness check" of whether our assumption based on the argument by Provan and Kenis (2008) holds.

The second note of context is that more than the previous two chapters, this chapter relies on an in-depth interpretive analysis of interviewee statements rather than the content analysis of quotations that were aggregated per concept (code). However, since in some spots it also does report some results that are based on the semi-quantitative content analysis of quotation frequencies, the same note of context as in the previous chapters 
applies here that the process of aggregating and "counting" quotations in this part of the content analysis implies a limited sensitivity to the exact content of individual quotations (for a detailed discussion see Section 3.4, as well as Section 7.3). Next to the other methodological safeguards discussed in those sections, in this chapter it is particularly the triangulation through an in-depth interpretive analysis of interview quotations which serves to mitigate this limitation.

The third contextual note is that it should also be highlighted again at this point that the central evidence base of the interpretive analysis in this chapter consists of semi-structured interviews, i.e. "guided conversations" in which respondents answered to a number of questions that were all asked in the light of the general question of what determines organisations' adoption of IOP standards (see also Section 3.3 for a discussion of the question guide). This has three important implications for the interpretation of the conclusions presented in this chapter. First, when reading the interview quotes provided in this chapter, the reader should be aware that whilst the quotes might not always contain the exact terms for a given theoretical concept (for instance "network complexity" or "adoption"), they still can reflect descriptions of that concept in the own words of the respondents. Second, the quotes do not always explicitly mention "adoption" or "intention to adopt" - however, since they represent interviewees' answers to questions on the determinants and processes of adoption, this should be taken as the default context of their answers (it would in fact be unnatural to expect that they would neatly add this expression to every sentence in their answer after that context has already clearly been established). Third and related to the previous point, the reader is reminded that the interpretive analysis here differs from quantitative methodology that would aim at calculating exact "probabilities" of adoption through a quantitative analysis. Instead, the nature of the findings is to identify general patterns of behaviour formation through interpretive analysis of the qualitative interview data. To reflect this, the central conclusions in this chapter are presented as empirically grounded theoretical "propositions" - even though they do serve as an application of previous theory on the effectiveness of different network governance approaches, future research may also validate this through quantitative analyses. ${ }^{131}$

\subsection{Theoretical Background: The Relationship of IOP Governance Centralisation and Network Complexity}

Out of all the determinants identified in Chapter 5, why focus on IOP Governance centralisation and Network Complexity in particular? One reason is that IOP Governance and Network Characteristics were shown in Chapter 5 to be the most relevant determinants for the interviewed stakeholders. Moreover, there is no certain theory on their relationship, except the argument by Provan and Kenis (2008) that the attainment of intended network-level

\footnotetext{
${ }^{131}$ The term "proposition" is used here to describe a theoretical statement characterised by three key features. First, the propositions here are inferences that are made based on inductive and deductive reasoning, combining existing theory and the empirical data collected. Second, following Popper (2002), they are seen as "conjectures", i.e. as unproven statements based on incomplete information that need to be subjected to subsequent refutation or verification. And third, related to the previous point that they need to be tested, propositions need to be distinguished from the notion of "hypotheses". Whilst propositions are theoretical statements in an abstract and more general form, hypotheses are specific instances of propositions to be tested with specific measurable variables. In summary, "propositions" are here defined as abstract theoretical statements in the form of conjectures derived from deductive and inductive inference.
} 
outcomes ("network effectiveness") depends in particular on matching a network's governance centralisation to the degree of complexity in that network. In other words, they claim that with increasing complexity of an inter-organisational network ${ }^{132}$, stronger centralisation of governance yields more effective network-level outcomes (in the context of this dissertation, this refers to the attainment of inter-organisational IOP). ${ }^{133}$

Several authors have based studies on network governance on this assumption put forward by Provan and Kenis' theoretical proposition (cf. Chen, 2012; Span et al., 2012; Willem \& Gemmel, 2013). However, there has so far been no empirical validation of this argument. It is therefore a key objective of this chapter to develop this theory further by applying and adapting it in the context of IOP in Government Information Networks. To this end, the sections below first operationalise the key concepts of IOP governance centralisation (6.2.1) and network complexity (6.2.2). The empirical investigation is then presented in Section 6.3.

\subsubsection{IOP Governance Centralisation}

Two sub-constructs of IOP Governance from the theoretical framework presented earlier are relevant in relation to IOP governance centralisation: Decision-Making Centralisation and Enforcement. As previous chapters have pointed out, Decision-Making Centralisation is conceptualised as consisting of the dimensions Brokerage and Stakeholder Involvement, and Enforcement is conceptualised as consisting of the dimensions Accountability and Coercion.

Brokerage, the first dimension of Decision-Making Centralisation, was defined as the existence and characteristics of a coordination body that is formally charged with the coordination of the network and its IOP architecture (see Table 2.4). The Brokerage concept is most clearly described by Provan and Kenis (2008). Whilst they do not explicitly refer to "governance centralisation", they essentially use different forms of brokerage to differentiate between various modes of network governance that range from strong centralisation of control to decentralised control. The most decentralised form of network governance, according to their model, is a network without any brokerage (i.e. each organisation can interact with any other organisation to govern the network). The other end of the spectrum is a highly brokered network, where interactions concerning governance are centrally brokered through a single organization (between individual organisations directly), acting as a network broker or "network administrative organization" (NAO). For IOP governance, this role might be played by "infomediaries", which are in charge of administering the IOP architecture of a given Government Information Network (such as the BKWI in the DKD case or Studielink Foundation for the Studielink case). Between these two extremes, there might be many hybrid forms where some governance interactions happen through a broker,

\footnotetext{
${ }^{132}$ The Provan and Kenis study identifies four structural and relational characteristics - not all of which refer to network complexity. The three characteristics that are here taken to be representing the Network Complexity construct are "size of the network" (number of participants), "goal consensus", and "complexity of the network's tasks" (i.e. the need for network-level competencies). The fourth characteristic, "trust", is not explicitly taken into consideration here, given that it is not directly relevant for the present study's focus on network complexity.

${ }^{133}$ This argumentation about the relation between network structure and network governance dates back to a broader discussion in organisational theory that the optimal management approach for organisations (e.g. whether centralised or decentralised) depends on the context of an organisation (e.g. the complexity of its structure, of its tasks and of its environment). For instance, this relationship is at the heart of the debate whether organisational structure should follow organisational strategy (Chandler, 1962) or vice versa (Hall \& Saias, 1980).
} 
and other interactions (to various degrees) are left to organisations. This classification is visually displayed in Table 6.1 below.

The second dimension of Decision-Making Centralisation was identified as Stakeholder Involvement. This had been defined as the level of stakeholders' participation in the network's IOP governance (see Table 2.4). Essentially, more stakeholder participation implies that there is less centralisation of IOP governance. This idea is also reflected in the second distinction made in Provan and Kenis' (2008) framework, which subdivides brokered networks into "participant-brokered networks" and "externally-brokered networks". Participant-brokered networks are governed by one or more of the network partners themselves, and externally brokered networks are administered by a single external NAO. Such an NAO can be either set up voluntarily by the network partners themselves, or it can be mandated as part of the network design. In total, the classification scheme by Provan and Kenis (2008) thus results in four specific modes of governance, with decreasing centralisation: externally-brokered with mandated NAO, externally brokered with voluntary NAO, participant-brokered, and non-brokered governance. This classification is also visually displayed in Table 6.1 below.

The other sub-construct with relevance to IOP governance centralisation is Enforcement. This sub-construct was presented in earlier chapters as consisting of the dimensions of Coercion and Accountability. Coercion concerns the pressure mechanisms exerted by more powerful actors, who constrain the partner organisations from non-compliant behaviour regarding the IOP standards (see Table 2.5). More concretely, this refers to the variables of Coercive Pressures, as well as the usage of Escalation Channels in cases of disagreement. The more usage is made of coercive pressures and escalation channels in a given network, the more centralised the governance of this network is considered to be. The spectrum of Coercion is also visually displayed in Table 6.1 below.

Accountability was defined as the control mechanisms for an organisation's compliance with the network's IOP standards (see Table 2.5). At the more detailed level, this consists of Formalised Obligations (in particular IOP standards), and the usage of Tracking Systems for results management (particularly the monitoring of standards adoption and compliance). The more the IOP standards are formally institutionalised, and the more usage is made of tracking systems for monitoring compliance with them, the more the IOP governance of a given network can be considered as being centralised. The spectrum of Accountability is also visually displayed in Table 6.1 below.

\begin{tabular}{|c|c|c|c|}
\hline Highly centralisec & & & y decentralised \\
\hline \multicolumn{4}{|c|}{ DECISION-MAKING CENTRALISATION } \\
\hline \multicolumn{2}{|c|}{ Externally brokered } & \multirow[t]{2}{*}{ Participant-brokered } & \multirow[t]{2}{*}{ Non-Brokered } \\
\hline Mandated NAO & Voluntary NAO & & \\
\hline \multicolumn{4}{|c|}{ ENFORCEMENT } \\
\hline \multicolumn{2}{|c|}{ High Coercive Pressures } & \multicolumn{2}{|c|}{ No Coercive Pressures } \\
\hline \multicolumn{2}{|c|}{ High Usage of Escalation Channels } & \multicolumn{2}{|c|}{ No Escalation Channels } \\
\hline \multicolumn{2}{|c|}{ Highly Formalised Obligations } & \multicolumn{2}{|c|}{ No Formalised Obligations } \\
\hline \multicolumn{2}{|c|}{ High Usage of Tracking Systems } & \multicolumn{2}{|c|}{ No Usage of Tracking Systems } \\
\hline
\end{tabular}

Table 6.1. Network governance centralisation 
An important role with regard to governance centralisation is played by coordination costs, i.e. costs related to coordinate the interactions between multiple agents: Gurbaxani and Whang (1991) distinguish several types of coordination costs ${ }^{134}$ : agency costs (costs resulting from differences between the objectives of principals and agents), decision information costs (costs of communicating information along a decision-making hierarchy), and transaction costs (the contractual and operational costs stemming from coordinating among multiple entities). As the analysis in this chapter shows, these coordination costs tend to increase with more centralised governance approaches.

In summary, IOP governance centralisation can thus be defined as the extent to which the administration of the IOP architecture of a given Government Information Network is characterised by centralised decision-making in combination with strong top-down enforcement mechanisms. Highly centralised IOP governance would thus be characterised by external brokerage, strong usage of coercive pressures, escalation channels, formalised obligations and tracking systems. Highly decentralised IOP governance, on the other hand, would be non-brokered, and lack coercive pressures, escalation channels, formalised obligations and tracking systems. The core of Provan and Kenis' (2008) argument is that no single degree of network governance centralisation is more effective than another "across the board", but that instead, its effectiveness depends on how it matches particular characteristics of a given network: trust, number of network participants, network goal consensus, and need for network-level competencies. The latter three of these characteristics are directly related to the concept of Network Complexity, which was introduced in earlier chapters as a key determinant, and which is described in more detail below.

\subsubsection{Network Complexity}

In the theoretical framework described earlier, Network Complexity has been defined as those features of the network that complicate the interactions within the Government Information Network and make it difficult for organisations in the network to align with each other in order to adopt its IOP standards (see Table 2.11). Three distinct dimensions were specified for this sub-construct: Structural Complexity, Diversity, and Task Complexity.

Structural Complexity refers to the degree to which the network size, i.e. the number of partners in the network, increases adoption efforts (see Table 2.11). Thus, the more organisations a network consists of, the more complex that network is. This dimension of Network Complexity relates directly to the "number of network participants" characteristic identified by Provan and Kenis' (2008).

Diversity was defined as the heterogeneity of partner organisations in the network along various dimensions that constrain any harmonisation activities between them (see Table 2.11). More concretely, this includes differences across organisations such as for instance diversity in technical and semantic environments, administrative structures, operational circumstances such as work processes, power and status, strategic goals, or organisational culture and identity. The more pronounced the diversity across all these aspects, the more

${ }^{134}$ Given their focus on intra-firm coordination, Gurbaxani and Whang group them into internal and external coordination costs. However, since the concepts here are applied to the inter-organisational level, this internal-external distinction does not apply here. 
complex the network is. This dimension of Network Complexity thus includes the "network goal consensus" factor identified by Provan and Kenis' (2008), but builds on the idea of homophily ${ }^{135}$ underlying that concept and therefore adds a number of additional relevant diversity variables next to goal diversity.

Task Complexity was specified as the degree of interdependence of partner organisations in achieving the network's primary tasks (see Table 2.11). This dimension of Network Complexity is related to the "need for network-level competencies" factor identified by Provan and Kenis (2008), which they define as those competencies required to achieve network-level goals. The close similarity between this concept and Task Complexity is that "if the network's task is one that requires significant interdependence among members, then the need for network-level coordinating skills and task-specific competencies will be great, meaning that governance needs to facilitate interdependent action" (Provan \& Kenis, 2008). High Task Complexity thus also contributes to higher Network Complexity.

In short, Network Complexity can be defined as the combination of the size of the network, the diversity of the organisations in the network and task complexity in the network. In line with the argument by Provan and Kenis (2008), we can expect that with higher complexity of a Government Information Network, its IOP governance should be organised in a more centralised manner. This question is investigated in detail in the following sections.

\subsection{The Effectiveness of Different Degrees of IOP Governance Centralisation Across Network Complexities: Findings from the Case Studies}

This section presents the findings from the case studies regarding the relationship between IOP Governance centralisation and Network Complexity. Sections 6.3.1 and 6.3.2 first describe the significance of IOP Governance and of Network Complexity for stakeholders in general. Sections 6.3.3 through 6.3.6 then discuss the interaction of IOP Governance and Network Complexity, each developing empirically grounded propositions on one of the four aspects of IOP governance centralisation discussed in Section 6.2.1 above: Brokerage, Stakeholder Involvement, Coercion, and Accountability.

As Sections 3.5.1 and 3.5.2 in Chapter 3 elaborated, the DKD case can be categorised as consisting of a complex inter-organisational network, both in terms of its size and diversity of partner organisations. The Studielink case on the other hand was categorised as a fairly non-complex network, with a relatively small network size and low diversity of organisations in the network. As the remaining sections in this chapter show, in terms of IOP governance there is a considerable variation in terms of the degree of centralisation across various IOP issues within the cases, so that they cannot be classified as either entirely decentralised or entirely centralised.

\footnotetext{
${ }^{135}$ Provan and Kenis (2008) explicitly acknowledge that the relevant concept here is not diversity of goals only, but rather the more general concept of homophily, or "domain similarity". They explain that the term "goals" is meant much broader, and actually includes many of the variables that were specified in this dissertation's framework as separate Diversity variables, such as for instance Operational Diversity.
} 


\subsubsection{The Influence of IOP Governance on IOP Standards Adoption}

The analysis in Chapter 5 (Section 5.2.2.1) has shown that IOP Governance is considered by stakeholders in the case studies as the most important determinant for adoption. Figure 6.1 below shows this again. As we can see in Figure 6.2 further below, governance centralisation appears to be of particular relevance for stakeholders, especially in the DKD case (the more complex network). As the figure shows, the relative share of the two sub-constructs that pertain to IOP governance centralisation (i.e. Decision-Making Centralisation and Enforcement) vis-a-vis the share for the governance sub-construct that is not directly associated with centralisation (i.e. Guidance) is larger for DKD than for Studielink. A plausible explanation, substantiated further by the interpretive analysis of interview quotations in the subsequent sections of this chapter, is that complex networks are in more need of top-down IOP governance that is predominantly characterised by centralisation of decisions and their enforcement, whereas non-complex networks are characterised by a bottom-up approach to governance where guidance is the major factor.
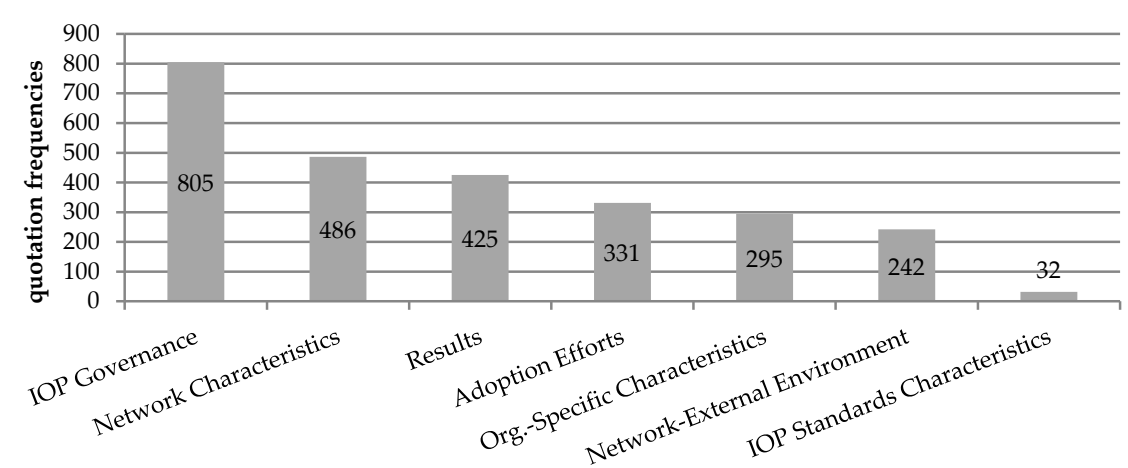

\section{Figure 6.1. Quotation frequencies for adoption determinants $(\mathrm{N}=2616)$}

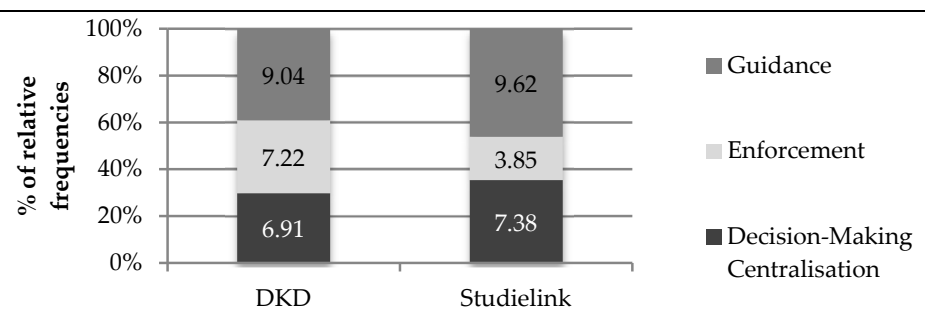

Figure 6.2. IOP Governance quotations (numbers in the bars show average quotation frequencies per case and aggregated per sub-construct; height of stacks indicates relative percentage share within each case. Absolute quotation frequencies are $\mathrm{N}=534$ for DKD and N= 271 for Studielink)

\subsubsection{The Influence of Network Complexity on IOP Standards Adoption}

In order to understand the role played by network complexity in relation to IOP governance centralisation, it is informative to consider how stakeholders in the cases evaluate the 
Network Complexity sub-construct. Telling from the large majority of negative evaluations in both cases as shown in Figure 6.3 and illustrated by many of the interview quotations shown in this chapter (see for instance Q19:24), network complexity is seen in both cases as something problematic. However, it is interesting to note that it is not exclusively evaluated as something negative, acknowledging that also positive things can come from a complex network. Looking a bit closer, the figure shows that these positive effects from network complexity almost exclusively are related to Network Diversity. One possible reason for this that interviewees suggested is that higher diversity can be a driver for more innovation, and thus might also be attributed with a range of benefits for partnering organisations.

I think that others in fact see the benefits from the systems being interconnected [...], so the effort for the organisations becomes less. So the complexity, and what the different partner organisations can contribute, was in fact a clear advantage for most of the partner organisations. (Q30:27)

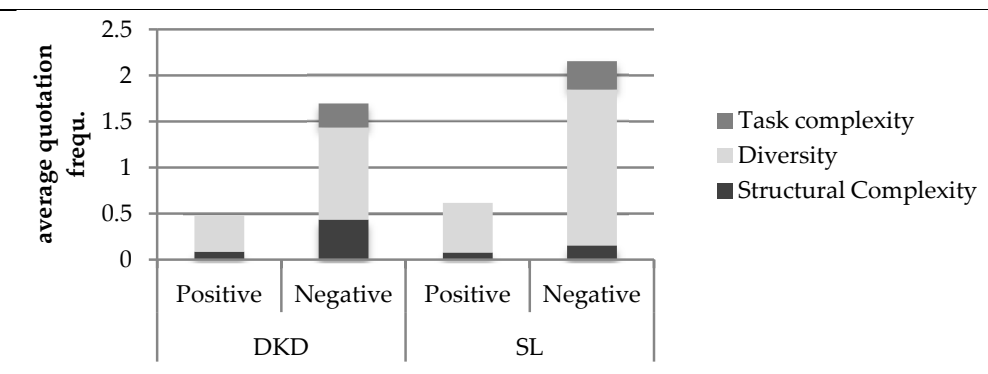

Figure 6.3. Co-occurrences (average quotation frequencies per case) of Network
Complexity (aggregated) and Evaluation quotations

Whilst the above findings from the frequency-based content analysis provide some initial insights into the role of network complexity for the intention to adopt and comply with IOP standards, we need more in-depth understanding of how network complexity interacts with the individual IOP governance dimensions. To this end, the following sub-sections draw on the interpretive analysis of the interview data to give a more in-depth picture on each of the four aspects of IOP governance centralisation: Brokerage (Section 6.3.3), Stakeholder Involvement (Section 6.3.4), Coercion (Section 6.3.5), and Accountability (6.3.6). The variables for each of these dimensions are discussed in turn, and for each variable, illustrative examples are given for what the interviewees considered good or bad practice regarding the matching of IOP governance centralisation and network complexity. Based on the analysis, each section concludes with the development of propositions on the relation between network complexity and the respective aspect of IOP governance centralisation addressed.

\subsubsection{The Interaction of Brokerage and Network Complexity}

The Brokerage dimension consists of two variables: Broker Existence and Broker Mission. Their relation to Network Complexity is discussed in this section. Figure 6.4 shows that the relative frequencies for Brokerage are higher in the DKD case, the more complex network. As the interpretive analysis in the following section argues, a plausible explanation is that the DKD as the more complex network has a higher need for more centralised governance through brokerage of the network. As the following sections show, even though the Studielink interviewees thus talked less about Brokerage, the content of their statements shown in the 
following section shows that when they talked about it, they generally support the argument that networks of higher complexity require a more centralised brokerage in their IOP governance approach.

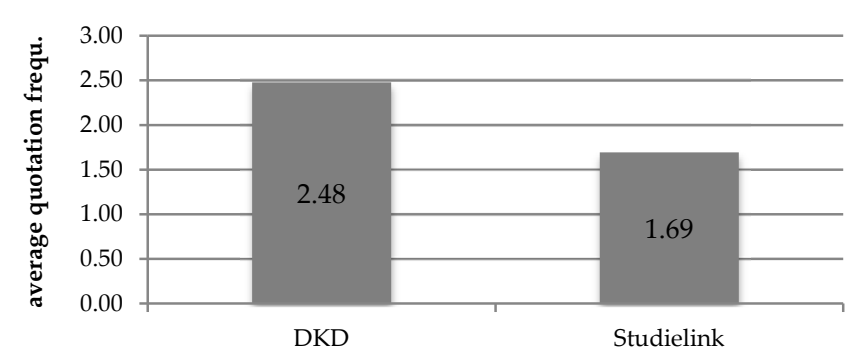

\section{Figure 6.4. Brokerage (average quotation frequencies per case)}

\subsubsection{Broker Existence}

Regarding the Broker Existence variable, the analysis reported in this section suggests that in face of higher complexity (both in terms of structural complexity and diversity), there is a bigger need for the existence of a broker. This is discussed in detail below.

Interviewees in the DKD case stated that it helped that even before the DKD project started, a broker (i.e. BKWI) existed which had already established an encompassing information infrastructure for the SUWI domain (Q16:2). However, the BKWI is not the only organisation in the DKD network that is in charge of IOP governance. Rather, there are various infomediary bodies that jointly take on different broker roles in DKD, including CPICT, KING, and Inlichtingenbureau (Q1:2). As a result of this fragmented brokerage, several interviewees from the DKD assessed the extent of brokerage in DKD as relatively low (Q1:24). This was seen as a less centralised governance approach, and described as more time-consuming and negatively affecting effectiveness in the network (Q8:10). Consequently, interviewees expressed the need for a broker organisation that has the necessary powers to negotiate and make IOP agreements on behalf of all network partners. This lack of having one central broker was seen as a particular disadvantage in face of the network's structural complexity (caused mainly by the multitude of municipalities) (Q16:7).

Even though it is a smaller network, stakeholders in Studielink shared a similar view that with more partner organisations, a more centralised governance actor becomes necessary:

\footnotetext{
And that's also a core problem in this network: there are a number of actors, but a hierarchical relationship isn't there. There isn't any one in the network who can impose 'this is how we will do it now'. We have to search together for commitment, and see what is possible [...]. (Q24:2) (36 $^{136}$
}

\footnotetext{
${ }^{136}$ Most quotes in this section (6.3.3.1) and the following (6.3.3.2) on Brokerage are in response to questions about the influence of external actors' expectations, network complexity and IOP governance on organisations' adoption of IOP standards, as provided in the interview question guides in Annexes F1 (questions 6, 7, and 9) and F2 (questions 5, 6, and 9). This implies that even when they do not make an explicit reference to "adoption", the answers should be interpreted against the background of adoption, as explained in more detail in the introduction to this chapter and Section 3.3.
} 
However, structural complexity does not necessarily need to be a barrier if it does not also imply strong diversity. As another interviewee from the DKD case argues, network diversity is what really determines the need for a broker for centralised enforcement:

\footnotetext{
You can easily have 100 different partners in such a network - but if these are 100 partners who have more or less the same interests in the network or the same role in the network, then this is easier to achieve than if you have three partners who all find themselves really important, more important than the other two. (Q13:29 ${ }^{137}$ )
}

As one interviewee from the Studielink case mentioned, this problem with diversity might be most likely in the early phases of a network's formation when there is no networkoriented thinking yet, thus creating a particular need for a broker in these early phases (Q24:22).

In summary, the analysis thus suggests that more complex Government Information Networks are in higher need of a broker body than less complex networks in order to coordinate the multitude of partner organisations, in particular if these partners are diverse. Having established this basic link between network complexity and the need for a broker, the next section discusses the implications of network complexity for how a broker's role should be designed.

\subsubsection{Broker Mission}

With regard to the Broker Mission variable, the interviews suggested a similar view that network complexity necessitates a broker with a clear mandate who has formal powers to make decisions and act as a strong intermediary and facilitator among organisations especially in early phases of the network's formation. In particular, the interviews pointed to several broker roles that they considered to be good practice.

First, several interviewees stated that more complex networks necessitate that the broker fulfils a role as intermediary between the multitude of organisations. Especially in situations of structural network complexity, interviewees observed a higher need for a broker which has the ability to generate and channel consensus among network partners:

\footnotetext{
We keep puzzling about how to handle those 450 municipalities. This remains the most difficult task for us. The principle from the Ministry's side is 'hold this system in the air together, and do this by making agreements with each other'. They're saying 'find each other, look for a common solution, make an agreement, and SZW [the Ministry] will then put it in a piece of legislation'. (Q3:12)
}

One strategy by which this was done in DKD is to bring key individuals from the partner organisations together in order to generate momentum from which further action can then develop (Q15:21). A broker may also serve an intermediary function by acting as a communication "relay" between organisations, channelling and thus simplifying their interactions. In the DKD case for instance, the BKWI as broker channelled the interaction between various parties in the network:

\footnotetext{
${ }^{137}$ For those quotes displayed in-text and that were translated from a Dutch interview transcript, the original Dutch version can be found in Annex $\mathrm{H}$.
} 
And these negotiations with other partners in the network, so to say the coordination, took place with the technical supplier of the information, in this case BKWI. The other partners that are in the DKD network, have been rather invisible to us. (Q13:4)

Such an intermediary function can also take the form of channelling the expectations from the network (for instance regarding compliance) towards individual partner organisations. An example is when the network brokers in DKD successfully enacted pressure on the $\mathrm{UWV}^{138}$ to supply a specific data package called Digital Insurance Message (DVB ${ }^{139}$ ) which other partners in the network wanted to receive (Q11:7).

Second, several interviewees argued that a broker should play a role as a proactive facilitator in order to deal with the complexity of a network. One key aspect of this is to provide a clear and central point of contact for clarifications on the network's IOP architecture. It was mentioned by the interviewees that with its central position, a broker bundles the necessary expertise on standards (Q25:33) and is in the position to advise individual partner organisations for instance on particular standards-related issues (Q13:9). In the DKD case for instance, the BKWI provides an assistance through the "connection protocol"140, an assistance routine for initiating new partners to the IOP architecture of the network (Q5:19). Another way in which brokers can act as facilitator is through technical assistance. In the Studielink case for instance, the broker (Studielink Foundation) was reported to have acted as a technical facilitator for the network by administering the required middleware for data translation across formats (Q24:16).

Third, interviewees argued that in complex networks, it is important for the broker to be institutionalised with a clear mandate and formal decision-making powers. Interviewees argued that governance roles need to be clearly assigned and formalised since otherwise, there is no means to coordinate adoption and compliance with standards. The first point in this regard is that the assignment of governance roles needs to be clear. Several interviewees for instance argued that in DKD, there was insufficient clarity of mandate in order to deal with the complexity of the network:

It's actually really difficult to use sanctions [to enforce standards compliance]. [...] It's not very clearly arranged who is the 'police' of the chain. Us as the network maintenance actor? The Ministry? Or the data suppliers? [...] What you see is that the responsibilities are not very clearly assigned on this. It's all about trust. (Q3:24)

The second key point made by interviewees in this regard is the need for a formalisation of powers to allow the broker to take effective measures, since otherwise there would be no means to coordinate the enforcement of compliance (3:24). Whilst interviewees virtually unequivocally advocated the necessity for stakeholder consultation, many stakeholders from both cases acknowledged that at the same time, in a complex environment with high diversity, there needs to be one designated actor that has the powers to identify a workable compromise and at key moments "pushes through" a decision in order to prevent that a stalemate keeps the processes from moving forward efficiently:

\footnotetext{
${ }^{138}$ Employee Insurances Agency (Uitvoeringsinstituut Werknemersverzekeringen), see Section 3.5.1.1.

${ }^{139}$ Digitaal Verzekeringsbericht.

${ }^{140}$ Aansluitprotocol.
} 
Then the steering becomes very important. And where it doesn't go well and you find yourself in such a setup like we're working in now, then partners keep circling around each other and in fact only produce compromises. Where does such a conflict of interest bring us? It takes long, it is not effective and it results in lower quality than you would want. (Q10:21)

Also in the Studielink case, interviewees argued that in a complex network, the governance approach should combine some degree of stakeholder consultation with a mandate for the broker to govern standards centrally; otherwise, it was argued, everyone would want to add an exception and no standardisation could be reached (Q28:26). This is especially important when there is high diversity among partners. The early phases of Studielink for instance saw a significant conflict of interest between two core partners, and an interviewee from one of these organisations argued that a centralised broker at that point could have been an effective solution:

\footnotetext{
And we missed that third party which would then simply take these other two parties by their ears and say 'Stop it there, now you're going to do what I say'. And I'm convinced that this approach would have helped enormously at that stage. (Q35:18)
}

Whilst thus there were clear arguments made in support of a strong broker role with coercive powers, there were also different views in interviews from both cases that explained that precisely their lack of strong coercive powers enabled the broker bodies to fulfil their functions as intermediary and facilitator, since they were perceived as more neutral:

It think it was done in a very good way - including the role that was given to BKWI, the fact that we're independent but we don't have any power, but of course we can keep the Minister updated perfectly, but formal power we don't have. So no one can ever be really mad at us, since we don't have any power (Q4:18)

In summary, the analysis of the Broker Mission variable shows a general agreement among stakeholders from both complex and non-complex networks that the more complex a network is, the more it requires a broker that can draw on a clear mandate and competences in order to coordinate the network's activities. This includes acting as a mediator, facilitating interactions and supporting partners, and having sufficient authority to formulate consensus on the IOP architecture and make decisions on behalf of the network.

In conclusion, concerning Brokerage, the interviewee statements from both cases are strongly in line with Provan and Kenis' (2008) argument that more complex network conditions require a more centralised broker, with a clear mandate and formalised power to coordinate interaction in the network towards consensus and make decisions at critical points. Therefore, the analysis of the interview data suggests that with higher complexity of Government Information Networks, there is a higher need for assigning centralised control to a broker in order to facilitate organisations' adoption and compliance with the network's IOP architecture. This results in the following proposition:

Proposition 1: More complex Government Information Networks require a higher degree of centralised control than less complex networks by means of assigning a clear mandate and formalised powers to a broker in order to facilitate partner organisations' adoption and compliance with the network's IOP standards. 


\subsubsection{The Interaction of Stakeholder Involvement and Network Complexity}

As Figure 6.5 shows, the relative share of quotations for Stakeholder Involvement is slightly higher in Studielink than in the DKD case. One possible explanation is that in a less complex network such as Studielink, stakeholders are more exposed to being involved in IOP governance. ${ }^{141}$ As the findings from the interpretative analysis reported below in Sections 6.3.4.1 and 6.3.4.2 show, the interview data from both cases (complex and less complex) supports the argument that less complex networks allow more stakeholder involvement in decision-making than complex networks. For purposes of readability and streamlining, only the two most-often mentioned variables for Stakeholder Involvement are discussed here. These variables are Partners Participation and Design and Use of Forums, and their relation to network complexity is discussed in the following.

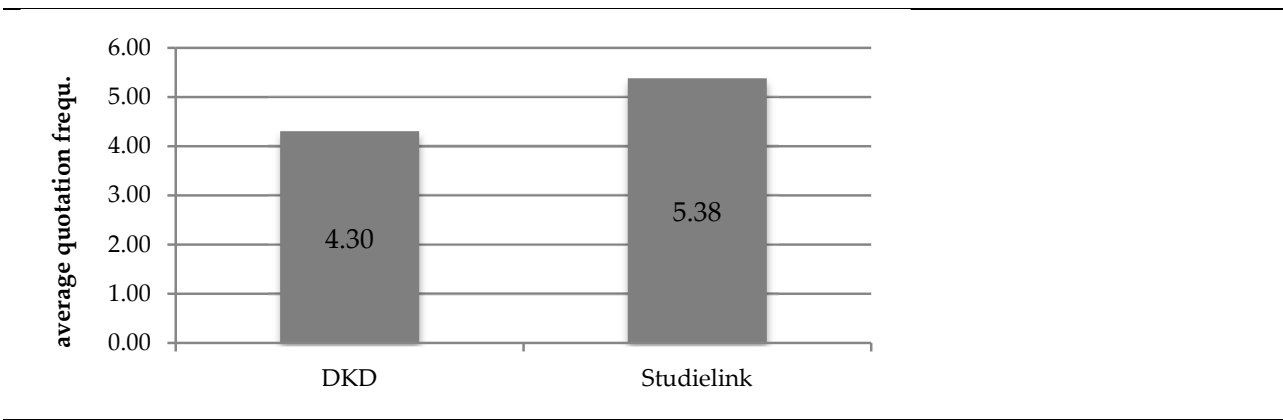

Figure 6.5. Stakeholder Involvement (average quotation frequencies per case)

\subsubsection{Partners Participation}

With regard to the Partners Participation variable, the interview data suggests that there is an inherent tension between the need for inclusive consultation on the one hand, and a cap on this participation by means of centralised governance on the other hand. Most interviewees expressed that inclusive consultation is desirable, and even necessary - but simultaneously also acknowledged that with higher network complexities, this becomes increasingly costly in terms of time and effort needed for finding consensus, and thus hardly workable beyond a certain level of complexity. These points are discussed in more detail below.

The interviews highlighted several mechanisms how partners' participation can support IOP standards adoption, in particular in complex networks. A key reason given by the interviews is that without consultation of partner organisations, the standards set might be too detached from the needs and interests of individual organisations, so that they perceive that adoption is not worth the effort for them (Q31:21). Another reason for organisations' request for influence is that a top-down "imposition" of standards which does not allow for partner participation can be perceived as highly intransparent (Q14:21). Moreover, the

\footnotetext{
${ }^{141}$ As described in more detail in Sections 3.5.2.3 and 6.3.4.2, the relatively small number of partner organisations in the Studielink network allowed to have a coordination body where each and every partner organisation is individually represented.
} 
importance of broad horizontal consultation to partner organisations also has to do with the general political culture. Several interviewees explained that the Dutch "polder mentality" (a historically rooted trait of political culture in the Netherlands that emphasises collective negotiations to identify political compromises) makes top-down approaches in a Dutch public-sector context prone to resistance (Q16:20). Finally, another benefit of partners' participation that was mentioned is that such consultation processes are creating a "network-conscious thinking", which is beneficial for the intention to adopt IOP standards, especially in large and diverse network circumstances (Q21:18).

However, despite all these reasons given by interviewees for the importance of stakeholder participation for supporting standards adoption, there was widespread agreement among all interviewees that this is only beneficial up to a certain point and that beyond this point, it becomes too costly in terms of time and effort needed for coordinating and negotiating consensus. Importantly, many respondents linked this "tipping point" to network complexity. In DKD for instance, the diversity among partners in terms of enthusiasm for participating in the network (Enthusiasm Diversity) was seen as creating a need to limit stakeholder participation in order to confront resisting organisations with a top-down decision (Q16:7). A key downside of partner participation in the face of high network complexity is that stakeholders find it so costly in terms of time:

\begin{abstract}
And we're very good at constructing a very complicated setup of working groups and teams and steering groups - everything very much layered. To comment again and again, which makes it take really, really long until we move ahead. [...] Well this is also more or less recognised - but eventually it is by creating something, by pushing through that you create a success factor for the network because it becomes clear that we can create something. (Q12:18) ${ }^{142}$
\end{abstract}

Essentially, as the following quote illustrates, there needs to be a balancing act between sufficient participation in order to create ownership and ensure the standards' alignment with the organisations' reality on the one hand, and on the other hand the usage of effective, responsive and non-bureaucratic consensus finding and centralised decision-making to enforce decisions widely:

Well, the ideal setup is not something completely centralised. It is a democratic, or decentralised steering. But well, then we're back at the same point: that can easily lead to a whole lot of bureaucracy. You don't want that either. So it's a matter of balancing. And at a certain point you simply need to make decisions. [...] But well, we are in the Netherlands, we always have to consult and we have to 'polder' and so on. Yes, that balance between democracy and centralisation, that's always difficult. (Q32:25)

One means for the balancing of inclusiveness and effectiveness which was used in the DKD case is to use a more centralised, top-down approach early in the emergence of the network in order to create a "beta version" of the envisaged standard as initial basis to work from, and then take a more horizontal approach from there onwards in order to develop this further. When creating the first version of the IOP architecture for the DKD, this was deliberately used to deal with the high complexity of the network: in early 2001 a dedicated

\footnotetext{
${ }^{142}$ Most quotes in this section (6.3.4.1) and the following (6.3.4.2) on Stakeholder Involvement are in response to questions about the influence of external actors' expectations, network complexity and IOP governance on organisations' adoption of IOP standards, as provided in the interview question guides in Annexes F1 (questions 6, 7, and 9) and F2 (questions 5, 6, and 9). This implies that even when they do not make an explicit reference to "adoption", the answers should be interpreted against the background of adoption, as explained in more detail in the introduction to this chapter and Section 3.3.
} 
SUWI Change Management Organisation ${ }^{143}$ was created to set out beta versions of key standards such as the SUWI chain architecture, the SGR, the SLA, and the "Norm Framework". These versions were created in a quick and centralised manner to provide a working basis and leave it for subsequent changes to be determined on a consensus basis (Q4:18).

In short, the analysis indicates that with regard to the Partners Participation variable, inclusive consultation in principle is beneficial for adoption and compliance. Therefore, a basic level of participatory engagement is important for Government Information Networks. The analysis also suggests, however, that this inclusive participation becomes increasingly costly with higher network complexity, and thus can only be beneficial up to a certain point where its costs become too high. Hence, an optimal point needs to be identified between sufficient participation that creates ownership on the one hand, and mechanisms for effective decision-making on the other hand. Since less complex networks have a relatively smaller number of organisations, we can moreover also deduce from the arguments above an expectation that this optimum point in such networks also allows for a relatively higher degree of participation and ownership than in more complex networks.

\subsubsection{Design and Use of Forums}

With regard to the Design and Use of Forums variable, the analysis of interview data from both cases suggests that with increasing network complexity (in particular network diversity), an inclusive design of deliberative forums becomes increasingly important. However, the analysis also indicates that higher network complexity also makes an effective forum design more difficult because it means that some compromise needs to be found between inclusiveness on the one side, and practicality and effectiveness of coordination on the other.

One approach to find this balance which was widely used in the cases is to use representative forums for consensus finding in order to deal with network complexity. A good example is DKD, where the number of organisations was considered by the interviewees as too large to include all of them in the consultation processes, so that a representative system was devised in order to cope with the complexity of the organisational network. This arrangement consisted of various formal governance bodies (such as working groups, domain groups and steering groups), as well as other representative consultation groups that were organised by umbrella bodies such as CP-ICT, consisting of a selected number of municipalities. ${ }^{144}$ For instance, the municipalities were consulted indirectly through an inter-municipal ICT commission organised by DIVOSA (the association of GSD managers), where typically only a handful of municipalities were invited to comment and give their views on specific proposals from the steering group SKI (Q19:29).

A representative consultation structure was also used in Studielink. For instance, since it was considered impractical to include all 50-plus universities in the WAR, there were representatives selected for each group of universities using the same SIS. However, it is

\footnotetext{
${ }^{143}$ Veranderorganisatie SUWI.

${ }^{144}$ For a detailed description of this system, see the DKD case description in Section 3.5.1.3.
} 
important to note that the degree of selectivity in the DKD case (the more complex network) was higher: whereas Studielink with its smaller network size could still afford to have a coordination body where all partner organisations were individually represented (called Coordinator Council ${ }^{145}$ ), the majority of partner organisations in DKD (mostly the municipalities) were represented in groups.

However, excluding stakeholders from the deliberations on standards, for instance through the above-mentioned selective representation schemes, can create a risk of alienating partner organisations from the network if as a result they feel no ownership (Q19:29) and if not all stakeholders groups are represented across all working and domain groups (Q5:21). Where there is a perceived low influence of partners on the deliberations on standards, they might try to exert influence nevertheless by means of non-adoption and non-compliance:

\begin{abstract}
Well again, I think that municipalities don't have an active role themselves in this standardisation. In any case not in the technical standardisation. [...] At most a municipality does this by having an input in the user consultations, and through these user consultations it gets to the suppliers of these applications, and they can again bring this up in the national consultations [consultation groups] - so it's a really long way. And it's chance whether someone from a municipality sits in such a consultation [group] - but mostly rather not. [...] I think that's the way through which municipalities have input on this: by working or not working together with a particular supplier, by using or not using a particular functionality, by using or not using the DKD completely. (Q19:25)
\end{abstract}

An important observation in this regard is the role played by network complexity in this example: due to the network's complexity, in particular the combination of structural complexity and complexity of communication channels (through user groups to ICT suppliers, from ICT suppliers to supplier groups, to DKD consultation bodies), the representative scheme failed to properly include stakeholders. This suggests that higher network complexity also increases the complexity of coordinating a suitable IOP governance arrangement, thus supporting previous findings from the network governance literature (cf. Kickert, Klijn, \& Koppenjan, 1997b; Kickert \& Koppenjan, 1997; Provan \& Kenis, 2008).

However, several interviewees also stated that selective or representative consultation bodies do not necessarily result in widespread feeling of exclusion that would lead to nonadoption, in particular if the organisations are aware of the constraints on inclusive consultation imposed by their network's complexity. For instance, even though not all municipalities were included in the DKD consultation bodies, there was an understanding among the municipalities that including more than 400 of them would be highly impractical in terms of coordination, and that instead, being represented by proxies can still contribute to the feeling of ownership. This representative system was also generally accepted by the municipalities:

\footnotetext{
The agreements were developed by the BKWI. They have a domain group, and there the municipalities had been represented by the Inlichtingenbureau. [...] It was always a representative body, I don't think that an individual municipality has ever participated in a domain group meeting. The municipalities simply accepted this at some point. [...] They also realised that not each of the 430 municipalities can have a say. (Q1:24)
}

An interviewee from Studielink also argued that a representative solution would be accepted among partners, as long as the main stakeholders feel represented appropriately

${ }^{145}$ Coordinatorenoverleg. 
and a demand for the information exchange persists (Q24:3). One recommended strategy therefore is to carefully select the representatives, ensuring that they have high legitimacy and leverage within their organisations (Q2:19).

Despite there being both positive and negative assessments of selective stakeholder consultation, there appeared to be an overall agreement among interviewees that, whether directly or indirectly through representative designs, there needs to be an inclusion of the key stakeholders in the standards deliberation forums to guarantee that these deliberations are made with adequate knowledge of what is feasible according to organisational realities (Q25:30), and to create sufficient ownership to support adoption of the standards (Q4:19). This is particularly important in complex network situations, where diversity of organisational interests is very likely (Q24:54).

Another strategy that interviewees recommended for governing IOP standards adoption in the face of a multitude and diversity of stakeholders in complex networks is the inclusion of the various stakeholders through a system of multiple consultation bodies that are functionally or thematically separate. Both the DKD and Studielink cases used such a system of multiple bodies working together. In the DKD case, this was the system of working groups, domain groups and steering groups (described in Section 3.5.1, see also Figure 3.4). In Studielink, a similar structure was used, consisting of working groups and change councils (see Figure 3.6). In both cases the interaction between these groups was organised in a hierarchical manner, where the lower levels (usually working groups and domain groups) are concerned with technical issues, and the higher level (the change councils and steering groups) are in charge of the more strategic decisions that build upon the work of the lower levels.

One interviewee from Studielink also reported that the relevance of the various groups can change over time, with the higher-level strategic groups being more significant in the beginning, and the technical consultation groups becoming more important in the operational phase (Q34:21). This suggests that in the early phases when there is still higher diversity among network partners, there is a need for more centralised governance that is dominated by high-level decision-makers. This falls in line with the observation reported earlier that a more centralised approach was used in the early phase of DKD in order to ensure that a beta-version of key standards is created in an effective manner.

A key feature of these multi-group arrangements is a thematic or functional separation of the groups. In Studielink, this is for instance reflected in the separation between the technical working group (TW) and the process working group (PW). As described earlier, the system in DKD is more complex (reflecting the higher complexity of the network) and consists of a number of working groups, domain groups, and steering groups. Most of the lower-level consultations are organised by the various infomediary bodies (BKWI, Inlichtingenbureau and $\left.\mathrm{CP}-\mathrm{ICT}^{146}\right)$. The steering groups, where most of the final decisionmaking happens, are non-brokered consortia consisting of the top-level management of key partner organisations.

${ }^{146}$ Later KING. 
In short, similar to the previously discussed Partners Participation variable, there needs to be a balancing act with regard to deliberative forums: while on the one hand, more complex networks require an inclusive design of deliberative forums, on the other hand the administrative complexity and coordination costs of inclusive forum design need to remain within the limitations of feasibility. As the interviewees report, this can for instance be achieved through representative forums design. In addition, interviewees reported that such forums can be efficiently designed by including stakeholders by means of multiple consultation bodies that cover distinct functional areas.

In summary, the interviews suggest that the relationship between stakeholder inclusion and network complexity seems to be a complex one of opposing forces. On the one hand, there is a negative relationship between network complexity and IOP standards adoption: the intention for widespread adoption decreases the more complex the network becomes. On the other hand, the analysis also identified several mechanisms through which this negative effect of network complexity can be countered by means of increased stakeholder inclusion, because more inclusive governance approaches are more suitable to create ownership and minimise the impact of an IOP architecture across large and diverse networks. The data from the cases even suggests that a certain minimum level of stakeholder participation is necessary to facilitate widespread adoption of the IOP architecture across the network, irrespective of the level of network complexity.

Whilst in principle, stakeholder inclusion can thus support IOP standards adoption, the analysis also showed that it is only practicable to a certain degree, because it is costly in terms of effort and time needed to reach agreement on discussions regarding IOP architecture. It indicated that there is a tipping point at which increasing stakeholder inclusion becomes so costly to coordinate that it gets in the way of effective IOP governance (see for instance quotations Q1:24 or Q12:18 quoted above), for instance as a result of the impossibility to reach agreement when everyone in a large and complex network can introduce complicating demands, or veto decisions. ${ }^{147}$ Furthermore, the costs of stakeholder inclusion are multiplied by the complexity of the network, because including all stakeholders in a large and diverse network is more difficult than including all stakeholders in a small and homogeneous network. Therefore, in more complex networks this tipping point is located at a - relatively speaking - lower point (i.e. less inclusive) than in less complex networks. As the above examples from the cases have shown, an optimum point thus needs to be found for each network where stakeholder inclusion is maximised but remains below this tipping point. Where this point should be located thus depends on the complexity of the network. A cost-benefit analysis, taking into account both financial as well as non-financial costs and benefits, can be a suitable approach to identify this tipping point in a given context.

In conclusion, concerning Stakeholder Involvement, the analysis is thus only partially in line with Provan and Kenis' (2008) argument that more complex network conditions require a

\footnotetext{
${ }^{147}$ Schaap and van Twist (1997) describe "veto powers" as an implication of the interdependence that is inherent to governance networks. Due to this interdependence, individual network partners may be in a position where they can obstruct decisions concerning the network's development and thus become a substantial barrier to steering of the network.
} 
more centralised IOP governance. Applying this argument unrevised into the context of stakeholder involvement in IOP governance would mean that the more complex a Government Information Network is, lower levels of stakeholder participation would be more effective. Instead, the preceding analysis however suggests that it is necessary to add a caveat, resulting in the following set of propositions:

Proposition 2a: A minimum level of stakeholder involvement in IOP governance facilitates partner organisations' adoption and compliance with a Government Information Network's IOP standards.

Proposition 2b: As stakeholder involvement increases, there are diminishing returns to its facilitating effect for partner organisations' adoption and compliance with a Government Information Network's IOP standards, eventually reaching a tipping point where coordination costs exceed the expected returns.

Proposition 2c: In more complex networks, the tipping point beyond which stakeholder involvement becomes too costly is reached at relatively lower levels of stakeholder involvement than in less complex networks.

\subsubsection{The Interaction of Coercion and Network Complexity}

The variables for Coercion are Coercive Pressures and Escalation Channels. As Figure 6.6 shows, relative frequencies of quotations for Coercion were higher for the DKD network than for Studielink. The interpretive analysis in the following section argues that a plausible explanation for this is that the DKD as the more complex network has a higher need for enforcement through coercive governance structures. Even though the Studielink interviewees thus talked less about Coercion, the content of their statements analysed in the following sections shows that when they talked about it, they generally agreed with the argument that networks of higher complexity require more centralised coercion in their IOP governance approach.

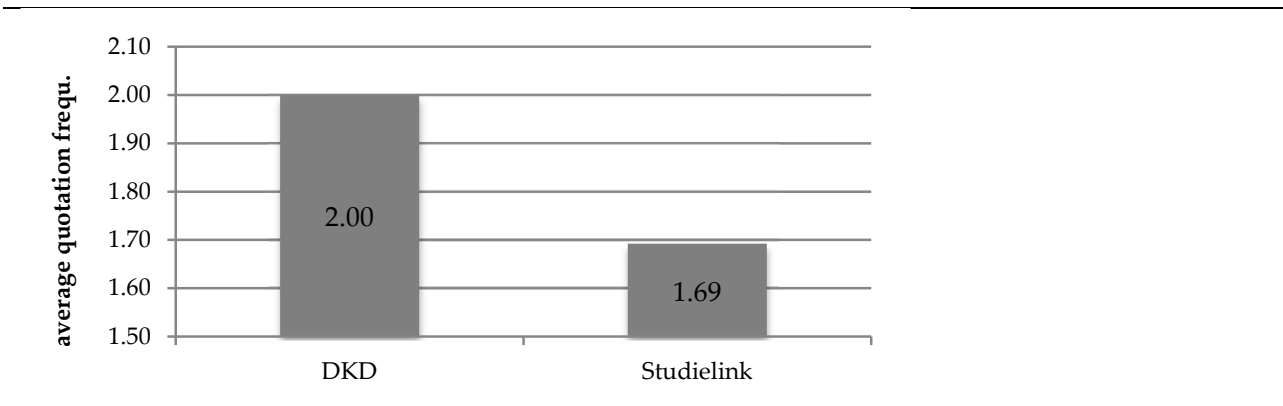

Figure 6.6. Coercion (average quotation frequencies per case)

\subsubsection{Coercive Pressures}

For the Coercive Pressures variable, the data suggests that just as there is a basic level of stakeholder involvement to ensure adoption and compliance with the IOP architecture, there is a need for a minimum level of coercive powers to enforce adoption and compliance, 
irrespective of network complexity. This is because even in networks with very low complexity, it is very unlikely that all partners want exactly the same. Hence, some control is needed to ensure a common line of action (Q28:26). However, the data also shows that higher network complexity is associated by the interviewees with a higher need for coercive powers. At the same time, the analysis also indicates that an effective organisation of coercive mechanisms becomes increasingly difficult to coordinate the more complex a network becomes. These issues are discussed in more detail below.

The primary need for coercive pressures stems from the difficulty to ensure adoption or compliance without it - a problem that grows with increasing size and diversity of a network. Several interviewees have stated that in the face of the structural network complexity in the DKD network, the absence of coercive powers causes a problem for adoption and compliance:

And I don't have a mandate, I can't force anyone. [...] And for instance there sits someone representing the municipalities and that person says 'Well that's certainly a good idea, but I have no idea what the other 430 municipalities think of it'. That's an enormous problem for collaborating. (Q19:24) ${ }^{148}$

A need for more coercion is also created by higher degrees of network diversity. The more diverse the partners are, the higher is the possibility that they will have different visions on the IOP standards, which can result in long, and possibly ineffective discussions unless they are rounded off with a decision that is backed up by some coercive power (Q15:23). As the following interviewee argues, a lack of coercive pressures that would limit partner organisations' deviation from standards could make the network very ineffective:

\footnotetext{
Look, as a single institution, you often face a problem like 'I'm so special' or ' $I$ 'm in such a special situation', and that's not being supported now. You encounter that. But on the other hand, when [from the network level] you allow room for this, the system becomes so complex and uncontrollable that it won't work either. (Q28:26)
}

However, while with increasing network complexity there is a higher need for centrally located coercive powers, cordinating this becomes increasingly difficult the more complex a network becomes. One significant barrier in this respect is formed by administrative fragmentation. This is particularly evident in the DKD case, where a major aspect of the network's diversity results from the administrative boundaries between key partners, with the municipalities in fact forming a separate level of government that is largely independent from the national government. This significantly increases coordination costs by making it very difficult to have any enforcement of IOP standards from a central level (Q17:26). The problem of administrative fragmentation is also expressed by the following interviewee:

\footnotetext{
The Ministry's opinion is that the Accountability Guideline applies to all network partners. But the municipalities say no, it doesn't apply to us. Because the GSD is not accountable to the SUWI partners, but it is accountable to the mayor and the municipal aldermen. So the municipalities have their opinion on this. Then we can say we have a certain central role in this network, but we're quickly reaching a dead end if municipality and ministry don't want to understand each other. (Q6:7)
}

\footnotetext{
${ }^{148}$ Most quotes in this section (6.3.5.1) and the following (6.3.5.2) on Coercion are in response to questions about the influence of external actors' expectations, network complexity and IOP governance on organisations' adoption of IOP standards, as provided in the interview question guides in Annexes F1 (questions 6, 7, and 9) and F2 (questions 5, 6, and 9). This implies that even when they do not make an explicit reference to "adoption", the answers should be interpreted against the background of adoption, as explained in more detail in the introduction to this chapter and Section 3.3.
} 
This agency problem is intensified because it spans from the network level all the way to the operational level within organisations. Even if coercive pressures are formalised with a central power at the network level (such as with a broker), this does not mean that they necessarily also can exert their influence within organisations because standards compliance (at least with certain organisational standards, such as the single data request prescribed by the WEU in the quote below) is determined by street-level bureaucrats at the operational level:

\begin{abstract}
At management level, with managers, you can still manage to get this working, but after that, it concerns the operational level which is dependent on people. [...] If eventually - and then I'm talking about the WEU imagine I'm an employee at the municipality and a client sits down at my desk: I have all the data here, which I received from UWV, from SGV, RDW, I have all of it. Then it still depends on me how I deal with this client. (Q16:13)
\end{abstract}

The remainder of this section discusses possible strategies for coercion that were suggested by stakeholders in order to deal with this agency problem. ${ }^{149}$ One solution that was suggested from a DKD interviewee is to decentralise the coercive power so that organisations are themselves responsible for enforcing their staff's compliance with standards:

I can't possibly from here [at network level] tell whether something like this is within the mandated task or not. Only the people in that municipality X can do that. [...] And we do our best to prevent that it [the data] is lying open on the street. For example, you can't access it by Internet. But with 52.000 users in the Netherlands, we cannot individually keep control on them by technological means. People have to do this themselves. (Q4:7)

Another suggestion to address this agency problem is to have a differentiated approach to coercion across standards, with those standards needed to facilitate the exchange in the network (in particular technological standards) being enforced with a higher degree of coercion, but leaving organisations more leeway for implementation when it comes to those standards concerning internal processes. This would decrease resistance, particularly since organisational IOP is much more sensitive:

So, where you have to seduce, you need a more horizontal governance of 'taking along'. And where
standardisation is of economic, and financial urgency for all participants, where it concerns an evident
common interest of all participants, you need to make it obligatory. Then you have to do it centrally. (Q33:15)

Finally, another strategy used in the Studielink case was to use de facto standardisation as a means of coercion: after reaching of a critical mass or majority of users, standards from a network's IOP architecture can assume a de facto status. This effect can be exacerbated by stopping to support the old mechanisms of exchange, thus effectively leveraging the opportunity costs from non-compliance as a pressure tool (Q28:25):

\footnotetext{
At one point we said 'Listen friends, the environment doesn't take into account another registration process. We're approaching a point where maybe 70, 80, 90 percent are connected to the new network [Studielink]. You have to realise that you'll have to finance the maintenance of your old process by yourself. We're not going to [support] this any more sector-wide'. But at that moment we were already far enough in seducing, so that we could enforce this. And when this happened, Studielink started to steer with a stronger hand, because we knew there is no way back. (Q33:15)
}

\footnotetext{
${ }^{149}$ Therefore, the quotes shown in the remainder of this section are by nature not explicitly addressing the issue of network complexity but rather a range of possible coercive strategies that are available in contexts of network complexity.
} 
The interviews also identified several alternative, or complementary strategies to coercion as a means of reducing the cost of coercive strategies in complex network settings. Several interviewees argued that adoption also requires persuasive strategies next to coercion. The consultation strategies that are discussed in the previous section were mentioned by several interviewees from both cases as a tool that can be in fact more effective than pure coercion:

\footnotetext{
And this brings us back to the coordinator [broker] role: what do you do if an institution is not conforming to a standard? Are we punishing them, are we supporting them, or is there someone else doing this for us? [...] Actually, our strategy is that we need to convince the others to conform to the standard. Until now we try this by talking to these partners, to let them see what the consequences are of their actions, and like this to convince them to conform to the standard. It's actually more of a consultation approach. (Q24:22)
}

In fact, one interviewee from the DKD case went as far as to describe any coercive power (such as e.g. a legal obligation) to be doomed for failure unless it builds on a collectively achieved consensus (Q4:5).

Focusing on support strategies was also mentioned as a suitable and possibly more effective alternative to strict coercion, particularly in cases where rather than a lack of willingness, non-adoption is a result from lacking capacities for complying with the standards:

\begin{abstract}
And they [some institutions] simply have big difficulties to implement the Studielink re-enrolment process correctly. And they point this out, and try together with us to solve this. But we can't ask from them to do exactly as we tell them. Because we know that this will only cause more trouble with their application. [...] We don't go in and say 'listen, you'd better do it like this, or else...' - that's not how it works in this network. (Q24:24)
\end{abstract}

Finally, in cases where there are no real coercive powers formalised for a broker, there is no means for central coordination of enforcement of compliance, and partners have to rely on trust, as an interviewee from a broker body in the DKD network explained (Q3:24).

In summary, the analysis for the Coercive Pressures variable indicates that there is a minimum level of coercion needed to facilitate widespread adoption and compliance with a network's IOP standards. This need for coercion was also shown to increase with higher network complexity. While more complex networks should thus be governed with more coercive powers, the analysis also showed that at the same time, the usage of coercive powers comes with coordination costs that are rising with increasing network complexity. For IOP governance design, this means that the use of coercive mechanisms needs to be carefully considered in view of the balance of costs from non-compliance and coordination costs - both of which are a function of network complexity.

\title{
6.3.5.2. Escalation Channels
}

In contrast to the Coercive Pressures variable, the analysis did not yield much evidence for a significant relation between the Escalation Channels variable and network complexity interviewees only mentioned these very little in relation to each other. Whilst this issue was hardly discussed at all by interviewees from Studielink, it came up at least to a small degree in the interview statements from the DKD case. Whilst due to the small quotation numbers here it cannot be seen as more than an assumption, this gives some plausibility to the idea that escalation channels might possibly matter more in complex networks like DKD (see Figure Annex B.11). 
The discussions from the DKD case described escalation channels as a useful instrument to "enforce consensus" in cases of non-adoption or non-compliance, due to the effects of political hierarchy:

If there is no consensus, we have an escalation level, the SKI, where you have representatives from the level of the partners' executive boards. And no one wants to draw attention to them from their executive boards in this way, so this really is a stick that ensures that people in the domain groups achieve consensus. [...] But this happens very rarely, an organisation would only do this once, then afterwards it's never as before any more. (Q4:8)

Another example where escalation was used to exert political pressure was when in 2009, DUO was required to conform its software infrastructure in order to supply required data to DKD, and the chair from the DKD programme council and SKI personally intervened, with the effect of getting DUO to comply with the required software changes (Q21:19). The same use of different hierarchical levels to put pressure on organisations to comply with standards could also be found in the Studielink case:

For a couple of things, where it really causes a lot of trouble in the network, we say this should be a topic for discussion at executive level. When diversion from a standard by a partner means that we have extra administrative cost, then it means that these extra costs are shared by all the other partners in the chain. And this, they of course find irresponsible, and it encounters resistance. In these cases, we also call upon the director of Studielink to set things straight. But this happens rarely. (Q24:23)

However, the interviews also revealed that escalation does not always result in adoption and compliance:

We have tried it [escalation] one other time with the tax service, but that didn't help. They also had to conform to the standard regarding their data supply to us. But they simply didn't do this, because they had other priorities internally. So there, escalation didn't help. (Q21:19)

In summary, the use of escalation channels thus can contribute to IOP standards adoption and compliance by exerting political pressure. Whilst they may be equally effective in noncomplex networks, escalation channels are seen as an intrusive measure with a high political cost, and they are therefore more of a "last resort" than a step that is taken light-heartedly. Therefore, they seem to be most appropriate for complex networks, where non-compliance with standards is more manifest.

In conclusion, concerning Coercion, the interviewee statements from both cases are thus largely in line with Provan and Kenis' (2008) argument that more complex network conditions require more centralised governance. The preceding analysis suggests that some degree of coercion seems to be indispensible in order to incentivise organisations to adopt and comply with IOP standards, and coercion seems to become more necessary the more complex a network is. However, this comes with a caveat that coercion also involves coordination costs that tend to increase as a network becomes more complex. Therefore, the costs of using coercion need to be assessed in comparison to the opportunity costs of not coercively enforcing the IOP architecture of a network, including the possibility of noncompliance. This results in the following propositions:

Proposition 3a: In more complex Government Information Networks, more usage of coercion is required to facilitate partner organisations' adoption and compliance with the network's IOP standards. 
Proposition 3b: In more complex Government Information Networks, the coordination costs associated with stronger coercion tend to be higher than in less complex networks - potentially cancelling out the benefits of using coercion.

\subsubsection{The Interaction of Accountability and Network Complexity}

The two variables for Accountability are Formalised Obligations and Tracking Systems. For both of these variables, the relative frequencies of quotations were much higher (more than double) for the DKD network than for Studielink (see Figure 6.7). As the interpretive analysis in the following section shows, this seems to be because the DKD as the more complex network has a higher need for enforcement of the IOP architecture through (centralised) accountability structures. However, the cross-case validation regarding this aspect of IOP governance centralisation is somewhat less "robust" since most of the interviewee statements supporting this conclusion came from the DKD case and not from both cases alike, as was the case with the other aspects of IOP governance centralisation. Nevertheless, it is important to note that none of the statements from Studielink interviewees concerning Accountability did contradict this conclusion either, hence leaving the data regarding Accountability nevertheless internally consistent.

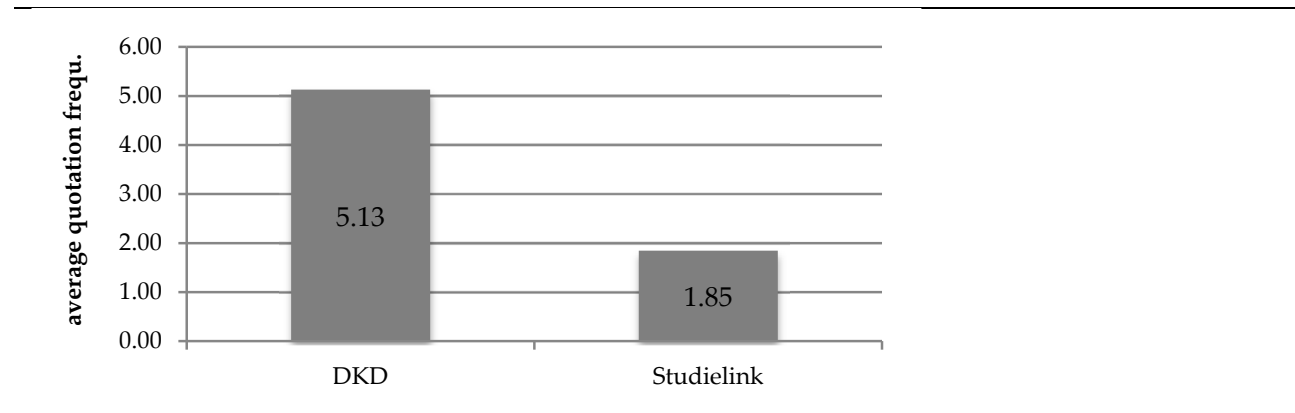

Figure 6.7. Accountability quotations (average quotation frequencies per case)

\subsubsection{Formalised Obligations}

With regard to the Formalised Obligations variable, the analysis reported in this section suggests that more complex networks have a higher need for formalisation of the IOP architecture. ${ }^{150}$ However, such formalisation of obligations also seems to become more difficult in complex network situations, and the coordination costs for formalisation become higher, both regarding the design and the implementation of formalisation. Recommendations given by the interviewees for dealing with these increased costs in more complex network situations include resorting to selective formalisation (where only those aspects are formalised that are indispensible for the functioning of network-level tasks), ensuring a high precision of formalisation of the IOP architecture to avoid creating leeway

\footnotetext{
${ }^{150}$ It should be noted that the argument outlined here concerns something different from the argument made above in Section 6.3.3.2 about the need for formalisation. The former is concerned with formal decision-making powers of the broker, whereas this argument here is concerned with formalisation of organisations' obligations and duties to comply with the decisions made.
} 
for deviations, and formalising obligations at the appropriate administrative level. These points are discussed in more detail below.

Statements from the interviewees strongly suggest that with higher network complexity, there is a higher need for formalisation of the obligations to adopt the IOP architecture. Especially in face of structural network complexity, there is higher possibility of resistance to the IOP standards, and thus a higher need for formal agreements that represent binding obligations for their adoption. One DKD interviewee argued that a reason why network complexity increases the need for formalised obligations is that in large networks, even a minority of non-compliant partners forms a mass that in absolute numbers is sufficiently large to have a detrimental impact on the achievement of IOP (Q16:9).

Several DKD interviewees cited the positive effect of legal formalisation as a success factor for standards adoption, explaining that the formalisation of the obligation for data exchange by means of the WEU law helped to ensure the network's effectiveness in face of its high degree of complexity:

\footnotetext{
So in principle at the moment that you exchange data through this system, you have to adhere to the standards of this system [...]. And they are legally obligatory, and that was one of the success factors. That was very good. (Q3:3). ${ }^{151}$
}

So the issue of centralisation with regard to the local situation, the accountability aspect of this, $[\ldots]$ that actually also happened in DKD, it was imposed on us that we have to use it. [...] Otherwise you would have never managed to pull those 400-plus municipalities along. [Interviewer: imposed in terms of the WEU?]. Yes, in terms of the WEU. (Q15:23)

In line with the argumentation from the previous section that higher network complexity requires more coercion, the positive effect of formalisation seems to be mostly attributed to the coercive effect it exerts on partner organisations (Q15:11). This effect can result for instance from the fact that having a legally formalised standardisation obligation provides a tool for holding organisations accountable through control mechanisms. In the DKD for instance, having the "Norm Framework" as a formal document enabled the work and income inspection (IWI) to hold organisations accountable to their obligations and successfully leverage pressure for coercing them to comply with the Norm Framework's requirement to set up a security plan (Q5:22).

Interviewees explained that even if a law does not give coercive powers, it can nevertheless be very useful in order to legitimise the network's IOP architecture (Q18:7), and serve as a normative ideal that works in the background to keep organisations accountable (Q19:32). In a similar vein, formalised obligations were also reported to support adoption by creating peer pressure among organisations. As a DKD interviewee from a municipality explained, once the WEU had a legal status, municipalities could not simply ignore the DKD any more, even if they had no other motivation to go along (Q19:14).

\footnotetext{
${ }^{151}$ Most quotes in this section (6.3.6.1) and the following (6.3.6.2) on Accountability are in response to questions about the influence of external actors' expectations, network complexity and IOP governance on organisations' adoption of IOP standards, as provided in the interview question guides in Annexes F1 (questions 6, 7, and 9) and F2 (questions 5, 6 , and 9). This implies that even when they do not make an explicit reference to "adoption", the answers should be interpreted against the background of adoption, as explained in more detail in the introduction to this chapter and Section 3.3.
} 
Besides its coercive function, another purpose of formalised obligations that was mentioned in the interviews is to increase transparency in the network, by providing clear specifications of organisations' obligations (Q5:2). This becomes even more important when a network has more partners and more diversity that potentially cause uncertainties about their obligations with regard to the standards. By means of increasing transparency, formalisation of obligations was also reported to increase trust among partners (Q17:29), which has been shown earlier to become increasingly important in complex networks as a complementary tool to coercive measures.

While formalisation of obligations thus can be useful to support adoption (especially in complex networks), there might also be a natural limit to the degree of formalisation that is feasible, due to the coordination costs it implies. This is even more of a problem in more complex networks. For instance, an interviewee from the DKD case mentioned that due to the structural complexity of the network, the IOP architecture consists of such a multitude of multilateral and bilateral agreements that even for the broker body (whose role is to administer them), it is challenging to keep an overview (Q6:1). The same problem comes with higher network diversity. In the Studielink case for instance, the umbrella body for the polytechnic universities (the $\mathrm{HBO}$ Council) was able to formalise a binding commitment decision ${ }^{152}$ which obliged all HBO institutions to go along with Studielink - whereas reportedly this did not work in the universities' case since they are too diverse to agree on something like this (Q24:4).

The interviews yielded several recommendations for strategies that could be taken for formalisation of obligations in the face of these costs. With regard to setting up formalised obligations, interviewees from both cases reported that a successful strategy was to limit formalisation of standards to only the really necessary aspects. The argument behind this is that standardisation should provide a general framework that concerns only those aspects that are of importance for the functioning of the key network-level tasks, and that other aspects should be left to the organisations (Q29:34). One strategy for this is to keep the formalisations generic. For instance, in the DKD this practice was reportedly used with regard to the WEU legislation:

\footnotetext{
The Ministry, they thought 'wait, then we're not calling it the "DKD law" or something similar, no we're calling it the "Law for Single Data Request" [WEU]. Because if we called it like that, then we keep it broad. Then we can put a lot of different things into it. [...] Because when it comes into being, we can tell the municipalities that don't cooperate: 'listen, you have to participate because you have to comply with the law'. (Q16:9)
}

At the same time, however, such selective formalisation comes with a risk of ambiguity, and the WEU was criticised for being too vague and ambiguous for providing clear accountability with regard to the DKD (Q7:29). In fact, many interviewees argued that in particular for complex networks, there is a need for high specificity and clear details for those aspects that are formalised. DKD interviewees upheld that whilst organisations may want flexibility in the standards, IOP cannot be achieved if everyone in a large and diverse network wants flexibility:

${ }^{152}$ Bindingsbesluit. 
No, for some things you have to be really strict. [...] If we make agreements in the name of the municipalities, then of course this is for the 400 of them behind us, all them wanting to have half a centimetre extra for themselves [to manoeuvre]. But one of them in this direction, the other in that direction, and yet another one in another direction [...]. So there you see that things are going - not exactly wrong, but they are going really difficult. (Q16:16)

Another example from the DKD case is the "Norm Framework" standard, which did not properly specify which organisations exactly were covered by it. Since they were not clearly accountable, some municipalities drew upon their status as a separate government level when they did not fully comply with it (Q7:7). Unclear formalisations are also seen as problematic because they make compliance more difficult for partner organisations. One risk of vagueness is that system requirement specifications might be misunderstood by ICT suppliers, possibly resulting in non-interoperable infrastructure (Q16:15). This is a key criticism that was voiced about existing government-wide IOP frameworks and reference architectures, which were claimed by some interviewees to open too much room for possible (deliberate or accidental) deviation (Q25:28).

Another strategy for limited formalisation was to use different degrees of formalisation across the different IOP dimensions, according to the degree of importance attached to them. In the DKD for instance, semantic and technological IOP were seen as the primary requirements for the basic functionality of the DKD, whereas organisational IOP was rather seen as the 'icing on the cake', and therefore also less formalised in order to minimise the impact from this dimension on organisations (Q1:12).

One danger of such selective approaches to formalisation is the potential for an uneven distribution of accountability. In the DKD case for instance, several interviewees argued that governing IOP was made more problematic because there were significant differences in the extent to which the various partner organisations were centrally accountable:

\footnotetext{
Then we see with regard to accountability, the executive organisations like UWV, SVB, but also supporting organisations like [BKWI] and Inlichtingenbureau, they are directly accountable towards the Minister. That's regulated by law. But the same law does not state that the municipalities are accountable towards the Minister. (Q17:26)
}

Several interviewees mentioned that it is important that formal specifications are aligned with each other and with the external environment. One strategy mentioned in this regard was that IOP standards should be designed along existing standards used across the network (Q16:16). In addition, since the political environment (and legislation) is bound to change over time along with shifting political priorities, there also needs to be some resilience built into formalisations of the IOP architecture to absorb these changes (Q4:10).

Next to strategies regarding the design of formalisations, the interviews also yielded several recommendations on their implementation. First, several interviewees argued that formalisation should be implemented at the appropriate administrative level, the core question being whether it should be implemented at the central level (national government), or at the sectoral level. Several interviewees argued that enforcing IOP architectures in individual sectors or domains is not efficient and that instead, there is a need for steering from a much higher, generic and abstract level (Q14:26). In a similar vein, many interviewees made a case for the benefit of having a government-wide set of standards that 
covers as many Government Information Networks as possible (Q13:9). The more complex the network is, including cross-sectoral collaboration networks such as the DKD, the more effective formalisation at a central level will be:

\begin{abstract}
Exactly, so you have to be really paying attention with regard to accountability. And I say 'take care that it's legally specified somewhere centrally - centrally for all municipalities. So that all municipalities are accountable in the same way. So take care that not all the accountability is distributed across all sectoral legislation, but so that municipalities are obliged to each year report about their entire data management which is only growing. (Q17:29)
\end{abstract}

However, the necessary legal framework at central government level is not likely to come into place if the central government itself is not interested in taking coercive governance into its own hands - for instance in cases where the central government feels no responsibility of the project, or where it has a different view of how this should be governed. In the DKD for instance, several interviewees shared the view that the central government did not actively engage in the enforcement of the DKD, but only wanted to set a general framework (such as the WEU and privacy legislation) and leave the details of its implementation to the network:

I would be rather an advocate for specifying a clearer way of working and agreements for organisations. But you see that the government says strongly 'I don't care, you coordinate it!' So the government is rather looking at the results, and not how they got to these results. Of course within some preconditions, so the $\mathrm{WEU}$ is one precondition and the privacy legislation is a precondition, and this sort of things. And it says 'Ok partners, you coordinate this yourself'. (Q18:13)

An example where central government favoured a more decentralised mode of governance is the way in which the SZW Ministry delegated the responsibility for implementing the SUWI policy to the municipalities (as for instance formalised in the budgetary frameworks), which was seen to have created a difficult situation with lack of accountability:

\footnotetext{
You see, the Ministry SZW is the financier. [...] The Ministry has said the execution [of the SUWI policy] isn't a national task, but it is decentrally delegated to the municipalities. That's also how the WWB is set up. The municipality has two bags of money and [the Ministry says] 'determine for yourself how you call it'. In that way they placed themselves in a position where they don't have any definitive steering on what is going on. [...] And you see that this resulted in a very difficult trajectory. (Q10:18)
}

In summary, the analysis of the Formalised Obligations variable showed that in more complex networks, formalising their obligations facilitates organisations' adoption and compliance with IOP standards. At the same time, in more complex networks such formalisation of the IOP architecture appeared to come with higher coordination costs, both concerning its design and implementation. Several recommendations were derived from the cases for dealing with this. Regarding design, one recommendation was that formalisations need to be clear and precise in detail. Whilst detailed formalisation can increase transparency and prevent non-compliance, especially in complex networks, achieving such detail also becomes increasingly unfeasible the more complex a network is, for practical and for political reasons. A strategy that can be used in complex networks therefore is to limit formalisation to only the most necessary areas. Whilst this is a sub-optimal solution (with the disadvantage of creating opportunities for deviance), it can provide a more feasible compromise. Furthermore, the analysis also yielded recommendations that when it comes to implementation, formalisation needs to be supported by central government (e.g. through appropriate legal and budgetary frameworks) and should ideally take place at a higher administrative level - particularly so in complex networks of large, cross-sectoral projects. 


\subsubsection{Tracking Systems}

With regard to the Tracking Systems variable, the analysis reported in this section suggests that since more complex networks have a higher likelihood of including more organisations that would not want to adopt or comply with the standards, there is more need for monitoring through a centralised authority in order to support the adoption and compliance with standards. Most of the interview quotations regarding monitoring came from the DKD case, the more complex network (see also Figure Annex B.10). Furthermore, the DKD interviewees were the source of all quotations that discussed the need for monitoring. Since there was a general agreement throughout these quotations that an IOP architecture needs a monitoring system in order to ensure compliance with it, this can be interpreted as a strong indication that the need for this aspect of enforcement is linked to network complexity.

Interviewees from the DKD case argued that without monitoring mechanisms throughout the network, simply having a formalised IOP architecture would be a weak fundament and intended outcomes might not be reached (Q16:13). Monitoring was also shown to have a coercive effect through the political pressure it can generate:

\footnotetext{
Well, we had this issue with the security plans, the question whether there are sanctions. Of course you don't get a ticket if you don't conform. But of course we have a monitoring system: the Inspectie Werk en Inkomen is regularly performing monitoring analyses about these things. And if they find something, then there can be parliamentary enquiries, or municipalities are questioned about these issues. (Q3:24)
}

Similarly, another DKD interviewee reported that monitoring mechanisms can provide a substitute for coercive sanctions. For instance, non-compliant municipalities were at times called to account directly by means of a formal letter from the SZW ministry's state secretary, which was reported to have a strong coercive effect (Q7:26). Another mechanism mentioned was that the published reports of the IWI monitoring provided a tool to create public pressure on the non-compliant organisations, with the eventual effect of their compliance (Q5:22).

Monitoring was also reported to strengthen trust throughout the network, which was deemed particularly necessary in situations of insufficient coercive pressures (Q24:32) something that becomes particularly relevant in complex networks where the political feasibility of coercion is lower. Tracking systems are not only useful for accountability, but also for transparency about achievements and results demonstrability (Q33:11).

Finally, interviewees stated that monitoring not only serves to enhance compliance, but also to stay updated on the diverse perspectives and opinions of partner organisations throughout the network (Q33:8), something that becomes even more relevant in more complex and diverse networks.

Just like with the Formalised Obligations variable discussed in the preceding section, interviewees also discussed the responsible actors and level at which monitoring should be located. In DKD, interviewees reported a mix of centralised monitoring and local-level monitoring. An interviewee from the DKD case argued that in a complex network like DKD, there is a high need for centralised monitoring, based on suitable indicators (Q10:21). At central level in DKD, for instance the IWI was institutionalised as a dedicated monitoring 
actor for the "Norm Framework" (Q7:34), the Inlichtingenbureau servicedesk was charged with monitoring the data supply (Q7:27), and external consultancies were hired for monitoring on specific issues (Q15:22).

In summary, the above analysis of the Tracking Systems variable suggests that more complex networks have a higher need for results-oriented monitoring mechanisms, institutionalised at a central level, in order to support the achievement of IOP - either through implying coercive pressures, by providing management information such as an overview regarding the partner's perspectives on the IOP architecture, or by creating transparency and trust throughout the network.

Therefore, in conclusion regarding the Accountability dimension, it can be said that the interviewee statements are largely in line with Provan and Kenis' (2008) argument that more complex network conditions require more centralised IOP governance. Even though this conclusion is largely based on interviewee statements from the more complex case (DKD), none of the Studielink interviewees contradicted the argument that networks of higher complexity require more centralised accountability structure in IOP governance. Whilst the findings hence might be somewhat less "robust" in terms of cross-case validation than for the other dimensions discussed in this chapter, the data nevertheless is internally consistent with regard to the argument. The analysis of the cases suggests that in more complex Government Information Networks, using accountability mechanisms tends to disincentivise organisations from non-adoption and non-compliance with the network's IOP architecture. However, the analysis also highlighted the caveat that at the same time, institutionalising stricter accountability becomes more costly in higher-complexity networks. As the analysis showed, recommended strategies to effectively institutionalise accountability in complex networks can be to approach formalisation selectively whilst simultaneously ensuring their clarity and precision for the aspects they cover, as well as ensuring that formalisation and monitoring is institutionalised at the appropriate administrative level. Based on the preceding analysis, the following propositions are made:

Proposition 4a: In more complex Government Information Networks, more usage of accountability mechanisms is required to facilitate partner organisations' adoption and compliance with the network's IOP standards.

Proposition 4b: In more complex Government Information Networks, the coordination costs associated with more usage of accountability mechanisms tend to be higher - potentially cancelling out the net benefits of using them.

\subsection{Conclusion}

This chapter has used empirical data from the DKD and Studielink case studies in order to provide a better understanding of the relationship between the effectiveness of IOP governance centralisation and the complexity of a given Government Information Network. The main research question it addressed is: "how do different degrees of IOP governance centralisation affect the adoption of IOP standards in Government Information Networks, and how can this be explained"? Several sub-questions followed from this question: What is the influence of different degrees of IOP governance centralisation across networks of 
different network complexity? Are the effects of IOP governance centralisation on IOP standards adoption independent or moderated by network complexity? Phrased differently, should the degree of IOP governance centralisation be chosen in dependence on other determinants such as network complexity? And in that case, which degree of governance centralisation should be used for which level of network complexity?

Overall, the case study analysis has provided strong empirical support for the theoretical argument by Provan and Kenis (2008) that networks with higher network complexity achieve more effective outcomes if more centralised governance approaches are chosen. Hence, network complexity seems to play a moderating role for the effect of IOP governance centralisation on organisations' intention to adopt IOP standards and that therefore, the degree of IOP governance centralisation for a given network should be chosen according to the complexity of that network. The analysis showed this by selecting four IOP governance dimensions that reflect governance centralisation, and tracing the relation between these dimensions and network complexity in their effect on the intended network-level outcome (IOP standards adoption and compliance). By doing so, the case studies also provided a discussion and examples of variation along the spectrum between centralised and decentralised IOP governance.

First, the chapter analysed the influence of IOP governance on IOP standards adoption in Government Information Networks. The analysis showed that IOP governance is considered by the stakeholders from the cases as one of the most important determinants for IOP standards adoption. In addition, the analysis suggested that the degree of centralisation of IOP governance is of particular relevance for IOP standards adoption - at least in more complex networks. This means that those stakeholders in charge of a given Government Information Network should carefully design its IOP governance based on an assessment of its complexity, in order to chose an appropriate degree of IOP governance centralisation. In a complex network, a more top-down IOP governance approach that is predominantly characterised by centralisation of decisions and their enforcement is proposed to be more appropriate, whereas in non-complex networks, a bottom-up approach to governance with an emphasis on guidance rather than coercion is proposed to be more effective.

Second, the chapter analysed the influence of network complexity on IOP standards adoption in Government Information Networks. The analysis suggests that network complexity has an impact on the intention to adopt and comply with IOP standards. In both cases, network complexity was argued to have a predominantly negative effect. However, it was not only seen as something negative, and some stakeholders also argued that some positive developments can originate from complexity in a network. Since network complexity is not usually something that can be changed, it becomes even more important for policy makers to realistically assess the complexity of a given network and the implications for IOP - and design its IOP governance in a way that supports its positive effects and limits its negative effects.

An overall strategy for IOP governance would be to try and address network complexity itself as the root cause for complicating adoption and compliance. However, in most cases this is very difficult, since many of the factors linked to network complexity are not possible to change, such as for instance the structural complexity of a network - in very few cases will 
it be possible to reduce the number of network partners (for instance the DKD would be unimaginable without including all of the several hundred municipalities). If certain partners are needed for functional purposes related to the network task, they will bring many aspects of diversity, and IOP governance should invest in reducing this diversity, if only partially. For the same reason just mentioned, diversity in terms of geographic spread and public-private mix might be hard to influence if the respective partners are needed for functional purposes. Diversity in resources and development can be addressed by support measures aimed at resolving such inequality, for instance budgetary frameworks that aim to equalise the distribution of resources necessary for participating in the network. Power diversity might be partially addressed by reviewing institutional frameworks to create more equal standing among partner organisations where possible. Institutional review should also address legal and regulatory frameworks in order to break down administrative boundaries and barriers to collaboration where possible. Diversity in problem interpretation and goals could possibly be more aligned through institutional revisions as well, especially if they provide targeted incentives across the network to achieve the same intended outcome. Ex-ante IOP (i.e. the previous existence of standards) across the network (and the differences in adoption implications in case this is weak) might also become less problematic if government-wide (rather than only sectoral) IOP architectures are strengthened. Examples for this are national IOP frameworks or government enterprise architectures with lists of accepted and recommended standards. Organisational cultures and values, as well as identity diversity might be more difficult to change, but might be addressed by means of communication strategies and training aimed at establishing common goals and values.

Finally, the remainder of this chapter analysed how the effectiveness of different degrees of IOP governance centralisation is dependent on the network complexity in a given Government Information Network. To this end, the analysis looked at the interplay between network complexity and each of the two sub-constructs of IOP governance centralisation Decision-Making Centralisation and Enforcement. For each dimension of these sub-constructs, propositions were derived based on Provan and Kenis' (2008) theory based on the case study data: Brokerage and Stakeholder Involvement for the Decision-Making Centralisation subconstruct, and Coercion and Accountability for the Enforcement sub-construct.

Concerning Brokerage, the analysis proposed that more complex Government Information Networks require a higher degree of assigning centralised control to a broker than less complex networks in order to facilitate organisations' adoption and compliance with the network's IOP standards (Proposition 1). The data suggests that in networks with higher complexity, there is a stronger need for the existence of a broker with a clear mandate and powers to make decisions. This means that IOP governance for such networks should thus be designed to designate a broker body and equip it with a clear mission and sufficient decision-making authority to fulfil its task.

In particular, such a broker should be designated to carry out several key roles: first, a broker should function as an intermediary between the partner organisations in the network. This involves bringing key individuals from the organisations together to exchange ideas and to settle differences. It thus also means acting as a communication relay that provides a channel through which relevant information about the network such as new 
developments or mutual expectations is routed efficiently among the partners. Second, the broker should be in a position to act as a proactive facilitator of the network's objectives. This means that it should be enabled to provide a central point of contact for network partners, for instance providing them with technical assistance. Third, the broker needs to balance this facilitation role with its role as a coercive institution. For this, it is important that a clear mandate is assigned to the broker, and that it is given formal and unambiguous decision-making powers to guide the network's development at key moments when its effectiveness is challenged, for instance by conflict, deadlocks or non-compliance.

Regarding the second dimension of Decision-Making Centralisation, Stakeholder Involvement, the analysis is only partially in line with Provan and Kenis' (2008) argument that more complex network conditions require a more centralised IOP governance. Whilst the analysis supported the argument that a minimum level of inclusion of relevant stakeholders always seems to have a positive effect on organisations' adoption and compliance with standards (Proposition 2a), it also revealed the caveat that this is only true up to a certain point beyond which such inclusion involves too much administrative burden and coordination cost (Proposition 2b) - and particularly so in more complex networks, where this tipping point seems to be reached already at lower levels of stakeholder inclusion (Proposition 2c). For the design of an appropriate governance approach, this has two key implications. First, it means that a basic level of stakeholder participation needs to be built into the governance process in any network, regardless of its complexity. Second, a careful analysis of the complexity of the network needs to be undertaken, in order to determine the optimum point that balances stakeholders' need for ownership through participatory measures with the necessary limitation of inclusive practices in order to curb administrative burden and cost.

There is thus a dilemma: whilst with higher network complexity (in particular network diversity), an inclusive design of deliberative forums becomes more important for creating a sense of ownership, it also becomes increasingly difficult to realise. Hence, the governance design needs to make some compromise between inclusiveness on the one side, and feasibility and effectiveness on the other. One recommended strategy for striking this balance is to design such forums in a representative manner, and select those key stakeholders that carry the most weight among their constituents and can thus provide the most legitimacy to the process. The larger the network, the more selective this needs to become - which, however, in turn brings increasing risk of alienating stakeholders. This approach can be facilitated by having multiple forums that are covering separate functional domains, so that key stakeholders can be selected in a more targeted and functionally relevant manner.

With regard to Coercion, the analysis was largely in line with Provan and Kenis' (2008) argument and proposed that in more complex Government Information Networks, more usage of coercion is required to facilitate organisations' adoption and compliance with the network's IOP standards (Proposition 3a). The analysis showed that without any coercive pressure, adoption can by no means be taken for granted, especially (but not only) in more complex networks. Hence, an effective IOP governance design should secure some coercive powers at the network level that can safeguard enforcement for at least the core aspects of 
the IOP architecture, including appropriate channels for escalating conflicts related to nonadoption or non-compliance.

However, similar to Stakeholder Involvement there is a dilemma that with increasing network complexity, there are also increasing coordination costs of coercion (Proposition $3 b$ ). For IOP governance design, this means that a cost comparison should be carried out that holds these coordination costs of coercion against the opportunity costs of not applying coercive pressures to enforce the adoption and compliance with IOP standards. Several strategies can be used in order to minimise these coordination costs. One is to limit coercion in terms of functional scope (i.e. to the core areas of the IOP architecture as suggested above), and for areas of lower priority to use alternative or supplementary strategies that build on support, trust and persuasion (which might be less costly). The analysis also suggested that establishing escalation channels can serve a "preventive" function by creating a source of pressure that makes non-compliance less attractive and can reduce costs associated with conflicts related to non-adoption or non-compliance. (It should be noted, however, that the actual usage of such escalation channels is perceived as politically disruptive and should thus be more of a last resort). Alternatively, IOP governance might also opt for an approach that decentralises coercive power, making organisations themselves responsible for enforcing compliance, rather than situating it with the broker. Finally, an indirect and less costly way to provide coercive pressure is to establish a situation of de facto standardisation, where the network effects from a critical mass of adopting organisations substitutes the need for coercion.

Concerning Accountability, the analysis of the cases largely concurred with Provan and Kenis' (2008) argument and proposed that in more complex Government Information Networks, more usage of accountability mechanisms is required to facilitate organisations' adoption and compliance with the network's IOP standards (Proposition 4a). One key finding for this dimension is that particularly in complex networks, IOP governance should ensure that goals and obligations are formalised into binding agreements. This can serve to legitimise the IOP architecture of a network, increase transparency and trust among the partners, and also exert a coercive pressure for adoption and compliance.

In addition to formalisation of goals and obligations, the analysis also found that more complex networks have more need for central monitoring. Monitoring can help to support the adoption and compliance with standards by providing regular information on adoption and compliance by partner organisations as well as their perspectives and opinions, thus increasing transparency and trust in the network. Moreover, it can also have a coercive effect, in particular if monitoring results are published and non-compliance is exposed to public scrutiny.

However, similar to the previous two dimensions discussed, it becomes increasingly costly to coordinate stricter accountability in higher-complexity networks (Proposition 4b). In order to deal with these increased coordination costs, one strategy for IOP governance can be to use formalisation of goals and obligations selectively, for instance by limiting it to the core areas of the IOP architecture, and by keeping formalisations generic and easy to maintain (whilst simultaneously being careful to maximise clarity in order to limit any leeway for possible deviation). Care also should be taken to make sure that formalised 
agreements are well aligned with each other and with their environment. Therefore, a key recommendation is to align standards as much as possible with existing IOP architectures across government, ideally by institutionalising a government-wide set of IOP standards. Finally, formalisation and monitoring of the IOP architecture also should be located at the appropriate administrative level, ideally at a central government level in order to ensure cross-sectoral coherence and support from central government.

In conclusion, this chapter has shown that IOP governance is the key driver for adoption and compliance with IOP standards in Government Information Networks, and that it can differ substantially in terms of its degree of centralisation. The chapter also showed that the effectiveness of IOP governance for achieving IOP across the network depends on how it matches the complexity of a given network. As the analysis showed, more complex networks require more centralised IOP governance, in particular in terms of decisionmaking centralisation and enforcement. This shows that there is no one-size-fits-all approach to effective IOP governance, but that network characteristics play an important moderation effect that needs to be taken into account for selecting an effective degree of IOP governance centralisation. In this way, the chapter also provides a semi-quantitative and qualitative application in the context of IOP governance of previously made arguments about the necessity of context-sensitive approach to network governance. 



\section{CHAPTER 7.}

\section{CONCLUSION}

\subsection{Introduction - Aim and Overview of the Dissertation}

This dissertation investigated a series of questions on the issue of standards adoption in eGovernance. Societies and governments around the world are becoming increasingly networked. Driven by new governance paradigms and fuelled by the possibilities of ICT to electronically store, process and exchange large amounts of data, we are witnessing a continuing trend towards governing societies through ICT-enabled, inter-organisational "Government Information Networks". Such networks are expected to improve public governance by enabling significant increases in its efficiency and effectiveness through enabling collaboration between various governmental and non-governmental actors. The successful achievement of these goals essentially rests upon the ability of the organisations in these networks to electronically exchange and use information and services among each other. In other words, they need to achieve "interoperability" (IOP), which necessitates their adherence to a common set of standards and agreements - their "IOP architecture". Unfortunately, in practice, Government Information Networks often encounter substantial difficulties to achieve IOP because their participating organisations fail to take the necessary measures to adopt and comply with the technical, semantic and organisational IOP standards specified in their network's IOP architecture.

This dissertation therefore aimed at contributing a better understanding of IOP standards adoption in Government Information Networks, in particular the process, drivers and barriers behind adoption, and aims at providing insights and guidance how to best approach the governance on IOP in such networks. To this end, it combined a theoretical modelling approach with two in-depth case studies to address a number of research questions that aimed at contributing to these objectives.

The main research question of this dissertation is: what are the factors that determine the adoption of IOP standards by organisations in Government Information Networks, and what are their implications for effective IOP Governance? In view of this main research question, three sets of sub-questions (SQs) were specified: SQ1) How can we conceptualise IOP standards adoption in Government Information Networks?; SQ2) What are the factors that determine the adoption of IOP standards by organisations in Government Information Networks?; and SQ3) How do different degrees of IOP governance centralisation affect the adoption of IOP standards in Government Information Networks?

The first chapter explained the policy problem motivating the thesis, the research questions, and introduced the central concepts as a basis for the subsequent chapters. Chapter 2 
provided a theoretical foundation for the empirical analysis in Chapters 4 to 6 by means of deriving a preliminary theoretical model of adoption determinants from the relevant fields of theory. Chapter 3 described the methodological approach of the dissertation, and gave an overview of the two case studies that formed the core of the empirical analysis in the remainder of the thesis. Chapter 4 then focused on SQ1 by providing a more detailed understanding of IOP standards adoption, by investigating what its implications are for organisations in Government Information Networks, what the processes of adoption are and which actors are involved. Chapter 5 subsequently focused on SQ2 by investigating what the determinants of IOP standards adoption are. Finally, Chapter 6 then focused on SQ3 by investigating whether and how for different degrees of network complexity, different degrees of IOP governance centralisation result in different effects on the adoption of IOP standards.

This concluding chapter gives a synthesising summary of the main findings of the dissertation, discusses its contribution to theory and practice, and provides an outlook on its significance for future research. To this end, it has started with providing a brief summary of the policy problem motivating this dissertation, its main objective and the contribution of each of the previous chapters to this end (Section 7.1). The contributions of the dissertation to theory and practice can be grouped into three overarching issues, aligned with the research questions addressed in this dissertation. The findings and conclusions of the dissertation on these issues are discussed in Section 7.2. Section 7.3 then discusses the limitations of the dissertation, and Section 7.4 gives recommendations for future work on this topic. Section 7.5 then concludes with some final thoughts on the contributions of the dissertation.

\subsection{Findings and Contribution to Theory and Practice}

This section discusses the findings and contribution of the dissertation to theory and practice along the research questions that guided the analysis. Section 7.2.1 addresses the conceptualisation of IOP standards adoption in Government Information Networks (SQ1). It discusses the types of IOP standards and their role in Government Information Networks (Section 7.2.1.1), the nature of the IOP standards adoption process (Section 7.2.1.2), and the actors involved in it (Section 7.2.1.3). Section 7.2.2 then addresses the determinants of IOP standards adoption by organisations in Government Information Networks (SQ2): IOP Standards Characteristics (Section 7.2.2.1), Network-External Environment (Section 7.2.2.2), Organisation-Specific Determinants (Section 7.2.2.3), Adoption Efforts and Results (discussed together in Section 7.2.2.4), Network Characteristics (Section 7.2.2.5), and IOP Governance (Section 7.2.2.6). The questions on the relation of IOP governance centralisation and network complexity (SQ3) are discussed in detail in Section 7.2.3.

\subsubsection{Conceptualising IOP Standards Adoption}

This section discusses the first set of research questions presented at the end of Chapter 1, centred around SQ1: how can we conceptualise IOP standards adoption in Government Information Networks? Section 7.2.1.1 discusses the types of IOP standards and their role in Government Information Networks, Section 7.2.1.2 discusses the nature of the IOP standards adoption process, and the actors involved in IOP standards adoption are 
discussed in Section 7.2.1.3. The sub-question on the implications of IOP standards adoption is discussed further below in Section 7.2.2.4.

\subsubsection{Types of IOP Standards and Their Role in Government Information Networks}

One of the questions under SQ1 was: what are the kinds of IOP standards encountered in Government Information Networks and how can we categorise them in a meaningful way? The three main findings on this question are that 1 ) the distinction of the three interrelated dimensions of technological, semantic and organisational IOP standards is a useful analytical framework; 2) overall, none of these dimensions is of significantly lower or higher concern for stakeholders in Government Information Networks than the other dimensions; and 3) there does seem to be a difference in their significance if the various adoption efforts and results are compared. These main findings and their significance for theory and practice are summarised below.

The analysis used a distinction that is widely applied in research on IOP, distinguishing between three major dimensions of IOP that allow us to differentiate between technical, semantic and organisational types of IOP standards. However, in addition to confirming this distinction as a useful analytical framework, the analysis also showed that the three IOP dimensions and the corresponding types of standards appear to be highly interrelated, rather than being separate issues as that typology might suggest and as often treated in academic and policy discourse. This was shown in Table 4.1 and by the observation that even those determinants that are very much tied to a specific IOP dimension (for instance Semantic Efforts) all co-occur considerably with all three IOP dimensions (whilst if there was no interrelation, they should be almost exclusively co-occurring with only one IOP dimension, e.g. semantic IOP in the case of Semantic Efforts). IOP governance should therefore take a holistic approach and take these connections into account.

Overall, whilst technological and organisational IOP seem to play a bigger role for organisations in Government Information Networks than semantic IOP, all three dimensions and the corresponding types of IOP standards play a considerable role for stakeholders. This was shown by the considerable share of quotations for all three dimensions (see Figure 4.1 and Figure 4.2). Therefore, IOP governance cannot afford to neglect any of the dimensions of an IOP architecture. Moreover, as the analysis of Figure 4.2 in Section 4.2 has shown, this is especially important with regard to organisation-level stakeholders who tend to have a less holistic view on IOP and tend to have less concern for semantic IOP in particular.

The analysis also showed that if separated by the various categories of adoption implications, there are considerable differences in the roles played by the different dimensions of IOP. The significance of the three IOP dimensions varies across the various efforts and results of adoption, as shown by Figure 4.3. Whilst keeping a holistic approach, IOP governance thus should also be mindful of this variation and pay particular attention to the most significant IOP dimension for each category of IOP adoption implications. 


\subsubsection{Processes of IOP Standards Adoption}

Another research gap addressed by this dissertation is the lack of process perspectives on standards adoption. Whilst standards adoption has been described in previous research as a dynamic process, the actual nature of this process, as well as the types and roles of the involved actors, largely remained a black box. This dissertation addressed this gap and asked: what are the processes of IOP standards adoption in Government Information Networks? The main findings on this question are 1) validating standards adoption as a phased process, and identifying three distinct phases (planning, implementation, operational) following the adoption decision; 2) showing a variation in the significance of the adoption determinants along these phases; and 3) showing that the operational phase is by far the most relevant in the adoption process, followed in relevance by the planning phase. These main findings and their significance for theory and practice are summarised below.

First, the findings concurred with previous theories in arguing that standards adoption is a process that consists of sequential phases, but found that the phases identified by existing theories are so diverse that the only identifiable common ground is a rudimentary distinction into two major stages - before and after the adoption decision. However, the analysis was able to advance this conceptualisation by using the case study data to identify three phases (planning, implementation and operational phase) for the latter stage (Section 4.4.2). This conceptualisation of adoption as a process of sequential stages and phases was supported by means of matching the case study data along these phases and stages (Sections 4.4.2.1 and 4.4.2.2).

Second, the theoretical contribution to the understanding of the adoption process also included the finding that the relative significance of the main determinants of adoption intention varies across the three phases of planning, implementation and operational phase. This was shown by the variations in co-occurrence of determinant constructs with Adoption Phase codes (Figure Annex B.4). By contributing a more detailed picture of this variation in the process, the analysis thus also made a relevant contribution to IOP governance by showing when to focus on which aspects of the adoption process.

Third, the analysis showed that the operational phase is the most relevant in the adoption process. To begin with, the results suggest that the part of the adoption process which is most influenced by the adoption determinants is the operational phase. This was shown by the observation that the largest number of co-occurrences of determinant constructs is with this phase (Figure Annex B.4). The implication for IOP governance is that it is important to consider the effects of the various determinants with particular care during the operational phase.

In addition, the analysis also showed that it is during the operational phase that noncompliance with a standard becomes a key concern, and that non-compliance is often not made explicit. This was suggested by evidence from both cases about several instances of such non-compliance (either "silent non-compliance" or "deviant adoption") that emerged during the operational phase (see Section 4.4.2.2). Hence, it becomes very important for IOP governance to carefully monitor adoption and compliance at the operational stage. 
However, despite the central role of the operational phase, the findings also showed that the adoption implications have a significant influence even before the actual adoption, during the planning phase. This was shown in Figure 4.13 and Figure 4.14 in Section 4.4.2.2, by analysing the co-occurrences of Adoption Efforts and Results codes with these three phases. This means that IOP governance should give substantial consideration to potential implications already at the outset of the planning phase.

\subsubsection{Actors in IOP Standards Adoption}

The dissertation also pointed to some shortcomings of existing theory on the actors involved in IOP standards adoption in Government Information Networks. One of the questions addressed under SQ1 therefore was: who are the relevant actors in IOP standards adoption? The findings provided several contributions to theorising the way in which decisions on IOP standards adoption are made in organisations, and concerning the key actors involved in this process. In particular, the findings 1) validated that the standards adoption process is an interplay of multiple actors at three levels, and provided a typology of the key actors at each level and their roles in the adoption process; 2) showed how these actors' roles vary in their significance for standards adoption, and in relation to the identified adoption determinants. By thus opening the "black box" of standards adoption, the dissertation offered several guiding insights for theory and practice of IOP governance, discussed below.

First, with regard to the actor analysis, the IOP standards adoption process was shown to be an interplay that involves an array of actors that can be grouped at three levels: the interorganisational level (central government, broker/infomediary bodies, umbrella organisations, standard-setters, and vendors), the intra-organisational management-level (top-level managers, senior project managers, project groups, dedicated units, and deliberative bodies), and the intra-organisational operational level (front-office staff and back-office staff). By identifying the actors from the case studies and producing an actor typology based on the documentation of their roles in the adoption process, the dissertation thus confirmed previous theoretical arguments that standardisation is a result of interaction among a range of actors across several levels, and also expanded this theory by identifying the relevant types of actors that play a role in standardisation in Government Information Networks (Section 4.4.1 and subsections). The key implication of these findings for practice is that IOP governance needs to recognise IOP standards adoption as a multi-stakeholder interaction and be based on systematic and continuous stakeholder analysis.

Second, the analysis also went beyond a mere typology, and expanded existing theory by showing that there are differences across the identified types of actors in their significance for IOP standards adoption. Concerning the inter-organisational level, the analysis suggested that there is a particularly important facilitating role played by the network-level IOP "infomediaries" such as network brokers. This was shown by the considerable majority of Actor quotations coming from this category, and also confirmed by the qualitative analysis of the interviews (see Section 4.4.1.3, in particular Figure 4.9). For practice, this implies that IOP governance needs to support these infomediaries at the network level, in particular by means of a facilitative institutional framework which provides clear mandates, effective decision-making powers and sufficient resources. 
Moreover, the analysis also highlighted that instead of being just a matter of public-sector actors like brokers and political actors, IOP governance is very much a public-private collaboration (see Figure 4.9 and Section 4.4.1.3). In particular, IOP governance should pay attention to the involvement of private-sector partners such as IT vendors to provide support with regard to various adoption efforts (see Section 4.4.1.3).

Concerning the intra-organisational management-level, the analysis showed that within organisations, the top-level management plays a central role regarding the IOP standards adoption decisions, which are typically based on a weighing of costs and benefits for their organisation. This was shown by the analysis of the role descriptions identified in the interviews (Section 4.4.1.1). It therefore is of central importance for IOP governance to take into account the relative significance of the various adoption determinants identified in this dissertation, and monitor their role continuously in order to be able to intervene with targeted measures.

However, whilst the strategic decisions on adoption of IOP standards are thus taken at the organisational management level, the analysis of the role descriptions in the interviews also revealed that compliance was found to be significantly influenced by actors at the operational level within organisations (Section 4.4.1.2). Hence, for IOP governance it is important that the determinants for adoption and compliance are monitored not only at the management level, but at all levels throughout the organisations.

Finally, by analysing the co-occurrences between determinant constructs and Actor codes (Figure Annex B.3, Section B1), the analysis showed that in general there is significant variation in terms of the roles of the various actors across the different main determinants of IOP adoption. A crucial question for IOP governance thus is who to involve, when, and how. For each determinant, the dissertation identified the key actors. IOP governance should therefore use this analysis for a targeted approach to strengthening the supportive capacity of the most important actors in each particular domain of factors influencing standards adoption across the network.

\subsubsection{Determinants of IOP Standards Adoption}

This section discusses the group of research questions presented at the end of Chapter 1 under SQ2, centred around the question: what determines the adoption of IOP standards by organisations in Government Information Networks? The main findings on this question are 1) the development of an empirically validated theoretical model on the determinants of such IOP standards adoption; and 2) determining the relative relevance of the identified determinants for stakeholders in Government Information Networks. These findings and their significance for theory and practice are summarised below.

A central gap in existing literature is the lack of theory concerning the determinants of IOP standards adoption in e-Governance contexts. Whilst a considerable body of literature discusses the need for IOP in government and its benefits, standards adoption has previously been almost exclusively studied in the private-sector context. However, theories on the private sector have rather limited potential to explain the - very different - reality of the public-sector environment of e-Governance. The studies looking at standards adoption 
in a public-sector context are very few and take little account of each other. In addition, most of the existing models focus on the individual level of analysis, whilst the highly relevant organisational level is hardly being studied. What is needed is thus a context-specific, multitheoretical model on the adoption of IOP standards by organisations in Government Information Networks.

This dissertation provides the missing integration of the rather disconnected existing studies by synthesising the relevant theory on this topic into a relevant model, and by validating this model based on empirical case study data, contributing newly identified determinants as well as contesting determinants that existent theory had suggested. Based on this, a theoretical model of the relevant determinants for adoption of IOP standards in Government Information Networks is provided, which consists of seven determinant constructs: IOP Governance, Network Characteristics, Results, Adoption Efforts, OrganisationSpecific Determinants, Network-External Environment, and IOP Standards Characteristics (listed in order of decreasing significance for stakeholders). For each of these main determinant constructs, an extensive and structured three-level set of sub-dimensions was identified as well (labelled as sub-constructs, dimensions, and variables). In addition, propositions about the relative significance of these determinants for stakeholders were derived from the empirical analysis.

The theoretical model provided by this dissertation thus fills an important gap in existing research, and can serve as a relevant basis for future studies on Government Information Networks, as well as for further validation in other contexts. Providing a theory on the determinants IOP standards adoption also serves as a basis for much-needed guidance for IOP governance practice. Having a clear understanding of what these factors are and what their relative significance is for stakeholders provides a useful guide for IOP governance: it can serve as a framework for monitoring partner organisations' intention to adopt specific standards, for assessing the feasibility of diffusing a standard and to identify key barriers, and for tailoring an IOP governance strategy to the specific context of a particular network.

The theoretical and practical contributions of the findings on this question are discussed in the following sections. First, some general conclusions on the model are reported in the remainder of this section, and subsequently the key conclusions for each determinant construct are reported in Sections 7.2.2.1 through 7.2.2.6.

Overall, the analysis showed that all seven main determinants seem to play a significant role for IOP standards adoption, although there appears to be some variation in their relative importance. This conclusion was supported by the analysis of Table 5.1 through Table 5.6 (see also Table 4.2, Table 4.3, Figure Annex B.1 and Figure 6.1), which showed considerable amounts of quotations for all determinant constructs, but also significant variation across determinants. All seven of these determinants therefore should be taken into account for effective IOP governance.

One key conclusion on the overall model is that stakeholders mentioned technology-related determinants consistently less frequently than organisational or process-related determinants (see Section 5.2.2.2). Therefore, whilst both the academic and policy literature is generally preoccupied with the technological dimension of IOP, this shows that in 
practice IOP is about much more than mere technological standardisation, and more attention needs to be given to its other dimensions. In the end, IOP is merely a means to an end, a tool for achieving organisational or process-related goals and outcomes.

The comparative aspects of the analysis also revealed interesting variations in the relevance of the identified determinants across the cases studied, as well as across stakeholder roles (organisational or network-level). The differences in the relevance of determinants across the two cases can be seen in the detailed results presented throughout Annexes A and B. Whilst the general observations hold across cases, this variation shows that IOP standards adoption by stakeholders in different Government Information Networks is also shaped by the idiosyncratic context of their network, highlighting the necessity for a context-sensitive approach to IOP governance that takes these idiosyncrasies into account.

When comparing the concerns of the investigated stakeholder roles, the analysis showed that organisation-level stakeholders generally are more concerned with the implementation and implications of IOP standards for their organisations, whereas network-level stakeholders tend to reflect more on policy and institutional foundations. Therefore, IOP governance needs to give special consideration to the findings regarding the implications of adoption discussed in Chapter 4 (see Section 7.2.2.4 below) and draw on the expertise with policy and institutional foundations that network-level stakeholders can provide.

\subsubsection{IOP Standards Characteristics}

As shown by the quotation frequencies displayed in Table 5.4 and Figure Annex B.1, IOP Standards Characteristics have the smallest relevance among the seven determinant constructs. Yet, the fact that in absolute terms the amount of quotations for this determinant is nevertheless substantial showed that their influence is by no means insignificant. In particular, as the analysis of the IOP Standards Characteristics determinant and its variables showed (see Table 5.4, Sections 5.2.2.1 and B7), maturity of the standards seems to be the most relevant characteristic. Therefore, IOP governance should ensure that in the design of a network's IOP architecture, as much as possible use is made of IOP standards that are well established and tested in practice.

\subsubsection{Network-External Environment}

The Network-External Environment construct, consisting of the sub-constructs Political Environment and Policy and Institutions, is the second-lowest relevant determinant construct for the interviewed stakeholders, as shown by the quotation frequencies in Table 5.3 and Figure Annex B.1. Policy and Institutions appeared to be the most important sub-construct, and the analysis pointed out that having a sound and sustainable IOP policy is of special relevance for the stakeholders. This was shown based on its dominant majority of quotations over Political Environment quotations in Table 5.3 (see also Sections 5.2.2.1 and B4). In particular the Legal Framework and Budgetary Framework matter most in this regard, as shown by the higher share of quotations for these two dimensions in Table 5.3 (see also Sections 5.2.2.1 and B4.2). Hence it is important that IOP governance of a given Government Information Network is supported by institutions to formalise the IOP architecture (in 
particular by means of a solid legal framework), and well aligned with dedicated IOP policies at the national level.

Concerning the political environment, the most relevant dimension appears to be Public Pressure. This conclusion is derived from the large majority share of Public Pressure among all quotations for Political Environment, as shown in Table 5.3 and discussed in Sections 5.2.2.1 and B4.1. Hence, to leverage this factor, IOP governance should take into account the political background and in particular the role and expectations of network-external stakeholders. In particular, given the conclusion that organisational stakeholders' participation in Government Information Networks seems to be largely driven by government-internal goals rather than directly responding to their clients' needs (see the discussion of Table 5.3 in Section 5.2.2.1), IOP governance should put more emphasis on the longer-term benefits of IOP in terms of public value to the end-users next to governmentinternal benefits.

\subsubsection{Organisation-Specific Determinants}

Organisation-Specific Determinants, comprising the Organisational Capacity and Organisational Needs sub-constructs, is the third-lowest in terms of relevance for stakeholders as shown in Table 5.5 (see also Sections 5.2.2.1 and B1). In particular for Organisational Capacity, the composite variables display significant variation across the two cases (see Table Annex B.18, Section B8.1), suggesting that their individual relevance for stakeholders is strongly casedependent. Those in charge of IOP governance should thus carefully analyse in each case which capacities are lacking in order to provide targeted assistance and guidance to partner organisations in these areas. In addition, they should clearly communicate how IOP can serve organisational needs.

\subsubsection{Implications of Adoption: Adoption Efforts and Results}

A specific question introduced in Chapter 1 was: what are the implications of adopting IOP standards in terms of the efforts required for adoption and the results from adoption? By enhancing our understanding of the implications of standards adoption on organisations, the dissertation contributes to more accurate assessments of the feasibility of diffusing IOP standards in Government Information Networks. The two determinant constructs referring to these implications, Results and Adoption Efforts, were discussed together in Chapter 4, and the conclusions on their role for IOP governance are jointly discussed below.

As shown in Table 5.6 (see also Section B1 and Figure Annex B.1), Results and Adoption Efforts are the third- and fourth-most relevant determinants to the interviewed stakeholders. Based on the content analysis of quotations for Adoption Efforts and Results (Section 4.3), the analysis revealed that certain implications are of considerably higher significance for stakeholders and should thus receive particular attention in IOP governance.

Overall, the findings showed that with regard to implications, organisational stakeholders in Government Information Networks primarily think along an organisation-centric functionalist logic, emphasising the short-term implications for their organisation rather than thinking along longer-term visions on network-wide institutional development. 
Regarding the Adoption Efforts required from organisations for the adoption of standards, the most relevant sub-construct seems to be that of Organisational Efforts (forming the large majority of quotations within the Adoption Efforts construct, as shown in Table 4.3). When looking at the Results construct, the most significant results are those that affect internal operations of the organisation (making up the overwhelming majority of quotations within the Results construct, as displayed in Table 4.2). Whilst the analysis showed that in this regard it is primarily Results in terms of Efficiency and Effectiveness that matters to stakeholders (Table 4.2), it also revealed an important caveat that in the long run, the pursuit of achieving IOP can in fact also result in negative results in these dimensions, such as cost increases and even a deterioration of service quality (see Section 4.3.2). In sum, organisational efforts and internal-operations results therefore should be treated as key areas of concern for IOP governance, with due caution to question overly optimistic and utopian promises by means of careful analysis.

The analysis also showed that there is a marked difference in stakeholders' stance towards the implications from IOP standards adoption between Adoption Efforts and Results constructs, showing that evaluations of Adoption Efforts are clearly negative, whereas for Results the majority is mostly positive. However, whilst this finding is rather intuitive, the analysis also added relevant details to this general picture, showing that there is a significant variation in the share of negative versus positive evaluations across subconstructs for Results. This was concluded from the analysis of co-occurrences of evaluation codes and the codes for Results and Adoption Efforts (discussed in Section 4.3.5, in particular Figure 4.6 and Figure 4.7). For IOP governance, this provides guidance as to which implications face the strongest opposition and need to be addressed with priority. In particular where adoption efforts and costs cannot be avoided, particular emphasis should be placed on communicating the long-term benefits implied.

As the interpretive analysis of interview statements reported in Section 4.3.4 showed, various implications appear to be interrelated, such as for instance technological and semantic adoption efforts. In addition, the interpretive analysis also revealed that there are clear trade-offs between certain efforts and results, which are typically weighed by stakeholders in their adoption decision (see Section 4.3.4). This means that IOP governance needs to be designed in a holistic approach in order to address such interlinkages and tradeoffs.

\subsubsection{Network Characteristics}

As the quotation frequencies displayed in Table 5.2 show (see also Figure Annex B.1), the second-most relevant determinant construct is Network Characteristics. By far the most dominant sub-construct here was shown to be Network Complexity (as shown by the large majority share of quotations from this sub-construct for Network Characteristics in Table 5.2 and Table Annex B.15). As the large majority of its negative evaluation (shown in Figure 6.3 in Section 6.3.2) and the interpretive analysis of interview data in Sections 6.3.3 through 6.3.6 suggested, Network Complexity has a predominantly negative effect on IOP standards adoption in most of its dimensions. Where possible, IOP governance thus should try to 
reduce the network's complexity in those dimensions, for instance through structural changes to the network, institutional review and appropriate communication strategies.

However, as the analysis of stakeholder evaluations of Network Complexity shows (Figure 6.3 in Section 6.3.2), the picture is more complex because in some cases, network complexity can even have some positive effects. IOP governance therefore needs to carefully assess the complexity of a network and provide support to those aspects of the network's complexity that have a net positive effect on adoption.

The dominant share of quotations for the Existence of Standards dimension within the Information Infrastructure shown in Table 5.2 (see also Sections 5.2.2.1 and B3.5) showed that it is very important for organisations that they are able to rely on existing standards rather than having to invest in new standards that require them to incur substantial changes. In addition, it appears from the findings that it is very helpful for adoption if there already is a critical mass of adopters for a given standard. Therefore, IOP governance of individual Government Information Networks should be aligned with national IOP frameworks. These should be supported by the necessary resources (such as funding and subsidies) and facilitating institutions (such as legal obligations).

\subsubsection{IOP Governance}

Based on Table 5.1 and the discussion in Sections 5.2.2.1 and B1, the analysis suggested that IOP governance is by a significant margin the most relevant determinant for standards adoption by organisational stakeholders. This underlines the necessity to carefully design IOP governance in order to achieve IOP throughout the network. A key finding here was that although formal institutions are of substantial relevance as well, it is particularly informal institutions and soft governance that are of primary importance to stakeholders, with effective guidance and leadership being the most important aspects (as shown the dominant share of frequencies for Guidance and Leadership and Support in Table 5.1). Such informal governance is particularly relevant in contexts where formal institutions are not sufficiently established: in particular, where obligations for adoption are not formally institutionalised, effective Communication strategies (especially communication about the value creation through IOP standards adoption) take on a relatively larger role whilst this role is much smaller for more formalised contexts (see the discussion of Figure Annex B.6 in Section 5.2.2.1), effectively creating a "pull" factor for organisations as a substitution for the "push" that formalised adoption obligations might otherwise provide.

This points to the central finding regarding IOP Governance: that it is crucial for IOP governance design to take a context-sensitive approach and align itself with key characteristics of the network. The conclusions on this question are discussed separately in the following section.

\subsubsection{Effectiveness of IOP Governance Modes Across Network Complexities}

The third major theoretical contribution of the dissertation stems from the third set of research questions (SQ3) introduced at the end of Chapter 1, centred around the question: 
how do different degrees of IOP governance centralisation affect the adoption of IOP standards in Government Information Networks? In particular, this included the sub-question whether (and how) the degree of network governance centralisation should be chosen in dependence on a network's complexity. The findings of the analysis 1) by means of a set of theoretical propositions, supported the argument that that higher network complexity requires more centralised IOP governance; 2) provided a framework for assessing and designing IOP governance centralisation; and 3) provided recommendations how IOP governance can best be designed in order to match a network's degree of complexity.

First, the findings contributed to the debate whether centralised and top-down, or decentralised and bottom-up approaches are more effective in governing interorganisational networks - a debate not limited to the particular domain of IOP governance, but also concerning network governance in general. Whilst most of this debate so far rested on purely theoretical argumentation, there has been a lack of empirical validation of these arguments. By means of a comparative analysis of the two cases, this dissertation addressed this gap by providing empirical evidence supporting the argument by Provan and Kenis (2008) that higher network complexity requires more centralised governance approaches.

Second, it also provided a context-specific adaptation of Provan and Kenis' (2008) framework for assessing network governance centralisation. By identifying and conceptualising the essential dimensions of both IOP governance centralisation and network complexity, the dissertation provided two analytical frameworks to be used to design IOP governance. IOP governance can use these frameworks to assess both the complexity of Government Information Networks (in terms of structural complexity, diversity and task complexity) and the degree of centralisation of IOP governance (in terms of decision-making centralisation and enforcement).

Third, the dissertation investigated how IOP governance can best be designed in order to match a network's degree of complexity, and provided several key conclusions and recommendations in this regard. Essentially, the dissertation argued that there is no universally applicable IOP governance approach, but that it should be aligned with the degree of network complexity: in more complex networks, a centralised IOP governance approach will be more successful in achieving IOP, whereas in less complex networks a bottom-up approach based on guidance rather than coercion will be more successful.

The argument that more complex networks require more centralised IOP governance approaches was supported by four major conclusions (each represented by one or more theoretical propositions) - one for each dimension of IOP governance centralisation. The first proposition argued that more complex networks require a higher degree of centralised control by means of assigning a clear mandate and formalised powers to a broker than less complex networks in order to facilitate partner organisations' adoption and compliance with the network's IOP standards (Proposition 1, Section 6.3.3.2). This was shown in Section 6.3.3 by means of an interpretive analysis of the interview data, in particular of the variables Broker Existence and Broker Mission. Therefore, IOP governance in complex networks should designate a broker body and provide it with a clear governance mandate and decisionmaking powers to carry out its coordinative functions, in particular to act as an intermediary 
and communication node among partner organisations, and as an institution enforcing the IOP architecture.

The second set of propositions argued that whilst a basic level of stakeholder participation in a network's IOP governance facilitates partner organisations' adoption and compliance with a Government Information Network's IOP standards irrespective of its complexity (Proposition 2a, Section 6.3.4.2), in more complex networks the diffusion of IOP standards will proceed more efficiently if stakeholder participation is capped at the point that creates an optimal balance of stakeholders' demand for inclusion and the affordable level of administrative burden and coordination costs implied. This is because as stakeholder involvement increases, there are diminishing returns to its facilitating effect on organisations' adoption and compliance with a Government Information Network's IOP standards, eventually reaching a tipping point (Proposition $2 \mathrm{~b}$, Section 6.3.4.2). Moreover, in more complex networks, the tipping point beyond which stakeholder involvement becomes too costly is reached at lower levels of stakeholder involvement than in less complex networks (Proposition 2c, Section 6.3.4.2). These propositions were developed in Section 6.3.4 by means of an interpretive analysis of the interview data, in particular of the variables Partners Participation and Design and Use of Forums. Therefore, IOP governance should carefully assess a given network's complexity and its implications for costs and burden of inclusion to identify this optimum point. A possible compromise between inclusiveness and cost limitation can be to design consultation forums in a representative manner, where the various functional domains are covered by separate forums, each including a selection of the key stakeholders that carry the most legitimacy for those domains.

The third set of propositions argued that in more complex networks, more usage of coercive governance is required to facilitate partner organisations' adoption and compliance with IOP standards (Proposition 3a, Section 6.3.5.2). However, the analysis also showed that a commitment for coercion comes with coordination costs that potentially outweigh its benefits and that in more complex networks, these coordination costs tend to be higher than in less complex networks (Proposition 3b, Section 6.3.5.2). This was shown in Section 6.3 .5 by means of an interpretive analysis of the interview data, in particular of the variables Coercive Pressures and Escalation Channels. Therefore, it is important for IOP governance to equip governing actors at the network level with coercive powers in order to enforce the IOP architecture of that network, for instance by means of escalation channels or the possibility to impose sanctions for non-adoption. However, such measures should be based on a comparison of the implied coordination costs with the likelihood and extent of costs from non-compliance (where such measures were not taken). Coordination costs from coercion might be also limited by restricting coercion to prioritised aspects of the IOP architecture, by establishing escalation channels, decentralising accountability and responsibility for compliance to the organisational level, and by means of de facto standardisation through securing a majority of adopters.

Finally, the fourth set of propositions argued that in more complex Government Information Networks, more usage of accountability mechanisms is required to facilitate organisations' adoption and compliance with IOP standards (Proposition 4a, Section 6.3.6.2) because it helps to legitimise the IOP architecture, increase transparency and trust throughout the 
network, and to exert coercive pressure for adoption. However, it also argued that more usage of accountability mechanisms might come at significant coordination costs, potentially cancelling out the net benefits of using them (Proposition 4b, Section 6.3.6.2). These propositions were developed in Section 6.3 .6 by means of an interpretive analysis of the interview data, in particular of the variables Formalised Obligations and Tracking Systems. Hence, the formalisation of the IOP architecture into binding obligations, and the institutionalisation of central monitoring is particularly important in complex networks. In order to minimise the costs of accountability mechanisms, they should be aligned with existing IOP architectures (such as national IOP frameworks) and be located at the appropriate administrative level in order to ensure cross-sectoral coherence. Moreover, costeffective accountability mechanisms might be achieved by limiting formalisations to core aspects of the IOP architecture and keep them generic and easy to maintain.

\subsection{Limitations}

This section identifies key limitations of this dissertation that need to be pointed out in order to assess its findings, and discusses how they can be addressed by subsequent work. It first discusses limitations regarding external validity, followed by limitations on internal validity of the research.

As an in-depth small-N study with only two cases, the dissertation faces some limitations regarding external validity. Due to the purposive sampling and small-N approach of the study which bars any probabilistic analyses like large-N random sampling would allow, its conclusions therefore can only be applied with certainty to cases that are similar to the ones under study. However, as with most qualitative in-depth studies, its strength instead lies in its internal validity. The intention is not wide generalisation, but it serves a different purpose of theory generation, as such research designs are more suitable for exploratory research and generating propositions for validation by future research. The theoretical model generated in this dissertation thus lays the groundwork for future research in this research field. When the presented theoretical model will be applied and tested in different contexts (such as other Government Information Networks, or possibly even other interorganisational systems and innovations), it will improve and grow in generalisability.

There are also some limitations regarding internal validity that should be noted. Some of these concern conceptual limitations. First, it should be noted that the literature review at the basis of the theoretical framework did not use a rigid selection frame like many "systematic literature reviews" (which usually involves specifying a range of parameters such as publication data range and list of journals and then selecting anything that passes through that filter). This approach may have the benefit of a typically very large, "semirandom" selection that might be useful to make claims for instance about the state of the art in a certain field (for instance identifying "hot topics" or dominant methodologies). However, a more targeted approach based on judgement of relevance through the researcher, as it was used in this dissertation, is deemed to be more meaningful for identifying the most relevant and context-specific sources. Even without using a rigid framework, the literature review nevertheless reviewed over 140 studies, providing a sufficiently large base for theory synthesis. However, as this dissertation showed, the body of determinants mentioned in the current literature is not set in stone, and new studies (such 
as this dissertation itself) can still identify additional determinants. The model presented in this dissertation is not exempted from such improvement by future studies, and therefore future research should continuously scan the growing body of on-going and existing literature in this field to identify possible additional determinants that are not included in the present theory.

A second conceptual limitation concerns the somewhat "selective" usage of Provan and Kenis' (2008) framework of network characteristics exclusively in the light of Network Complexity. It was acknowledged that in fact only three of the four characteristics mentioned in their study relate to Network Complexity (network size, goal consensus and task complexity), and that the fourth characteristic (trust) was not explicitly taken into consideration in this dissertation. However, this was a deliberate choice, and a justified one since the focus of this dissertation was on network complexity as the key factor of interest, and "trust" is therefore not directly relevant for the objective of this dissertation. Future research might look into additional characteristics, including "trust". By doing so, it can contribute to further validate the argument that the effectiveness of network (IOP) governance is depending on a range of network characteristics, and contribute to further identifying the salient characteristics.

Third, one might criticise the measurement and selection of cases along the key variables of governance centralisation and network complexity as fuzzy and subjective: for instance, why should Studielink with roughly 70 organisations be judged as non-complex? In fact, it is argued here that it would be impossible, and in fact misguided, to try to identify an "absolute" cut-off for these two case characteristics. Instead, the focus should be on a comparative perspective that distinguishes the cases in relative position to each other and their larger environment based on a sound argumentation. Hence, differentiations such as for instance the assessment of certain governance practices as more or as less centralised are justified when it is based on expert views by insiders, taking into account the comparative perspective. Future studies intending on replicating the research in this dissertation might nevertheless opt to take a different approach, and use absolute rather than relative cut-off measures as a basis for case selection. This might provide additional arguments and insights as to what the more suitable approach to case selection should be.

There are also some limitations for internal validity stemming from the sampling. The main issue in this regard is the representativeness of the interviewed stakeholders, as they were selected as individuals to represent an organisation. Whilst the ideal scenario would be to have a large amount of interviewees for each of the many organisations studied, this is also a highly unrealistic ambition for a study of this scope. As its unit of analysis only included the key stakeholders at the network level and top management at the organisational level, it thus was not taking into account the (possibly different) picture at various levels within the organisations. However, having chosen for an in-depth study based on interviews rather than a survey approach (which would not have been able to address the exploratory purposes at the core of this dissertation), the selection of one key informant for each of the various organisations in both cases was deemed to be one of the best strategies available for several reasons. First, key individuals such as organisational managers are the central actors when it comes to making decisions on behalf of the organisation (and thus their perspective 
is the most influential for adoption and thus the most important to measure). Second, such key decision-makers in the organisation typically are in a more informed position to report on the organisation-wide perspectives (whereas operational staff usually has a more limited overview due to their position). Finally, this approach to use accounts given by key informants as organisational representatives is not new and has been used in the past in several studies in information systems research (cf. Bala \& Venkatesh, 2007; Chau \& Tam, 1997).

Nevertheless, future research might be able to come to a more accurate picture of an organisation as a whole, by using other techniques to also include the perspectives of other levels within organisations. For instance, future work might try for instance to also interview street-level bureaucrats at the operational level, or to use surveys in each organisation in order to validate whether the picture given by a key stakeholder accurately represents the organisation as a whole.

A related point concerns the nature of inferences from interpretive research. Interpretive research does not allow to draw the kind of conclusions on causality that quantitative approaches might allow by deriving effect sizes from measuring concrete values of explanatory and dependent variables. Instead, the comparative advantage of interpretive research lies in its richness of detail, making it more suitable for exploratory research questions like those of this dissertation. Unlike quantitative approaches, an interpretive analysis allowed us to identify which factors stakeholders perceive as relevant determinants for their adoption behaviour, and to provide in-depth accounts of the possible causal mechanisms and processes at work.

In addition, there is a risk of respondent bias concerning both the interpretive and quantitative analysis, in particular the risk that individual interviewee statements are not more than an opinion or speculation by a single individual. In fact, in some instances they might have been just that. However, this makes them no less valuable as data since the research objective here was to identify the range of possible perceptions of the influence of certain factors. As such, individual interpretations are relevant "informed insights", even if they are just an individual insight or interpretation shared by one person. In addition, these statements are not originating from random individuals, but from key figures who were carefully selected to be the most informed about their organisations' adoption intentions. Moreover, since the interviewed stakeholders were key figures in making adoption decisions on behalf of their organisation, this does make their statements highly relevant, precisely because they reflect the individual perspective of these influential individuals. Nevertheless, future replication of the study in other contexts will help to increase the range of perspectives on adoption surveyed, as it will interview different stakeholders in different contexts.

A limitation specifically concerning the interpretive analysis is the risk of researcher bias. There is a potential for interpretive bias since in the qualitative analysis process, each researcher might differ in the way of assigning specific codes to individual units of data. However, whilst individual researcher interpretations have in the past also been presented as a particular strength of qualitative research, several safeguards were used to reduce the potential negative effects of such bias. For reasons of validity and reliability, steps were 
taken to ensure a consistency of the coding and analysis done by the individual researcher: first, each code included a detailed definition in order to ensure it was applied in a consistent manner. Secondly, using the atlas.ti software package for qualitative data analysis helped to ensure a consistent data analysis. Third, key policy documents were consulted to triangulate the findings from the interview analysis, and care was taken in the analysis to include and discuss any discrepancies in the evidence. An additional means to minimise the potential influence of researcher bias on the theoretical model can be a replication of the study by other researchers. Moreover, future studies might consider using researcher triangulation by conducting the study, and in particular the coding, as a team of multiple researchers.

There are also some limitations specifically regarding the content analysis of the interview data. One key limitation is that since the content analysis only counted the instances of each topic (or code), it did not capture what exactly was being said in each instance. Hence, in principle the same code could have included quotations with very different perspectives, such as both positive and negative statements on a given code, say Organisational Efforts. Therefore, all inferences drawn from the content analysis can be treated as indicative conclusions only. A second limitation related to the content analysis is that for several of the comparative analyses in Chapters 4 and 5 across cases or across stakeholder levels, the amount of quotations for a particular code was too low to allow certainty in statements about the "significance" of the identified differences. Therefore, these findings thus were interpreted with caution and cannot be seen as more than indicative clues about possible or likely patterns. Still, they provide useful indications for further analysis. Future research should therefore also include large- $\mathrm{N}$ samples that allow stronger conclusions on the specific patterns identified by this dissertation. In addition, follow-up research in the future should check with interviewed stakeholders whether they would attach a similar weight or relevance to the individual determinants as suggested by the content analysis. Finally, the limitation of respondent bias discussed earlier needs to be mentioned again here, suggesting that future quantitative analyses also explore other data types in addition to interview data.

\subsection{Recommendations for Future Work}

There are at least three ways in which this dissertation provides a basis for future research: first, as a follow-up to address the limitations discussed in the previous section; and second, by opening up new research questions; and third, because it provided frameworks that can help to (re-)address both old and new research questions. This section gives some recommendations for future work that can draw upon this dissertation.

First, whilst the case study approach allowed some empirical validation of the proposed theoretical framework, future studies should investigate whether the listed determinants can be validated in other contexts by investigating other cases as well, in particular in other policy sectors and countries. This dissertation already showed that there are significant differences between sectors in the relevance of individual determinants, and it is possible that other sectors will yield additional determinants that were not of relevance in the sectors studied in this dissertation. It is conceivable that organisations in policy sectors that are by their nature closely linked to technological innovation, such as for instance energy policy or industrial policy might consider additional, or different factors for IOP standards adoption 
decisions. In addition, the proposed relevance of determinants should be validated by means of survey research with larger samples. Such research designs could for instance target a range of organisations - either all partners in the same Government Information Network or from various networks - and implement a survey based on the presented theoretical framework across a larger number of staff in each of these organisations.

Second, since the presented theoretical framework only provided a "catalogue" of determinants, future work should measure their actual effects. The presented framework can provide a useful basis for this work. Qualitative research could help to identify the precise causal pathways through which they operate. This would necessitate asking targeted questions about the individual determinants, and using analytical techniques like process tracing to document and identify the precise nature of these causal relationships. Quantitative research with large samples, as described above, could investigate the (relative) strengths of these causal relationships. Both types of research should be conducted in diverse contexts, as elaborated above.

Third, whilst this dissertation identified which impact areas are priorities and require special attention by IOP governance, the range of concrete policy instruments and tools to address them should be identified, including studying their effects. This was partly done in Chapter 6, but future work could provide more detailed analyses of such questions, for instance by selecting and comparing specific policy instruments by means of impact analyses. In the same vein, future research should also try to identify appropriate monitoring approaches and instruments to detect non-compliance. For both purposes, it might be good to investigate and survey a wider range of Government Information Networks for such policy instruments than this dissertation has covered. It will also be worthwhile to investigate not only Government Information Networks, but also other collaborative public sector networks and investigate whether additional tools can be identified there and transferred to the context of IOP governance in Government Information Networks.

Fourth, more insights are also needed about the interaction of the actors involved in IOP standards adoption. Whilst the analysis showed that IOP standards adoption is an interplay of a range of actors, future research should analyse the nature and processes of this interaction in more detail. One specific area for such research would be to investigate the interdependencies of actors in the adoption process and to examine whether, and how, they might change over time. Social network analysis can be a useful research strategy for this line of research, for instance by showing which actors interact with which other actors more or less at specific points in the process.

Fifth, future work should provide more detailed insights into the adoption process: it should validate the suggested phases, see whether a more fine-grained distinction between the different phases can be identified, and also investigate the transition between those phases. For instance, can we distinguish between various parts of the planning, implementation and operational phases described in this dissertation? Can we theorise what characterises their beginning and end, and what factors are triggering these transitions? Applying process analysis techniques to the qualitative study of Government Information Networks might be a suitable approach for future research addressing these questions. 
Finally, since the interpretive analysis only addressed the two most relevant variables for each dimension, future research should also provide such analyses of the collected data for the remainder of variables in the theoretical framework. The case studies have collected a large body of interview data which provides a vast pool for a similar in-depth analysis as has been conducted on the selected key variables.

\subsection{Final Thoughts}

Our world is becoming increasingly interconnected and characterised by complex information-intense "wicked" problems that are difficult to be solved by single actors such as individual nation-states, single government departments or public agencies alone. Increased collaboration across government entities and non-governmental stakeholders, as well as the ability to harness the potential of ICT in order to manage and utilise the unprecedented amounts of information and data in our societies, will continue to be key strategies to deal with this complexity. IOP, as this dissertation has argued, is an essential prerequisite for such collaborative governance, but one that is difficult to achieve. Having a good understanding of what drives organisations in Government Information Networks to adopt and comply with IOP standards, and how this can be effectively governed, therefore is an essential requirement for dealing with these governance challenges.

This dissertation offered a number of findings that contribute to a better theoretical understanding of IOP standards adoption and IOP governance in Government Information Networks, and provided a number of policy-relevant recommendations how IOP in such networks should be governed. It identified and addressed significant gaps in existing research in this area, and identified a number of misconceptions and misguided emphases both in existing research and policy practice. Its central contributions cover three main areas.

First, it contributed to a better conceptualisation of IOP standards adoption in Government Information Networks, showing that a holistic perspective across the dimensions of technological, semantic and organisational IOP is necessary and that the frequent focus on technological IOP is misaligned with reality. The dissertation also pointed at the lack of process perspectives on standards adoption, and provided several findings to open the "black box" of this process, by identifying key phases as well as a typology of the relevant actors involved.

Second, this dissertation developed and empirically validated a theoretical model on the determinants of IOP standards adoption in Government Information Networks, thus contributing a previously missing integration of the disparate existing theory on this topic, as well as providing the basis for future measurement instruments. Moreover, the research presented in this dissertation determined the relative relevance of the identified determinants for the different groups of stakeholders in Government Information Networks, thus identifying the key areas for IOP governance. In particular, the findings highlighted the necessity for a context-sensitive approach to IOP governance, especially with regard to the complexity of a given network. 
Third, the dissertation therefore provided relevant recommendations as to how the degree of network governance centralisation should be chosen in dependence on a network's complexity. To this end, it developed a framework for assessing and designing IOP governance centralisation and network complexity. It then provided several theoretical propositions that support previous theoretical arguments that higher network complexity requires more centralised IOP governance. And finally, it gave a number of evidence-based recommendations on how IOP governance can best be designed in order to match a network's degree of complexity.

In conclusion, this dissertation did not only provide a number of theoretical and practiceoriented conclusions that addressed previous gaps in theory and practice, it also provided the ground for future research on this topic. However, the dissertation also highlighted that in practice, stakeholders still seem far from having a solid understanding of IOP governance. Considering this in view of the continuing trend towards connected forms of eGovernance, IOP governance promises to provide a challenging agenda for the foreseeable future, for practice and research alike. 
ADDITIONAL ANNEXES 


\section{Annex C. Full References for Determinants Identified in Chapter 2}

\begin{tabular}{|c|c|}
\hline $\begin{array}{l}\text { Decision-Making } \\
\text { Centralisation }^{\Delta 1}\end{array}$ & $\begin{array}{l}\text { (cf. Ansell \& Gash, 2007; Bekkers, 2007; Bryson et al., 2006; Clarke, } \\
\text { Elliman, \& Lehaney, 2000; Crosby \& Bryson, 2010; Dawes \& Eglene, } \\
\text { 2008; Fountain, 2001; Gulati \& Singh, 1998; Kumar \& van Dissel, } \\
\text { 1996; Lee \& Kim, 2007; Provan \& Kenis, 2008; Span et al., 2012; } \\
\text { Weitzel et al., 2006) }\end{array}$ \\
\hline $\begin{array}{l}\text { Stakeholder } \\
\text { Involvement }\end{array}$ & $\begin{array}{l}\text { (Bekkers, 2007; Bryson et al., 2006; Nelson \& Shaw, 2005; Oliver, } \\
\text { 1990; Teo et al., 2003; Yang \& Maxwell, 2011) }\end{array}$ \\
\hline Coercion $^{\Delta 3}$ & $\begin{array}{l}\text { (Bala \& Venkatesh, 2007; Brass et al., 2004; Dawes, 1996; Dawes \& } \\
\text { Eglene, 2008; DiMaggio \& Powell, 1983; Fountain, 2007; Kamal, } \\
\text { 2006; Moore \& Benbasat, 1991; Nelson \& Svara, 2011; Rogers, 2003; } \\
\text { Schermerhorn, 1975; Teo et al., 2003; Van de Ven \& Walker, 1984) }\end{array}$ \\
\hline $\begin{array}{l}\text { Tracking } \\
\text { Systems }{ }^{\Delta 4}\end{array}$ & $\begin{array}{l}\text { (Bryson et al., 2006; Bryson et al., 2009; Crosby \& Bryson, 2010; } \\
\text { Fountain, 2007; Hellman, 2010; Kamal et al., 2011; Soares \& Amaral, } \\
\text { 2011; Yang \& Maxwell, 2011) }\end{array}$ \\
\hline $\begin{array}{l}\text { Leadership and } \\
\text { Support }{ }^{\Delta 5}\end{array}$ & $\begin{array}{l}\text { (cf. Agranoff \& McGuire, 1998, 1999, 2001; Ansell \& Gash, 2007; } \\
\text { Brown et al., 1998; Bryson et al., 2006; Bryson et al., 2009; Crosby \& } \\
\text { Bryson, 2010; Daley, 2008; dos Santos \& Reinhard, 2012; Emerson et } \\
\text { al., 2011; Kamal et al., 2011; Kickert \& Koppenjan, 1997; } \\
\text { Schermerhorn, 1975; Scholl \& Klischewski, 2007; Soares \& Amaral, } \\
\text { 2011; Tambouris et al., 2007; Yang \& Maxwell, 2011) }\end{array}$ \\
\hline Funding $^{\Delta 6}$ & $\begin{array}{l}\text { (Damanpour \& Schneider, 2006; Fountain, 2007; Gil-Garcia et al., } \\
\text { 2007; Kamal, 2006; Kamal et al., 2011; Lee \& Kim, 2007; Nelson \& } \\
\text { Svara, 2011; Williams et al., 2009) }\end{array}$ \\
\hline $\begin{array}{l}\text { Knowledge- } \\
\text { Building } \\
\text { Activities }^{\Delta 7}\end{array}$ & $\begin{array}{l}\text { (Dawes \& Eglene, 2008; Nelson \& Svara, 2011; Tambouris et al., } \\
\text { 2007; West \& Berman, 1997) }\end{array}$ \\
\hline $\operatorname{Plan}^{\Delta 8}$ & $\begin{array}{l}\text { (Bryson et al., 2006; Crosby \& Bryson, 2010; Ebbers \& van Dijk, 2007; } \\
\text { Kamal et al., 2011; Nelson \& Svara, 2011; West \& Berman, 1997) }\end{array}$ \\
\hline $\begin{array}{l}\text { Knowledge } \\
\text { Dissemination }^{\Delta 9}\end{array}$ & $\begin{array}{l}\text { (Andersen et al., 2010; Fountain, 2007; Gil-Garcia et al., 2007; } \\
\text { Hellman, 2010; Soares \& Amaral, 2011) }\end{array}$ \\
\hline $\begin{array}{l}\text { Community } \\
\text { Size }^{\Delta 10}\end{array}$ & $\begin{array}{l}\text { (Bingham, } 1976 \text {; Jun \& Weare, 2010; Kamal, 2006; Nelson \& Svara, } \\
\text { 2011) }\end{array}$ \\
\hline $\begin{array}{l}\text { Policy and } \\
\text { Institutions }{ }^{\Delta 11}\end{array}$ & $\begin{array}{l}\text { (cf. Ansell \& Gash, 2007; Emerson et al., 2011; Fountain, 2001; } \\
\text { Fountain, 2007; Kamal, 2006; Luna-Reyes et al., 2007; Tolbert et al., } \\
\text { 2008) }\end{array}$ \\
\hline
\end{tabular}




\begin{tabular}{|c|c|}
\hline $\begin{array}{l}\text { EGOV and IOP } \\
\text { Policy }\end{array}$ & $\begin{array}{l}\text { (Hellman, 2010; Soares \& Amaral, 2011; Tambouris et al., 2007; Yang } \\
\text { \& Maxwell, 2011) }\end{array}$ \\
\hline $\begin{array}{l}\text { Legal } \\
\text { Framework } \\
\text { L13 }\end{array}$ & $\begin{array}{l}\text { (cf. Andersen et al., 2010; Brass et al., 2004; Dawes \& Eglene, 2008; } \\
\text { dos Santos \& Reinhard, 2012; Gil-Garcia et al., 2007; Scholl \& } \\
\text { Klischewski, 2007; Soares \& Amaral, 2011; Tambouris et al., 2007; } \\
\text { Zhu et al., 2006) }\end{array}$ \\
\hline $\begin{array}{l}\text { Privacy } \\
\text { Legislation } \Delta 14\end{array}$ & $\begin{array}{l}\text { (Hellman, 2010; Landsbergen \& Wolken, 2001; Soares \& Amaral, } \\
\text { 2011; Tambouris et al., 2007) }\end{array}$ \\
\hline $\begin{array}{l}\text { Ambiguous } \\
\text { Legislation }{ }^{\Delta 15}\end{array}$ & $\begin{array}{l}\text { (Hellman, 2010; Landsbergen \& Wolken, 2001; Soares \& Amaral, } \\
\text { 2011; Tambouris et al., 2007) }\end{array}$ \\
\hline $\begin{array}{l}\text { Budgetary } \\
\text { Framework } \Delta 16\end{array}$ & $\begin{array}{l}\text { (Damanpour \& Schneider, 2006; Fountain, 2001, 2007; Gil-Garcia et } \\
\text { al., 2007; Kamal, 2006; Kamal et al., 2011; Lee \& Kim, 2007; Nelson \& } \\
\text { Svara, 2011; Williams et al., 2009) }\end{array}$ \\
\hline $\begin{array}{l}\text { Structural } \\
\text { Complexity }{ }^{\Delta 17}\end{array}$ & $\begin{array}{l}\text { (dos Santos \& Reinhard, 2012; Provan \& Kenis, 2008; Scholl \& } \\
\text { Klischewski, 2007; Van de Ven, 1976) }\end{array}$ \\
\hline $\begin{array}{l}\text { Power Diversity } \\
\Delta 18\end{array}$ & $\begin{array}{l}\text { (Ansell, 2006; Ansell \& Gash, 2007; Bala \& Venkatesh, 2007; Benson, } \\
\text { 1975; Brass et al., 2004; Bryson et al., 2006; Crosby \& Bryson, 2010) }\end{array}$ \\
\hline Goal Diversity ${ }^{\Delta 19}$ & $\begin{array}{l}\text { (Agranoff \& McGuire, 2003; Bryson et al., 2006; Bryson et al., 2009; } \\
\text { Crosby \& Bryson, 2010; Daley, 2008; Dawes, 1996; Dawes \& Eglene, } \\
\text { 2008; dos Santos \& Reinhard, 2012; Emerson et al., 2011; Gil-Garcia } \\
\text { et al., 2007; Hellman, 2010; Hjern \& Porter, 1981; Kickert \& } \\
\text { Koppenjan, 1997; Klijn, 1997; Provan \& Kenis, 2008; Samuelson \& } \\
\text { Björk, 2010; Scholl \& Klischewski, 2007; Soares \& Amaral, 2011; } \\
\text { Yang \& Maxwell, 2011) }\end{array}$ \\
\hline $\begin{array}{l}\text { Operational } \\
\text { Diversity }{ }^{\Delta 20}\end{array}$ & $\begin{array}{l}\text { (Bekkers, 2007; Hellman, 2010; Yang \& Maxwell, 2011; Yang et al., } \\
\text { 2011) }\end{array}$ \\
\hline $\begin{array}{l}\text { Administrative } \\
\text { Boundaries } \Delta 21\end{array}$ & $\begin{array}{l}\text { (Bekkers, 2007; Dawes, 1996; dos Santos \& Reinhard, 2012; Lee \& } \\
\text { Kim, 2007; Scholl \& Klischewski, 2007; van Dijk, 2007; Yang \& } \\
\text { Maxwell, 2011; Yang et al., 2011) }\end{array}$ \\
\hline $\begin{array}{l}\text { Culture and Value } \\
\text { Diversity }{ }^{\Delta 22}\end{array}$ & $\begin{array}{l}\text { (Bekkers, 2007; Dawes \& Eglene, 2008; Hellman, 2010; Kumar \& van } \\
\text { Dissel, 1996; Samuelson \& Björk, 2010; Yang \& Maxwell, 2011) }\end{array}$ \\
\hline $\begin{array}{l}\text { Public-Private } \\
\operatorname{Mix}^{\Delta 23}\end{array}$ & $\begin{array}{l}\text { (McGuire, 2006; Soares \& Amaral, 2011; Tambouris et al., 2007; Yang } \\
\text { et al., 2011) }\end{array}$ \\
\hline $\begin{array}{l}\text { Task } \\
\text { Complexity }{ }^{\Delta 24}\end{array}$ & $\begin{array}{l}\text { (cf. Bryson et al., 2006; Crosby \& Bryson, 2010; dos Santos \& } \\
\text { Reinhard, 2012; Scholl \& Klischewski, 2007) }\end{array}$ \\
\hline Trust $\triangle 25$ & $\begin{array}{l}\text { (cf. Bekkers, 2009; Bryson et al., 2006; Daley, 2008; Emerson et al., } \\
\text { 2011; Kamal, 2006; Landsbergen \& Wolken, 2001; Oliver, 1990; } \\
\text { Provan \& Kenis, 2008; Soares \& Amaral, 2011; Yang \& Maxwell, } \\
\text { 2011) }\end{array}$ \\
\hline $\begin{array}{l}\text { Prior } \\
\text { Experiences } \Delta 26\end{array}$ & $\begin{array}{l}\text { (Ansell \& Gash, 2007; Crosby \& Bryson, 2010; Dawes \& Eglene, } \\
\text { 2008; Klijn \& Teisman, 1997) }\end{array}$ \\
\hline
\end{tabular}




\begin{tabular}{|c|c|}
\hline $\begin{array}{l}\text { Inter- } \\
\text { Organisational } \\
\text { Trust }^{\Delta 27}\end{array}$ & $\begin{array}{l}\text { (Brass et al., 2004; Gil-Garcia et al., 2007; Kamal, 2006; Provan \& } \\
\text { Kenis, 2008) }\end{array}$ \\
\hline Critical Mass ${ }^{\Delta 28}$ & $\begin{array}{l}\text { (Dahl \& Hanssen, 2006; Kamal et al., 2011; Moore \& Benbasat, 1991; } \\
\text { Nelson \& Svara, 2011; Tolbert et al., 2008) }\end{array}$ \\
\hline $\begin{array}{l}\text { Competitive } \\
\text { Forces } \triangle 29\end{array}$ & $\begin{array}{l}\text { (Crosby \& Bryson, 2010; Jun \& Weare, 2010; Kamal, 2006; Kamal et } \\
\text { al., 2011; Nelson \& Shaw, 2005) }\end{array}$ \\
\hline $\begin{array}{l}\text { Unilateral } \\
\text { Options }{ }^{\triangle 30}\end{array}$ & $\begin{array}{l}\text { (Ansell \& Gash, 2007; Bryson et al., 2006; Crosby \& Bryson, 2010; } \\
\text { Emerson et al., 2011; Kamal, 2006) }\end{array}$ \\
\hline $\begin{array}{l}\text { Financial } \\
\text { Resources } \triangle 31\end{array}$ & $\begin{array}{l}\text { (Dahl \& Hanssen, 2006; dos Santos \& Reinhard, 2012; Hellman, } \\
\text { 2010; Kamal, 2006; Nelson \& Svara, 2011; Scholl \& Klischewski, } \\
\text { 2007; Soares \& Amaral, 2011) }\end{array}$ \\
\hline ICT Capability $\triangle 32$ & $\begin{array}{l}\text { (cf. Gil-Garcia et al., 2007; Kamal, 2006; Kamal et al., 2011; } \\
\text { Samuelson \& Björk, 2010; Williams et al., 2009) }\end{array}$ \\
\hline $\begin{array}{l}\text { ICT } \\
\text { Infrastructure }^{\Delta 33}\end{array}$ & $\begin{array}{l}\text { (cf. Chwelos et al., 2001; Gil-Garcia et al., 2007; Kamal, 2006; Kamal } \\
\text { et al., 2011; Samuelson \& Björk, 2010; Williams et al., 2009) }\end{array}$ \\
\hline $\begin{array}{l}\text { Organisational } \\
\text { Structure } \triangle 34\end{array}$ & $\begin{array}{l}\text { (Dahl \& Hanssen, 2006; Kamal, 2006; Kamal et al., 2011; Nelson \& } \\
\text { Shaw, 2005) }\end{array}$ \\
\hline $\begin{array}{l}\text { ICT Know-How } \\
\triangle 35\end{array}$ & $\begin{array}{l}\text { (Gil-Garcia et al., 2007; Kamal, 2006; Kamal et al., 2011; Samuelson \& } \\
\text { Björk, 2010; Williams et al., 2009; Yang \& Maxwell, 2011) }\end{array}$ \\
\hline $\begin{array}{l}\text { Networking } \\
\text { Experience }^{\Delta 36}\end{array}$ & $\begin{array}{l}\text { (Brass et al., 2004; Daley, 2008; Gil-Garcia et al., 2007; Soares \& } \\
\text { Amaral, 2011) }\end{array}$ \\
\hline $\begin{array}{l}\text { Staff Motivation } \\
\triangle 37\end{array}$ & $\begin{array}{l}\text { (Dawes \& Eglene, 2008; Gil-Garcia et al., 2007; Hellman, 2010; } \\
\text { Kamal, 2006; Nelson \& Svara, 2011; Samuelson \& Björk, 2010; Soares } \\
\text { \& Amaral, 2011; Yang \& Maxwell, 2011) }\end{array}$ \\
\hline $\begin{array}{l}\text { Manager's } \\
\text { Background }^{\Delta 38}\end{array}$ & $\begin{array}{l}\text { (Damanpour \& Schneider, 2006; Dawes, 1996; Kearney et al., 2000; } \\
\text { Nelson \& Svara, 2011) }\end{array}$ \\
\hline $\begin{array}{l}\text { Manager's } \\
\text { Attitude to } \\
\text { Innovation } \\
\triangle 39\end{array}$ & $\begin{array}{l}\text { (Damanpour \& Schneider, 2006; Kamal, 2006; Kearney et al., 2000; } \\
\text { Nelson \& Svara, 2011) }\end{array}$ \\
\hline $\begin{array}{l}\text { Management } \\
\text { Practices } \Delta 40\end{array}$ & $\begin{array}{l}\text { (cf. Andersen et al., 2010; dos Santos \& Reinhard, 2012; Kamal, 2006; } \\
\text { Scholl \& Klischewski, 2007) }\end{array}$ \\
\hline $\begin{array}{l}\text { Top Management } \\
\text { Support } \Delta 41\end{array}$ & $\begin{array}{l}\text { (Bryson et al., 2006; Ebbers \& van Dijk, 2007; Gil-Garcia et al., 2007; } \\
\text { Kamal, 2006; Kamal et al., 2011; Kickert \& Koppenjan, 1997; Nelson } \\
\text { \& Shaw, 2005) }\end{array}$ \\
\hline $\begin{array}{l}\text { Decision-Making } \\
\text { Centralisation }^{\Delta 42}\end{array}$ & $\begin{array}{l}\text { (Gil-Garcia et al., 2007; Jun \& Weare, 2010; Kamal et al., 2011; Nelson } \\
\text { \& Svara, 2011; Whetten \& Leung, 1979) }\end{array}$ \\
\hline $\begin{array}{l}\text { Existing } \\
\text { Networks }^{\Delta 43}\end{array}$ & $\begin{array}{l}\text { (Brass et al., 2004; Bryson et al., 2006; Bryson et al., 2009; Crosby \& } \\
\text { Bryson, 2010; Emerson et al., 2011; van Dijk, 2007; Whetten \& Leung, } \\
\text { 1979) }\end{array}$ \\
\hline
\end{tabular}




\begin{tabular}{|c|c|}
\hline $\begin{array}{l}\text { IOP Standards } \\
\text { Characteristics } \Delta 44\end{array}$ & $\begin{array}{l}\text { (cf. Ahn, 2010; Akbulut, 2003; Chen, 2003; Mustonen-Ollila \& } \\
\text { Lyytinen, 2004; Raus et al., 2009; Veit et al., 2011) }\end{array}$ \\
\hline Trial & $\begin{array}{l}\text { (cf. Chen, 2003; Mustonen-Ollila \& Lyytinen, 2004; Raus et al., 2009; } \\
\text { Rogers, 2003) }\end{array}$ \\
\hline $\begin{array}{l}\text { Adoption Efforts } \\
\Delta 46\end{array}$ & $\begin{array}{l}\text { (cf. Bala \& Venkatesh, 2007; Kamal, 2006; Mohr, 1969; Moore \& } \\
\text { Benbasat, 1991; Rogers, 2003; Samuelson \& Björk, 2010) }\end{array}$ \\
\hline $\begin{array}{l}\text { Information } \\
\text { Infrastructure }^{\Delta 47}\end{array}$ & $\begin{array}{l}\text { (Andersen et al., 2010; Dawes \& Eglene, 2008; Gil-Garcia et al., 2007; } \\
\text { Kamal, 2006; Tambouris et al., 2007; Williams et al., 2009) }\end{array}$ \\
\hline $\begin{array}{l}\text { Organisational } \\
\text { Efforts }^{\Delta 48}\end{array}$ & $\begin{array}{l}\text { (cf. Bala \& Venkatesh, 2007; Kamal, 2006; Landsbergen \& Wolken, } \\
\text { 2001; Yang \& Maxwell, 2011; Zhu et al., 2006) }\end{array}$ \\
\hline $\begin{array}{l}\text { Legal Framework } \\
\text { (Efforts) }\end{array}$ & $\begin{array}{l}\text { (Andersen et al., 2010; Brass et al., 2004; Dawes \& Eglene, 2008; dos } \\
\text { Santos \& Reinhard, 2012; Gil-Garcia et al., 2007; Scholl \& } \\
\text { Klischewski, 2007; Soares \& Amaral, 2011; Tambouris et al., 2007; } \\
\text { Zhu et al., 2006) }\end{array}$ \\
\hline $\begin{array}{l}\text { Public } \\
\text { Procurement } \\
\text { Legislation } \triangle 50\end{array}$ & $\begin{array}{l}\text { (Hellman, 2010; Landsbergen \& Wolken, 2001; Soares \& Amaral, } \\
\text { 2011; Tambouris et al., 2007) }\end{array}$ \\
\hline $\begin{array}{l}\text { Ambiguous } \\
\text { Legislation } \Delta 51\end{array}$ & $\begin{array}{l}\text { (Hellman, 2010; Landsbergen \& Wolken, 2001; Soares \& Amaral, } \\
\text { 2011; Tambouris et al., 2007) }\end{array}$ \\
\hline Resource Costs ${ }^{\triangle 52}$ & $\begin{array}{l}\text { (cf. Dawes, 1996; Kamal et al., 2011; Weitzel et al., 2006; Zhu et al., } \\
\text { 2006) }\end{array}$ \\
\hline Quality $\triangle 53$ & $\begin{array}{l}\text { (Chen, 2010; Dawes, 1996; Gil-Garcia et al., 2007; Kubicek et al., } \\
\text { 2011; Tseng et al., 2008) }\end{array}$ \\
\hline Efficiency $\triangle 54$ & $\begin{array}{l}\text { (cf. Jun \& Weare, 2010; Kubicek et al., 2011; Landsbergen \& Wolken, } \\
\text { 2001; Oliver, 1990; Samuelson \& Björk, 2010; Tseng et al., 2008) }\end{array}$ \\
\hline $\begin{array}{l}\text { Operations Cost } \\
\Delta 55\end{array}$ & $\begin{array}{l}\text { (Gil-Garcia et al., 2007; Kubicek et al., 2011; Samuelson \& Björk, } \\
\text { 2010; Weitzel et al., 2006; Zhu et al., 2006) }\end{array}$ \\
\hline $\begin{array}{l}\text { Data } \\
\text { Management } \triangle 56\end{array}$ & $\begin{array}{l}\text { (cf. Dawes, 1996; Gil-Garcia et al., 2007; Kubicek et al., 2011; } \\
\text { Samuelson \& Björk, 2010; Tseng et al., 2008) }\end{array}$ \\
\hline Data Quality ${ }^{\Delta 57}$ & $\begin{array}{l}\text { (Dawes, 1996; Gil-Garcia et al., 2007; Kamal et al., 2011; Kubicek et } \\
\text { al., 2011; Samuelson \& Björk, 2010; Weitzel et al., 2006) }\end{array}$ \\
\hline Coordination ${ }^{\Delta 58}$ & $\begin{array}{l}\text { (cf. Bala \& Venkatesh, 2007; Dawes, 1996; Gil-Garcia et al., 2007; Zhu } \\
\text { et al., 2006) }\end{array}$ \\
\hline Power $\triangle 59$ & $\begin{array}{l}\text { (Crosby \& Bryson, 2010; Jun \& Weare, 2010; Kamal, 2006; Kamal et } \\
\text { al., 2011; Nelson \& Shaw, 2005; Yang \& Maxwell, 2011) }\end{array}$ \\
\hline $\begin{array}{l}\text { External } \\
\text { Autonomy } \\
\triangle 60\end{array}$ & $\begin{array}{l}\text { (Gil-Garcia et al., 2007; Oliver, 1990; Schermerhorn, 1975; Soares \& } \\
\text { Amaral, 2011; Yang \& Maxwell, 2011) }\end{array}$ \\
\hline Image $^{\Delta 61}$ & $\begin{array}{l}\text { (cf. DiMaggio \& Powell, 1983; Moore \& } \text { Benbasat, 1991; } \\
\text { Schermerhorn, 1975; Teo et al., 2003) }\end{array}$ \\
\hline
\end{tabular}




\section{Annex D. IOP Standards in the Case Studies}

In this annex, the most relevant IOP standards from the IOP architectures of the two case studies are described. ${ }^{153}$

\section{D1. Technological IOP standards}

\section{D1.1. Technological IOP standards in DKD}

A fundamental set of technological specifications relates to the connectivity with the closed networks that DKD utilises for exchange of information. One of these networks is SUWINET, and data transmission in this network is based on a number of specified transmission standards (specifically, Ethernet and TCP/IP). For the municipalities, connectivity to SUWINET is facilitated through their connection to GEMNET (the municipalities' network). An important requirement here is the specification of a minimum bandwidth that connecting municipalities need to comply with.

Another key standard related to message exchange is the SUWI transaction standard. This is centred around an XML standard that was developed for the SUWI domain, called SUWIML (see Section A2.1.3 on semantic IOP standards for details). The message exchange is managed through webservices: these webservice scripts run continuously on the receiving application (e.g. of a GSD), looking for incoming data requests, and make sure that these requests are answered with messages that contain the correct data. The technological standards for the webservices are SOAP, as well as WSDL (Webservice Definition Language), and WSRP (Webservices for Remote Portlets) for the correct addressing.

It is noteworthy here that such standards have specific versions that need to be adhered to. One example for this is that the UWV WERKbedrijf organisation was handling an out-dated WSRP version, which was not capable of including certain data in the messages (Q21:12). For the municipalities, a lot of this versioning concerns the adapter of their internal systems. For instance, this includes the need to adhere to the opening of specific ports for communication with the DKD broker. Many municipalities were at some point running behind with this versioning, preventing proper data exchange.

Technological performance standards are specified in a Service Level Agreement (SLA). This SLA has been developed based on the SLA that BKWI had in the past already introduced in the SUWI domain, and is subject to bilateral contractual agreements between BKWI and partner organisations: this includes performance requirements such as a $24 / 7$ availability of webservices for data requests, and the requirement to comply with a standardised response time of 15 seconds to data requests.

\footnotetext{
${ }^{153}$ It should be noted that this description does not make any claim to be exhaustive - since an IOP architecture includes all IOP standards of a network, including very small technical details and minute processes, the following discussion limits itself to those IOP standards that were mentioned by the interviewees, and thus can be assumed to be of relevance to their organisation's adoption intention.
} 
Finally, DKD also prescribes a standardised data presentation layer, which specifies for instance items such as the amount of context information that the web interface for clients ("Klantbeeld") will allow to present for specific data.

\section{D1.2. Technological IOP standards in Studielink}

In terms of technical architecture, Studielink is based on the SOAP architecture. (The more general architecture follows the ROSA ${ }^{154}$ model, which is the Dutch national reference architecture for the education sector.)

More specifically, technical standards regulate the data transmission in Studielink. Whereas previously, data in the sector was mainly transmitted batch-wise by means of text files, Studielink instead relies on a live data exchange via XML messages. This is facilitated by "adapters": a "specific adapter" that handles transport and integration of the messages to the SIS (taking care of any translation that might be necessary), and a "generic adapter" which handles the communication towards the Studielink broker, including a verification of message content (see Figure 3.5). As the institutional context and legislation are continuously changing, the "specific adapter" of the SIS continuously needs to be updated in line with these legislative developments, and in line with the Studielink "generic adapter". This includes compliance with Studielink's XSD standard, which is the standard used for specifying the data fields in the XML messages.

Like in DKD, there also is an SLA that specifies specific performance standards in the Studielink network. For instance, the SLA specifies the requirement for synchrony of data processing, and a 24/7 availability of the data (i.e. round-the-clock openness of the systems).

\section{D2. Semantic IOP standards}

\section{D2.1. Semantic IOP standards in DKD}

The key semantic standard of DKD is the SUWI data registry $\left(\mathrm{SGR}^{155}\right)$. The primary function of the SGR is to specify all data definitions that are handled in the exchange via DKD. For instance, this concerns the meaning of data items, which traditionally can have many different meanings across various organisations (such as for instance "income" is defined in some organisations" systems as "gross income" and in others as "net income"). In order to ensure consistency of data definitions across the SUWI domain, the SGR has been built around the definitions handled in BUS, a dictionary that described the data packages that were traditionally provided by the municipalities to the Dutch Central Statistical Agency (CBS156). Being formalised as an addendum to the SUWI law, the SGR has a legally binding status. It is subject to a fixed release schedule that prescribes at least one, and up to four,

\footnotetext{
${ }^{154}$ Referentie Onderwijs Sector Architectuur (ROSA) is a reference architecture that is derived from the Dutch Government Reference Architecture NORA (Nederlandse Overheids Referentie Architectuur). NORA and its derived reference architectures provide principles, descriptions, definitions and standards for the design and implementation of the Dutch public sector information infrastructure. NORA has been established as an official norm for the government in 2009 by the cabinet.

${ }^{155}$ SUWI Gegevens Register.

${ }^{156}$ Centraal Bureau voor de Statistiek.
} 
updates per year, in which new definitions and changes to existing definitions can be specified.

A core element of the SGR is formed by the specifications of the SUWI-ML standard, which is used for the XML messages exchange in the DKD network. As such, it for instance defines the format of the data package that the GSDs share about their clients with the DKD broker (called "GSD personenbericht"). As part of SGR, SUWI-ML is updated along with the SGR releases.

\section{D2.2. Semantic IOP standards in Studielink}

In Studielink, semantics are also regulated by means of an XML dialect that is a specification based on the international IMS-LIP standard in combination with the Dutch STUF standard that is used by the municipalities (for instance for exchange of GBA data). This implies that there are standardised reference tables that include a prescribed set of data fields (including their definitions), such as for instance codes for denoting previous educational degrees. These data fields and definitions form the standard that needs to be implemented in the organisations' SIS (or in the "specific adapter") in order to enable message exchange.

\section{D3. Organisational IOP standards}

\section{D3.1. Organisational IOP standards in DKD}

In terms of process standards, a key standard in DKD is the "reversed intake" of clients, which standardises the data registration process in the front offices. This standardises components of this process, such as for instance how many variables the GSDs may ask from new applicants, and it also standardises the sequence of steps in the data registration process (for instance, registered data from a client consultation is supposed to be entered into the system immediately, rather than at a later point at the convenience of the case manager). It also prescribes that the intake becomes a one-time event, in contrast to the situation before when it was repeated every eight months.

Another set of key process standards in DKD relates to data security and privacy. These are specified in the "Norm Framework" 157 and "Accountability Guideline"158. They standardise ICT management, by prescribing standardised practices concerning for instance data management and monitoring (such as fixed processes with regard to the organisation of data management, data processing, and specific requirements for archiving and logging). They also specify a privacy and security standard that for instance requires steps such as setting up and maintaining authorisation levels for access to DKD data, nominating a security officer in the organisation, and developing a security plan document. Both the Norm Framework and Accountability Guideline are published as part of the SUWI law, but have a differing coverage across the DKD network (for instance, the Accountability Guideline is not mandatory for the GSDs).

\footnotetext{
${ }^{157}$ Normenkader.

${ }^{158}$ Verantwoordigingsrichtlijn.
} 
Another set of organisational standards relates to service processes. These are specified in the SLA which is signed bilaterally among partners, and updated once per year. There is also a standardised process regarding change management and release scheduling, which prescribes a fixed release schedule with a standardised timing for implementing changes to organisation-internal systems. Finally, DKD also specifies standardisation in terms of organisational structure, for instance by setting requirements for setting up specific organisational components such as a front-desk.

\section{D3.2. Organisational IOP standards in Studielink}

Just like in DKD, a key process standardisation in Studielink concerns the intake process: here, the information registration is strictly standardised by specifying a fixed set of data fields that need to be registered during the intake, as well as a prescribed sequence in which incoming messages have to be handled in the enrolment administration. The Studielink intake process also builds on standardised organisation functions. For instance, the sequence of steps in the intake process has been standardised by Studielink, so that for instance certain data fields cannot be "left empty" any more until later, but need to be filled before proceeding to another step. Another example of process standardisation is that parts of the intake process that previously were under the discretion of the higher education institutions is now taken over by the Studielink application. Interviewees from the institutions also mentioned that their previously idiosyncratic processes in the intake that allowed for personal contact with students, have now largely been replaced by a uniform, digital interaction. Another example is the standardisation of information supply processes: whereas organisations previously were free to request original documents from the students (e.g. diplomas of previous degrees), this information provision is now fed automatically into the institutions' SIS from a central source (DUO).

Related to the standardisation of the intake process is data quality standardisation, in that Studielink specifies minimum quality requirements (in terms of auditing) for the data sources. In addition, it prescribes continuous data monitoring due to the continuous inflow of student registration data (unlike in the pre-Studielink situation, where the data was only checked at the moment of a data batch import).

Finally, Studielink also sets standards for the communication between institutions and students. For one, a prescribed timing of communication towards the student is imposed through the electronic exchange: for instance, where institutions previously were free to reply to a student's registration once the new academic year came closer (which could have been months after the registration), Studielink now requires an immediate response from the admissions office. Furthermore, through Studielink the role distribution between the institutions and students became standardised: for instance, students have now become responsible for their re-enrolment, whereas previously some institutions had preferred to take that step for them. The re-enrolment process has also been standardised into a continuous live-feed, instead of what formerly had been a batch-wise exchange. The standardisation of institution-student communication goes even further, to the point of standardised design of the 'look and feel' of communication with (prospective) students: for instance, where previously a master's programme could request specific information by 
including specific fields in the registration form, this is now not possible in the standardised forms of Studielink. Another example is the usage of standard messages in the communication through Studielink, which for instance means that applicants for mid-career master programmes are by default addressed in the more informal tone chosen for Studielink messages. 


\section{Annex E. Attributes Description for Adoption Efforts and Results Constructs}

The following sections provide additional detail from the case studies on the variables' attributes that are listed in Annex A. It primarily aims to give illustrative examples from the cases for the interested reader, in order to explain and contextualise the findings reported in the chapter. It should be noted that the amount of detail and examples provided below differs across the variables, since these attributes were discussed in varying depth by the respondents (which is in part also related to the different amounts of quotations for the variables). Hence, where less (or no) description is given in the sections below, this indicates that this attribute was mentioned, but not discussed in depth.

\section{E1. Internal-Operations Results}

\section{E1.1. Efficiency: Operations Cost}

\section{E1.1.1. Financial Cost}

In Studielink for example, estimations of the impact of IOP in the network amount to saving around $50 \%$ of student enrolment costs, from previously 45 Euro per student to less than half of that (Q24:36). Similarly, interviewees report that data management has become cheaper as a result of the DKD (Q14:8). One central factor appears to be the potential to incur savings due to economies of scale that can be reaped through IOP:

\footnotetext{
Secondly, there is the argument that I think it is stupid that 55 institutions invest in 16 different student information systems. [...] In the moment that you in any case do not have to invest in 16 different systems any more but only in one, then the costs are going down. Also for the institutions. (Q36:11)
}

\section{E1.1.2. Time Cost}

As IOP standards adoption does away with many manual control activities of paper documents, this leads to a reduced need for monitoring activities. In Studielink for example, estimates are that now only $20 \%$ of diplomas need to be checked in paper (Q24:33). With costs of about 10 Euro for requesting a diploma and an annual student inflow of about 600,000 in the whole country, this amounts to roughly 4.8 million Euros in terms of financial cost reductions (Q24:33).

The opposite is also possible: for instance, the reduction of registration burdens for prospective students resulting from Studielink can also come at higher cost for the organisations, because students have less inhibition to register at multiple universities before making a final decision, thus causing excess work for those universities where they eventually cancel their registration (Q30:17). 


\section{E1.1.3. Human Resource Cost}

Higher education institutions in Studielink reported that they saved about $50 \%$ in personnel in student administration (Q29:7), and an interviewee from a municipality estimated that due to DKD, they save approximately two fulltime positions (Q15:9).

\section{E1.1.4. Material and Hardware Cost}

Moving from paper-based to electronic information exchange was reported to generate substantial cost savings, for instance with regard to mailings and archiving:

Another important benefit is that we don't have the all the paper traffic [any more]. The whole process is digitalised. [...] There was an entire circus; you don't want to know how many bags of mail arrived at a Hogeschool Utrecht, or other large institutions. So this has been dramatically reduced. And it has become much more efficient, cheaper. Because all the paper handling, and all the archiving of it... (Q26:19)

\section{E1.1.5. Opportunity Costs from Non-Adoption}

Without standards adoption, organisations can incur substantial conversion costs, especially once a significant part of their domain has switched to exchange via the network's IOP architecture (Q7:35).

\section{E1.2. Efficiency: Usability}

\section{E1.2.1. Availability of Client Data}

The following quote from DKD is illustrative in this regard:

For the case manager internally, it is an improvement, because of doing it that way, $40 \%$ of his job is already done in advance. (Q15:3)

This is also the case in Studielink: when registering students that are switching from another university (a process that before Studielink was a work-intensive procedure), now the data on these students is already available automatically (Q31:12).

\section{E1.2.2. Process Complexity}

One attribute of this is that processes can become unnecessary, either because they are taken over by other organisations, for instance because they have already done the recording of client data (Q19:10), or because they are taken over by automation:

\footnotetext{
You also have all kinds of benefits in the area of systems [...]. So, where before the front desk staff needed to memorise all kinds of decision rules, and needed to make decisions themselves based on the data that they inquired, this can be automated [...] Instead of having the front desk staff request all the data, having them interpret it, having them calculate and contemplate it, the system is doing this for you. [...] Of course this is a great application that you can have based on this sort of data. (Q21:13)
}

In DKD for instance, by means of the interoperable linking of data, a previously complicated procedure based on filling paper forms has been entirely replaced by a simple search for a client's BSN (Q3:20). As a result of such process simplification, for instance in DKD case entire departments became obsolete: 
We have examples where an entire department has been abolished, because of the fact that, well, the paper stream wasn't there any more, and everything went via the electronic stream. And that's of course a benefit for the data suppliers. (Q21:14)

\title{
E1.2.3. Interface Complexity
}

As a result of IOP standards adoption in DKD for instance, several data streams can now be accessed from the same interface - so that by accessing a client's BSN, several processes related to that person can be initiated from within one and the same application, rather than having a different paper-based exchange with another partner organisation for each process (Q4:21).

\section{E1.2.4. Archiving Complexity}

Before Studielink for example, paper evidence needed to be requested, assessed, and archived by universities for 10 years (Q36:11):

\begin{abstract}
The data on previous education doesn't have to be filled in by the student any more, but it can be directly received from DUO. The administrative burden reduction is considerable: if you have to check these things yourself manually, you have to request it yourself from the student, who has to submit this information, then you have to manually verify it, you have to keep the paper records for 10 years, etc. If you do this digitally you don't have to do any of that. (Q24:14)
\end{abstract}

\section{E1.3. Data Management: Data Quality}

\section{E1.3.1. Data Quality Requirements}

In Studielink for example, there are specifications of minimum data quality requirements, including requirements for external auditing for specific data sources:

\begin{abstract}
But this trust is also enhanced, because there are a number of minimum requirements that organisations have to fulfil. DUO for example is externally audited in order to see that their information sources are legitimate, mandated and integer. Next to this, Studielink is also externally audited, to check that the data input it receives is put out correctly and not manipulated. (Q24:32)
\end{abstract}

\section{E1.3.2. Data Quality Awareness}

For instance, in the DKD case an interviewee mentioned that as a result of adopting IOP standards, there is increased awareness in the partner organisations for the importance of data quality across the network, which in turn results in improved consideration for data quality:

That means that the feeling of data quality in terms of correctness of the data in the systems, that this plays a stronger role. And part of that is, [...] that we realise more that we together form a chain. (Q15:9)

\section{E1.3.3. Data Reliability}

In DKD for example, some partner organisations are providing data corroboration for other organisations, and thus provide "free" data consistency checks: 
You get a sort of free external quality control in case your data are not correct. For example the UWV issues benefits of about 14 billion a year. Even if a tiny percentage of these benefits is issued based on incorrect data, you can be really happy if others point you to the wrong data. (Q4:22)

The live-link of data in DKD for instance allows that data is automatically checked for authenticity (Q3:20). Interviewees from the DKD case also reported that the adoption of the CBS BUS data definition standard across the network enhanced information consistency (Q17:14). Consistency of data was also reported to be improved because adoption of IOP standards reduces the possibility for faulty data entry. For instance, the live link of organisation-internal applications with the basic data registry prevents faulty data entry because it allows for automatic verifications, i.e. data authenticity is validated because it comes directly from the data source (Q3:20). In addition, there are fewer opportunities for mistakes in the data registration to begin with, because due to electronically pre-filled forms, there simply is less manual data registration during the intake process (Q6:13).

\section{E1.3.4. Data Timeliness}

For instance, the fact that there is a live link that feeds data to partner organisations functions also as a pressure to case managers to enter client data more on time than they needed to previously (Q30:31). However, interviewees also stated that the clients themselves can possibly have more current information than the agencies: if someone for instance becomes unemployed, then this will not immediately be registered in the basic registry on employment ${ }^{159}$ (Q1:30). Another example is that data can be out-dated when a supplying organisation has a backlog of updating its internal data, so that requesting their data will only yield old information (Q26:7).

\section{E1.3.5. Data Quality Dependency}

For instance in DKD, respondents mentioned that it can even cause legal liabilities for datasupplying organisations if their (up-to-date) data is coupled with out-dated data from another organisation and thus results in misleading information (Q8:22). Whilst data coupling provides a potential for increased information quality, the coupling of (potentially) faulty data creates ripple effects, i.e. if a data source supplies its faulty data to the network, every other organisation will be relying on the same faulty data (Q10:12).

\section{E1.4. Data Management: Data Security}

\section{E1.4.1. Data Abuse}

Security standards serve to protect data security and prevent abuse. An example is the Accountability Guideline in DKD that is supposed to guarantee that the principles of mandated competence and of proportionality are strengthened in the SUWI domain (Q6:3), for instance by specifying a requirement for strict assignment of authorisation levels with differential access rights to DKD information, depending on employees' functions. However, interviewees reported that in many municipalities, access rights are not strictly

\footnotetext{
${ }^{159}$ Basisregistratie Dienstverbanden.
} 
assigned or updated, for example in cases where employees leave the organisation (Q6:3). As a result, cross-referencing of data can not only be advantageous, but also can have a "bigbrother effect" (Q10:25).

\title{
E1.4.2. Control Loss
}

As a result of the data exchange, some responsibilities actually become delegated to other actors and their correct implementation thus becomes uncontrollable for the data owner, so that their own data potentially "lands on the street" (Q14:13). This is all the more troubling for data owners, because Dutch privacy legislation (WBP ${ }^{160}$ ) makes the data owner responsible for what others to with their data (Q17:25).

\section{E1.5. Effectiveness: Service Quality}

\section{E1.5.1. Administrative Burden for Clients}

One instance of such burden reduction is described by this interviewee with regard to the DKD intake:

\begin{abstract}
Imagine a GSD: earlier a client turned up at your desk, and asked for unemployment benefits. You had to have him fill in a form of more than 20 pages, asking him all sort of things like whether he owned a car, and had to request evidence for all that. Enormous forms. People had to come there with bags full of evidence papers, sometimes around 150 different evidence papers. All this then had to be controlled for authenticity, and then finally the person got their benefit. And now with the DKD this is all not necessary any more. They only ask that person for his BSN, put it in Inkijk, and you get all the data. (Q3:20)
\end{abstract}

A related issue mentioned by the interviewees is that services can be provided much faster, as there is less time lost for repeatedly asking the client for the same data (Q10:2).

\section{E1.5.2. Integrated Services}

For instance, in DKD pre-filled forms make it possible that clients are served directly by the one department which they are dealing with, rather than having to go around to have the various partial processes handled by different agencies individually (Q10:16). As the respondents further indicated, the understanding, and navigation of the services offered becomes also easier for clients as a result of the network-wide unified service model and client interface:

\footnotetext{
With Studielink, the idea is that for the students, it is one standard process that they are facing when interacting with Studielink. It would be confusing for them if this would be different for each institution. So you have to have process standardisation to have the system running smoothly, and to give clarity to the clients. (Q24:35)
}

\section{E1.5.3. Targeting of Services}

Interviewees indicated that for instance in DKD, as a result of improved services, it is possible that clients feel taken more seriously:

\footnotetext{
${ }^{160}$ Wet Bescherming Persoonsgegevens.
} 
If you as a person are approached with the right questions, then you feel taken more seriously. Because if every time he has to repeat 'my name is [says name] and I'm 29 years old' and so on, then he also thinks 'are you from Mars?' It doesn't make any sense. (Q9:16)

\title{
E1.6. Effectiveness: Responsiveness
}

\section{E1.6.1. Speed of Reaction}

For instance, in DKD the combination of data from multiple organisations is valued as providing a rich knowledge base that allows immediate and targeted answering of specific questions:

\footnotetext{
That means that for example the case manager in principle can pre-check data, and as a result, can more effectively approach the conversation with the client, and really knows the actual data and knows that he doesn't need to ask for them again. (Q15:9)
}

Services can also be provided more quickly, with less waiting time, which was previously for instance caused by mail delays: in Studielink for example, the enrolment process was stretched over a much longer time period due to all the paper forms that had to be mailed back and forth between students and institutions:

\begin{abstract}
The old mail-based process took on average six weeks. The entire enrolment process is characterised strongly by all kinds of strict deadlines [...]. And if you're then depending on a lot of mail delays, that is really problematic. (Q28:12)
\end{abstract}

\section{E1.6.2. Proactive Action}

An example of this is that in DKD, processes previously were started only after they were triggered by a certain life event and the client had filed a request based on this. As a result of the DKD, the necessary actions are now carried out, without needing to be prompted by a client requesting a certain service:

You are increasingly moving towards that as a municipality, you are approaching service delivery from the view of the data that are available to you. We know what we can do proactively, sometimes you can provide services without that there was a request from the client. (Q10:26)

\section{E1.6.3. Early Contact}

In Studielink for instance, it is seen as allowing universities to attract interested, but still undecided students:

\footnotetext{
Positively, Studielink offered the possibility, because it's based on messages, to communicate with the students in a much earlier phase. So, via Studielink, a student would say 'hey I'm interested, maybe I will come to study at your institution'. And through Studielink you could immediately communicate with the student, so in this way you could pull them already towards you. (Q26:4)
}

As another respondent confirms, the old situation was a cause for dissatisfaction on the side of the students, as they would send their forms to the institution but got a reply only several weeks later (Q26:17). 


\title{
E1.7. Internal Autonomy
}

\section{E1.7.1. Internal Control}

Interviewees mentioned that they fear implications with regard to their wish to keep control over their own work (Q14:25), including their own contacts with clients (Q31:9). They have for instance shared experiences that the resulting loss of flexibility paralyses the steering of an organisation, for instance by preventing corrective manoeuvres:

\begin{abstract}
You need to have autonomy and steering possibilities, otherwise you cannot collaborate. You can only collaborate if you can move with each other in your everyday tasks. If you are on your bike, you can bike in a pretty straight line. But try to ride on your bike inside of the tram rails, then you crash because you cannot correct anything any more. (Q19:23)
\end{abstract}

\section{E1.7.2. Idiosyncratic Approaches}

Organisations fear that they lose influence to correct mistakes once they agree with an IOP standard designed with other partners in mind ("not-invented-here-syndrome") (Q1:6). For instance, standardisation of processes for student intake in Studielink is seen as limiting the freedom to choose a specific sequence of work steps (Q30:5). Also in DKD, interviewees mention that their own data registration procedure becomes bound to process timing that is designed with the network-wide requirements in mind. Such alignment of internal processes with the network timing has implications all the way down to the operational level: for instance, whereas in the past, GSD case workers could enter the data which they had registered in a client intake at a later point, they now are required to enter it immediately (Q17:5). The same applies to a standardised timing of client interaction imposed by Studielink (Q24:19). An unintended outcome of this is that organisations feel as if the network's IOP standards can be a straightjacket to address their own problems in their own way, causing them to "stray" from compliance with the standard:

If you always only stay with the standard, then you never move ahead, then you won't go faster than the rest of the group. [...] So, an entrepreneurial and ambitious municipality will not wait until it has convinced 340 other municipalities that it has a good plan - it thinks 'This is a good plan, and I will simply do it'. (Q19:19)

\section{E1.7.3. Internal Change Management}

For instance in DKD, organisation-internal changes to aspects connected to the DKD need to be registered with the network administration according to a rigid change management protocol that is designed with the entire network in mind. Previously internally "owned" processes thus become subject to network-wide agreements and consultation procedures. The requirement to go through collective impact analysis procedures with the network means that the flexibility in making short-notice changes to internal systems is thus effectively lost. A good illustration is the following example from DKD: when the UWV WERKbedrijf organisation decided to implement some changes to its "Digital Insurance Message" (DVB ${ }^{161}$ ) which includes labour-market reintegration data for its clients, it had omitted the requirement to file this as a change request with the DKD's Central Registry for

${ }^{161}$ Digitaal Verzekeringsbericht. 
Chain Changes $\left(\mathrm{CMK}^{162}\right)$ and as a result, the electronic supply of a substantial part of the DVB data to the GSDs did not work any more (Q11:5). Whilst the standardised change management is thus essential for functioning information exchange in the network, this requirement is also perceived as a strong limitation by those organisations that need to implement internal changes:

\footnotetext{
If you try to connect this within a network, than you get a situation where something that you previously have been responsible for only by yourself, has to comply with all kinds of standards and agreements. [...] The normal way is that you file each change within the SUWI domain with the network bodies that exist for this - whilst we don't want this in this case at all, because it is our own digital insurance message. (Q11:4)
}

Examples of similar implications for internal change management include restrictions on adaptations to the layout of the organisation's communication with clients (Q30:3), or that an organisation is not allowed to decide by itself which (additional) data it is exchanging along the data specified in network-wide agreements (Q11:5).

In both DKD and Studielink cases, there is a fixed release schedule that determines when change requests can be filed centrally and when they are implemented in an official release (Q2:12). Interviewees report that this can lead to very long implementation trajectories (Q23:14). This interdependency in change management creates problems by holding back organisations where internal system changes may be ready for implementation, or maintenance may be needed (Q29:13), but where these changes cannot be implemented due to their dependence on the network-wide consultation procedures and change management schedule (Q19:16). This may then also conflict with organisation-internal change schedules, in that internal projects might not be ready on time as a result of the dependence on the network-wide schedule (Q11:13).

\section{E1.7.4. External Relations Management}

This can for instance mean that limitations are imposed on agreements previously made with other partners: for instance, such a problem can occur if organisations are to comply with (new) standards where they previously already had made connections to other organisations based on different standards (Q20:10). Another example are limitations in organisations' communication with their clients, for instance in Studielink where due to process standards, universities are not free any more to choose the time for replying to applying students, but due to the live data link are bound to an immediate reaction:

\footnotetext{
So you have to assign an account very quickly to the student, and assign a student number, whilst before you only did this for the 20 students who selected the faculty: 'This one I want to do'. [...] And that all happened [before] at the moment where it suited you. Now it's the other way round: everything comes in centrally and live. (Q30:13)
}

\section{E1.7.5. Future Autonomy}

Once that an organisation becomes a partner in the network, it may be embarking on a 'slippery slope' and will have to continue making efforts along the future development of the network and its IOP architecture (Q14:21).

${ }^{162}$ Centraal Meldpunt Ketenwijzigingen. 


\title{
E1.7.6. Understanding for Autonomy Implications
}

Interviewees showed for instance a realisation that with a large and diverse network, IOP cannot be achieved if everyone wants autonomy. Several interviewees made it clear that (similar to other adoption efforts), autonomy loss is weighed against the expected benefits (Q24:19). This is also illustrated in the following quote:

Every municipality gives up some autonomy, but together they will have a more efficient work process. That's a trade-off consideration which they make. (Q19:24)

Nevertheless, as another respondent states, this understanding has clear limits:

\begin{abstract}
I always say 'the standards will be there as long as they suit you'. So, complying with the standard is always very easy as long as it suits you. [...] And when it is easier not to comply with it, then you simply don't do it. And well, this is also human. If you get the possibility, you take it. (Q16:16)
\end{abstract}

\section{E1.8. Resource Acquisition: Information Acquisition}

\section{E1.8.1. Automated Information Provision}

This happens for instance in DKD through automatic pre-filling of forms (Q4:24): since all data for a client can be linked by the citizen-unique ID number (BSN), standard forms are pre-filled by typing in that BSN, and the case worker only needs to check whether all the data is correct. Another example is the "Signalen" feature in DKD, which automatically informs organisations about changes to certain data fields for a client in the databases of partner organisations (Q1:18).

\section{E1.8.2. Timeliness of Information}

For instance, the possibility for receiving the right information in (real-)time allows them to take pre-emptive measures if necessary. In DKD for example, this helps an organisation to take pre-emptive measures against youth unemployment:

\footnotetext{
Since we can see from what educational background students come to the labour market, in our mission for a comprehensive approach against youth [unemployment] we can anticipate and have a good overview who is leaving school and who we need to have in our offices. In that sense it is very useful information (Q12:17).
}

\section{E1.8.3. Completeness of Information}

In Studielink for example, this was mentioned as a benefit that allows universities to contact potential students early on and in a targeted manner (Q26:4). An important contribution to this is the possibility for acquiring information that was previously inaccessible, or difficult to access. For instance, partners' databases can be able to provide certain information that the case managers cannot even get from the client themselves (for example if clients try to conceal it, or are unaware of it themselves) (Q9:2). Finally, interviewees mentioned an improved ability to acquire more information from within their own organisation: for instance, in one municipality the DKD was mentioned as providing a tool to access data from another database within the same organisation, which was previously difficult to access because the two databases were not interoperable (Q19:6). 


\title{
E1.8.4. Management Information
}

Interviewees mentioned that acquiring a wide range of digital information allows for better internal analyses. In Studielink for example, an interviewee reported how the electronic data records of where their registered students come from allows the institution to analyse their own recruitment strategies (Q30:7). Another interviewee reports that the ability for deeper analyses of the newly available data enables them to give more targeted advice to their clients:

\begin{abstract}
Due to all this chain integration, because we look at the source databases like GBA and also previous education degree records, we eventually get the basis that we want for institutional research. [...] So we can [...] advise and guide participants in a much more targeted way as a result of the data that you can get from these databases. [...] So you can much better target your offer to the characteristics of the population. And give much more targeted advice. And eventually, reach much more added value as an institution. And that's where according to me, the gains are ultimately. (Q34:9)
\end{abstract}

\section{E1.9. Resource Acquisition: Financial Resources Acquisition}

\section{E1.9.1. Financial Risk}

For instance, due to the specific provisions of the WWB, being able to leverage the DKD to get people out of unemployment means for the GSDs that they actually run a lower financial risk (Q22:12).

\section{E1.9.2. Speed of Resource Acquisition}

For instance, one of the positive implications of Studielink mentioned in the interviews is that revenue can be collected much quicker through digital means:

There was also a lot of financial gains, for example once Studielink introduced a sort of digital payment, the institutions using this had their tuition fees collected much quicker. They had suddenly already in the first tuition collection round in September brought in more than 2 million [Euro] more than in the previous year. (Q24:6)

\section{E1.9.3. Safeguard Status Quo}

It is for instance possible that previously guaranteed benefits are not available any more unless new processes are complied with. In Studielink for example, institutions receive a large share of their funding based on the students that are enrolled there. And as a result of Studielink's linkage with the basic registry on residence (GBA), an institution will now not get this funding for any student that is not registered in a Dutch municipality (Q31:7).

\section{E1.9.4. Return-on-Investment Distribution}

An example from the Studielink case is that while all participating institutions share the costs for Studielink, the return on that investment is lower for some institutions in the network than for others. For instance those universities with a large share of international students will not profit to the same degree from Studielink as those with a predominantly 
Dutch student body, as they cannot use the digital enrolment procedure of Studielink for foreign students (Q27:11).

\title{
E1.9.5. Return-on-Investment Timeliness
}

The return on investment in the adoption of IOP standards can also come with considerable delay. In Studielink for example, interviewees stated that the costs at the beginning of the project are very high, whereas the returns on those investments often only materialise at a much later point in time (Q26:22).

\section{E1.9.6. Potential Revenue Loss}

Adoption can also create a potential for actually losing revenue, when data exchange in the network is not functioning properly. The following is an illustration of this attribute from the Studielink case:

\begin{abstract}
DUO sends [to the institutions] the information which of these students are financed, so that they know how much financing they get for these students. That's a new development that also is going to run through Studielink. That's a sensitive issue for institutions, because it concerns money. Because even if data for only one student is not properly exchanged, then they will forego a substantial amount of money. (Q24:38)
\end{abstract}

\section{E1.10. Coordination: Reporting}

\section{E1.10.1. Range of Data}

Interviewees mention the information held by other organisations as the key source of getting access to a wider range of reporting data (Q31:7). Respondents state for instance that inter-organisational data-pooling gives them encompassing information on the sector, in contrast to organisation-based databases that are built from a narrower perspective:

\footnotetext{
Another goal was to get sector-information, management information on the sector: How is the sector doing? What are the developments in the sector? And to get this information independently from the government. In the past DUO had its information on enrolments and saw how the sector was developing, but it was always only from the perspective of DUO. [...] And Studielink gives this overview of all students. (Q24:62)
}

\section{E1.10.2. Management Information}

This is especially so because IOP gives the possibility for real-time reporting. For instance the "Signalen" Service in DKD is a service that automatically informs connected organisations when something in the data portfolio of a client changes. If for example in the RDW data, something changes for a particular BSN, this update is signalled to the "Signalen" service, and everyone who subscribed to it will receive a signal (Q1:18).

\section{E1.10.3. Organisation of Data}

For instance, respondents from the Studielink case mentioned that it allows for more centralisation of management information, thus making it more accessible:

One benefit is that you now have insight into all enrolments and thus also can centrally at the management level follow how many enrolments there are, for which programmes, which previous degrees people have, 
and how many were rejected. So, insight in enrolments and also in strategy is improved. Before, all of this really happened in the little kingdoms of the faculties. (Q30:18)

Another example from the Studielink case is its "dashboard" functionality, which gives an encompassing overview of the communication history with clients (Q31:10).

\title{
E1.11. Coordination: Uncertainty Reduction
}

\section{E1.11.1. Future-Proofing}

The interviewees see future-proofing as relevant both for future standards developments and in terms of expansion of organisations' network (Q8:11).

\section{E1.11.2. Fraud Detection}

In DKD for instance, the "Signalen" service provides a tool that has led to the reduction of fraud by identifying illegitimately received social benefits:

\begin{abstract}
Signalen is a service that informs a professional if something in the data of a client changes. If for example in the RDW data, something changes for a particular BSN, this update is signalled to the Signalen service, and everyone who subscribed to this service will receive a signal. And now we have piloted this service with five data items out of around 380 items that we identified as potentially eligible for this service. And this has led to some benefits being stopped because it turned out the beneficiary was actually not eligible any more. (Q1:18)
\end{abstract}

Another example is that for higher education institutions, Studielink provided an opportunity to safeguard themselves from fraud in the institutions themselves. In particular, respondents referred to the "HBO fraud crisis" that had taken place a few years earlier, where institutions had falsely enrolled non-existent students into their programmes to receive government funding $(\mathrm{Q} 34: 1)$.

\section{E2. External-Relations Results}

\section{E2.1. Political Effects: External Autonomy}

\section{E2.1.1. Delegation of Decision-Making}

This includes for instance a loss in the ability to choose organisational partners (Q1:13), so that they might have to work with partners that are not trusted or not desired (Q35:6). Similarly, respondents also mentioned a loss of autonomy in designing their organisation's relationships and interaction with their clients (Q31:11).

\section{E2.1.2. External Obligations}

This was for instance the case in DKD, when the DKD specifications on data display clashed with the obligations that UWV had towards the SZW Ministry about displaying DVB data (Q11:6). Another example is organisations' dependency on other partners for carrying out their own tasks: 
And many parties - in particular UWV was a problem, but also other municipalities - did not always supply the data. So if you have a business process and you request data, and in 10 per cent of all cases it doesn't work because one of the parties has not supplied their data, then you run great risks in your business processes (Q19:3)

\title{
E2.1.3. External Accountability
}

One example for this which interviewees mentioned is that their organisation's compliance with privacy laws becomes dependent on how their partners handle the exchanged data:

\begin{abstract}
Now, previously each organisation was responsible for this by itself. But now, with the WEU, data that was collected by one chain partner also is compulsory to be exchanged with other chain partners, and now the adherence to principles of competence and proportionality lies with the organisation that eventually carries out a task with the received data. (Q4:15)
\end{abstract}

\section{E2.2. Political Effects: Responsibility}

\section{E2.2.1. Responsibility for Own Data}

Even data supplying organisations that are not officially obliged to conform to any IOP standards, can effectively end up with more work as a result of participation in the network, for instance because they will still have to explain their semantics to other partners, or because they are contacted with more questions from clients:

\footnotetext{
You try to be ahead of certain things. Imagine that we would not give any explanation on the dataset, then you would afterwards have a lot of impact on your own organisation because you then would get a lot of questions from the receiving organisation over what the meaning is of certain information. And then your client contact centre would get more questions to deal with, in order to clarify afterwards what these data signify exactly. (Q8:5)
}

\section{E2.2.2. Responsibility for Data Use by Others}

Several interviewees mentioned a fear related to liability for the data exchange resulting from IOP, in that the data that the organisation is responsible for is being used by other organisations. Conversely, similar concerns were mentioned regarding their own use of data from other organisations in its own processes, which might be faulty and make them liable for basing wrong decisions on faulty data:

If the data sources and the information in them are not well aligned, then you can supply incorrect information without having much [control]. [...] In my opinion that is a demotivating factor if partners think about this (Q8:22)

\section{E2.2.3. New Responsibilities}

For example, organisations can be facing additional legal or contractual obligations for compliance (for instance as a result from adopting the SLA in DKD, which implies specific responsibilities such as the data being available 24/7, or the creation of a service desk) (Q13:13). Besides responsibilities for the organisation's own services, there are also shared responsibilities that can result from standards adoption: for instance, once a product like Studielink is in the air, collective responsibilities emerge in the sense that all partners are to 
some degree accountable for it, and it becomes very difficult for individual partners to simply step away from collaboration:

Both parties are then jointly responsible for the production process. If you are not in production then you can always run to each other and blame each other, because in that situation this works. If you are jointly responsible to keep the production upright, then this doesn't work any more, then you really have to collaborate (Q35:6)

\title{
E2.2.4. Conflicting Responsibilities
}

An illustration of this is the case of the DVB described earlier, whose data the UWV was not able to show any more via DKD, although it had earlier made clear legal obligations towards the Ministry of SZW to show this data to citizens (Q21:9).

\section{E2.3. Image: Results Demonstrability}

\section{E2.3.1. Output Legitimacy}

Respondents in DKD for instance reported that organisations emphasise their electronic service delivery resulting from IOP as a public image-booster for their organisation (Q21:15). In fact, as another interviewee asserted, this is being done even when the implementation is going much slower than claimed (Q10:3).

\section{E2.3.2. Bandwagoning}

Respondents stated that it can be an important motivation to be able to show that their organisation is at the spearhead of innovation in their sector - or at least, to be jumping the bandwagon of innovation in their domain (Q18:5).

\section{E2.3.3. Ownership}

For instance, in the situation of Studielink as a project that was initiated by the institutions themselves, interviewees stated that they could not blame anyone but themselves in case of lacking results, and that organisations feel jointly responsible:

\begin{abstract}
Of course there are many processes where information is being exchanged between government agencies and institutions. Now there are two parties responsible for a piece of infrastructure, and they might not agree on it. But both feel responsible for achieving a good end result. That makes the difference. (Q36:22)
\end{abstract}

\section{E2.4. Image: Accountability Image}

\section{E2.4.1. Information Management Transparency}

This attribute is seen as a contribution to general political goals of government:

\footnotetext{
I find that the DKD is based on a certain philosophy, which is part of the whole process in the Netherlands to get the government information management on a higher level, where [...] we have a transparent information management across all segments of the government. [...] And in the work and income domain, this is manifested concretely in the form of the DKD. (Q19:26)
} 


\section{E2.4.2. Data Quality Accountability}

For example, standards adoption is seen as leading to more accountability regarding data quality due to the mutual cross-checking and data corroboration enabled by IOP - however, this is not necessarily seen as making things easier.

DUO is handling the study financing, so there's a lot of money flowing. And if there are mistakes in this and a student isn't properly enrolled, well then DUO at a certain point steps in, done. Or they say 'we have given money to you, but according to the data you had already left when you received the money, so give it back'. So DUO is also designing the system in a way that they can see very well whether there is abuse of the study financing. And I think that's fine, but it also doesn't make things easier (Q27:15)

\section{E2.4.3. Protection from Flawed Processes}

For instance, IOP adoption was reported to prevent corrupted processes, because it enforces transparency through electronic recording of processes (Q34:1). In addition, because it produces more management information, it keeps departments in the organisation more accountable about their work, in various areas:

The fact that there now is a centralised system made the processes in the faculties a lot more visible at the centre. Suddenly, they realised 'wait a minute, you reject so and so many students, and if you reject them for programme X, why don't you send them to programme Y?' And this sort of things they didn't see before. [...] And this sort of thing, although no one admits it, this creates resistance. (Q30:7)

\section{E2.5. Image: Reach Expansion}

\section{E2.5.1. Clients Reach}

In Studielink for instance, an interviewee mentioned that participation in the network enabled his institution to reach more potential students early on:

I talked before about the portal function of Studielink. And that is that in fact, incoming students can communicate their interest for a number of institutions. [...] And one of the expected benefits is that you get more students, because your name is seen by more eyes than otherwise. So it's an expansion of the market, that is the assumption. (Q27:17)

Furthermore, interviewees in Studielink say that the communication with potential students has become more timely and dynamic, thus better satisfying client demands (Q26:17).

\section{E2.5.2. Partner Reach}

One attribute of this is that participation in the network is seen as a means to acquire more knowledge about the organisation's peers:

\footnotetext{
The SVB [has] to do with the municipalities on a number of issues and [wants to] streamline and intensify the collaboration with the municipalities. [...] And that's why it is important that the SVB has a good collaboration with the municipalities, and knows what happens there. But also a good infrastructure in order to share information and collaborate with each other. [...] And that's why I say the chain is important for us and we want to do more with it. And that's really future expectations. (Q14:18)
}

IOP standards adoption can also be seen as a way of safeguarding the organisation's reach in the future, for instance in terms of expanding the organisational network: 
As Kadaster, we want to be at the front. So if there are municipalities that need real estate information, then we certainly want to collaborate on this and gain experience. And the benefits then are really in the experience we gain by participating in this. So, in that sense, this is very much with the future in mind. (Q8:11)

\title{
E3. Return-on-Investment Results
}

\section{E3.1. Sow-Harvest Equality}

\section{E3.1.1. Intra-Organisational Sow-Harvest Equality}

For instance in DKD, one interviewee illustrated how within municipalities, the beneficiaries from DKD-related standardisation (e.g. case managers in the GSDs who now have access to a range of data on a client from other organisations) may be quite remote from those in that same municipality who have to make sure that their municipality supplies data to other DKD partners in a standardised way:

And the person who sits here, who needs to deal with the difficulties of supplying [the data], is not the same person who sits there and profits from receiving data. Those are two different people within the municipality. (Q7:21)

\section{E3.1.2. Inter-Organisational Sow-Harvest Equality}

An example for this from the DKD case is that there are large discrepancies between the appreciation of required efforts for standardisation and the results, because different organisations have rather diverse goals, for instance because they serve different target groups:

\begin{abstract}
Municipalities say they have to do much more than the UWV, since they do not only have to bring people back into the labour market but they also have to carry out policies like debt relief, schooling, housing for homeless persons - all that kind of policies. [...] And UWV says 'but that's not our target group. Our target group is the WW [unemployment policy] target group'. And that's only those people who generally are simply between jobs. So in this collaboration, you could see very clearly that UWV said 'Yes we want to collaborate, but only in the domain that we are concerned with'. (Q21:5)
\end{abstract}

\section{E3.1.3. Policy-Level Sow-Harvest Equality}

One example given here is that positions or decisions taken at the political level for all higher education institutions in the Netherlands are not necessarily in the interest of all of these institutions, in particular those who target a specific group of clients such as international students (Q30:25).

\section{E3.1.4. Cross-Sectoral Sow-Harvest Equality}

One interviewee in the Studielink case reported that the perceived imbalance of efforts and results for DUO with regard to this network is accepted because it is still considered to be a contribution to their own policy sector (higher education), and that this would be much less accepted if it concerned cross-sectoral sow-harvest inequality:

What you see is that the benefits are still generated within the same commissioning sector. So the Ministry of Education pays DUO as well as the higher education institutions. In other words, for the highest 
commissioning body, if you so want the 'owner' of the network, there is a remunerative business case. Otherwise it would indeed be altruism. And well, sorry, but we don't do that with tax money. (Q35:14)

\title{
E3.2. Timing
}

\section{E3.2.1. Inaccurate Estimates}

For example, stakeholders reported that at the beginning of the project, the actual timing of breaking even the investment costs in Studielink was projected to be much sooner than the eventual outcome:

\begin{abstract}
The original business case of Studielink had set the time of break-even for the investments at 5 years, I believe. So due to all the central verification, all the reductions in data entry, in short due to all the benefits, you would have earned back our project costs for your connection to Studielink. And we're not going to be there in 10 years' time. [...] But in the beginning all of this was presented as a very rosy picture and that's why we all went along with it (Q29:17)
\end{abstract}

\section{E3.2.2. Lengthy Negotiations}

One example of this is the complaint by stakeholders in the DKD case that its complex negotiation structure resulted in delayed results materialisation and lacking results demonstrability:

\begin{abstract}
For some things you'd really say 'it can't be that difficult to get this done within a few months', but it takes us really very long. Especially in our chain of consultation. It's quite recognised that eventually it's by getting things done, by achieving something, by pushing them through that we have a success factor in the network, showing that we can get something done. And it's recognised that next time we really have to keep in check the time which it takes us to get there. (Q12:18)
\end{abstract}

Another problem which is related to this is that with such long duration for achieving results on standardisation, the original political owners or initiators of a specific standard may have already discontinued to play a role:

\begin{abstract}
Since all those organisations have to first agree with each other [...] this takes very long, making it not very effective. [...] Because the downside of this long duration is that when solutions finally are implemented and become available, nobody recognises them any more - because in this political context, by that time a part of the political players that have defined what was needed have disappeared again. And then everyone has forgotten what was the idea to begin with. (Q10:19)
\end{abstract}

\section{E3.2.3. Delay Distribution}

Because there can be quite some diversity in organisations' development of the information infrastructure necessary for information exchange, a timely return on investment can mean quite an amplification of differences between organisations.

\footnotetext{
So, the starting point for the partners is never equal. So for the ones whom it suits, they have an advantage over those whom it doesn't suit as much. Well, and for everyone the fact applies that you first have to make some sacrifices before you can harvest the improvements. So you're asking the organisations and the people in them to make an investment that only provides its returns a few years down the road. (Q36:3)
}

Also within organisations, ROI can be more delayed for the operational level than for the management level in organisations, as explained by the following quote from the Studielink case: 
The lesson thus is that the message about the long-term interest in standards compliance, that is of interest mostly to the managers in the top of the organisation [...]. And you have to accept that lower in the organisation, there are people who have worked with heart and soul for developing or maintaining tailored solutions, that it will hurt them. (Q36:8)

\title{
E4. Network-Level Results
}

\section{E4.1. Network Effectiveness}

\section{E4.1.1. Network-Specific Effectiveness}

One interviewee in the Studielink case described this as a "positive business case for the network as a whole":

\begin{abstract}
But there you see something that you can observe in several networks, namely that you don't always have to ask the question if it benefits an individual partner in the network, but if it is a positive business case for the network as a whole. I could name a few examples where we had to invest spectacularly, and the benefits actually accrue to another partner in the network. (Q35:13)
\end{abstract}

\section{E4.1.2. General Effectiveness}

For example in the DKD case, one interviewee explained how the network-level results of the DKD network contribute to a much wider set of goals for more efficient and effective public-sector information management as a result of public-data exchange by means of standardisation:

\begin{abstract}
I think that DKD is based on a certain philosophy, which is a part of the entire process to improve public sector information management in the Netherlands. And the idea behind [this] is eventually that the majority of information exchange between a client in need of a service, and the government happens digitally. [...] And I think this is a good strategy. And it is implemented in the work and income network in the form of the DKD. (Q19:26)
\end{abstract}

\section{E4.2. Future Innovation}

\section{E4.2.1. Basis for Future Innovation}

In the case of Studielink for instance, one of the official objectives of Studielink is to serve as a platform for future innovation in the higher education sector. One example for this is given by an interviewee from the Studielink case, stating that "with this standardisation you gain the flexibility to adapt to other changes and specific situations" (Q24:35).

\section{E4.2.2. Obstacles for Future Innovation}

Contrasting the previous account, interviewees also mention that standardisation in fact can serve as a potential barrier to future innovation because it takes away the flexibility of organisations to innovate, as this interviewee from the DKD case states:

If you have so many organisations and all the systems they manage, that constantly have to be aligned with each other. [...] If you turn a screw here, then it doesn't fit there any more, and vice versa [...]. I can imagine that this also can lead to a sort of mutual paralysis, that you take the dynamics out of the network (Q19:15) 


\title{
E5. Adoption Efforts
}

\section{E5.1. Organisational Efforts: Process Efforts}

\section{E5.1.1. Change to Nature of Processes}

For instance, this can be a change of the information stream in the intake process due to the introduction of an automated system, thus causing a shift from paper work to more monitoring work:

And the information stream changed completely because of that. The institution simply gets information and is not busy any more with requesting all sorts of evidence pieces, since this is done already in the chain. [...] In place of designing and administering the registration process themselves, this is taken over by Studielink and [the institutions'] task now has shifted to control what they have received, whether it is correct. (Q24:7)

\section{E5.1.2. Alterations to Existing Processes}

The following quote gives a description of how processes in the client intake changed as a consequence from DKD:

\begin{abstract}
The situation with a request for the subsistence benefit is that we now always consult a client's data from DKD, via Suwinet Inkijk, before we invite them to come for a meeting. We get the information from there that is necessary, and based on this information in addition to the basic client data, we determine 'ok, I still need to get these and these evidence documents from you. [...]'. Before DKD, it was 'you ask for this benefit from us, and you have to bring paper documents for this entire shopping list, and we need to see paper evidence for it.' And that's what the DKD does now for us, and hence our business process has been adapted. (Q15:3)
\end{abstract}

The implementation of IOP standards can also mean that possibly, there even need to be changes to organisation-internal processes that work perfectly fine from the adopting organisation's point of view.

\footnotetext{
The complexity of such a process, of the development of such a project, of the development of a standard, is that you have to tell organisations that already have a business process which works: 'you have to change it, and everything will be better'. But what everyone knows, and certainly after Studielink we know this even better $[\ldots]$, is that you always have to go through this curve where after implementing the change, everyone first is worse off. It's not going better, but it's worse. And only after you got through this, then you have the chance that things go better than where you began. (Q36:2)
}

\section{E5.1.3. Changed Roles and Tasks}

An illustration is the shift from decentralised to more centralised bundling of work processes in Studielink, from the faculty-level to the central student registration (Q24:55). Another example is the re-assignment of roles in terms of provider-client role relations: for instance as a result of Studielink, students have become the responsible agent for their reenrolment, whereas before, this had been handled by the SIS (Q24:63).

\section{E5.1.4. Changed Process Sequence and Timing}

For instance, Studielink specified a standardised message handling sequence that conflicted with previous message sequences (Q24:20). There can also be changes to the timing of 
certain processes, for instance the requirement for immediate entry of intake data in $\mathrm{DKD}$, in order to safeguard that the data available for partners is up-to-date (Q17:5).

\section{E5.1.5. Changes to Communication}

One example of this is that more individualised communication is replaced by standardised templates (Q27:12). Another instance of communication changes is altered timing of communication towards clients: for example in Studielink, it is for instance not possible any more for institutions to determine flexibly when they want to contact students with specific communications (Q24:29), as the constant message inflow requires a continuous, rather than asynchronous batch-wise handling of enrolments (Q26:6).

\section{E5.1.6. Ripple Effects}

One form of ripple effects are side effects on other units within an organisation, i.e. more units are affected than just the one primarily concerned with the changed process (Q36:7). Another attribute are side-effects on other processes in the organisation: for instance, since standardised processes often do not take into account all organisations' idiosyncratic processes, the organisations that have different processes in place have to take remedial action ex-post in order to deal with the inconsistencies caused by the "imposed" standardised process. This can for instance be extra work that becomes necessary in order to rectify or follow-up to standardised messages that are sent automatically (Q32:7). Another example is the requirement of fixating other processes which are not immediately part of the standard: as a result of Studielink for instance, the list of an institutions' study programmes now needs to be "set in stone" one year before their start, and cannot be changed later on in the year any more (Q29:2).

\section{E5.1.7. Process Eradication}

This can concern (core) functions of the organisation, such as for instance the replacement of manual evidence-checking by automatic checking of evidence in both DKD and Studielink, or the eradication of manual steps in the collection of tuition fees in Studielink as a result of automated digital tuition collection (Q28:6).

\section{E5.1.8. New Processes}

Examples for this include new processes for data management (Q23:5), creating new helpdesk processes (Q23:9), or the addition of new processes related to changing from organisation-centric to client-centric work (Q24:25). Introducing such new processes can involve substantial design efforts for the new (or revised) processes, for instance how to integrate pre-filled forms into the work flow (Q15:8). 


\title{
E5.2. Organisational Efforts: Organisational Structure Efforts
}

\section{E5.2.1. Creation of Roles, Jobs, Units}

For instance, the Norm Framework in DKD required municipalities to specify precisely the roles of their employees with regard to assigning data access rights in the Inkijk application:

\footnotetext{
In Inkijk for example there are about 20 different authorisation levels, according to their role. This means that a municipality has to get its organisation structured accordingly. You have to go through the entire organisation, and check the staff's function in order to assign the correct authorisation level in the DKD. Authorisation remains a really complicated issue. (Q3:14)
}

The creation of new functions or jobs is another attribute of this. The same Norm Framework makes a specific requirement that municipalities create the function of a privacy officer, who is in charge of all the data security and privacy processes in the organisation and has to monitor that it is all working well (Q3:14). As another interviewee reports, DKD requirements for data management also imply that there has to be a data manager function set up in the organisation:

\footnotetext{
So the arrival of DKD required a good data management. [...] Well, in concrete terms this means that there has to be a man or woman that is taking care of creating, and maintaining, a data dictionary. (Q24:3)
}

Similarly, as a result of participation in the Government Information Network, new units in the organisations might have to be set up, such as for instance helpdesks that deal with client requests (Q23:9).

\section{E5.2.2. Eradication of Roles, Jobs, Units}

As a result of IOP standards adoption, there can thus also be a necessity to replace former staff with new staff that has the required skills related to inter-organisational information exchange, in particular staff that has combined organisational-technical expertise (Q26:26), as the following quote illustrates:

\begin{abstract}
And I think we also underestimated the impact of this on institutions. It means they have new functions, need different staff. Before Studielink you had many people that institutions hired from temp agencies, to type in the forms, compiling student files with evidence pieces, and that's now hardly the case any more. [...] And you need a different sort of people for this, people who are used to monitor, to see if a process isn't going completely as it should and possibly correct it manually. (Q24:8)
\end{abstract}

\section{E5.3. Technological Efforts}

\section{E5.3.1. New/Overhauled Technology}

With regard to the new technology, in DKD for instance there is the need to connect to the physical network used for data exchange in the SUWI domain, SUWINET - a link that some organisations did not yet have established (Q5:16). Connecting to such networks can come with additional effort requirements, such as for instance the need for some municipalities to increase the bandwidth for their connection to DKD via the GEMNET network (Q7:17). 
With regard to overhauling technology, there can for instance be a need to recode parts of the organisation-internal applications in order to support the new processes required by the project (Q24:24). For instance, there are standards about data presentation and layout that require a redesign of the presentation layer of the organisations' systems or messages, which was for instance the case with the UWV's DVB dataset (Q21:9). There can also be requirements for specific software supporting the data supply, such as the web services in DKD (Q7:11), where the updating of the transaction standard implies considerable effort for participating organisations (Q21:12). In cases where organisations use old legacy systems that cannot be connected to the network broker by means of such adapters, there can also be the need for more elaborate middleware, as for instance DUO needed to install in order to fully supply its data to the DKD (Q23:2). Similarly, building a "specific adapter" is a requirement for organisations whose SIS are not able to connect directly to the "generic adapter" that is provided by Studielink itself:

So Studielink delivers a certain message to the generic adapter KVA, and then from there it is the responsibility of the institution, which we name the specific adapter. This is very specific with regard to the SIS that lies behind this. So what the KVA does is that all the incoming messages are stored in a proper format, they are put in a queue and also it takes care of data protection. And the translation of this for the specific SIS is what the organisation has to do. (Q24:58)

\section{E5.3.2. Data Security Efforts}

An example for this would be the need for (re-)configuring an organisation's security infrastructure for external communication such as the need for adapting the organisation's firewall, each time when the adapters are renewed in DKD (Q19:2), or the creation of a safety copy of the system in order to prevent potential damage from the connection of internal databases to the network (Q17:3).

\section{E5.3.3. Data Transmission Efforts}

One example is the requirement to comply with standardised response time in DKD (Q3:17). Another example would be the change from asynchronous (file-based) exchange to a realtime link for data exchange, and the associated efforts such as activities to monitor the live message exchange:

\footnotetext{
There needed to come a live link, with a broker technology, so the live management of messages in two directions. Whereas the old technology with ISIS, the predecessor of SAP, still was [based on] simple input of text-files. [...] And that means, well since these are live messages, the UM had to get used to it. And SAP as well, of course. It also has to work without errors, so you have to monitor. During the entire week, someone has to monitor if there is anything going wrong. (Q30:14)
}

\section{E5.3.4. Testing and Maintenance Efforts}

For instance, with every new release of Studielink, the SIS are required to go through a recertification procedure that involves running functionality tests in the institutions that comprise about 40 test scenarios (Q25:14). Even after such testing, especially in the beginning, the (re-)building of the applications creates a lot of initial bugs that may require substantial repair efforts (Q26:16), such as service interruptions as a result from updates to the system (Q28:7). As one interviewee asserted, it can thus get more difficult to understand 
and maintain the own system as a result of integrating it with the Government Information Network (Q27:4).

\title{
E5.4. Semantic Efforts
}

\section{E5.4.1. Data Translation}

For example, in the SUWI domain, manifold definitions are used for "income" (Q8:12), for time and dates (Q9:13), or for working hours (Q11:14) :

\footnotetext{
At the level of 'data and messages there is the SGR, which defines in a hierarchy all data that we are using, and that means that when you exchange data from a municipal system with another party through the DKD, then you have to 'translate' your data to the joint language of the chain. (Q3:4)
}

This means that after it first has been checked whether definitions are coherent, organisations might consequently be required to make changes to their own definitions. This is further complicated by the fact that often, such definitions also change in the partners' databases or as a result of the inclusion of new partners into the network (Q2:4), so that this checking needs to be repeated on a continuous basis (Q11:14). Once such divergences have been identified, there needs to be a translation into a shared language defined by the network's semantic standards. Such translations can for instance imply that organisations need to make sure that the format of their messages conforms to the network's message standards. This for instance concerns the data mark-up translation for message exchange in the network, such as for instance in the DKD case the translation of organisation-specific XML formats into the network standards, SUWI-ML:

\begin{abstract}
All the network partners use their own XML dialect as a standard for communication among their own systems. So for instance UWV uses UWV-ML, and similarly there are XML dialects of the former CWI, of the SVB or the GSDs. [...] But in the moment that data items are exchanged in the chain, then the local XML dialects have to be transformed into SUWI-ML. And there you have an impact of course. (Q2:5)
\end{abstract}

\section{E5.4.2. Middleware}

Several interviewees reported that this is particularly difficult for organisations that operate in multiple domains and exchange data across different Government Information Networks that all use different standards:

\footnotetext{
The municipality is bigger than just the GSD. Within the municipal field the standard is by default not SUWIML, but STUF. [...] And that's the official method to exchange data within the municipal domain. And also all IT suppliers are acquainted with it, they use it for exchange. And SUWI-ML is very specific for the SUWI domain. But now there is the municipality, which sits both in the municipal domain, but in the SUWI domain as well. [...] And that in turn was a job for the IT suppliers to make it possible that everything that came from all these packages could also speak SUWI-ML. Well that was a larger impact, because you then shift from one data standard to another standard. [...] If there then is yet another sector that says you have to talk with us as well, and they in turn have their own standards, that's not very handy. (Q7:16)
}

\section{E5.4.3. Data Storage}

This is an issue for instance with regard to the need for re-designed databases that can handle the data exchange (Q7:11) and support the (new) data fields that are required by the 
semantic IOP standards (Q29:3), including the mapping of these fields across databases (Q27:10).

\title{
E5.4.4. Mutual Understanding
}

A thorough mutual understanding of the joint definitions, respective to own definitions, is perceived by stakeholders as a significant effort:

\begin{abstract}
In the SGR, terms and definitions are neatly specified, but still you realise that in consultations with network partners how much you are using your own terminology, your own frame [of reference], and how difficult it is and that it simply costs time every time to adjust it to each other. [...] [ You have to] realise that you are speaking different languages. And every time you have to take care to translate it and take the time for it. (Q14:28)
\end{abstract}

\section{E5.5. Legal Efforts}

\section{E5.5.1. Legal Compatibility Analysis}

For instance, interviewees in DKD mentioned a need to perform a legal compatibility analysis (Q11:6), in order to investigate (and if necessary, acquire) the legislative mandate for the organisation to exchange data in the network, as the following quote from DKD illustrates:

\begin{abstract}
But before that, there needs to be checked whether there is a legal mandate or legislation for legitimacy. Legitimacy means that you have to be able to show that your primary process fulfils a legal task that requires access to these data items, also with regard to proportionality. The data recipients have to be able to prove this to the data suppliers. (Q2:5)
\end{abstract}

\section{E5.5.2. Ambiguous Legislation}

An ambiguous legal framework can pose significant legal obstacles for organisations, for instance by making the legal compliance checks highly complex and time-intensive exercises:

\begin{abstract}
We asked, 'where do we need to look [for what we need to do to comply with the legal mandate]?'. But we were told that the SUWI law had to be checked again, and it was very complex. But no single legal advisor could tell us where we had to look. [...] but the entire process didn't work out. (Q9:5)
\end{abstract}

\section{E5.5.3. Privacy Legislation}

Stakeholders reported for instance that their organisation encountered difficulties to ensure privacy standard compliance within and beyond their own organisations:

Well the legal aspect is important. That is one of the things that weigh very heavily in the entire exchange. But above all the privacy protection, that has to be set up very well. And why is this especially important for exchange within a network? Because of course you have to take care for your own work that you handle privacy of your clients carefully. [...] But in one way or the other, this always requires a lot of attention, it is very important: how do I know that my data are also safe with others? And vice versa of course, that the data of others are safe with me? So, standardisation in this area is very important. (Q14:13) 


\title{
E5.6. Resource Costs: Infrastructure Costs
}

\section{E5.6.1. ICT Infrastructure Costs}

The upgrading and new development of new ICT is in many cases done by ICT vendors who, except in some cases, charge the organisations for their services:

\footnotetext{
The municipalities have to bear the costs of the applications. They are complex and really expensive systems. [...] So this all requires a substantial level of technology and infrastructure. And this costs a lot of money. So the data standard is primarily a question for the municipalities to get everything arranged well on application level. And this is for a large part done by the IT suppliers. (Q3:13)
}

This includes the costs for new hardware such as buying a connection to the physical network for data exchange (Q5:16), or upgrading bandwidth (Q7:17). Similarly, organisations incur costs for software. In DKD for instance, municipalities run systems that are provided by ICT vendors, and many updates of specific IOP standards (for instance of the SGR) require them to get an upgrade to their system from these vendors (Q6:14).

\section{E5.6.2. Testing and Maintenance Costs}

Testing new infrastructure can cost a lot of time and man-hours:

\begin{abstract}
And the entire continuous adjustment of Studielink with adapters, with testing, with all extra efforts that this implies, that causes a significant extra amount of costs, through which the time for your return in investment is simply a bit longer. (Q29:17)
\end{abstract}

One interviewee from the Studielink case reported for example that the testing of a new adapter takes at least a month of time (Q28:7). Another interviewee added that the (more advanced) ICT infrastructure needed for digital information exchange is also more complex, and therefore more costly in terms of getting technical support and maintenance from the ICT vendors (Q26:20).

\section{E5.6.3. Consultancy Costs}

Consultancy costs add another layer of costs, and interviewees mentioned for instance research and advice about required technical adaptation or technical feasibility assessments as examples for this cost category (Q13:10).

\section{E5.6.4. Human Resource Infrastructure Costs}

Such costs, as mentioned by the interviewees, can stem for instance from the fact that IOP adoption may require the hiring of new and better qualified staff, both operational and management staff:

\footnotetext{
The quality and capacity of your staff needs to be improved, which causes extra costs for schooling and salaries, because an employee who simply enters data is cheaper than someone who is controlling the data management. (Q29:17)
} 


\section{E5.7. Resource Costs: Training Costs}

\section{E5.7.1. Schooling}

For instance, in Studielink interviewees acknowledged that the new system requires new, and higher, skills from the staff in the organisation, so that schooling of staff becomes necessary (Q29:17). This can be done in-house, which implies lower costs than the typical alternative, which would be to outsource it (for instance to the ICT vendors) (Q23:12).

\section{E5.7.2. Salaries}

As the following quote from a Studielink interview shows, costs do not stop with training, but this also involves a more structural dimension since better-skilled staff will also imply higher long-term costs in terms of salaries:

The quality and capacity of your staff has to be improved, which is an extra drain on your budget for training and salary, because an employee who simply enters data into a system costs less than someone who is responsible for controlling your information management. (Q29:17) 


\section{Annex F. Interview Materials}

\section{F1. Interview Questions for Organisation-Level Interviewees}

[Questions were asked in Dutch. English translations are provided here behind each question]

\section{INTRODUCTIE}

1) Kunt u mij, ter introductie, kort uw rol in het netwerk beschrijven? [As an introduction, could you briefly describe your role in the network to me?]

\section{STANDAARDEN: BESCHRIJVING \& IMPACT}

2) Wat zijn de standaarden in het netwerk die een impact op uw organisatie hebben gehad m.b.t. organisatieverandering? [Which were the standards in the network that had an impact on your organisation with regard to organisational change?]

- Wat waren/zijn de inspanningen die uw organisatie verwacht van het adopteren/naleven van standaarden in het netwerk? [What were/are the efforts that your organisation expects from the adoption of/compliance with standards in the network?]

- Kunt u deze impact/inspanningen in enkele concrete voorbeelden beschrijven? [Could you describe these impacts/efforts in a few concrete examples?]

\section{STANDAARDEN: INVLOEDFACTOREN ADOPTIE}

3) Bij welke van deze standaards was/is er discussie of weerstand in uw organisatie m.b.t. adoptie/naleving? [For which of these standards was/is there a discussion or resistance in your organisation with regard to adoption/compliance?]

- Kunt u dit in concrete voorbeelden beschrijven? [Could you describe this in a few concrete examples?]

- Wat zijn volgens uw ervaring de factoren die verklaren waarom in deze gevallen de adoptie/naleving een discussiepunt was? [What, according to your experience, are the factors that explain why adoption/compliance was a point of discussion in these instances?]

- (Voor welke redenen) was het bij andere standaarden makkelijker? [Was it easier with other standards - and if so, for which reasons?]

4) Batenverwachting: Wat zijn de baten die in uw organisatie verwacht worden van het adopteren/naleven van de verschillende standaarden in het netwerk? [Benefit expectancy: what are the benefits that are expected in your organisation from adopting/complying with the various standards in the network?]

5) Ondersteunende omstandigheden: Welke organisatorische en technologische omstandigheden (in uw organisatie en op netwerkniveau) waren/zijn belangrijk om het adopteren/naleven van de verschillende standaarden in het netwerk door uw organisatie te faciliteren? [Facilitating conditions: Which organisational and technological circumstances - in your organisation and at network level - are/were important to facilitate the adoption of/compliance with the various standards in the network by your organisation?] 
6) Verwachtingen door anderen: Wat zijn de spelers in (en buiten) het netwerk die van uw organisatie verwachten dat de verschillende standaarden in het netwerk geadopteerd/nageleefd worden? [Expectations by others: What are the stakeholders in and outside of the network who expect from your organisation that the various standards in the network are adopted/complied with?]

- In hoeverre waren/zijn deze externe verwachtingen van belang voor uw organisatie (en zo ja, waarom?) [In how far are/were these external expectations of importance for your organisation - and if so, why?]

7) Netwerk complexiteit: In de documentatie die ik u heb gestuurd staat een beschrijving van netwerk complexiteit (aantal netwerkpartners en diversiteit). [Network complexity: The documentation that I have sent to you included a desciption of network complexity - the number and diversity of actors in the network]

- Zou u het netwerk als complex of niet complex beschrijven? [Would you describe the network as complex or non-complex?]

- Welke invloed heeft deze complexiteit op de adoptie/naleving van de verschillende standaarden in het netwerk door uw organisatie? [Which influence did this complexity have for the adoption of/compliance with the various standards in the network by your organisation?]

8) Andere invloedfactoren: Naast de factoren die we net besproken hebben, kunt u nog andere belangrijke factoren noemen die een invloed hebben op de adoptie/naleving van de verschillende standaarden in het netwerk door netwerkpartners? [Other influence factors: Next to the factors that we just talked about, could you also list additional relevant factors that have an influence on the adoption of/compliance with the various standards in the network by the network partners?]

\section{INTEROPERABILTY GOVERNANCE}

9) Governance centralisering: In de documentatie die ik u gestuurd heb staat een beschrijving wat met decentrale/centrale sturing op netwerkniveau bedoeld is (centrale brokerage/formalisering en dwang). [Governance centralisation: In the documentation which I sent to you, there is a description of what is meant by decentralised/centralised governance-central brokerage/formalisation and coercion]

- In een voor uw organisatie ideale situatie, hoe zou de sturing op standaarden in dit netwerk langs deze dimensies moeten uitzien om de adoptie en naleving van deze standaarden te bevorderen (uw aanbeveling, aangezien de factoren die we tot nu hebben besproken)? [In a situation that would be ideal for your organisation, how would the governance on standards in this network look along these dimensions in order to improve adoption and compliance with the standards - your recommendation, given the influence factors that we have talked about so far?]

- In hoeverre is de bestaande besturingsstructuur afwijkend van dit ideaalbeeld? [In how far does the existing governance structure diverge from this ideal picture?] 
10) M.b.t. het motiveren van uw organisatie voor adoptie en naleving van standaarden in het netwerk, wat waren/zijn de meest succesvolle aspecten van de bestaande besturingsstructuur, en wat waren de grootste drempels? [With regard to the motivation of your organisation to adopt/comply with the standards in the network, what are/were the most successful aspects of the existing governance structure, and what were the biggest barriers?]

\section{AFRONDING}

11) Zijn er nog andere aspecten die u belangrijk vind maar die in dit interview nog niet besproken werden? [Are there any other aspects that you find important and that were not covered yet in this interview?]

\section{F2. Interview Questions for Network-Level Interviewees}

[Questions were asked in Dutch. English translations are provided here behind each question]

\section{INTRODUCTIE}

1) Kunt u mij, ter introductie, kort uw rol in het netwerk beschrijven? [As an introduction, could you briefly describe your role in the network to me?]

\section{STANDAARDEN: INVLOEDFACTOREN ADOPTIE}

2) Bij welke standaards in het netwerk heeft $u$ verschillen geobserveerd in hoeverre ze door netwerkpartner organisaties geadopteerd en nageleefd werden? [For which standards in the network did you observe differences as to how they were adopted and complied with by partner organisations in the network?]

- Kunt u concrete voorbeeld geven hoe zich dergelijke niet-naleving manifesteerd?

[Could you give concrete examples of how such non-compliance manifested itself?]

- Wat zijn volgens uw ervaring de factoren die verklaren waarom in deze gevallen de adoptie/naleving een discussiepunt was? [What are, according to your experience, the factors that explain why adoption/compliance in these instances was a point of discussion?]

- (Voor welke redenen) was het bij andere standaarden makkelijker? [Was this easier with other standards - and if so, for which reasons?]

3) Batenverwachting: Wat zijn de baten die netwerkpartner organisaties verwachten van het adopteren/naleven van de verschillende standaarden in het netwerk? [Benefit expectancy: what are the benefits that are expected by organisations in the network from adopting/complying with the various standards in the network?]

4) Ondersteunende omstandigheden: Welke organisatorische en technologische omstandigheden (in de netwerkpartner organisaties en op netwerkniveau) waren/zijn belangrijk om het adopteren/naleven van de verschillende standaarden in het netwerk door netwerkpartner organisaties te faciliteren? [Facilitating conditions: Which organisational and technological circumstances - in your organisation and at network level-are/were important to facilitate the adoption of/compliance with the various standards in the network by organisations in the network?] 
5) Verwachtingen door anderen: Wat zijn de spelers in (en buiten) het netwerk die van netwerkpartner organisaties verwachten dat ze de verschillende standaarden in het netwerk adopteren/naleven? [Expectations by others: What are the stakeholders in and outside of the network who expect from partner organisations in the network that the various standards in the network are adopted/complied with?]

- In hoeverre waren/zijn deze externe verwachtingen van belang voor netwerkpartner organisaties (en zo ja, waarom?) [In how far are/were these external expectations of importance for partner organisations in the network - and if so, why?]

6) Netwerk complexiteit: In de documentatie die ik u heb gestuurd staat een beschrijving van netwerkcomplexiteit (aantal netwerkpartners en diversiteit). [Network complexity: The documentation that I have sent to you included a desciption of network complexity - the number and diversity of actors in the network]

- Zou u het netwerk als complex of niet complex beschrijven? [Would you describe the network as complex or non-complex?]

- Welke invloed heeft deze complexiteit op de adoptie/naleving van de verschillende standaarden in het project door netwerkpartner organisaties? [Which influence did this complexity have for the adoption of/compliance with the various standards in the network by the partner organisations in the network?]

8) Andere invloedfactoren: Naast de factoren die we net besproken hebben, kunt u nog andere belangrijke factoren nomen die een invloed hebben op de adoptie/naleving van de verschillende standaarden in het netwerk door netwerkpartners? [Other influence factors: Next to the factors that we just talked about, could you also list additional relevant factors that have an influence on the adoption o/compliance with the various standards in the project by the network partners?]

\section{INTEROPERABILTY GOVERNANCE}

9) Governance centralisering: In de documentatie die ik u gestuurd heb staat een beschrijving wat met decentrale/centrale sturing op netwerkniveau bedoeld is (centrale brokerage/formalisering en dwang). [Governance centralisation: In the documentation which I sent you there is a description of what is meant by decentralised/centralised governance-central brokerage/formalisation and coercion]

- In een voor uw organisatie ideale situatie, hoe zou de sturing (op netwerkniveau) op standaarden in dit netwerk langs deze dimensies moeten uitzien om de adoptie en naleving van deze standaarden te bevorderen (uw aanbeveling, aangezien de factoren die we tot nu hebben besproken)? [In a situation that would be ideal for your organisation, how would the governance on standards in this network look along these dimensions in order to improve adoption and compliance with the standards-your recommendation, given the influence factors that we have talked about so far?]

- In hoeverre is de bestaande besturingsstructuur op netwerkniveau afwijkend van dit ideaalbeeld? [In how far does the existing governance structure at network level diverge from this ideal picture?] 
- Hoe verklaart u dit verschil, en hoe zou het opgelost kunnen worden? [How do you explain this divergence, and how could this be solved?]

10) M.b.t. het motiveren van netwerkpartner organisaties voor adoptie en naleving van standaarden in het netwerk, wat waren/zijn de meest succesvolle aspecten van de bestaande besturingsstructuur op netwerkniveau, en wat waren de grootste drempels? [With regard to the motivation of partner organisations in the network to adopt/comply with the standards in the network, what are/were the most successful aspects of the existing governance structure at network level, and what were the biggest barriers?]

\section{AFRONDING}

11) Zijn er nog andere aspecten die $u$ belangrijk vind maar die in dit interview nog niet besproken werden? [Are there any other aspects that you find important and that were not covered yet in this interview?] 


\section{F3. Interview Consent Form}

Research project: "Governing Interoperability: Network-level decision-making structures and standards adoption in inter-organisational e-government projects"

This interview is being conducted within the frame of the research project "Governing Interoperability: Network-Level Decision-Making Structures and Standards Adoption in Inter-Organisational e-Governance Projects", carried out by the Maastricht Graduate School of Governance, in support of Stichting ICTU and the Ministerie van Binnenlandse Zaken en Koninkrijksrelaties.

The purpose of this research project is to study the change processes associated with interoperability requirements in inter-organisational public-sector ICT projects, and to give theoretical recommendations on the governance of such projects.

The information gathered in this interview will only be used within the scope of this research project. The analyses and conclusions within this research might be used for scientific publications (such as a dissertation, academic papers submitted to scientific journals and conferences, etc.) and policy reports.

All personal data will be anonymised, so that information given by the interviewee might not be linked back to the interviewee. The recordings and interview transcripts will be kept at a secured location, and be destroyed after completion of the research project.

I hereby declare that I have understood and agree to the above information.

(Interviewee Name, Signature)

(Date, Location)

$\underline{\text { Researcher/Interviewer Contact: }}$

Florian Henning

Maastricht Graduate School of Governance

Keizer Karelplein 19

6211 TC Maastricht, The Netherlands

Telephone: +31 (0)43 3884472

Email: florian.henning@maastrichtuniversity.nl 


\section{Annex G. Glossary}

Back Office The supporting office or process of a delivery chain, which the client does not directly interact with.

Co-occurrence The co-occurrence tool in atlas.ti lists all codes that co-occur in the margin area, by combining the operators WITHIN, ENCLOSES, OVERLAPS, OVERLAPPED BY and AND. So, if for instance a single quotation is coded by two codes, or if in overlapping quotations each of the two quotations is coded by one of the codes, this would count as a single co-occurrence.

Code Analytical category, referring to a particular concept. Codes are used in the qualitative analysis to "tag" individual segments of data (i.e. text) for retrieval and analysis.

Construct

The highest level of abstraction in the conceptual hierarchy of the theoretical framework on adoption determinants developed in this dissertation. The level of constructs overarches the following subordinate determinants levels (in order of decreasing abstraction): subconstructs, dimensions, and variables.

Determinant An antecedent or influence factor, having a causal effect.

Dimension The third-highest level of abstraction in the conceptual hierarchy of the theoretical framework developed in this dissertation.

Electronic The transformative application of ICT in public governance systems Governance and processes - "governance" being the framework through which government and its partners (such as the private sector and civil society) make decisions and manage their day-to-day activities, and the ways in which they interact with one another, and society at large (based on Asgarkhani, 2005).

Electronic "The use of information and communication technology (ICT) in public

Government administration to change structures and processes of government organisations" (Löfstedt, 2005).

Enterprise A systematic road-mapping approach to organising enterprise design Architecture and management, based on applying architectural analysis of structure and processes (typically focusing, but not restricted to information and ICT infrastructure and processes).

Front Office Physical or virtual unit of a service provider that clients of a service, such as citizens or businesses, directly interact with when requesting a service. 
Governance Irrespective of the actual subject domain of interest, "governance " can be defined as "the definition of rules, processes and procedures guiding strategic decisions; roles, relationships and responsibilities of organizations/people involved; objective evaluation metrics of performance" (Abramowicz, et al., 2008).

Government The application of Enterprise Architecture to the enterprise of Enterprise Architecture

Government Information Networks

Group

Infomediaries Government.

"All ICT-enabled policy networks, collaboration networks and governance networks" (Janowski, Pardo, \& Davies, 2011).

Analytical grouping of interviews for the comparative analysis. Interviews were divided in four groups in total: two across stakeholder levels (organisational and network level), and by cases (DKD and Studielink).

Organisations that provide support concerning knowledge management, information exchange and ICT use in inter-organisational systems (Soeparman et al., 2009)

Interoperability "The ability of a system or process to use information and/or (IOP) functionality of another system or process through the adherence to common standards" (dos Santos \& Reinhard, 2006).

Interoperability

Architecture

"The range of technical specifications, systems, standards, guidelines and policies that are supplementary to each other" (dos Santos \& Reinhard, 2006).

Interoperability A specified and dynamic set of standards and guidelines that specifies Framework the way in which entities have agreed to interact with each other (based on European Communities, 2004).

Interoperability The existence of appropriate decision-making rules and procedures to Governance direct and oversee government IOP initiatives that are planned or underway (based on Pardo \& Burke, 2009).

IOP Standard The abstract specifications of the necessary features of a component, technological and non-technological, and created through de facto or de jure processes, that make it compatible with the rest of a system (based on Schmidt \& Werle, 1998).

IT Governance "Specifying the decisions, rights and accountability framework to encourage desirable behavior in the use of IT" (Weill \& Ross, 2004).

Legacy system An out-dated (information) system.

One-Stop

Service Centre

"An umbrella organization that operates on top of existing functional departments and is intended to maximize the convenience and satisfaction of users through service integration" (Ho, 2002). 
Ontology A formal system and structured framework for knowledge representation in a given domain, specifying a common vocabulary to represent its concepts, their properties and relations.

Organisational Organisational IOP refers to institutions and processes that enable Interoperability separate organisations to exchange services in a way that allows them to operate effectively together (Gottschalk \& Solli-Saether, 2009; Vernadat, 2010).

Quotation In the coding analysis, an individual segment of data to which one or several analytical codes are applied.

Quote

Semantic

Interoperability

The in-text citation of (part of) a quotation from the data.

Semantic IOP concerns the "meanings" of exchanged information: the specifications that ensure that the communicating component systems interpret shared information in a consistent way (Vernadat, 2010).

Service Level

Agreement

An agreement between providers and recipients of a service that specifies parameters for service performance, such as services definition, performance measures, incident management and responsibilities

Sub-Construct The second-highest level of abstraction in the conceptual hierarchy of the theoretical framework developed in this dissertation.

Syntax Generally, a framework of rules for specifying an order in the arrangement of elements in a system. In information science, syntax refers to the rules for structuring documents (e.g. trough specifying rules for the combination of symbols or operators in a programming language).

Technological Technological IOP refers to the "plumbing" of a government Interoperability information network, i.e. the standards that regulate the linkage of applications and services (Vernadat, 2010).

Transformative

Government

“The ICT-enabled and organization-led transformation of government operations, internal and external processes and structures to enable the realization of services that meet public-sector objectives such as efficiency, transparency, accountability and citizen centricity" (Weerakkody, Janssen, \& Dwivedi, 2011).

Transmission A framework that specifies the rules for information transmission and Protocol communication in computer networks, specifying the syntax and meanings of transmitted data as well as the sequence of actions in communication.

Variable The lowest level of abstraction in the conceptual hierarchy of the theoretical framework developed in this dissertation.

Webservice A piece of software that enables constant interoperation between computers over the World Wide Web. 


\section{Annex H. Original Versions of Translated Quotes}

Q6:7 Het Ministerie is van mening dat de verantwoordingsrichtlijn geldt voor alle deelnemende partijen, maar de gemeenten zeggen nee, die is niet voor ons van toepassing. Want de GSD legt geen verantwoording af aan de SUWI partijen, maar die legt verantwoording af aan het college van burgemeester en wethouders in de gemeente. Dus de gemeenten hebben hun mening hierover. Dan kunnen wij zeggen we hebben een bepaalde centrale rol in deze keten, maar we zijn hier heel snel uitgepraat als gemeente en Ministerie elkaar niet goed willen verstaan.

Q7:16 De gemeente is groter dan alleen maar de GSD. Binnen het gemeenteveld wordt er in principe geen SUWI-ML gepraat, maar STUF. Dat is het Standaard Uitwisselings Formaat. En dat is de officiële methode om uit te wisselen binnen de gemeentelijke domein. En daarmee zijn ook alle leveranciers bekend, en wisselen daarmee uit, en SUWI-ML is heel specifiek binnen de SUWI keten. Maar nu krijg je natuurlijk de gemeente, die zowel binnen de gemeentelijke domein zit, maar ook in het SUWI domein. [...] En dat is wederom een opdracht geweest aan de leveranciers, om dus mogelijk te maken dat hetgeen wat uit die pakketten kwam, SUWI-ML sprak. Nou dat is een grotere impact geweest omdat je dus dan verschuift van de ene standaard uitlevering naar de andere standaard uitlevering. [...] Als dan weer een andere sector komt en zegt je moet ook met ons praten, en die verzint weer iets anders, dat is allemaal niet handig.

Q7:21 En diegene die hier zit, die dus de last heeft om te zorgen dat het aangeleverd wordt, is niet dezelfde die hier zit en dus profijt van heeft dat het aangeleverd wordt en er dus iets inkomt. Dat zijn twee verschillende mensen binnen de gemeente.

Q8:5 Je probeert bepaalde zaken voor te zijn. Stel dat we geen toelichting zouden geven op de gegevensset, dan zou je achteraf wel veel impact kunnen hebben op je eigen organisatie omdat je dan veel vragen krijgt van de afnemende organisatie over wat nu de betekenis is van bepaalde informatie. En dan zal jouw klant contactcenter meer vragen binnenkrijgen, en meer vragen moeten afhandelen om achteraf duidelijk te maken wat de gegevens nu exact betekenen.

Q8:11 Als kadaster willen we er toch wel voorop in lopen. Dus als er organisaties zijn die vastgoedinformatie nodig hebben, dan willen we daar zeker aan meewerken en ervaring mee opdoen. En de baten zijn dan te vinden in de ervaring die we opdoen door hierin te participeren. Ja, dus ook heel sterk in het zicht op de toekomst in die zin.

Q8:22 Als die gegevensbronnen en die informatie daaruit niet goed zijn afgestemd, dan kun je onjuiste informatie verstrekken zonder dat je daar erg [invloed] in hebt. [...]Dat is volgens mij een demotiverende factor zou het kunnen zijn als je daar als partijen goed over gaat nadenken. 
Q9:5 We hebben nog gezegd, waar moeten we het zoeken. Maar er werd ook aangegeven, ja de SUWI wet zelf moest ook opnieuw bekeken worden en zat lastig in elkaar. Geen enkele jurist kon aangeven waar wij het moesten zoeken. [...] Maar het hele traject lukte niet.

Q9:16 Als je als persoon met de juiste vragen wordt benaderd, dat je je ook serieuzer gevoeld vindt. He want als ik steeds moet komen van nou heet jij wim janssen en ben je 29 jaar en noem maar op dan denkt hij ook van kom jij van mars? Ja maar dat slaat nergens op.

Q10:18 Ja kijk het SZW het ministerie is de financier. [...] Het ministerie heeft gezegd de uitvoering is geen landelijke taak maar is decentraal belegd bij de gemeenten. Zo zit ook de WWB in elkaar. Die gemeente hebben dus 2 zakken met geld en [het ministerie zegt] 'regel nou zelf hoe je dat noemt'. Daarmee hebben ze zichzelf ook in een positie geplaatst dat ze geen definitieve sturing hebben op wat er gebeurt. [...] En je ziet dat dat een heel moeizaam traject tot stand gekomen is.

Q10:19 Omdat al die organisaties het met elkaar eens moesten worden [...] dat duurt heel lang, dat maakt weinig slagvaardig. [...] want het nadeel van die lange doorlooptijd is dat als je oplossingen gaat implementeren die komen beschikbaar, dat niemand ze meer herkent. Want in die politieke context zijn een deel van de spelers op het moment dat het vraagstuk gedefinieerd werd van 'wat hebben we nodig' zijn alweer vertrokken. En dan is iedereen vergeten wat men toen gevraagd heeft.

Q10:21 Die sturing wordt dan heel belangrijk. En daar waar het niet goed gaat en je zit in zo'n opzet als waarin we nu werken, dan blijven partijen heel lang om elkaar heen draaien en produceren eigenlijk alleen maar compromissen. In die belangentegenstelling, waar komen we dan uit? Het duurt lang, het is niet slagvaardig en het zorgt voor mindere kwaliteit dan je zou willen

Q10:26 Je gaat er eigenlijk steeds meer naartoe dat je de gegevens waar je als gemeente over beschikt, dat je vanuit die gegevens gaat redeneren in je dienstverlening. Wat weten we al wat kunnen we al proactief doen. Soms kun je al zaken gaan verstrekken zonder dat er een aanvraag heeft plaatsgevonden.

Q11:4 Als je probeert dat dan in ketenverband te ontsluiten, dan krijg je een situatie dat je iets waar je eerst uitsluitend zelfs voor verantwoordelijk was, dat aan allerlei standaards en afstemmingen moet voldoen. [...] De normale weg is dat elke wijziging binnen de SUWI domein leg je voor naar de ketenoverleggen die er daarvoor zijn. Terwijl we dat in dit geval helemaal niet willen, want het is ons eigen digitaal verzekeringsbericht.

Q11:6 Het begint gewoon met een feitelijke analyse van waar voorzien de standaards wel of niet in, en als we dingen willen doen, kan dat formeel - omdat er natuurlijk ook allerlei wettelijke kaders ook omheen zitten. Dat is gewoon een feitelijke analyse die je heel goed gezamenlijk met de ketenpartners kunt maken. Want ook die snappen dat ook voor het UWV het lastig is om hun autonomie helemaal kwijt te raken om dit soort dingen. Dus je begint met zo'n feitelijke analyse, over wettelijke en technische aspecten. 
Q12:17 Want als we dan zien in welke opleiding, hoe heet dat, waar jongeren van school komen naar de arbeidsmarkt, dan kunnen wij in onze opdracht, een sluitende aanpak voor jongeren, kunnen wij daarin anticiperen en hebben wij goed in beeld wie van school komen en wie we in onze vestigingen moeten hebben. In die zin is het wel hele nuttige informatie.

Q12:18 En we zijn ook heel goed in staat om via een hele ingewikkelde constructie van werkgroepen en teams en stuurgroepen, allemaal zaken, heel erg gelaagd op te stellen, vast te stellen. Nog een eens een keer weer te becommentariëren en dergelijke, waardoor het voortbrengingsproces echt, echt heel lang duurt. [..] Nou dat is ook wel een beetje onderkent, maar uiteindelijk is het ook wel door wel iets te realiseren, door door te zetten, door te pakken, is het toch wel een succesfactor voor de keten dat het duidelijk wordt dat we toch wel wat kunnen realiseren. [...]

Sommige zaken waarvan je echt zegt van: joh, dat moet toch niet moeilijk zijn om dat in een paar maanden te realiseren, maar daar doen we echt heel lang over. Juist in de afstemketen van ons. Nou dat is ook wel een beetje onderkent, maar uiteindelijk is het ook wel door wel iets te realiseren, door door te zetten, door te pakken, is het toch wel een succesfactor voor de keten dat het duidelijk wordt dat we toch wel wat kunnen realiseren. Ook wel de onderkenning dat we de volgende keer ook echt wel moeten kijken naar die doorlooptijden.

Q13:4 En de gesprekken met andere partijen in de keten, zeg maar de afstemming heeft dus ook met name plaatste gevonden met de technische leverancier van de informatie, in dit geval BKWI. De andere partijen die in die hele DKD-keten zitten, waren voor ons dus ook redelijk onzichtbaar.

Q13:29 Je kan best 100 verschillende partijen hebben in zo'n keten, maar als dat 100 partijen zijn die ongeveer dezelfde belangen in die keten hebben, of dezelfde rol in die keten hebben; dan is het denk ik nog makkelijker om te bereiken dan op het moment dat je drie partijen hebt, maar dat zijn drie partijen die zichzelf allemaal heel belangrijk vinden - belangrijker dan de andere twee.

Q14:13 Ja juridisch is belangrijk, dat is een van die zaken die in die hele uitwisseling heel zwaar weegt. Maar vooral gezien in de beveiliging in de privacy, dat moet goed geregeld zijn. En waarom is dat nou bij ketenuitwisseling extra belangrijk, want je moet natuurlijk ook voor je eigen werk zorgen dat je goed met de privacy van je klanten omgaat. [...] Maar daar vraagt dat op de een of andere manier altijd heel veel extra aandacht, dat is een heel belangrijke, hoe weet ik nou dat mijn gegevens ook veilig zijn bij die andere, en omgekeerd natuurlijk ook dat die gegevens van die andere bij mij veilig zijn. Dus een standaardisatie op dat gebied is wel heel belangrijk.

Q14:18 De SVB [heeft] op een aantal punten met gemeenten te maken en [wil] de samenwerking met gemeentes wel stroomlijnen en intensiveren. [...] En daarom is het belangrijk dat de SVB een goede samenwerking met gemeenten heeft, en weet wat daar gebeurt maar ook goede infrastructuur heeft om informatie te delen en om met elkaar samen te werken. [...] Ja en daarom zeg ik die keten is voor ons belangrijk en willen we daar meer in doen. En dat is echt toekomstverwachting. 
Q14:28 In het SUWI-gegevensregister worden netjes begrippen en definities vastgelegd, maar dan nog merk je als je in zo'n ketenoverleg treedt hoezeer je je eigen begrippen hanteert, je eigen kader hebt, en hoe moeilijk het is en dat het gewoon tijd nodig heeft telkens om dat weer op elkaar af te stemmen. [...] [...Je moet] realiseren dat je verschillende talen spreekt. En telkens de moeite neemt om de vertaling te doen en daar tijd voor nemen ja.

Q15:3 Het is voor de casemanager intern een verbetering, die eigenlijk doordat hij dat zo doet, aan de voorkant $40 \%$ van zijn werk al doet. Namelijk hij heeft alle informatie die hij normaliter aan de achterkant zou gaan beoordelen, hij beoordeelt ergens al gelijk aan de voorkant, waardoor hij op het moment als hij het gesprek met de klant ingaat al een heel goed beeld heeft van hoe de klant in elkaar zit. Terwijl nu voor deze ontwikkeling was dat in de achterkant. [...]

Bij het aanvraagproces van het levensonderhoud is het zo dat wij nu standaard voordat we de klant uitnodigen om op gesprek te komen, de gegevens uit SUWI-net Inkijk raadpleegt, dus het digitaal klantdossier. Daar de informatie ophaalt die we voor ons noodzakelijk is. En op basis van die beschikbare informatie plus de klantgegevens, de basale klantgegevens bepalen we oke ik krijg van u nog deze bewijs[stukken]. Als u de volgende week komt voor een aanvraaggesprek dan willen we graag dat $\mathrm{u}$ alleen die gegevens nog meebrengt. Voor het digitaal klantdossier ging het als...u heeft hier een heel verhaal, $\mathrm{u}$ vraagt aan mij een uitkering aan, en $u$ moet een hele boodschappenlijst meebrengen en daar moet ik allemaal een bewijsstuk van zien. En dat levert dus het digitaal klantdossier op en zo is het werkproces dus aangepast.

Q15:9 Dat betekent wel dat het kwaliteitsgevoel rondom de juistheid en de correctheid van de gegevens in de systemen, dat dat verhaal in ieder geval sterker speelt. En daar hoort bij, [...] dat we dan meer beseffen met elkaar dat we een keten vormen. [...]

Dat betekent bijvoorbeeld dat de medewerker in principe gegevens kan voorchecken en daardoor effectiever het gesprek met de klant kan ingaan en echt daadwerkelijk gegevens al weet die hij niet meer hoeft uit te vragen.

Q15:23 Dus het centralisatieverhaal ten opzichte van de lokale situatie, de verantwoordelijkheid erin. [...] Dat is eigenlijk bij DKD ook gebeurd, het is ons opgelegd dat we het moeten gebruiken. Anders had je die 400 zoveel gemeenten niet meegekregen. [reactie: opgelegd in de zin van de WEU?]. Ja in het kader van de WEU.

Q16:9 Het ministerie, die dachten 'wacht even, dan noemen we het niet een wet DKD of zo, nee dan doen we de wet eenmalige gegevensuitvraag'. Want als we een wet op eenmalige gegevensuitvraag doen, dan houden we hem breed. Kun je van alles onderstoppen. [...] Want op het moment dat die wet er komt, kunnen wij tegen die gemeentes zeggen die niet meedoen van 'doe nou wel mee, want je moet aan de wet voldoen'. 
Q16:13 Op managementniveau en op bestuurdersniveau krijg je dat nog wel voor mekaar, maar wat je daarna krijgt, is dat op werkvloer-niveau dat afhangt van de mensen. [...]Als uiteindelijk - en dan bedoel ik even de WEU - stel ik ben gemeentemedewerker aan de balie en die klant komt tegenover mij zitten. Ik heb hier alle gegevens staan. Die heb ik van het UWV binnengekregen, van het SGV, RDW, ik heb alles staan. Dan is het aan mij nog steeds, hoe ik met die klant omga.

Q16:16 Nee, op sommige dingen moet je echt heel strak zijn. [...] als wij afspraken maken namens de gemeenten, hebben wij natuurlijk die vierhonderd daarachter zitten, die het liefst allemaal een half centimetertje erbij hebben. Maar de een die kant op, en de ander die kan op, en de ander die kant op, [...]. Nou daar, zie je dat dingen, nou stuklopen doen ze niet, maar wel heel lastig lopen. [...]

Dat standaardafspraken zijn er altijd zo lang dat het jou ook uitkomt, zeg ik altijd maar. Dus je aan de standaard houden is altijd heel makkelijk als het jou ook uitkomt. [...] En als het even makkelijker is om je er niet aan te houden, dan doe je dat gewoon even niet. En dat is, ja, dat is ook mensen eigen. Als je de ruimte krijgt, dan pak je hem ook.

Q17:21 Dus wat heb je nodig? Je hebt intern, moet je een projectgroep neerzetten en dat bestaat uit procesbegeleiders. Dat bestaat uit ICT mensen in techniek maar ook de beheerders van de apps. Dus de functionele en de technische beheerders heb je nodig. En je hebt de gebruikers nodig. En je hebt een manager nodig. Want je gaat dingen veranderen. Wat ik net zei, die bijhoudprocessen, die ga je veranderen. Dan moet de manager wel toestemming geven. En hij moet ook roepen dat zijn proces gaat veranderen, dat we iemand meer op zijn blauwe ogen gaan moeten geloven. [...]Dus de projectgroep bestaat uit minstens 5 disciplines, er zitten vaak meerdere mensen in maar het bestaat uit minstens 5 disciplines.

Q17:26 Dan zien we in de verantwoording dat de uitvoerdersorganisaties, zoals de UWV, de sociale verzekeringsbank, ook de zeg maar ondersteunende organisaties als WKI [means: BKWI] en Inlichtingenbureau, die verantwoorden rechtstreeks naar de minister toe. Staat in de wet. Maar in dezelfde wet staat niet dat gemeenten naar de minister moeten verantwoorden.

Q17:29 Juist, dus je moet heel goed kijken naar ook een stukje verantwoording. En dan zeg ik 'zorg er nou voor dat dat wettelijk op een centrale plek wordt neergelegd, toch weer centraal, voor alle gemeenten. Dat alle gemeenten ook op dezelfde manier kunnen verantwoorden. Dus zorg nou dat niet die verantwoording of het gebruik ervan in al die sectorale wetjes zitten maar dat gemeenten gewoon elk jaar verplicht zijn om het te geven over hun gehele gegevenshuishouding die alleen maar groeiende is. 
Q18:13 Ik zou er wel meer voorstander van zijn om aan organisaties een meer eenduidige manier van werken en afspraken daartussen neer te leggen. Maar je ziet dat de overheid heel nadrukkelijk zegt: maakt me niet uit, regel het!' Dus de overheid kijkt meer naar de resultaten en niet naar hoe ze tot resultaat zijn gekomen. Wel binnen bepaalde randvoorwaarden, dus dan de WEU is wel een randvoorwaarde en de privacywetgeving is een randvoorwaarde, en dat soort dingen. En die zegt wel van 'nou ok, partners regel het lekker zelf'.

Q19:3 En veel partijen - met name het UWV was dan natuurlijk een probleem, maar ook andere gemeenten - die leveren niet altijd aan. Dus als je als werkproces hebt dat het wordt binnengehaald en ingelezen en dan ga je pas wat doen, en in 10 procent van de gevallen werkt het niet omdat een van de partijen niet heeft geleverd, dan loop ik te grote risico's in mijn bedrijfsprocessen.

Q19:15 Als je zoveel organisaties hebt die allemaal systemen beheren die voortdurend op elkaar afgestemd moeten worden. [...] En als deze hier een schroefje verzet, dan kan het er daar niet meer in, en omgekeerd. [....] En ik zou me kunnen voorstellen dat dat ook tot een soort wederzijdse bevriezing gaat leiden, en dat je de dynamiek uit je stelsel haalt.

Q19:19 Als je altijd maar op die standaardtoepassing blijft zitten, dan kom je nooit vooruit; dan ga je niet harder dan de groep. [...] Dus een ondernemende en ambitieuze gemeente, die gaat niet wachten tot hij 340 gemeenten overtuigd heeft dat hij een goed plan heeft, die denkt 'Dit is een goed plan, ik ga het gewoon doen'.

Q19:23 Je moet autonomie en sturingsmogelijkheden hebben, anders kan je niet samenwerken. Je kan alleen maar samenwerken als je met elkaar mee kan bewegen in de opgaven van iedere dag. ... Als je op een fiets rijd kan je best in een rechte lijn rijden, redelijk. Maar probeer jij maar eens met een fiets in een tramrails te rijden, dan val je om want je kan niks meer corrigeren.

Q19:24 En ik heb geen mandaat, ik kan niemand dwingen. [...] En dan zit daar iemand namens de gemeenten en die zegt van 'Tja, best een goed idee, maar ik heb geen idee wat die andere 430 gemeenten er van vinden'. Dat is een enorm probleem in samenwerking. [...]

Iedere gemeente op zichzelf een stukje autonomie inlevert, maar dat ze samen een veel efficiënter werkproces hebben. Dat is een afweging die ze maken.

Q19:25 Nou, nogmaals, ik denk dat gemeenten zelf geen actieve rol in die standaardisatie hebben. In ieder geval niet in technische standaardisatie. [...] Hooguit doet een gemeente dat doordat ze inbreng hebben in gebruikersoverleggen, en via die gebruikersoverleggen komt dat dan bij de leveranciers van die applicaties, en die kunnen dat weer inbrengen in landelijk overleggen, dus een hele lange weg. En het is toeval of er vanuit een gemeente iemand in zo'n overleg zit, maar meestal eerder niet dan wel. [...] Dat is denk ik de manier waarop gemeenten daar invloed op hebben. Doordat ze wel of niet met een bepaalde leverancier werken, wel of niet een bepaalde functionaliteit gebruiken, wel of niet het DKD vol inzetten. 
Q19:26 Ik vind dat het DKD is gebaseerd op een bepaalde filosofie, en dat is een onderdeel van het hele proces in Nederland om de overheidsinformatiehuishouding op een hoger plan te krijgen, waarbij [...] we een transparante informatie huishouding hebben over alle segmenten van de overheid heen. [...] En die is dus toegepast binnen de keten 'Werk en inkomen' in de vorm van een DKD. [...]

Ik vind dat het DKD is gebaseerd op een bepaalde filosofie, en dat is een onderdeel van het hele proces in Nederland om de overheidsinformatiehuishouding op een hoger plan te krijgen, waarbij denk ik het idee is uiteindelijk dat het overgrote deel van de informatieuitwisseling tussen een burger die een dienst nodig heeft, en de overheid een digitale uitwisseling is. [...] Ja, dat vind ik een goede strategie. En die is dus toegepast binnen de keten 'Werk en inkomen' in de vorm van een DKD.

Q21:5 Gemeenten die zeggen, die moeten veel meer doen dan UWV, want die moeten niet alleen toeleiden naar werk, maar die moeten ook minimabeleid bijvoorbeeld voeren, dus schuldhulpverlening moeten ze doen, ze moeten scholing, huisvesting voor mensen die dakloos zijn - al dat soort hulpverlening moeten zij ook doen. [...]. UWV die zegt van, 'ja, dat is niet onze doelgroep. Onze doelgroep is de WW doelgroep'. En dat zijn de mensen die gewoon van baan naar baan over het algemeen gaan. Dus, in die samenwerking, zag je heel sterk dat het UWV zei 'Ja, wij willen wel samenwerken maar dan wel binnen het domein waarvoor wij staan'.

Q21:8 Qua standaardisatie hebben we ons volledig qua techniek gehouden aan wat er in de keten over dat soort zaken is afgesproken. Maar omdat er op het procesgebied geen standaard beschikbaar was, hebben we daar te weinig naar gekeken. En dat resulteerde in een technische oplossing, die dus wel aan de technische standaarden voldoet, maar die niet voldoende rekening houdt met de processen, die daaraan gekoppeld zitten

Q21:13 Je hebt ook allerlei baten op het gebied van de systemen[...]. Dus daar waar het voorheen zo was dat professionals allerlei beslisregels in hun hoofd moesten hebben, en zelf op basis van gegevens die ze ophalen, besluiten moeten nemen, dat kun je ook automatiseren. [...] We hebben bijvoorbeeld een [...] snelbalie, en op basis daarvan kunnen ze, bijna voor 90\%, al vast stellen of iemand in aanmerking komt voor een uitkering. In plaats van dat een professional al die gegevens moet opvragen, moet gaan interpreteren, moet gaan zitten rekenen, moet gaan bekijken, doet dat systeem dat al voor je. [...] Nou dat is natuurlijk een prachtige toepassing die je met dit soort gegevens kunt doen.

Q21:14 We hebben voorbeelden waarbij een hele afdeling werd opgeheven, vanwege het feit dat, nouja, die papieren stroom gewoon verviel, en gewoon nu via een elektronische stroom. En dat is natuurlijk een baat bij de leverancier van de gegevens. [...] het leveren van die gegevens [is] veel makkelijker is geworden, omdat die daar in feite niks meer voor hoeft te doen. Het is al of op vraagbasis, of met pushbericht kan het. 
Q21:19 We hebben het [escalatie] een andere keer met de belastingdienst [geprobeerd], maar dat heeft niet geholpen. Die moesten zich ook conformeren aan de standaard, ten aanzien van het leveren van gegevens aan ons. Maar dat hebben ze gewoon niet gedaan, omdat ze zelf andere prioriteiten hadden intern. Dus daar heeft de escalatie niet geholpen.

Q23:10 'Wat is er al?'; ‘Wat is er nog niet?'; ‘Wat moet er allemaal nog komen?'; 'Wat betekent dat voor mijn organisatie?' - bestuurders zouden die vragen moeten stellen. Ook zij weten heel vaak niet hoe het zit, vinden de materie ook heel erg lastig. Kijken er graag bij weg, en bemoeien zich dan met dingen die ze wel snappen.

Q24:3 Dus de komst van het DKD eiste gewoon een goed gegevens management. [...] Nou, dat betekent heel concreet dat er een mannetje of vrouwtje bezig gaat met het maken, en beheren, van een gegevenswoordenboek.

Q26:4 Positief bood Studielink de mogelijkheid, omdat het op basis van berichten is, om in een veel eerdere fase al te gaan communiceren met de student. Dus via Studielink zei een student van hey wellicht kom ik bij jou studeren, ik heb wel belangstelling. Dan kon je gelijk via Studielink gaan communiceren met die student. Dus op die manier kon je hem eigenlijk al een beetje naar je toe gaan trekken.

Q26:19 Ja wat ook wel een belangrijke baat is dat er heel veel papierenstroom [niet meer is]...het hele proces is gedigitaliseerd. Voorheen gingen er een informatiepakket op de post naar de student, de student die vult de formulieren in. De student die ging kopietjes van zijn diploma's erbij doen en wat er zoal gevraagd werd. En dat ging dan als pakketje weer terug en dan moest dat gedigitaliseerd worden. Dus er zat een heel circus, dat wil je niet weten wat bij zo'n Hogeschool Utrecht of zo, grote instellingen, wat daar aan postzakken binnenkwam. Nou dat is echt dramatisch minder geworden. Dus ook veel efficiënter, goedkoper. Want al dat papieren gedoe en al die archivering van dit spul en zo.

Q26:27 Als je in staat bent om dat statement vanuit het college van je zegt ik vind het belangrijk dat dat gebeurt, om dat op de goede manier door te vertalen naar een veranderingsproces op de werkvloer, dan is een hele belangrijke randvoorwaarde vervult. [...] Dus om daar die vertaalslag te maken vanuit het college naar echte veranderingen, en dat veranderproces op de werkvloer, is veel complexer.

Q27:15 DUO verstrekt de beurzen, dus daar gaat heel veel geld in om. En als er fouten zijn op dat traject en iemand staat wel of niet goed ingeschreven nou dan zet DUO op een gegeven moment de aanval in, klaar. Of we hebben geld aan $u$ gegeven maar volgens de gegevens was $u$ al weg toen $u$ dat geld kreeg dus terug ermee. Dus DUO richt ook zo'n systeem in dat zij heel goed kunnen zien of er geen misbruik wordt gemaakt van gelden. Nou ik vind dat prima, alleen het maakt het er niet gemakkelijker op. 
Q27:17 Ik heb al een paar keer gesproken over die portalfunctie van Studielink. En dat is dus in feite het gegeven dat aankomende studenten hun interesse kunnen kenbaar maken voor een aantal universiteiten. [...] Een van de baten die men verwacht, ook vanuit de instellingen, is dat men toch meer studenten gaat krijgen. Want jouw naam komt onder ogen als het goed is van veel meer dan voorheen. Dat is een soort verruiming van de markt, dat is een aanname.

Q28:12 Dat oude systeem met post en zo dan had je een doorlooptijd van ongeveer 6 weken. Het hele inschrijfproces dat kenmerkt zich heel erg door allemaal keiharde deadlines [...]. Naja als je dan afhankelijk bent van heel veel postvertragingen ja is dat heel lastig.

Q28:26 Kijk als losse instelling zit je heel vaak tegen het probleem aan van ja maar ik ben zo bijzonder of ik heb zo'n bijzondere situatie en die wordt nu niet ondersteund. Daar loop je tegen aan. Maar aan de andere kant, op het moment dat je daar ruimte voor gaat bieden wordt het systeem zo complex en onbeheersbaar dat het ook niet werkt.

Q29:17 En het hele voortdurende aanpassingstraject van Studielink met koppelvlakken met testen met alle extra inzet die je erbij krijgt, die zorgt toch wel voor een behoorlijke hoeveelheid extra kosten, waardoor de terugverdientijd ja gewoon een stuk langer is. Ik heb geen idee waar die inmiddels op staat maar ik geloof dat er ergens 20 jaar genoemd is. [...]

De kwaliteit/capaciteit van je medewerkers moet omhoog waardoor je extra budget kwijt bent aan scholing aan salaris omdat een medewerker die gewoon gegevens zit in te typen is minder duur dan iemand die gegevensbeheer zit te controleren. [...]

Daarnaast was de oorspronkelijke business case van Studielink zodanig dat de terugverdientijd van de investering was dacht ik op 5 jaar gezet. Dus je zou met alle centrale verificatie, met alle minder invoerwerk, met alle voordelen zeg maar, zou je binnen 5 jaar je projectkosten en je aansluiting op Studielink terug verdienen. En dat gaan we denk ik de komende 10 jaar niet redden. [...] Maar aanvankelijk was dat dus als een erg rooskleurig plaatje voorgesteld en daardoor zijn we daar met zijn allen ook in meegegaan.

Q30:7 Dus het feit dat het nu in een centraal systeem binnenkwam maakte ook het proces voor de faculteiten veel zichtbaarder voor centraal zeg maar. Dus opeens zagen ze van 'wacht even, jullie wijzen zoveel studenten af, en als jullie die nu afwijzen voor opleiding $X$, waarom sturen jullie ze dan niet door naar opleiding $Y$ ?' En dat soort dingen zag men vroeger dus niet. Maar opeens werd dus het werk binnen die faculteiten zichtbaar voor centraal. En dat lokt ook wel, en dat geeft niemand toe, dat lokt ook wel weerstand uit.

Q30:13 Dus je moet ook heel snel een account uitgeven aan die student en een studentnummer uitgeven terwijl je dat vroeger alleen maar deed op die 20 studenten die de faculteit selecteerden van 'deze wil ik gaan doen.' [...] En dat gebeurde [vroeger] allemaal op het moment dat je het zelf uitkomt. $\mathrm{Nu}$ is het dus andersom. Alles begint centraal en komt live binnen. 
Q30:14 Er moest een live koppeling tussenkomen, met een broker technologie, dus het live verwerken van berichten in twee richtingen. Terwijl de oude techniek met ISIS toen nog, de voorloper van SAP, is gewoon het inlezen van txt-bestanden. [...] En dat betekent, ja het zijn live berichten, daar moest de UM aan wennen. En natuurlijk ook SAP. Je moet dus ook foutloos, je moet gaan monitoren. Gedurende de hele week moet er iemand monitoren of er iets fout gaat.

Q30:18 Een baat is wel dat men nu inzicht heeft in alle aanmeldingen en dus ook centraal op managementniveau veel beter kan volgen hoeveel aanmeldingen er zijn, voor welke opleidingen, welke vooropleidingen die mensen hebben, hoeveel er worden afgewezen. Dus dat inzicht in aanmeldingen en dus ook in beleid zeg maar. Dat wordt een stuk verhoogd. Dat gebeurde vroeger echt in koninkrijkjes bij de faculteiten.

Q30:27 Ik denk dat anderen juist de baten erin zien omdat die systemen aan mekaar hangen en dus ook de IBgroep en het diplomaregister eraan hangt gaat dus de effort voor die instellingen naar beneden. Dus die complexiteit en wat de verschillende partners kunnen bijdragen was een duidelijk voordeel voor het grootste deel van de ketenpartners.

Q32:25 Nou ja, de ideale opzet is niet een heel gecentraliseerd iets. Wel een democratische of gedecentraliseerde aansturing. Maar goed dan komen we net weer terug, dat kan weer snel leiden tot heel veel bureaucratie. Dat wil je ook weer niet. Dus dat is balanceren. En dan moeten op een bepaald moment wel knopen worden doorgehakt. [...] Maar goed, we zitten ook in NL, we moeten altijd wel overleggen en polderen en weet ik allemaal. Ja, daar die balans tussen democratie en centralisme, dat is altijd lastig.

Q33:15 Dus, daar waar je moet verleiden, daar heb je een governance van meenemen en meer horizontaliseren. Daar waar de standaardisatie door economische, financiële urgentie van alle deelnemers, respectievelijk een evident gezamenlijk belang van alle deelnemers, is te duiden, dan wel op een manier verplicht is te stellen. Dan is het handig om centraal te doen. [...]

Daar hebben we op een gegeven moment van gezegd 'ja, vrienden, luister wel, de omgeving voorziet niet in een ander inschrijfproces. Dus we naderen een punt waar misschien 70, 80, $90 \%$ is aangesloten op de nieuwe keten. Weet dat je dan zelf moet bekostigen het instand houden van het oude proces. Dat gaan we dan niet meer als sector [ondersteunen].' En toen, dat was het moment, maar toen waren we al zo ver in de verleiding. Dat we het eigenlijk gingen afdwingen. En op het moment dat dat is gebeurd, zijn we harder gaan sturen als studielink, want we wisten de weg terug is er niet meer.

Q34:9 Door die hele ketenintegratie, doordat we naar bronbestanden gaan als we GBA en straks ook vooropleidingniveau en vooropleidingshistorie, krijgen we uiteindelijk ook de basis die we willen voor institutionele research. [...] Dus we kunnen [...] veel gerichter je deelnemers adviseren en begeleiden op basis van de gegevens die je uit de databases kunt halen. [...] Dus je kunt veel meer ook je aanbod gaan richten op de kenmerken van de populatie. En veel gerichter adviezen geven. En uiteindelijk dus als instelling een hogere toegevoegde waarde gaan bereiken. En daar zit uiteindelijk de winst volgens mij. 
Q35:6 Beide partijen zijn dan samen verantwoordelijk voor het uitvoerend proces, want als je niet in productie bent dan kan je nog steeds naar elkaar lopen wijzen en de zwarte piet over en weer gooien, want ja in die situatie werkt dat nog. Als je samen verantwoordelijk om de productie overeind te houden, dan werkt dat niet meer, dan moet je wel samenwerken.

Q35:13 Ja, maar daar zie je iets wat je in meerder ketens terug ziet. Namelijk dat je volgens mij niet altijd de vraag moet stellen of een individuele ketenpartner er beter van geworden is, maar of de keten integraal een positive business case oplevert. Ik zou een paar voorbeelden kunnen noemen waarbij wij spectaculair moeten investeren, [...] alleen dat de baten dus bij een andere ketenpartner vallen.

Q35:14 Want wat je ziet is dat de baten nog weldegelijk binnen hetzelfde opdrachtgevende departement gegenereerd worden. Dus het Ministerie van Onderwijs betaalt zo wel DUO, als de universiteiten en hogescholen. Dus met andere woorden, voor de hoogste opdrachtgever, zegmaar de eigenaar van de keten, is er sowieso integraal een renderende business case. [...] [anders] zou het inderdaad altruïsme zijn. En ja sorry, dat doen we niet met belastinggeld.

Q35:18 En er was niet die $3^{\text {e }}$ partij die dan gewoon directief de 2 partijen bij de lurven grijpt en zegt 'Nu houdt het op, nu gaan jullie doen wat ik zeg.' En ik ben ervan overtuigd dat die aanpak in dat stadium enorm goed had kunnen werken.

Q36:2 Het ingewikkelde bij zo een proces, bij zo een ontwikkeling van zo een project, van zo een ontwikkeling van een standaard, is dat je aan partijen die op zichzelf een werkproces hebben wat functioneert zegt 'je moet het veranderen en dan wordt de wereld mooier.' Maar wat we allemaal weten, en zeker na Studielink weten we dat nog veel meer, weet ik dat nog veel indringender, dat je altijd zo een curve door moet, dat je na zo een verandering ga je eerst met $z^{\prime} n$ allen een dal in. Het gaat helemaal niet beter, het gaat slechter. En pas als je daar doorheen komt heb je kans dat het beter gaat dan waar toen je begon.

Q36:3 Dus de startpositie van de partners is dus nooit gelijk. Dus degene die het uitkomt, die hebben een voordeel ten opzichte van degene die het niet zo goed uitkomt. Nou ja en voor allemaal geldt de wet van je moet eerst de diepte in voordat je de verbetering kunt maken. Dus je vraagt aan organisaties en aan mensen om een investering te doen die pas over een paar jaar een zichtbaar rendement oplevert.

Q36:8 De les is dus dat die boodschap van het langetermijnbelang van aan de standaard voldoen, dat is een belang dat vooral bij de bestuurders, in de top van de organisatie, dat moet daar ervaren en gesteund worden. En je moet accepteren dat je dan lager in de organisatie mensen, die met hart en ziel die maatwerkoplossing hebben ontwikkeld of onderhouden of gebruiken, dat je die pijn moet doen. 
Q36:11 Het tweede is denk ik het argument dat het stompzinnig is dat 55 instellingen investeren in 16 verschillende studenteninformatiesystemen. [...] Op het moment dat je in ieder geval voor een deel niet meer in 16 verschillende systemen hoeft te investeren maar in 1, dan worden de kosten gewoon lager. Ook voor die instellingen.

Q36:22 Er zijn natuurlijk tal van processen war informatie tussen overheid en instellingen worden uitgewisseld - daar zijn nu twee partijen verantwoordelijk voor een stuk infrastructuur die met elkaar in gesprek zijn of in gevecht, dat kan niet schelen. Maar allebei voelen ze zich verantwoordelijk voor dat er een goed eindresultaat uit komt. Dat is het verschil. 


\section{Annex I. List of Determinants}

This table alphabetically lists all determinants included in the (preliminary and final) theoretical models and is primarily intended as a quick-reference for the reader (for a conceptually structured overview, the reader is referred to Table 5.1 through Table 5.4, as well as Table 4.2 and Table 4.3).

Accountability

Table 2.5

Accountability Image

Table 2.22

Administrative Boundaries

Table 2.11

Administrative Creativity

Table 2.6

Administrative Structure

Table 2.9

Adoption Efforts

Table 2.19

Ambiguous Legislation

Table 2.9

Ambiguous Legislation

Table 2.19

Broker Existence

Table 2.4

Broker Mission

Table 2.4

Brokerage

Budgetary Framework

Table 2.4

Budgetary Mechanisms

Table 2.9

Business Process Know-How

Table 2.9

Business-Case Communication

Table 2.17

Championship

Section 5.3.1.2

Change Management Approach

Table 2.6

Citizen Demand

Section 5.3.1.1

Clarification

(Table 2.8

Table 2.6

Clarity of Image

Table 2.22

Clear Responsibilities

Table 2.6

Clout

Coercion

Section 5.9.1

Table 2.5

Coercive Pressures

Table 2.5

Coherence Across Standards

Collective Impact Analysis

Section 5.3.1.1

Communication

Table 2.4

Communication

Table 2.6

Community Size

Section 5.9.1

Community Socio-Economic Environment

(Table 2.8

(Table 2.8

Competitive Forces

Table 2.14

Conflict Management

Table 2.6

Constituency Characteristics

(Table 2.8

Coordination

Table 2.21

Correction Mechanisms

Section 5.8

Credibility

Table 2.22 
Critical Mass

Table 2.13

Culture and Value Diversity

Table 2.11

Customisability

Table 2.18

Data Management

Table 2.21

Data Processing Reliability

Table 2.21

Data Quality

Table 2.21

Data Security

Table 2.21

Decision-Making Centralisation

Table 2.4

Decision-Making Centralisation

Table 2.17

Dedicated Units

Design and Use of Forums

Section 5.9.1.2

Developmental Diversity

Table 2.4

Table 2.11

Diversity

Table 2.11

Documentation Quality

Table 2.6

Domain Structure

Table 2.14

Duration

Economic IOP Governance

Section 5.4 .3

Table 2.9

Effectiveness

Table 2.21

Efficiency

Table 2.21

eGov/IOP Policy

Table 2.9

Enforcement

Table 2.5

Enthousiasm Diversity

Section 5.4.1.1

Escalation Channels

Section 5.3.3.2

Ex-Ante IOP Diversity

Section 5.4.1.1

Existence of Standards

Table 2.15

Existing Networks

Table 2.17

External Autonomy

Table 2.22

External Information Infrastructure

Table 2.19

External-Relations Results

Table 2.22

Feasibility Assessment

Table 2.17

Financial Resources

Table 2.17

Financial Resources Acquisition

Table 2.21

Formalised Obligations

Table 2.5

Frequent Interaction

Table 2.13

Funding

Table 2.6

Future Innovation

Geographic Proximity

Table Annex A.21

Table 2.11

Goal Clarification

Table 2.21

Goal Diversity

Table 2.11

Goal Efforts

Section 4.3.5.1

Government Demand

(Table 2.8

Government-Citizen Roles

Section 5.4 .2

Guidance

Table 2.6

Homophily

Table 2.13

Human Resources

Table 2.17 
Human Resources Amount

Table 2.17

ICT Capability

Table 2.17

ICT Department Support

Table 2.17

ICT Infrastructure

Table 2.17

ICT Know-How

Table 2.17

Identity Diversity

Image

Incident Management

Informal Leadership

Information Acquisition

Information Awareness

Section 5.4.1.1

Table 2.22

Section 5.3.1.1

Table 2.6

Table 2.21

Information Infrastructure

Table 2.17

Infrastructure Costs

Table 2.15

Table 2.19

Innovation

Table 2.22

Innovation Catalyst

Section 4.3.1.3

Inter-Organisational Trust

Table 2.12

Inter-Personal Trust

Table 2.12

Interaction Complexity

Section 5.4.3

Interdependence

Table 2.11

Internal Autonomy

Internal Unity

Internal-Operations Results

Annex A. 8

IOP Governance

Table 2.17

Table 2.21

Table 2.3

IOP Standard Experience

Table 2.17

IOP Standards Adaptation

Table 2.4

IOP Standards Characteristics

Table 2.18

IP Legislation

Table 2.9

Knowledge Dissemination

Table 2.6

Knowledge Management

Table 2.17

Knowledge-Building Activities

Table 2.6

Leadership and Support

Table 2.6

Legacy System

Section 5.4.5

Legal Diversity

Section 5.4.1.1

Legal Efforts

Table 2.19

Legal Framework

Table 2.9

Legal Framework

Table 2.19

Legitimacy

Table 2.22

Legitimacy-Building

Table 2.6

Maintaining Relationship Efforts

Table 2.19

Management Practices

Table 2.17

Manager Characteristics

Table 2.17

Manager's Attitude to Innovation

Table 2.17

Manager's Background

Table 2.17

Manager's Emotions

Section 5.9.1

Manager's ICT Skills

Table 2.17 
Manager's Non-ICT Know How

Section 5.9.1

Manager's Power

Table 2.17

Maturity

Section 5.8

Mimetic Dynamics

Table 2.13

Misunderstandings

Section 5.4.3

Monitoring

Table 2.17

Monitoring/Enforcement Efforts

Table 2.19

Monitoring/Enforcement Costs

Table 2.19

Need for Innovation

Table 2.14

Network Characteristics

Table 2.10

Network Complexity

Table 2.11

Network Effectiveness

Table Annex A.20

Network Structure Adaptation

Table 2.4

Network Think

Section 5.9.1

Network-External Environment

Table 2.7

Network-Level Results

Section 4.3 .4

Networking Experience

Table 2.17

Operational Diversity

Table 2.11

Operations Cost

Table 2.21

Operations Speed

Table 2.21

Organisation Size

Table 2.17

Organisation-Specific Determinants

Table 2.16

Organisational Capacity

Table 2.17

Organisational Efforts

Table 2.19

Organisational Information Infrastructure

Table 2.19

Organisational Needs

Section 5.9.2

Organisational Structure

Table 2.17

Organisational Structure Efforts

Other Stakeholders

Table Annex A.24

Ownership

Section 5.5.1.3

Table 2.4

Partners Participation

Table 2.4

Path Dependency

Section 5.5.2.3

Perseverance

Section 5.3.1.1

Plan

Table 2.6

Planning

Section 5.3.1.1

Policy Adaptation

Table 2.4

Policy and Institutions

Table 2.9

Policy Contribution

Table 2.21

Policy Domain Know-How

Table 2.17

Political Effects

Table 2.22

Political Environment

(Table 2.8

Power

Table 2.22

Power Diversity

Table 2.11

Prior Experiences

Table 2.12

Privacy Legislation

Table 2.9 
Privacy Legislation

Table 2.19

Problem-Solving

Table 2.21

Process Efforts

Table 2.19

Public Pressure

(Table 2.8

Public Procurement Legislation

Table 2.9

Public Scrutiny

(Table 2.8

Public-Private Mix

Table 2.11

Reach Expansion

Table 2.22

Realistic Goals

Table 2.6

Relational Mechanisms

Table 2.17

Relational Specificity

Table 2.17

Relationship Extendability

Table 2.17

Reporting

Table 2.21

Resilience

Table 2.6

Resource Acquisition

Table 2.21

Resource Cost

Table 2.19

Resource Diversity

Table 2.11

Responsibility

Responsiveness

Results

Results Demonstrability

Results Diversity

Return-on-Investment Results

Reward Structures

Scope Monitoring

Semantic Diversity

Semantic Efforts

Service Quality

Sow-Harvest Equality

Staff Motivation

Stakeholder Involvement

Stovepipes

Strategic Plan

Structural Complexity

Task Complexity

Technical Diversity

Technical Environment

Technical Facilitation

Technological Efforts

Testing Support

Time

Timeliness

Timing

Top Management Support

Tracking Systems

Table Annex A.14

Table 2.21

Table 2.20

Table 2.22

Section 5.4.1.1

Section 4.3.3

Table 2.6

Section 5.3.1.1

Table 2.11

Table Annex A.26

Table 2.21

Table Annex A.18

Table 2.17

Table 2.4

Table 2.9

Table 2.17

Table 2.11

Table 2.11

Table 2.11

Table 2.15

Section 5.3.1.1

Table 2.19

Section 5.3.1.1

Table 2.14

Section 5.3.1.2

Table Annex A.19

Table 2.17

Table 2.5 
Training

Table 2.17

Training Costs

Table 2.19

Training Efforts

Table 2.19

Trialability

Table 2.18

Trust

Table 2.12

Trust- and Consensus Building Activities

Table 2.6

Turbulence

Table 2.14

Type of Information Shared

Table 2.11

Type/Level of Collaboration

Table 2.11

Uncertainty Reduction

Table 2.21

Uncoordinated Action

Section 5.4 .3

Unilateral Options

Table 2.14

Unresolved Conflicts

Section 5.4 .3

Usability

Table 2.21

User Participation

Table 2.4

Value Efforts

Section 4.3.5.1

Version Control

Section 5.3.1.1

Visibility

Table 2.17

Vision

Section 5.3.1.1 


\section{Annex J. References}

6, P. (2004). Joined-Up Government in the Western World in Comparative Perspective: A Preliminary Literature Review and Exploration. Journal of Public Administration Research and Theory, 14(1), 103-138.

Abramowicz, W., Bassara, A., Wisniewski, M., \& Zebrowski, P. (2008). Interoperability Governance for e-Government. Paper presented at the International United Information Systems Conference Klagenfurt, Austria.

Agranoff, R., \& McGuire, M. (1998). Multinetwork Management: Collaboration and the Hollow State in Local Economic Policy. Journal of Public Administration Research and Theory, 8(1), 67-91.

Agranoff, R., \& McGuire, M. (1999). Managing in network settings. Policy Studies Review, 16(1), 18.

Agranoff, R., \& McGuire, M. (2001). Big Questions in Public Network Management

Research. Journal of Public Administration Research and Theory, 11(3), 295-326.

Agranoff, R., \& McGuire, M. (2003). Collaborative Public Management. Washington, DC: Georgetown University Press.

Ahn, M. J. (2010). Adoption of E-Communication Applications in U.S. Municipalities: The Role of Political Environment, Bureaucratic Structure, and the Nature of Applications. The American Review of Public Administration, 41(4).

Ajzen, I. (1991). The theory of planned behavior. Organizational Behavior and Human Decision Processes, 50(2), 179-211.

Ajzen, I., \& Fishbein, M. (1980). Understanding Attitudes and Predicting Behaviour. Englewood Cliffs: Prentice Hall.

Akbulut, A. Y. (2003). An Investigation Of The Factors That Influence Electonic Information Sharing Between State and Local Agencies. (PhD), Louisiana State University.

Al-Shafi, S., Weerakkody, V., \& Janssen, M. (2009). Investigating the Adoption of eGovernment Services in Qatar Using the UTAUT Model. Paper presented at the 15th Americas Conference on Information Systems, San Francisco.

Al-Sobhi, F., Weerakkody, V., \& El-Haddadeh, R. (2011). The Relative Importance of Intermediaries in eGovernment Adoption: A Study of Saudi-Arabia. Paper presented the 10th IFIP International Conference EGOV 2011, Delft.

AlAwadhi, S., \& Morris, A. (2008). The Use of the UTAUT Model in the Adoption of EGovernment Services in Kuwait. Paper presented at the 41st Hawaii International Conference on Systems Science (HICSS), Honolulu, Hawaii.

Andersen, K. N., Veit, D., Medaglia, R., \& Henriksen, H. Z. (2010). One Inch Wide and One Inch Deep: The Role of Policies in Shaping the Adoption of Open Standards and Software in Government. Paper presented at the Electronic Government and the Information Systems Perspective (EGOVIS), Bilbao, Spain.

Ansell, C. (2006). Network Institutionalism. In R. A. W. Rhodes, S. A. Binder \& B. A. Rockman (Eds.), The Oxford Handbook of Political Institutions (pp. 75-89). Oxford: Oxford University Press. 
Ansell, C., \& Gash, A. (2007). Collaborative Governance in Theory and Practice. Journal of Public Administration Research and Theory, 18(4), 543-571.

Arthur, B. W. (1989). Competing Technologies, Increasing Returns, and Lock-In by Historical Events. The Economic Journal, 99(394), 116-131.

Asgarkhani, M. (2005). Digital Government and its Effectiveness in Public Management Reform. Public Management Review, 7(3), 465-487.

Bala, H., \& Venkatesh, V. (2007). Assimilation of Interorganizational Business Processes. Information Systems Research, 18(3), 340-362.

Bardach, E. (1998). Getting Agencies to Work Together: The Practice and Theory of Managerial Craftsmanship. Washington, DC: Brookings Institution Press.

Bardach, E. (2001). Developmental Dynamics: Interagency Collaboration as an Emergent Phenomenon. Journal of Public Administration Research and Theory, 11(2), 149-164.

Bekkers, V. (2007). The governance of back-office integration. Public Management Review, $9(3), 377-400$.

Bekkers, V. (2009). Flexible information infrastructures in Dutch E-Government collaboration arrangements: Experiences and policy implications. Government Information Quarterly, 26(1), 60-68.

Bekkers, V., \& Zouridis, S. (1999). Electronic service delivery in public administration: some trends and issues. International Review of Administrative Sciences, 65, 183-195.

Bélanger, F., \& Carter, L. (2008). Trust and risk in e-government adoption. The Journal of Strategic Information Systems, 17(2), 165-176.

Bennett, A. (2004). Case Study Methods: Design, Use, and Comparative Advantages. In D. Sprinz \& Y. Wolinsky-Nahmias (Eds.), Models, Numbers, and Cases: Methods for Studying International Relations. Ann Arbor: University of Michigan Press.

Benson, J. K. (1975). The Interorganizational Network as a Political Economy. Administrative Science Quarterly, 20(2), 229-249.

Bingham, L. B., \& O'Leary, R. (2006). Conclusion: Parallel Play, Not Collaboration: Missing Questions, Missing Connections. Public Administration Review, 66(s1), 161-167.

Bingham, R. D. (1976). The adoption of innovation by local government. Lexington: D.C. Heath. Botzem, S., \& Dobusch, L. (2012). Standardization Cycles: A Process Perspective on the Formation and Diffusion of Transnational Standards. Organization Studies, 33(5-6), 737762.

Boudreau, M.-C., \& Robey, D. (2005). Enacting Integrated Information Technology: A Human Agency Perspective. Organization Science, 16(1), 3-18.

Brass, D. J., Galaskiewicz, J., Greve, H. R., \& Wenpin, T. (2004). Taking Stock of Networks and Organizations: A Multilevel Perspective. Academy of Management Journal, 47(6), 795817.

Brown, D. (2005). Electronic government and public administration. International Review of Administrative Sciences, 71(2), 241-254.

Brown, M. M., O'Toole, L. J., Jr., \& Brudney, J. L. (1998). Implementing Information Technology in Government: An Empirical Assessment of the Role of Local Partnerships. Journal of Public Administration Research and Theory, 8(4), 499-526.

Brunsson, N., Rasche, A., \& Seidl, D. (2012). The Dynamics of Standardization: Three Perspectives on Standards in Organization Studies. Organization Studies, 33(5-6), 613632. 
Bryson, J. M., Crosby, B. C., \& Middleton Stone, M. (2006). The Design and Implementation of Cross-Sector Collaborations: Propositions from the Literature. Public Administration Review, 66(s1), 44-55.

Bryson, J. M., Stone, M. M., Crosby, B. C., \& Saunoi-Sandgren, E. O. (2009). Designing and Managing Cross-Sector Collaboration: A Case Study in Reducing Traffic Congestion Collaboration: Networks and Partnerships Series. Washington, DC: IBM Center for The Business of Government.

Buchanan, D., Claydon, T., \& Doyle, M. (2006). Organisation development and change: the legacy of the nineties. Human Resource Management Journal, 9(2), 20-37.

Buchanan, D., Fitzgerald, L., Ketley, D., Gollop, R., Jones, J. L., Lamont, S. S., . . Whitby, E. (2005). No going back: A review of the literature on sustaining organizational change. International Journal of Management Reviews, 7(3), 189-205.

Budd, R., Thorp, R., \& Donohew, L. (1967). Content Analysis of Communications. London: The Collier - McMillan.

Busch, L. (2011). Standards. Recipes for Reality. Cambridge: MIT Press.

Bysted, R., \& Hansen, J. R. (2013). Comparing Public and Private Sector Employees' Innovative Behaviour: Understanding the role of job and organizational characteristics, job types, and subsectors. Public Management Review, Published online.

Caffrey, L. (1998). Information sharing between and within governments. London: Commonwealth Secretariat.

Capgemini. (2010). Interoperabiliteit binnen en tussen sectoren. Verkenning voor het Forum Standaardisatie naar e - dossiers, verwijsindexen en registers. Utrecht: Capgemini.

Chandler, A. D. (1962). Strategy and Structure: Chapters in the History of the American Industrial Enterprise. Cambridge: MIT Press.

Chau, P. Y. K., \& Tam, K. Y. (1997). Factors Affecting the Adoption of Open Systems: An Exploratory Study. MIS Quarterly, 21(1), 1-24.

Chen, M. (2003). Factors affecting the adoption and diffusion of XML and Web services standards for E-business systems. International Journal of Human-Computer Studies, 58 , 259-279.

Chen, Y.-C. (2010). Citizen-Centric E-Government Services: Understanding Integrated Citizen Service Information Systems. Social Science Computer Review, 28(4), 427-442.

Chen, Y.-C. (2012). A comparative study of e-government XBRL implementations: The potential of improving information transparency and efficiency. Government Information Quarterly, 29(4), 553-563.

Chen, Y.-C., Doumeingts, G., \& Vernadat, F. B. (2008). Architectures for enterprise integration and interoperability: Past, present and future. Computers in Industry, 59, 647659.

Chituc, C.-M., Zazevedo, A., \& Toscano, C. (2009). A framework proposal for seamless interoperability in a collaborative networked environment. Computers in Industry, 60, 317-338.

Christensen, T., \& Laegreid, P. (2007). The whole-of-government approach to public sector reform. Public Administration Review, 67, 1059-1066.

Chu, P.-Y., Hsiao, N., Lee, F.-W., \& Chen, C.-W. (2004). Exploring success factors for Taiwan's government electronic tendering system: behavioral perspectives from endusers. Government Information Quarterly, 21, 219-234. 
Chwelos, P., Benbasat, I., \& Dexter, A. S. (2001). Research Report: Empirical test of an EDI Adoption Model. Information Systems Research, 12(3), 304-321.

Cimander, R., \& Kubicek, H. (2009). Organizational Interoperability and Organizing for Interoperability in E-Government. Paper presented at the Second European Summit on Interoperability in the iGovernment. ESIIG2, Rome, Italy.

Clarke, S., Elliman, T., \& Lehaney, B. (2000). Reengineering an Information System: A Case Study in Risk Reduction. The International Journal of Flexible Manufacturing Systems, 12, 305-320.

Coffey, A., \& Atkinson, P. (1996). Making Sense of Qualitative Data: COmplementary Research Strategies. London: Sage.

Cooper, R., \& Zmud, R. (1990). Information technology implementation research: A technological diffusion approach. Management Science, 36(2), 123-139.

Cowan, R. (1993). The Informatisation of Government: From Choice of Technology to Economic Opportunity. Paper presented at the International Conference "The Changing Role of Governments in Introducing New Information Technologies and Strategies in Establishing Relevant National IT Enhancement Plans", Ankara, Turkey.

Crosby, B. C., \& Bryson, J. M. (2010). Integrative leadership and the creation and maintenance of cross-sector collaborations. The Leadership Quarterly, 21, 211-230.

Dahl, P. S., \& Hanssen, K. M. (2006). Diffusion of Standards: The Importance of Size, Region, and External Pressures in Diffusion Processes Public Administration, 84(2), 441-459.

Daley, D. M. (2008). Interdisciplinary Problems and Agency Boundaries: Exploring Effective Cross-Agency Collaboration. Journal of Public Administration Research and Theory, 19(3), 477.

Damanpour, F., \& Schneider, M. (2006). Phases of the adoption of innovation in organizations: Effects of environment, organization and top managers. British Journal of Management, 17, 215-236.

David, P. A., \& Greenstein, S. (1990). The Economics of Compatibility Standards: An Introduction to Recent Research. Economics of Innovation and New Technology, 1, 3-41.

Davis, F. D. (1989). Perceived Usefulness, Perceived Ease of Use, and User Acceptance of Information Technology. MIS Quarterly, 13(3), 319-340.

Dawes, S. S. (1996). Interagency Information Sharing: Expected Benefits, Manageable Risks. Journal of Policy Analysis and Management, 15(3), 377-394.

Dawes, S. S., \& Eglene, O. (2008). New models of collaboration for delivering e-government services: a dynamic model drawn from multi-national research. Working Paper. Working Paper. Center for Technology in Government.

Dekker, H. C. (2004). Control of inter-organizational relationships: Evidence on appropriation concerns and coordination requirements. Accounting Organization Society, 29(1), 27-49.

DiMaggio, P. J., \& Powell, W. W. (1983). The iron cage revisited: Institutional isomorphism and collective rationality in organizational fields. American Sociological Review, 48(2), 147-160.

Dimitrova, D., \& Chen, Y.-C. (2006). Profiling the Adopters of E-Government Information and Services: The Influence of Psychological Characteristics, Civic Mindedness, and Information Channels. Social Science Computer Review, 24(172-188). 
dos Santos, E. M., \& Reinhard, N. (2006). Interoperability standards and e-Government: perspectives and challenges. Paper presented at the Twelfth Americas Conference on Information Systems, Acapulco, Mexico.

dos Santos, E. M., \& Reinhard, N. (2012). Electronic Government Interoperability: Identifying the Barriers for Frameworks Adoption. Social Science Computer Review, 30(1), 71-82.

Dunleavy, P., Margetts, H., Bastow, S., \& Tinkler, J. (2005). New Public Management Is Dead-Long Live Digital-Era Governance. Journal of Public Administration Research and Theory, 16, 467-494.

Ebbers, W. E., \& van Dijk, J. A. G. M. (2007). Resistance and support to electronic government, building a model of innovation. Government Information Quarterly, 24(3), 554-575.

Ebbinghaus, B. (2005). When Less is More: Selection Problems in Large-N and Small-N Cross-National Comparisons. International Sociology, 20(2), 133-152.

Egyedi, T. M. (1996). Shaping Standardization: A study of standards processes and standard policies in the field of telematic services. Delft: Delft University Press.

Emerson, K., Nabatchi, T., \& Balogh, S. (2011). An Integrative Framework for Collaborative Governance. Journal of Public Administration Research and Theory(Published Online May 2, 2011).

EPAN. (2004). Key Principles of an Interoperability Architecture. Technical Report. Brussels: EPAN.

Estevez, E. (2009). Programmable Messaging for Electronic Government. Doctoral Thesis in Computer Science. (PhD), National University of the South, Bahia Blanca.

Estevez, E., Fillottrani, P., \& Janowski, T. (2012). Information Sharing in Government Conceptual Model for Policy Formulation. European Conference on e-Government, ECEG, 152-162.

Estevez, E., Fillottrani, P., Janowski, T., \& Ojo, A. (2010). Government Information Sharing: A Framework for Policy Formation. In Y.-C. Chen \& P.-Y. Chu (Eds.), Electronic Governance and Cross-Boundary Collaboration: Innovations and Advancing Tools (pp. 23-55). Hershey: IGI Global.

European Communities. (2003). Linking up Europe: the Importance of Interoperability for eGovernment Services. Brussels: European Commission.

European Communities. (2009). Ministerial Declaration on eGovernment. Malmö: 5th Ministerial eGovernment Conference.

European Communities. (2010a). COM(2010) 245 final/2. A Digital Agenda for Europe. Brussels: European Communities.

European Communities. (2010b). European Interoperability Framework (EIF) for European Public Services. Annex 2 to COM(2010) 744 final. Brussels: European Commission.

Fedorowicz, J., Gelinas Jr., U. J., Gogan, J. L., \& Williams, C. B. (2008). Strategic alignment of participant motivations in e-government collaborations: The Internet Payment Platform pilot. Government Information Quarterly, 26(51-59).

Fedorowicz, J., Gogan, J. L., \& Williams, C. B. (2007). A collaborative network for first responders: Lessons from the CapWIN case. Government Information Quarterly, 24, 785807. 
Fichman, R. G. (2001). Aggregation in the measurement of IT-related innovation. MIS Quarterly, 25(4), 427-455.

Fishbein, M., \& Ajzen, I. (1975). Belief, Attitude, Intention, and Behaviour: An Introduction to Theory and Research. Reading: Addison-Wesley.

Fountain, J. (2001). Building the Virtual State: Information Technology and Institutional Change. Washington DC: Brookings Institution.

Fountain, J. (2007). Challenges to Organizational Change. Multi-Level Integrated Information Structures (MIIS). In V. Mayer-Schönberger \& D. Lazer (Eds.), Governance and Information Technology. From Electronic Government to Information Government (pp. 6394). Cambridge: MIT Press.

Fountain, J. (2009). Bureaucratic reform and e-government in the United States: an institutional perspective. In A. Chadwick \& P. N. Howard (Eds.), The Handbook of Internet Politics (pp. 99-113). New York: Routledge.

Frambach, R. T., \& Schillewaert, N. (2002). Organizational innovation adoption: a multi-level framework of determinants and opportunities for future research. Journal of Business Research, 55(2), 163-176.

Gasco, M. (2003). New technologies and institutional change in public administration. Social Science Computer Review, 21(1), 6-14.

Gasco, M. (2012). Approaching E-Government Interoperability. Social Science Computer Review, 30(1), 3-6.

Gerring, J. (2008). Case Selection For Case-Study Analysis: Qualitative and Quantitative Techniques. In J. Box-Steffensmeier, H. Brady \& D. Collier (Eds.), The Oxford Handbook of Political Methodology (pp. 645-684). Oxford: Oxford University Press.

Gibbs, G. R. (2007). Analyzin qualitative data. London: Sage.

Gil-Garcia, J. R., Chun, S. A., \& Janssen, M. (2009). Government information sharing and integration: Combining the social and the technical. Information Polity, 14(1-10).

Gil-Garcia, J. R., \& Martinez-Moyano, I. J. (2007). Understanding the evolution of egovernment: The influence of systems of rules on public sector dynamics. Government Information Quarterly, 24(2), 266-290.

Gil-Garcia, J. R., Pardo, T., \& Cresswell, A. M. (2010). Conceptualizing inter-organizational information integration in government. In J. Scholl (Ed.), Electronic government: Information, technology, and transformation (pp. 179-202). Armonk: ME Sharpe.

Gil-Garcia, R. J., Chengalur-Smith, I., \& Duchessi, P. (2007). Collaborative e-Government: impediments and benefits of information-sharing projects in the public sector. European Journal of Information Systems, 16(2), 121-133.

Gottschalk, P. (2009). Maturity levels for interoperability in digital government. Government Information Quarterly, 26, 75-81.

Gottschalk, P., \& Solli-Saether, H. (2009). Interoperability in E-Government: Stages of Growth. In G. P. Sahu, Y. K. Dwivedi \& V. Weerakkody (Eds.), E-Government Development and Diffusion: Inhibitors and Facilitators of Digital Democracy (pp. 50-66). Hershey: IGI Global.

Granovetter, M. (1983). The Strength of Weak Ties: A Network Theory Revisited. Sociological Theory, 1, 201-233.

Gray, B. (1989). Collaborating: Finding Common Ground for Multiparty Problems. San Francisco: Jossey-Bass. 
Gray, B. (2000). Assessing Inter-Organizational Collaboration: Multiple Conceptions and Multiple Methods. In D. Faulkner \& M. de Rond (Eds.), Cooperative strategy: economic, business and organizational issues (pp. 243-260). Oxford: Oxford University Press.

Gray, B., \& Wood, D. J. (1991a). Collaborative Alliances: Moving from Practice to Theory. Journal of Applied Behavioral Science, 27(1), 3-22.

Gray, B., \& Wood, D. J. (1991b). Toward a Comprehensive Theory of Collaboration. Journal of Applied Behavioral Science, 27(2), 139-162.

Grönlund, Å., \& Horan, T. A. (2004). Introducing e-Gov: History, Definitions, and Issues. Communications of the Association for Information Systems, 15(1), 713-729.

Guijarro, L. (2007). Interoperability frameworks and enterprise architectures in egovernment initiatives in Europe and the United States. Government Information Quarterly, 24(1), 89-101.

Gulati, R., \& Singh, H. (1998). The Architecture of Cooperation: Managing Coordination Costs and Appropriation Concerns in Strategic Alliances. Administrative Science Quarterly, 43(4), 781-814.

Gupta, B., Dasgupta, S., \& Gupta, A. (2008). Adoption of ICT in a government organization in a developing country: An empirical study. The Journal of Strategic Information Systems, 17(2), 140-154.

Gurbaxani, V., \& Whang, S. (1991). The Impact of Information Systems on Organizations and Markets. Communications of the ACM, 34(1), 59-73.

Hair, J. F., Black, W. C., Babin, B. J., Anderson, R. E., \& Tatham, R. L. (2010). Multivariate Data Analysis (7th ed.). Upper Saddle River Pearson Education.

Hall, D. J., \& Saias, M. A. (1980). Strategy Follows Structure! Strategic Management Journal, $1(2), 149-163$.

Heeks, R. (2006). Implementing and Managing eGovernment. An International Text. London: Sage.

Heeks, R., \& Santos, R. (2009). Understanding Adoption of e-Government: Principals, Agents and Institutional Dualism. Centre for Development Informatics: Working Paper No. 19.

Hellman, R. (2010). Organisational Barriers to Interoperability. Paper presented at the eChallenges e-2010 Conference, Warsaw, Poland.

Henning, F. (2013a). Adoption of Interoperability Standards in Government Information Networks: An Initial Framework of Influence Factors. In T. Janowski, J. Holm \& E. Estevez (Eds.), Proceedings of ICEGOV2013, 7th International Conference on Theory and Practice of Electronic Governance, October 22-25, Seoul, Korea: ACM Press.

Henning, F. (2013b). The Impact of Interoperability Standards Adoption on Organisations in Government Information Networks. In T. Janowski, J. Holm \& E. Estevez (Eds.), Proceedings of ICEGOV2013, 7th International Conference on Theory and Practice of Electronic Governance, October 22-25, Seoul, Korea: ACM Press.

Henning, F. (2015). Investigating the Relationship of Network Governance Centralisation and Network Complexity - The Case of Interoperability in Government Information Networks. Paper presented at the 19th Conference of the International Research Society for Public Management (IRSPM 2015), Birmingham, United Kingdom.

Hjern, B., \& Porter, D. (1981). Implementation Structures: A New Unit of Administrative Analysis. Organization Studies, 2(3), 211-227. 
Ho, A. T.-K. (2002). Reinventing Local Governments and the E-Government Initiative. Public Administration Review, 62(4), 434-444.

Homburg, V. M. F., \& Bekkers, V. J. J. M. (2002). The Back-Office of e-Government. Paper presented at the 35th Hawaii Conference on System Sciences (HICCS), Hawaii, Big Island.

Hung, S.-Y., Chang, C.-M., \& Yu, T.-J. (2006). Determinants of user acceptance of the eGovernment services: The case of online tax filing and payment system. Government Information Quarterly, 23(1), 97-122.

Hung, S.-Y., Tang, K.-Z., Chang, C.-M., \& Ke, C.-D. (2009). User acceptance of intergovernmental services: An example of electronic document management system. Government Information Quarterly, 26(387-397).

Iacovou, C., Benbasat, I., \& Dexter, A. S. (1995). Electronic Data Interchange and Small Organizations: Adoption and Impact of Technology. MIS Quarterly, 19(4), 465-485.

Janowski, T., Pardo, T. A., \& Davies, J. (2011). Government Information Networks Mapping Electronic Governance cases through Public Administration concepts. Government Information Quarterly, 29, 1-10.

Janssen, M., Joha, A., \& Weerakkody, V. (2007). Exploring relationships of shared service arrangements in local government. Transforming Government: People, Process E Policy, 1(3), 271-284.

Jeyaraj, A., Rottman, J. W., \& Lacity, M. C. (2006). A review of the predictors, linkages, and biases in IT innovation adoption research. Journal of Information Technology, 21(1), 1-23.

Jiménez, C. E. (2012). Impacto de la Ley Reguladora del Uso de las TIC en la Administración de Justicia (Impact of the Law Regulating the Use of ICT in the Administration of Justice). Barcelona: Centre of Legal Studies and Specialised Formation (CEJFE).

Joseph, B. K. (2010). E-Government Adoption Landscape Zambia: Context, Issues, and Challenges. In C. G. Reddick (Ed.), Comparative E-Government (pp. 241-258). New York: Springer.

Jun, K.-N., \& Weare, C. (2010). Institutional Motivations in the Adoption of Innovations: The Case of E-Government. Journal of Public Administration Research and Theory, 21, 495-519.

Kahn, K. B. (1996). Interdepartmental integration: a definition with implications for product development performance. Journal of Product Innovation Management, 13, 137-151.

Kamal, M. M. (2006). IT innovation adoption in the government sector: identifying the critical success factors. Journal of Enterprise Information Management, 19(2), 192-222.

Kamal, M. M., Weerakkody, V., \& Irani, Z. (2011). Analyzing the role of stakeholders in the adoption of technology integration solutions in UK local government: An exploratory study. Government Information Quarterly, 28(2), 200-210.

Kauffman, R. J., \& Tsai, J. Y. (2010). With or without you: The countervailing forces and effects of process standardization. Electronic Commerce Research and Applications, 9, 305322.

Kearney, R. C., Feldman, B. M., \& Scavo, C. P. (2000). Reinventing government: City manager attitudes and actions. Public Administration Review, 60, 535-547.

Kelle, U., Prein, G., \& Bird, K. (1995). Computer-aided Qualitative Data Analysis: Theory, Methods and Practice. London: Sage. 
Keller, W., Groen, U., \& van Lunteren, J. (2005). De burger bediend! Expertcommissie informatievoorziening en elektronische dienstverlening SUWI. Den Haag: Ministerie van Sociale Zaken en Werkgelegenheid.

Kickert, W. J. M., Klijn, E.-H., \& Koppenjan, J. F. M. (1997a). Introduction: A Management Perspective on Policy Networks. In W. J. M. Kickert, E.-H. Klijn \& J. F. M. Koppenjan (Eds.), Managing Complex Networks: Strategies for the Public Sector (pp. 1-13). London: Sage.

Kickert, W. J. M., Klijn, E.-H., \& Koppenjan, J. F. M. (1997b). Managing Networks in the Public Sector: Findings and Reflections. In W. J. M. Kickert, E.-H. Klijn \& J. F. M. Koppenjan (Eds.), Managing Complex Networks: Strategies for the Public Sector (pp. 166191). Londong: Sage.

Kickert, W. J. M., Klijn, E.-H., \& Koppenjan, J. F. M. (Eds.). (1997c). Managing Complex Networks: Strategies for the Public Sector. London: Sage.

Kickert, W. J. M., \& Koppenjan, J. F. M. (1997). Public Management and Network Management: An Overview. In W. J. M. Kickert, E.-H. Klijn \& J. F. M. Koppenjan (Eds.), Managing Complex Networks: Strategies for the Public Sector (pp. 35-61). London: Sage.

Kinder, T. (2003). Mrs Miller moves house: the interoperability of local public services in Europe. Journal of European Social Policy, 13(2), 141-157.

Kitthananan, A. (2006). Conceptualizing Governance: A Review. Journal of Societal and social Policy, 5(3), 1-19.

Kjaer, A. M. (2004). Governance. Cambridge: Polity.

Klievink, B., \& Janssen, M. (2009). Realizing joined-up government - Dynamic capabilities and stage models for transformation. Government Information Quarterly, 26, 275-284.

Klijn, E.-H. (1997). Policy Networks: An Overview. In W. J. M. Kickert, E.-H. Klijn \& J. F. M. Koppenjan (Eds.), Managing Complex Networks: Strategies for the Public Sector (pp. 14-34). London: Sage.

Klijn, E.-H., \& Teisman, G. R. (1997). Strategies and Games in Networks. In W. J. M. Kickert, E.-H. Klijn \& J. F. M. Koppenjan (Eds.), Managing Complex Networks: Strategies for the Public Sector (pp. 98-118). London: Sage.

Kling, R. (1978). Automated welfare client-tracking and service integration: the political economy of computing. Communications of the ACM, 21(6), 484-493.

Klischewski, R., \& Askar, E. (2012). Linking service development methods to interoperability governance: The case of Egypt. Government Information Quarterly, 29, $22-$ 31.

Korteland, E., \& Bekkers, V. J. J. M. (2007). Diffusion of E-Government Innovations in the Dutch Public Sector: The Case of Digital Community Policing. In M. A. Wimmer, H. J. Scholl \& A. Grönlund (Eds.), Proceedings of the 6th International Conference EGOV 2007 (pp. 252-264). Heidelberg: Springer.

Kracauer, S. (1952). The Challenge of Qualitative Content Analysis. Public Opinion Quarterly, 16(4), 631-642.

Kraemer, K. L., \& Dutton, W. H. (1979). The Interests Served By Technological Reform: The Case of Computing. Administration \& Society, 11, 80-106.

Kraemer, K. L., \& King, J. L. (1986). Computing and Public Organizations. Public Administration Review, 46(6), 488-496. 
Kraus, W. A. (1980). Collaboration in Organizations. Alternatives to Hierarchy. New York: Human Sciences Press.

Krebs, T. B., \& Pelissero, J. P. (2010). Urban managers and public policy: Do institutional arrangements influence decisions to initiate policy? Urban Affairs Review, 45, 393-411.

Kuan, K. K. Y., \& Chau, P. Y. K. (2001). A perception-based model for EDI adoption in small businesses using a technology-organization-adoption framework. Information $\mathcal{E}$ Management, 38, 507-521.

Kubicek, H. (2009). Governance of Interoperability in Intergovernmental Services - Towards an Empirical Taxonomy. Journal of Systemics, Cybernetics and Informatics, 6(6), 61-66.

Kubicek, H., Cimander, R., \& Scholl, H. J. (2011). Organizational Interoperability in EGovernment: Lessons from 77 European Good-Practice Cases. Heidelberg: Springer.

Kumar, K., \& van Dissel, H. G. (1996). Sustainable Collaboration: Managing Conflict and Cooperation in Interorganizational Systems. MIS Quarterly, 20(3), 279-300.

Kwon, H., Pardo, T. A., \& Burke, G. B. (2009). Interorganizational collaboration and community building for the preservation of state government digital information: Lessons from NDIIPP state partnership initiative. Government Information Quarterly, 26(1), 186-192.

Kwon, T. H., \& Zmud, R. W. (1987). Unifying the fragmented models of information systems implementation. In R. J. Boland \& R. A. Hirschheim (Eds.), Critical issues in information systems research (pp. 227-251). New York: John Wiley \& Sons.

Lam, W. (2005). Investigating success factors in enterprise application integration: a casedriven analysis. European Journal of Information Systems, 14(2), 175-187.

Landsbergen, D., \& Wolken, G. (2001). Realizing the Promise: Government Information Systems and the Fourth Generation of Information Technology. Public Administration Review, 61(2), 206-220.

Laskaridis, G., Markellos, K., Markellou, P., Panayiotaki, A., Sakkopoulos, E., \& Tsakalidis, A. (2007). E-government and Interoperability Issues. International Journal of Computer Science and Network Security, 7(9), 28-38.

Laudon, K. (1974). Computers and Bureaucratic Reform: The Political Functions of Urban Information Systems New York: John Wiley and Sons.

Layne, K., \& Lee, J. (2001). Developping fully functional E-government: A four stage model. Government Information Quarterly, 18, 122-136.

Lazar, D. (2004). Selected issues in teh philosophy of social science. In C. Seale (Ed.), Researching Society and Culture (pp. 7-21). London: Sage.

Lee, A. (1991). Integrating Positivist and Interpretive Approaches to Organizational Research. Organization Science, 2(4), 342-365.

Lee, J., Kim, H. J., \& Ahn, M. J. (2011). The willingness of e-Government service adoption by business users: The role of offline service quality and trust in technology. Government Information Quarterly.

Lee, J., \& Kim, J. (2007). Grounded theory analysis of e-government initiatives: Exploring perceptions of government authorities. Government Information Quarterly, 24(1), 135-147.

Lewins, A., \& Silver, C. (2007). Using Software in Qualitative Research: A Step-by-Step Guide. London: Sage.

Lincoln, Y., \& Guba, E. (1985). Naturalistic Inquiry. London: Sage. 
Löfstedt, U. (2005). E-Government - Assessment Of Current Research And Some Proposals For Future Directions. International Journal of Public Information Systems, 2005(1), 39-52.

Luna-Reyes, L. F., Gil-Garcia, J. R., \& Cruz, C. B. (2007). Collaborative digital government in Mexico: Some lessons from federal Web-based interorganizational information integration initiatives. Government Information Quarterly, 24, 808-826.

McGuire, M. (2006). Collaborative Public Management: Assessing What We Know and How We Know It. Public Administration Review, 66(s1), 33-43.

Meesters, M., \& Zuurmond, A. (2008). The transformation of government organizations. A theoretical and empirical exploration. Leiden: Centre for Government Studies.

Merton, R. K. (1968). Social theory and social structure. New York: Free Press.

Miles, M., \& Huberman, A. (1994). Qualitative Data Analysis: an Expanded Sourcebook. London: Sage.

Mill, J. S. (1904 [orig. 1843]). A system of logic, ratiocinative and inductive, being a connected view of the principles of evidence and the methods of scientific investigation London: Longmans, Green, and Co.

Minichiello, V., Aroni, R., \& Hays, T. N. (2008). In-Depth Interviewing: Principles, Techniques, Analysis (3rd ed.). Sydney: Pearson Education.

Mohr, L. B. (1969). Determinants of Innovation in organizations. American Political Science Review, 63(1), 111-126.

Moore, G. C., \& Benbasat, I. (1991). Development of an Instrument to Measure the Perceptions of Adopting an Information Technology Innovation. Information Systems Research, 2(3), 192-222.

Mustonen-Ollila, E., \& Lyytinen, K. (2004). Why organizations adopt information system process innovations: a longitudinal analysis. European Journal of Information Systems, 13(1), 35-51.

Myers, M. D., \& Klein, H. K. (1999). A Set of Principles for Conducting and Evaluating Interpretive Field Studies in Information Systems. MIS Quarterly, 23(1), 67-93.

National Performance Review. (1993). From Red Tape to Results, Creating A Government That Works Better and Costs Less: The Report of the National Performance Review. Washington, D.C.: Government Printing Office.

Nelson, K. L., \& Svara, J. H. (2011). Form of Government Still Matters: Fostering Innovation in U.S. Municipal Governments. The American Review of Public Administration(Published online 15 March 2011), 1-25.

Nelson, M. L., \& Shaw, M. J. (2001). Adoption Of Technology Standards In Supply Chains: A Case Of Adopting Rosettanet Standards. Paper presented at the DIGIT - 2001 IT Adoption \& Diffusion Workshop.

Nelson, M. L., \& Shaw, M. J. (2005). Interorganizational System Standards Diffusion: The Role of Industry-Based Standards Development Organizations Working Paper. UrbanaChampaign: University of Illinois.

O'Toole, L. J. (1997). Treating Networks Seriously: Practical and Research-Based Agendas in Public Administration. Public Administration Review, 57(1), 45-52.

O'Toole, L. J., Hanf, K. I., \& Hupe, P. L. (1997). Managing Implementation Processes in Networks. In W. J. M. Kickert, E.-H. Klijn \& J. F. M. Koppenjan (Eds.), Managing Complex Networks: Strategies for the Public Sector (pp. 137-151). London: Sage. 
OECD. (2003). The e-Government Imperative. Paris: Organisation for Economic Cooperation and Development.

Oliver, C. (1990). Determinants of Interorganizational Relationships: Integration and Future Directions. Academy of Management Review, 15(2), 241-265.

Osborne, S. P., \& Brown, K. (2005). Managing Change and Innovation in Public Service Organizations. New York: Routledge.

Parasie, N. (2010). Adoption of E-Government Standards: Increasing Interoperability in the Public Sector. Giessen: VVB Lauferweiler Verlag.

Pardo, T. (2007). Interorganizational information integration: A key enabler for digital government. Government Information Quarterly, 24, 691-715.

Pardo, T., \& Burke, B. G. (2009). IT Governance Capability: Laying the foundation for government interoperability. Albany: Center for Technology in Government.

Pardo, T., Nam, T., \& Burke, B. G. (2012). E-Government Interoperability: Interaction of Policy, Management, and Technology Dimensions. Social Science Computer Review, 30(1), 7-23.

Pasquero, J. (1991). Supraorganizational Collaboration: The Canadian Environmental Experiment. Journal of Applied Behavioral Science, 27(1), 38-64.

Perry, J. L., \& Rainey , H. G. (1988). The Public-Private Distinction in Organization Theory: A Critique and Research Strategy The Academy of Management Review, 13(2), 182-201.

Popper, K. R. (2002). Conjectures and refutations: the growth of scientific knowledge. London: Routledge.

Premkumar, G., \& Ramamurthy, K. (1995). The Role of Interorganizational and Organizational Factors on the Decision Mode for Adoption of Interorganizational Systems. Decision Sciences, 26(3), 303-336.

Provan, K. G., \& Kenis, P. (2008). Modes of Network Governance: Structure, Management, and Effectiveness. Journal of Public Administration Research and Theory, 18(2), 229-252.

Pugh, D. S., Hickson, D. J., \& Hinings, C. R. (1969). An Empirical Taxonomy of Work Organizations. Administrative Science Quarterly, 14, 115-126.

Rainey, H. G. (1999). Using comparisons of public and private organizations to assess innovative attitudes among members of organizations. Public Productivity $\mathcal{E}$ Management Review, 23(2), 130-149.

Rainey, H. G. (2009). Understanding and Managing Public Organizations (4th ed.). San Francisco: Jossey-Bass.

Rainey , H. G., Backoff, R. W., \& Levine, C. H. (1976). Comparing Public and Private Organizations. Public Administration Review, 36(2), 233-244.

Raus, M., Flügge, B., \& Boutellier, R. (2009). Electronic customs innovation: An improvement of governmental infrastructures. Government Information Quarterly, 26(2), 246.

Richards, L. (2005). Handling Qualitative Data. London: Sage.

Ridley, D. (2012). The literature review: a step-by-step guide for students. London: Sage.

Ring, P., \& Van De Ven, A. H. (1994). Developmental Processes of Cooperative Interorganizational Relationships. Academy of Management Review, 19(1), 90-118.

Roberts, P., \& Henderson, R. (2000). Information technology acceptance in a sample of government employees: a test of the technology acceptance model. Interacting with Computers, 12(5), 427-443. 
Rogers, E. (2003). Diffusion of Innovations (5th Edition, first published 1962). New York: Free Press.

Sabherwal, R., Jeyaraj, A., \& Chowa, C. (2006). Information System Success: Individual and Organizational Determinants. Management Science, 52(12), 1849-1864.

Saldaña, J. (2009). The Coding Manual for Qualitative Researchers. London: Sage.

Samuelson, O., \& Björk, B.-C. (2010). Adoption processes for EDM, EDI and BIM technologies in the construction industry. Pre-print version. Hanken University. Helsinki.

Sandholtz, K. W. (2012). Making Standards Stick: A Theory of Coupled vs. Decoupled Compliance. Organization Studies, 33(5-6), 655-679.

Schaap, L., \& van Twist, M. J. V. (1997). The Dynamics of Closedness in Networks. In W. J. M. Kickert, E.-H. Klijn \& J. F. M. Koppenjan (Eds.), Managing Complex Networks: Strategies for the Public Sector (pp. 62-78). London: Sage.

Schaupp, L. C., Carter, L., \& McBride, M. E. (2010). E-file adoption: A study of U.S. taxpayers' intentions. Computers in Human Behaviour, 26(4), 636-644.

Schermerhorn, J. R. (1975). Determinants of Interorganizational Cooperation. The Academy of Management Journal, 18(4), 846-856.

Schmidt, S. K., \& Werle, R. (1998). Coordinating Technology: Studies in the International Standardization of Telecommuincations. Cambridge: MIT Press.

Scholl, H. J., \& Klischewski, R. (2007). E-Government Integration and Interoperability: Framing the Research Agenda. International Journal of Public Administration, 30(8/9), 889920.

Seale, C. (2010). Using Computers to Analyse Qualitative Data. In D. Silverman (Ed.), Doing Qualitative Research (pp. 251-267). London: Sage.

Seawright, J., \& Gerring, J. (2008). Case Selection Techniques in Case Study Research. A Menu of Qualitative and Quantitative Options. Political Research Quarterly, 61(2), 294308.

Shapiro, C., \& Varian, H. R. (1999). Information Rules. A Strategic Guide to the Network Economy. Boston: Harvard Business School Press.

Shareef, M. A., Kumar, V., Kumar, U., \& Dwivedi, Y. K. (2010). e-Government Adoption Model (GAM): Differing service maturity levels. Government Information Quarterly, 28(1), 17-35.

Sheppard, B. H., Hartwick, J., \& Warshaw, P. R. (1988). The Theory of Reasoned Action: A Meta-Analysis of Past Research with Recommendations for Modifications and Future Research. Journal of Consumer Research, 15(3), 325-343.

Silcock, R. (2001). What is e-Government? Parliamentary affairs, 54, 88-101.

Silverman, D. (2010). Doing Qualitative Researcj. London: Sage.

Slager, R., Gond, J.-P., \& Moon, J. (2012). Standardization as institutional work: The regulatory power of a responsible investment standard. Organization Studies, 33(5-6), 763-790.

Smith, C. R. (2009). Institutional Determinants of Collaboration: An Empirical Study of County Open-Space Protection Journal of Public Administration Research and Theory, 19(1), 1-21.

Soares, D., \& Amaral, L. (2011). Information Systems Interoperability in Public Administration: Identifying the Major Acting Forces through a Delphi Study. Journal of Theoretical and Applied Electronic Commerce Research, 6(1), 61-94. 
Soeparman, S., van Duivenboden, H., \& Oosterbaan, T. (2009). Infomediaries and collaborative innovation: A case study on Information and Technology centered Intermediation in the Dutch Employment and Social Security Sector Information Polity, 14(4), 261-278.

Solli-Saether, H. (2010). Analytical Framework for e-Government Interoperability. Paper presented at the eChallenges e-2010 Conference, Warsaw, Poland.

Span, K. C. L., Luijkx, K. G., Schols, J. M. G. A., \& Schalk, R. (2012). The Relationship Between Governance Roles and Performance in Local Public Interorganizational Networks: A Conceptual Analysis. The American Review of Public Administration, 42(2), 186-201.

Stichting Studielink. (2008). Beheerplan Studielink. Utrecht: Stichting Studielink.

Strauss, A. L., \& Corbin, J. M. (1998). Basics of qualitative research: techniques and procedures for developing grounded theory. Thousand Oaks: Sage.

Stummer, M., \& Zuchi, D. (2010). Developing roles in change processes - A case study from a public sector organisation. International Journal of Project Management, 28, 384-394.

Tambouris, E., Tarabanis, K., Peristeras, V., \& Liotas, N. (2007). Study on Interoperability at Local and Regional Level. Brussels: European Commission.

Tansey, O. (2007). Process Tracing and Elite Interviewing: A Case for Non-probability Sampling. Political Science and Politics, 40(4), 765-772.

Taylor, S., \& Todd, P. A. (1995). Assessing IT Usage: The Role of Prior Experience. MIS Quarterly, 19(2), 561-570.

Teo, H. H., Wei, K. K., \& Benbasat, I. (2003). Predicting Intention to Adopt Interorganizational Linkages: An Institutional Perspective. MIS Quartely, 27(1), 19-49.

Thaens, M. (2009). "Fatsoenlijk besturen" ten aanzien van de elektronische overheid: Een verkenning van de 'governance van interoperabiliteit'. Nieuwegein: Ordina.

Thomson, A. M., \& Perry, J. L. (2006). Collaboration Processes: Inside the Black Box. Public Administration Review, 66(s1), 20-32.

Thomson, A. M., Perry, J. L., \& Miller, T. K. (2009). Conceptualizing and Measuring Collaboration. Journal of Public Administration Research and Theory, 19(1), 23-56.

Tolbert, C. J., Mossberger, K., \& McNeal, R. (2008). Institutions, Policy Innovation, and EGovernment in the American States. Public Administration Review, 68(3), 549-563.

Torabkhani, R., Smits, M., \& van der Pijl, G. (2007). Improving the Performance of Business Networks in E-Government. Paper presented at the 20th Bled eConference Bled, Slovenia.

Tornatzky, L. G., \& Fleischer, M. (1990). The Processes of Technological Innovation. Lexington: Lexington.

Tornatzky, L. G., \& Klein, K. J. (1982). Innovation Characteristics and Innovation AdoptionImplementation: A Meta-Analysis of Findings. IEEE Transactions on Engineering Management, 29(1), 28-43.

Tseng, P. T. Y., Yen, D. C., Hung, Y.-C., \& Wang, N. C. F. (2008). To explore managerial issues and their implications on e-Government deployment in the public sector: Lessons from Taiwan's Bureau of Foreign Trade. Government Information Quarterly, 25(4), 734756.

United Nations. (2008). United Nations e-Government Survey 2008: From e-Government to Connnected Governance. New York: United Nations. 
United Nations. (2010). E-Government Survey 2010: Leveraging e-government at a time of financial and economic crisis. New York: United Nations.

United Nations. (2012). E-Government Survey 2012: E-Government for the People. New York: United Nations.

United Nations, \& American Society for Public Administration. (2002). Benchmarking egovernment: A global perspective. New York: UN Publications.

Vaidya, K., Sajeev, A. S. M., \& Callender, G. (2006). Critical Factors That Influence EProcurement Implementation Success in the Public Sector. JOURNAL OF PUBLIC PROCUREMENT, 6, 70-99.

Van de Ven, A. H. (1976). A Framework For Organization Assessment. Academy of Management Review, 1(1), 64-78.

Van de Ven, A. H., \& Walker, G. (1984). The Dynamics of Interorganizational Coordination. Administrative Science Quarterly, 29(4), 598-621.

van Dijk, J. A. G. M., Peters, O., \& Ebbers, W. (2008). Explaining the acceptance and use of government Internet services: A multivariate analysis of 2006 survey data in the Netherlands. Government Information Quarterly, 25(3), 379-399.

van Dijk, T. (2007). Kink in de keten: Inventarisatie van de bevorderende en belemmerende factoren bij samenwerking tussen landelijke overheidsorganisaties op het gebied van ICT Enschede: Twente University.

van Gunsteren, H. R. (1976). The quest for control: a critique of the rational-central-rule approach in public affairs. London: John Wiley.

van Slyke, D. M. (2007). Agents or Stewards: Using theory to understand the governmentnonprofit social service contracting relationship. Journal of Public Administration Research and Theory, 17, 157-187.

Vann, J. L. (2004). Resistance to Change and the Language of Public Organizations: A Look at "Clashing Grammars" in Large-Scale Information Technology Projects Public Organization Review: A Global Journal, 4, 47-73.

Veit, D., \& Parasie, N. (2010). Common Data Exchange Standards: Determinants for Adoption at the Municipal Level. Paper presented at the 16th Americas Conference on Information Systems, Lima, Peru.

Veit, D. J., Parasie, N. P., \& Huntgeburth, J. C. (2011). E-Procurement Adoption at the Municipal Level: Influence of Organizational, Technological and Environmental Factors. Paper presented at the 44th Hawaii International Conference on System Sciences (HICSS), Kauai, Hawaii.

Venkatesh, V., \& Davis, F. D. (2000). A Theoretical Extension of the Technology Acceptance Model: Four Longitudinal Field Studies. Management Science, 45(2), 186-204.

Venkatesh, V., Morris, M. D., Davis, G. B., \& Davis, F. D. (2003). User Acceptance of Information Technology: Toward a Unified View. MIS Quartely, 27(3), 425-478.

Vernadat, F. B. (2010). Technical, semantic and organizational issues of enterprise interoperability and networking. Annual Reviews in Control, 34, 139-144.

Walker, R. M. (2008). An empirical evaluation of innovation types and organizational and environmental characteristics: Towards a configuration approach. An empirical evaluation of innovation types and organizational and environmental characteristics: Towards a configuration approach., 18, 591-615. 
Wang, Y.-S., \& Shih, Y.-W. (2009). Why do people use information kiosks? A validation of the Unified Theory of Acceptance and Use of Technology. Government Information Quarterly, 26(1), 158-165.

Weill, P., \& Ross, J. W. (2004). IT governance: how top performers manage IT decision rights for superior results. Boston: Harvard Business School Press.

Weiss, R. S. (1994). Learning from Strangers: The Art and Method of Qualitative Interview Studies. New York: The Free Press.

Weitzel, T., Beimborn, D., \& Konig, W. (2006). A unified economic model of standard diffusion: The impact of standardization cost, network effects, and network topology MIS Quarterly, 30, 489-514.

Welp, Y., Urgell, F., \& Aibar, E. (2007). From Bureaucratic Administration to Network Administration? An Empirical Study on E-Government Focus on Catalonia. Public Organization Review, 7, 299-316.

West, J. P., \& Berman, E. M. (1997). Administrative creativity in local government. Public Productivity \& Management Review, 20, 446-458.

Westholm, I. (2005). Models of Improving e-Governance by Back-Office Re-Organisation and Integration. Journal of Public Policy, 25(1), 99-132.

Weston, C., Gandell, T., Beauchamp, J., McAlpine, L., Wiseman, C., \& Beauchamp, C. (2001). Analyzing Interview Data: The Development and Evolution of a Coding System. Qualitative Sociology, 24(3), 381-400.

Wetenschappelijke Raad voor het Regeringsbeleid. (2011). iOverheid. Den Haag/Amsterdam: WRR/Amsterdam University Press.

Whetten, D. A., \& Leung, T. K. (1979). The Instrumental Value of Interorganizational Relations: Antecedents and Consequences of Linkage Formation. Academy of Management Journal, 22(2), 325-344.

Willem, A., \& Gemmel, P. (2013). Do governance choices matter in health care networks?: an exploratory configuration study of health care networks. BMC Health Services Research, 13, 229-239.

Williams, C. B., Dias, M., Fedorowicz, J., Jacobson, D., Vilvovsky, S., Sawyer, S., \& Tyworth, M. (2009). The formation of inter-organizational information sharing networks in public safety: Cartographic insights on rational choice and institutional explanations. Information Polity, 14, 13-29.

Williams, M. (2002). Generalization in interpretive research. In T. May (Ed.), Qualitative research in action (pp. 125-143). London: Sage.

Wise, L. R. (1999). The Use of Innovative Practices in the Public and Private Sectors: The Role of Organizational and Individual Factor. Public Productivity \& Management Review, 23(2), 150-168.

Yang, T.-M., \& Maxwell, T. A. (2011). Information-sharing in public organizations: A literature review of interpersonal, intra-organizational and inter-organizational success factors. Government Information Quarterly, 28, 164-175.

Yang, T.-M., Zheng, L., \& Pardo, T. (2011). The boundaries of information sharing and integration: A case study of Taiwan e-Government. Government Information Quarterly(Published online 3 December 2011).

Yildiz, M. (2007). E-government research: Reviewing the literature, limitations, and ways forward. Government Information Quarterly, 24(3), 646-665. 
Zhan, Y., Wang, P., \& Xia, S. (2011). Exploring the Drivers for ICT Adoption in Government Organization in China Paper presented at the Fourth International Conference on Business Intelligence and Financial Engineering (BIFE), Wuhan.

Zhu, K., Kraemer, K. L., Gurbaxani, V., \& Xu, S. X. (2006). Migration to open-standard interorganizational systems: network effects, switching costs, and path dependency. MIS Quarterly, 30, 515-539. 


\section{Annex K. Samenvatting in het Nederlands}

\section{K1. Onderzoeksproblematiek en vraagstellingen}

Dit proefschrift onderzoekt een aantal vraagstellingen over het onderwerp van de adoptie van standaarden in e-Governance. Gedreven door nieuwe governance paradigma's en bevorderd door de mogelijkheden van ICT om elektronisch grote hoeveelheden van data op te slaan, te bewerken en uit te wisselen, zien we een trend naar een maatschappelijk bestuur dat gebruik maakt van ICT-gesteunde, inter-organisatorische netwerken "Overheidsinformatienetwerken" ("Government Information Networks"). Deze netwerken worden beschouwd als een bijdrage aan significante verbeteringen in efficiëntie en effectiviteit van het openbaar bestuur, omdat ze de samenwerking tussen verschillende overheids- en niet-overheids-actoren bevorderen. Het bereiken van deze doelen eist de vaardigheid van de organisaties in deze netwerken om elektronisch informatie en diensten onderling uit te wisselen. Met andere woorden moeten ze "interoperabiliteit" (IOP) bereiken, wat inachtneming van een gezamenlijke groep van standaarden en afspraken vereist; hun "IOP-architectuur". Echter, we zien in de praktijk dat Overheidsinformatienetwerken grote moeite hebben om IOP te bereiken, omdat de organisaties in deze netwerken de technologische, semantische, en organisatorische IOPstandaarden die in de IOP-architectuur van hun netwerk gespecificeerd zijn niet adopteren en naleven.

Dit proefschrift heeft daarom tot doel om aan een beter begrip van de adoptie van IOPstandaarden in Overheidsinformatienetwerken bij te dragen, vooral het proces van adoptie, de bevorderende en belemmerende invloedsfactoren van adoptie.Tevens wil dit proefschrift ook inzichten geven in hoe "IOP-governance" (de regels en procedures rond het maken van beslissingen over hun IOP-architectuur) het beste kan benaderd worden. Het proefschrift onderzoekt dit door een theoretisch model te ontwikkelen en twee case studies te onderzoeken om een aantal onderzoeksvragen ten aanzien van deze doelstellingen te beantwoorden.

De centrale onderzoeksvraag in dit proefschrift is: wat zijn de invloedsfactoren van de adoptie van IOP-standaarden door organisaties in Overheidsinformatienetwerken, en wat zijn hun implicaties voor effectieve IOP-governance? Ten aanzien van deze centrale onderzoeksvraag worden drie deelvragen (DV) gesteld: DV1) Hoe kunnen we de adoptie van IOPstandaarden in Overheidsinformatienetwerken conceptualiseren?; DV2) Wat zijn de invloedfactoren die de adoptie van IOP-standaarden in Overheidsinformatienetwerken bepalen?; en DV3) Hoe beïnvloeden de verschillende niveaus van centralisatie van IOPgovernance de adoptie van IOP-standaarden in Overheidsinformatienetwerken?

\section{K2. Opbouw van het proefschrift in hoofdstukken}

Het eerste hoofdstuk van het proefschrift beschrijft het beleidsprobleem, de onderzoeksvragen en de centrale concepten als basis voor de volgende hoofdstukken. Hoofdstuk 2 legt de theoretische basis voor de empirische analyse in Hoofdstukken 4 tot en 
met 6, door een voorlopig theoretisch model van invloedsfactoren van adoptie uit de relevante theorievelden af te leiden. Hoofdstuk 3 beschrijft de methodologische benadering van het proefschrift, en geeft een overzicht van de twee case studies die de kern van de empirische analyse en de rest van het proefschrift vormen. Hoofdstuk 4 richt zich op DV1 en geeft een gedetailleerde omschrijving van de adoptie van IOP-standaarden, door te onderzoeken wat de implicaties zijn voor organisaties in Overheidsinformatienetwerken, wat de processen van adoptie zijn en welke actoren betrokken zijn. Hoofdstuk 5 richt zich dan op DV2 door te onderzoeken wat de invloedfactoren zijn van de adoptie van IOPstandaarden door organisaties in Overheidsinformatienetwerken. Hoofdstuk 6 richt zich op DV3 door te onderzoeken in hoeverre, voor netwerken van verschillende complexiteit, de verschillende niveaus van centralisatie van IOP-governance verschillende effecten op de adoptie van IOP-standaarden door organisaties hebben. Hoofdstuk 7 trekt conclusies over de bevindingen van het proefschrift.

\section{K3. Methoden van dataverzameling en analyse}

Ten aanzien van de explorerende aard van de onderzoeksvraag wordt voor een kwalitatieve methodologische benadering gekozen. In plaats van een positivistische benadering die probeert om de precieze effecten van de individuele invloedsfactoren van adoptie te meten, wordt een interpretivistische benadering gekozen die kwalitatieve data over de ervaringen en percepties van stakeholders gebruikt om: de invloedsfactoren van adoptie te identificeren en te beschrijven; een gedetailleerde beschrijving te geven van hoe stakeholders de relevantie van deze factoren ervaren; het adoptieproces te analyseren, en om de wisselwerking tussen specifieke invloedsfactoren te onderzoeken (namelijk tussen de centralisering van IOP-governance en netwerk complexiteit).

De data voor dit onderzoek is afkomstig van 37 semigestructureerde interviews met belangrijke informanten ("key informants") uit twee Overheidsinformatienetwerken in Nederland, die door de onderzoeker in de periode van januari tot september 2011 werden afgenomen. De twee case studies werden geselecteerd als representatieve voorbeelden van Overheidsinformatienetwerken. De eerste case, het Digitaal Klantdossier (DKD), vormt een complex netwerk rond een landelijk informatiesysteem dat verschillende databases uit het werk- en inkomensdomein (SUWI) verbindt en de mogelijkheid geeft om relevante informatie over individuele SUWI-klanten in een digitaal dossier te bundelen. De tweede case, Studielink, is een niet-complex netwerk uit de sector Hoger Onderwijs rond een centraal informatiesysteem dat de elektronische uitwisseling van studenteninschrijvingsgegevens tussen organisaties in de sector Hoger Onderwijs mogelijk maakt.

De interviews werden gevoerd met "key informants" uit partner organisaties in de twee netwerken, en met "key informants" op netwerkniveau van elke case. De data-analyse is gebaseerd op het kwalitatieve coderen van de interviewtranscripten met hulp van de atlas.ti software. Kwalitatief coderen, algemeen beschreven, houdt in dat segmenten van de data met conceptuele categorieën ("codes") "getagged" worden, waarbij elke code een specifiek concept uit het theoretische kader representeert. De codes werden ontwikkeld door een deductieve (theorie-gebaseerde) en inductieve (data-gebaseerde) benadering. Twee strategieën werden voor de analyse van de gecodeerde tekstsegmenten ("quotations") gebruikt. Ten eerste gebruikte een interpretatieve analysestrategie de codes als een manier 
om de statements van de geïnterviewden (quotations) te verzamelen, met als doel om de onderliggende dimensies van elk concept en de patronen van onderlinge relaties tussen de concepten te identificeren. Ten tweede heeft een inhoudsanalyse de frequenties voor alle codes gebruikt om hun relatieve relevantie voor de geïnterviewde stakeholders en de verbindingen tussen concepten vast te stellen.

\section{K4. Centrale Bevindingen van het proefschrift}

Dit proefschrift biedt een aantal bevindingen die aan een beter theoretisch begrip van de adoptie van IOP-standaarden en van IOP-governance in Overheidsinformatienetwerken bijdragen, en geeft tevens een aantal aanbevelingen ten aanzien van hoe IOP in deze netwerken bestuurd moet worden. De centrale contributies omvatten drie gebieden.

De eerste belangrijke contributie van het proefschrift (met betrekking tot DV1, behandeld in Hoofdstuk 4) is een betere conceptualisering van de adoptie van IOP-standaarden in Overheidsinformatienetwerken. Deze conceptualisering toont aan dat een holistisch perspectief op de technologische, semantische en organisatorische dimensies van IOP nodig is en dat de gebruikelijke focus op de technologische dimensie alleen niet de realiteit weerspiegelt. Het proefschrift wijst ook naar een gebrek aan proces-geörienteerde perspectieven op de adoptie van standaarden, en biedt een aantal bevindingen die de "black box" van deze processen openen, door de essentiële fasen en een typologie van de relevante actoren te identificeren.

De tweede belangrijke contributie van dit proefschrift (met betrekking tot DV2, behandeld in Hoofdstuk 4 en 5) is het ontwikkelen en empirisch valideren van een theoretisch model van de invloedsfactoren van de adoptie van IOP-standaarden door organisaties in Overheidsinformatienetwerken. Dit draagt bij aan een voorheen ontbrekende integratie van de verspreide bestaande theorieën over dit onderwerp, en geeft tevens een basis voor toekomstige metingsinstrumenten. Daarnaast stelt het onderzoek in dit proefschrift de relatieve relevantie vast van de geïdentificeerde invloedsfactoren voor de verschillende groepen van stakeholders in Overheidsinformatienetwerken, en identificeert tevens de centrale aandachtspunten voor IOP-governance. In het bijzonder wijzen de bevindingen naar de noodzaak voor een context-sensitieve benadering van IOP-governance, vooral met betrekking tot de context van de complexiteit van en bepaald netwerk.

De derde belangrijke contributie is gebaseerd op de vorige bevinding van dit proefschrift. Deze contributie heeft betrekking op DV3 (behandeld in Hoofdstuk 6) en geeft relevante aanbevelingen over hoe gecentraliseerd de IOP-governance van een bepaald netwerk moet zijn ten aanzien van de complexiteit van dit netwerk. Hiervoor ontwikkeld het proefschrift eerst een theoretisch kader om de centralisering van IOP-governance en de complexiteit van Overheidsinformatienetwerken te beoordelen. Dit wordt gedaan door de essentiële dimensies van de complexiteit van Overheidsinformatienetwerken (structurele complexiteit, diversiteit en taakcomplexiteit) en van IOP-governance centralisering (de centralisering van beslissingen en handhaving met betrekking tot IOP-standaarden) te identificeren. Hiernaast wordt een aantal theoretische voorstellen ontwikkeld die bestaande theoretische argumenten valideren, namelijk dat een hogere complexiteit van netwerken een meer gecentraliseerde governance vereist. Tenslotte geeft het proefschrift een aantal op empirisch onderzoek gebaseerde aanbevelingen ten aanzien van het ontwerpen van IOP-governance 
zodat deze overeen komt met de verschillende niveaus van complexiteit van Overheidsinformatienetwerken.

Dit proefschrift trekt niet alleen een aantal theoretische en praktijk-georiënteerde conclusies die bestaande hiaten in de theorie en praktijk belichten, maar vormt ook de basis voor toekomstig onderzoek over dit onderwerp. Het proefschrift toont echter ook aan dat in de praktijk een degelijk begrip van IOP-governance ontbreekt. Met oog op de continuerende trend naar inter-organisatorische samenwerking in e-Governance, belooft IOP-governance ook in de nabije toekomst een uitdagend onderwerp te blijven. 


\section{Annex L. Summary in English}

\section{L1. Research Problem and Research Questions}

This dissertation investigates a series of questions on the issue of standards adoption in eGovernance. Driven by new governance paradigms and fuelled by the possibilities of ICT to electronically store, process and exchange large amounts of data, we are witnessing a continuing trend towards governing societies through ICT-enabled, inter-organisational networks ("Government Information Networks"). Such networks are expected to improve public governance by enabling significant increases in its efficiency and effectiveness through enabling collaboration between various governmental and non-governmental actors. The successful achievement of these goals essentially rests upon the ability of the organisations in these networks to electronically exchange and use information and services among each other. In other words, they need to achieve "interoperability" (IOP), which necessitates their adherence to a common set of standards and agreements - their "IOP architecture". Unfortunately, in practice Government Information Networks often encounter substantial difficulties in achieving IOP because the organisations participating in them fail to take the necessary measures to adopt and comply with the technical, semantic and organisational IOP standards specified in their network's IOP architecture.

This dissertation therefore aims at contributing to a better understanding of IOP standards adoption in Government Information Networks, in particular of the process of adoption as well as the drivers and barriers behind adoption, and aims at providing insights and guidance on how to best approach "IOP governance" in such networks (i.e. the decisionmaking rules and procedures to direct and oversee their IOP architecture). To this end, it combines a theoretical modelling approach with two in-depth case studies to address a number of research questions that aim at contributing to these objectives.

The main research question of this dissertation is: what are the factors that determine the adoption of IOP standards by organisations in Government Information Networks, and what are their implications for effective IOP Governance? In view of this main research question, three sets of sub-questions (SQs) are specified: SQ1) How can we conceptualise IOP standards adoption in Government Information Networks?; SQ2) What are the factors that determine the adoption of IOP standards by organisations in Government Information Networks?; and SQ3) How do different degrees of IOP governance centralisation affect the adoption of IOP standards in Government Information Networks?

\section{L2. Dissertation Chapter Structure}

The first chapter explains the policy problem motivating the thesis, the research questions, and introduces the central concepts as a basis for the subsequent chapters. Chapter 2 provides a theoretical foundation for the empirical analysis in Chapters 4 to 6 , by means of deriving a preliminary theoretical model of determinants of adoption from the relevant fields of theory. Chapter 3 describes the methodological approach of the dissertation, and gives an overview of the two case studies that form the core of the empirical analysis in the 
remainder of the thesis. Chapter 4 then focuses on SQ1 by providing a more detailed understanding of IOP standards adoption, by investigating what its implications are for organisations in Government Information Networks, what the processes of adoption are and which actors are involved. Chapter 5 subsequently focuses on SQ2 by investigating what the determinants of organisations' adoption of IOP standards are. Chapter 6 then focuses on SQ3 by investigating whether and how for different degrees of network complexity, different degrees of IOP governance centralisation result in different effects on organisations' adoption of IOP standards. Finally, Chapter 7 provides concluding remarks on the dissertation's findings.

\section{L3. Methods of Data Collection and Analysis}

Due to the exploratory nature of the research question, a qualitative methodological approach was chosen. Instead of a quantitative approach aiming at measuring the precise effects of individual determinants on adoption, an interpretivist approach is taken that uses qualitative data on stakeholders' experiences and perceptions in order to identify and describe what the factors are that influence adoption, to give an in-depth understanding of how stakeholders experience their relevance, to analyse the adoption process, and to investigate the interplay of specific determinants (IOP governance centralisation and network complexity).

The data for this study comes from 37 semi-structured interviews with key informants from two Government Information Networks in the Netherlands, conducted by the researcher in the period from January until September 2011. The two cases were selected as representative instances of Government Information Networks. The first case, the Digital Client Dossier (Digitaal Klantdossier, DKD), forms a highly complex network which is centred around a nation-wide information system linking various databases from the work and income (SUWI) sector, allowing to collate relevant information on individual SUWI clients into a digital dossier. The second case, Studielink, on the other hand is a fairly non-complex network from the higher education domain, based on a central information system for the electronic exchange of student registration data across organisations in the Dutch higher education sector.

Interviews have been conducted with key informants from partner organisations from the two networks, as well as informants at the network level for each case. The data analysis is based on the qualitative coding of the interview transcripts, using the atlas.ti software package. Qualitative coding, broadly described, refers to the "tagging" of the data with conceptual categories ("codes"), each representing a different key concept from the theoretical framework. The codes were generated through a combined deductive (theorydriven) and inductive (data-driven) approach. Two strategies were used for the analysis of the coded text segments ("quotations"). First, an interpretive analysis strategy used the codes as a means of "filing" interviewees' statements (quotations) by the concepts defined in the theoretical framework, in order to identify the subdimensions of a concept and patterns of relationships across them. Second, a content analysis used the frequencies of quotations per code in order to assess their relevance to the interviewed stakeholders and to assess relationships between concepts. 


\section{L4. Key Findings of the Dissertation}

This dissertation offers a number of findings that contribute to a better theoretical understanding of IOP standards adoption and IOP governance in Government Information Networks, and provides a number of policy-relevant recommendations on how IOP in such networks should be governed. Its central contributions cover three main areas.

The first major contribution of the dissertation (addressing SQ1, discussed in Chapter 4) is a better conceptualisation of IOP standards adoption in Government Information Networks, showing that a holistic perspective across the technological, semantic and organisational dimensions of IOP is necessary and that the frequent focus on technological IOP is misaligned with reality. The dissertation also points to the lack of process perspectives on standards adoption, and provides several findings to open the "black box" of this process, by identifying key phases as well as a typology of the relevant actors involved.

The second key contribution of this dissertation (addressing SQ2, discussed in Chapters 4 and 5) is that it develops and empirically validates a theoretical model on the determinants of the adoption of IOP standards by organisations in Government Information Networks, thus contributing a previously missing integration of the disparate existing theory on this topic, as well as providing the basis for future measurement instruments. Moreover, the research presented in this dissertation determines the relative relevance of the identified determinants for the different groups of stakeholders in Government Information Networks, thus identifying the key areas for IOP governance. In particular, the findings highlight the necessity for a context-sensitive approach to IOP governance, especially with regard to the context formed by the complexity of a given network.

Based on the finding that IOP governance design should take a context-sensitive approach and align itself with key characteristics of the network, the third major contribution of the dissertation (addressing SQ3, discussed in Chapter 6) is to provide relevant recommendations as to how the degree of IOP governance centralisation should be chosen in relation to a given network's complexity. To this end, it first develops a framework for assessing and designing IOP governance centralisation and network complexity by identifying and conceptualising the essential dimensions of both the complexity of Government Information Networks (structural complexity, diversity and task complexity) and the degree of centralisation of IOP governance (decision-making centralisation and enforcement). It also provides several theoretical propositions that support previous theoretical arguments that higher network complexity requires more centralised IOP governance. And finally, it gives a number of evidence-based recommendations on how IOP governance can best be designed in order to match a network's degree of complexity.

In conclusion, this dissertation does not only provide a number of theoretical and practiceoriented conclusions that address previous gaps in theory and practice, it also provides the ground for future research on this topic. However, the dissertation also highlights that in practice, stakeholders still seem far from having a solid understanding of IOP governance. Considering this in view of the continuing trend towards connected forms of e-Governance, IOP governance promises to provide a challenging agenda for the foreseeable future, for practice and research alike. 


\section{Annex M. Valorisation}

This annex discusses the valorisation of this dissertation. It begins with a brief description of the general background, explaining why interoperability (IOP) in Government Information Networks is a relevant source of social and economic value, and why the problems in achieving it require the scientific knowledge presented in this dissertation. This is followed by a discussion how the main knowledge contributions presented in this dissertation can be translated into social and economic value.

It is the ultimate goal of studying public policy study to generate knowledge that translates into recommendations about how policies should be made in order to improve public welfare. As such, a great deal of public value lies in the subject domain which this dissertation addresses. The social, policy-related and economic value creation that is the objective of e-Governance, and in particular Government Information Networks, is discussed in depth in Chapter 1 of this dissertation and summarised further below in this annex. Achieving these objectives essentially rests upon the ability of the organisations in these networks to electronically exchange information and services among each other - in other words, they must be "interoperable". To achieve IOP, organisations need to adhere to a common set of standards and agreements. Achieving IOP, however, is challenging because often organisations in Government Information Networks do not adopt and comply with these standards.

The potential for public value creation from this dissertation is that it provides relevant findings and recommendations that can help stakeholders to achieve the potential benefits of Government Information Networks by contributing a better understanding of IOP standards adoption by organisations in Government Information Networks, in particular of the process, actors, drivers and barriers behind their adoption, and by providing insights and guidance how to best approach the governance on IOP in such networks.

As argued by OECD (2003), e-Governance can generate public value by 1) improving the efficiency of public administrations; 2) improving public service provision for customers; 3 ) improving the outcomes of specific policies; 4) contributing to economic policy objectives; 5) serving as a major catalyst for administrative modernisation and reform; and 6) contributing to better democracy. More specifically regarding Government Information Networks, the benefits can be of organisational, political and technological nature (cf. Dawes 1996; GilGarcia, Chengalur-Smith, \& Duchessi, 2007). Organisational benefits include improved decision-making, reduced administrative burden and costs, and better enforcement due to the availability of more and higher-quality information. In particular, Government Information Networks facilitate public services that are oriented at citizens' "life events" rather than following bureaucratic structures. Political benefits include increased accountability, better service provision, as well as improved interactivity, responsiveness and an improved public image as a result. Technical benefits include for instance the formation of a shared infrastructure and reduced duplication of data collection, processing and storage with an associated reduction of administration costs. 
It is one key contribution of this dissertation to identify and discuss in detail the potential benefits from IOP in Government Information Networks. In particular, the benefits from IOP in Government Information Networks identified in this dissertation include gains in administrative efficiency (such as operations cost, usability), effectiveness (including service quality, responsiveness), public data management (for instance data quality and security), resource acquisition (such as information and financial resources), benefits for coordination (improved reporting and uncertainty reduction), improved image (demonstrability of results and accountability), greater reach of organisations, and enhanced innovativeness of public governance (for instance creating new services and delivery mechanisms). For each of these points, the dissertation provides further detail and discusses concrete examples how public value can be generated.

However, the dissertation does not only generate value by identifying and discussing the benefits from IOP in Government Information Networks, it also provides both a theoretical basis and concrete guidance how to overcome the barriers to achieving IOP and reaping these benefits. These are discussed in the remainder of this annex.

One major contribution of the dissertation to this is to provide an empirically validated conceptualisation of IOP and its implications for adopting organisations. First, the dissertation validates the distinction of the three interrelated dimensions of technological, semantic and organisational IOP standards as a useful analytical framework that stakeholder can use. Beyond providing an analytical framework, the analysis also shows that these three IOP dimensions and the corresponding types of standards appear to be highly interrelated. This translates into the concrete advice for stakeholders that they should therefore take a holistic approach to IOP governance which considers these connections. Second, the dissertation finds that none of these IOP dimensions is of significantly lower or higher concern for stakeholders in Government Information Networks than the other dimensions. A concrete advice for stakeholders in IOP governance resulting from this is that they cannot afford to neglect any of the dimensions of an IOP architecture - in particular, the findings alert stakeholders that in practice IOP is about much more than mere technological standardisation. Third, the dissertation finds that there does seem to be a difference in the significance of the three IOP dimensions if the various adoption efforts and results are compared. This results in the advice to stakeholders that whilst keeping a holistic approach, IOP governance thus should also be mindful of this variation and pay particular attention to the most significant IOP dimension for each category of IOP adoption implications.

The second major contribution of the dissertation is to provide insights into the "black box" of IOP standards adoption by organisations in Government Information Networks, and accordingly providing advice that stakeholders can translate into improved IOP governance to produce the expected benefits from IOP. First, the findings validate standards adoption as a phased process, and identify three distinct phases (planning, implementation, operational) following the adoption decision that stakeholders in IOP governance need to take into account. Second, by contributing a more detailed picture of variation in the significance of the adoption determinants along these phases, the dissertation also contributes to IOP governance by showing when to focus on which aspects of the adoption process. Third, by 
showing that the operational phase is by far the most relevant in the adoption process, the dissertation alerts stakeholders that it is important to consider the effects of the various determinants with particular care during this phase. Moreover, by also showing that it is during the operational phase that non-compliance with standards becomes a key concern, the findings provide important governance advice as to when it is the most important to monitor adoption and compliance.

A third major contribution that can be translated by stakeholders into better IOP governance towards realisation of the benefits from Government Information Networks is to analyse the way in which decisions on IOP standards adoption are made in organisations, and to identify the key actors involved in this process. First, by providing a typology of the key actors at three levels (inter-organisational, intra-organisational management and operational levels) and their roles in the adoption process, the recommendation for IOP governance is given to recognise IOP standards adoption as a multi-stakeholder interaction which requires systematic and continuous stakeholder analysis. Moreover, the findings suggest that IOP governance should pay attention to the involvement of private-sector partners such as IT vendors to provide support with adoption (this can translate not only into public value but also stimuli for the private ICT sector). In addition, the findings also indicate at which levels it is particularly important for IOP governance to monitor the determinants for adoption and compliance are monitored, namely not only at the management level, but at all levels throughout the organisations. Finally, the dissertation identifies the key actors with regard to the major adoption determinants. IOP governance can use this analysis for a targeted approach to strengthening the supportive capacity of the most important actors for each particular factor determining adoption. Overall, the findings show that IOP governance needs to especially support "infomediaries" at the network level.

A fourth key contribution of the dissertation is to provide an empirically validated theoretical model on the determinants of IOP standards adoption. This is a relevant contribution to producing public value from Government Information Networks because having a clear understanding of what these factors are and what their relative significance is for stakeholders is imperative for IOP governance: it can serve as a framework for monitoring partner organisations' intention to adopt specific standards, for assessing the feasibility of diffusing a standard and to identify key barriers, and for tailoring an IOP governance strategy to the specific context of a particular network. First, the findings show that all the major determinants in this framework should be taken into account for effective IOP governance. Second, the findings show that IOP standards adoption is also shaped by the idiosyncratic context of a given network, highlighting the necessity for a contextsensitive approach to IOP governance.

In particular, the dissertation provides recommendations concerning how the degree of IOP governance centralisation should match the degree of a given network's complexity. To this end, it provides an analytical framework that stakeholders can use as a tool to assess both the complexity of a given network and the degree of centralisation of IOP governance. Moreover, based on its finding that higher network complexity requires more centralised IOP governance, the dissertation also provides recommendations how IOP governance can best be matched to a network's complexity. It gives four key recommendations in this 
regard. First, IOP governance in complex networks should designate a broker body and provide it with a clear governance mandate and decision-making powers, in particular to act as an intermediary and communication node among partner organisations, and as an institution enforcing the IOP architecture. Second, it recommends that a minimum level of stakeholder involvement in IOP governance is indispensible. Third, the dissertation recommends that IOP governance actors at the network level are equipped with sufficient coercive powers in order to enforce the IOP architecture of that network. And fourth, the dissertation recommends that particularly in complex networks, accountability mechanisms are important such as a formalised IOP architecture into binding obligations, and central monitoring. Importantly, the dissertation also recommends that with regard to stakeholder involvement, coercion and accountability, the coordination costs of these measures need to be carefully assessed, and it identifies several mechanisms that can be used to minimise such costs.

The fifth key contribution of the dissertation to public value is that it identifies the relative relevance of the various adoption determinants for stakeholders in Government Information Networks, thus providing important guidance as to what should be priority areas of IOP governance in order to materialise the benefits from IOP. First, it is important to ensure that in the design of a network's IOP architecture, as much as possible use is made of IOP standards that are well established and tested in practice. Moreover, it is important that IOP governance is supported by institutions to formalise the IOP architecture (in particular a solid legal framework), and that it is well aligned with dedicated IOP policies at the national level. Furthermore, the results show that it is informal institutions and soft governance in particular that are of primary importance, with effective guidance and leadership being a key issue for facilitating standards adoption. Second, with regard to the network-external environment, the political background and the role of network-external stakeholders should be taken into account. In addition, the advice is given to increase the consideration in the organisations for the longer-term public-value benefits of IOP, rather than focusing on government-internal benefits. Third, recommendations concerning the characteristics of adopting organisations are given. In particular, a needs analysis is recommended in each case that identifies which capacities are lacking in order to provide targeted assistance and guidance to partner organisations in these areas. In addition, a clear communication how IOP can serve organisational needs is needed. Fourth, the dissertation provides recommendations regarding the implications of standards adoption for organisations. Especially, it shows that certain implications (organisational efforts and internal-operations results in particular) are of considerably higher significance for stakeholders and should thus receive special attention. Moreover, where adoption efforts and costs cannot be avoided, particular emphasis should be placed on communicating the long-term benefits implied. In addition, the dissertation recommends that IOP governance needs to be designed in a holistic approach in order to address the interlinkages and trade-offs between adoption implications. Fifth, the dissertation also provides recommendations regarding the characteristics of a given Government Information Network. Most importantly, IOP governance should aim at reducing the negative effect on adoption from a network's complexity insofar possible, for instance through structural changes to the network, institutional review and appropriate communication strategies. 
In conclusion, e-Government and in particular Government Information Networks offer a rich source of public value creation. By contributing a better understanding of IOP standards adoption by organisations in Government Information Networks, in particular of the process, actors, drivers and barriers behind their adoption, and by providing insights and guidance how to best approach the governance on IOP in such networks, the findings from the research in this dissertation provide a number of recommendations that can help to better leverage this value potential in the future. 


\section{Annex N. Biography}

Florian Henning was born in 1982 in Trier Germany. After graduating from high school in 2001 and completing his Social Service, he moved to Maastricht in 2002 to pursue a BA degree in European Studies at Maastricht University. After an exchange semester at Dokuz Eylül University in Izmir (Turkey) in 2004, where he studied International Relations, he returned to Maastricht in 2005 to receive his BA degree in European Studies. During his BA studies, Florian developed a curiosity for the relation between (new) media and politics, which he decided to pursue with an MA in Media Culture at Maastricht University. During this MA, from which he graduated cum laude in 2006, Florian focused in particular on the role of ICT-enabled "new public spheres". He wrote an award-winning MA thesis on this topic, and it was particularly the experience of writing this MA thesis that sparked a fascination with conducting academic research and motivated him to pursue a PhD. Florian consequently decided to deepen his academic research skills by following an MPhil programme in Science and Technology Studies at Maastricht University, in which he continued to study the socio-technological dimensions of ICT from a variety of perspectives and methodological approaches. He graduated cum laude in 2007.

Florian started working for the Maastricht Graduate School of Governance (MGSOG) in 2007 as a project coordinator, and in 2008 joined the first cohort of MGSOG's PhD programme in Public Policy and Policy Analysis (PPPA). His dissertation topic was developed in close coordination with ICTU foundation and the Dutch Ministry of the Interior and Kingdom Relations, which had a strong interest in this topic and decided to fund part of his PhD studies. In 2011, Florian also became a PhD fellow at the United Nations University Maastricht Economic and Social Research Institute for Innovation and Technology (UNU-MERIT). Next to his PhD research, Florian was involved at UNUMERIT/MGSOG in a number of academic activities, such as teaching postgraduate students and professionals both on topics of e-governance and research methodology, coordinating various e-learning activities, and participating in various research projects and grant applications.

In late 2012, Florian joined the Center for Electronic Governance at the United Nations University International Institute for Software Technology (UNU-IIST) in Macau SAR, China, as a visiting PhD fellow for 17 months. At the Center for Electronic Governance (now UNU-EGOV), Florian was involved in grant applications, conference organisation (ICEGOV) and contract research in the field of electronic governance. In particular, he made significant contributions to the production of the world's first extensive National Mobile Governance Strategy that was developed by UNU for the Republic of Vanuatu and Commonwealth Telecommunications Organisation (CTO).

Florian's research interests continue to evolve and currently revolve around the topics of government information sharing, interoperability in electronic governance, mobile governance, ICT for development (ICT4D), the diffusion and adoption of public-sector innovations, and network governance. 


\title{
Annex O. MGSOG Dissertation Series
}

\author{
Niels P. Groen \\ The Never-ending Project \\ Understanding E-Government Project Escalation \\ MGSoG Dissertation Series, nr 59 (2015) \\ Derek Copp \\ Teacher-based Reactivity to Provincial Large-scale Assessment in Canada \\ MGSoG Dissertation Series, nr 58 (2015)
}

Michaella Vanore

Family-Member Migration and the Psychosocial Health Outcomes of Children in Moldova and

Georgia

MGSoG Dissertation Series, nr 57 (2015)

\section{Sonja Fransen}

The Economic and Social Effects of Remittances and Return Migration in Conflict-Affected Areas:

The Case of Burundi

MGSoG Dissertation Series, nr 56 (2015)

Ibrahim Khalil Conteh

The Impact of Floods on Primary School Education in Zambia

MGSoG Dissertation Series, nr 55 (2015)

Richard Bluhm

Growth Dynamics and Development

Essays in Applied Econometrics and Political Economy

MGSoG Dissertation Series, nr 54 (2015)

Nevena P. Zhelyazkova

Work-Family Reconciliation and Use of Parental Leave in Luxembourg

Empirical Analysis of Administrative Records

MGSoG Dissertation Series, nr 53 (2015)

Sachin Kumar Badkas

Metachoice and Metadata

Innovating with Environmental Policy Analysis in Europe

MGSoG Dissertation Series, nr 52 (2014)

Irina S. Burlacu

An Evaluation of Tax-Benefit Systems Impact on the Welfare of Frontier Workers

The Case of Luxembourg and Belgium

MGSoG Dissertation Series, nr 51 (2014) 
Özge Bilgili

Simultaneity in Transnational Migration Research:

Links Between Migrants' Host and Home Country Orientation

MGSoG Dissertation Series, nr 50 (2014)

Yulia Privalova Krieger

Reshaping the Big Agenda: Transnational Politics and Domestic Resistance

Financial crisis and social protection reform in Bosnia and Herzegovina

MGSoG Dissertation Series, nr 49 (2014)

Marieke van Houte

Moving Back or Moving Forward?

Return migration after conflict

MGSoG Dissertation Series, nr 48 (2014)

Oxana Slobozhan

Global Governance in the Management of Natural Resources

The Case of the Extractive Industries Transparency Initiative (EITI)

MGSoG Dissertation Series, nr 47 (2014)

Luis Bernardo Mejia Guinand

The Changing Role of the Central Planning Offices in Latin America:

A Comparative Historical Analysis Perspective (1950-2013)

MGSoG Dissertation Series, nr 46 (2014)

Cheng Boon Ong

Ethnic Segregation in Housing, Schools and Neighbourhoods in the Netherlands

MGSoG Dissertation Series, nr 45 (2014)

Luciana V. Cingolani

Bureaucracies for Development: Oxymoron or Reality?

Studies on State Capacity in Challenging Governance Contexts

MGSoG Dissertation Series, nr 44 (2014)

Carlos Cadena Gaitán

Green Politics in Latin American Cities - Sustainable Transport Agendas

MGSoG Dissertation Series, nr 43 (2014)

Katie Kuschminder

Female Return Migration and Reintegration Strategies in Ethiopia

MGSoG Dissertation Series, nr 42 (2014)

Metka Hercog

Highly-Skilled Migration and New Destination Countries

MGSoG Dissertation Series, nr 41 (2014) 
Margaret Agaba Rugadya

Can Remittances Influence the Tenure and Quality of Housing in Uganda?

MGSoG Dissertation Series, nr 40 (2014)

Ilire Agimi

New Governance Under Limited Statehood

The Case of Local Government Reform in Kosovo

MGSoG Dissertation Series, nr 39 (2014)

Kristine Farla

Empirical Studies on Institutions, Policies and Economic Development

MGSoG Dissertation Series, nr 38 (2013)

Marina Petrovic

Social Assistance and Activation in the Pursuit of Happiness:

Shedding New Light on Old Policy Solutions to Social Exclusion

MGSoG Dissertation Series, nr 37 (2013)

Laura Torvinen

Assessing Governance Assessments; The Case of Mozambique

Governance Assessments in the Context of Aid Effectiveness Discourse

MGSoG Dissertation Series, nr 36 (2013)

Biniam Egu Bedasso

Institutional Change in the Long Shadow of Elites

Essays on Institutions, Human Capital and Ethnicity in Developing Countries

MGSoG Dissertation Series, nr 35 (2013)

Sepideh Yousefzadeh Faal Deghati

Childhoods Embargoed

Constructing and Reconstructing Multidimensional Child Poverty in Iran 1984-2009

MGSoG Dissertation Series, nr 34 (2013)

Robert Bauchmüller

Investing in Early Childhood Care and Education:

The Impact of Quality on Inequality

MGSoG Dissertation Series, nr 33 (2013)

Martin Rehm

Unified Yet Separated

Empirical Study on the Impact of Hierarchical Positions within Communities of Learning

MGSoG Dissertation Series, nr 32 (2013) 
Dorcas Mbuvi

Utility Reforms and Performance of the Urban Water Sector in Africa

MGSoG Dissertation Series, nr 31 (2012)

Lina Salanauskaite

Distributional Impacts of Public Policies:

Essays in Ex-Ante and Ex-Post Evaluation

MGSoG Dissertation Series, nr 30 (2012)

Esther Schüring

To Condition or not - is that the Question?

An Analysis of the Effectiveness of Ex-Ante and Ex-Post Conditionality in Social Cash Transfer

Programs

MGSoG Dissertation Series, nr 29 (2012)

Joe Abah

Strong Organisations in Weak States

Atypical Public Sector Performance in Dysfunctional Environments

MGSoG Dissertation Series, nr 28 (2012)

Zina Samih Nimeh

Social Citizenship Rights: Inequality and Exclusion

MGSoG Dissertation Series, nr 27 (2012)

Lenka Eisenhamerová

Legitimacy of 'Humanitarian Military Intervention'

MGSoG Dissertation Series, nr 26 (2011)

Sonila Tomini

Informal Payments for Health Care Services in Albania

MGSoG Dissertation Series, nr 25 (2011)

Jinjing Li

Dynamic Microsimulation in Public Policy Evaluation

MGSoG Dissertation Series, nr 24 (2011)

Aziz Atamanov

Rural Nonfarm Employment and International Migration as Alternatives to Agricultural

Employment:

The Case of Kyrgyzstan

MGSoG Dissertation Series, nr 23 (2011)

Frieda Vandeninden

Poverty Alleviation: Aid and Social Pensions

MGSoG Dissertation Series, nr 22 (2011) 
Juliana Nyasha Tirivayi

The Welfare Effects of Integrating AIDS Treatment with Food Transfers:

Evidence from Zambia

MGSoG Dissertation Series, nr 21 (2011)

Agnieska Ewa Sowa

Who's Left Behind? Social Dimensions of Health Transition and Utilization of Medical Care in Poland

MGSoG Dissertation Series, nr 20 (2011)

Emmanaouil Sfakianakis

The Role of Private Actors in the Provision of Public Goods with Applications to Infrastructure and Financial Stability

MGSoG Dissertation Series, nr 19 (2011)

\section{Siu Hing Lo}

White Collars Green Sleeves

An Interorganizational Comparison of Determinants of Energy-Related Behaviors among Office Workers

MGSoG Dissertation Series, nr 18 (2011)

Treena $\mathrm{Wu}$

Constraints to Human Capital Investment in Developing Countries:

Using the Asian Financial Crisis in Indonesia as a Natural Experiment

MGSoG Dissertation Series, nr 17 (2011)

Henry Espinoza Peña

Impact Evaluation of a Job-Training Programme for Disadvantaged Youths:

The Case of Projoven

MGSoG Dissertation Series, nr 16 (2011)

Florian Tomini

Between Family and Friends

Understanding the Interdependency of Private Transfers

MGSoG Dissertation Series, nr 15 (2010)

Michał Polalowski

The Institutional Transformation of Social Policy in East Central Europe:

Poland and Hungary in comparative and historical perspective

MGSoG Dissertation Series, nr 14 (2010)

Maha Ahmed

Defining, Measuring and Addressing Vulnerability:

The Case of Post Conflict Environments

MGSoG Dissertation Series, nr 13 (2010) 
Pascal Beckers

Local Space and Economic Success

The role of spatial segregation of migrants in the Netherlands

MGSoG Dissertation Series, nr 12 (2010)

Victor Cebotari

Conflicting Demands in Ethnically Diverse Societies

Ethnopolitical Contention and Identity Values in Europe

MGSoG Dissertation Series, nr 11 (2010)

Dennis Gyllensporre

Competing and Complementary Perspectives on the EU as a Crisis Management Actor:

An Examination of the Common Security and Defence Policy through the Lenses of Idealism and

Realism

MGSoG Dissertation Series, nr 10 (2010)

Judit Vall Castello

Business Cycle and Policy Effects on Labour Market Transitions of Older and Disabled Workers in Spain

MGSoG Dissertation Series, nr. 9 (2010)

Keetie Roelen

False Positives or Hidden Dimensions: the definition and measurement of child poverty

MGSoG Dissertation Series, nr. 8 (2010)

Denisa Maria Sologon

Earning Dynamics in Europe

MGSoG Dissertation Series, nr. 7 (2010)

Melissa Siegel

Money and Mobility: Migration and Remittances

MGSoG Dissertation Series, nr. 6 (2010)

Jessica S. Hagen-Zanker

Modest Expectations: Causes and effects of migration on migrant households in source countries

MGSoG Dissertation Series, nr. 5 (2010)

Mirtha R. Muniz Castillo

Human Development and Autonomy in Project Aid: Experiences from four

bilateral projects in Nicaragua and El Salvador

MGSoG Dissertation Series, nr. 4 (2009) 
Christiane Arndt

Governance Indicators

MGSoG Dissertation Series, nr. 3 (2009)

Britta Augsburg

Microfinance - Greater Good or Lesser Evil?

MGSoG Dissertation Series, nr. 2 (2009)

Geranda Notten

Measuring and Managing Poverty Risks

MGSoG Dissertation Series, nr. 1 (2008) 